\title{
Steam Generator Tube Failures
}

\author{
RECEIVED
}

MAY 221996

OSTI

Prepared by

P. E. MacDonald, V. N. Shah, L. W. Ward, P. G. Ellison

Idaho National Engineering Laboratory

Lockheed Idaho Technologies Company

\section{Prepared for}

U.S. Nuclear Regulatory Commission:

\section{DISCLAIMER}

This report was prepared as an account of work sponsored by an agency of the United States Government. Neither the United States Government nor any agency thereof, nor any of their employees, makes any warranty, express or implied, or assumes any legal liability or responsibility for the accuracy, completeness, or usefulness of any information, apparatus, product, or process disclosed, or represents that its use would not infringe privately owned rights. Reference herein to any specific commercial product, process, or service by trade name, trademark, manufacturer, or otherwise does not necessarily constitute or imply its endorsement, recommendation, or favoring by the United States Government or any agency thereof. The views and opinions of authors expressed herein do not necessarily state or reflect those of the United States Government or any agency thereof. 


\section{AVAILABILITY NOTICE}

Availability of Reference Materials Cited in NRC Publications

Most documents cited in NRC publications will be available from one of the following sources:

1. The NRC Public Document Room, 2120 L Street, NW., Lower Level, Washington, DC 20555-0001

2. The Superintendent of Documents, U.S. Government Printing Office. P. O. Box 37082 , Washington, DC $20402-9328$

3. The National Technical Information Service, Springfield, VA 22161-0002

Although the listing that follows represents the majority of documents cited in NRC publications, it is not intended to be exhaustive.

Referenced documents available for inspection and copying for a fee from the NRC Public Document Room include NRC correspondence and internal NRC memoranda: NRC bulletins, circulars, information notices, inspection and investigation notices; licensee event reports; vendor reports and correspondence; Commission papers; and applicant and licensee documents and correspondence.

The following documents in the NUREG series are available for purchase from the Government Printing Office: formal NRC staff and contractor reports, NRC-sponsored conference proceedings, international agreement reports, grantee reports, and NRC booklets and brochures. Also available are regulatory guides, NRC regulations in the Code of Federal Regulations, and Nuclear Regulatory Commission Issuances.

Documents avallable from the National Technical Information Service include NUREG-series reports and technical reports prepared by other Federal agencies and reports prepared by the Atomic Energy Commission, forerunner agency to the Nuclear Regulatory Commission.

Documents available from public and special technical libraries include all open literature items, such as books. journal articles, and transactions. Federal Register notices. Federal and State legislation, and congressional reports can usually be obtained from these libraries.

Documents such as theses, dissertations, foreign reports and translations, and non-NRC conference proceedings are available for purchase from the organization sponsoring the publication cited.

Single coples of NRC draft reports are available free, to the extent of supply, upon written request to the Office of Administration, Distribution and Mail Services Section. U.S. Nuclear Regulatory Commission, Washington, DC 20555-0001.

Coples of industry codes and standards used in a substantive manner in the NRC regulatory process are maintained at the NRC Library. Two White Fint North, 11545 Rockville Pike, Rockville, MD 20852-2738, for use by the public. Codes and standards are usually copyrighted and may be purchased from the originating organization or, if they are American National Standards, from the American National Standards Institute. 1430 Broadway, New York, NY 10018-3308.

\section{DISCLAIMER NOTICE}

This report was prepared as an account of work sponsored by an agency of the United States Government. Neither the United States Government nor any agency thereof, nor any of their employees, makes any warranty, expressed or implied, or assumes any legal liability or responsibilify for any third party's use, or the results of such use, of any information, apparatus, product, or process disclosed in this report, or represents that its use by such third party would not infringe privately owned rights. 


\section{DISCLAMER}

Portions of this document may be illegible in electronic image products. Images are produced from the best avallable original document. 
NUREG/CR--6365

NUREG/CR-6365

INEL-95/0383

\section{Steam Generator Tube Failures}

Manuscript Completed: April 1996

Date Published: April 1996

Prepared by

P. E. MacDonald, V. N. Shah, L. W. Ward, P. G. Ellison

Idaho National Engineering Laboratory Lockheed Idaho Technologies Company Idaho Falls, ID 84315

J. R. Boardman, NRC Project Manager

Prepared for

Safety Programs Division

Office for Analysis and Evaluation of Operational Data

U.S. Nuclear Regulatory Commission

Washington, DC 20555-0001

NRC Job Code E8238 


\section{ABSTRACT}

A review and summary of the available information on steam generator tubing failures and the impact of these failures on plant safety is presented. The following topics are covered: pressurized water reactor (PWR), Canadian deuterium uranium (CANDU) reactor, and Russian water moderated, water cooled energy reactor (VVER) steam generator degradation, PWR steam generator tube ruptures, the thermal-hydraulic response of a PWR plant with a faulted steam generator, the risk significance of steam generator tube rupture accidents, tubing inspection requirements and fitness-for-service criteria in various countries, and defect detection reliability and sizing accuracy.

A significant number of steam generator tubes are defective and are removed from service or repaired each year. This wide spread damage has been caused by many diverse degradation mechanisins, some of which are difficult to detect and predict. In addition, spontaneous tube ruptures have occurred at the rate of about one every 2 years over the last 20 years, and incipient tube ruptures (tube failures usually identified with leak detection monitors just before rupture) have been occurring at the rate of about one per year. These ruptures have caused complex plant transients which have not always been easy for the reactor operators to control. Also, nuclear power plant design basis accidents, such as a main steam line break, may cause multiple failures of badly degraded steam generator tubes. Our analysis shows that if more than 15 tubes rupture during a main steam line break, the system response could lead to core melting. Although spontaneous and induced steam generator tube ruptures are small contributors to the total core damage frequency calculated in probabilistic risk assessments, they are risk significant because the radionuclides are likely to bypass the reactor containment building. The frequency of steam generator tube ruptures can be significantly reduced through appropriate and timely inspections and repairs or removal from service. However, a continuing issue has been exactly what constitutes an appropriate and timely inspection and which degraded tubes are still fit for service. There have been many different approaches to this problem throughout the world. Also, the most widely used inspection equipment is not able to detect and size all the degradation of concern.

Job Code E8238-Specialized Technical Assistance 


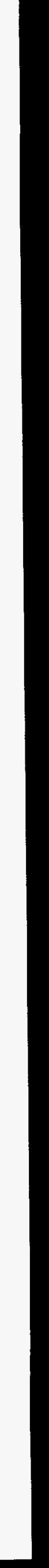




\section{CONTENTS}

ABSTRACT $\ldots \ldots \ldots \ldots \ldots \ldots \ldots \ldots \ldots \ldots \ldots \ldots \ldots \ldots \ldots$ iii

LIST OF FIGURES $\ldots \ldots \ldots \ldots \ldots \ldots \ldots \ldots \ldots \ldots \ldots \ldots \ldots \ldots$

LIST OF TABLES $\ldots \ldots \ldots \ldots \ldots \ldots \ldots \ldots \ldots \ldots \ldots \ldots \ldots \ldots \ldots$

EXECUTIVE SUMMARY $\ldots \ldots \ldots \ldots \ldots \ldots \ldots \ldots \ldots \ldots \ldots \ldots \ldots \ldots \ldots$

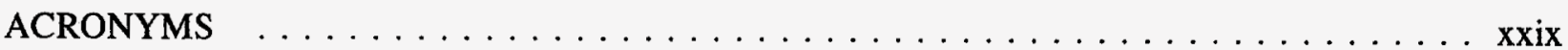

ACKNOWLEDGMENTS $\ldots \ldots \ldots \ldots \ldots \ldots \ldots \ldots \ldots \ldots \ldots \ldots \ldots$

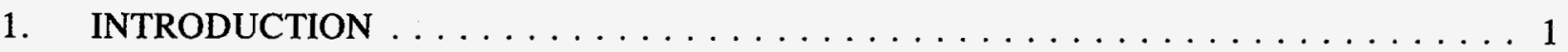

2. STEAM GENERATOR DESIGN $\ldots \ldots \ldots \ldots \ldots \ldots \ldots \ldots \ldots \ldots$

2.1 Pressurized Water Reactor Recirculating Steam Generators $\ldots \ldots \ldots \ldots \ldots$

2.2 CANDU Reactor Recirculating Steam Generators $\ldots \ldots \ldots \ldots \ldots \ldots$

2.3 Pressurized Water Reactor Once-Through Steam Generators . . . . . . . . . . . 14

2.4 Russian VVER Steam Generators $\ldots \ldots \ldots \ldots \ldots \ldots \ldots \ldots \ldots$

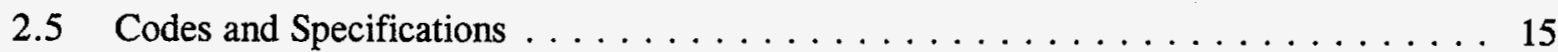

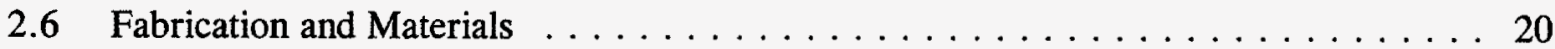

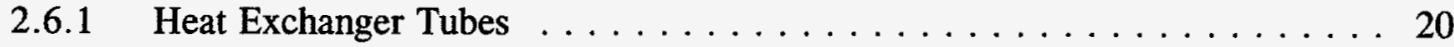

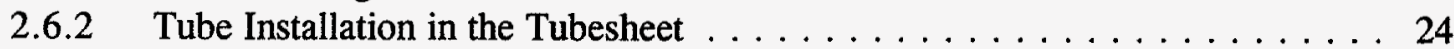

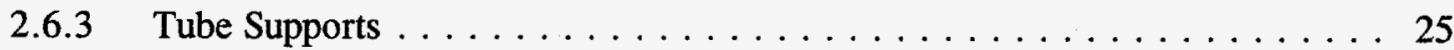

2.6.4 Steam Generator Shells and Feedwater Nozzles . . . . . . . . . . . 28

3. STEAM GENERATOR DEGRADATION MECHANISMS,

SITES, AND FAILURE MODES $\ldots \ldots \ldots \ldots \ldots \ldots \ldots \ldots \ldots \ldots \ldots$

3.1 Summary of the PWR and CANDU Tube Degradation Problems $\ldots \ldots \ldots \ldots$

3.2 Pressurized Water Reactor and CANDU Reactor Recirculating Steam

Generator Tubes . . . . . . . . . . . . . . . . . . . . . . . 39

3.2.1 Primary Water Stress Corrosion Cracking . . . . . . . . . . . . . . . 39

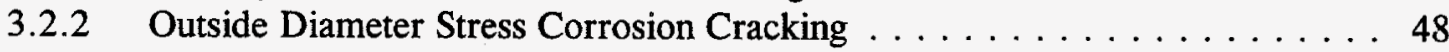

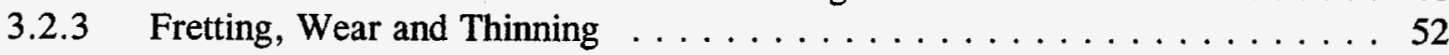

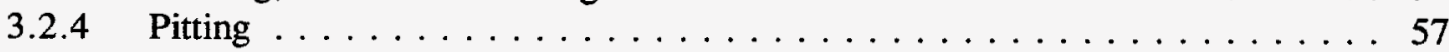

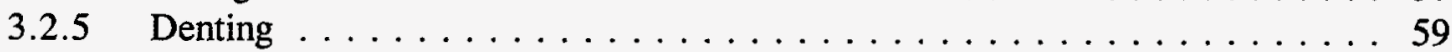

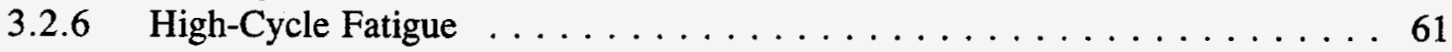

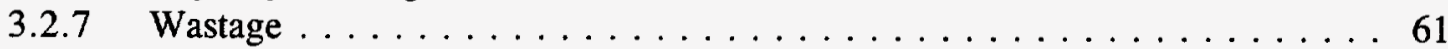


3.3 Pressurized Water Reactor Once-Through Steam Generator Tubes . . . . . . . . . . 62

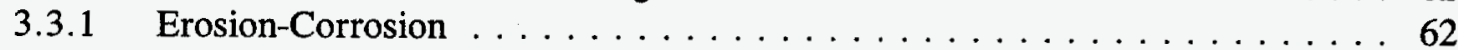

3.3 .2 High-Cycle Fatigue $\ldots \ldots \ldots \ldots \ldots \ldots \ldots \ldots \ldots \ldots \ldots \ldots$

3.3.3 Low-Temperature Primary-Side Stress Corrosion Cracking . . . . . . . . . 64

3.3.4 Outside Diameter Intergranular Stress Corrosion Cracking and

Intergranular Attack . . . . . . . . . . . . . . . . . . . 64

3.4 Russian VVER Steam Generator Tubes $\ldots \ldots \ldots \ldots \ldots \ldots \ldots$

3.5 Steam Generator Tubing Residual Life Estimates $\ldots \ldots \ldots \ldots \ldots$

3.6 Pressurized Water Reactor and CANDU Reactor Steam Generator Shell,

Feedwater Nozzle, and Tubesheet Degradation . . . . . . . . . . . . . . . 67

3.6.1 PWR Steam Generator Shells . . . . . . . . . . . . . . . . . . 70

3.6.2 Feedwater Nozzles . . . . . . . . . . . . . . . . . . . 71

3.6.3 Erosion-Corrosion of the Thermal Sleeves, J-tubes, Feedrings, and

Divider Plates . . . . . . . . . . . . . . . . . . 71

3.7 Russian VVER Collector, Shell, and Feedwater Distribution System Degradation . . . 73

3.7.1 Stress Corrosion Cracking of the VVER-1000 Collectors . . . . . . . . . 73

3.7.2 Erosion-Corrosion of the VVER Feedwater Distribution Systems . . . . . . . 75

3.7.3 Failure of Collector Cover Bolts . . . . . . . . . . . . . . . 76

4. STEAM GENERATOR TUBE RUPTURE EVENTS $\ldots \ldots \ldots \ldots \ldots \ldots \ldots \ldots$

4.1 Point Beach Unit $1 \ldots \ldots \ldots \ldots \ldots \ldots \ldots \ldots$

4.1 .1 Cause of the Tube Rupture $\ldots \ldots \ldots \ldots \ldots \ldots \ldots \ldots \ldots$

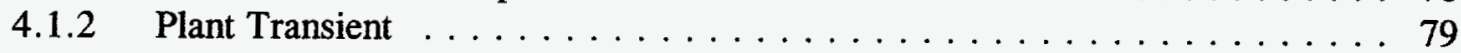

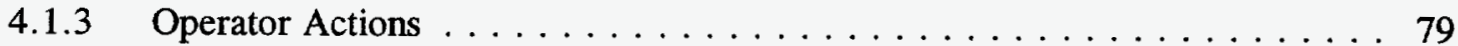

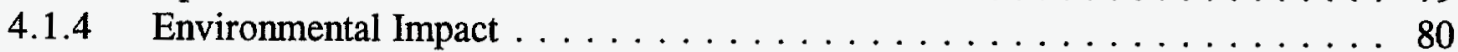

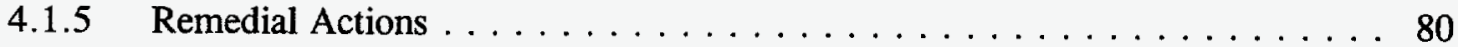

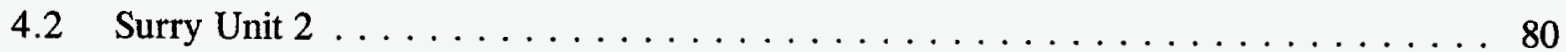

4.2.1 Cause of the Tube Rupture $\ldots \ldots \ldots \ldots \ldots \ldots \ldots \ldots$

4.2 .2 Plant Transient $\ldots \ldots \ldots \ldots \ldots \ldots \ldots \ldots \ldots \ldots \ldots \ldots$

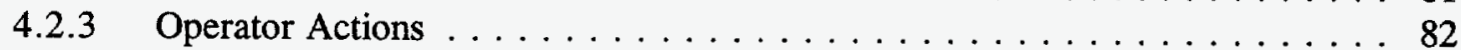

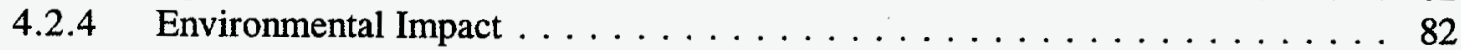

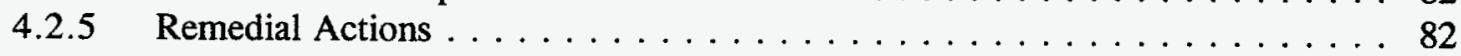

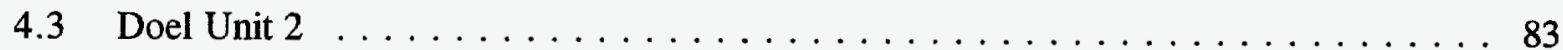

4.3.1 Cause of the Tube Rupture $\ldots \ldots \ldots \ldots \ldots \ldots \ldots \ldots \ldots \ldots$

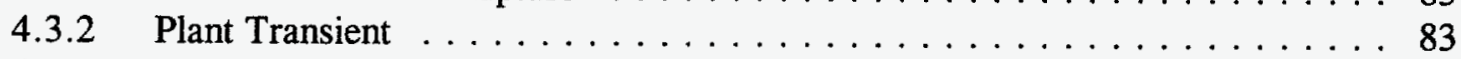

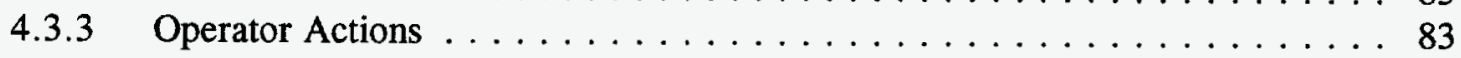

4.3 .4 Environmental Impact $\ldots \ldots \ldots \ldots \ldots \ldots \ldots \ldots \ldots \ldots \ldots \ldots$

4.3 .5 Remedial Actions . . . . . . . . . . . . . . . . 84 


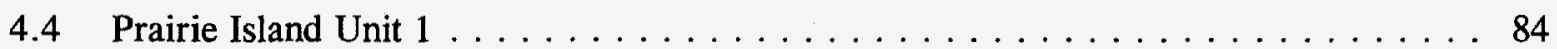

4.4 .1 Cause of the Tube Rupture $\ldots \ldots \ldots \ldots \ldots \ldots \ldots \ldots$

$4.4 .2 \quad$ Plant Transient $\ldots \ldots \ldots \ldots \ldots \ldots \ldots \ldots \ldots \ldots$

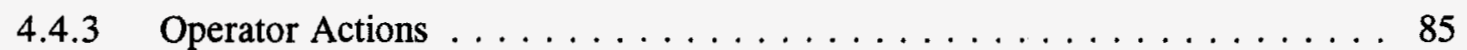

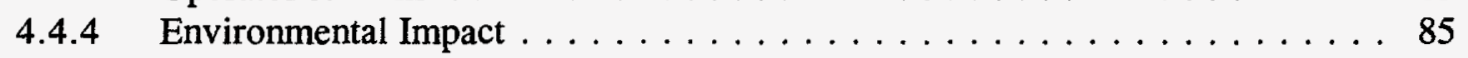

4.4.5 Remedial Actions . . . . . . . . . . . . . . . . . 85

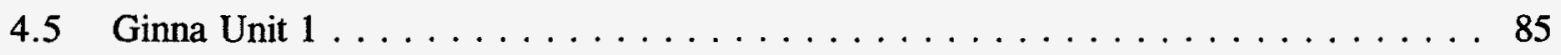

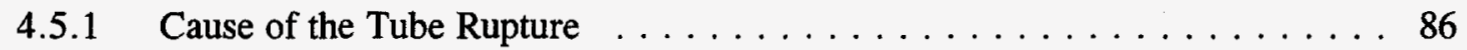

4.5 .2 Plant Transient . . . . . . . . . . . . . . . . . . 89

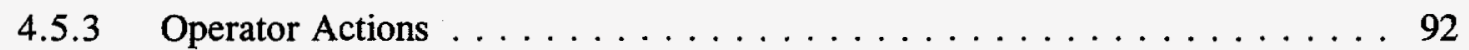

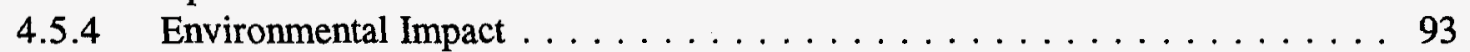

4.5.5 Remedial Actions . . . . . . . . . . . . . . . . . 93

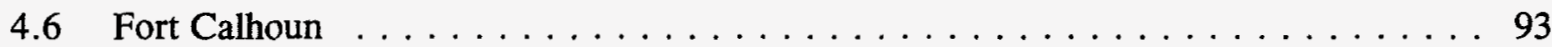

4.6.1 Cause of the Tube Rupture $\ldots \ldots \ldots \ldots \ldots \ldots \ldots \ldots \ldots \ldots$

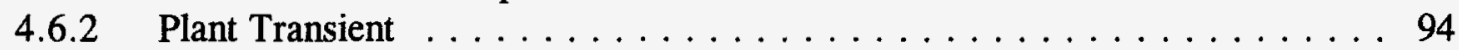

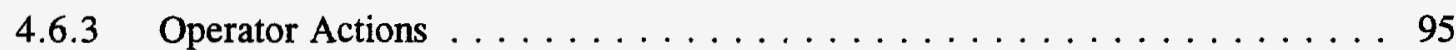

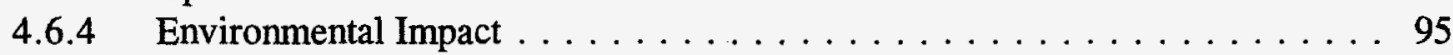

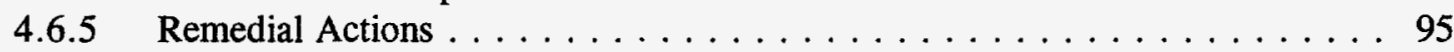

4.7 North Anna Unit $1 \ldots \ldots \ldots \ldots \ldots \ldots \ldots \ldots \ldots \ldots$

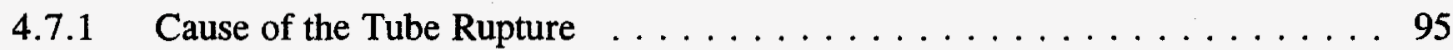

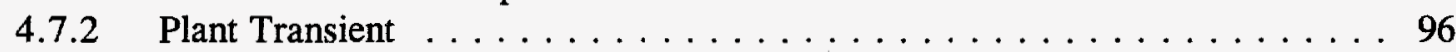

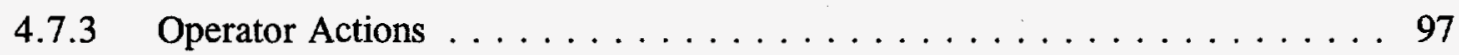

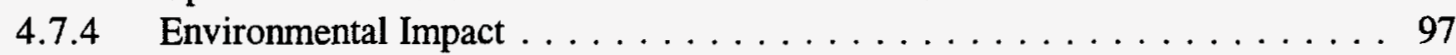

4.7 .5 Remedial Actions . . . . . . . . . . . . . . . . . 97

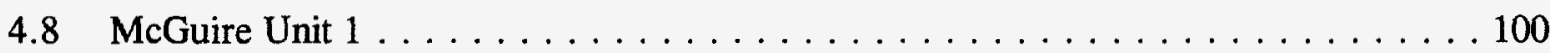

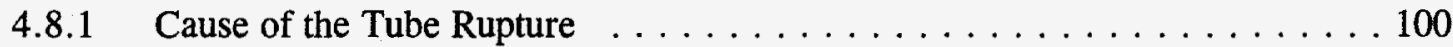

4.8 .2 Plant Transient . . . . . . . . . . . . . . . . . . . . 100

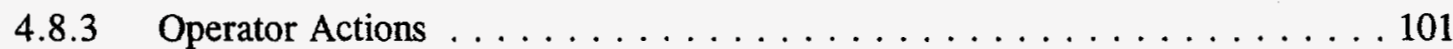

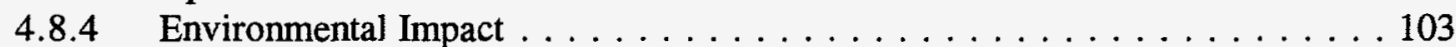

4.8 .5 Remedial Actions . . . . . . . . . . . . . . . . . 103

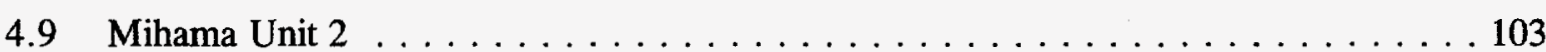

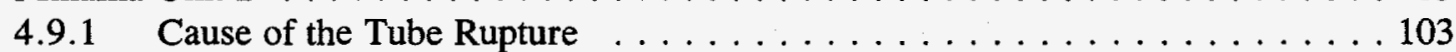

4.9 .2 Plant Transient . . . . . . . . . . . . . . . . . . . . . . . 104

4.9 .3 Operator Actions . . . . . . . . . . . . . . . . . . . . 104

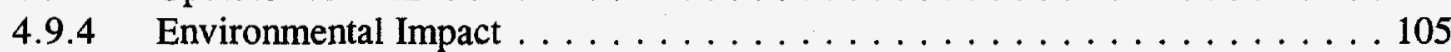

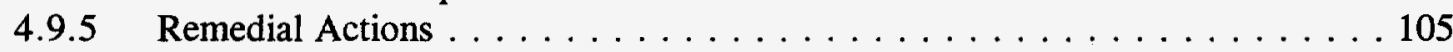

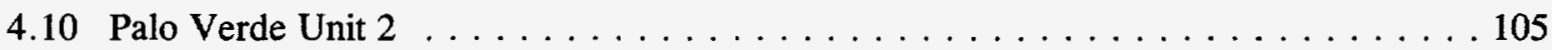

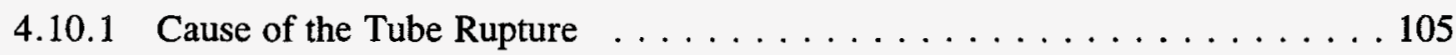

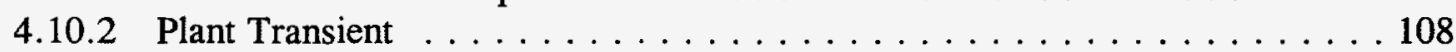

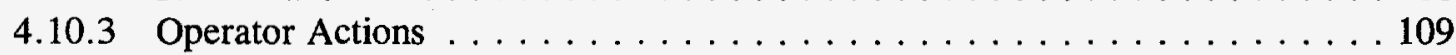

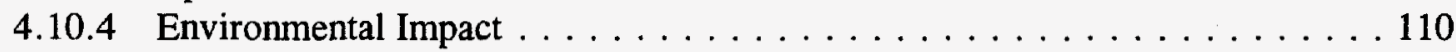

4.10 .5 Remedial Actions . . . . . . . . . . . . . . . . . . . . . 110 
4.11 Summary and Comparison of the Information from the Ten Steam Generator Tube Ruptures

4.12 Incipient Tube Rupture Events 114

5. THERMAL-HYDRAULIC RESPONSE OF A TYPICAL PWR PLANT WITH

A DEFECTIVE STEAM GENERATOR . 118

5.1 Surry Plant and RELAP5 Model $\ldots \ldots \ldots \ldots \ldots \ldots \ldots \ldots \ldots$

5.2 Evaluation of the Steam Generator Tube Rupture Event . . . . . . . . . . . . . 122

5.3 Results of the RELAP5 Simulation of a Double-Ended Rupture of a Steam

Generator Tube . . . . . . . . . . . . . . . . . . . . . . . . . . . 123

5.4 Results of the RELAP5 Simulation of a Steam Line Break with One Steam

Generator Tube Failed $\ldots \ldots \ldots \ldots \ldots \ldots \ldots$

5.5 Results of the RELAP5 Simulation of a Steam Line Break with 15 Steam

Generator Tubes Failed . . . . . . . . . . . . . . . . . . 140

5.6 Results of the RELAP5 Simulation of a Steam Line Break with 15 Steam

Generator Tubes Failed and No Operator Actions . . . . . . . . . . . . . . . 144

5.7 Operator Actions During Combined Steam Line Break-Tube Rupture Events . . . . . 144

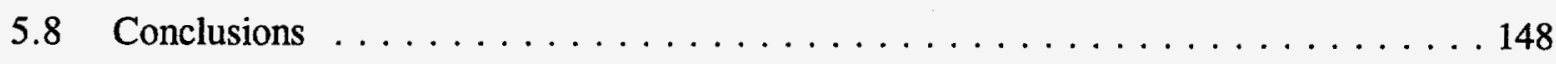

6. THE RISK SIGNIFICANCE OF STEAM GENERATOR TUBE

RUPTURE ACCIDENTS

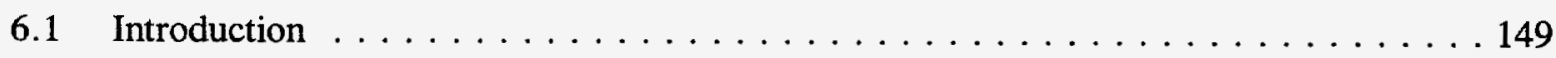

6.2 U.S. Individual Plant Examination Core Damage Frequency and Risk Profile $\ldots \ldots 149$

6.3 Steam Generator Tube Rupture Risk Contributions . . . . . . . . . . . . 153

6.3.1 Spontaneous Steam Generator Tube Rupture . . . . . . . . . . . . 153

6.3.2 Induced Steam Generator Tube Rupture . . . . . . . . . . . . . . . 154

6.4 Risk Significant Steam Generator Tube Rupture Failures . . . . . . . . . . . 157

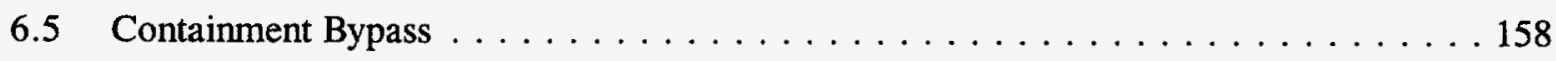

6.6 Steam Generator Tube Degradation . . . . . . . . . . . . . . . 159

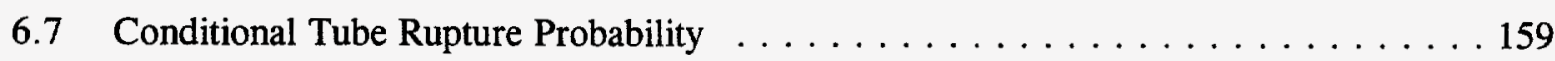

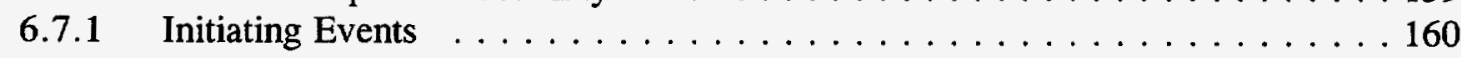

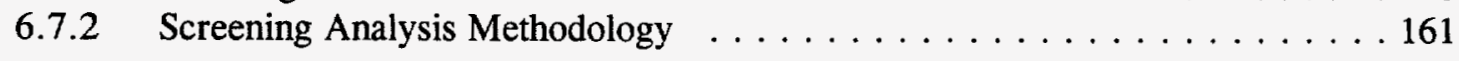


6.7.3 Screening Computation of Induced Steam Generator Tube Rupture Probabilities

6.7.4 Identification and Selection of Dominant Induced Steam Generator

Tube Rupture Accident Contributors . . . . . . . . . . . . . . . 165

6.7.5 Mechanistic Induced Steam Generator Tube Rupture Frequency . . . . . . . 165

6.7.6 Typical Values for the Induced Steam Generator Tube Rupture Containment Bypass Frequencies . . . . . . . . . . . . . 168

6.8 Reactor Coolant System Natural Circulation $\ldots \ldots \ldots \ldots \ldots \ldots \ldots \ldots \ldots$

6.8.1 Importance of Natural Circulation Flows $\ldots \ldots \ldots \ldots \ldots \ldots \ldots$

6.8.2 Hot Leg Countercurrent Flow in Recirculating Steam Generators . . . . . . 171

6.8 .3 Coolant Loop Flow . . . . . . . . . . . . . . . . . . . 173

6.8.4 Description of Scenarios Leading to Natural Circulation . . . . . . . . 174

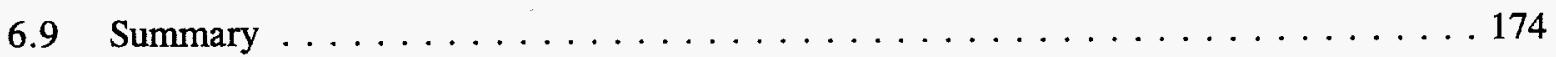

7. REGULATORY PRACTICES AND FITNESS-FOR-SERVICE GUIDELINES

IN VARIOUS COUNTRIES $\ldots \ldots \ldots \ldots \ldots \ldots \ldots \ldots \ldots \ldots$

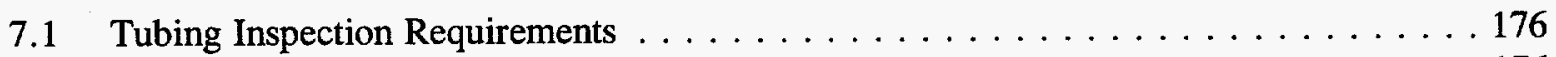

7.1.1 Tubing Inspection Requirements in the United States . . . . . . . . . . 176

7.1.2 Tubing Inspection Requirements in the Czech Republic . . . . . . . . 180

7.1 .3 Tubing Inspection Requirements in France $\ldots \ldots \ldots \ldots \ldots 18 \ldots \ldots \ldots$

7.1.4 Tubing Inspection Requirements in Germany $\ldots \ldots \ldots \ldots \ldots \ldots 1$

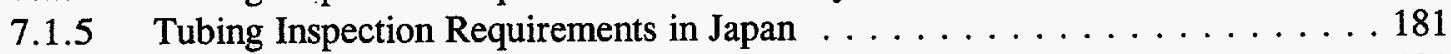

7.1 .6 Tubing Inspection Requirements in Russia $\ldots \ldots \ldots \ldots \ldots \ldots 1$

7.1.7 Tubing Inspection Requirements in Slovenia $\ldots \ldots \ldots \ldots \ldots \ldots \ldots \ldots$

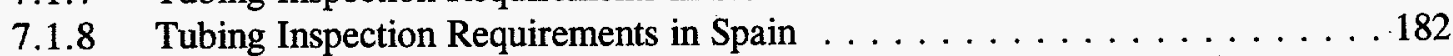

7.1 .9 Tubing Inspection Requirements in Sweden . . . . . . . . . . . 182

7.1 .10 Tubing Inspection Requirements in Switzerland . . . . . . . . . . . 182

7.1.11 EPRI Tubing Inspection Recommendations . . . . . . . . . . . . . 182

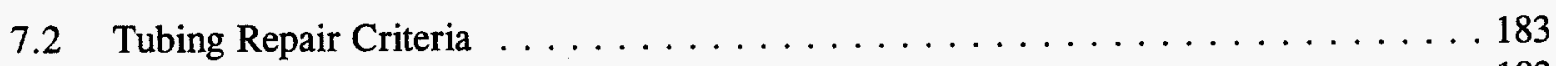

7.2.1 Generic Fitness-For-Service Criteria . . . . . . . . . . . . . . 183

7.2.2 Defect Type and Location Specific Repair Criteria . . . . . . . . . . . . 184

7.3 Tubing Fitness-For-Service Guidelines in Various Countries . . . . . . . . . . 185

7.3.1 Regulatory Practices and Fitness-For-Service Guidelines in the

United States . . . . . . . . . . . . . . . . . 187

7.3.2 Alternative U.S. Fitness-For-Service Guidelines for Outside Diameter IGSCC/IGA at Tube Support Plates . . . . . . . . . . . . . . . 189

7.3.3 Alternative U.S. Fitness-For-Service Guidelines for PWSCC in the Roll Transition Region Proposed by EPRI . . . . . . . . . . . . . . . . 193

7.3.4 Other Alternative Fitness-For-Service Guidelines in the U.S. . . . . . . . . . 194

7.3.5 Regulatory Practices and Fitness-For-Service Guidelines in Belgium . . . . . 194

7.3.6 Fitness-for-Service Guidelines in Canada . . . . . . . . . . . . . 196

7.3.7 Regulatory Practices and Fitness-For-Service Guidelines in the

Czech Republic . . . . . . . . . . . . . . . . . . . . . . . . 198

7.3.8 Regulatory Practices and Fitness-For-Service Guidelines in France . . . . . . 198

7.3.9 Regulatory Practices and Fitness-For-Service Guidelines in Germany . . . . . 200 
7.3.10 Regulatory Practices and Fitness-For-Service Guidelines in Japan . . . . . . 200

7.3.11 Regulatory Practices and Fitness-For-Service Guidelines in Russia . . . . . . . . 201

7.3.12 Regulatory Practices and Fitness-For-Service Guidelines in Slovenia . . . . . 201

7.3.13 Regulatory Practices and Fitness-For-Service Guidelines in Spain . . . . . . . 201

7.3.14 Regulatory Practices and Fitness-For-Service Guidelines in Sweden . . . . . 202

7.3.15 Fitness-For-Service Guidelines in Switzerland . . . . . . . . . . . 203

8. STEAM GENERATOR TUBE DEFECT DETECTION RELIABILITY AND

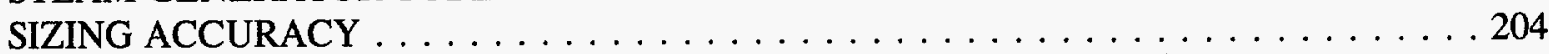

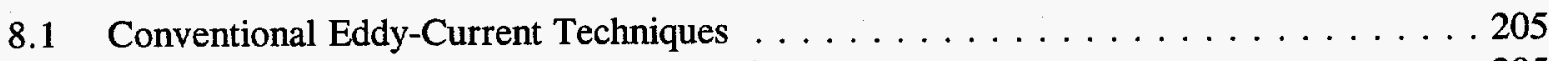

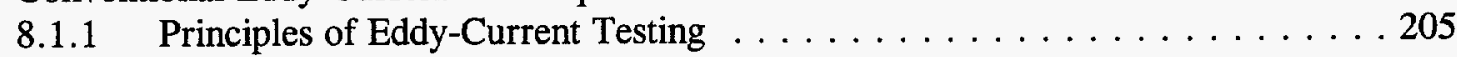

8.1 .2 Basic Probes . . . . . . . . . . . . . . . . . . . . 207

8.1.3 Multifrequency/Multiparameter Eddy-Current Methods . . . . . . . . . . 214

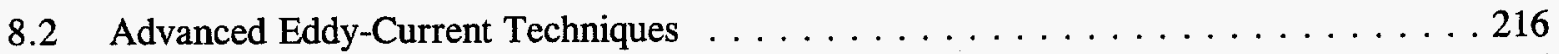

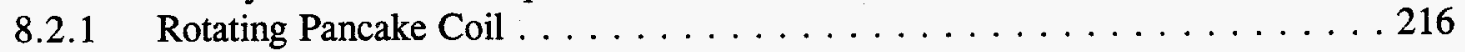

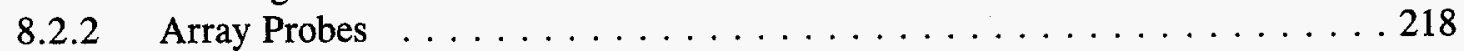

8.2.3 Transmit/Receive Probes . . . . . . . . . . . . . . . . . . 219

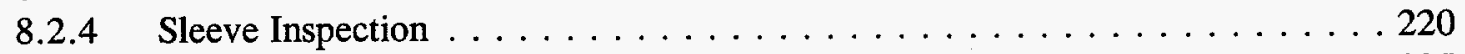

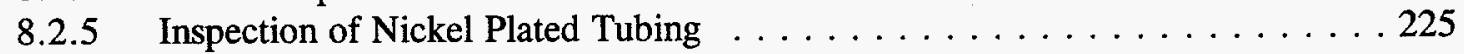

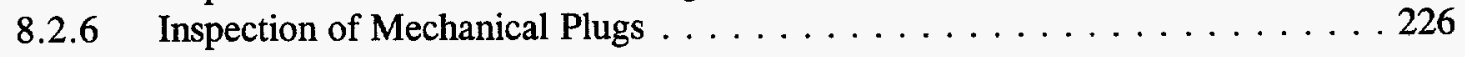

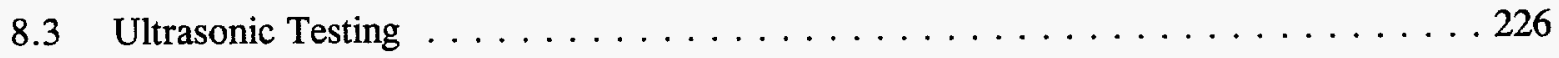

8.4 Limitations of Inservice Inspection Methods for Steam Generator Tubes . . . . . . . 230

8.4.1 Primary Water Stress Corrosion Cracking . . . . . . . . . . . . 230

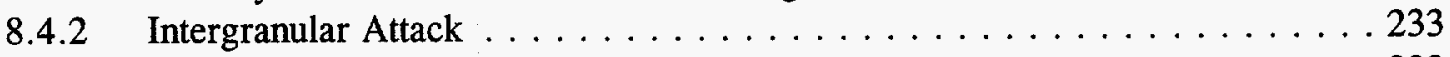

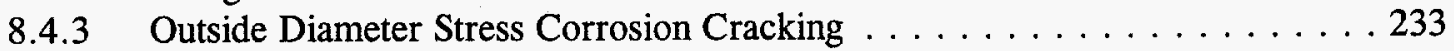

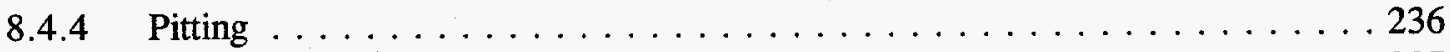

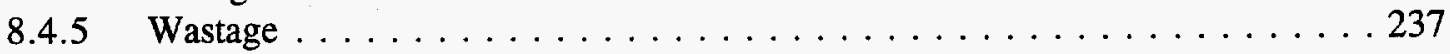

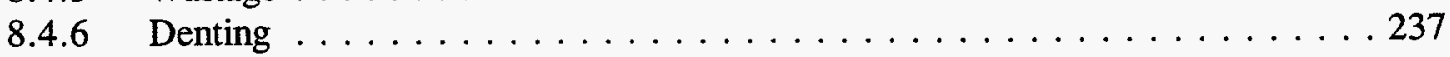

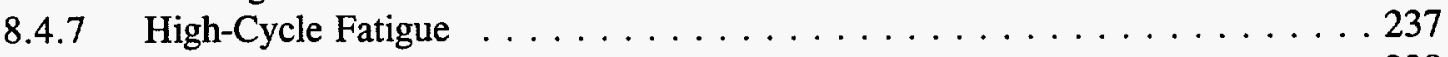

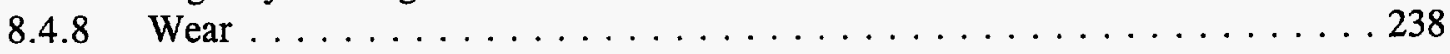

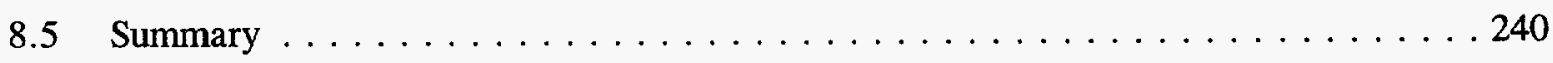

9. OBSERVATIONS AND CONCLUSIONS $\ldots \ldots \ldots \ldots \ldots \ldots \ldots \ldots \ldots$

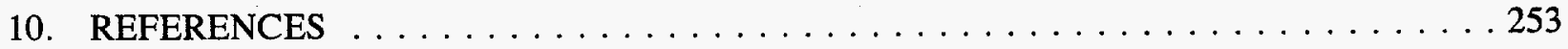

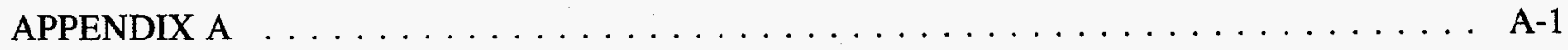




\section{LIST OF FIGURES}

1. PWR recirculating steam generator cross section $\ldots \ldots \ldots \ldots \ldots \ldots \ldots$

2. Cut-away view of a typical recirculating steam generator $\ldots \ldots \ldots \ldots \ldots$

3. Typical design of a steam generator with a preheater $\ldots \ldots \ldots \ldots \ldots \ldots$

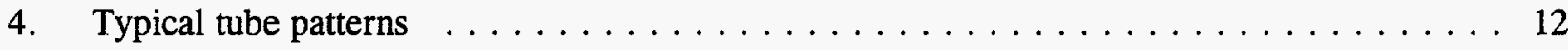

5. CANDU Recirculating Steam Generator used at the Darlington Station $\ldots \ldots \ldots$

6. PWR once-through steam generator cross section $\ldots \ldots \ldots \ldots \ldots \ldots \ldots$

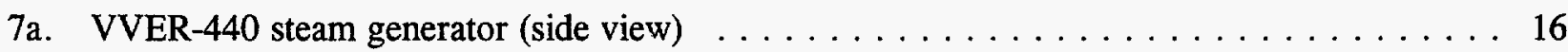

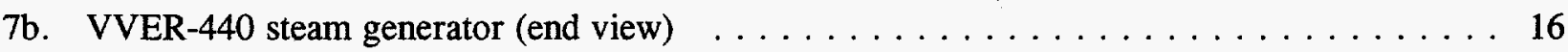

8a. Cut-away drawing of a VVER-1000 steam generator $\ldots \ldots \ldots \ldots \ldots$

8b. VVER-1000 steam generator (end view) $\ldots \ldots \ldots \ldots \ldots \ldots \ldots \ldots$

9a. Top view sketch of the tube layout in VVER-440 and VVER-1000 steam generators $\ldots \ldots$. . 18

9b. Basic arrangement of the heat exchanger tubes and headers used in VVER-1000

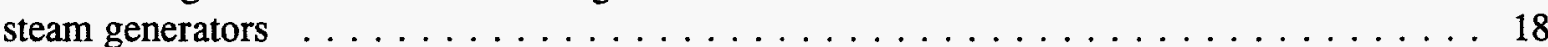

10. Profilometry readings from a typical tube in one of the Siemens/KWU replacement

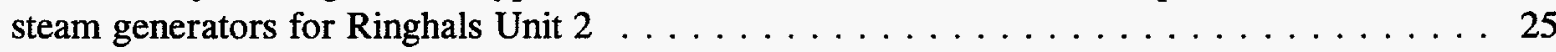

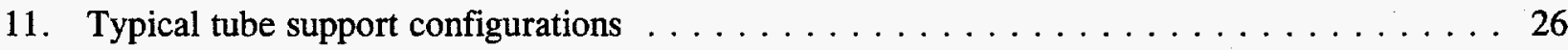

12. Typical steam generator tube support layouts used in the United States with tube support plate and tubesheet nomenclature $\ldots \ldots \ldots \ldots \ldots \ldots \ldots$

13. Typical recirculating steam generator antivibration bar arrangement $\ldots \ldots \ldots$. . . . . 29

14. Typical CANDU steam generator tube support structures $\ldots \ldots \ldots \ldots \ldots$

15. PWR steam generator showing shell welds $\ldots \ldots \ldots \ldots \ldots \ldots \ldots$

16a. Typical Westinghouse feedwater nozzle and thermal sleeve design with the sites susceptible to high-cycle thermal fatigue damage caused by turbulent mixing of leaking feedwater and hot steam generator coolant identified $\ldots \ldots \ldots \ldots \ldots \ldots$

16b. Westinghouse feedwater piping-to-nozzle weld design at the D.C. Cook plant

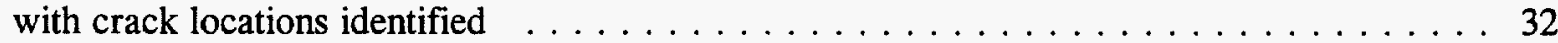

17. Percentage of PWR and CANDU steam generator tubes plugged $\ldots \ldots \ldots \ldots$ 
18. Worldwide causes of steam generator plugging $\ldots \ldots \ldots \ldots \ldots$

19. Locations of known tube wall degradations in recirculating steam generators . . . . . . . 40

20. Degradation mechanisms and locations in CANDU recirculating steam generators $\ldots \ldots . .41$

21. Schematic diagram showing the influence of nickel content on the cracking processes occurring in three steam generator tubing materials stressed slightly above the yield point in $350^{\circ} \mathrm{C}$ water $\ldots \ldots \ldots \ldots \ldots \ldots \ldots \ldots \ldots \ldots \ldots$

22. Effect of austenitic alloy chromium content on material lost due to corrosion to deaerated, borated water flowing at a velocity of $5.5 \mathrm{~m} / \mathrm{s} \ldots \ldots \ldots \ldots$

23. Resistance to stress corrosion cracking of mill-annealed or heat treated Alloy 600 , Alloy 690 , Alloy 800 , and Type 316 stainless steel as a function of sodium hydroxide

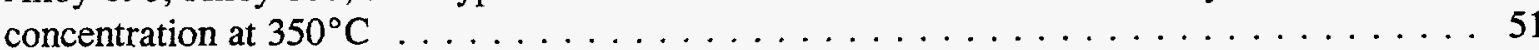

24. CANDU recirculating steam generators staggered scallop bar arrangement $\ldots \ldots \ldots 54$

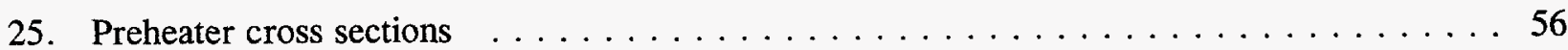

26. Weibull analysis of data for PWSCC at hot leg roll transitions and rolled area below the top of the tubesheet for plants with full depth rolls $\ldots \ldots \ldots \ldots$

27. Phenomena occurring during erosion-corrosion $\ldots \ldots \ldots \ldots \ldots \ldots \ldots \ldots$

28. Ginna B steam generator hot leg tubesheet map before event of January $25,1982 \ldots \ldots$. . . 87

29. Photograph of segment of ruptured tube (R42-C55) removed from the Ginna

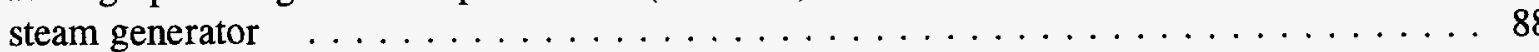

30. Schematic diagram of Westinghouse-designed pressurized water reactor of Rochester Gas and Electric Corporation's Ginna Nuclear Power Plant . . . . . . . . . . . . . . . 90

31. Ginna reactor coolant and steam generator parameters as a function of time, January 25,1982

32. North Anna Unit 1 reactor coolant system pressure versus time during the first 58 minutes of the transient

33. North Anna Unit 1 pressurizer level versus time during the first $\mathbf{5 8}$ minutes of the transient

34. North Anna Unit 1 reactor coolant system temperature versus time during the

35. Time-dependent leakage curve 
36. Pressurizer level during the first 39 minutes of the McGuire Unit 1 steam generator tube rupture event of March 7 and 8, 1989

37. Reactor coolant system and B steam generator secondary side pressure during

the McGuire Unit 1 steam generator tube rupture event of March 7 and 8, 1989

38. Palo Verde Upper Tube Bundle Geometry on the hot leg side 106

39. Palo Verde steam generator cross section in the region of the tube bundle with

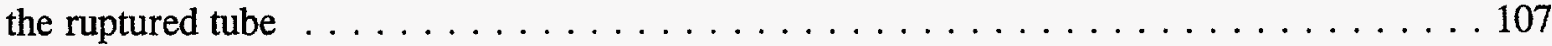

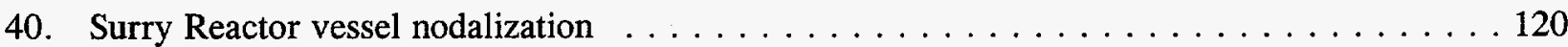

41. Surry primary coolant loop $\mathrm{C}$ nodalization $\ldots \ldots \ldots \ldots \ldots \ldots \ldots \ldots \ldots$

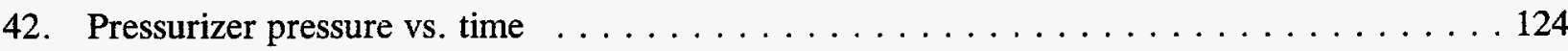

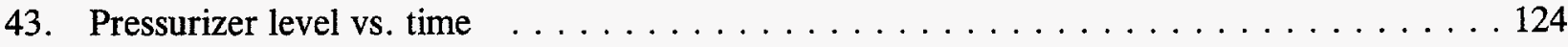

44. Break and high pressure safety injection flow vs. time $\ldots \ldots \ldots \ldots \ldots \ldots \ldots$

45. Steam generator secondary pressure vs. time $\ldots \ldots \ldots \ldots \ldots \ldots \ldots \ldots \ldots \ldots \ldots \ldots \ldots$

46. Primary steam generator and secondary pressure vs. time $\ldots \ldots \ldots \ldots \ldots \ldots \ldots$

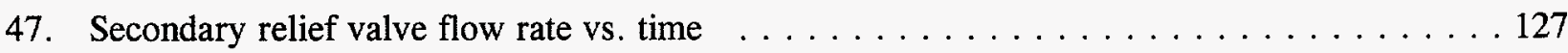

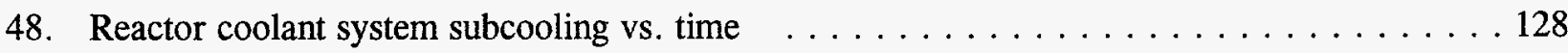

49. Failed steam generator wide and narrow range levels vs. time $\ldots \ldots \ldots \ldots \ldots \ldots$

50. Residual heat removal system inlet and outlet temperatures vs. time . . . . . . . . . . . 129

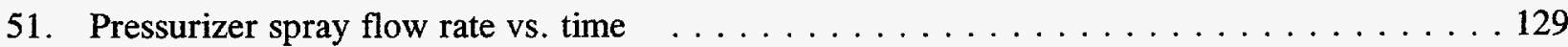

52. Reactor coolant system letdown flow rate vs. time $\ldots \ldots \ldots \ldots \ldots \ldots \ldots \ldots$

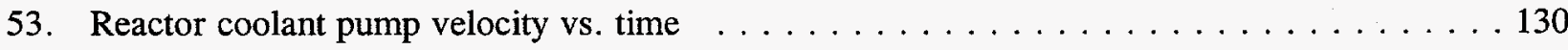

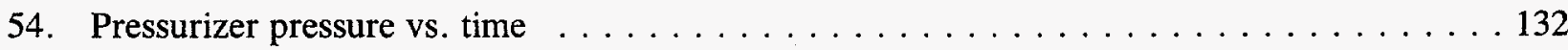

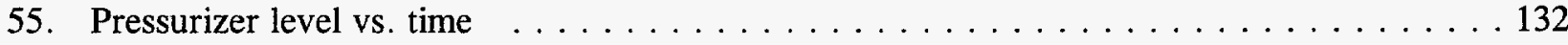

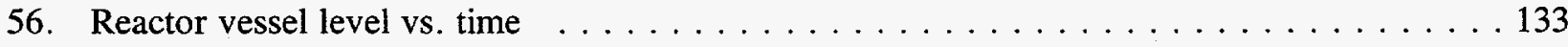

57. Reactor coolant system hot leg temperature vs. time $\ldots \ldots \ldots \ldots \ldots \ldots \ldots \ldots$

58. Break and high pressure safety injection flow rates vs. time $\ldots \ldots \ldots \ldots \ldots$

59. Integrated safety injection flow vs. time $\ldots \ldots \ldots \ldots \ldots \ldots \ldots \ldots \ldots \ldots \ldots \ldots \ldots$ 
60. Residual heat removal system inlet and outlet temperature vs. time $\ldots \ldots \ldots \ldots$

61. Failed steam generator secondary pressure vs. time $\ldots \ldots \ldots \ldots \ldots$

62. Failed steam line break flow rate vs. time $\ldots \ldots \ldots \ldots \ldots \ldots \ldots \ldots \ldots \ldots$

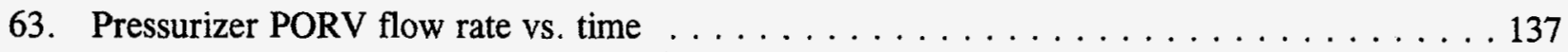

64. Reactor coolant pump speed vs. time $\ldots \ldots \ldots \ldots \ldots \ldots \ldots$

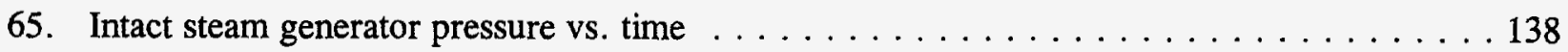

66. Steam generator steam dump flow rate vs. time $\ldots \ldots \ldots \ldots \ldots$

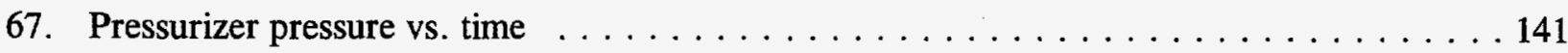

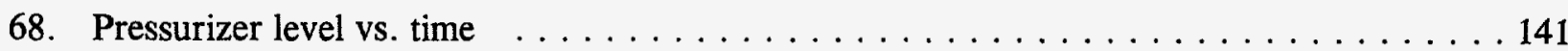

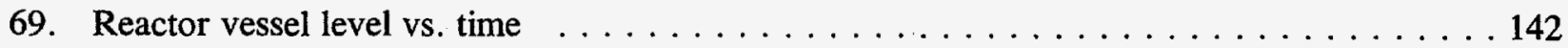

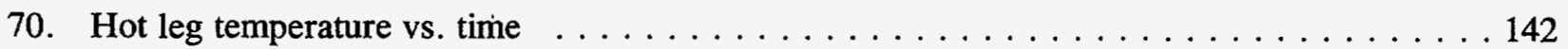

71. Break and emergency core cooling injection flow rates vs. time $\ldots \ldots \ldots \ldots$

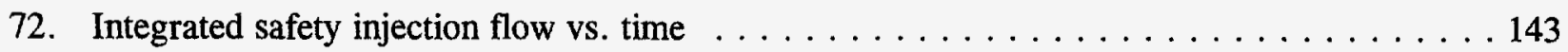

73. Residual heat removal system inlet and outlet temperatures vs. time $\ldots \ldots \ldots \ldots$

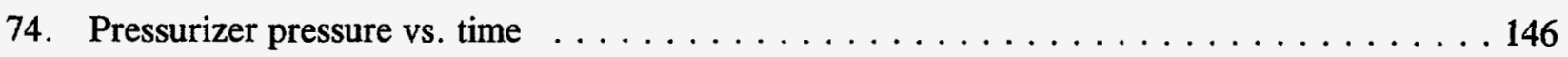

75. Reactor coolant system hot leg temperature vs. time $\ldots \ldots \ldots \ldots \ldots \ldots$

76. Integrated emergency core cooling injection flow vs. time $\ldots \ldots \ldots \ldots \ldots$

77. Fuel rod cladding surface temperature vs. time $\ldots \ldots \ldots \ldots \ldots \ldots$

78. The U.S. nuclear power plants' core damage frequency distribution as reported to

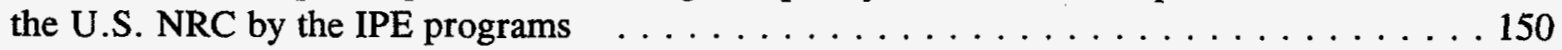

79. Typical steam generator tube rupture contribution to the total core damage frequency $\ldots \ldots 152$

80. Steam generator tube rupture contribution to the total containment bypass fraction

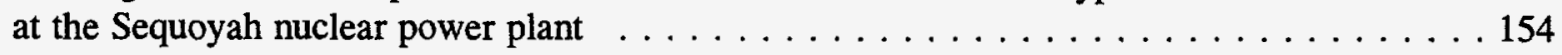

81. Comparison of two different conditional tube rupture probability screening methods $\ldots \ldots 163$

82. Estimated steam generator tube failure probability as a function of pressure and crack depth 
83. Demonstration of induced steam generator tube rupture frequency for a single defective tube . . . . . . . . . . . . . . . . . . . . . . . . . . . . . . . . . 169

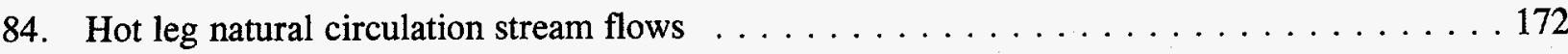

85. Typical eddy-current signal displayed on a cathode ray tube . . . . . . . . . . . 207

86. Eddy-current bobbin probe with flexible wafter guides, used for inspection

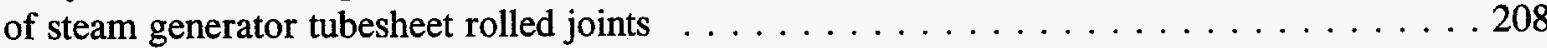

87. Schematic showing (a) the location of the probe coils in an ac bridge circuit, (b) an absolute probe configuration, and (c) a differential probe configuration

88. Eddy-current signals from a typical calibration tube using (a) an absolute probe and (b) a differential probe

89. A cross section of an eddy-current probe showing how the spring loaded pancake

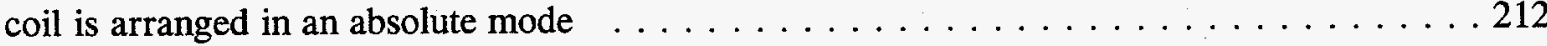

90. Typical differential hybrid coil arrangement $\ldots \ldots \ldots \ldots \ldots \ldots \ldots \ldots \ldots \ldots$

91. Example of support-plate suppression: (a) shows a normal single-frequency response from a $60 \%$ flaw, (b) shows the same response when the flaw is under a support plate, (c) shows the response of a three-frequency multi-parameter mix $\ldots \ldots \ldots 215$

92. Illustration of a motorized rotating pancake coil helical scan $\ldots \ldots \ldots \ldots \ldots$

93. Schematic of a shielded 3-coil motorized rotating pancake coil probe $\ldots \ldots \ldots \ldots$

94. A multiple coil probe for detecting circumferential cracks in steam generator tubing $\ldots \ldots 218$

95. Typical hybrid-expansion-joint sleeve installation $\ldots \ldots \ldots \ldots \ldots \ldots \ldots \ldots \ldots$

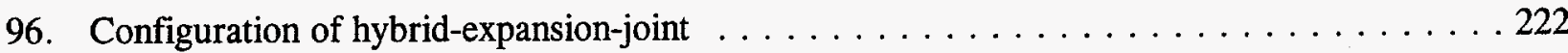

97. Schematic of a cross wound bobbin coil probe for sleeve inspections $\ldots \ldots \ldots 223$

98. Schematic of the "I" type motorized rotating pancake coil probe for sleeve inspections _. . . 224

99. Orientation of the coils in the Zetec Plus-Point probe and typical responses from a weld scan with the probe configured in the standard differential mode . . . . . . . . . . 224

100. Nickel plating of a roll-transition region with PWSCC cracks $\ldots \ldots \ldots \ldots \ldots \ldots$

101. Sketches of unexpanded and expanded mechanical plugs $\ldots \ldots \ldots \ldots \ldots \ldots \ldots$

102. Schematic of rotating ultrasonic beam scanning device $\ldots \ldots \ldots \ldots \ldots \ldots \ldots$

103. Comparison of actual arc length of circumferential cracks in pulled tubes with the ones estimated using eddy-current inspection 
104. Comparison of actual arc length of circumferential ODSCC cracks in pulled tubes with the ones estimated using eddy-current inspection $\ldots \ldots \ldots \ldots \ldots \ldots$

A-1. RHR primary inlet and outlet temperatures $\ldots \ldots \ldots \ldots \ldots \ldots \ldots \ldots \ldots$

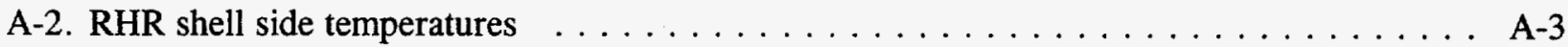

\section{LIST OF TABLES}

1. Typical U.S. steam generator models and their parameters $\ldots \ldots \ldots \ldots \ldots$

2. Typical Mitsubishi Heavy Industries recirculating steam generator models and

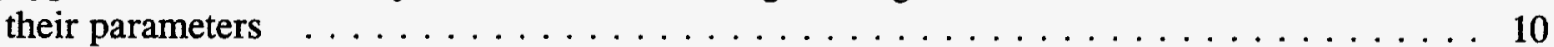

3. Typical Siemens/KWU recirculating steam generators and their parameters $\ldots \ldots \ldots 11$

4. VVER steam generator parameters $\ldots \ldots \ldots \ldots \ldots \ldots \ldots \ldots \ldots$

5. Chemical composition of typical tubing materials $\ldots \ldots \ldots \ldots \ldots \ldots \ldots$

6. Units reporting steam generator problems $\ldots \ldots \ldots \ldots \ldots \ldots \ldots$

7. PWR plants with more than 2,000 steam generator tubes plugged or sleeved $\ldots \ldots \ldots$

8. Summary of PWR recirculating steam generator tube degradation processes $\ldots \ldots \ldots 4$

9. Summary of major CANDU steam generator degradation $\ldots \ldots \ldots \ldots \ldots$

10. Summary of once-through steam generator tube degradation processes $\ldots \ldots \ldots 3$

11. Summary of degradation processes for PWR feedwater nozzles and steam

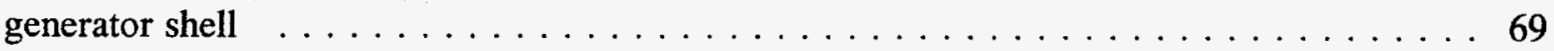

12. Summary of the leak rate, degradation mechanism, rupture size, rupture location, and stressor information associated with the ten ruptures discussed in Section 4

13. Summary of plant transient information $\ldots \ldots \ldots \ldots \ldots \ldots \ldots \ldots$

14. Recent incipient steam generator tube rupture events $\ldots \ldots \ldots \ldots \ldots \ldots \ldots$

15. Double-ended failure of a steam generator tube: sequence of events and key assumptions

16. Steam line break with one steam generator tube failed: sequence of events and key assumptions 
17. Steam line break with 15 steam generator tubes failed: sequence of events and key assumptions

18. U.S. PWR IPE results

19. Identification of initiating events 156

20. Impact of the number of tubes failed on defense in depth $\ldots \ldots \ldots \ldots \ldots \ldots \ldots$

21. Information of screening induced steam generator tube rupture $\ldots \ldots \ldots \ldots$

22. Steam generator tubing inspection guidelines $\ldots \ldots \ldots \ldots \ldots \ldots \ldots \ldots$

23. Steam generator tube inspection requirements in the United States $\ldots \ldots \ldots \ldots \ldots$

24. General information on repair criteria currently implemented $\ldots \ldots \ldots \ldots \ldots$

25. Fitness-for-service guidelines in eight countries $\ldots \ldots \ldots \ldots \ldots \ldots \ldots \ldots$

26. Sites, typical characteristics, and inspection of steam generator tube damage $\ldots \ldots \ldots 241$ 


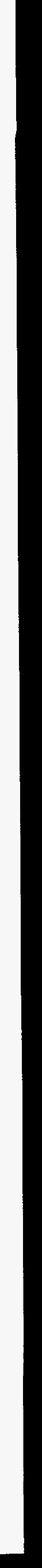




\section{EXECUTIVE SUMMARY}

\section{Introduction.}

The steam generators in the pressurized water reactor (PWR), Canadian deuterium uranium (CANDU) reactor, and Russian water moderated, water cooled energy reactor (VVER) plants are large heat exchangers that use the heat from the primary reactor coolant to make steam in the secondary-side to drive turbine generators. The primary reactor coolant passes through the tubes and boils water on the outside of the tubes (secondary-side) to make steam. The design confines radioactivity from neutron activation or fission products to the primary coolant during normal operation. However, the primary reactor coolant is at a higher pressure than the secondary coolant, so any leakage from defects in the tubes (or in the VVER collectors or PWR tubesheets) is from the primary to the secondary-side, and rupture of the heat exchanger tubing can result in release of radioactivity to the environment outside the reactor containment through the pressure relief valves, the condenser off-gas, or other paths in the secondary system.

\section{Steam Generator Degradation.}

To prevent the release of radionuclides, the steam generator tubing must be essentially free of cracks, perforations, and general deterioration. However, widespread degradation of the steam generator tubes has occurred at a number of plants. As a result, about one-half of the PWR nuclear power plants in the world have been removing from service (plugging) or repairing (sleeving) steam generator tubes in any given year. The number of steam generator tubes plugged per year during the last few years has ranged from about 10,000 to 12,000 tubes. A total of about 48,000 tubes had been sleeved by the end of 1994. These data indicate that at any given time, and prior to their tubes being sleeved or plugged, a significant number of the PWR plant steam generators are operating with tubing defects near, or beyond the limits set by their country.

The relative impact of the tube degradation mechanisms on overall PWR steam generator performance has dramatically changed over time. Phosphate wastage was the major cause of tube failures in PWR steam generators until about 1976. From 1976 to about 1979 , denting was the major cause of PWR steam generator tube failures. After about 1979, a variety of corrosion mechanism became important, including outside diameter stress corrosion cracking/intergranular attack (ODSCC/IGA) and pitting on the outside diameters of the tubes and primary water stress corrosion cracking (PWSCC) on the inside surfaces. Fretting damage became more apparent after about 1983. In 1994, ODSCC (42\%), PWSCC (22\%), and fretting (4\%) accounted for about $68 \%$ of all the tubes plugged. However, the degradation mechanism is unknown for a significant number of defective tubes (about $30 \%$ ). Over $50 \%$ of the PWR units worldwide have now reported some occurrence of tube fretting wear. Not all steam generators are degrading equally. At least 14 plants have each plugged and sleeved over 2,000 steam generator tubes. However, some plants report no problems, even after 5 years of operation $(7-10 \%$ of the plants report no problems after 5 years of operation).

Most of the PWR and CANDU steam generator tubes which have failed over the years have been mill-annealed Alloy 600 tubes. However, some failures of thermally treated Alloy 600 tubing have been reported, primarily due to fretting and denting; degradation mechanisms due to the design of the support plates and antivibration bars (AVBs) and the presence of loose parts, rather than the tubing material. There have also been failures of thermally treated Alloy 600 tubing due to primary and secondary-side stress corrosion cracking, primarily in plants with roll-transitions. 
The Monel-400 tubes have also been susceptible to pitting degradation. Tubes made of Alloy $800 \mathrm{M}$ and Alloy 690 have been resistant to stress corrosion cracking and have exhibited relatively few failures. However, there have been Alloy $800 \mathrm{M}$ tubing failures due to wastage and fretting in the older Siemens/KWU steam generators.

PWSCC is an intergranluar cracking mechanism requiring at least the following conditions to be present:

- high applied or residual tensile stress or both (near the yield strength),

- a corrosive environment (high temperature water), and

- $\quad$ susceptible tubing microstructure (alloy content and few intergranular carbides).

PWSCC occurs at locations on the inside surfaces of recirculating steam generator (RSG) tubing with high residual stresses. These locations are primarily the expansion-transition regions in the tubesheets, the U-bend regions of the tubing in the inner rows (i.e., the tubes with a small bend radius), and any dent locations at the tube support plate, tubesheet, or sludge pile elevations. Both axial and circumferential cracks can occur at some expansion-transition and dent regions. An axial PWSCC crack will generally leak before the critical crack size for rupture is achieved; however, the evolution of circumferential cracks is not known and they are usually plugged or sleeved upon detection. Tubes with axial cracks have ruptured before the leakage was detected.

Approximately 14,180 RSG tubes with PWSCC at or near the expansion-transitions have been plugged at 85 plants, as of December 1993. Tubes with PWSCC have also been sleeved at 17 plants. Approximately 8,430 RSG tubes with PWSCC in the U-bend regions have also been plugged at 63 plants. Fifty-three PWR plants have experience both expansion-transition and Ubend PWSCC and tubes with PWSCC at dents have been plugged at, at least five plants.

ODSCC is a degradation mechanism which includes both intergranular stress corrosion cracking (IGSCC) and IGA on the outside surfaces of the tubing. IGSCC requires the same three conditions as PWSCC: tensile stress, material susceptibility, and a corrosive environment (in this case, high-temperature water containing aggressive chemicals). IGA is a similar form of attack but, unlike IGSCC, it can occur without large tensile stresses present. The cracks caused by IGSCC can be single cracks or networks of multiple cracks generally oriented normal to the maximum principal stress. The IGA is characterized by a relatively uniform attack on all the grain boundaries in a particular area. Often, IGA is a precursor to IGSCC. Most outside diameter stress corrosion cracks are primarily oriented in the axial direction, however, significant circumferential cracking has been observed in the expansion-transition region of the tubing in some steam generators and circumferential ODSCC is sometimes found near dents. Shallow circumferential cracks may sometimes occur in the IGA affected regions producing a grid-like pattern of axial and circumferential cracks termed "cellular corrosion."

ODSCC strongly depends on the concentration of corrosive impurities in the steam generator. The impurities are brought into the steam generator with the feedwater at low concentrations as a result of condenser in-leakage, makeup water system impurities, corrosion of piping and heat exchanger equipment, and condensate polisher leakage. The bulk boiling process concentrates the impurities over time in the steam generator coolant and even higher impurity concentrations form in the tubesheet and tube support plate crevices, the sludge pile, and occasionally between tubes in the upper free-span regions where crud collects. The impurities concentrate in these regions because the coolant circulation is 
poor and local boiling or dryout (steam blanketing) occurs.

Approximately 14,140 RSG tubes with ODSCC at the tube support plate locations have been plugged at 63 PWR plants, as of December 1993. Approximately 13,860 RSG tubes with ODSCC in the tubesheet crevice and sludge pile regions have also been plugged at 75 PWR plants (49 PWR plants have had both tube support plate and tubesheet ODSCC repairs). Tubes with ODSCC have also been sleeved at 25 plants. This degradation has occurred primarily in Combustion Engineering (8 plants) and Westinghousetype plants (79 plants) with Alloy 600 millannealed tubing. Only one tube with ODSCC has been found in the Siemens/KWU steam generators with Alloy $800 \mathrm{M}$ tubing and only one plant with thermally treated Alloy 600 tubing has reported ODSCC. The only CANDU plant with extensive ODSCC has been Bruce-A2 where 1,399 tubes failed (were plugged) due to lead assisted stress corrosion cracking. The most extensively degraded steam generators have had as many as 40 to $56 \%$ of all their tubes plugged or sleeved as a result of ODSCC and have been replaced at a number of plants (or in some cases, the plants have been shut down). However, similar steam generators (same model number) at other plants have experienced only a few percent failures due to ODSCC.

The major stressor in fretting and wear is flowinduced vibration. Tube vibration can be induced by fluid cross flow or by parallel flow. Initiation, stability, and growth characteristics of damage by these mechanisms may be functions of a large number of variables, including support locations, stiffness of the supports, gap size between tube and support, secondary flow velocities and directions, and oxide layer characteristics.

There have been 4,633 tubes plugged because AVB wear/fretting, mostly in Westinghouse-type steam generators. This damage has occurred in the more recent Westinghouse steam generator designs at 17 plants (Westinghouse models F, $44 \mathrm{~F}$, and $51 \mathrm{~F}$ and Mitsubishi Heavy Industries Model 51F) as well as in the earlier model steam generators. Steam generator tubes have also been plugged due to AVB (batwing or vertical strap) wear/fretting at, at least seven Combustion Engineering designed plants and one CANDU plant. AVB wear/fretting has also occurred in most of the older Siemens/KWU RSGs. At least 841 tubes have been plugged because of loose parts damage in 78 plants, although most of these plants (44 plants) have plugged less than 10 tubes each.

Pitting is a degradation mechanism appearing as groups of small-diameter wall penetrations resulting from local corrosion cells. It is probably promoted by the presence of chloride or sulfate acids. Condenser leaks and leakage of beads, resin fines, or regeneration chemicals from ion exchangers can introduce impurities such as chlorides and sulfates, which result in local acidic conditions conducive to pitting. Oxidizing conditions and the presence of copper are probable accelerators. Significant pitting was first reported in an operating PWR steam generator about 1981. As of December 1993, only 11 PWR plants with RSGs had plugged tubes because of pitting and a few other plants had reported minor pitting degradation of $15 \%$ throughwall depth or less. However, a few plants have experienced significant pitting degradation.

The term denting describes the mechanical deformation or constriction of a tube at a carbon steel tube support plate intersection or within the tubesheet caused by the buildup of deposits and the growth of a voluminous support-plate or tubesheet corrosion product in the annulus between the tube and support plate or tubesheet. Dents do not themselves result in tube wall penetration or reduction in wall integrity. However, denting at some plants has been sufficiently severe that it caused structural damage to the tube supports and denting is a concern because even small dents can induce 
tensile stresses above yield strength in the tube wall. As a result, these tubes may be subject to PWSCC or IGSCC at the dents during subsequent operation. As of December 1993, 1,471 RSG tubes at 41 plants (4 Combustion Engineering and 37 Westinghouse-type plants) had been plugged because of tubesheet and sludge pile denting, and 9,092 RSG tubes at 17 plants (4 Combustion Engineering and 13 Westinghouse-type plants) had been plugged because of support plate denting.

High-cycle fatigue occurs in steam generators with high recirculation flow factors (causing flow-induced vibrations in the U-bend region) and improper AVB support. A high mean stress (e.g., residual stress) or a tube defect (fretting mark or crack) significantly reduces the fatigue strength. High-cycle fatigue ruptures have occurred in the U-bend regions of the North Anna Unit 1 and Mihama Unit 2 steam generators. These ruptures were located high up in the steam generator where the leak location can more readily become uncovered by secondary water. This can allow escape of fission products from the primary coolant without partitioning in the secondary water.

Most of the earlier tube failures in CANDU steam generators tubed with Alloy 600 have been due to high-cycle fatigue. These failures were caused by flow-induced vibration and were initiated at either fret marks at the land area of the upper trefoil tube support plates or more recently at stress corrosion cracks on the outside surfaces in the U-bend area and at the seventh support plate. These failures continue to occur in the older CANDU steam generators. The resulting fatigue cracks were circumferential, but did not lead to a tube rupture.

Once-through steam generators in the United States (U.S.) use the same Alloy 600 tubing materials as RSGs, yet these steam generators have experienced substantially fewer tube fail- ures. The lower failure rate is attributed to the differences in the steam generator design, manufacturing processes, and operation. Many of the chemical concentration processes do not operate in once-through steam generators, as they do in RSGs. Failures have occurred in oncethrough steam generators due to erosioncorrosion, environmentally assisted high-cycle fatigue and low-temperature primary-side stress corrosion cracking.

The VVER tubing has been relatively trouble free; however, the collectors in the VVER-1000 steam generators have been a problem. As of July 1993, 33 steam generators at 8 VVER-1000 plants had been replaced because of failure or the potential of failure of the cold collectors. Unfortunately, many (most) of the replacement steam generators are not significantly different than the original equipment so additional cracking is expected. The collector cracks and crack propagation rates can be large. Cracks up to $1,000 \mathrm{~mm}$ ( $40 \mathrm{in}$.) in length have been found and crack propagation rates up to six ligaments per operating cycle have been observed.

PWR and CANDU steam generator shell, feedring, feedwater nozzle and divider plate degradation has also occurred and is discussed in the report. Erosion-corrosion of the VVER feedwater distribution systems is also discussed.

\section{Steam Generator Tube Ruptures.}

Ten steam generator tube ruptures have occurred over the past 20 years at a rate of about 1 rupture every 2 years. In addition, incipient tube rupture events have been occurring in the U.S. at the rate of about once a year in recent years. Five different tube degradation mechanisms caused the ten ruptures: three ruptures were caused by ODSCC, two ruptures were caused by high-cycle fatigue, two ruptures were caused by loose part wear, two ruptures were caused by PWSCC, and one rupture was caused by wastage. 
The rupture locations have generally been either just above the tubesheet (three ruptures), or in the U-bend region (six ruptures). Only the McGuire rupture was near one of the lower support plates. (Although the Palo Verde Unit 2 rupture was in the U-bend region, it was in the straight portion of a row 117 tube between the $08 \mathrm{H}$ and $09 \mathrm{H}$ partial support structures.) The ruptures caused by loose parts wear have occurred just above the tubesheet whereas the ruptures caused by high-cycle fatigue have occurred just above the top tube support plate. Any future ruptures caused by those mechanisms will probably occur in the same locations.

The size and shape of the ruptures varies. Seven of the ruptures were axial cracks ranging in size from 32 to $250 \mathrm{~mm}$ (1.25-10 in.) in length. Some of the axial crack ruptures became so called "fishmouth" openings (4 tubes). Two of the ruptures were 360-degree circumferential breaks and one rupture consisted of two adjacent bulges, each about $20 \mathrm{~mm}$ (0.75 in.) long. The ten ruptures caused leak rates that ranged in size from $425 \mathrm{l} / \mathrm{min}$ (112 gpm) to $2,900 \mathrm{l} / \mathrm{min}$ (760 gpm).

During a tube rupture transient, the reactor operators are expected to (a) maintain the primary coolant subcooled, (b) minimize the leakage from the reactor coolant system to the faulted steam generator secondary side, and (c) minimize the release of radioactive material from the damaged steam generator. The success of the reactor operators has been mixed, some were slow to understand what was occurring, slow to start reducing power, and slow to isolate the defective steam generator. Others reduced power and isolated the faulted steam generator promptly. Some operators were slow to cool and depressurize the primary system, others took prompt action. The result was that the faulted steam generators were overfilled in a number of cases and more radioactive material was released to the environment than necessary.
Despite these variations in timing, it should also be noted that in all cases the plants were properly cooled down and the radioactive material releases were small and well below regulatory limits. Also, the operator performance was sometimes hampered by inadequate Emergency Operating Procedures (Palo Verde, for example) or by defective equipment (Mihama, for example). At other times, the operators were hampered by plant conditions that did not allow rapid employment of Emergency Operating Procedures. There are still numerous reasons for (a) continued operator training on steam generator tube ruptures, and (b) training on the recognition of events based on the indications that are available.

For some of the incipient steam generator tube rupture events, the operators were able to quickly shut down the reactor and isolate the defective steam generator. (In other cases, the cracks stopped growing for unknown reasons.) These actions limited the contamination of the secondary coolant and may have prevented actual tube rupture. Also, some of these events demonstrated how quickly very low leak rates can increase as the crack grows. Leak rate monitoring programs that provide close to real time information can limit the frequency of steam generator tube ruptures.

\section{Thermàl-hydraulic Response of a Nuclear Power Plant.}

Analyses of the spontaneous steam generator tube rupture and combined steam line break-induced tube rupture events are presented to demonstrate system behavior and the associated methods for bringing the reactor coolant system to shut down cooling conditions while minimizing radiological releases and controlling the reactor coolant system inventory. Our analysis of the spontaneous steam generator tube rupture event demonstrate that, with a timely diagnosis, the break flow and release of secondary steam from the 
affected steam generator can be terminated within 1 hour of initiation of the tube failure. Cooldown and initiation of residual heat removal for longterm cooling can be achieved in approximately 4 hours following opening of the break.

Following a combined steam line break-induced tube rupture event, it is necessary to cool down and throttle the emergency core cooling system flow as soon as possible to prevent exhaustion of the refueling water storage tank. Since the combined steam line break-tube rupture event results in exhausting the refueling water storage tank through the secondary system, it is not possible to develop a containment sump inventory to eventually transfer injection from the refueling water storage tank. As a consequence, there is the need to more quickly cool and lower the pressure in the reactor coolant system using the pressurizer power operated relief valves. Analysis of the combined steam line break-single tube rupture event demonstrates that there is sufficient time or about 7 hours for operator action to cool down the reactor coolant system and actuate the residual heat removal system to assure long-term coolability of the core. Analyses of the steam line break-multiple tube failure event demonstrates that, in the unlikely event 15 tubes are failed, operator action within 1 hour to throttle emergency core cooling and initiate the residual heat removal system can assure long-term cooling. If more than 15 induced steam generator tubes rupture, the system response could lead to core melting.

\section{The Risk Significance of Steam Generator Tube Rupture Accidents.}

Section 6 of this report summarizes a few key risk observations regarding spontaneous and induced steam generator rupture accidents. A spontaneous steam generator tube rupture is the rupturing of one or more steam generator tubes that is not caused by another event or an upset in normal expected operational parameters. Unlike spontaneous steam generator tube ruptures, an induced steam generator tube rupture is an accident that is associated with an upset condition. Induced steam generator tube ruptures are conditional based on the occurrence of other events, and the presence of severely degraded steam generator tubes. (Note: As of April 1996 no induced steam generator tube ruptures have occurred). The relative risk importance of spontaneous steam generator tube ruptures and induced steam generator tube ruptures is a. function of the amount of tube degradation found in the steam generators. Induced steam generator tube ruptures become more risk important than spontaneous tube ruptures as the steam generator tubes' ultimate pressure capacity degrades.

Both spontaneous and induced steam generator tube ruptures may be risk significant due to the fact that the radionuclides may bypass the reactor containment building during these events. Containment bypass events with subsequent core damage result in a disproportionate amount of radionuclides being released to the environment. This risk significant observation is valid even though steam generator tube ruptures are small contributors to the total core damage frequency in most probablistic risk assessments.

As noted above, containment bypass events are very important in understanding the risk associated steam generator tube rupture and the steam generator tube rupture accident's thermalhydraulic progression. The important containment bypass effects are: (a) containment bypass influences the number, reliability, and types of systems needed to prevent core damage from occurring, (b) containment bypass events influence the core damage frequency distribution associated with a range of multiple tube rupture events, and (c) containment bypass provides a direct release path to the environment for radionuclides.

The conditional probability of a steam generator tube(s) failing is a function of the type of aging degradation and the extent of the degradation. 
The thermal-hydraulic conditions imposed on the tube are also important. The important thermalhydraulic parameters are: (a) steam generator tube temperature, and (b) the steam generator tube pressure differential. These thermalhydraulic conditions are a function of the transient and/or accident, as discussed above.

The risk associated with induced steam generator tube ruptures has contributions from the following type of events or accidents: (a) operational transients, (b) rare events, and (c) severe accidents. All of these events introduce moderate to large increases in the pressure differential across the steam generator tubes. For degraded tube conditions, the moderate to large increases in the pressure differential increases the probability of a steam generator tube failure. Operational transients occur frequently and may result in slight or moderate increases in the pressure drop across the steam generator tubes. These types of transients include: (a) turbine trip, (b) loss of main feed, (c) temporary loss of off site power, (d) failed open turbine bypass valve, and (e) loss of a reactor coolant pump.

Rare events are design basis or other events that have a low frequency of occurrence, but may result in significant steam generator tube over pressures. These types of events typically include: (a) main feed line break, (b) main steam line break, (c) anticipated transients without scram, and (d) loss of coolant accidents (reversed pressure drop). Rare events with moderate tube degradation can be less risk significant than the operational events with severely degraded steam generator tubes due to the lower frequency of occurrence of a rare event. However, rare events are typically used to conservatively bound the worst case accident for regulatory purposes.

Severe accidents are very low frequency events. In some cases, severe accidents may cause elevated pressure-temperature conditions in the steam generators over that found under typical design bases accident conditions. Typical severe accidents of concern for degraded steam generator tubes include: (a) anticipated transient without scram, (b) station black out, and (c) station blackout with a stuck open atmospheric dump valve or safety relief valve. Even minor tube degradation in association with severe accident induced elevated pressure-temperature conditions can increase the probability of tube failure.

Insights into the U.S. steam generator tube rupture risk profile can be gained from an examination of the U.S. Nuclear Regulatory Commission (USNRC) and industry probabilistic risk assessment (PRA) and Individual Plant Examination (IPE) program results. These insights indicate that the risk associated with a steam generator tube rupture is dominated by a few significant failures. Typically the dominate steam generator tube rupture failure contributors are human error (the operator fails to depressurize the primary system) and mechanical system failures along with human errors that cause a loss of the refueling water storage tank inventory.

Steam Generator Tubing Inspection Requirements and Fitness-for-Service Criteria in Various Countries.

The probability of steam generator tube failures can be reduced through timely and effective inspections and appropriate acceptance (fitnessfor-service) criteria. We summarize in this report the inspection requirements and fitnessfor-service criteria used in a large number of countries. Some countries have chosen to have somewhat more conservative fitness-for-service criteria and less inspection. Other countries have chosen less conservative fitness-for-service criteria (thereby saving money on repairs) and more inspections. Some countries have more or less of both, compared to other countries. These differences are due, in part, to the fact that different steam generator designs and materials, and specific plant sites, are susceptible to different types of aging degradation, some of which is easier to detect or has less severe safety 
consequences than other types of degradation. Also, these differences are due to the fact that some countries are willing to accept more risk than other countries.

To determine the number of steam generator tubes to be inspected and the frequency of the inspections, some countries group their steam generators into two categories with quite different numbers of tubes inspected in each category. The categories used are either "susceptible tubing and less susceptible tubing" or "previous defects or no defects." Other countries apply the same inspection criteria to all their steam generators. Some countries inspect a small fraction of the tubes (for example 3\%) and then more tubes when defects are found. Other countries inspect a much larger fraction of the tubes, especially in steam generators with susceptible tubing, or previous defects. Some countries inspect all the tubes every year in steam generators with defects. The types of inspection equipment in use varies greatly from plant to plant and country to country. The defect detection reliability and defect sizing accuracy of the various inspection techniques is discussed below. In addition, the locations within the tubes that are inspected varies somewhat. Some countries inspect the full tube length; other countries focus their inspections on selected areas where the degradation is most likely to be found. Some countries do both.

Repair or removal from service criteria can be grouped into two families: generic and defecttype and location specific fitness-for-service criteria. The simplest and most conservative generic approach is no detectable defects. The most widely implemented fitness-for-service criterion is a minimum wall thickness criterion, usually the value specified in the American Society for Mechanical Engineers (ASME) Code.

The occurrence in recent years of new types of tube degradation, such as PWSCC within the tubesheet or axial ODSCC within the support plates, led to the development of defect-type and location specific repair criteria. The $\mathrm{P}^{*}$ and $\mathrm{F}^{*}$ criteria allow tubes with flaws in the tubesheet region to remain in service without repair if the flaws are low enough so that the damaged tube remains in the tubesheet even if it separates at the flaw. Because steam generator tubing is very ductile, reasonably short through wall axial cracks exhibit slow propagation. Therefore, axial cracks located close to the top of the tubesheet, and shorter than about 10 to $13 \mathrm{~mm}$, may remain in service in some countries even if they are through the wall. The complex morphology of ODSCC and the difficulties in detecting and sizing this degradation have led some plants to use a statistical voltage based criteria. The allowable eddy-current signal is based on: (1) a burst pressure correlation together with allowances for defect progression and inspection uncertainties, and (2) a leak rate correlation, the recent population of defects in the steam generator, and, again, allowances for defect progression and inspection uncertainties.

Some countries depend, in part, on very good leak detection (nitrogen-16) and the assumption that degraded steam generator tubes will leak before they rupture. However, long throughwall cracks have been found that are rather leak tight. The current tendency is, therefore, to put increasing weight on the use of inspections and to use leak detection as an added safety feature.

\section{Steam Generator Tube Defect Detection Reliability and Sixing Accuracy.}

Inspection of steam generator tubes has faced two types of challenges that have made reliable detection and accurate characterization of defects difficult: (1) appearance of newer and much more subtle forms of degradation in the aging steam generator tubes, and (2) the presence of a variety of design features (such as support plates, tubesheets and AVBs) and deposits on the outside surface of the tubes which produce signals that mask the signals from the defects. During the 
last 25 years, steam generator tubes have been damaged by about 10 different degradation mechanisms ranging from stress corrosion cracking, high-cycle fatigue, and pitting to wastage, denting, and wear. The morphology of the damage caused by each of these mechanisms is different and complex. For example, stress corrosion cracking defects are small-volume flaws, whereas wall thinning caused by wastage and wear are large-volume flaws. The stress corrosion cracking initiates either at the outside or at the inside surface and generally has an axial or a circumferential orientation. Sometimes, both axial and circumferential cracks are present at the same location.

Eddy-current testing is well suited for inspecting thin-walled steam generator tubes with large surface areas because it offers high scanning speed and high sensitivity. Different eddycurrent probes have been designed in response to the difficulties associated with the steam generator tube inspections. Eddy-current probes with bobbin coils and rotating pancake coils are usually used for inspection of steam generator tubes, and reliably detect flaws, but their detection threshold is high, some deep cracks have been missed, and defect sizing and resolution are not accurate. As a result, advanced eddy-current probes employing different arrangements of the pancake coils and multiple transmit-receive coils, and ultrasonic inspection probes employing pulse echo and tip diffraction techniques are being developed for more reliable detection and accurate sizing of stress corrosion cracking. The capabilities and limitations of these probes for inspection of steam generator tubes are summarized next.

Inspection of PWSCC and IGSCC. Bobbin coils are sensitive to axial cracks and volumetric flaws. However, field studies have shown that bobbin coils can detect axial PWSCC in a rolltransition region only when multiple axial cracks with near throughwall penetration are present. Similarly, the bobbin coil probe appears to be able to detect axial cracks in the U-bend regions only when the total number of cracks are beyond a certain threshold or the cracks are long. Rotating pancake coil probes are used for sizing the axial PWSCC. Comparison with pulled tube results show that a rotating pancake coil can measure axial PWSCC within $\pm 1.5 \mathrm{~mm}$.

Single-frequency bobbin coils may not reliably detect axial ODSCC if extraneous variables, such as a support plate, denting, or a deposit on the outside surface, are present. Therefore, multifrequency/multiparameter eddy-current methods employing bobbin coils are used for inspection of axial ODSCC. These methods suppress the changes produced by the extraneous variables and can detect and size deep ODSCC ( $>40 \%$ throughwall). However, reliable detection and accurate sizing of ODSCC/IGA defects with bobbin coil probes is difficult. Some ODSCC/ IGA defects greater than $40 \%$ throughwall have been missed. Therefore, the indications detected with bobbin coils are often confirmed with rotating pancake coil inspections.

The rotating pancake coil probe is used for detection of circumferential PWSCC and ODSCC. This probe can reliably detect circumferential PWSCC in the expansion-transition region once it exceeds $50 \%$ throughwall depth. Based on the analyses of pulled tube data at North Anna, the detection limits of these probes for circumferential cracks in dents is about $50 \%$ throughwall and a 50-degree arc length, or $100 \%$ throughwall and a 23-degree arc length.

No eddy-current methods are qualified at present for sizing the length and depth of circumferential cracks. Based on comparisons between measurements from rotating pancake coil probes and Cecco-5 probes, and metallographic data from pulled tubes, the nuclear industry has estimated that the arc lengths of circumferential cracks are being measured to within \pm 37 to 45 degrees. The nuclear industry is also currently working on developing qualified techniques for sizing the depth of circumferential cracks using Plus-Point probes, which are sensitive to both circumferential and axial indications. 
Ultrasonic inspection methods are being developed for sizing and resolution of the ODSCC detected during eddy-current inspections. For example, rotating pancake coil inspection of the expansion-transition region of steam generator tubes at one U.S. plant revealed extensive circumferential cracks at the outside surface. Ultrasonic measurements revealed that the cracks ranged in circumference from 84 to 329 degrees, and ranged in depth up to $100 \%$ throughwall. The ultrasonic measurements compared well with the actual crack profile determined from examinations of pulled tube specimens. The ultrasonic inspection also revealed that the cracks consisted of several discontinuous microcracks separated by small ligaments of sound material. The discontinuous nature of the array of microcracks was confirmed by the examination of the pulled tube specimens.

Inspection of IGA. It is difficult to detect and characterize IGA damage with conventional bobbin coil or rotating pancake coil probes; as revealed by the inspection experience at the Trojan plant. These probes are not sensitive to the slow changes in the electrical conductivity and magnetic permeability caused by IGA. However, an $8 \times 1$ array probe can estimate the circumferential extent and depth of IGA.

Inspection of Pitting. Pitting appears as a group of small diameter wall penetrations with a diameter to depth ratio greater than 1.0. Once pitting has initiated, the rate of pit growth can be rapid. The accuracy of the eddy-current pit depth measurements is severely limited because of the small size of the pits and because the pits are often filled with copper containing corrosion products with a high conductivity. A rotating ultrasonic inspection probe has accurately measured pit depths to $\pm 2 \%$ of the wall thickness in Monel 400 tubes in CANDU steam generators.

Inspection of Dents. Bobbin coils are usually employed to detect and size denting. Specialized probes such as array probes with eight contactless pancake coils or rotating ultrasonic inspection probes are being used for estimating the radial profiles of dented tube cross-sections.

Inspection of High-Cycle Fatigue Cracking. High-cycle fatigue cracking has occurred at the top tube support plate in once-through steam generators. Detection of a high-cycle fatigue crack with an eddy-current probe is difficult because of the presence of the tube support plates and because the crack produces a low-amplitude signal. However, an $8 \times 1$ array probe is likely to provide reliable detection and accurate sizing information.

High-cycle fatigue-induced tube ruptures in the $\mathrm{U}$-bend region of recirculating steam generators pose another inspection problem; the initiation time for a high-cycle fatigue crack is long and the crack growth is very rapid. This makes timely detection of the fatigue crack difficult. Ultrasonic examination with tip diffraction techniques could be used for detection and characterization of high-cycle fatigue cracks.

Inspection of Fretting and Wear. Eddy-current inspection of tube fretting caused by the AVBs is difficult because the bars, which are made from Alloy 600 or 690 , are typically chrome plated. In addition it is difficult to estimate the wear depth because fretting wear may take place at one or both sides of the outer tube surface, depending on the AVB configuration. Therefore, for each AVB design and material, eddy-current signal amplitude calibrations have been developed for one-sided and two-sided wear at selected depths. Using these calibrations, the tube fretting damage can be characterized with a two-frequency eddycurrent inspection system.

Loose part induced wear is generally limited to peripheral tubes and is relatively easy to detect when it is suspected. However, the sizing of the affected area may not be accurate. Also, the rate of loose part induced wear is unpredictable. 


\section{ACRONYMS}

ASDTV Accident Specific Degradation Threshold Value

ASME American Society of Mechanical Engineers

AVB antivibration bar

AVT all volatile treatment

CANDU Canadian deuterium uranium

EdF Èlectricitè de France

EFPY effective full power years

EPRI Electric Power Research Institute

IAEA International Atomic Energy Agency

IGA intergranular attack

IGSCC intergranular stress corrosion cracking

IPE individual plant examination

LOCA loss-of-coolant accident

MFEC multifrequency eddy-current

MPEC multiparameter eddy-current

MTFS maximum tolerable flaw size

NDE non-destructive examination

NPAR Nuclear Plant Aging Research (Program)

ODSCC outside diameter stress corrosion cracking

PNL Pacific Northwest Laboratories

PORV power operated relief valve

PRA probabilistic risk assessment

PWR pressurized water reactor

PWSCC primary water stress corrosion cracking

RCP reactor coolant pump

RHR residual heat removal

RSG recirculating steam generator

U.S. United States

USNRC United Stated Nuclear Regulatory Commission

VVER water moderated, water cooled energy reactor 


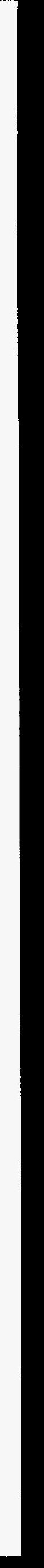




\section{ACKNOWLEDGMENTS}

The authors would like to thank Dr. Denwood F. Ross who provided the initial direction for this project and articulated the need for a comprehensive and integrated evaluation of steam generator tube degradation, tube rupture, the thermal-hydraulic response of a plant with a defective steam generator, tubing inspection requirements and fitness-for-service criteria, tube defect detection reliability and sizing accuracy, and plant risk. The authors would also like to thank the following USNRC staff for their careful review of this report and helpful comments: J. R. Boardman, J. E. Donoghue, and K. J. Karwoski.

The steam generator design and degradation material (Sections 2 and 3), and the information on steam generator tubing inspection requirements and fitness-for-service criteria (Section 7), was developed, in part, during iwo other projects: the USNRC's Nuclear Plant Aging Research (NPAR) Program and a project sponsored by the International Atomic Energy Agency (IAEA) to develop guidelines for the aging management of the major nuclear power plant components. The authors would very much like to thank the managers of those projects, J. Vora and J. Pachner, for their support and advice. Also, we would like to acknowledge the support of A. P. L. Turner and J. A. Gorman of Dominion Engineering, on the original NPAR work. We would also like to acknowledge the technical contributions to the IAEA project (used mainly in Sections 2 and 7) of J. Bros, Tecnatom, Spain; L. Cizelj, Jozef Stefan Institute, Slovenija; P. Cornet, Électricité de France, France; Y. G. Dragunov, OKB Gidropress, Russia; G. Fluckiger, NOKBeznau, Switzerland; R. E. Gold, Westinghouse Electric Co., USA; N. Ito, Mitsubishi Heavy Ind., Japan; C. Maruska, Ontario Hydro, Canada; K. Matocha, Vitkovice, Czech Republic; F. M. Remy, Électricité de France, France; G. Roussel, Nuclear Safety Institute, Belgium; and T. Schwarz, Siemens/KWU, Germany.

The authors would also like to acknowledge the work of A. M. Porter who wrote parts of Section 8 and provided valuable advice on the subject of tube defect detection reliability and defect sizing accuracy. Finally, the authors would like to thank Paula Olsen who typed the many initial drafts of this report and Ann Grimes who typed the many final versions of this report and did the final layout. Also, we would like to thank Jim Bryce for providing programmatic guidance, editing and other services to complete the report in a timely manner. 



\section{Steam Generator Tube Failures}

\section{INTRODUCTION}

Background. The steam generators in the pressurized water reactor (PWR), Canadian deuterium uranium (CANDU) reactor, and Russian water moderated, water cooled energy reactor (VVER) plants are large heat exchangers that use the heat from the primary reactor coolant to make steam in the secondary-side to drive turbine generators. A typical plant has two to six steam generators per reactor; although some units have up to twelve steam generators. The steam generators are shell-and-tube heat exchangers each with several to tens of thousands of tubes. The primary reactor coolant passes through the tubes and boils water on the outside of the tubes (secondary-side) to make steam. The design confines radioactivity from neutron activation or fission products to the primary coolant during normal operation. However, the primary reactor coolant is at a higher pressure than the secondary coolant, so any leakage from defects in the tubes (or in the VVER collectors or PWR tubesheets) is from the primary to the secondary-side, and rupture of the heat exchanger tubing can result in release of radioactivity to the environment outside the reactor containment through the pressure relief valves in the secondary system.

The thin-walled steam generator tubes are, therefore, an important part of the reactor coolant pressure boundary and, in fact can compromise well over $50 \%$ of the area of the total primary system pressure-retaining boundary. To act as an effective barrier, this tubing must be essentially free of cracks, perforations, and general deterioration. However, widespread degradation of the steam generator tubes has occurred at a number of plants. As a result, about one-half of the PWR nuclear power plants in the world have been removing from service (plugging) or repairing (sleeving) steam generator tubes in any given year. The total number of steam generator tubes plugged per year during the last few years has ranged from about 10,000 to 12,000 tubes. Also, about 48,000 tubes had been sleeved by the end of 1994. This means that a large fraction of the PWR plants are operating with tubing defects near or beyond the national limits at any given time. Also, new forms of steam generator tubing degradation have occurred in recent years, some of which is not easily detected.

Ten spontaneous steam generator tube ruptures ${ }^{a}$ have occurred over the last 20 years. These ruptures have been caused by a variety of tubing degradation mechanisms including stress corrosion of the outside surface of the tubing, high-cycle fatigue, loose parts wear, stress corrosion on the inside surfaces, and wastage (uniform corrosion). The 10 ruptures resulted in leak rates ranging from $425 \mathrm{l} / \mathrm{min}$ (112 gpm) to $2,900 \ell / \mathrm{min}$ (760 gpm) and complex plant transients which have not always been easy for the operators to control. In some cases the plant operators took a relatively long time to realize that a steam generator tube rupture had occurred and, therefore, they were slow to start reducing power and isolate the defective steam generator. Also, at some plants, the reactor coolant system pressures were held well above the defective steam generator secondary side pressures for relatively long periods of time and the defective steam generators were overfilled.

a. A spontaneous tube rupture is the rupture of one or more steam generator tubes that is not caused by another event or an upset in normal expected operational parameters. 
Certain nuclear power plant design basis accidents, such as a sudden break in the steam line, can lead to rapid depressurization of the secondary coolant system. The pressure difference across the tubing walls generated during these accidents may result in simultaneous leakage or rupture of a number of steam generator tubes when an active degradation mechanism has severely damaged a large number of tubes. Simultaneous leakage or rupture of several tubes can lead to a plant transient which is even more difficult to control than a spontaneous tube rupture transient, and radioactivity levels released to the environment which may exceed site limits. The sudden rupture of several steam generator tubes also results in a rapid depressurization of the primary coolant system and possibly may uncover the core and cause core melting.

The frequency and consequences of steam generator tube failures can be significantly reduced through appropriate and timely inspections and plugging or sleeving of excessively damaged steam generator tubing. Most steam generators are routinely inspected during plant outages, when their internal structures become accessible to non-destructive inspection equipment, and the defective tubes repaired or plugged as necessary. However, a continuing issue has been exactly what constitutes an appropriate and timely inspection and which partly defective tubes are still fit for service. The steam generator tube inspection requirements and fitness-for-service criteria vary from country to country, and are even somewhat different at separate plants within certain countries such as the United States (U.S.). This is because:

- Different steam generator designs and materials and specific plant sites are susceptible to different types of aging degradation. Some types of degradation are easier to detect or have less severe safety consequences than other types of degradation.
- An appropriate level of steam generator and plant safety can only be maintained by a suitable combination of inspection and acceptance (fitness-for-service) requirements. Some countries have chosen to have somewhat more conservative fitness-for-service criteria and less inspection. Other countries have chosen less conservative fitness-for-service criteria (thereby saving money on repairs) and more inspection.

- The frequency and extent of the inspections often increase as problems develop.

Also, a wide variety of steam generator inspection equipment is used in various countries. Unfortunately, the most widely used inspection technique (eddy-current bobbin coils and rotating pancake coils) is not able to detect and size all of the degradation of interest, and equipment that is able to detect certain degradation is slow and expensive.

Steam generator performance is important to nuclear power plant safety. For example, the various nuclear power plants in the U.S. have a core damage frequency which ranges from a low of $3 \times 10^{-5}$ per year to about $3 \times 10^{-4}$ per year. Steam generator tube rupture accidents are relatively small contributors to these values, but are risk significant because the radionuclides bypass the containment. A review of 20 U.S. PWR Individual Plant Examinations (IPEs) has shown that the risk associated with steam generator tube ruptures at most PWR plants is above $10 \%$ and at many plants is as high as 75 to $99 \%$ of the total risk. These numbers are based on the past history of spontaneous tube ruptures, but do not consider the possibility of induced tube ruptures in badly degraded steam generators and radionuclide bypass of the containment during other transients and accidents. 
Objective. The objective of this report is to put the issue of steam generator tubing failure, and its impact on nuclear power plant safety, in perspective. To do this, we have summarized much of the available information on the following topics:

- $\quad$ steam generator degradation,

- $\quad$ steam generator tube ruptures,

- the thermal-hydraulic response of a nuclear power plant with a defective steam generator,

- the risk significance of steam generator tube rupture accidents,

- steam generator tubing inspection requirements and fitness-for-service criteria in various countries, and

- $\quad$ steam generator tube defect detection reliability and sizing accuracy.

We have tried to integrate, evaluate, and update the relevant worldwide information on these topics. The sources of information include technical reports issued by the U.S. Nuclear Regulatory Commission (USNRC), the Electric Power Research Institute (EPRI), and various reactor vendors, utilities, and national laboratories; USNRC Inspection and Enforcement Bulletins, Notices, and Generic Letters; workshops and conferences; media publications such as Nucleonics Week; the Nuclear Power Experience database; and technical journals. Discussions with technical experts have been, in some cases, the only available source of information on some subjects. The focus of this report is steam generator tubing degradation at PWR plants; however, we have included relevant information about CANDU reactor and VVER steam generator degradation.

Report Structure. The steam generator designs are discussed in Section 2. The stressors, susceptible sites, and failure modes associated with the various steam generator degradation mechanisms are presented in Section 3. These degradation mechanisms include primary water, outside diameter, and transgranular stress corrosion cracking; intergranular attack; fretting, wear, and thinning; pitting; denting; high-cycle fatigue; wastage; erosion-corrosion; and corrosion-fatigue. The steam generator tube rupture events, which have occurred to date, are discussed in Section 4. The cause of the tube rupture, the plant transient, the effectiveness of the operator actions during the transient, the environmental impact and the remedial actions after the accident are all discussed. The thermalhydraulic response of a typical PWR plant with a defective steam generator is presented in Section 5. The risk significance of steam generator tube rupture accidents is discussed in Section 6. The steam generator tubing inspection requirements and fitness-for-service guidelines in various countries are discussed in Section 7. The efficacy and accuracy of the various steam generator tube defect detection and sizing techniques is discussed in Section 8. And, the major findings are summarized in Section 9. 


\section{STEAM GENERATOR DESIGN}

This section first describes the currently operating steam generators. Recirculating steam generators (RSGs), designed by Westinghouse (U.S.), Combustion Engineering (U.S.), Framatome (France), Mitsubishi Heavy Industries (Japan), and Siemens-Kraftwerke Union (Germany), are described first. The Canadian designs are discussed next, followed by the Babcock \& Wilcox (U.S.) once-through steam generator design, and then the Russian (VVER) designs. The codes and specifications used to design steam generators and the materials and methods used to fabricate the steam generator components are then discussed. Emphasis is placed on the design aspects and fabrication methods which may affect steam generator degradation.

\subsection{Pressurized Water Reactor Recirculating Steam Generators}

A sketch of a simplified PWR RSG cross section is shown in Figure 1. A cut-away view of a typical RSG is shown in Figure 2. The RSG is a vertical, shell and U-tube heat exchanger with integral moisture separation equipment. A large cylindrical vessel encloses an inverted U-shaped tube bundle consisting of many thousands of individual tubes, each welded to a thick plate with a hole for each tube end (called a tubesheet) located near the bottom of the RSG vessel. The reactor coolant enters the hemispherical bottom head through an inlet nozzle, flows through the U-tubes and exits the lower plenum through an outlet nozzle. A plate in the lower plenum below the tubesheet (labeled the divider plate in Figure 2) separates the inlet and outlet primary coolant and directs the flow through the tubing.

The tubes are supported with plates or eggcrate type dividers at a number of fixed axial locations along the tube bundle and with various shaped

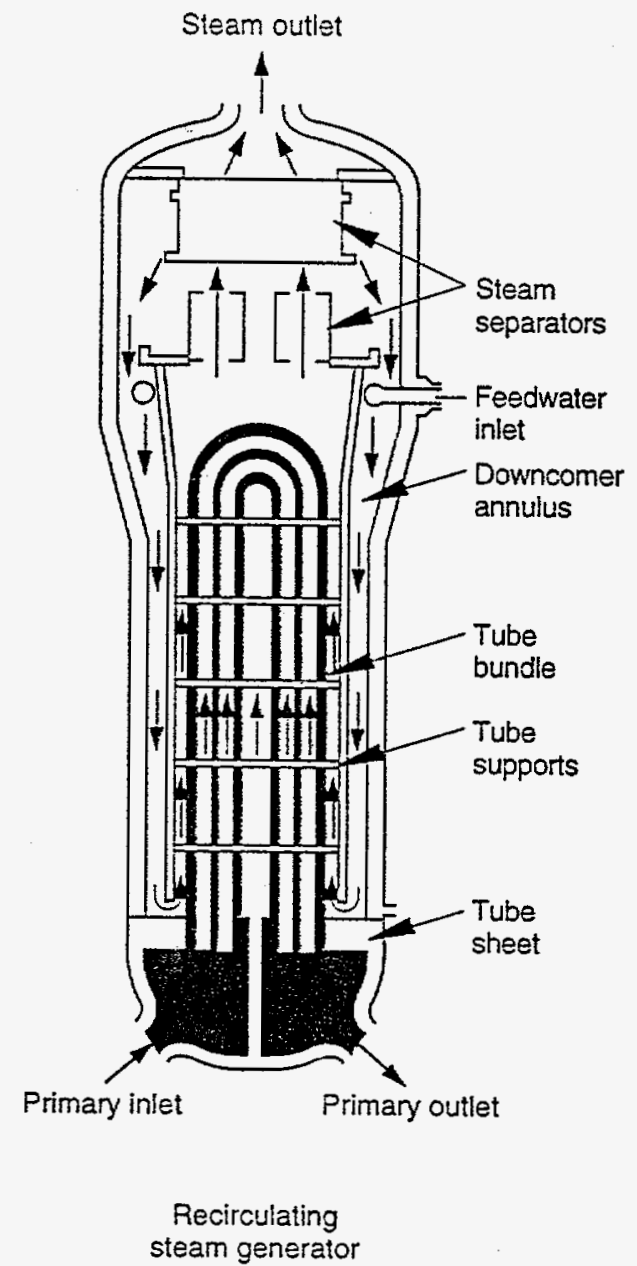

RED 0772

Figure 1. PWR recirculating steam generator cross section.

bars and small plates in the U-bend region of the tube bundle. The upper region of the RSG vessel contains the feedwater inlet piping and various swirl or cyclone-type steam-water separators and 


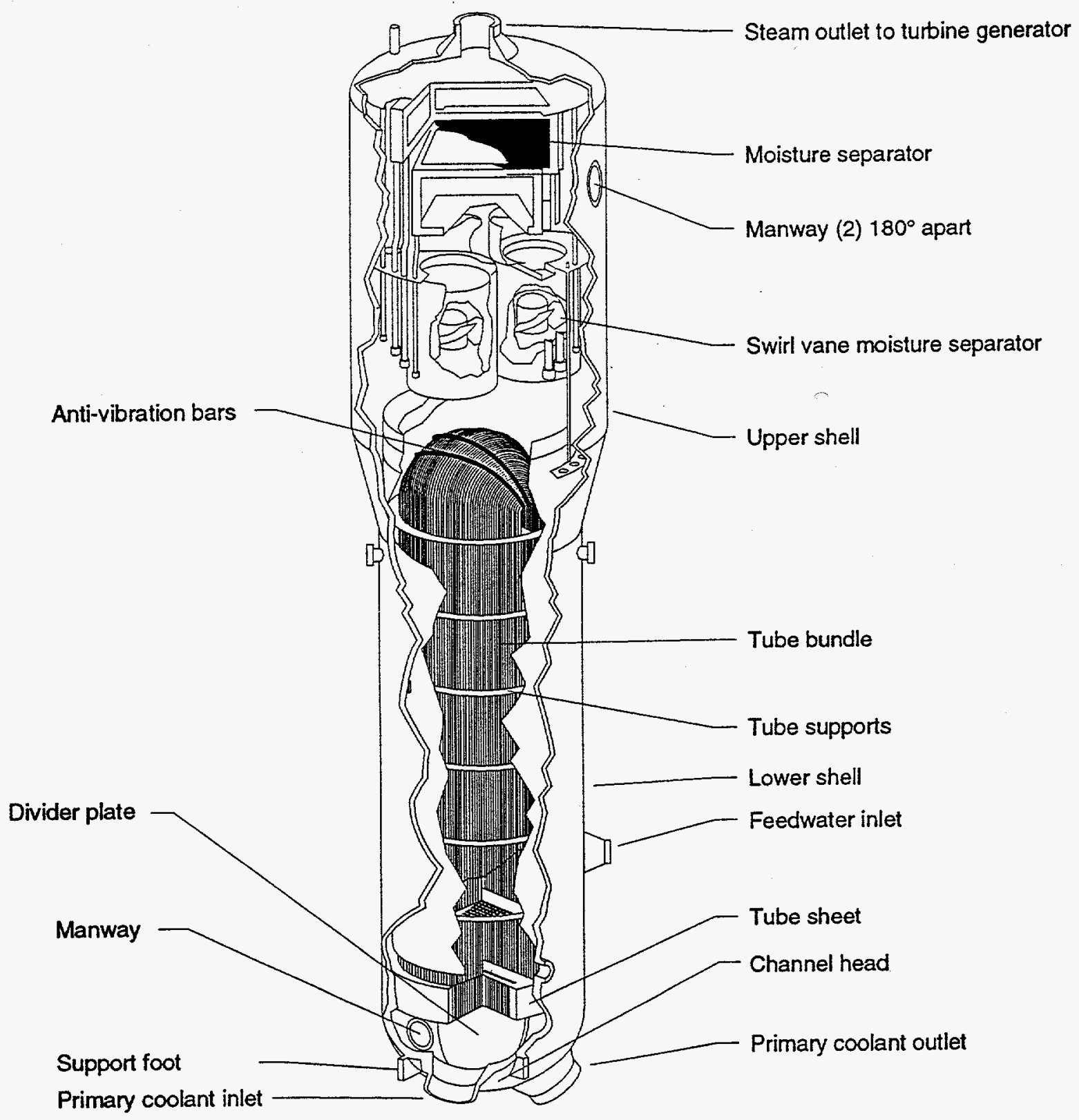

M96 0081

Figure 2. Cut-away view of a typical recirculating steam generator. 
steam dryers. The materials of construction consist mainly of carbon or low alloy steel (except the tubes and the tube supports in later models) with all surfaces in contact with the reactor coolant fabricated or clad with corrosion resistant material.

The primary coolant enters the steam generator at 315 to $330^{\circ} \mathrm{C}$ on the hot leg side and leaves at about $288^{\circ} \mathrm{C}$ on the cold leg side. The secondary system water (feedwater) is fed through a feedwater nozzle, to a feedring, into the downcomer, where it mixes with recirculating water draining from the moisture separators. This downcomer water flows to the bottom of the steam generator, across the top of the tubesheet, and then up through the tube bundle where steam is generated. About $25 \%$ of the secondary coolant is converted to steam on each pass through the generator; the remainder is recirculated. The steam generators are generally designed to produce, at rated steam flow, saturated steam with less than $0.25 \%$ moisture by weight.

Some RSGs include an economizer section (preheaters), which is a separate section in the steam generator near the cold leg outlet, shown in Figure 3. The feedwater flows into the preheater through a nozzle located in the lower part of the vessel (there is no feedring in these steam generators) and auxiliary feedwater is injected through a separate nozzle in the upper part of the vessel. Heat from the primary fluid leaving the steam generator is used to preheat the feedwater to near the saturation temperature before it is mixed with the recirculating secondary system coolant.

Table 1 lists the design features for eleven Westinghouse and two Combustion Engineering type steam generator models. Table 2 lists the design features of seven Mitsubishi Heavy Industries steam generator models and Table 3 lists the design features of the steam generators delivered by Siemens/KWU. The Westinghouse,
Framatome, Mitsubishi Heavy Industries, and Siemens/KWU plants have from two to four steam generators per plant, depending on plant capacity (two loop plants have two steam generators, three loop plants have three, and four loop plants have four steam generators). The Combustion Engineering plants have only two steam generators, even in the large plants (except for Maine Yankee which has three steam generators). Therefore, the Combustion Engineering RSGs at large plants have a larger number of tubes than the other PWR RSGs. The tubes in the Westinghouse, Framatome, and Mitsubishi Heavy Industries RSGs are arranged in a square pattern, those in the Combustion Engineering and Siemens/KWU RSGs in a triangular pattern. The tube patterns in the Combustion Engineering and Westinghouse RSGs are shown in Figure 4. Note, that there is an open lane down the center of the steam generator between the legs of the innermost $U$ tubes.

\subsection{CANDU Reactor Recirculating Steam Generators}

Currently operating CANDU steam generators are vertical, RSGs built by Babcock and Wilcox Canada Ltd. The only exception is the Wolsung 1 unit in Korea which uses similar steam generators built by Foster Wheeler. Atomic Energy Canada Limited, and for some units Ontario Hydro, selected the key design parameters for the CANDU steam generators including the tubing materials and size, the steam generator size, and the key thermal hydraulic parameters. The fabricators did the detailed design of the equipment. CANDU RSGs are very similar to the PWR RSGs with some subtle differences in size, materials, operating temperatures and tube support structure. Figure 5 depicts the steam generator used in the Darlington Generating Station which has all the most current features of CANDU RSGs. 


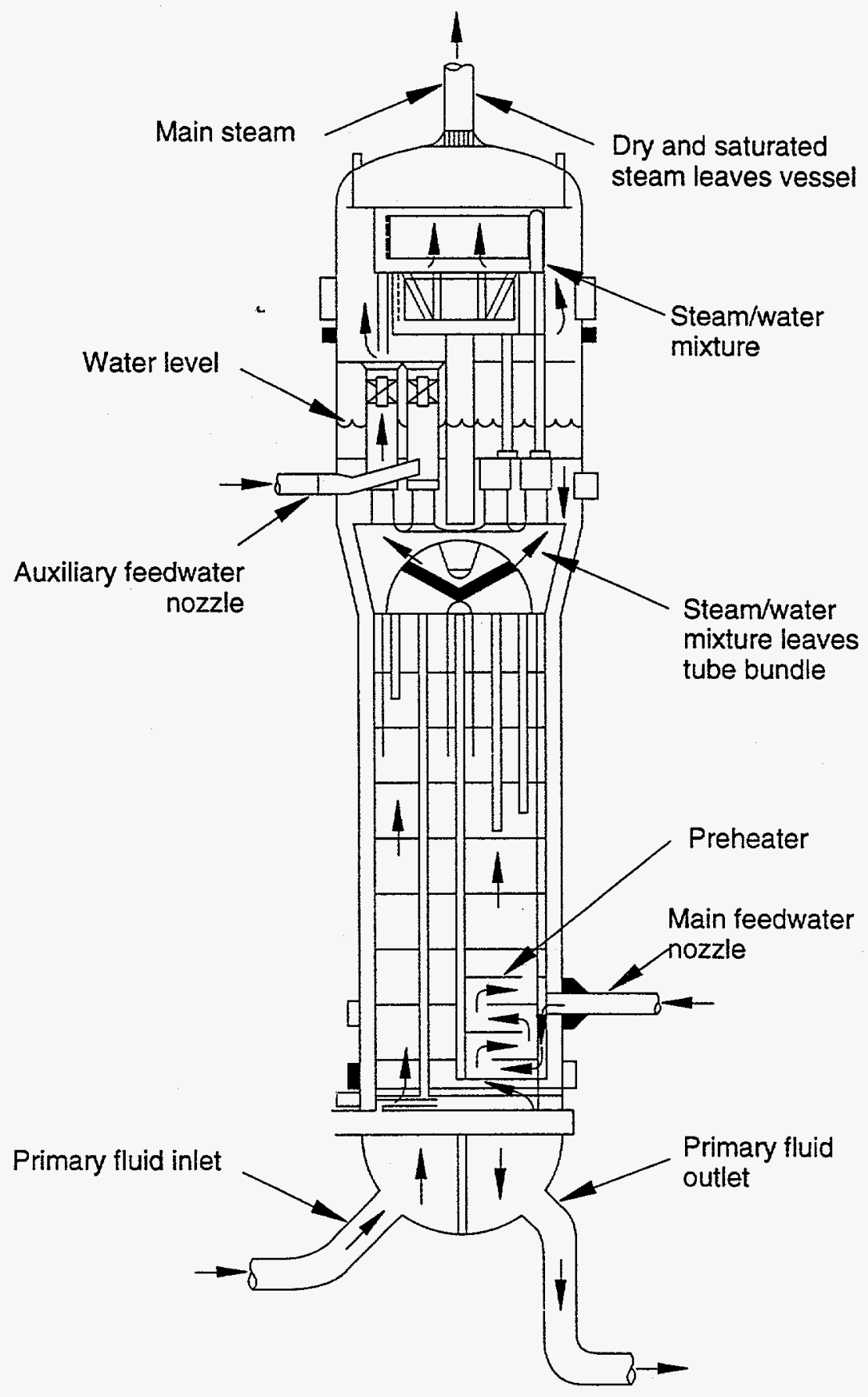

RED 0769

Figure 3. Typical design of a steam generator with a preheater (CSGORG 1983). 
Table 1. Typical U.S. steam generator models and their parameters.

Manufacturer type and model:

Westinghouse (recirculating)

\begin{tabular}{|c|c|c|c|c|c|c|c|}
\hline & 24 & 27 & 33 & $44^{a}$ & $51, A-M^{2}, 8$ & $\mathrm{D} 2 / \mathrm{D} 3$, & $D 4^{z}$ \\
\hline $\begin{array}{l}\text { Heat transfer area } \\
\left(\mathrm{ft}^{2}\right)^{\mathrm{b}}\end{array}$ & 24,834 & 27,700 & 33,340 & 44,500 & 51,500 & 48,000 & 47,000 \\
\hline No. of tubes & 2,604 & 3,794 & 2604 & 3,260 & 3,388 & 4,674 & 4,578 \\
\hline No. of tow-1 tubes & 82 & 100 & 82 & 92 & 94 & 114 & 114 \\
\hline Tube pattern & Square & Square & Square & Square & Square & Square & Square \\
\hline Tube spacing (in.) & 1.2187 & 1.026 or 1.031 & 1.25 & 1.200 or 1.234 & 1.281 & 1.063 & 1.063 \\
\hline $\begin{array}{l}\text { Tube dimensions } \\
\text { (in.) }\end{array}$ & $0.875 \times 0.050$ & $0.750 \times 0.055$ & $0.875 \times 0.050$ & $0.875 \times 0.050$ & $0.875 \times 0.050$ & $0.750 \times 0.043$ & $0.750 \times 0.043$ \\
\hline Tubing material & Alloy 600 & Alloy 600 & Alloy 600 & Alloy 600 & Alloy 600 & Alloy 600 & Alloy 600 \\
\hline $\begin{array}{l}\text { Tubing heat } \\
\text { treatment }\end{array}$ & Mill-annealed & Mill-annealed & Mill-annealed & Mill-annealed & Mill-annealed & Mill-annealed & Mill-annealed \\
\hline $\begin{array}{l}\text { Tubesheet } \\
\text { expansion method }\end{array}$ & $\begin{array}{l}\text { Part-depth } \\
\text { rolled }\end{array}$ & $\begin{array}{l}\text { Part-depth } \\
\text { rolled }\end{array}$ & $\begin{array}{l}\text { Part-depth } \\
\text { rolled }\end{array}$ & $\begin{array}{l}\text { Part-depth } \\
\text { rolled }\end{array}$ & $\begin{array}{l}\text { Part-depth } \\
\text { rolted }^{*}\end{array}$ & $\begin{array}{l}\text { Full-depth } \\
\text { rolled }\end{array}$ & $\begin{array}{l}\text { Full-depth } \\
\text { rolled }\end{array}$ \\
\hline $\begin{array}{l}\text { Tubesheet crevice } \\
\text { depth(in.) }\end{array}$ & 18.25 & 18 & 18 & 18,19, or 20 & $\begin{array}{l}18,18.75 \text { or } \\
19^{d}\end{array}$ & None & None \\
\hline Tube support type & Drilled hole & Drilled hole & Drilled hole & Drilled hole & Drilled hole & Drilled hole & Drilled hole \\
\hline $\begin{array}{l}\text { Tube support } \\
\text { material }\end{array}$ & Carbon steel & Carbon steel & Carbon steel & Carbon steel & Carbon steel $^{r}$ & Carbon steel & Carbon steel \\
\hline Preheater type & None & None & None & None & None & Split flow & $\begin{array}{l}\text { Counterflow, } \\
\text { expanded } \\
\text { preheater } \\
\text { tubes }\end{array}$ \\
\hline $\begin{array}{l}\text { Flow distribution } \\
\text { baffles }\end{array}$ & None & None & None & None & Nones & $\begin{array}{l}\text { D2 no, } \\
\text { D3 yes }\end{array}$ & Yes \\
\hline
\end{tabular}

a. Replacement Models $44 \mathrm{~F}, 51 \mathrm{~F}$ and $54 \mathrm{~F}$ use hydraulically expanded, thermally treated Alloy 600 tubing and 405 stainless steel tube support plates, except for the model 54Fs at D.C. Cook and Indian Point Unit 3 which have thermally treated Alloy 690 tubing. The replacement models generally match the heat transfer area of the steam generators they replaced except for the 54 Fs with Alloy 690 tubing which are slightly larger than the original 51 s due to the slightly lower thermal heat transfer properties at the Alloy 690 material vis-à-vis the Alloy 600 material.

b. $1 \mathrm{ft}^{2}=0.093 \mathrm{~m}^{2}, 1$ in $=25.4 \mathrm{~mm}$.

c. Later Model $51 \mathrm{~s}$ used full-depth rolled or explosively expanded tubes. The tubesheet thickness ranges from 525 to $610 \mathrm{~mm}$. 
Table 1. Typical U.S. steam generator models and their parameters (continued).

\begin{tabular}{|c|c|c|c|c|c|c|c|}
\hline \multirow[t]{2}{*}{$\begin{array}{l}\text { Manufacturer type } \\
\text { and model: }\end{array}$} & \multicolumn{3}{|c|}{ Westinghouse (recirculating) } & \multirow[b]{2}{*}{$\Delta 75$} & \multirow{2}{*}{$\begin{array}{c}\begin{array}{c}\text { B\&W once- } \\
\text { through }\end{array} \\
177\end{array}$} & \multicolumn{2}{|c|}{$\begin{array}{c}\text { Combustion Engineering } \\
\text { (recirculating) }\end{array}$} \\
\hline & D5 & $E^{g}$ & $\mathrm{~F}$ & & & 67 & 80 \\
\hline $\begin{array}{l}\text { Heat transfer area } \\
\left(\mathrm{ft}^{2}\right)^{b}\end{array}$ & 47,000 & 50,000 & 50,000 & 75,180 & 132,500 & 90,700 & N/A \\
\hline No. of tubes & 4,570 & 4,864 & 5,626 & 6,307 & 15,531 & 8,519 & 11012 \\
\hline No. of row -1 tubes & 114 & 120 & 122 & 70 & - & 167 & $\mathbf{N} / \mathbf{A}$ \\
\hline Tube pattern & Square w/T slot & Square w/T slot & Square w/T slot & Triangle & Triangle & Triangle & Triangle \\
\hline Tube spacing (in.) ${ }^{\mathrm{b}}$ & 1.063 & 1.080 & 0.980 & 0.980 & 0.875 & $0.974,1.00$ & 1.000 \\
\hline $\begin{array}{l}\text { Tube dimensions } \\
\text { (in.) }\end{array}$ & $0.750 \times 0.043$ & $0.750 \times 0.043$ & $0.688 \times 0.040$ & $0.688 \times 0.040$ & $0.625 \times 0.034$ & $0.750 \times 0.048$ & $0.750 \times 0.042$ \\
\hline Tubing material & Alloy 600 & Alloy 600 & Alloy 600 & Alloy 690 & Alloy 600 & Alloy 600 & Alloy 600 \\
\hline $\begin{array}{l}\text { Tubing heat } \\
\text { treatment }\end{array}$ & $\begin{array}{l}\text { Thermally } \\
\text { treated }\end{array}$ & $\begin{array}{l}\text { Mill-annealed or } \\
\text { therm. treated }\end{array}$ & $\begin{array}{l}\text { Thermally } \\
\text { treated }\end{array}$ & $\begin{array}{l}\text { Thermally } \\
\text { treated }\end{array}$ & Mill-annealed & Mill-annealed & Mill-annealed \\
\hline $\begin{array}{l}\text { Tubesheet } \\
\text { expansion method }\end{array}$ & Hydraulic & $\begin{array}{l}\text { Full-depth rolled } \\
\text { or hydraulic }\end{array}$ & Hydraulic & Hydraulic & $\begin{array}{l}\text { Partial-depth } \\
\text { rolled }\end{array}$ & Explosive & Explosive \\
\hline $\begin{array}{l}\text { Tube sheet crevice } \\
\text { depth(in.) }\end{array}$ & None & None & None & None & 22 & None & None \\
\hline Tube support type & $\begin{array}{l}\text { Broached } \\
\text { quatrefoil }\end{array}$ & Drilled & $\begin{array}{l}\text { Broached } \\
\text { quatrefoil }\end{array}$ & $\begin{array}{l}\text { Broached } \\
\text { trefoil }\end{array}$ & $\begin{array}{l}\text { Broached } \\
\text { trefoil }\end{array}$ & $\begin{array}{l}\text { Eggcrate/ } \\
\text { vertical }\end{array}$ & $\begin{array}{l}\text { Eggcrate/ } \\
\text { vertical }\end{array}$ \\
\hline $\begin{array}{l}\text { Tube support } \\
\text { material }\end{array}$ & Stainless steel & $\begin{array}{l}\text { Carbon or } \\
\text { stainless }\end{array}$ & $\begin{array}{l}405 \text { stainless } \\
\text { steel }\end{array}$ & $\begin{array}{l}405 \text { stainless } \\
\text { steel }\end{array}$ & $\begin{array}{l}\text { Carbon or } \\
\text { MnMo steel }\end{array}$ & Carbon steel & Stainless steel \\
\hline Preheater type & $\begin{array}{l}\text { Counterflow, } \\
\text { expanded pre- } \\
\text { heater tubes }\end{array}$ & $\begin{array}{l}\text { Counterflow, } \\
\text { expanded } \\
\text { preheater tubes }\end{array}$ & None & None & None & None & Axial flow \\
\hline $\begin{array}{l}\text { Flow distribution } \\
\text { baffles }\end{array}$ & Yes & Yes & Yes & $\begin{array}{l}\text { Broached } \\
\text { plate }\end{array}$ & No & None & Yes \\
\hline
\end{tabular}

d. For Model 51 s with part-depth rolled tubes only.

e. The crevice radial gaps varied from 0.005 to 0.011 inches, except in the Model 24 where they were $0.0135-0.0175$ inches.

f. Some later Model 51 s were equipped with alloy steel tube support plates and flow distribution baffles.

g. The row 1 and 2 tubes in most Model 51, D2/D3, D4 and E stean generators have been u-bend heat treated and shot or rotopeened for added resistance to PWSCC. 
Table 2. Typical Mitsubishi Heavy Industries recirculating steam generator models and their parameters.

\begin{tabular}{|c|c|c|c|c|c|c|c|}
\hline $\begin{array}{c}\text { Manufacturer } \\
\text { and Model }\end{array}$ & $\begin{array}{c}\text { MHI } \\
44 \\
\end{array}$ & $\begin{array}{l}\text { MHI } \\
46 \mathrm{~F} \\
\end{array}$ & $\begin{array}{r}\text { MHI } \\
51,51 \mathrm{~A} \\
\end{array}$ & $\begin{array}{l}\text { MHI } \\
51 \mathrm{M} \\
\end{array}$ & $\begin{array}{c}\text { MHI } \\
\text { 51F,51FA } \\
\end{array}$ & $\begin{array}{c}\text { MHI } \\
\text { 52F,52FA }\end{array}$ & $\begin{array}{c}\text { MHI } \\
\text { 54F,54FA }\end{array}$ \\
\hline Heat transfer area $\left(\mathrm{m}^{2}\right)$ & 4,130 & 4,300 & 4,785 & 4,780 & 4,780 & 4,870 & 5,055 \\
\hline No. of tubes & 3,260 & 3,382 & 3,388 & 3,382 & 3,382 & 3,382 & 3,382 \\
\hline No. of row-1 lubes & 92 & 94 & 94 & 94 . & 94 & 94 & 94 \\
\hline Tube pattern & Square & Square & Square & Square & Square & Square & Square \\
\hline Tube spacing(mm) & 31.35 & 32.54 & 32.54 & 32.54 & 32.54 & 32.54 & 32.54 \\
\hline Tube dimensions(mm) & $22.23 \times 1.27$ & $22.23 \times 1.27$ & $22.23 \times 1.27$ & $22.23 \times 1.27$ & $22.23 \times 1.27$ & $22.23 \times 1.27$ & $22.23 \times 1.27$ \\
\hline Tubing material & Alloy 600 & Alloy 690 & Alloy 600 & Alloy 600 & Alloy 600 & Alloy 690 & Alloy 690 \\
\hline Tubing heat treatment & Mill-annealed & Thermally treated & Mill-annealed & $\begin{array}{l}\text { Mill-annealed, } \\
\text { Thermally treated }\end{array}$ & Thermally treated & Thermally treated & Thermally treated \\
\hline $\begin{array}{l}\text { Tubesheet expansion } \\
\text { method }\end{array}$ & Part-depth rolled & $\begin{array}{l}\text { Full-depth hydraulic } \\
\text { and one step rolled }\end{array}$ & $\begin{array}{l}\text { Part-depth rolled, } \\
\text { Full-depth rolled }\end{array}$ & $\begin{array}{l}\text { Full-depth rolled, } \\
\text { Full-depth hydraulic } \\
\text { and rolled }\end{array}$ & $\begin{array}{l}\text { Full-depth hydraulic } \\
\text { and one step rolled }\end{array}$ & $\begin{array}{l}\text { Full-depth hydraulic } \\
\text { and one step rolled }\end{array}$ & $\begin{array}{l}\text { Full-depth hydraulic } \\
\text { and one step rolled }\end{array}$ \\
\hline $\begin{array}{l}\text { Tubesheet crevice } \\
\text { depth(mm) }\end{array}$ & $\begin{array}{l}497^{\mathrm{a}} \\
\text { (original design) }\end{array}$ & None & $488^{2}$, None & None & None & None & None \\
\hline Tube support type & Drilled & Broached eggerate & Drilled & $\begin{array}{l}\text { Drilled, } \\
\text { Drilled chamfer }\end{array}$ & Broached eggcrate & Broached eggcrate & Broached eggcrate \\
\hline Tube support material & Carbon Steel & 405 stainless steel & Carbon steel & $\begin{array}{l}\text { Carbon steel, } \\
405 \text { stainless steel }\end{array}$ & 405 stainless steel & 405 stainless steel & 405 stainless steel \\
\hline Preheater type & None & None & None & None & None & None & None \\
\hline $\begin{array}{l}\text { Flow distribution } \\
\text { baffles }\end{array}$ & None & Yes & None & Yes & Yes & Yes & Yes \\
\hline
\end{tabular}

${ }^{\mathrm{a}}$ Tubesheet radial gap of $0.185 \mathrm{~mm}$ 
Table 3. Typical Siemens/KWU recirculating steam generators and their parameters

\begin{tabular}{|c|c|c|c|c|c|c|c|c|}
\hline & $\begin{array}{l}\text { Munufucturer } \\
\text { and model }\end{array}$ & $\begin{array}{l}\text { MAN-GFIII } \\
\text { Ohrigheim (Orig.) }\end{array}$ & $\begin{array}{l}\text { MAN-GIH } \\
\text { Obrigheim (Repl.) }\end{array}$ & $\begin{array}{l}\text { lsalcke } \\
\text { Stade }\end{array}$ & $\begin{array}{l}\text { lababcock } \\
\text { libiblis A }\end{array}$ & $\begin{array}{l}\text { 1) Standard with } \\
\text { preheater }\end{array}$ & $\begin{array}{l}\text { MAN-GHII } \\
\text { Konvol " }\end{array}$ & $\begin{array}{l}\text { A) Replacenient SGs } \\
\text { for } 51 \mathrm{C} / 51 \mathrm{M} / \mathrm{D} 3\end{array}$ \\
\hline & Heat transfer area $\left(m^{2}\right)$ & 2750 & 3070 & 2930 & 4510 & 5386 & 5427 & $5105 / 6103 / 7155^{\prime)}$ \\
\hline & No. of tubes & 2605 & 3010 & 2993 & 4060 & 4086 & 4118 & $5130 / 5428 \mathrm{ml}$ \\
\hline & No. of row-1 tubes & 81 & 46 & 49 & 55 & 48 & 54 & $57 / 59^{\mathrm{m})}$ \\
\hline & Tube pattern & rectangular & triangular & triangular & triangular & triangular & triangular & triangular \\
\hline & Tube spacing (mm) & $27.9 \times 28.8$ & 29.0 & 29.3 & 30.0 & 30.0 & 30.0 & 26.164 \\
\hline & Tube dimensions (mm) & $22 \times 1.23(1.5)^{n)}$ & $22 \times 1.23$ & $22 \times 1.23$ & $22 \times 1.23$ & $22 \times 1.23$ & $22 \times 1.23$ & $19.05 \times 1.09$ \\
\hline & Tubing material & Alloy 600 & Alloy $800 \mathrm{M}^{\mathrm{p} \text { ) }}$ & Alloy $800 \mathrm{M}^{\mathrm{p})}$ & Alloy $800 \mathrm{M}^{p)}$ & Alloy $800 \mathrm{M}^{\mathrm{p})}$ & Alloy $800 \mathrm{M}^{\mathrm{pl}}$ & $\begin{array}{l}\text { Alloy } 690^{\mathrm{n}} \\
\text { Alloy } 80 \mathrm{M}^{\mathrm{p}}\end{array}$ \\
\hline & Tubing heat treatment & Mill annealed & 8) & g) & g) & 8) & 8) & $\begin{array}{l}\text { Alloy } 690 \text { : Therm. } \\
\text { treated } \\
\text { Alloy } 800 \mathrm{M}^{\mathrm{p})} \mathrm{s}\end{array}$ \\
\hline & $\begin{array}{l}\text { Tubesheet expansion } \\
\text { medhod }\end{array}$ & $\begin{array}{l}\text { Part-depth rolled } \\
\text { (3 locations) }\end{array}$ & $\begin{array}{l}\text { Part-depth rolled } \\
\text { (both ends) } \\
\text {, }\end{array}$ & $\begin{array}{l}\text { Part-depth rolled } \\
\text { (both ends) }\end{array}$ & $\begin{array}{l}\text { Part-depth rolled } \\
\text { (both ends) }\end{array}$ & $\begin{array}{l}\text { Part-depth rolled } \\
\text { (both ends) }\end{array}$ & $\begin{array}{l}\text { Part-depth rolled } \\
\text { (both ends) }\end{array}$ & $\begin{array}{l}\text { Full-depth hydraulic } \\
\text { plus part-depth } \\
\text { rolled (both ends) }\end{array}$ \\
\hline \multirow{7}{*}{ • } & TS crevice depth (mm) & None & None & None & None & None & None & None \\
\hline & Tube support type & eggerate b) & eggcrate ${ }^{c)}$ & eggcrate d) & eggcrate ${ }^{c)}$ & eggcrate $^{c)}$ & eggcrate ${ }^{s}$ & eggcrate ${ }^{n}$ \\
\hline & Tube support material & stainless steel & stainless steel & stainless steel & stainless steel & stainless steel & stainless steel & stainless stecl \\
\hline & Preheater type & None & None & None & None & Split-flow design & None & None \\
\hline & Flow distribution baffles & None & Yes & None & None & Yes & None & Yes \\
\hline & U-Bend Treatment & None & None & None & None & None & None & Alloy 690: Yes ${ }^{\circ)}$ \\
\hline & $\begin{array}{l}\text { Peening of the roll- } \\
\text { transition zone }\end{array}$ & None & None & None & None & None & None & None \\
\hline
\end{tabular}

\footnotetext{
Notes:

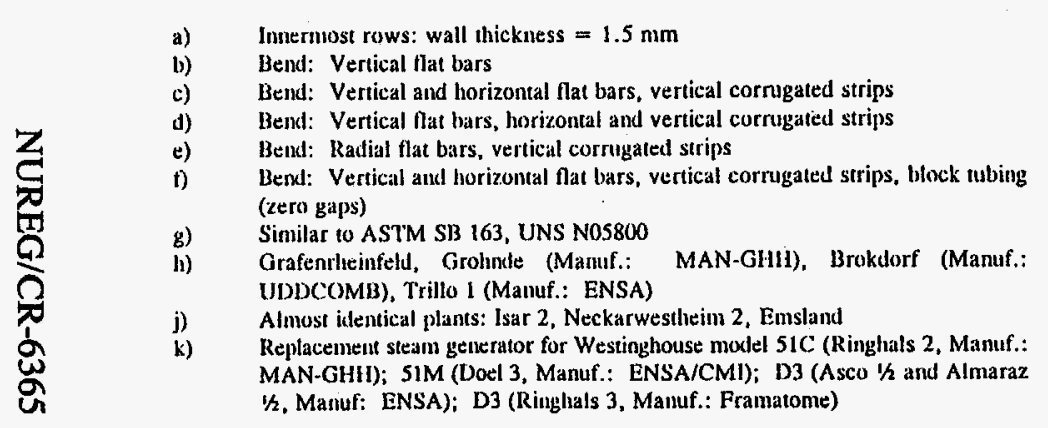

1) Replacement steam generator for Ringhals 2: $5105 \mathrm{~m}^{2}$; Doel 3, Asco $1 / 2$ and Almaraz 12 : $6103 \mathrm{~m}^{2}$; Ringlats 3 : $7155 \mathrm{~m}^{2}$

m) Replicement stean generator for Ringhials 2, Doel 3. Asco 1/2 atul Almaraz 1/2: 5130 tubes, 57 row- 1 tubes; Ringlaals 3: 5428 tubes, 5) row-1 tubes

11) Replacement penerator for Ringhals 2 and Ringhals 3: Alluy 690); Duel 3, Asco 1/2 and Almaraz 1/2: Alloy 800 M

o) Alloy 690: Tubes with Radius $<300 \mathrm{~mm}$

p) Modified according to Siemens/KWU specification 

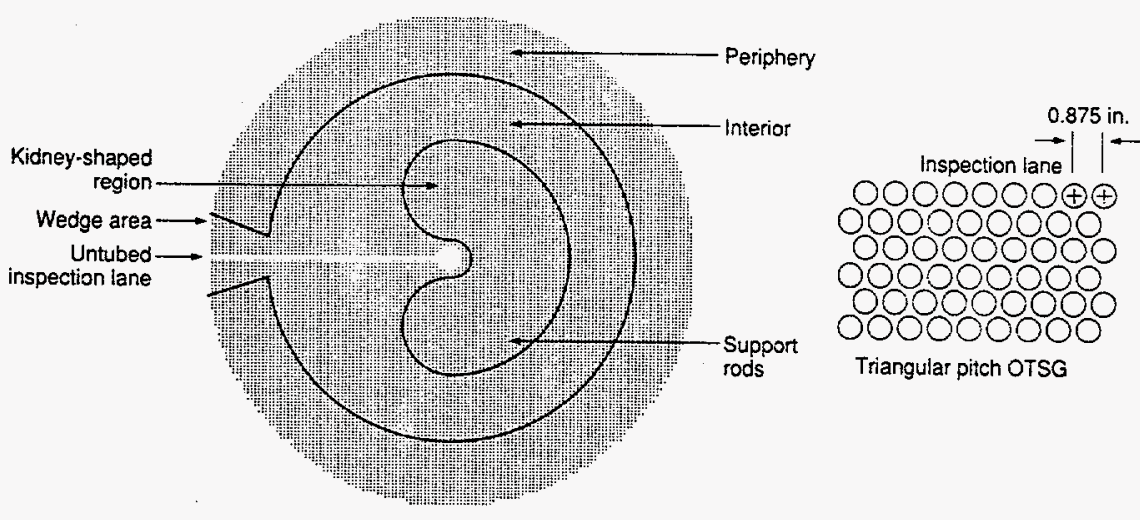

Typical B\&W OTSG tube pattern

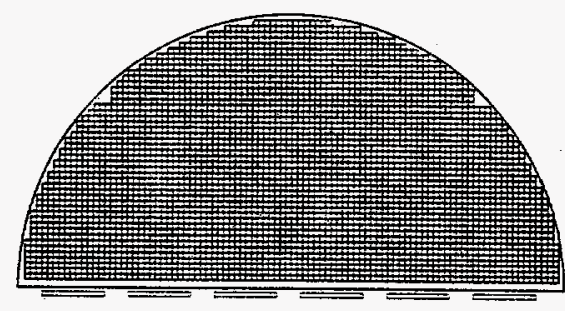

Typical Mocel 51 RSG tube pattern

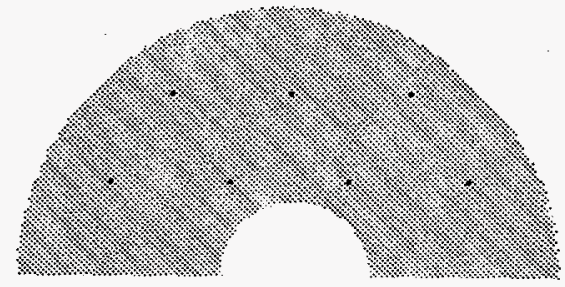

Typical CE RSG tube pattern

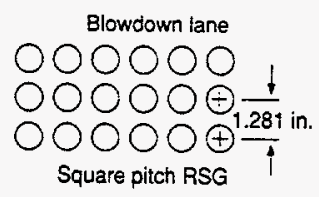

Blowdown lane

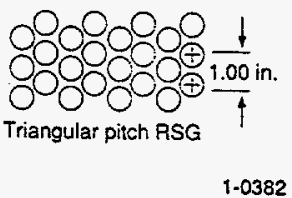

Figure 4. Typical tube patterns. Courtesy of A. P. L. Turner, Dominion Engineering. 


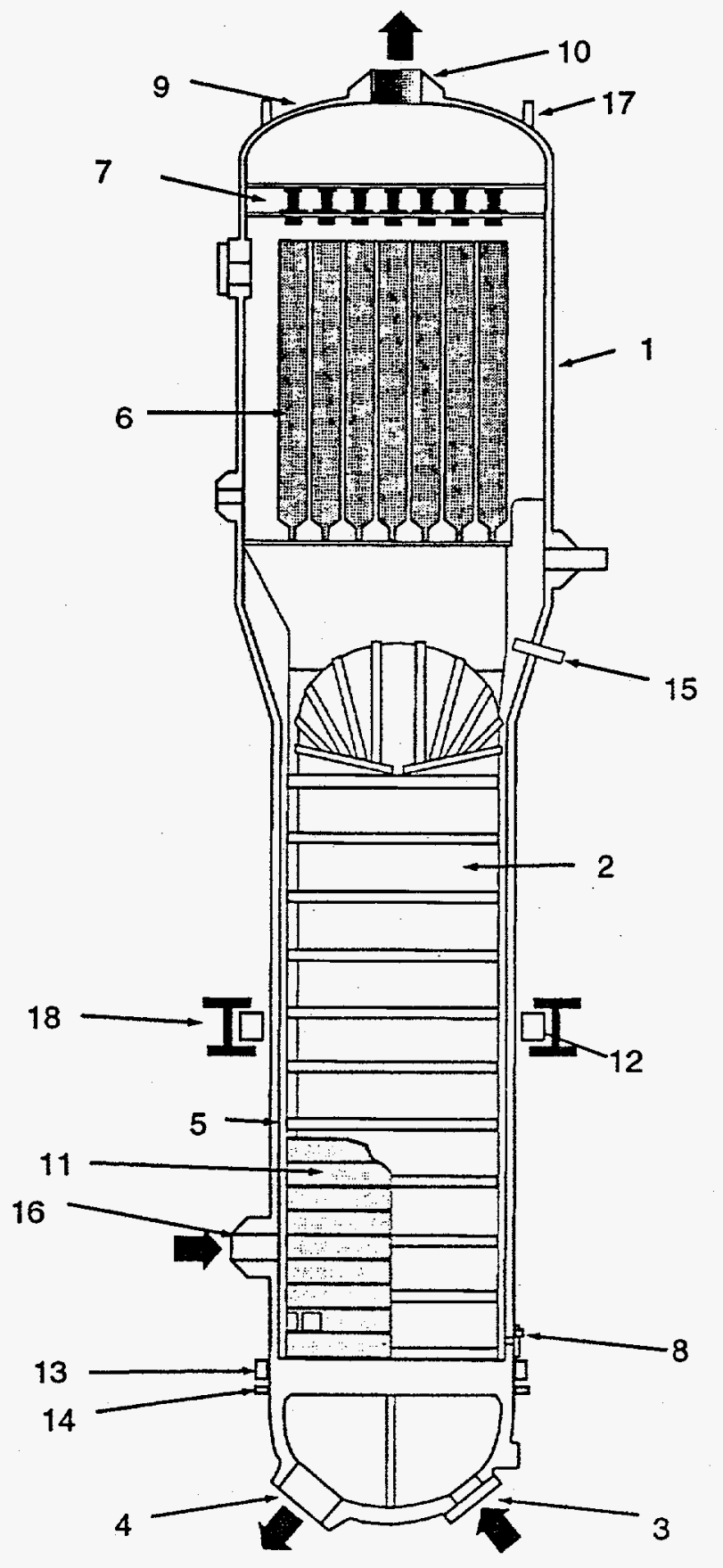

Legend

1. Steam drum.

2. Steam generator

3. Heavy water inlet (2)

4. Heavy water outlet

5. Downcommer annulus

6. Primary cyclones

7. Secondary cyclones

8. Blowdown nozzles

9. Manway

10. Main steam outlet nozzles

11. Preheater

12. Steam generator support

13. Contaminant seal bar/skirt

14. Lower lateral restraint lugs

15. Reheat condensate return nozzle

16. Feedwater nozzle

17. Upper lateral restraint lugs

18. Ring beam

Figure 5. CANDU Recirculating Steam Generator used at the Darlington station. This design is typical of the current CANDU models. Courtesy of C. Maruska, Ontario Hydro. 
Although the size of CANDU RSGs has escalated greatly with successive reactor designs, they are generally smaller than PWR RSGs, and operate at lower temperatures $\left(290^{\circ} \mathrm{C}\right.$ to $310^{\circ} \mathrm{C}$ primary inlet temperature). The lower temperatures generally delay the onset of thermally activated corrosion processes such as primary water stress corrosion cracking (PWSCC) or intergranular stress corrosion cracking (IGSCC). Because the primary coolant in a CANDU reactor is heavy water $\left(D_{2} O\right)$, relatively small tube sizes $[12.7 \mathrm{~mm}$ $\left(1 / 2^{\prime \prime}\right)$ outside diameter and, in more recent units, $15.9 \mathrm{~mm}(5 / 8$ ") outside diameter] have been used to minimize the heavy water inventory. The smaller size of the primary (lower) head and tubes increases the difficulty in performing maintenance activities such as tube inspection, plugging, removal, etc. The nominal tube wall thickness ranges from $1.13 \mathrm{~mm}$ to $1.2 \mathrm{~mm}$ depending on the type of tube alloy used (for example Alloy $800 \mathrm{M}$ has a lower thermal conductivity than Alloy 600 requiring thinner tubes).

The most important area of diversity in the CANDU design is in the choice of tube material, the CANDU steam generators currently operate with tubes made from high-temperature, mill annealed Alloy 600, Monel 400 and titanium stabilized Alloy 800 . These materials are susceptible to different types of degradation.

\subsection{Pressurized Water Reactor Once-Through Steam Generators}

The Babcock \& Wilcox once-through steam generators use straight heat exchanger tubes with a tubesheet at both the top and bottom of the tube bundle, as shown in Figure 6. Primary coolant is pumped through the tubes from top to bottom while the secondary coolant moves around the outside of the tubes from bottom to top in a counter-flow direction. The secondary-system water enters a feed annulus above the ninth tube support plate level where it mixes with steam aspirated from the tube bundle area and is

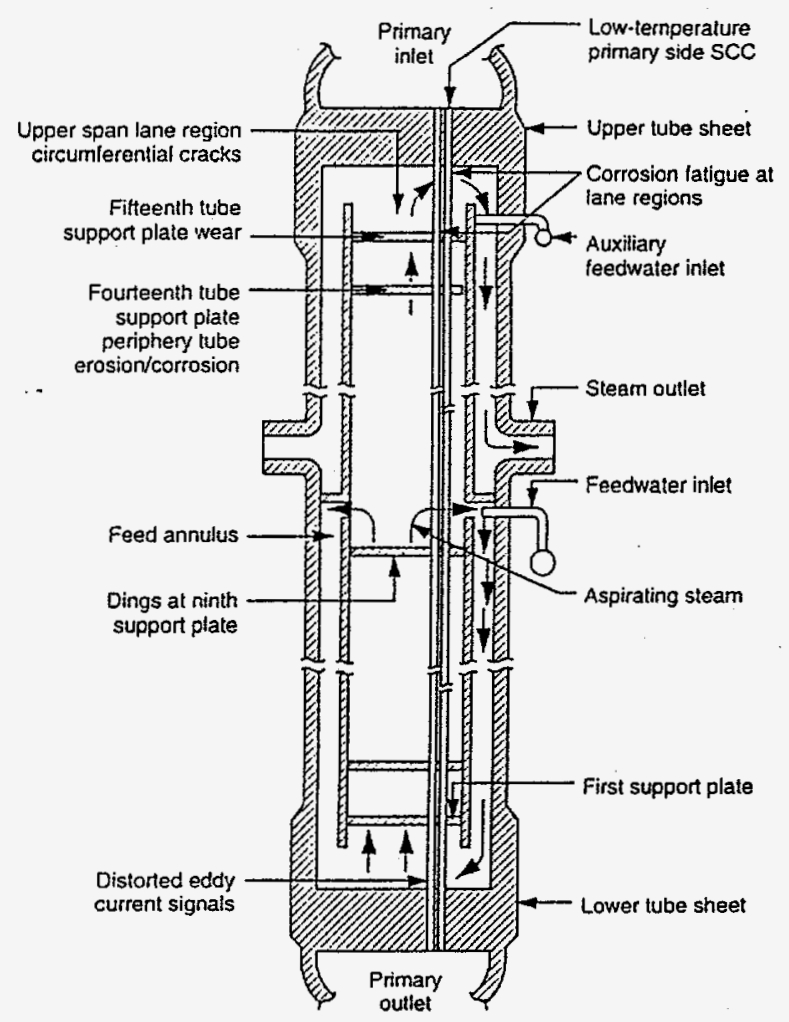

RED 0776

Figure 6. PWR once-through steam generator cross section (EPRI 1985a). Copyright 1985 Electric Power Research Institute; reprinted with permission.

preheated to saturation. The saturated water flows down the annulus, across the lower tubesheet, and up into the tube bundle where it becomes steam. This superheated steam flows radially outward near the top of the tube bundle and then down the annulus to the steam outlet connection. Most of the secondary coolant is completely evaporated in a single pass through the steam generator.

The Babcock \& Wilcox plants have two steam generators per plant, each with approximately 15,500 tubes arranged in a triangular pattern. The once-through steam generator key design 
parameters are listed in Table 1 and the tube pattern is shown in Figure 4. Note that an untubed lane provides access for secondary-side inspections.

\subsection{Russian VVER Steam Generators}

The steam generators used in the Russian designed VVER-440 and VVER-1000 plants are horizontal shell-and-tube heat exchangers manufactured by ZiO (Podolsk, Moscow Region), Atommash (Volgodonsk, Volgograd Region), and Vitkovice (Czech Republic). They consist of a pressure vessel, a horizontal heat exchange tube bundle, two vertical primary collectors, a feedwater piping system, moisture separators and steam collector. A sketch of a VVER-440 steam generator is shown in Figures $7 \mathrm{a}$ and $7 \mathrm{~b}$ (side and end views). A sketch of a VVER-1000 steam generator is shown in Figures $8 \mathrm{a}$ and $8 \mathrm{~b}$. The tube bundle arrangement in the VVER-440 and VVER-1000 steam generators, as seen from the top, is shown in Figure 9.

Primary coolant enters the steam generator through a vertical collector, travels through the horizontal U-shaped submerged stainless steel tubing, and exits through a second vertical collector. The tube ends penetrate the collector wall (which performs the same function as the tubesheet in a PWR steam generator) and are expanded using either a hydraulic or explosive expansion process and then welded at the collector inside wall surface. The VVER-440 collectors are made of Ti-stabilized austenitic stainless steel. The VVER-1000 collectors are made of low-alloy steel with higher tensile properties, clad with stainless steel. The VVER440 tubes are arranged in line (square array). The VVER-1000 tubes are staggered (triangular array). Grids consisting of stainless steel bars and stamped wave-like plates are used to separate and support the tubes. The distance between the tube supports is $700-750 \mathrm{~mm}$.
The steam generator vessel is a carbon steel (VVER-440) or low-alloy pearlitic steel (VVER1000) horizontal cylinder consisting of forged shells, stamped elliptical ends and stamped branch pipes and hatches welded together. The vertical hot and cold primary coolant collectors penetrate the vessel near its mid-point. Feedwater is supplied to the middle of the VVER -400 tube bundle by perforated piping. In the VVER-1000 steam generators, the feedwater is supplied to the top of the hot side of the tube bundle under a submerged perforated sheet. The tube bundle is completely submerged in both designs.

The VVER-440 and VVER-1000 steam generator designs are similar except for the (a) size (the VVER-1000 steam generator is about 4 meters longer), (b) tube arrangement (square versus triangular), (c) collector material, (d) feedwater supply location, (e) submerged perforated top plate (VVER-1000 only), (f) steam dryer arrangement, (g) emergency feedwater distribution system (VVER-1000 only), (h) steam header arrangement, (i) and vessel material. The VVER-1000U steam generator has been designed to replace the original VVER-1000 steam generators as needed. The VVER-1000U has the perforated region of the collectors fabricated from austenitic stainless steel. Table 4 lists the VVER-440, VVER-1000, and VVER-1000U design features.

\subsection{Codes and Specifications}

Although many countries have, or are developing their own standards and codes for the design of nuclear power plant components, the load restrictions are generally based on Section III of the American Society of Mechanical Engineers (ASME) Boiler and Pressure Vessel Code. The objective of designing and performing a stress analysis with the rules of Section III is to afford protection of life and property against ductile and brittle failure. The ASME Class 1 design requirements are used for all the primary-side 


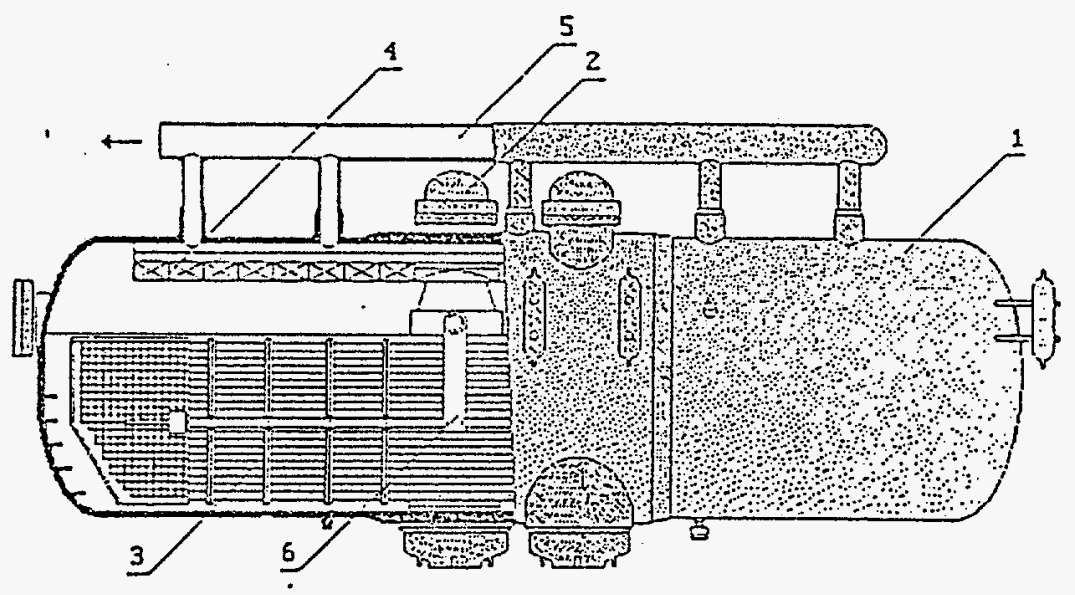

\section{Sleam generator pressure vessel \\ 2. Primary collector}

3. Heat exchange tubes
4. Moisture separator

5. Steam collector

6. Feedwater inlet

Figure 7a. VVER-440 steam generator (side view). Courtesy of Y. G. Dragunov, OKB Gidropress.

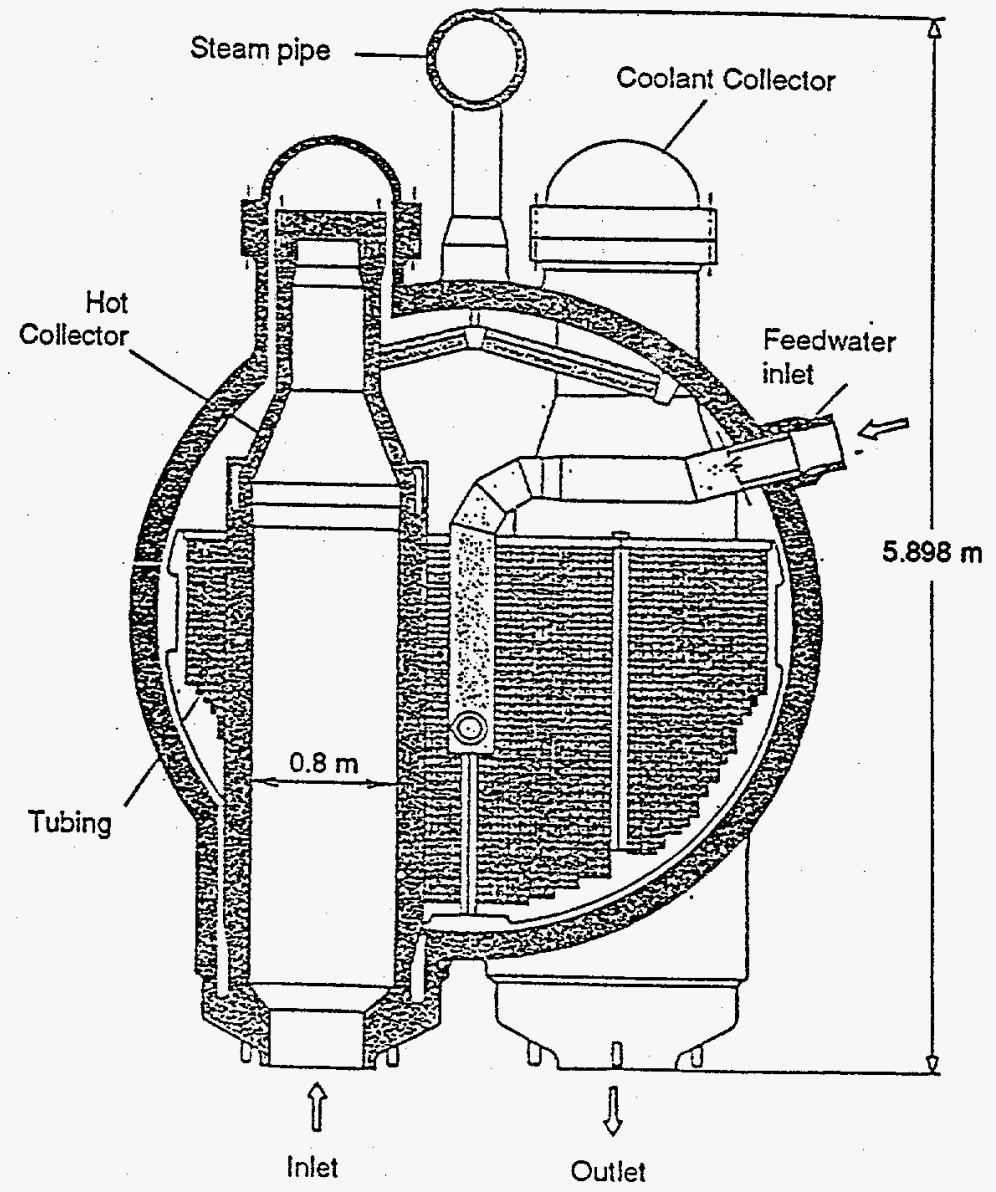

Figure 7b. VVER-440 steam generator (end view). Courtesy of Y. G. Dragunov, OKB Gidropress. 


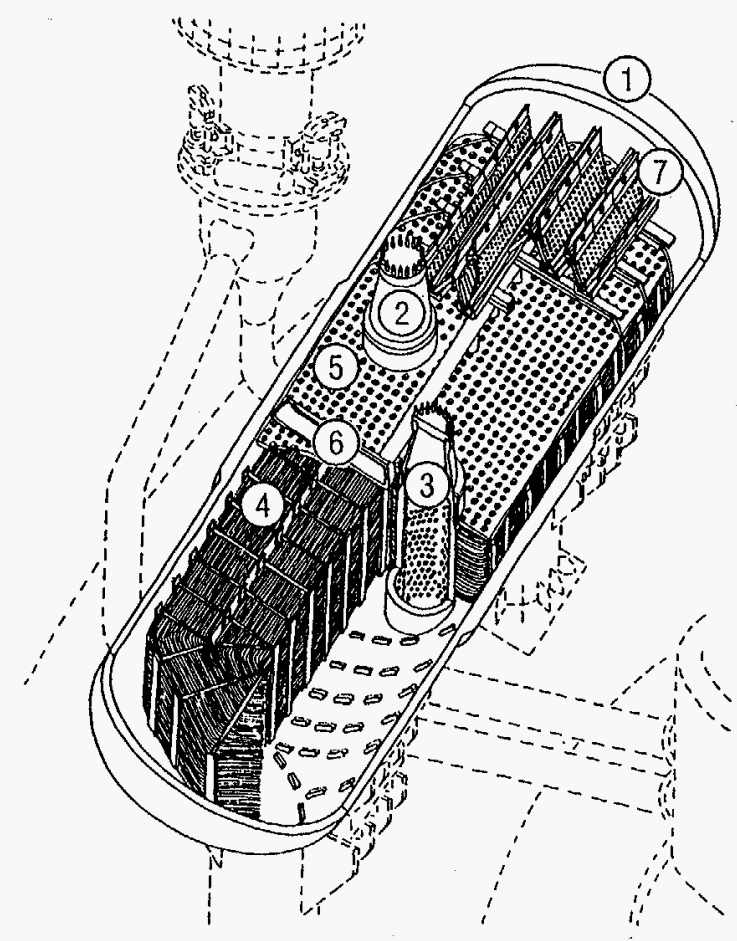

Figure 8a. Cut-away drawing of a VVER-1000 steam generator. Key: 1-Steam generator drum; 2-Cold header; 3-Hot header; 4Heat exchanger tubes; 5-Submerged perforated separator; 6Feedwater header; 7-Steam separators (Koryakin 1993). permission.

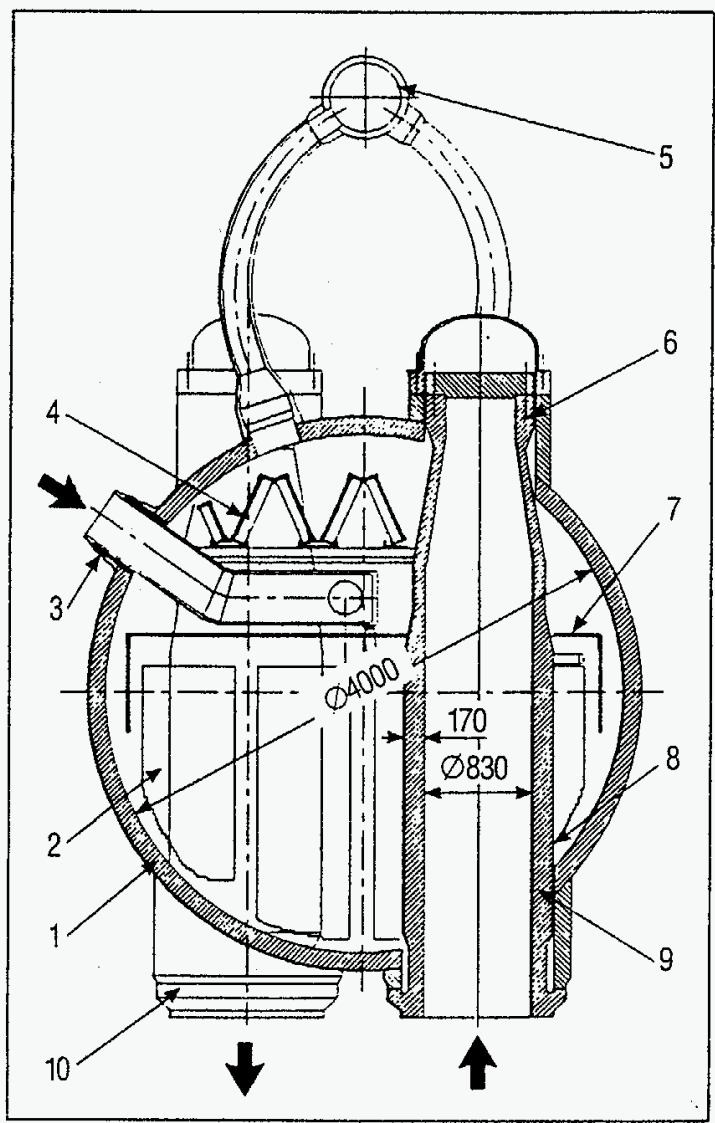

Figure 8b. VVER-1000 steam generator (end view). Key: 1-SG shell; 2-Tube bundle; 3Feedwater branch pipe; 4-Separation device; 5Steam collecting heater; 6-Point of header jamming; 7-Immersed perforated sheet; 8Unperforated section in perforated zone; 9-Inlet ("hot") header; 10-Outlet ("cold") header. Courtesy of Y. G. Dragunov, OKB Gidropress. Copyright Nuclear Engineering International; reprinted with permission. 


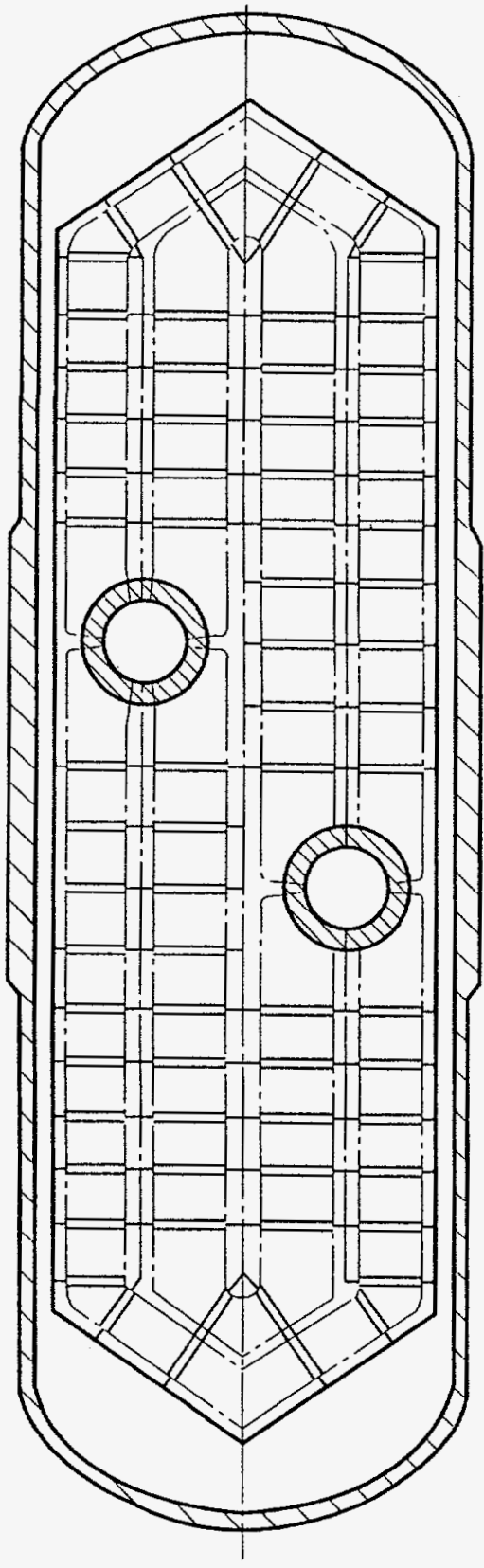

Figure 9a. Topview sketch of the tube layout in VVER-440 and VVER-1000 steam generators. Courtesy of Y. G. Dragunov, OKB Gidropress.

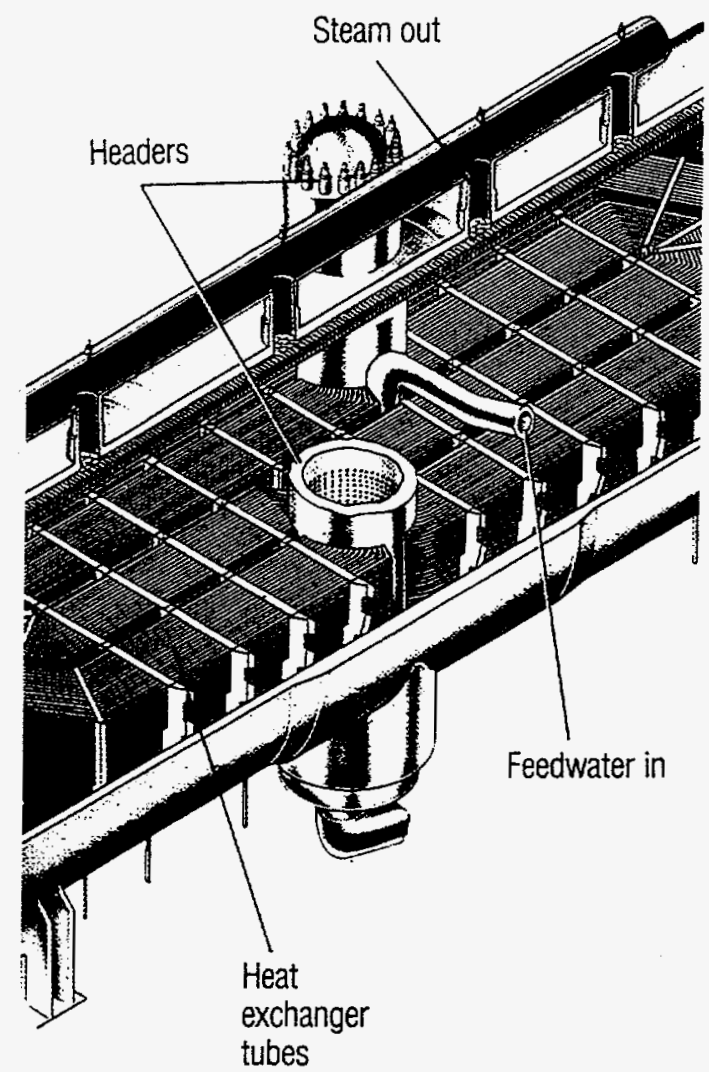

Figure 9b. Basic arrangement of the heat exchanger tubes and headers used in VVER-1000 steam generators (Titov 1991), Copyright, Nuclear Engineering International; reprinted with permission. 
Table 4. VVER steam generator parameters.

\begin{tabular}{|c|c|c|c|}
\hline Parameters & VVER-440 & VVER-1000 & VVER-1000U \\
\hline Thermal power, MW & 229.2 & 750 & 750 \\
\hline Steam capacity, $\mathrm{kg} / \mathrm{s}$ & 125 & 408.33 & 408.33 \\
\hline Pressure of steam, $\mathrm{MPa}$ & 4.61 & 6.27 & 6.27 \\
\hline Steam temperature, ${ }^{\circ} \mathrm{C}$ & 258.9 & 278.5 & 278.5 \\
\hline Feedwater temperature, ${ }^{\circ} \mathrm{C}$ & $164-223$ & $164-220$ & $164-220$ \\
\hline $\begin{array}{l}\text { Coolant temperature, }{ }^{\circ} \mathrm{C} \\
\text { - at steam generator inlet } \\
\text { - at steam generator outlet }\end{array}$ & $\begin{array}{l}295 \\
267\end{array}$ & $\begin{array}{l}320 \\
290\end{array}$ & $\begin{array}{l}320 \\
292\end{array}$ \\
\hline Coolant flow rate, $\mathrm{m}^{3} / \mathrm{hr}$ & 7100 & 21200 & 21200 \\
\hline Coolant pressure, $\mathrm{MPa}$ & 12.26 & 15.7 & 15.7 \\
\hline Coolant flow rate in tubes, $\mathrm{m} / \mathrm{s}$ & 2.71 & 4.21 & 4.91 \\
\hline Average heat transfer factor, $\mathrm{kW} / \mathrm{m}^{2} \mathrm{~K}$ & 4.7 & 5.4 & 6.1 \\
\hline Mean logarithmic temperature head, ${ }^{\circ} \mathrm{C}$ & 18.7 & 22.9 & 24 \\
\hline Specific heat flux (average), $\mathrm{kW} / \mathrm{m}^{2}$ & 89.23 & 123 & 141 \\
\hline Total heat exchanging surface, $\mathrm{m}^{2}$ & 2576.6 & 6115 & 5126.6 \\
\hline Total number of tubes & 5536 & 11000 & 9157 \\
\hline Diameter and thickness of tube walls, mm & $16 \times 1.4$ & $16 \times 1.5$ & $16 \times 1.5$ \\
\hline Tube mean length, $\mathrm{m}$ & 9.26 & 11.10 & 11.14 \\
\hline Pressure loss along the coolant path, $\mathrm{MPa}$ & 0.075 & 0.126 & 0.169 \\
\hline Reduced outlet steam rate from the evaporation surface, $\mathrm{m} / \mathrm{s}$ & 0.240 & 0.382 & 0.382 \\
\hline Steam humidity at steam generator outlet, $\%$ & 0.25 & 0.2 & 0.2 \\
\hline Vessel material & $22 \mathrm{~K}$ & 10GN2MFA & 10GN2MFA \\
\hline Collector material & $08 \times 18 \mathrm{~N} 10 \mathrm{~T}^{2}$ & $\begin{array}{c}\text { 10GN2MFA } \\
\text { with inner cladding }\end{array}$ & $\begin{array}{l}08 \mathrm{X} 18 \mathrm{~N} 10 \mathrm{~T} \\
\text { perforated area }\end{array}$ \\
\hline Heat exchanging tube material & $08 \mathrm{X} 18 \mathrm{~N} 10 \mathrm{~T}$ & $08 \mathrm{X} 18 \mathrm{~N} 10 \mathrm{~T}$ & 08X18N10T \\
\hline $\begin{array}{l}\text { Collector dimensions in the perforated area } \\
\text { - inner diameter, } \mathrm{mm} \\
\text { - wall thickness, } \mathrm{mm}\end{array}$ & $\begin{array}{l}800 \\
136\end{array}$ & $\begin{array}{c}834 \\
171 \\
\text { with cladded layer }\end{array}$ & $\begin{array}{l}780 \\
198\end{array}$ \\
\hline $\begin{array}{l}\text { Hole array in the header perforated area } \\
\text { - dimensions of minimum ligament, } \mathrm{mm} \\
\text { - number of horizontal rows along the height } \\
\text { - number of tubes in a horizontal row }\end{array}$ & $\begin{array}{c}11.34 \\
77 \\
89\end{array}$ & $\begin{array}{c}6.93^{\mathrm{b}} \\
110 \\
120\end{array}$ & $\begin{array}{c}9.75 \\
94 \\
112\end{array}$ \\
\hline
\end{tabular}


Table 4. VVER steam generator parameters (continued).

\begin{tabular}{lccc}
\hline Parameters & VVER-440 & VVER-1000 & VVER-1000U \\
\hline Tube array in tube bundle & square array & staggered & staggered \\
- array pitch along the vertical axis, mm & 24 & 19 & 22.1 \\
- array pitch along the horizontal axis, mm & 29.5 & 23 & $25,2^{\mathrm{c}}$ \\
Submerged perforated sheet & absent & installed & installed \\
Steam generator circulating factor (minimum) & $4-6$ & 1.5 & 1.9 \\
Void fraction, \% & 0.32 & 0.493 & 0.485
\end{tabular}

a. This material is also labeled $08 \mathrm{Cr} 18 \mathrm{Ni10Ti}$ which is a titanium stabilized austenitic stainless steel with $.08 \%$ carbon, $18 \%$ chrome, $10 \%$ nickel and less than $1 \%$ titanium.

b. Along medium surface.

c. $\quad 25 \mathrm{~mm}$ for the central set and $23 \mathrm{~mm}$ for the lateral set.

pressure retaining components. The components on the secondary-side are required to satisfy ASME Class 2 requirements. However, common practice is to design the entire steam generator shell to the ASME Class 1 requirements. Therefore, Article NB-2300 of Section III of the ASME Code is employed for assurance of adequate fracture toughness of all pressure retaining materials in the steam generator. In addition, the steam generator tube/tubesheet complex meets the stress limitations and fatigue criteria specified in the ASME Code.

\subsection{Fabrication and Materials}

Materials and methods used to fabricate steam generator components significantly affect their susceptibility to corrosion, especially to stress corrosion cracking. Degradation of the steam generator tubing is also influenced by other aspects of the steam generator design and construction, such as the tube support design and the method of tube installation.

\subsubsection{Heat Exchanger Tubes}

Initially, the heat exchanger tubing in most of the PWR steam generators placed inservice in the western countries (except Germany) was made from nickel based Alloy $600(76 \% \mathrm{Ni}, 15.5 \%$ $\mathrm{Cr}, 8 \% \mathrm{Fe},<0.15 \% \mathrm{C}$ ). The German steam generators designed by Siemens/KWU use Alloy $800 \mathrm{M}$ tubing $(33.5 \% \mathrm{Ni}, 21.5 \% \mathrm{Cr}, 44 \% \mathrm{Fe}$, $<0.03 \% \mathrm{C},<0.6 \% \mathrm{Ti})$. Now, most steam generators designed by Westinghouse, Framatome, Siemens/Framatome, Babcock \& Wilcox and Mitsubishi Heavy Industries are being fabricated with thermally treated Alloy 690 $(61 \% \mathrm{Ni}, 29.5 \% \mathrm{Cr}, 9 \% \mathrm{Fe},<0.025 \% \mathrm{C}$ ). Siemens/KWU and Babcock \& Wilcox Canada are also supplying replacement steam generators with Alloy $800 \mathrm{M}$ tubing. The chemical compositions of these alloys are listed in Table 5.

Tube fabrication generally starts with extrusion of a shell from an ingot and then several cold reduction steps by either drawing or pilgering. Each reduction step is followed by millannealing, which typically consists of passing tube lengths through a furnace on a traveling belt at temperatures high enough to recrystallize the material and dissolve all the carbon (about $980^{\circ} \mathrm{C}$ or above).

The mill-annealing temperature and initial carbon content are two of the important parameters in 
Table 5. Chemical composition of typical tubing materials.

\begin{tabular}{|c|c|c|c|c|c|c|c|c|c|c|c|}
\hline Alloy & $\mathrm{Ni}$ & $\mathrm{Cr}$ & $\mathrm{Fe}$ & $\mathrm{C}$ & $\mathrm{Mn}$ & $\mathrm{Si}$ & $\mathrm{Cu}$ & $\mathrm{Al}$ & Co & $\mathrm{T}$ & $S$ \\
\hline $600^{1}$ & $\geq 72$ & $14-17$ & $6-10$ & $\leq 0.15$ & $\leq 1.0$ & $\leq 0.5$ & $\leq 0.5$ & - & - & - & $\leq 0.015$ \\
\hline $690^{2}$ & $\geq 58$ & $28-31$ & $7-11$ & $0.015-0.025$ & $\leq 0.5$ & $\leq 0.5$ & - & $\leq 0.5$ & $\leq 0.02$ & $\leq 0.5$ & $\leq 0.01$ \\
\hline $800 \mathrm{M}^{3}$ & $32-35$ & $20-23$ & $\geq 39.5$ & $\leq 0.03$ & $0.4-1.0$ & $0.3-0.7$ & $\leq 0.75$ & $0.15-0.45$ & $\leq 0.1$ & $\leq 0.6$ & \\
\hline Monel $400^{1}$ & $\geq 63.0$ & & $\leq 2.5$ & $\leq 0.3$ & $\leq 2.0$ & $\leq 0.5$ & $28-34$ & - & - & - & $\leq 0.024$ \\
\hline
\end{tabular}

'Inco Alloys International Inc. Product Handbook

${ }^{2}$ EPRI Specifications (EPRI 1990a)

${ }^{3}$ Siemens/KWU Specification 
controlling the mechanical and corrosion behavior of nickel based alloys such as Alloy 600 . The object of the mill-annealing steps is to first dissolve all the carbides and obtain a relatively large grain size and then cover the grain boundaries with carbides upon slow cooling in air. A higher carbon content requires a higher mill-annealing temperature to dissolve all the carbides. Undissolved intragranular carbides are undesirable because they provide nucleation sites for the dissolved carbides and prevent precipitation of the carbides on the grain boundaries.

Undissolved carbides also prevent grain growth and, therefore, prevent appropriate grain boundary carbide coverage because the smaller grains have a much larger grain boundary area. The mill-annealing temperature also controls the material yield strength and, therefore, the residual stresses. Higher mill-annealing temperatures result in lower residual stresses (in tubes which are not stress relieved). Starting in the late 1970s, the mill-annealed Alloy 600 tubes from some vendors were also given a final thermal treatment at about $705^{\circ} \mathrm{C}$ for 15 hours in order to relieve fabrication stresses and to further improve the microstructure. The thermal treatment process promotes carbide precipitation at the grain boundaries and diffusion of chromium to the grain boundaries. Therefore, the chromium used to form the chromium carbides is replenished on the grain boundary. Alloy 600 tubing with grain boundary chrome depletion is susceptible to outside diameter stress corrosion cracking. Alloy 600 tubing with insufficient carbides on the grain boundaries is susceptible to primary water stress corrosion cracking.

Subsequent to the final mill-anneal, the tubing is passed through roll straighteners to produce a straight product. The- straightening process plastically deforms the tubing, imparting some residual stresses. After straightening, the tubing may be abrasively polished (e.g., using belt abra- sives) to remove about $0.025 \mathrm{~mm}(1 \mathrm{mil})$ from the exterior surface. This step removes surface imperfections, but also results in the tubes having a thin cold-worked surface layer and significant residual surface stresses, which can range from compressive to highly tensile.

The final manufacturing steps for straight tubes involve visual, ultrasonic, and eddy-current inspections, also various cleaning operations, including blasting the interior surfaces with ceramic grit. For RSGs, the straight tubes are bent to the desired U-tube configuration. For tight radius bends, internal mandrels are often used to minimize ovality of the bent portion of the tube (Shah et al. 1992). In addition, the tight radius U-bends of tubes in some of the existing steam generators which had not been thermally treated, were stress relieved at $705^{\circ} \mathrm{C}$ for at least five minutes to relieve bend-induced stresses.

The annealing and thermal treatment temperatures and other details of the tube processing were somewhat different for the various manufactures and steam generator models and are briefly discussed below.

Babcock \& Wilcox Practice. Babcock \& Wilcox practice was to mill-anneal at a relatively high temperature, about 1065 to $1095^{\circ} \mathrm{C}$ (Jones 1982). In addition, after tube installation, Babcock \& Wilcox heat treated the entire steam generator at about $595^{\circ} \mathrm{C}$ for 15 hours to reduce residual stresses from tube fabrication and installation (e.g., at roll transitions), and to increase resistance to PWSCC by developing more carbides at grain boundaries. However, it also resulted in sensitization (chromium depletion at grain boundaries), making the tubing susceptible to other forms of corrosion (stress corrosion cracking in oxidizing acidic conditions).

Combustion Engineering Practice. The Combustion Engineering tubing was annealed at a relatively high temperature of 980 to $1065^{\circ} \mathrm{C}$ 
(Owens 1987a). This final mill-anneal resulted in a relatively low maximum yield stress below 55 $\mathrm{ksi}$ and relatively large grain sizes and carbides at the grain boundaries, which was initially found to be relatively resistant to PWSCC.

Westinghouse Practice. Up until the late 1970s, Westinghouse practice involved use of relatively low temperature mill-annealed tubing which was not thermally treated (Hunt and Gorman 1986). For these earlier steam generators, prior to introduction of improved heat treatment and other fabrication improvements discussed below, the residual stresses and microstructure of the tube material are such that the tubes are relatively susceptible to primary- and secondary-side stress corrosion cracking.

Starting in the late 1970s, Westinghouse used an array of features to reduce the potential for tube corrosion. These features included thermal treatment of tubing for 15 hours at $705^{\circ} \mathrm{C}$ to relieve the residual stresses and improve the microstructure, followed by stress relief of tight radius U-bends. The improvement of the microstructure due to the thermal treatment involved precipitation of chromium carbides at the grain boundaries. In addition, holding the tubing in the precipitation range for a long period of time allows the chromium to diffuse from the grain interiors to chromium depleted regions near the grain boundaries, preventing sensitization. Because of the improvements associated with this thermal treatment, experience with thermally treated Alloy 600 tubing has shown that only a small fraction of it is susceptible to PWSCC in highly stressed areas.

Current Practice. Current practice by the steam generator suppliers in France, Japan and the U.S. is to use thermally treated Alloy 690. This alloy, which is similar to Alloy 600 but has about twice as much chromium (29.5\% rather than $15.5 \%$ ) and proportionally less nickel, has been found in tests to be more resistant to primary water stress corrosion cracking and to have improved corrosion resistance in secondary-side environments.
Most vendors are using a thermal treatment of about $705^{\circ} \mathrm{C}$ for 15 hours to relieve the fabrication stresses and improve the microstructure. Some vendors thermally treat the tight radius U-bends for various times up to an additional two hours at about $700^{\circ} \mathrm{C}$ to relieve the residual stresses induced by bending and peen the inside surfaces of the tube legs to produce a layer of cold worked material a few tèns of microns deep.

Siemens/KWU Practice. The first two Siemens/KWU steam generators were supplied with Alloy 600 mill-annealed tubing and began leaking after two years of operation. Thereafter, all Siemens/KWU steam generators were fabricated with Alloy $800 \mathrm{M}$ tubing (about onehalf as much nickel as Alloy 600). Compared to the standard Alloy 800 ASTM specification, Siemens Alloy $800 \mathrm{M}$ has a reduced carbon content to minimize sensitization, an increased stabilization ratio ( $\mathrm{Ti} / \mathrm{C}>12$ ), and slightly increased chromium and nickel contents to achieve a higher resistance to pitting and transgranular stress corrosion cracking.

CANDU Practice. Following the use of Alloy 600 in a small demonstration reactor, the material used in the 1960s in the CANDU steam generators was Monel 400, a high nickel/copper alloy. This alloy has good corrosion properties but is extremely sensitive to oxygen content. Its ferromagnetic properties also increase the difficulty of inspection with standard eddycurrent coils.

The material used for later units was changed to Alloy 600 . The practice for Babcock \& Wilcox Canada Ltd. for manufacturing Alloy 600 tubing (high temperature mill-annealing and heat treatments) was very similar to the practice of its parent company as described for PWRs. As a result, this type of tubing tends to behave similarly, with respect to degradation mechanisms, to that used in once-through steam generators built by Babcock \& Wilcox in the U.S. 
The current practice for CANDU RSGs is to use titanium stabilized Alloy $800 \mathrm{M}$ tubing and a manufacturing method which precludes any random heat addition to the tubing.

VVER Tubing Material. The VVER-440 and VVER-1000 steam generator tubing is made of Type $08 \mathrm{X} 18 \mathrm{~N} 10 \mathrm{~T}$ stainless steel which is a Tistabilized austenitic stainless steel with $0.08 \%$ carbon, $18 \%$ chrome, $10 \%$ nickel and less than $1 \%$ titanium.

\subsubsection{Tube Installation in the Tubesheet}

PWR and CANDU steam generator tubes have been installed in a thick carbon or low alloy steel tubesheet, which is clad on the primary coolant side with the same material as the tubing, by mechanical rolling, hydraulic expansion, or explosive expansion (which may introduce high residual stresses) and seal welding to the tubesheet cladding. The VVER steam generator tubes have been installed in somewhat thinner walled collectors in a similar manner. For the early PWR plants, the mill-annealed tubing was connected to the tubesheet by hard rolling the tube into the bottom of the tubesheet for a length of about 60 to $100 \mathrm{~mm}$. This left an approximately $0.2 \mathrm{~mm}$ wide, radial crevice (where chemical impurities could concentrate) between the tube and tubesheet along the top portion (about $460 \mathrm{~mm}$ ) of the tubesheet. In later steam generators of Westinghouse design (early to mid 1970s), the tubing was expanded for the rest of the tubesheet height using an explosive expansion process (Wextex expansion) in the field or by additional hard rolling in the shop. In cases where the expansion was done by additional rolling, field experience has shown that high residual stresses were introduced into some tubes during rolling anomalies, e.g., at regions rolled twice or at transition regions where rolling was skipped. For Westinghousetype steam generators made in the later part of the 1970s, full-depth tube expansion was accom- plished in the shop using hydraulic methods. The Siemens/KWU steam generators were fabricated with either a three or two step mechanical hard roll until the late 1980s. The most recent procedure used by most of the PWR and CANDU steam generator manufactures is to perform a hydraulic expansion over nearly the entire tubesheet thickness (stopping and starting within a few mm of each end) followed by a one (near the top) or two step mechanical hard roll near the top and near the bottom (called a kiss roll). The transition region is formed by the hydraulic expansion, which leaves significantly lower residual stresses in the tubing than the hard mechanical roll expansions. The hard mechanical rolling near the top or near both ends of the tubesheet provides a larger holding force than can be obtained with a hydraulic expansion. A profilometry measurement of the inside diameter of a typical tube in one of the Siemens/KWU replacement steam generators for Ringhals Unit 2 is shown in Figure 10. Typical radial deformations associated with both the hydraulic and mechanical expansions are shown, along with the length of each of those expansions along the tubesheet.

Kiss rolls have been used to install the tubes in the tubesheets of the French steam generators since 1980. This has resulted in lower residual stresses on the secondary side of the tubing, but an increased sensitivity to axial cracking on the primary side surfaces. Westinghouse uses only a hydraulic tube expansion. Westinghouse also machines the tubesheet faces parallel to within $0.38 \mathrm{~mm}$ so that the secondary side crevice depth is less than $2.5 \mathrm{~mm}$.

Tubesheet crevices generally do not exist in the CANDU steam generators. Early units closed the tubesheet crevices by a second roll near the top (secondary-side) of the tubesheet. Current CANDU models use a hydraulic method to close the tubesheet crevice. 


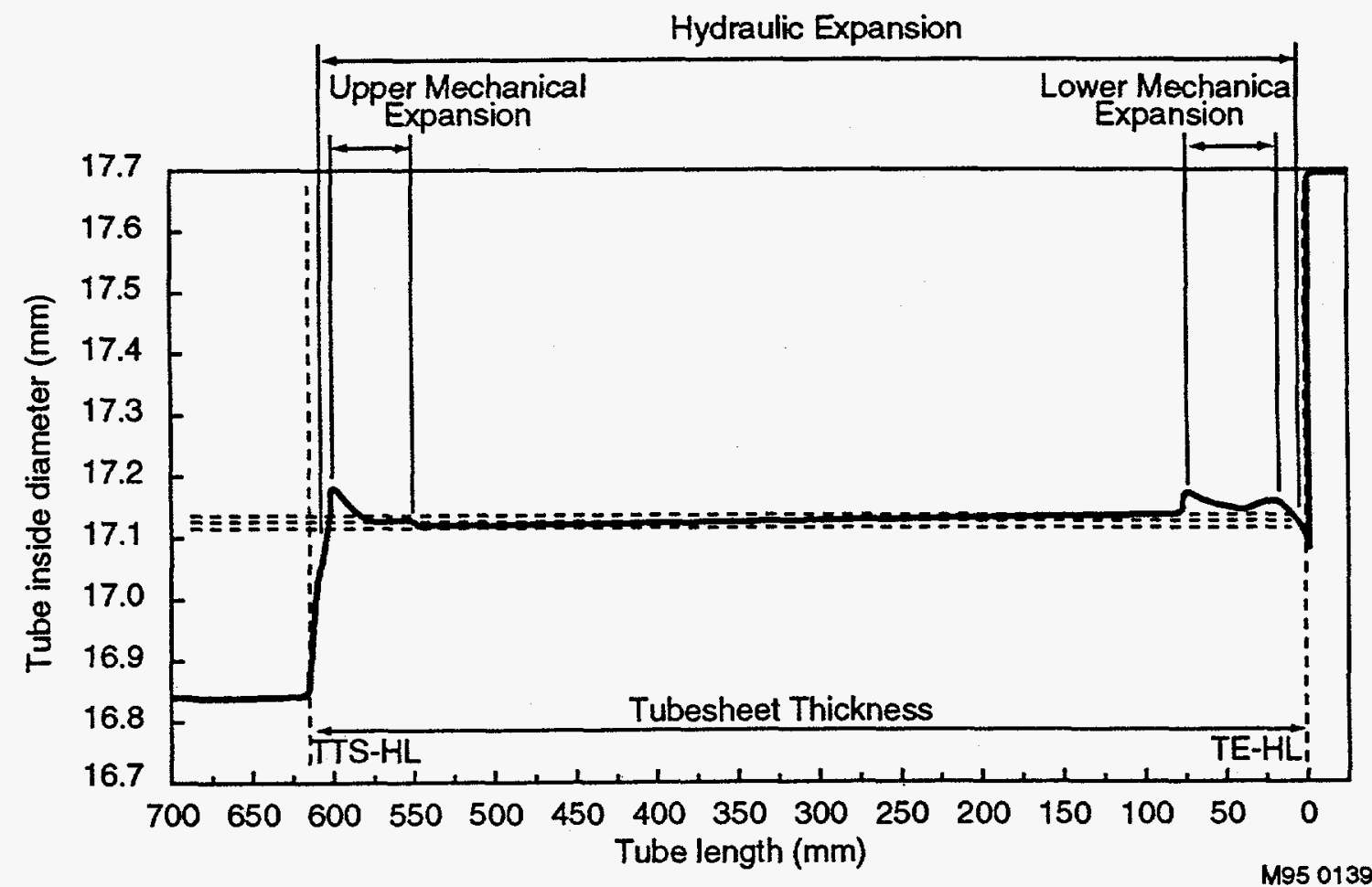

Figure 10. Profilometry readings from a typical tube in one of the Siemens/KWU replacement steam generators for Ringhals Unit 2. Courtesy of P. J. Meyer, Siemens AG.

The VVER steam generators use two vertical cylindrical collectors or headers, each with an inside diameter of $800 \mathrm{~mm}$ (VVER-440) or $834 \mathrm{~mm}$ (VVER-1000) and a wall thickness of $136 \mathrm{~mm}$ (VVER-440) or $171 \mathrm{~mm}$ (VVER-1000) rather than a thick-wall tubesheet. As mentioned above, the VVER-440 collectors are made of the same Ti-stabilized stainless steel as the tubing. The VVER-1000 collectors are made of the same low alloy pearlitic steel (Type 10GN2MFA) as the vessel, with stainless steel cladding on the inside surface. The tubes are embedded against the collector wall by explosion or hydraulic expansion and welded at the collector inside surface using argon-arc welding. Collector-tube crevices generally do not exist, however, some "under-rolling" of the heat exchanger tubes into the collector wall has been reported, resulting in crevices with depths up to $20 \mathrm{~mm}$ (explosive expansions) or $2 \mathrm{~mm}$ (hydraulic expansions).

\subsubsection{Tube Supports}

Several types of tube support systems have been used in PWR steam generators, as shown in Figures 11 and 12. Most of the original steam 


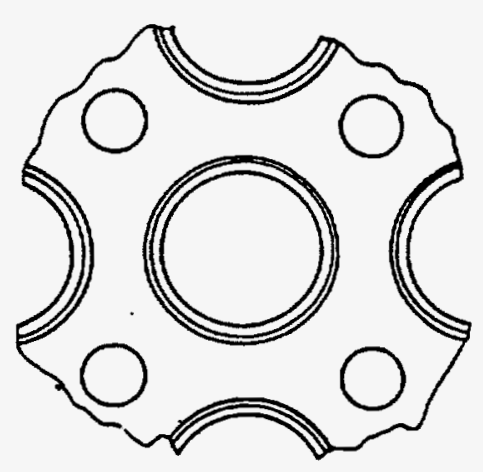

Drilled Plate (with flow holes)

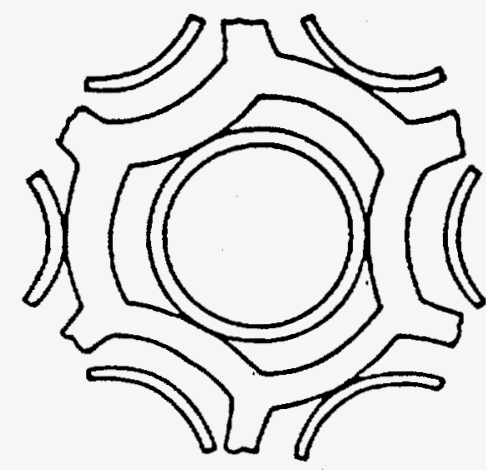

Broach-Trefoil

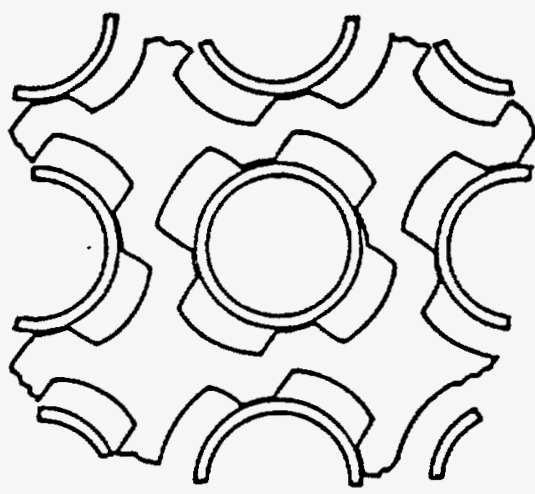

Broach-Quatrefoil

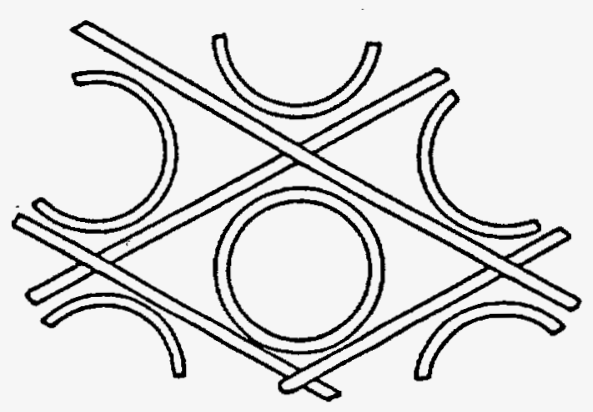

Eggcrate

Figure 11. Typical tube support configurations (EPRI 1985a). Copyright 1985 Electric Power Research Institute; reprinted with permission. 


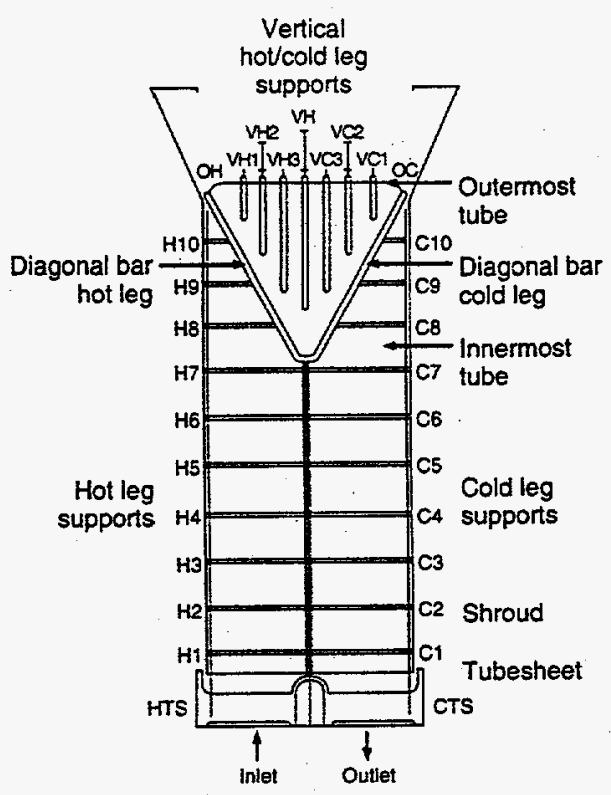

CE recirculating steam generator

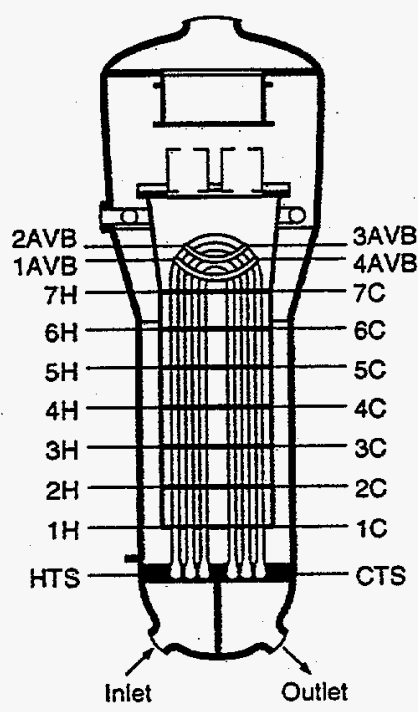

Westinghouse recirculating steam generator

Tube Support Plate/Tubesheet Nomenclature Westinghouse model 51

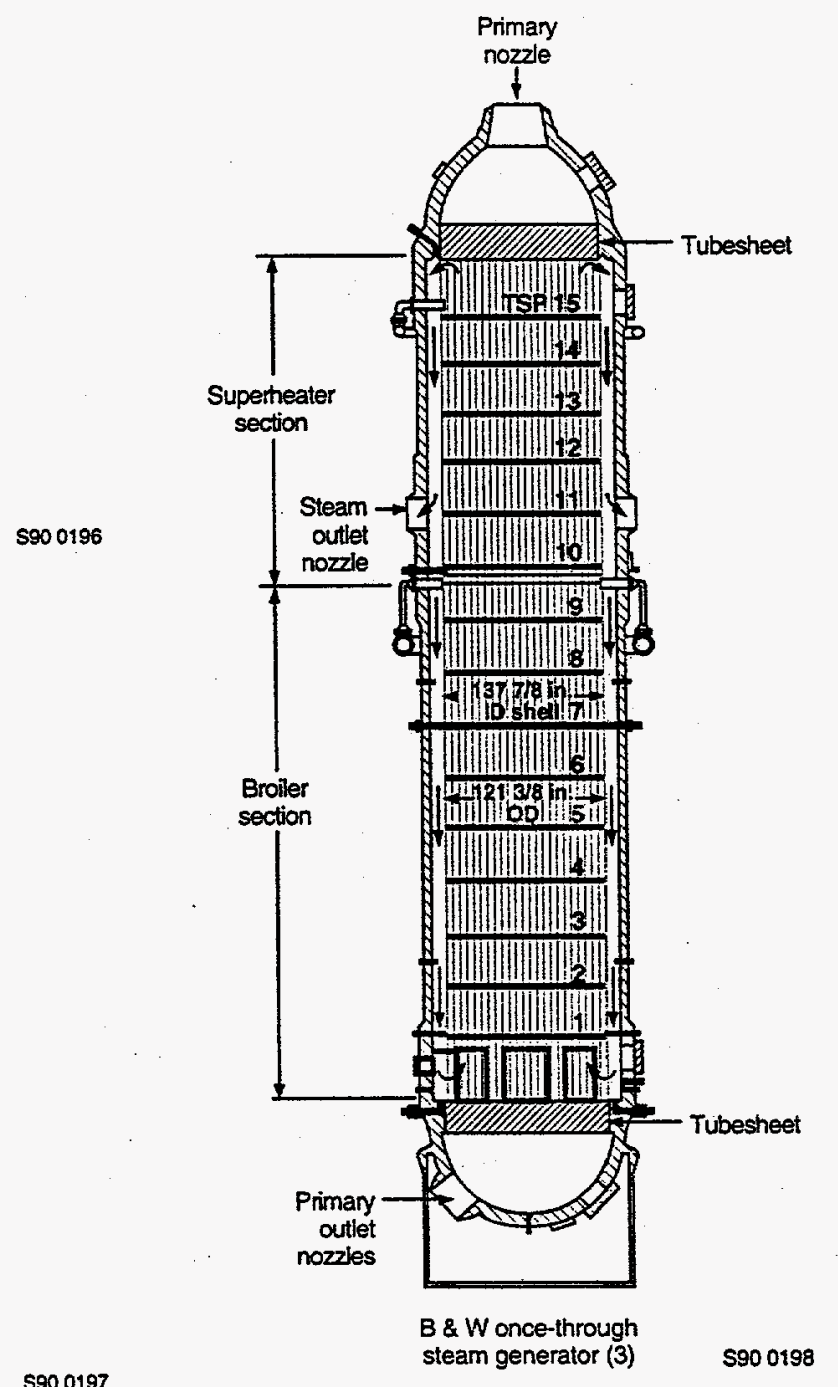

Figure 12. Typical steam generator tube support layouts used in the United States with tube support plate and tubesheet nomenclature. 
generators of Westinghouse design have plate-type tube supports, where tubes pass through drilled holes in the plate. This construction leaves a narrow gap around the tube, between the tube and plate, which allows secondary coolant to flow through. Separate smaller holes also provide for the secondary coolant flow. Combustion Engineering steam generators mostly use supports formed from a lattice arrangement of bars (eggcrate tube supports), but also use drilled plates in some locations in the U-bend region (see Figures 11 and 13). Babcock \& Wilcox steam generators have plate-type tube supports, but the holes are broached to give a noncircular hole with three lands to support the tube, with a larger diameter between the lands to allow coolant flow adjacent to the tube (trefoil-design broached hole). Later Westinghouse designs also use broached hole tube support plates (with four lands to support the tube-quatrefoil design). The earlier models have carbon steel as the tube support material, whereas the later models have corrosion resistant Type 405 ferritic stainless steel.

Antivibration bars (AVBs) or plates are used in the U-bend regions of RSG tube bundles to stiffen the tubes and limit vibration amplitudes. Typical arrangements for AVBs in Westinghouse and Combustion Engineering steam generators are shown in Figure 13. The AVBs in Westinghouse-type RSGs are installed to provide support to at least Row 11, though many were installed to deeper depths, e.g., to row eight. The AVBs in later Westinghouse models have a square cross section and are made from Alloy 600 and are chrome plated. The arrangement of the AVBs in Combustion Engineering steam generators includes vertical, horizontal, and bat wing strips, as shown in Figure 13.

The CANDU steam generator tube support design has gone through many changes. Older operating units have a carbon steel lattice grid arrangement, or carbon steel trefoil broached plates (see description of Babcock \& Wilcox de- sign above). Recent models use an advanced version of the lattice grids made of stainless steel (see Figure 14). Antivibration (U-bend) supports have also undergone changes, from carbon steel scallop bars (stacked and staggered) to the current stainless steel flat bar type. The VVER440 and VVER-1000 steam generators use stainless steel bar and stamped wave-like plates to separate and support the tubes.

\subsubsection{Steam Generator Shells and Feedwater Nozzles}

Figure 15 shows the locations of the feedwater nozzle and the girth welds in a schematic of the shell of a Westinghouse PWR recirculating steam generator without a preheater. Figure 16a shows a typical Westinghouse feedwater nozzle and thermal sleeve. The Westinghouse thermal sleeve is welded to the feedring (not shown in figure). It fits snugiy against the nozzle, but is not attached to the nozzle. Figure $16 \mathrm{~b}$ shows the original configuration for the piping-to-nozzle weld. (The cracks shown in Figures 16a and 16b are discussed in Section 3.6.2.) The steam generator shell, including the feedwater nozzle, is made of low-alloy ferritic steel, typically SA533 Type A, Class 1 or 2 for the Westinghouse steam generator shells and SA-508 C12 for the feedwater nozzle forgings. (Some of the earlier steam generators made by Westinghouse in their Lester plant used SA-302 Grade B for the plate material, but all the steam generators built at the Tampa plant used SA-533.) The thermal sleeve inside the feedwater nozzle is made of SA-106 Grade B carbon steel.

As stated in Section 2.6.1, Babcock \& Wilcox heat treated the entire Babcock \& Wilcox oncethrough steam generator at about $595^{\circ} \mathrm{C}$ for 15 hours, thus reducing residual stresses in the shell and feedwater nozzle, as well as in the tubing. Most of the other steam generator vendors did not heat treat the entire steam generator. 
Typical Anti-Vibration Bar (AVB) Arrangements
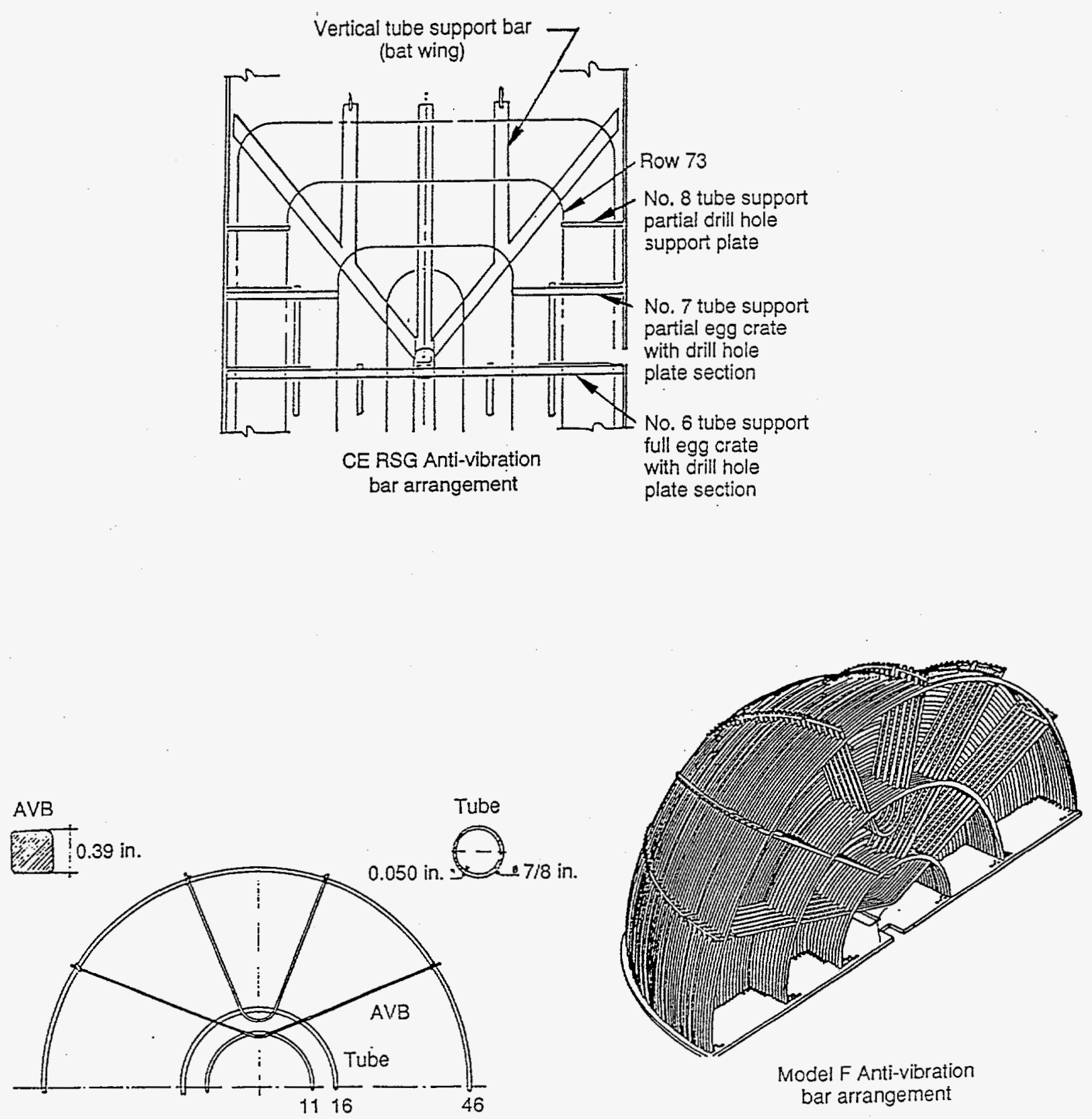

Model 51 Anti-vibration bar arrangement

Figure 13. Typical recirculating steam generator antivibration bar arrangement. 

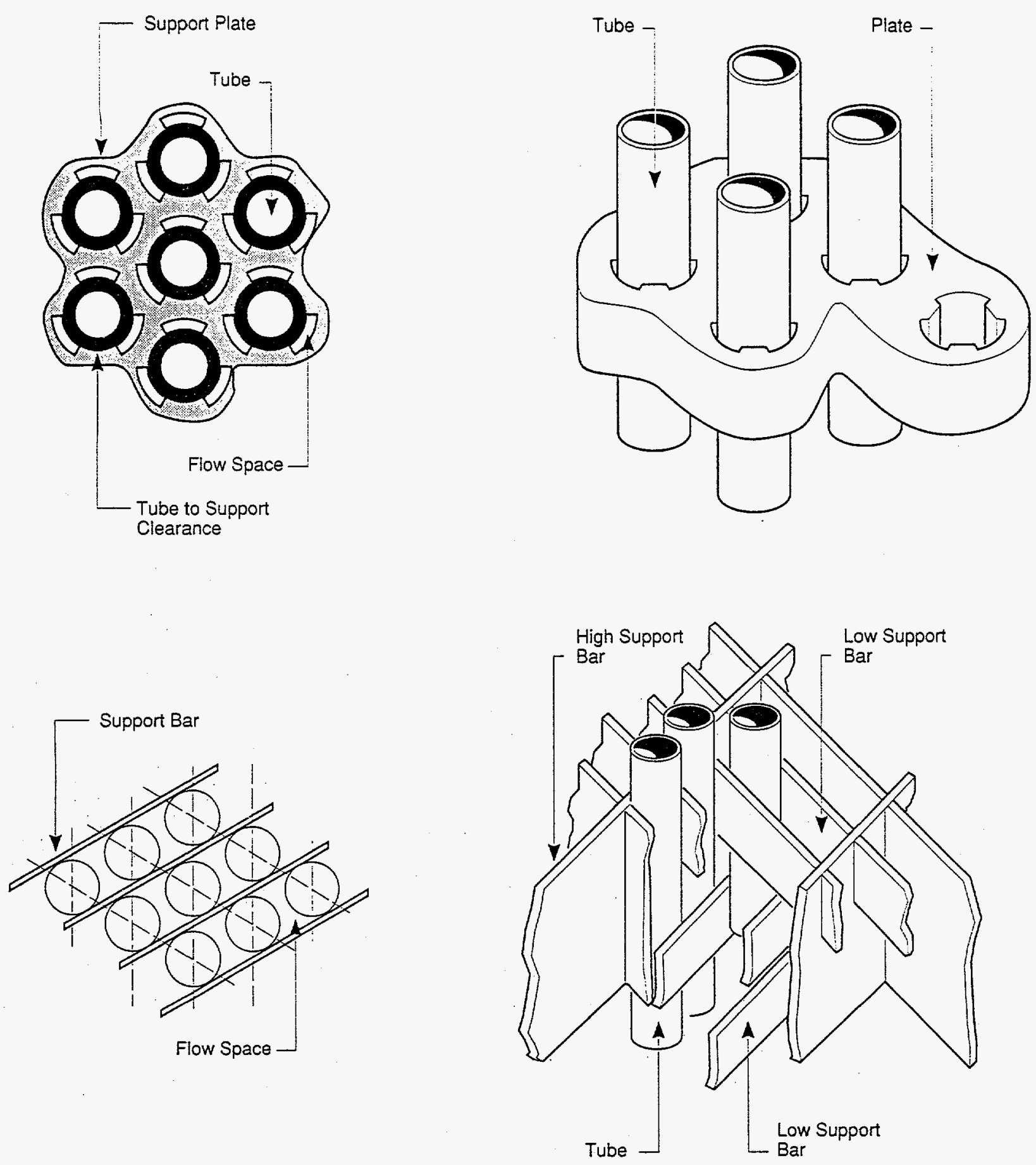

Free Flow Space Between B\&W Lattice Grid and Broached Plate Design

Figure 14. Typical CANDU steam generator tube support structures. Courtesy of C. Maruska, Ontario Hydro. 


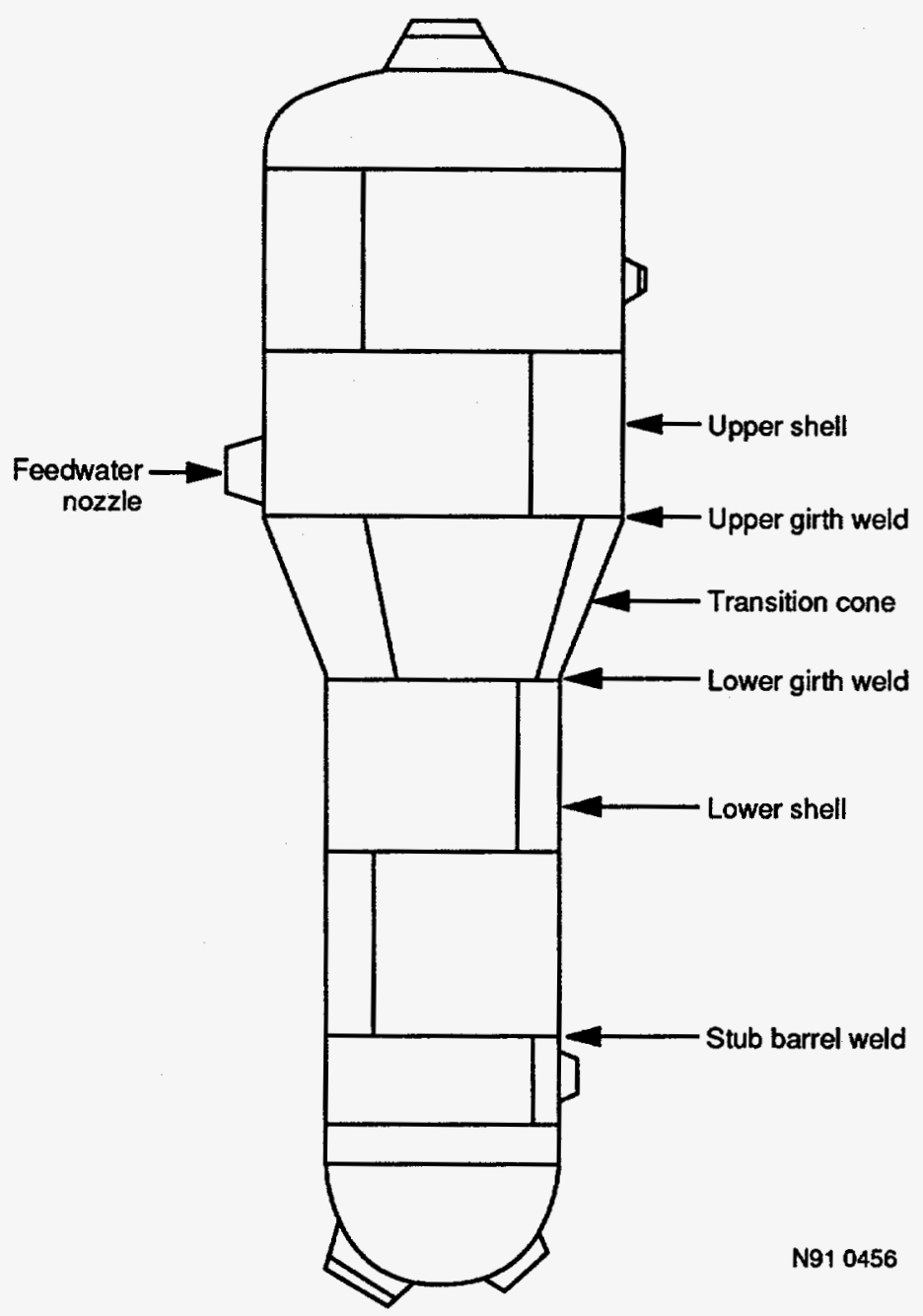

Figure 15. PWR steam generator showing shell welds (Westinghouse 1990). Copyright Westinghouse Electric Corporation; reprinted with permission. 

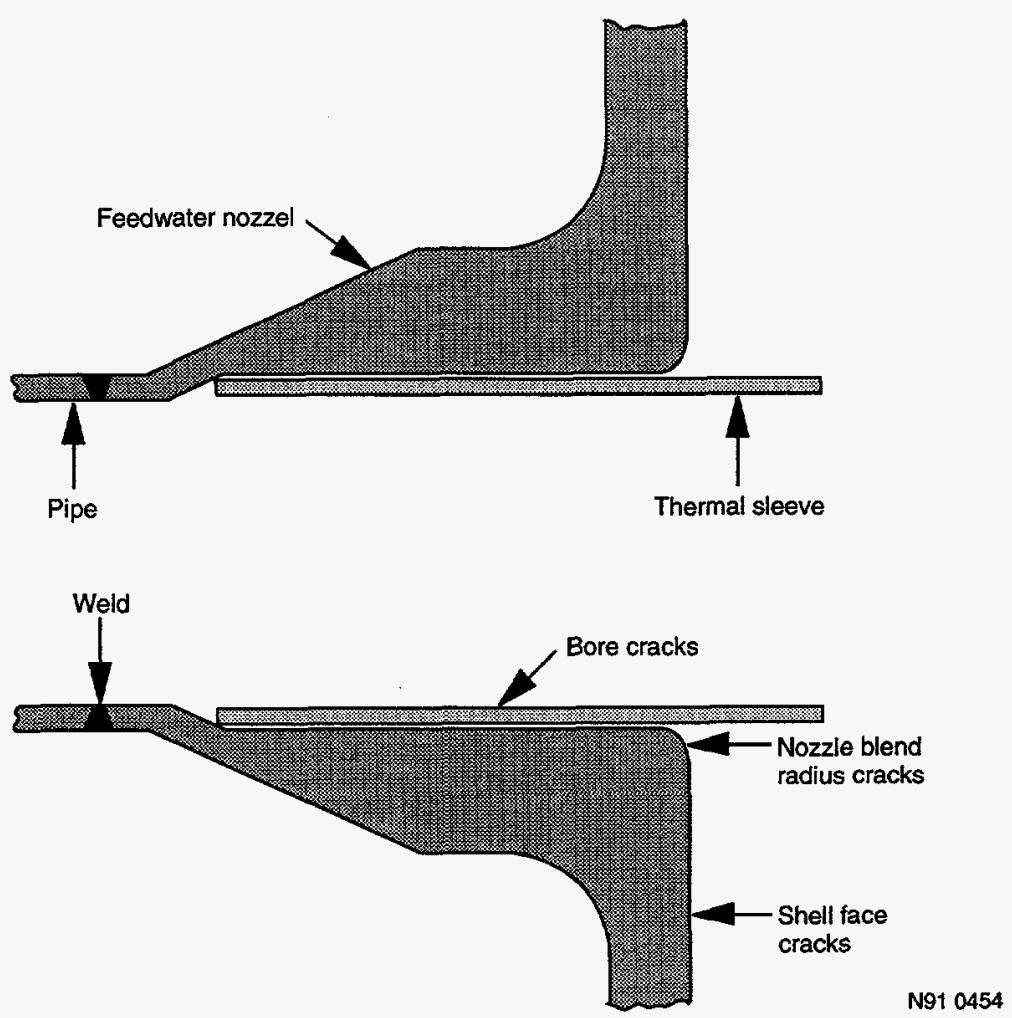

Figure 16a. Typical Westinghouse feedwater nozzle and thermal sleeve design with the sites susceptible to high-cycle thermal fatigue damage caused by turbulent mixing of leaking feedwater and hot steam generator coolant identified (Westinghouse 1990). Copyright Westinghouse Electric Corporation; reprinted with permission.

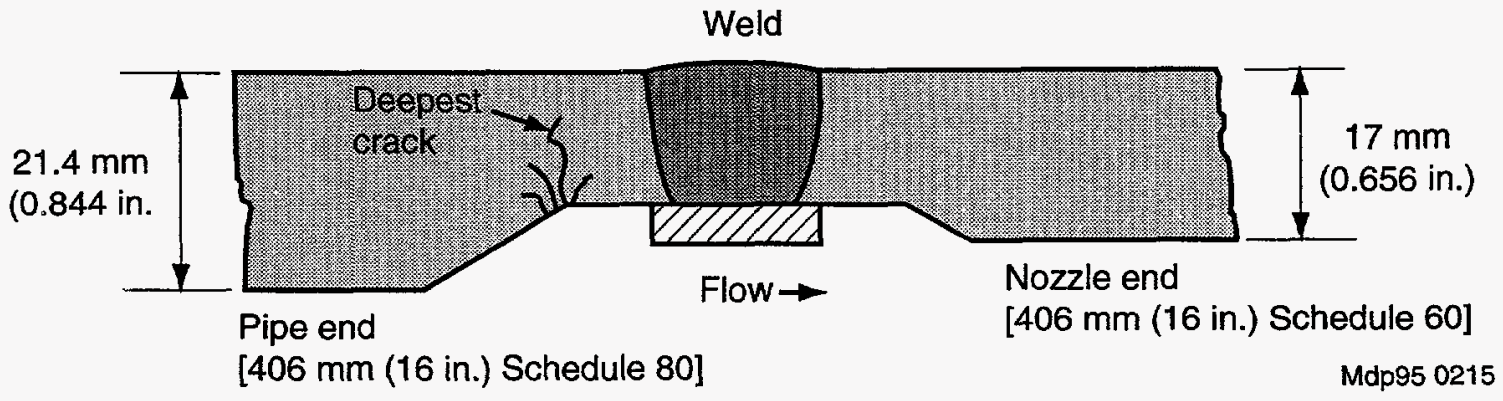

Figure 16b. Westinghouse feedwater piping-to-nozzle weld design at the D.C. Cook plant with crack locations identified (USNRC 1980).. 
The VVER steam generator pressure vessels and feedwater nozzles are shown in Figures 7, 8, and 9. The VVER-440 steam generator shell is made of Type $22 \mathrm{~K}$ carbon steel. The VVER-1000 steam generator shell and feedwater nozzle is made of Type 10GN2MFA low alloy steel with the following chemical composition: 0.08 to $0.12 \%$ carbon, 0.17 to $0.37 \%$ silicon, 0.8 to $1.1 \%$ manganese, $\leq 0.30$ chromium, 1.8 to $2.3 \%$ nickel, 0.4 to $0.7 \%$ molybdenum, 0.03 to $0.07 \%$ vanadium, and less than $0.02 \%$ sulfur and phosphorus. 


\section{STEAM GENERATOR DEGRADATION MECHANISM, SITES, AND FAILURE MODES}

This section discusses the stressors, susceptible sites and failure modes associated with the various steam generator degradation mechanisms. PWR and CANDU RSG tube degradation is discussed first, including primary water stress corrosion cracking, outside diameter stress corrosion cracking (ODSCC), fretting, pitting, denting, high-cycle fatigue, and wastage. This material is followed by similar information on PWR once-through steam generator tube and VVER steam generator tube degradation. Information on how to perform steam generator tubing residual life estimates is then presented, followed by information on PWR steam generator shell and feedwater nozzle degradation and VVER collector stress corrosion cracking and feedwater system erosion-corrosion.

\subsection{Summary of the PWR and CANDU Tube Degradation Problems}

In recent years, about one-half of the PWR nuclear power plants in the world were plugging or sleeving steam generator tubes in any given year. This implies that about one-half of these plants were operating with tubing defects near or beyond the national limits in any given year. Figure 17 shows the PWR and CANDU steam generator tubes plugged per year as a percentage of the total number of steam generator tubes in service. In recent years, the percentage of tubes plugged per year has been about 0.3 to $0.34 \%$ (of a total steam generator tube population which was more than 3.4 million in 1994). Although an average plugging rate of $0.3 \%$ per year may seem acceptable, over a 40 year steam generator life, this amounts to about 10 to $12 \%$ of the available tubes plugged. The total number of steam generator tubes plugged per year during the last few years has ranged from about 10,000 to 12,000 tubes. In addition, more than 48,000 steam generator tubes had been sleeved as of
December 1994 and about 17,000 more tubes were sleeved at Main Yankee during 1995 and 1996.

The relative impact of the tube degradation mechanisms on overall PWR steam generator performance has dramatically changed over time. Figure 18 shows the percent of the total number of tube failures ${ }^{a}$ caused by each of the major degradation mechanisms for the years 1975 through 1994 (EPRI 1995a). Both PWR and CANDU RSG and PWR once-through steam generator tube failures worldwide are included. (Figure 18 does not include data from the VVER reactors, except Loviisa Units 1 and 2.) Phosphate wastage was the major cause of tube failures in PWR steam generators until about 1976. From 1976 to about 1979, denting was the major cause of PWR steam generator tube failures. After about 1979, a variety of corrosion mechanisms became important, including intergranular stress corrosion cracking/intergranular attack and pitting on the outside diameters of the tubes and PWSCC on the inside surfaces. Fretting damage became more apparent after about 1983.

Table 6 lists the number of PWR and CANDU plants reporting various problems in 1977, 1982, and 1993 (EPRI 1994). There was a dramatic increase over the last 15 years in the number of plants reporting ODSCC, PWSCC, and fretting problems. In 1994, ODSCC (42\%), PWSCC

a. Failure is defined as a nondestructive examination indication requiring the tube to be removed from service (plugged) or repaired. The tubes that actually leaked primary coolant are a small proportion of the tubes plugged or repaired. Steam generator tubes are sometimes plugged as a preventive action if they are judged to have a high probability of future failure. 


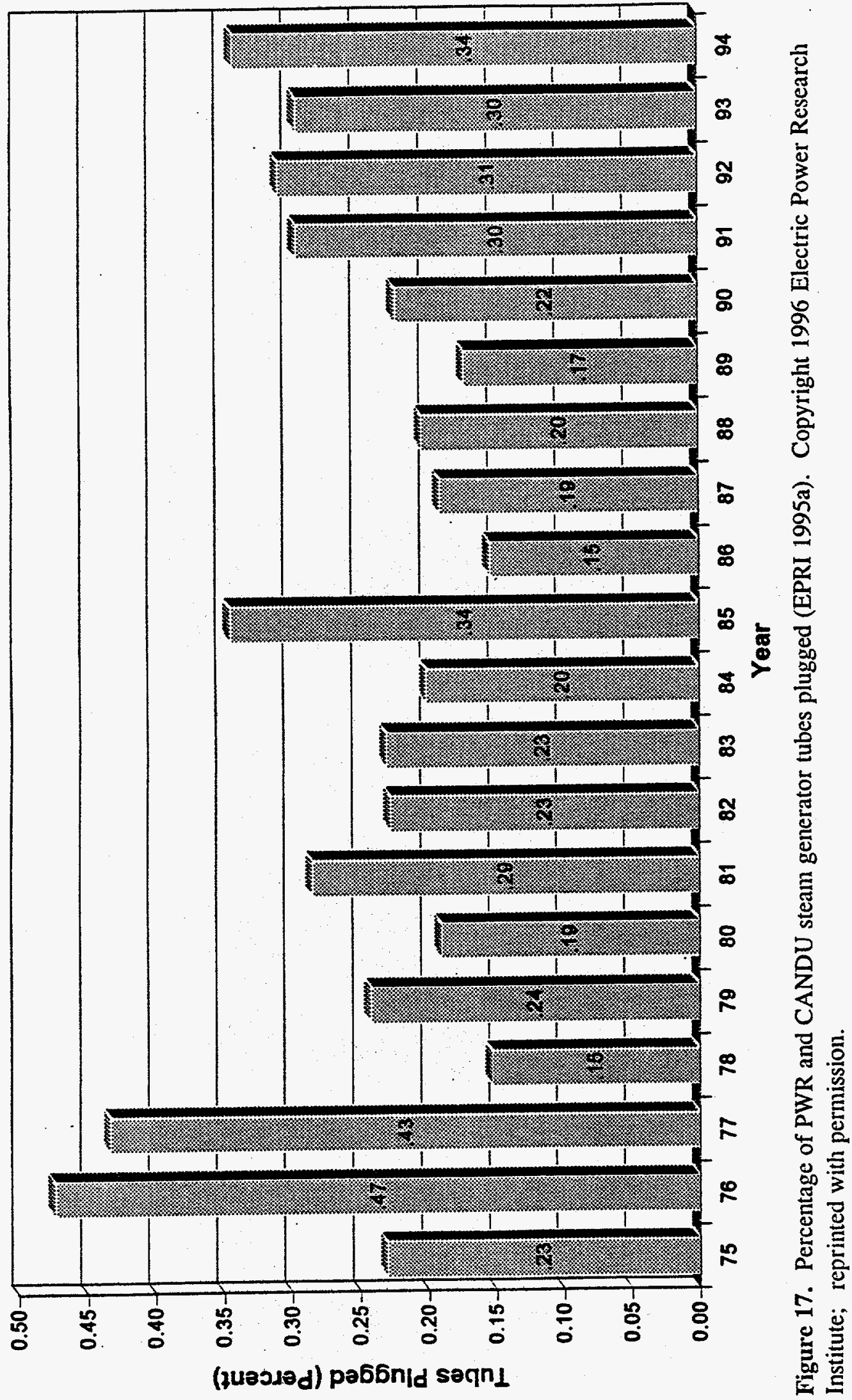




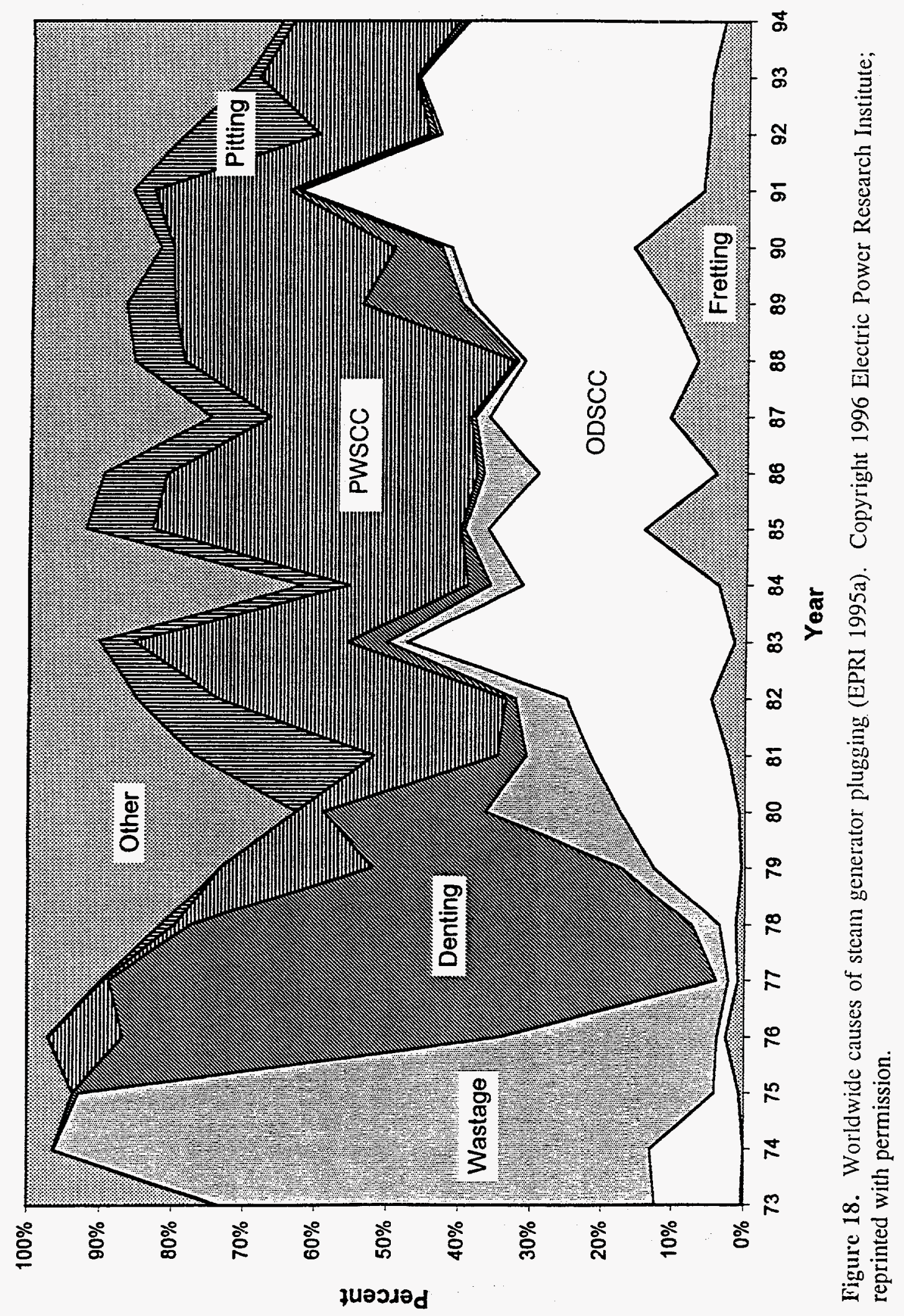


Table 6. Units reporting steam generator problems, (EPRI 1995a).

DATE
NO. UNITS:
REPORTED PROBLEMS

Denting

- Tube Support Corrosion

15

$30 \quad 37$

- Tubesheet Corrosion

6

12

49

Tubing Corrosion

- Wastage

- Pitting

0

3

- ID Cracking

- OD SCC/IGA

1

22

6

22

87

Mechanical Damage

- Fretting

9

15

- Fatigue Cracking 3

- Impingement

0

4

2

8

No Problems 26

32 56

No problems after 5 years ops (no. of units/no. $>5 y$ rs. ops).

Units reporting no problems after five years of operation

\begin{tabular}{ll}
$3 / 77$ & \multicolumn{1}{c}{$8 / 82$} \\
\hline Trillo & Kewaunee \\
& Mihama 3 \\
& Neckarwestheim \\
& Davis Besse
\end{tabular}

\begin{tabular}{ll} 
& $12 / 94$ \\
\hline Brokdorf & Obrigheim (Rpl) \\
Chinon B 3 & Philippsburg 2 \\
Cook 2(Rpl) & Pickering A 2 \\
Cruas 3 & Pickering A 3 \\
Cruas 4 & Pickering A 4 \\
Emsland & Pickering B 7 \\
Genkai 1(Rpl) & Pickering-B 8 \\
Genkai 2 & Ringhals 2 (Rpl) \\
Grafenrheinfeld & Robinson 2 (Rpl) \\
Indian Point 3(Rpl) & Tomari 1 \\
Isar 2 & Trillo 1 \\
Loviisa 1 & Ulchin 1 \\
Loviisa 2 & Ulchin 2 \\
Neckarwestheim 2 & Wolsung 1
\end{tabular}


(22\%), and fretting (4\%) accounted for about $68 \%$ of all the tubes plugged. However, the degradation mechanism is unknown for a significant number of defective tubes (about $30 \%$ ). Over $50 \%$ of the PWR units worldwide have now reported some occurrence of tube fretting and wear. Not all steam generators are degrading equally. Table 7 lists some of the plants that have plugged and sleeved over 2,000 steam generator tubes. However, some plants report no problems, even after five years of operation $(7-10 \%$ of the plants report no problems after five years of operation).
It should be noted that there have been far fewer tubing failures in the replacement steam generators than in the original equipment. Therefore, one would expect that the numbers of degraded and plugged steam generator tubes will, at some point, begin to decline as more replacement steam generator come on-line. As of December 1994, a total of 61 steam generators at 22 nuclear plants in Belgium, France, Germany, Japan, Sweden, Switzerland, and the U.S. had been replaced.

Table 7. PWR plants with more than 2,000 steam generator tubes plugged or sleeved.

\begin{tabular}{ccc} 
PLANT & NUMBER OF TUBES PLUGGED & \multicolumn{2}{c}{ NUMBER OF TUBES SLEEVED } \\
ASCO-1 & 1,866 & 249 \\
Cook-1 & 1,468 & 1,840 \\
Doel-4 & 2,290 & 12,970 \\
Ginna & 648 & 2,198 \\
Kewaunee & 1,017 & 4,202 \\
Kori-1 & 1,531 & 1,544 \\
Maine Yankee & 573 & $-16,536$ \\
McGuire-1 & 2,960 & - \\
McGuire-2 & 2,189 & - \\
Ohi-1 & 2,647 & 5,511 \\
Point Beach-2 & 945 & 3,674 \\
San Onofre-1 & 1,456 & 6,929 \\
Three Mile Island & 1,641 & 502 \\
Trojan & 2,444 & 1,115 \\
\end{tabular}

a. All the data except Maine Yankee is for the time period up to the end of December 1994 (EPRI 1995a). The Main Yankee numbers include the sleeving done in 1995 and 1996. 
Most of the PWR and CANDU steam generator tubes which have failed over the years have been mill-annealed Alloy 600 tubes. However, some failures of thermally treated Alloy 600 tubing have been reported, primarily due to fretting and denting (degradation mechanisms due to the design of the support plates and AVBs and the presence of loose parts, rather than the tubing material). But there have also been a few failures of thermally treated Alloy 600 tubing due to primary and secondary-side stress corrosion cracking. The Alloy $800 \mathrm{M}$ tubing used in the Siemens/KWU steam generators has performed relatively well. There were Alloy $800 \mathrm{M}$ tubing failures due to wastage in the Siemens/KWU steam generators which began operation in the 1970s with phosphate water chemistry, but there have been no wastage failures in the Siemens/ KWU steam generators which began operation in the 1980 s with an all volatile water treatment. There have also been some Alloy $800 \mathrm{M}$ tubing fretting failures in the Siemens/KWU steam generators which began operation before 1986 . But, only one Alloy $800 \mathrm{M}$ pulled tube has exhibited a stress corrosion crack, pits have been found on only two Alloy $800 \mathrm{M}$ tubes, and no Alloy $800 \mathrm{M}$ tubes have exhibited detectable intergranular attack or primary water stress corrosion cracking. There have been no Alloy 690 tube defects of any kind reported to date.

\subsection{Pressurized Water Reactor and CANDU Reactor Recirculating Steam Generator Tubes}

Figures 19 and 20 identify degradation sites for PWR and CANDU steam generators, respectively. Table 8 lists PWR steam generator degradation mechanisms, sites, stressors, failure mode and inspection methods for tubes and tubesheets. Table 9 lists the degradation mechanisms and sites currently active in the CANDU steam generators and the corresponding countermeasures completed or in progress.

\subsubsection{Primary Water Stress Corrosion Cracking}

The corrosion behavior of austenitic alloys is strongly dependent on the nickel and chromium content. The influence of the nickel content on the stress corrosion cracking processes in $18 \%$ chromium austenitic alloys when stressed slightly above the yield point of the material in demineralized water or water containing $1 \mathrm{~g} / \mathrm{l}$ chloride ions is shown in Figure 21 (Berge 1993). As indicated on the figure, Alloy $600 \mathrm{can}$ be susceptible to pure (primary) water stress corrosion cracking, whereas, Alloy 690 and Alloy $800 \mathrm{M}$ are generally not susceptible to PWSCC. Austenitic stainless steels with a nickel content below about $15 \%$ are susceptible to transgranular stress corrosion cracking when exposed to water containing significant amounts of chlorides $(1 \mathrm{~g} / \mathrm{l})$. The effects of chromium content on austenitic alloy material release rates due to corrosion in high temperature, low oxygen, borated water flowing at $5.5 \mathrm{~m} / \mathrm{s}$ are shown in Figure 22. The high chromium alloys (800 and 690) appear to lose much less material, probably because of the low solubility of chromium oxides in low oxygen primary coolant (Berge and Donati 1981).

The data plotted in Figures 21 and 22 suggest that Alloy 600 is much more susceptible to PWSCC than Alloys 800 or 690 and, in fact, PWSCC of Alloy (Inconel) 600 was identified in the laboratory as early as 1959 , when Coriou et al. (1959) reported cracking of this material in "high purity" water at $350^{\circ} \mathrm{C}\left(662^{\circ} \mathrm{F}\right)$. PWSCC of Alloy 600 steam generator tubing was first observed in the hot leg roll-transitions at the Obrigheim plant in 1971. Subsequent research showed that this was an intergranular cracking mechanism requiring at least the following conditions to be present: 


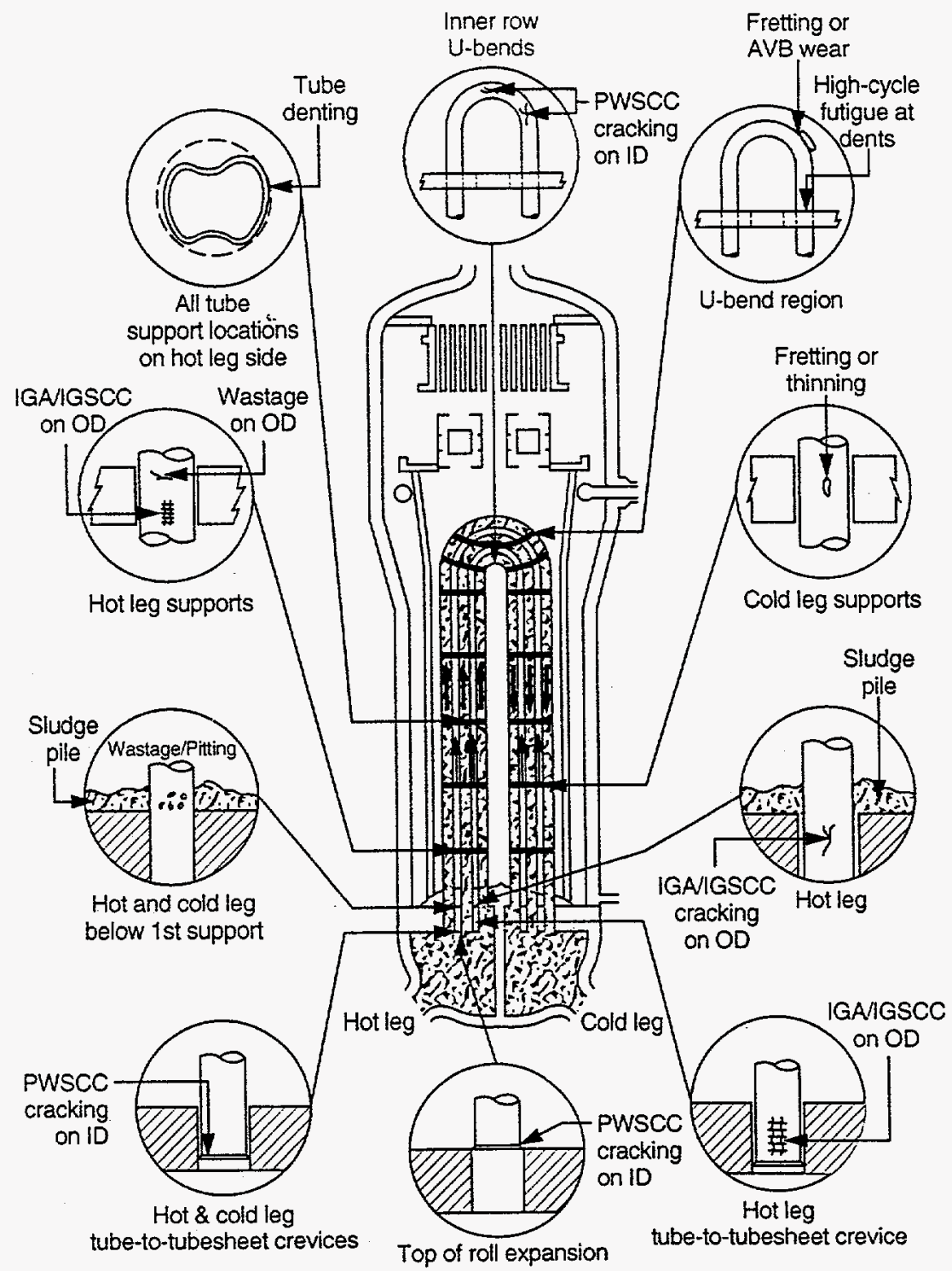

N91 0406

Figure 19. Locations of known tube wall degradations in recirculating steam generators. (Courtesy of K. J. Krzywosz of the Electric Power Research Institute NDE Center; modified.) 


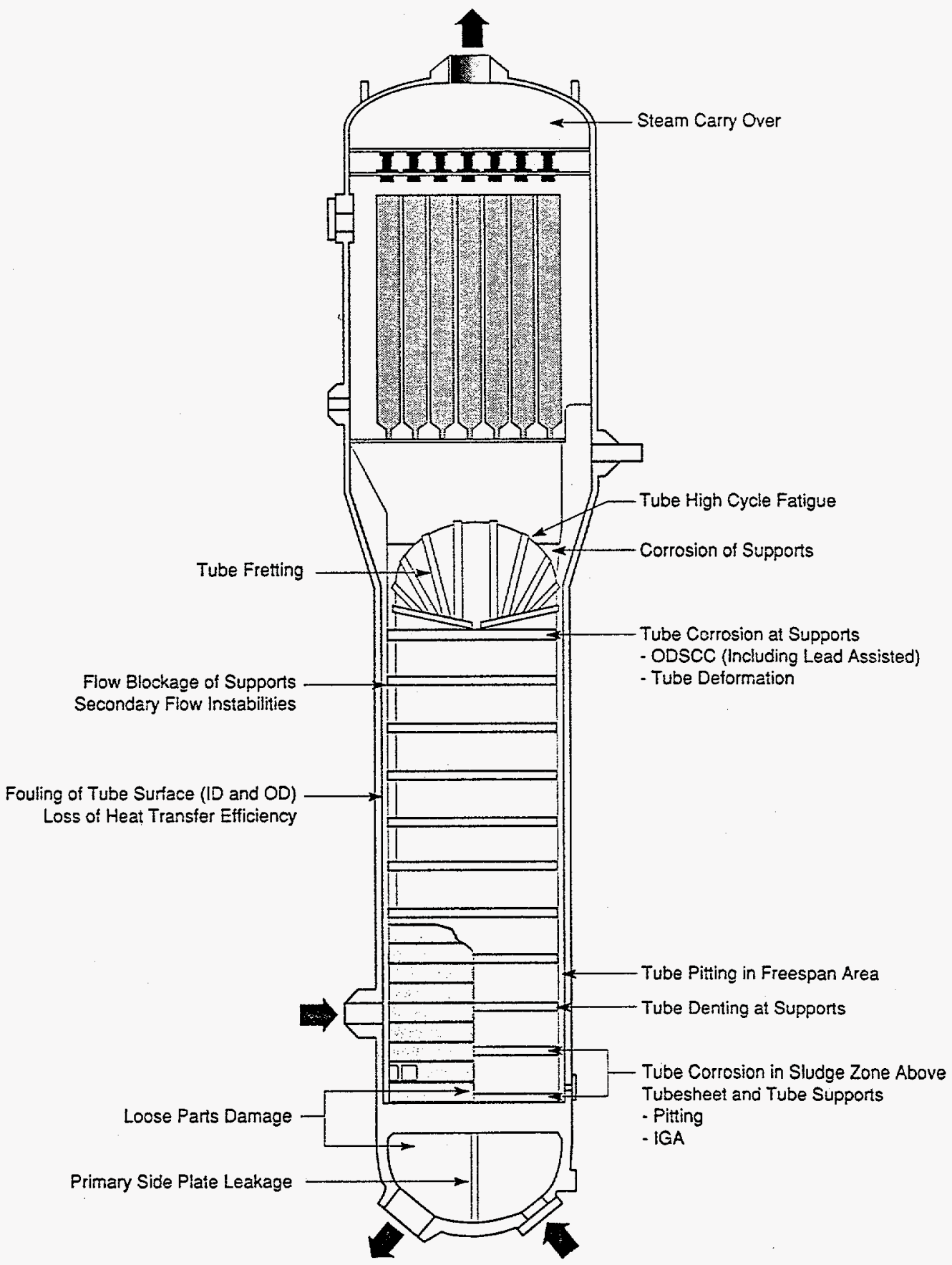

Figure 20. Degradation mechanisms and locations in CANDU recirculating steam generators. Courtesy of C. Maruska, Ontario Hydro. 
Table 8. Summary of PWR recirculating steam generator tube degradation processes.

\begin{tabular}{|c|c|c|c|c|c|}
\hline Rank: $^{-1}$ & $\begin{array}{l}\text { Degradation } \\
\text { Mechanism }\end{array}$ & Stressor & Degradation Sites & $\begin{array}{c}\text { Potential Failure } \\
\text { Mode } \\
\end{array}$ & ISI Method \\
\hline 1 & ODSCC & $\begin{array}{l}\text { Tensile stresses, } \\
\text { impurity } \\
\text { concentrations, } \\
\text { scusitive materials }\end{array}$ & $\begin{array}{l}\text { - Tube-to-tubesheet crevices } \\
\text { - Sludge pile } \\
\text { - Tube support plate } \\
\text { - Free span }\end{array}$ & $\begin{array}{l}\text { Axial or circumferential } \\
\text { crack } \\
\text { Circumferential crack } \\
\text { Axial crack } \\
\text { Axial crack } \\
\end{array}$ & $\begin{array}{l}\text { MRPC } \\
\text { MRPC/Cecco } 5 \\
\text { Bobbin coil/Cecco } 5 \\
\text { Bobbin coil (in absolute mode) }\end{array}$ \\
\hline 2 & PWSCC & $\begin{array}{l}\text { Temperature, residual } \\
\text { tensile stresses, } \\
\text { sensitive materials } \\
\text { (low mill anneal } \\
\text { temperature) } \\
\end{array}$ & $\begin{array}{l}\text { - Inside surface of U-bend } \\
\text { - Roll transition w/o kiss rolling } \\
\text { - Roll transition with kiss rolling } \\
\text { - Dented tube regions }\end{array}$ & $\begin{array}{l}\text { Mixed Crack } \\
\text { Mixed Crack } \\
\text { Axial Crack } \\
\text { Circumferential Crack }\end{array}$ & $\begin{array}{l}\text { MRPC } \\
\text { MRPC } \\
\text { MRPC } \\
\text { Bobbin coil or MRPC }\end{array}$ \\
\hline 3 & $\begin{array}{l}\text { Fretting, } \\
\text { Wear }\end{array}$ & $\begin{array}{l}\text { Flow induced } \\
\text { vibration, aggressive } \\
\text { chemicals }\end{array}$ & $\begin{array}{l}\text { - Contact points between tubes and the } \Lambda \text { VBs, or } \\
\text { tubes and the preheater bafnes } \\
\text { - Contact between tubes and loose parts } \\
\text { - Tube-to-tube contact }\end{array}$ & $\begin{array}{l}\text { Local wear } \\
\text { Depends on loose part } \\
\text { geometry } \\
\text { Axial Wear } \\
\end{array}$ & $\begin{array}{l}\text { Bobbin coil } \\
\text { Bobbin coil } \\
\text { Bobbin coil }\end{array}$ \\
\hline 4 & $\begin{array}{l}\text { High-cycle } \\
\text { fatigue }\end{array}$ & $\begin{array}{l}\text { High mean stress level } \\
\text { and flow induced } \\
\text { vibration, initiating } \\
\text { defect (crack, dent, } \\
\text { pit, etc.) }\end{array}$ & At the upper support plate if the tube is clamped. & $\begin{array}{l}\text { Transgranular } \\
\text { circumferential cracking }\end{array}$ & $\begin{array}{l}\text { Leak detection or by detection of } \\
\text { precursor }\end{array}$ \\
\hline 5 & Denting & $\begin{array}{l}\text { Oxygen, copper oxide, } \\
\text { chlorides, } \\
\text { temperature, pH, } \\
\text { crevice condition, } \\
\text { deposits } \\
\end{array}$ & $\begin{array}{l}\text { At the tube support plates, in the sludge pile, in } \\
\text { the tubesheet crevices }\end{array}$ & $\begin{array}{l}\text { Flow blockage in tube, } \\
\text { may lead to circumferential } \\
\text { cracking (see PWSCC), } \\
\text { decreases the fatigue } \\
\text { resistance }\end{array}$ & Profilometry, bobbin coil \\
\hline 6 & Pitting & $\begin{array}{l}\text { Brackish water, } \\
\text { clilorides, sulfates, } \\
\text { oxygen, copper oxides }\end{array}$ & $\begin{array}{l}\text { Cold leg in sludge pile or where scale containing } \\
\text { copper deposits is found, under deposit pitting in } \\
\text { hot leg }\end{array}$ & $\begin{array}{l}\text { Local attack and tube } \\
\text { thinming, may lead to a } \\
\text { hole }\end{array}$ & Bobbin coil, ultrasonics \\
\hline 7 & Wastage & $\begin{array}{l}\text { Phosphate chemistry, } \\
\text { chloride concentration, } \\
\text { resin leakage }\end{array}$ & $\begin{array}{l}\text { Tubesheet crevices, sludge pile, tube support } \\
\text { plates, AVBs }\end{array}$ & General thiming & Bobbin coil \\
\hline
\end{tabular}

"Based on operating experience and number of defects (as of 1993).

"Multifrequency rotating pancake coil probe. 
Table 9. Summary of major CANDU steam generator degradation.

\begin{tabular}{|c|c|c|c|c|c|}
\hline Rank & $\begin{array}{l}\text { Degradation } \\
\text { Mechanism } \\
\end{array}$ & Stressor & Degradation Sites & $\begin{array}{c}\text { Potential Failure } \\
\text { Mode } \\
\end{array}$ & ISI Method \\
\hline 1 & ODSCC & $\begin{array}{l}\text { High stress, } \\
\text { corrosive } \\
\text { environment due to } \\
\text { deposit build-up }\end{array}$ & $\begin{array}{l}\text { U-bend support } \\
\text { intersections } \\
7 \text { th support plate }\end{array}$ & $\begin{array}{l}\text { Circumferential } \\
\text { cracking } \\
\text { Predominantly } \\
\text { circumferential, } \\
\text { some axial }\end{array}$ & $\begin{array}{l}\text { Cecco } 3 \\
\text { Cecco } 3\end{array}$ \\
\hline 2 & $\begin{array}{l}\text { Outside diameter } \\
\text { pitting }\end{array}$ & $\begin{array}{l}\text { Deposits which } \\
\text { cause a corrosive } \\
\text { environment }\end{array}$ & $\begin{array}{l}\text { Tubesheet area } \\
\text { under sludge pile } \\
\text { and at lower tube } \\
\text { support } \\
\text { intersections and at } \\
\text { freespan tubes }\end{array}$ & $\begin{array}{l}\text { Local tube thinning } \\
\text { leading to holes }\end{array}$ & $\begin{array}{l}\text { E/C [carter] } \\
\text { Ultrasonics }\end{array}$ \\
\hline 3 & Fretting & $\begin{array}{l}\text { Flow induced } \\
\text { vibration, loose } \\
\text { supports } \\
\end{array}$ & $\begin{array}{l}\text { U-bend support } \\
\text { intersections }\end{array}$ & $\begin{array}{l}\text { Metal loss which } \\
\text { may lead to large } \\
\text { hole }\end{array}$ & Bobbin coil \\
\hline 4 & $\begin{array}{l}\text { Corrosion of } \\
\text { carbon steel } \\
\text { supports }\end{array}$ & $\begin{array}{l}\text { Corrosive } \\
\text { environment, stress }\end{array}$ & U-bend supports & $\begin{array}{l}\text { Support } \\
\text { disintegration and } \\
\text { metal loss/may lead } \\
\text { to tube degradation } \\
\text { from flow induced } \\
\text { vibration due to } \\
\text { lack of support } \\
\end{array}$ & $\begin{array}{l}\text { Visual (secondary } \\
\text { access) }\end{array}$ \\
\hline 5 & $\begin{array}{l}\text { Erosion-corrosion, } \\
\text { high or low cycle } \\
\text { fatigue }\end{array}$ & Bolt failure & Primary head & $\begin{array}{l}\text { Break up of bolted } \\
\text { plates may lead to } \\
\text { blockage of PHT } \\
\text { inlet }\end{array}$ & $\begin{array}{l}\text { Visual and } \\
\text { metallography of } \\
\text { bolts }\end{array}$ \\
\hline
\end{tabular}

- $\quad$ high applied or residual tensile stress or both (near the yield strength),

- a corrosive environment (high temperature water), and

- $\quad$ susceptible tubing microstructure (alloy content and few intergranular carbides).
PWSCC occurs at locations on the inside surfaces of RSG tubing with high residual stresses (introduced during fabrication and installation of the tubes, as discussed in Section 2.6). These locations are primarily the expansion-transition regions in the tubesheets, the U-bend regions of the tubing in the inner rows (i.e., the tubes with a small bend radius), and any dent locations at 


\section{Susceptibility to SCC}

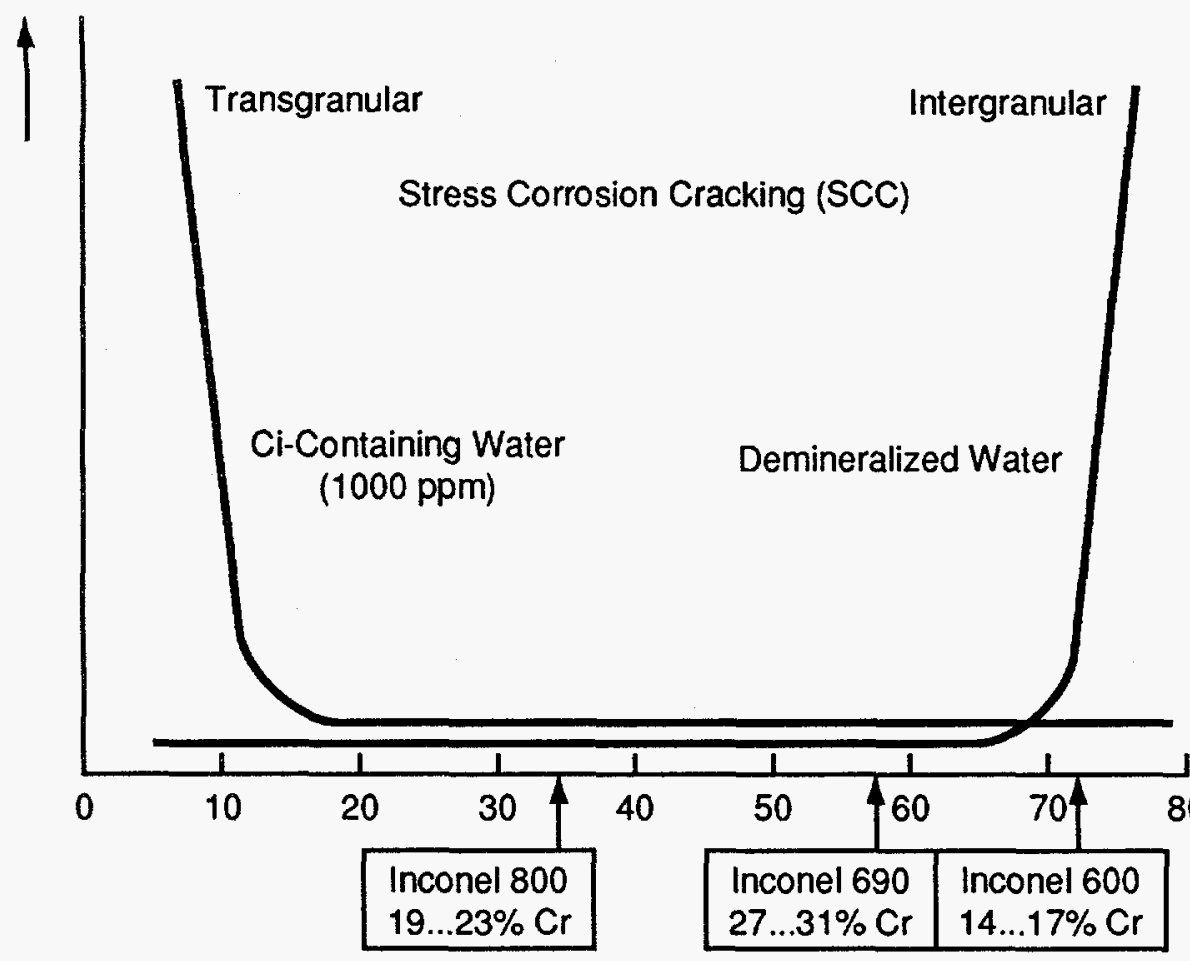

Ni-Content

M950140

Figure 21. Schematic diagram showing the influence of nickel content on the cracking processes occurring in three steam generator tubing materials stressed slightly above the yield point in $350^{\circ} \mathrm{C}$ water (From Coriou 1971, as reported by Berge 1993). Copyright 1993 Electric Power Research Institute; reprinted with permission.

the tube support plate, tubesheet, or sludge pile elevations. Section 3.1.5 discusses tube denting, e.g., deformation resulting in residual stresses due to buildup of corrosion products. PWSCC generally occurs on the hot leg side of the recirculating steam generations; however, cold leg PWSCC has been observed.

In the case of an axial crack, a leak will occur before the critical crack size (leading to tube rupture) is achieved. On the other hand, the evolution of circumferential cracks is not known. Consequently, a tube with a circumferential crack is usually plugged or sleeved immediately after detection to avoid possible tube rupture.
Status. As of December 1993, at least 94 PWR plants worldwide (36 plants in the U.S.) with RSGs had experienced significant PWSCC at the expansion-transition (tubesheet), dent, and/or Ubend locations of the tubing (EPRI 1994). Approximately 14,180 RSG tubes with PWSCC at or near the expansion-transitions have been plugged at 85 plants. Tubes with PWSCC have also been sleeved at 17 plants. Approximately 8,430 RSG tubes with PWSCC in the U-bend regions have also been plugged at 63 plants (however, several hundred tubes were preventively plugged and may not have been defective). Fifty-three PWR plants have experienced both expansion-transition and $\mathrm{U}$ - 


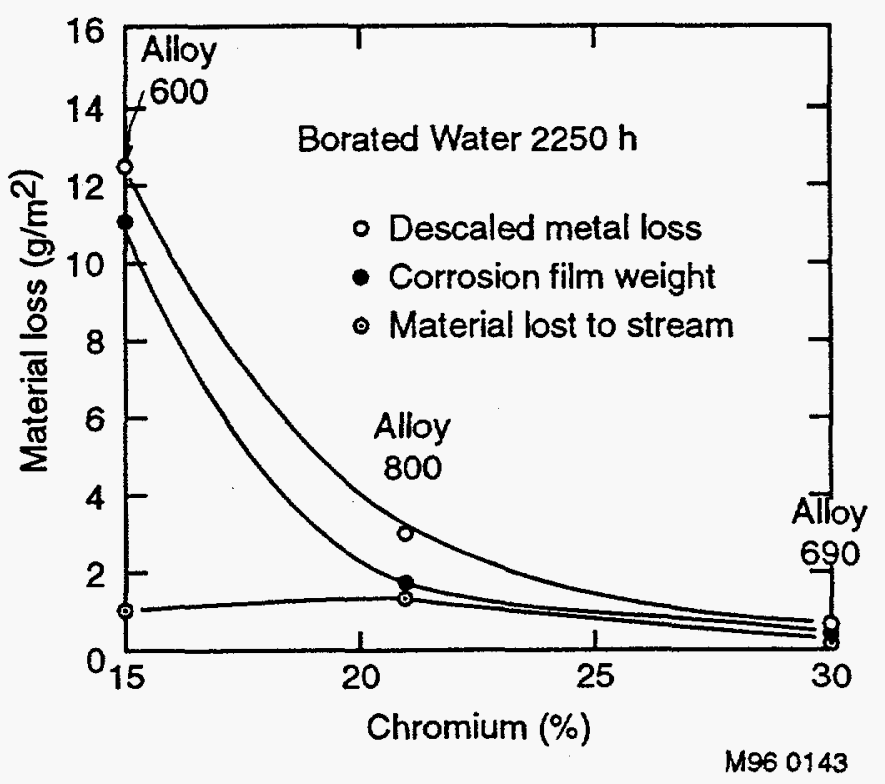

Figure 22. Effect of austenitic alloy chromium content on material lost due to corrosion in deaerated, borated water flowing at a velocity of $5.5 \mathrm{~m} / \mathrm{s}$ (From Sedriks et. al 1979, as reported by Berge and Donati 1981). Copyright 1981 American Nuclear Society, Inc., LaGrange, Illinoise; reprinted with permission.

bend PWSCC and tubes with PWSCC at dents have been plugged at, at least five plants.

This degradation has occurred primarily at Westinghouse-type plants (steam generators built by Westinghouse and by Westinghouse licensees in Europe and Japan) in Belgium, France, Japan, Korea, Spain, Sweden, Switzerland, and the U.S. with Alloy 600 mill-annealed tubing, typically expanded by hard rolling (which introduces high residual stresses at the roll transition and where rolling anomalies occurred). The most extensively degraded steam generators have had as many as 20 to $38 \%$ of all their tubes plugged as a result of PWSCC and have been replaced at some plants. However, similar steam generators (same model number) at other PWR plants have experienced only a few tube failures due to PWSCC.

The Combustion Engineering plants with relatively high-temperature mill-annealed tubing initially reported less PWSCC. However, both explosive-transition and U-bend PWSCC occurred at Maine Yankee after about 16 years of operation (model CE-67 steam generators) and a few cracks at the expansion-transition regions occurred at Palo Verde Units 1 and 3 after five to seven years of operation (model CE-80 steam generators). Recently, it has been reported that after 22 years of operation $60 \%$ of the Maine Yankee steam generator tubes have indications of circumferential cracking at or near the expansion transition and the utility has sleeved all 17,000 tubes in its three steam generators (INSIDE NRC 1995, USNRC 1995a).

Nine French plants with thermally treated Alloy 600 tubing have plugged tubes because of PWSCC at the expansion-transition region. However, the number of steam generator tubes involved (a total of 82 plugged) is rather small, in part, because the tubes were not plugged unless they also had dents (i.e., the possibility of circumferential cracking). As of December 1993, there had been no PWSCC of thermally 
treated Alloy 600 tubes in the U.S. or elsewhere outside of France and there had been no PWSCC of Alloy 690 or Alloy 800M tubing. (PWSCC of thermally treated Alloy 600 tubing has occurred only in steam generators in which the tubes were mechanically rolled into the tubesheet.)

CANDU units using high-temperature millannealed Alloy 600 tubing, running at relatively low inlet temperatures have not experienced PWSCC to date (EPRI 1994). The oldest running plant with Alloy 600 tubing has over 11 effective full power years (EFPY) or approximately 18 calendar years of operation with no evidence of this degradation mechanism. It is believed that the lower operating temperatures of the CANDU primary system and more resistant material may have contributed to the delay in onset of this type of cracking. The other tubing alloys used in the CANDU steam generators, Monel 400 and Alloy 800, are not susceptible to PWSCC.

Crack Patterns. Examination of removed tubes affected by PWSCC and in situ inspection by rotating pancake coil eddy-current test probes indicate that PWSCC cracks typically have the following patterns (Dobbeni et al. 1985, Engstrom 1985):

1. Cracks in U-bends typically are axial in orientation, though occasional off-axial cracks have been detected.

2. Cracks in standard roll transitions are mostly axial, though occasional short circumferential cracks occur between axial cracks. Rarely are isolated circumferential cracks detected.

3. Some large circumferential cracks have been detected in the sludge pile area of kiss-rolled plants in France. In some cases, large circumferential cracks have been located at the same transition as multiple axial cracks. In other cases, large circumferential cracks have occurred without any axial cracks.

4. Cracks at explosive transitions are typically circumferential in orientation, though occasionally axial PWSCC is noted by rotating pancake coil eddycurrent testing.

5. Primary-side cracks at dented tube support plate intersections are typically axial, though some circumferential segments have been noted.

6. Cracks at dents associated with sludge pile deposits at the top of the tubesheet (observed in France) have been circumferential in orientation.

Effect of Stress. The PWSCC damage rate in Alloy 600 material increases as a function of stress to an exponent. Test results have shown this exponent to be in the range of four to seven (Hunt and Gross 1994). An exponent of four is typically used, i.e., damage rate $\propto \sigma^{4}$ where $\sigma$ is the maximum principal tensile stress, which includes both applied and residual stresses (Bandy and Rooyen 1984). An exponent of four on damage rate is typical of stress exponents for creep and, thus, is consistent with modern models for PWSCC, which say that slow straining at the crack tip is an essential part of the cracking process. This correlation suggests that a $50 \%$ reduction in the effective stress will result in a sixteen-fold decrease in the damage rate and a corresponding increase in PWSCC initiation time. The correlation was developed using tensile specimen data and is widely used. A threshold stress, a stress below which PWSCC does not initiate, has not been determined experimentally for Alloy 600 . However, use of the strain rate damage model, which is based on slow strain rate test data, leads to an estimated threshold stress of about $241 \mathrm{MPa}(35 \mathrm{ksi})$ at an operating temperature of about $315^{\circ} \mathrm{C}\left(600^{\circ} \mathrm{F}\right)$ (Begley 1988). 
All the PWSCC failures reported in the field resulted from high residual tensile stresses; the applied operating stresses are generally low. The high residual stresses are caused by tube bending and expansion during fabrication and installation, and by any tube denting at the support plates during operation. The magnitude of the residual stresses at the affected sites are of yield strength level; in a cold-worked steam generator tube the residual stress can be as high as $690 \mathrm{MPa}(100$ ksi).

Effect of Temperature. PWSCC of Alloy 600 material is a thermally activated process, which can be described by an Arrhenius relationship of the form

$$
\text { damage rate } \propto \boldsymbol{o}^{\mathrm{n}} \mathrm{e}^{\mathrm{Q} / \mathrm{RT}}
$$

where $Q$ is an activation energy, $R$ is the universal gas constant, $T$ is temperature, and $n$ is a constant of four to seven as discussed above. This is the standard form for thermally activated processes and is supported by several recent studies. The best estimate for the activation energy from laboratory studies and field experience is about $210 \mathrm{~kJ} / \mathrm{mole}(50 \mathrm{kcal} / \mathrm{mole})$ and the estimates vary from about 160 to 270 $\mathrm{kJ} /$ mole (Gorman et al. 1991). As such, a small decrease in steam generator operating temperature will significantly slow the initiation and growth of PWSCC at any location in the steam generator (Hunt and Gorman 1986, Bandy and van Rooyen 1984a, Stein and Mcllree 1986).

Use of this type of time-temperature relationship to model the time delay expected between a given percentage of PWSCC failures in the hot and cold leg tubesheet regions, shows a delay factor of five to eight in time, depending on plant temperatures and the value of activation energy $\mathrm{Q}$ used. However, cold leg tubesheet PWSCC has recently been observed in some plants after somewhat shorter times, e.g., a factor of two to three later than hot leg tubesheet PWSCC. This may have been caused simply by the significant improvement in non-destructive examination (NDE) detection capabilities that have occurred in recent years.

Effect of Microstructure. Field experience and research results show that the PWSCC resistance of Alloy 600 is highest when the grain boundaries are covered with continuous or semicontinuous carbides. The PWSCC resistance is lower when the grain boundaries are covered with widely spaced, discrete carbides. The PWSCC initiation time increases by a factor of five as the grain boundary carbide coverage increases from 0 to $100 \%$ (Rao 1994). The reasons for this beneficial effect of the intergranular carbides are not yet fully understood. According to Bruemmer, Charlot, and Henager (1988), the intergranular carbides act as a source of dislocations, resulting in plastic strains that cause crack tip blunting and, thus, reduce PWSCC susceptibility. Another possible explanation, according to Smialowska of the Ohio State University, is that the Alloy 600 material passivates more readily in the presence of intergranular carbides (Hunt and Gross 1994).

The percentage of the grain boundary covered with intergranular carbides depends on the heat treatment temperature and time, carbon content, and grain size. During the heat treatment, if the temperature is high enough, the Alloy 600 material recrystallizes, and new grain boundaries are formed. If all the carbides are dissolved during the heat treatment, the carbon is then in solution, and carbides will precipitate at the new grain boundaries during subsequent cooldown. As a result, the grain boundaries may be fully covered with carbides and the material becomes resistant to PWSCC. If all the carbides are not dissolved, then the undissolved carbides remain as intragranular carbides (at old grain boundaries), and during subsequent cooldown the intragranular carbides will limit the grain growth. As a result, the grain boundary surface area will be much greater and not fully covered with carbides, and the material will be less resistant to 
PWSCC (small grain material has a much larger grain boundary surface area than large grain material).

The solubility of carbon in Alloy 600 is fairly low and depends on the weight percent carbon and the temperature. For example, a temperature of $980^{\circ} \mathrm{C}\left(1800^{\circ} \mathrm{F}\right)$ will dissolve a carbon content of $0.03 \mathrm{wt} \%$, whereas, a temperature of $1204^{\circ} \mathrm{C}$ $\left(2200^{\circ} \mathrm{F}\right)$ is needed to dissolve a carbon content of $0.15 \mathrm{wt} \%$. So, if the heat treatment temperature is not high enough or the carbon content is too large, such that all the carbides are not dissolved, the resulting microstructure will be less resistant to PWSCC. Review of several PWSCC failures supports this observation (Campbell and Fyfitch 1994). However, it is also desirable to avoid carbon contents that are extremely low ( $\mathrm{C} \leq 0.015 \%$, for example) because adequate strength requires the presence of carbides in the material. In general, plant experience has shown that the high stress or temperature locations in steam generators with tubing that was mill-annealed at a relatively low temperature (low-temperature mill-annealed tubing) may exhibit PWSCC after one to ten EFPYs of operation (Hunt and Gorman 1986, Gorman and Hunt 1986). Plants with hightemperature mill-annealed tubing may experience significant PWSCC after ten or more EFPYs of operation (Kuchirka and Cunningham 1986, Benson 1988).

Effect of Coolant Chemistry. Tests over the range of high temperature $\mathrm{pH}$ values from 6.9 to 7.4 show that the primary coolant chemistry has a secondary effect on PWSCC initiation in Alloy 600 material (Lott et al. 1992). Some preliminary results show that PWSCC initiation is sometimes accelerated when the lithium content is high. For example, PWSCC initiation time was reduced by about a factor of two when the lithium concentration was increased from 2.2 ppm to $3.5 \mathrm{ppm}$ at a constant boron concentration of $1200 \mathrm{ppm}$. A recent Japanese study showed that PWSCC damage is minimized at $2 \mathrm{ppm}$ lithium, compared to $1 \mathrm{ppm}$ and $3.5 \mathrm{ppm}$ (Millett and Wood 1994). EPRI-sponsored studies indicate that increasing the hydrogen concentration in the primary coolant increases the rate of PWSCC. Consequently, the EPRI Primary Water Chemistry Guidelines recommend that utilities maintain hydrogen concentrations in the range of 25 to $35 \mathrm{~cm}^{3} / \mathrm{kg}$, which is near the lower end of the typically used range of 25 to 50 $\mathrm{cm}^{3} / \mathrm{kg}$ (EPRI 1990b, Gorman 1989).

\subsubsection{Outside Diameter Stress Corrosion Cracking}

ODSCC is a degradation mechanism which includes both IGSCC and intergranular attack (IGA) on the outside surfaces of the tubing. ODSCC of Alloy 600 was first seen in the field in the early 1970 s and has since become the most pervasive secondary-side steam generator corrosion problem. It has been experienced in many steam generators operating at fresh-watercooled locations, and to a lesser extent at seawater-cooled units. Most of this degradation takes place in the tube-to-tubesheet and tube-totube support plate crevices, however, ODSCC in the sludge pile and/or free-span locations has been observed at some plants. IGSCC requires the same three conditions as PWSCC: tensile stress, material susceptibility, and a corrosive environment (in this case, high-temperature water containing aggressive chemicals). As a result of the corrosive environment on the secondary-side, this mechanism apparently occurs at somewhat lower stresses, material susceptibilities, and temperatures than those required for stress corrosion cracking on the primary-side (EPRI 1985a, Partridge 1986a,b,c). IGA is a similar form of attack but, unlike IGSCC, it can occur without large tensile stresses present. However, it is believed that stress has an accelerating effect on IGA initiation and growth.

The IGSCC corrosion morphology consists of single or networks of multiple major cracks generally oriented normal to the maximum 
principal stress with limited patches of IGA. Virtually all the crack propagation is intergranular. The IGA morphology is characterized by a relatively uniform attack on all grain boundaries at the tube surface. It occurs at dry out areas such as in crevices and sludge piles. It is believed that IGA is often a precursor to IGSCC, i.e., that relatively uniform IGA occurs until stresses increase (e.g., as a result of tube wall thinning) to the point that isolated fingers of IGA accelerate and become IGSCC cracks (EPRI 1985a, Partridge 1986a,b,c). Most outside diameter stress corrosion cracks are primarily oriented in the axial direction, however, significant circumferential cracking has been observed in the expansion-transition region of the tubing in some steam generators and circumferential ODSCC is sometimes found near dents. For example, circumferential ODSCC at the expansion-transition region of the tubing had occurred in about $50 \%$ of the tubes in each of the three steam generators at Doel Unit 4 by the end of the 8 th cycle. Shallow circumferential cracks may sometimes occur in the IGA affected regions producing a grid-like pattern of axial and circumferential cracks termed "cellular corrosion."

Corrosive Impurities. ODSCC strongly depends on the concentration of corrosive impurities in the steam generator. The impurities are brought into the steam generator with the feedwater at low concentrations as a result of condenser in leakage, makeup water system impurities, corrosion of piping and heat exchanger equipment, and condensate polisher leakage. In some cases, phosphates from previous operation with phosphate water chemistry are still present in hideout locations and can contribute to tube corrosion. The bulk boiling process then concentrates the impurities over time in the steam generator coolant and even higher impurity concentrations form in the tubesheet and tube support plate crevices, the sludge pile, and occasionally between tubes in the upper free span regions where crud collects. The impurities concentrate in these regions because the coolant circulation is poor and local boiling or dry out (steam blanketing) occurs. The impurity levels in secondary-side systems are highly variable, and are likely influenced by at least the following: crevice geometry, cooling water type (fresh, brackish, sea), secondary plant materials (e.g., presence of copper), condenser leakage history, air in leakage history, water treatment history, plant attention to secondary-side chemistry, and types and application history of remedial measures.

From analytical determinations, it appears that for IGA to occur a highly alkaline condition must exist in the crevice caused by the concentration of alkaline species present in the secondary-side water. It was noted that a combination of IGA and IGSCC is often present close to each other in failed tube samples, with the IGA being more extensive than the IGSCC. In general, plant experience has shown that the high-temperature/high-caustic concentrating locations in a steam generator (e.g., the hot leg tubesheet crevice region) may exhibit IGA/IGSCC after two to ten EFPYs operation.

The presence of various anions strongly influences the corrosion attack. Carbonates and sulfates, and to a lesser extent phosphates, are very deleterious and can develop deep IGA and IGSCC, depending on the value of the electrochemical potential. The electrochemical potential of the Alloy 600 tubes is governed by the composition of the secondary water during operation. When AVT control is used, reductive conditions are encountered, and in the case of caustic pollution, IGA should preferentially occur in crevice regions. On the other hand, when oxygen enters the steam generator (either in the form of oxygen or metallic oxides), the potential is raised and favors an IGSCC mechanism. For this reason, the composition of the sludge and, in particular, the oxidizing potential could be the deciding factor in whether IGA or IGSCC or both will occur. Tubes removed from existing plants (Airey and Pement 1982) indicate that both 
the outside diameter surfaces and the intergranular fracture faces had in addition to the three major elements (nickel, chromium, and iron), the presence of sodium, potassium, calcium, phosphorus, sulfur, aluminum, and chloride.

Laboratory tests also show that Alloy 600 tubes exposed to high temperatures $\left[324^{\circ} \mathrm{C}\left(615^{\circ} \mathrm{F}\right)\right]$ for 4,000 hours are susceptible to stress corrosion cracking in an aqueous environment contaminated with lead. Lead has been found on the crack faces and tube surfaces of some tubes removed from operating steam generators (Miglin and Sarver 1991).

Status. As of December 1993, at least 89 PWR plants (44 U.S. plants) with RSGs and a few CANDU plants have experienced some degree of ODSCC in the tubesheet crevice, sludge pile, tube support plate intersection, or free-span locations (EPRI 1994). Approximately 14,140 RSG tubes with ODSCC at the tube support plate locations have been plugged at 63 PWR plants. Approximately 13,860 RSG tubes with ODSCC in the tubesheet crevice and sludge pile regions have also been plugged at 75 PWR plants (49 PWR plants have had both tube support plate and tubesheet ODSCC repairs). Tubes with ODSCC have also been sleeved at 25 plants. This degradation has occurred primarily in Combustion Engineering (eight plants) and Westinghouse-type plants (79 plants) with Alloy 600 mill-annealed tubing. Only one tube with ODSCC has been found in the Siemens/KWU steam generators with Alloy $800 \mathrm{M}$ tubing and only one plant with thermally treated Alloy 600 tubing has reported ODSCC (Kori-2 has reported finding ODSCC in the tubesheet region and plugging 125 tubes). The only CANDU plant with extensive ODSCC has been Bruce-A2 where 1,399 tubes failed (were plugged) due to lead assisted stress corrosion cracking. The most extensively degraded steam generators have had as many as 40 to $56 \%$ of all their tubes plugged or sleeved as a result of ODSCC and have been replaced at a number of plants (or in some cases, the plants have been shutdown). However, similar steam generators (same model number) at other plants have experienced only a few percent failures due to ODSCC.

ODSCC has appeared in PWR steam generator tubes with both high and low mill-annealed temperature, but generally not in thermally treated tubes because the thermally treated tubes do not have chrome depletion at the grain boundaries. Tests were conducted using high-temperature electrochemical measurements to identify conditions leading to IGA (Pinard-Legry and Plante 1983). The results of these tests indicate that in $10 \%$ caustic media at $320^{\circ} \mathrm{C}$, IGA is commonly observed in Alloy 600 in the mill-annealed condition whereas, material thermally-treated at $700^{\circ} \mathrm{C}$ shows definite improvement over the mill-annealed material in resistance to both IGA and IGSCC. Similar results have been reported by Berge and Donati (1981) and are plotted in Figure 23. The minimum times for inducing a $500 \mu \mathrm{m}$ crack in various C-ring samples of mill-annealed and heat treated $\left(16\right.$ hours at $\left.700^{\circ} \mathrm{C}\right)$ Alloy 600 , Alloy 800 , Alloy 690, and Type 316 stainless steel material, exposed to a deaerated caustic soda solution $(\mathrm{NaOH})$ at $350^{\circ} \mathrm{C}$ and subjected to stresses at about yield (according to ASTM STP 425 ), are plotted versus $\mathrm{NaOH}$ concentration. Note, that the Alloy 690 and 800 samples appear to be immune to stress corrosion cracking in $350^{\circ} \mathrm{C} \mathrm{NaOH}$ solutions with a concentration of about $50 \mathrm{~g} / \ell$ or less, however, all of the materials are susceptible to stress corrosion cracking within a few thousand hours at $\mathrm{NaOH}$ concentrations over about $100 \mathrm{~g} / \ell$. The thermally treated Alloy 600 material is susceptible to stress corrosion at $\mathrm{NaOH}$ concentrations of $50 \mathrm{~g} / \ell$ or less, but less susceptible than the mill-annealed Alloy 600 material.

The oldest running CANDU units tubed with Alloy 600 are currently experiencing widespread, but relatively shallow $(5-10 \%$ of the wall thickness) ODSCC at the tube U-bend supports. 


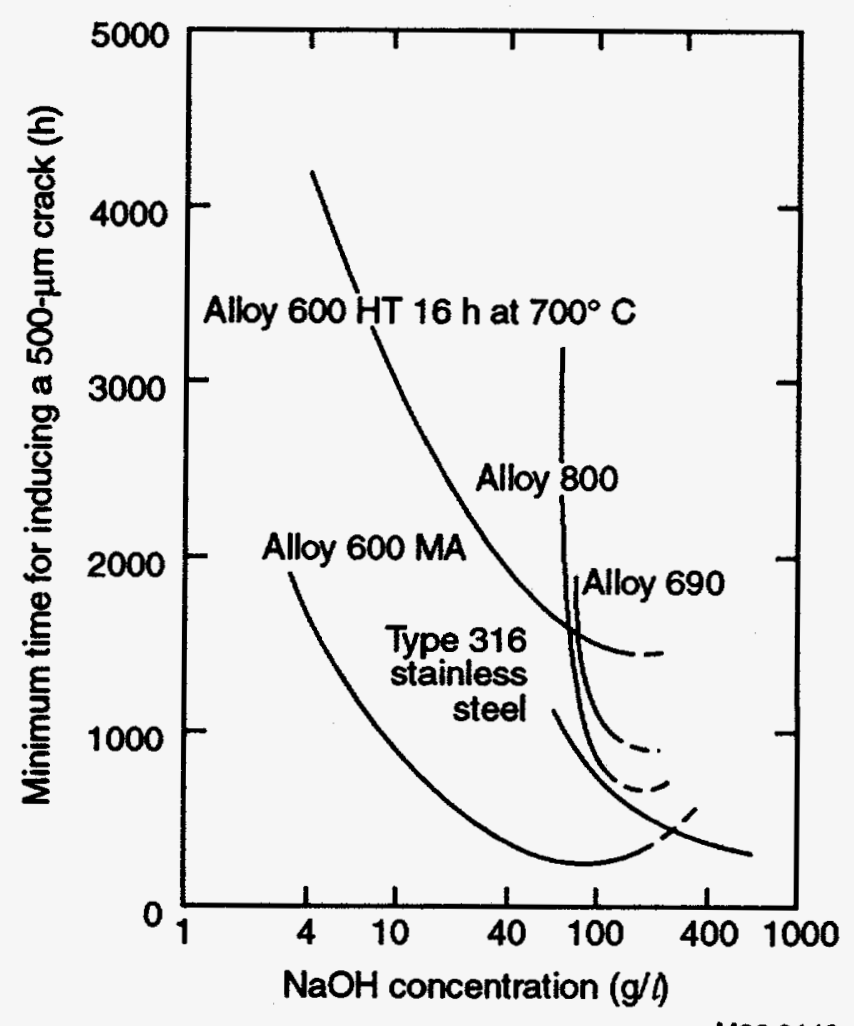

Figure 23. Resistance to stress corrosion cracking of mill-annealed or heat treated Alloy 600, Alloy 690, Alloy 800 , and Type 316 stainless steel as a function of sodium hydroxide concentration at $350^{\circ} \mathrm{C}$ (Berge and Donati 1981). Copyright 1981 American Nuclear Society, Inc., LaGrange, Illinoise; reprinted with permission.

This degradation has been due to a combination of heavy secondary-side deposits which created an aggressive environment on the tube surface and corrosion of the carbon steel supports which caused high stresses in the area. The heavy deposits in the steam generators were due to early water treatment plant problems, condenser leakage, abnormal chemistry incidents, and feedtrain corrosion problems. Final failure of a few tubes occurred due to high-cycle fatigue. ${ }^{a}$

The degradation was severely aggravated in Bruce- $A 2$ by contamination due to a lead blanket

a. Maruska, C. C. 1995. Unpublished material provided by C. C. Maruska to the authors. inadvertently left in one steam generator during maintenance activities. The lead was transported into the other steam generators at the unit through the water in the common steam drum. Cracking in the lead contaminated steam generators was typical of lead assisted cracking: mixed mode, transgranular and intergranular, ranging from $0-100 \%$ throughwall. Lead shielding was also inadvertently left behind in the Doel Unit 4 Steam Generator B in Belgium and is believed to have contributed to the severe ODSCC which subsequently occurred in that steam generator.

Because ODSCC can take several forms (short axial cracks, long axial cracks, circumferential cracking, cellular corrosion, etc.) and the ease of 
detection of these various kinds of ODSCC degradation varies considerably, the potential safety consequences of ODSCC at separate plants can be quite different. For example, ODSCC within the tubesheet is much more difficult to detect with a standard eddy-current bobbin coil probe than PWSCC within the tubesheet or axial ODSCC at the tube support plates. However, it is possible to detect ODSCC within the tubesheet before it reaches a critical size and, therefore, make repairs before tube rupture. To date, there have been no tube ruptures due to undetected ODSCC in the tubesheet region. Axial ODSCC at the tube support plates can usually be readily detected with a bobbin coil probe, however, detection of circumferential ODSCC at the tube support plates requires special probes as does the sizing of ODSCC. Also, the evolution of the ODSCC depends significantly on the local environment within the crevice or under the crud, the details of which are often unknown. Therefore, the future crack growth rate cannot always be accurately estimated. However, some tube supports (and the tubesheet) can provide reinforcement in the event of a throughwall crack, provided the support does not move relative to the tube during the event and the crack is within the support. Freespan IGA/IGSCC can occur if there are deposits on the tube, which concentrate impurities. The sensitivity of the eddy-current signal is poor and a special analysis in absolute mode is needed to detect a freespan flaw before the flaw achieves a critical size. Tube ruptures have occurred due to freespan ODSCC.

\subsubsection{Fretting, Wear and Thinning}

These steam generator degradation types are broadly characterized as mechanically-induced or -aided degradation mechanisms. Degradation from small amplitude, oscillatory motion, between continuously rubbing surfaces, is generally termed fretting. Tube vibration of relatively large amplitude, resulting in intermittent sliding contact between tube and support, is termed sliding wear, or wear. Thinning generally results from concurrent effects of vibration and corrosion. However, thinning occurs at some locations where flow-induced vibrations are not expected, so it is not certain that tube motion is required for this mechanism; in some cases it may simply be the result of corrosion wastage.

The major stressor in fretting and wear is flowinduced vibration. Tube vibration can be induced by fluid cross flow or by parallel flow. Initiation, stability, and growth characteristics of damage by these mechanisms may be functions of a large number of variables, including the support locations, the stiffness of the supports, the gap size between tube and support, secondary flow velocities and directions, and oxide layer characteristics. A complete understanding of flow-induced tube vibration and resultant tube fretting/wear/thinning can only be achieved by quantifying the structural, hydraulic, and material wear characteristics of a specific steam generator. These topics are beyond the scope of this section, but note that this type of analysis has been performed during efforts to mitigate certain wear/fretting problems (CSGORG 1983). Also, EPRI has sponsored the development of a mechanistic computer model that predicts the fretting and wear caused by flow-induced vibrations in RSGs (Stuhmiller et al. 1988). The model calculates local turbulence to determine the unsteady flows in the vicinity of AVBs and near the bundle peripheral tubes, and provides time histories of the resulting buffeting loads.

Whenever mild wear occurs on a tube, the fatigue strength of the material can be reduced. In most cases, the reduction in fatigue strength is attributed to the wear process assisting in the nucleation or early growth of a fatigue crack. However, fretting-fatigue failures of steam generator tubing have not occurred. The absence of such failures is attributed to the low probability that high cyclic stresses will be present at the sites where the fretting is occurring. The span between tube supports is 
typically too small to allow excitation of high amplitude vibrations of the segments of tube between supports (Jacko 1983).

Status. Fretting/wear/thinning degradation was first identified as a problem in about 1973 and has been noted to some degree in all major PWR steam generator designs. This includes preheater and AVB wear/fretting in Westinghouse-type RSGs, cold leg thinning in Westinghouse-type RSGs, AVB (diagonal support) wear/fretting in Combustion Engineering RSGs, and AVB wear/fretting in Siemens/KWU RSGs (EPRI 1985a).

As of December 1993, 116 plants with RSGs had experienced tubing failure due to AVB wear/ fretting, 78 plants had reported wear/fretting failures due to loose parts damage, and 12 plants had reported wear/fretting failures associated with the steam generator preheaters (EPRI 1994). 4,633 tubes have been plugged because of AVB wear/fretting (920 tubes were preventively plugged and the rest were plugged due to NDE indications), mostly in Westinghouse-type steam generators. This damage has occurred in the more recent Westinghouse steam generator designs at 17 plants (Westinghouse models $F$, $44 \mathrm{~F}$, and $51 \mathrm{~F}$ and Mitsubishi Heavy Industries model 51F) as well as in the earlier model steam generators. Steam generator tubes have also been plugged due to AVB (batwing or vertical strap) wear/fretting at, at least seven Combustion Engineering designed plants, three Siemens/ KWU plants and one CANDU plant. At least 941 tubes have been plugged because of loose parts damage in 78 plants, although most of these plants (44 plants) have plugged less than ten tubes each. One plant did plug 176 tubes due to loose parts damage.

Antivibration Bars Fretting. As discussed in Section 2, AVBs are used in the U-bend regions of RSG tube bundles to stiffen the tubes and limit vibration amplitudes. Various arrangements of bars and plates have been used for this purpose by the various steam generator manufacturers. Typical arrangements for AVBs are shown in Figure 13. Wear/fretting at AVBs in Westinghouse-type RSGs is believed to be caused at least in part, by insufficient tube restraint, but the appropriate flow excitation phenomena has not been established in the open literature. In some RSG models, wear requiring tube plugging has occurred only in peripheral regions of the tube bundle, while other plants have experienced random AVB wear/fretting degradation, but no consistent differences among the different RSG models have been identified. Most plants with 6 to 10 EFPYs or more of operation have experienced AVB wear to at least some degree. Several plants experiencing AVB wear/fretting have performed AVB replacement, where an improved AVB design was considered necessary or excessive clearance between tube and AVB in the existing configuration was demonstrated. Some plants have accumulated significant operating experience following AVB replacement, and subsequent inspections indicate that this modification has been successful at reducing AVB wear/fretting in these units to a level of minor concern. Alternatively, other units have not yet determined the primary cause of their AVB wear/fretting and, as such, are currently experiencing degradation that is of a more significant operating concern (Blomgren 1986).

AVB (or diagonal support) wear in Combustion Engineering RSGs is believed to be caused, in part, by the secondary-side flows causing the diagonal supports to move. The AVB configuration for these RSGs is also shown in Figure 13. The flow exerts a pressure on the diagonal support, which deflects it into the tubes, resulting in contact forces between the two. The in-plane flow-induced vibration of the tubes results in a relative sliding of the tube and support, and tube and support wear occurs. The degradation, generally, appears in the tubes near the inner periphery of the central cylinder, in the 


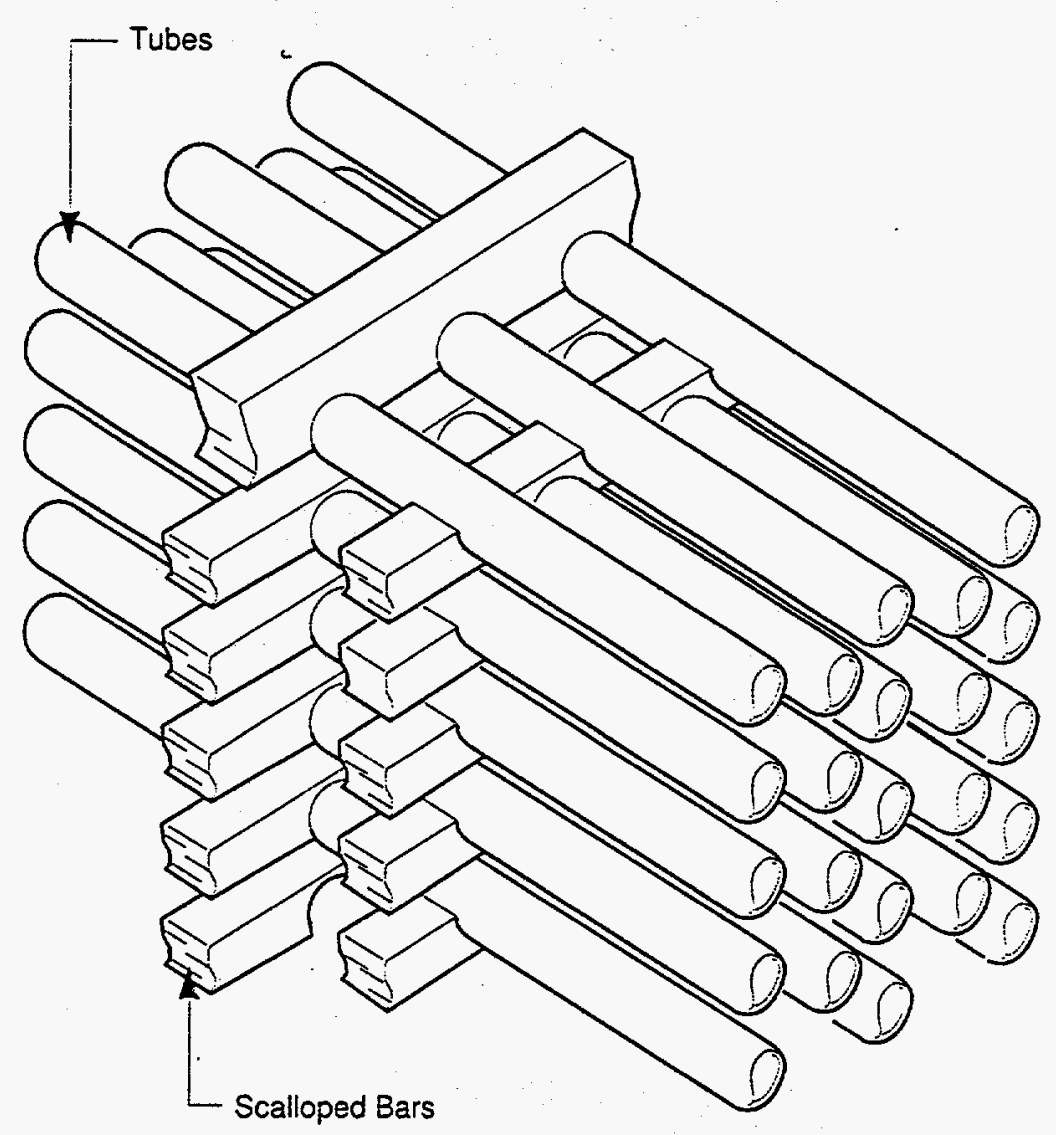

Figure 24. CANDU recirculating steam generators staggered scallop bar arrangement. Courtesy of C. Maruska, Ontario Hydro.

region of the longest diagonal support span. Plants experiencing this AVB wear have plugged tubes as indicated necessary by NDE wall-loss evaluations. Vendor analysis of the problem has concluded that the degradation is self-limiting since only a relatively small fraction ( 3 to $4 \%$ ) of the tubes experience the requisite cross flow force for degradation to occur. As a result, preventive plugging of all these tubes is possible without threatening steam generator life (Harberts 1986).

Fretting is occurring in CANDU steam generators with U-bend supports made of staggered scalloped bars (the U-bend support bar stack is split into two offset stacks as shown in Figure 24, and the tubes are held in semicircular holes). This degradation is caused by flowinduced vibration of the tubes which is due to $\mathrm{U}$ bend supports which were widely spaced and perhaps insufficiently rigid. ${ }^{2}$ Although tube fretting is severe and widespread, no tube failures have occurred in CANDU steam generators due to this degradation mechanism to date. There is evidence to indicate that the fretting rate in these steam generators is decreasing with time, suggesting that this mechanism is self limiting.

a. P. E. MacDonald, Personal communication with C. Maruska, Ontario Hydro, Canada, 1995. 
Loose Parts Damage. As indicated by the number of tubes plugged due to loose parts damage, loose parts and other debris have been found on the secondary-side of the steam generators at a large number of PWRs over the years. These parts include tools (for example, a $152 \mathrm{~mm}$ flat file at Wolf Creek, a grinder wheel at Watts Bar Unit 1, a weld rod at Turkey Point 4, parts of a pocket knife at D.C. Cook Unit 1, and a $152 \mathrm{~mm}$ C-clamp at Point Beach), valve and pump parts (for example, a check valve pin at Turkey Point Unit 4), equipment used for previous inspections, broken steam generator material, debris left from previous modifications and repairs (for example, pieces of steel plate, copper tubing, weld material, wire, etc.), and other things. These loose parts have also been implicated in at least two tube rupture events in operating plants in the U.S.

One of the worst examples of this problem occurred at Ginna from 1975 to 1982 . Foreign objects including various size pieces of carbon steel plate up to about $150 \mathrm{~mm}$ in length fell onto the tubesheet outside the periphery of the tube bundle during steam generator modifications performed in 1975 and later. This debris then impacted on the exposed peripheral tubes during subsequent operation and caused defects. The damaged tubes were plugged as a result of eddycurrent indications and/or small leaks. However, the debris continued to damage the plugged tubes and eventually caused the tubes to collapse and in some cases to become completely severed near the top of the tubesheet. The severed tubes and debris then interacted with the adjacent inboard tubes resulting in fretting type wear of the adjacent tubes. These tubes, in turn, were plugged as a result of eddy-current indications or leaks, however, damage continued until they also became severed. Eventually, an unplugged tube in the third row in from the outside row was subjected to fretting type wear over about 150 $\mathrm{mm}$ of length and burst. The wear removed about $84 \%$ of the wall thickness over about 100 $\mathrm{mm}$ of length, which caused a relatively long "fish mouth" type burst. The peripheral tube damage mechanisms were primarily mechanical and included impact, collapse, fatigue, fretting type wear, abrasion, and ductile overload and tearing. The transient that resulted from this rupture is discussed in Section 4.5

USNRC Generic Letter 85-02 requested the U.S. PWR owners perform visual inspections in the vicinity of the tubesheet along the entire periphery of the tube bundle and the tube lane to identify and remove any foreign objects (USNRC 1985). Such an examination should be done after any secondary-side repairs. Obviously, all tools and equipment going into a steam generator during an inspection should come out.

Although most loose parts damage has occurred on the secondary-side of the steam generators, there have also been cases of primary-side damage, primarily to protruding tube ends and tube-to-tubesheet welds.

Preheater Fretting. Several different arrangements have been used for the preheaters in different Westinghouse plants, as shown in Figure 25. Wear/fretting in the outer tube rows near the inlet nozzle has occurred in Model D2/D3 split-flow preheater RSGs and Model D4/D5/E counterflow preheater RSGs. The degradation was determined to be caused by large flow velocities and turbulence, and insufficient tube restraint (Hoffman et. al. 1986). The wear/fretting problem in the D2/D3 RSGs was addressed by redistributing feedwater flow between the primary and auxiliary feedwater inlets to reduce the flow into the preheater through the primary inlet, and by incorporating a preheater manifold to reduce cross flow vibration. Turbulence and peak flow velocities were reduced. Model D4/D5/E RSGs were modified by performing an expansion of the tubes within the tube baffle plates at certain preheater locations, in effect changing the tube natural frequency. In addition, a split of the feedwater flow between primary and auxiliary inlets was also implemented on the D4/D5 RSGs. These modifications appear to have been successful, 


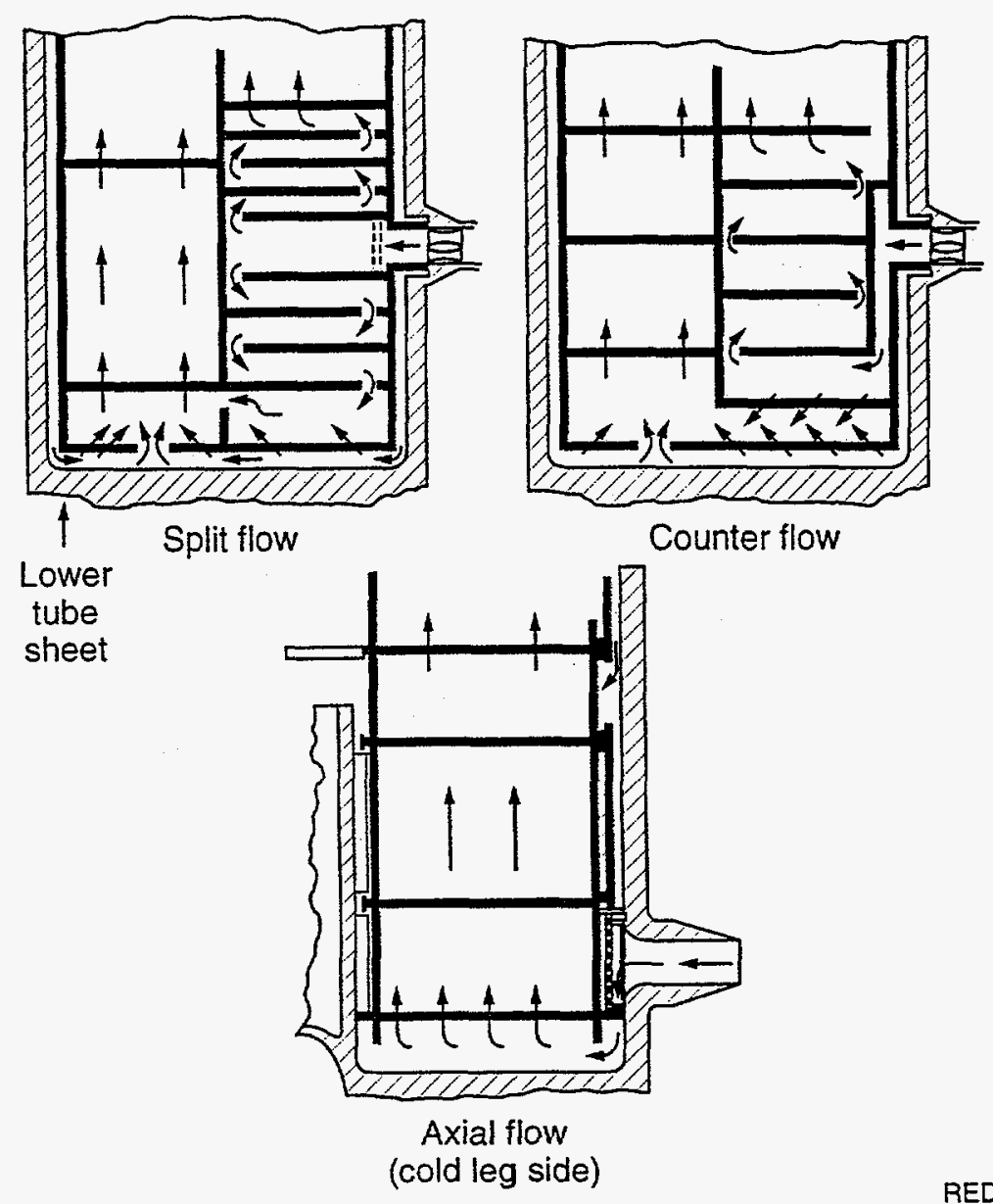

RED 0777

Figure 25. Preheater cross sections (EPRI 1994a). Copyright 1994 Electric Power Research Institute; reprinted with permission.

there have been no tubes plugged because of preheater wear/fretting in the D4 and D5 type RSGs and only one tube plugged in the Model E RSGs (at South Texas Unit 1). This tube was located one row in from the inside row of expanded tubes near the tee slot opening where there were relatively high flow velocities (the Model E steam generators have about 230 to 250 tubes expanded at two elevations). The tube was prematurely plugged after losing about $30 \%$ of its wall thickness. Also, only 206 tubes have been plugged (at eight plants) with model D2 and D3
RSGs due to preheater wear/fretting (EPRI 1994).

Three-hundred ten tubes have been plugged in the Combustion Engineering model CE- 80 RSGs with axial flow preheaters because of preheater wear/fretting (at the only three plants operating with that design RSG). This fretting occurred at the eggcrate-type tube support above the top of the preheater divider plate near the tube lane (see Figures 4 and 25). The secondary-side flow in the downcomer enters the cold leg side of the 
tube bundle above the preheater, between the second and third tube supports. At the inside of the tube bundle (tube lane), a unique condition exists where the recirculating flow preferentially seeks the low flow resistance open tube lane. The fretting was caused by the relatively high (on the order of $7.6 \mathrm{~m} / \mathrm{s}$ ) radial velocities in this area (Schever 1987).

Cold Leg Thinning. Cold leg thinning in Westinghouse-type RSGs is believed to be the result of a corrosive mechanism (i.e., wastage) in combination with tube vibration. The degradation has been seen primarily in peripheral tubes exposed to high cross flow velocities, and at the first and second tube support plate locations. The identity of the chemical presence responsible has not been determined, but acidic sulfates may be the cause. No conclusive evidence of the necessity for tube motion has yet been obtained. However, pulled tube results show a strong correlation exists between tubes exhibiting cold leg thinning and those showing AVB wear. As a result, it is expected that both corrosion and tube motion play a role in the degradation. Cold leg thinning is easily detected by conventional NDE methods and has been shown to progress at a limited rate [about $6 \%$ throughwall depth per EFPY] (Baum et al. 1987, USNRC 1983). No unscheduled plant shutdowns caused by throughwall leakage have resulted from cold leg thinning. Affected plants have plugged limited numbers of tubes as indicated necessary by NDE wall loss evaluations. One plant has implemented a trial program to hydraulically expand the tubes at the tube-to-tube support plate Intersections one through three, in an attempt to eliminate the tube motion component of the degradation mechanism. Initial inspection results regarding the effectiveness of this technique were inconclusive (Weakland 1988). Maintenance of low secondary-side impurity levels is also considered necessary to reduce the effects of crevice chemical concentration (Baum et al. 1987).

\subsubsection{Pitting}

Pitting is a steam generator degradation type appearing as groups of small-diameter wall penetrations resulting from local corrosion cells, probably promoted by the presence of chloride or sulfate acids. Condenser leaks and leakage of beads, resin fines, or regeneration chemicals from ion exchangers can introduce impurities such as chlorides and sulfates, which result in local acidic conditions conducive to pitting. Oxidizing conditions and the presence of copper are probable accelerators. Any barriers to diffusion such as sludge accumulation on the tube wall will accelerate the pitting process by enhancing the chemical concentrations.

Pitting corrosion typically occurs at locally weak spots in the passivated surface of the Alloy 600 tube. These susceptible locations may be the result of localized cold work of the metal, the presence of metal carbides, sulfides, or other secondary phase particles, or emergence of grain boundaries at the metal surface. The pits are characterized by an undercut geometry (i.e., having a larger subsurface than surface diameter) and are typically found to be filled with corrosion products such as chromium oxide, sulfides, and copper metal. Some investigations have also noted some shallow IGA degradation at pit bottoms (Theus and Daniel 1984, Angwin 1984).

Status. Significant pitting was first reported in an operating PWR steam generator about 1981. As of December 1993, only 11 PWR plants with RSGs had plugged tubes because of pitting and a few other plants had reported minor pitting degradation of $15 \%$ throughwall depth or less (EPRI 1994). However, a few plants have experienced significant pitting degradation including Indian Point Unit 3 (1,290 tubes plugged because of pitting in the original steam generators and 3,606 tubes sleeved), Kori Unit 1 (804 tubes plugged because of pitting and 1,578 tubes sleeved for various reasons), and Millstone 
Unit 2 (1,655 tubes plugged because of pitting in the original steam generators and 5,164 tubes sleeved for various reasons). Most of this degradation occurred in the cold leg and cold leg sludge pile regions, however, pitting has also been found on the hot leg side of the RSGs (Laskowski and Hudson 1986, Angwin 1984, Theus and Daniel 1984). And, most of the pitting has been associated with Alloy 600 tubing exposed to severe secondary-side chemistry incursions. However, 332 Type 304 stainless steel steam generator tubes at the Yankee Rowe plant were also plugged because of pitting degradation.

Severe pitting has been experienced in CANDU units tubed with Monel 400 (1994 tubes plugged at one unit). This pitting is more accurately described as tube outside surface under-deposit corrosion and is caused by heavy secondary-side deposits, both on top of the tubesheet and in the lower tube support areas. These deposits concentrate aggressive species such as chlorides and sulfides present due to condenser leakage and water treatment problems. One CANDU unit tubed with Alloy $800 \mathrm{M}$ has experienced a small number of tube failures due to pitting (underdeposit chloride pitting) at the first and second support plates. Early condenser tube leakage (seawater) and sludge deposits contributed to this degradation. ${ }^{\mathbf{a}}$

Laboratory Studies. As a result of the extensive pitting in the Millstone Unit 2 and Indian Point Unit 3 steam generators ( $40 \%$ throughwall pits), the EPRI conducted a workshop (Angwin 1984) on steam generator tube pitting. It was reported that both affected plants had pits of similar morphology (chromium oxide and copper metal-filled undercut pits). These pits were found under scale and in similar locations (e.g., the cold leg side near the sludge pile).

a. P. E. MacDonald, Personal communication with

C. Maruska, Ontario Hydro, Canada, 1995.
It has been shown in the laboratory that it is possible to pit Alloy 600 under a variety of conditions but only a few of the laboratory-grown pits have the same morphology found in operating plants. Électricité de France (EdF) has produced pits in low-oxygen, high-chloride (740 ppb), high-sulfate (760 ppb) water. These pits had chromium-rich, copper-included scabs similar to those found in the Millstone and Indian Point steam generators. There is no universal agreement as to whether steam generator pit initiation and growth is primarily an operating temperature (hot) phenomenon or a layup (cold) phenomenon. However, chromium oxide-filled pits are seen in high-temperature tests, but not in low-temperature laboratory tests.

Once pitting has initiated, the rate of initiation of new pits can be rapid. The growth of pitting indications has not been well-quantified. Pits have grown up to $50 \%$ throughwall depth per cycle, but the degradation is generally considered to progress at approximately $10 \%$ throughwall depth/cycle (Laskowski and Hudson 1986). However, even widespread pitting is not considered to pose a significant safety hazard, since deep, small volume defects such as pits typically show a well-defined leak-before-break character (Laskowski and Hudson 1986).

Mitigation Activities. A number of design and operational modifications can be implemented to limit the occurrence of pitting degradation. In general, maintenance of proper water chemistry is considered critical. Condenser leakage, particularly in seawater or brackish water-cooled plants, should be quickly remedied. Control of oxygen and chlorides during operation and layup are also important. Leakage of ion exchanger beads, resin fines, or regeneration chemicals should be minimized, and extended heatup/ cooldown periods should be avoided. Removal of sludge pile accumulations by sludge lancing or chemical cleaning, or both, is also recommended. These operational modifications, with the exception of sludge lancing, are similar to those considered important for minimizing the occur- 
rence of ODSCC and denting. The primary design modification to be considered is the removal of all copper from the secondary-coolant system.

\subsubsection{Denting}

The term denting describes the mechanical deformation or constriction of a tube at a carbon steel tube support plate intersection or within the tubesheet caused by the buildup of deposits and the growth of a voluminous support-plate or tubesheet corrosion product in the annulus between the tube and support plate or tubesheet. Denting has also been reported in the sludge pile region of certain plants where iron particles were embedded in the sludge pile. Dents do not themselves result in tube wall penetration or reduction in wall integrity. However, denting at some plants has been sufficiently severe that it caused structural damage to the tube supports and denting is a concern because even small dents can induce tensile stresses above yield strength in the tube wall. As a result, these tubes may be subject to PWSCC or IGSCC at the dents during subsequent operation, (EPRI 1985a, Clark and Lewis 1985). Also, tubes with dents at the top tube support plate in the U-bend region of the RSGs are more susceptible to high-cycle fatigue failure. Tubes with small dents can be kept inservice unless subsequently found to have stress corrosion cracking. Tubes with dents large enough to restrict calibrated go/no go probes must be plugged because they are not inspectable and are expected to crack.

Status. Denting of Alloy 600 tubes at tube-totube support plate intersections was first identified as a significant steam generator degradation mechanism in about 1975 , shortly after the time when many PWRs switched from phosphate to AVT secondary-side water chemistry, and this degradation mechanism became the primary cause of steam generator tube plugging during the period 1976 through 1979 (Figure 18). As of December 1993, 1,471 RSG tubes at 41 plants (four Combustion Engineering and 37 Westinghouse-type plants) had been plugged because of tubesheet and sludge pile denting and 9,092 RSG tubes at 17 plants (four Combustion Engineering and 13 Westinghouse-type plants) had been plugged because of support plate denting (EPRI 1994). Significant support plate denting occurred at only five plants: Millstone Unit 2 (796 tubes), Surry Unit 1 (1,996 tubes), Surry Unit $2(1,964$ tubes), Turkey Point Unit 3 (1,249 tubes), and Turkey Point Unit 4 (1,835 tubes); all of the original steam generators at those plants have since been replaced. The majority of the support plate denting has occurred on the hot leg side at plants with seawater or brackish water for condenser cooling.

CANDU units with the older Alloy 600 and Monel 400 steam generators with carbon steel supports have also experienced tube deformation due to deposit buildup in the tube-support gaps and corrosion of the supports. However, tube cracking has not been detected in the deformed areas.

Mechanism. The denting mechanism has been studied extensively and its causes are relatively well-defined. Chlorides in the secondary-side feedwater resulting from condenser leaks or other water chemistry excursions are concentrated by local boiling in, for example, a crevice between a tube and drilled tube support plate. The chlorides result in an acidic environment, which causes rapid corrosion of the carbon steel support plate when sufficient oxygen is present, forming a nonprotective magnetite corrosion product more than twice the volume of the base metal. Growth of the corrosion product is linear with time because it is nonprotective and it gradually fills the annulus. Subsequent growth constricts the tube and can also cause deformation of the support plate. The primary factors influencing the corrosion rate are degree of superheat in the crevice and bulk water chloride and oxygen concentration. Copper oxide or ions may also 
play an important role as a supplier of oxygen to the carbon steel support plates. Sulfates (e.g., from condensate polisher leakage) are believed to cause denting in the same manner as chlorides, though the laboratory test database is not as extensive. Some evidence of alkaline-induced denting has been seen in laboratory and field data, but this mechanism is not considered a significant source of field denting degradation (EPRI 1985a, Theus and Daniel 1984, Nordmann et al. 1983, McKay 1983).

Denting was relatively uncommon when most plants used phosphate water chemistry, since the phosphates kept the crevice $\mathrm{pH}$ high. With AVT water chemistry, no buffering of the crevice environment occurs, and the potential for corrosion increases. Since the degradation is a strong function of crevice superheat, rates of denting progression are generally much higher in the hot leg. Widespread denting with growth up to 50 mils in depth has been experienced during single operating cycles in plants with high feedwater chloride concentrations. More commonly, somewhat lesser initial chloride concentrations produce much shallower dents; subsequent modifications to water chemistry can then be made before significant denting degradation has occurred.

Onset of Tube Support Plate Denting. In contrast to mechanisms such as PWSCC or IGSCC, denting does not tend to occur progressively on a time scale of operational cycles with increasing numbers of tubes affected at each inspection. Denting, when it occurs, generally affects large numbers of tubes at approximately the same time (i.e., the scatter in the times required to produce denting under proper chemical conditions is small). Most plants having experienced denting have implemented one or more remedial actions, once denting was discovered. These remedial methods are generally highly effective at halting the initiation and progression of dents.
In regard to predicting the initial onset of denting, recent work (Balkrishnan and Pathania 1988) has resulted in the ability to produce rough estimates of the time-to-denting initiation based on bulk water chloride type and concentration and the tube-to-tube support plate radial gap. The time-to-denting initiation is relatively short in plants with sea or brackish water contamination (i.e., acid chloride contamination). The time-to-denting initiation will be much longer in plants with neutral salt in the bulk water. For example, plants with an acid chloride concentration of $20 \mathrm{ppb}$ and a radial gap of 0.305 $\mathrm{mm}(0.012$ in.) could expect denting to initiate in about 2.5 years, while the plants with a neutral chloride concentration of $20 \mathrm{ppb}$ and the same radial gap could expect denting in about 50 years. For plants operating with chloride concentrations below the EPRI Water Chemistry Guidelines (EPRI 1993c), the time-to-denting initiation would be longer yet.

Several factors in addition to chloride type and concentration and the tube-to-tube support plate radial gap can affect the corrosion rate. They include an exceptionally high or low degree of crevice superheat, excessive crevice fouling, crevice geometry (e.g., plain drilled, or quatrefoil), dissolved oxygen, and presence of copper.

Sludge Pile Denting. Denting failures away from the tube support plates in the newer steam generators at EdF plants have also been reported. (Nucleonics Week 1989; de Keroulas and Lunven 1990). Oxidation of metallic grit (iron shot) in the sludge around the tubes next to the tubesheet apparently caused swelling of the sludge and constriction (denting) on the hot leg tubes in the middle part of the tube bundle. The iron shot was used for surface cleaning of certain secondary-side components during initial construction of the plant (Nucleonics Week 1990). A crack at one dent, probably due to PWSCC, leaked at a rate of about $3.1 \mathrm{\ell} / \mathrm{hr}(0.82$ gph). As of December 1993, steam generator 
tubes had been plugged at 31 French plants due to denting in the tubesheet region (EPRI 1994). Most of this degradation was apparently due to sludge pile expansion, but tubes with dents caused by tubesheet corrosion may also have been plugged. EdF has developed improved cleaning processes to mitigate this problem.

Tubesheet Denting. A few plants have operated with a relatively acidic secondary-side water chemistry for significant periods of time which caused corrosion of their low alloy tubesheets and tube denting. Most of the dents caused by this mechanisms have been relatively small, but a few have been large enough to require plugging.

\subsubsection{High-Cycle Fatigue}

The combination of high vibration amplitude and low fatigue strength may lead to catastrophic fatigue failure. Vibration occurs in steam generators with high recirculation flow factors (causing flow-induced vibrations in the U-bend region) and improper AVB support. A high mean stress (e.g., residual stress) or a tube defect (fretting mark or crack) significantly reduces the fatigue strength. Therefore, tubes with dents, fret marks, or cracks at the top tube support plate in the U-bend region of the RSGs are susceptible to high-cycle fatigue failure.

High-cycle fatigue ruptures have occurred in the U-bend regions of the North Anna Unit 1 and Mihama Unit 2 steam generators. Though high-cycle fatigue from tube vibrations is not a general problem in PWR steam generators, tube ruptures, such as those at North Anna and Mihama Unit 2, are of particular concern because they were $360^{\circ}$ breaks located high up in the steam generator where the leak location can more readily become uncovered by secondary water. This can allow escape of fission products from the primary coolant without partitioning in the secondary water. For example, upon failure of the Mihama Unit 2 Steam Generator A tube, the primary system leak rate rapidly escalated from a very low level to a value exceeding the normal capacity of the charging pumps. The ruptured tube eventually released about $55,000 \mathrm{~kg}$ (55 tons) of primary coolant to the secondarycoolant system. Approximately $1,300 \mathrm{~kg}(1.3$ tons) of steam, 0.6 curie of radioactive noble gases, and 0.01 curie of radioactive iodine subsequently escaped from the damaged steam generator's relief valve to the environment. The reactor core remained submerged owing to the operation of the high-pressure injection system. The North Anna and Mihama tube ruptures are discussed in more detail in Section 4.

Most of the earlier tube failures in CANDU steam generators tubed with Alloy 600 have been due to high-cycle fatigue. These failures were caused by flow-induced vibration and were initiated at either fret marks at the land areas of the upper trefoil tube support plates or more recently at stress corrosion cracks on the outside surfaces in the U-bend area and at the seventh support plate. These failures continue to occur in the older CANDU steam generators. The resulting fatigue cracks were circumferential, but did not lead to a tube rupture.

\subsubsection{Wastage}

The term wastage describes the relatively uniform corrosion and thinning of a steam generator tube on its outside surface (secondaryside of the steam generator). This degradation tends to occur in relatively stagnant regions in RSGs with secondary-side phosphate water chemistry, where phosphate solutions have become concentrated. These regions include the tube-to-tubesheet crevices, the tube-to-tube support plate annuli, and the sludge pile on the tubesheet. In addition, extensive wastage of the short radius U-bends in the vicinity of the AVBs in a few Combustion Engineering RSGs has also been reported (Stoller 1979). The $100 \mathrm{~mm}$ (4in.-) wide flat carbon steel AVBs and the first 11 rows of tubes formed a tight configuration that 
caused steam blanketing; wastage was concentrated at the boundary of this region.

Wastage of the peripheral tubes near the lower support plates on the cold leg sides of the RSGs in a few plants might also have been caused by acidic sulfates. Resin leakage from the condensate polisher beds could have produced the acidic sulfate environment. The phosphate corrosion or wastage is transgranular and may lead to significant thinning and, ultimately, to local ductile rupture and leakage. Phosphate wastage was the major cause of tube failures in PWR steam generators until about 1976. However it is no longer an active degradation mechanism in most of the PWR and CANDU plants because phosphate water chemistry is no longer used in most plants.

\subsection{Pressurized Water Reactor Once-Through Steam Generator Tubes}

Once-through steam generators in the U.S. use the same Alloy 600 tubing materials as RSGs, yet these steam generators have experienced substantially fewer tube failures. The lower failure rate is attributed to the differences in the steam generator design, manufacturing processes, and operation. Many of the chemical concentration processes do not operate in once-through steam generators, as they do in RSGs. Table 10 lists once-through steam generator tube degradation mechanisms, sites, stressors, failure mode and inspection methods. The most com-mon tube degradation mechanisms are briefly discussed here. However, as noted below, even these mechanisms affect a relatively small per-centage of the tubes inservice.

\subsubsection{Erosion-Corrosion}

Entrained solid particles impinging on metal surfaces can cause material removal, wear, and mechanical damage, especially if there is a protective surface film present. This has happened to a variety of piping and tubing materials affected by particles with certain sizes, shapes, and hardnesses, and impinging velocities and angles. When the erosion factor is combined with a corrosive environment, the mechanical damage can be accelerated. In a noncorrosive environment, the erosion process simply removes metal from the tube wall. In a corrosive environment, the erosion process may first remove a protective film from the tube, thus making the tube susceptible to more corrosion and then more erosion. In both cases, wall metal loss occurs, either directly or by accelerated corrosion of the tube surface.

Inspection of removed tubes indicates that erosion-corrosion has occurred in once-through steam generators, principally around the fourteenth tube support plate at the periphery of the tube bundle. The erosion-corrosion degradation mechanism results in dished-shaped depressions and metal loss on the outside of the tube. It is thought that solid particle impingement on the tubing is the most probable cause. This solid particle impingement, continually striking the tube, wears away the metal's protective oxide as well as the base metal. The source of the solid particles has not been positively identified but is thought to be caused by debris in the steam from the generator or the feedtrain.

The fraction of tubes for all once-through steam generators affected by erosion-corrosion is small. Through December 1993, 1,622 tubes in four Babcock \& Wilcox designed plants (about $0.75 \%$ of the tubes inservice) have been taken out of service due to erosion-corrosion (EPRI 1994). More than half ( 991 ) have been from one plant, hence, the mechanism is not occurring at the same rate in all steam generators. No remedial measures to eliminate degradation of affected once-through steam generator tubes by erosion-corrosion have been identified, though some consideration has been given to chemical cleaning of the generators to remove solid corrosion products on the tube support plates. 
Table 10. Summary of once-through steam generator tube degradation processes.

\begin{tabular}{clllll}
\hline Rank & \multicolumn{1}{c}{$\begin{array}{c}\text { Degradation } \\
\text { site(s) }\end{array}$} & \multicolumn{1}{c}{ Stressors } & \multicolumn{1}{c}{$\begin{array}{c}\text { Degradation } \\
\text { mechanism(s) }\end{array}$} & $\begin{array}{c}\text { Potential } \\
\text { failure mode }\end{array}$ & $\begin{array}{c}\text { Inservice inspection } \\
\text { method(s) }\end{array}$ \\
\hline 1 & $\begin{array}{l}\text { Outside surfaces } \\
\text { of the tubes on } \\
\text { the periphery of } \\
\text { the tube bundle } \\
\text { near the 14th } \\
\text { tube support } \\
\text { plate }\end{array}$ & $\begin{array}{l}\text { Velocities, sizes, shapes, } \\
\text { impact angle, and } \\
\text { hardness of particles }\end{array}$ & $\begin{array}{l}\text { Erosion-corrosion from } \\
\text { impingement of particles }\end{array}$ & Wear of material & Eddy-current testing \\
2 & $\begin{array}{l}\text { Tube outside } \\
\text { surfaces near the } \\
\text { upper tubesheet } \\
\text { and the open } \\
\text { lane or near the } \\
\text { uppermost tube } \\
\text { support plate } \\
\text { and the open } \\
\text { lane }\end{array}$ & $\begin{array}{l}\text { Aggressive chemicals, } \\
\text { vibration }\end{array}$ & $\begin{array}{l}\text { Environmentally } \\
\text { assisted high-cycle } \\
\text { fatigue }\end{array}$ & Circumferential cracks & Eddy-current testing \\
$\begin{array}{l}\text { Inside surfaces } \\
\text { of tubes near the } \\
\text { upper tubesheet } \\
\text { roll transitions } \\
\text { and welds } \\
\text { (primary side) }\end{array}$ & Sodium thiosulfate, air & $\begin{array}{l}\text { Low-temperature } \\
\text { primary-side stress } \\
\text { corrosion cracking }\end{array}$ & Circumferential cracks & Eddy-current testing \\
\hline a. Based on operating experience and number of defects. & & & \\
\hline
\end{tabular}

This would reduce the particulate content of the steam and, thus, reduce the rate of erosion.

\subsubsection{High-Cycle Fatigue}

Throughwall circumferential cracking has occurred in once-through steam generator tubes at the top tube support plate (i.e., 15th tube support plate) and at the bottom of the upper tubesheet in the inspection lane region. The inspection lane region includes about three rows of tubes on either side of the inspection lane and a few additional rows at the periphery. The cracks initiated at the outside diameter of the tubes and propagated circumferentially in a transgranular mode. Tube samples revealed a serpentine band of metal loss in the areas near the upper tube support plate and just below the lower face of the upper tubesheet (EPRI 1985a, Theus and Daniel 1984). Sometimes these metal loss areas contained microcracks that acted as the site for fatigue crack initiation. Laboratory tests indicate that the corrosive metal loss, including the microcracks, can be achieved with concentrations of sodium sulfate, silicates, and chlorides (Monter and Theus 1982). Thus, the degradation mechanism has been described as environmentally assisted high-cycle fatigue.

The stressors for this corrosion fatigue cracking are believed to be deposits of concentrated impurities and cyclic vibration. Evaporation of the secondary-side water in the lower elevations of the once-through steam generators concentrates any contaminants or impurities into the remaining droplets. The steam flow then carries these droplets up the open inspection lane to the upper tubesheet area, where the droplets impinge on the hot tubes around the inspection lane, dry out, and deposit the impurities. This process further concentrates the chemicals at selected locations on the steam generator tubes. 
Babcock \& Wilcox has reported that a total of 158 tubes have been taken out of service (through August 1989) because of corrosion fatigue in seven domestic operating once-through steam generators (Snider 1989). These cumulative failures represent about $0.06 \%$ of the tubes inservice. Togo et al. (1985) indicate that the failures have mainly been associated with Oconee Units $1 \mathrm{~B}$ and $2 \mathrm{~B}$, and the Arkansas Nuclear One Unit 1 once-through steam generator. Hence, the occurrence of this degradation mechanism for all once-through steam generators is minor, and the mechanism is not occurring at the same rate in all steam generators. Further, failures were occurring in the above generators when the plants were partially bypassing their condensate polishers. The failure rates went down when the condensate polishers were fully used (Theus and Daniel 1984).

\subsubsection{Low-Temperature Primary-Side Stress Corrosion Cracking}

Stress corrosion cracking on the inside surfaces (primary-side) was detected in the tubes of a once-through steam generator at TMI-1 in 1981, where essentially all the tubes were affected and 1,619 tubes plugged and 502 tubes sleeved (Jones et al. 1982, Giacobbe et al. 1988). The incident is unique and the combination of conditions necessary to promote this type of attack is not expected to occur at other plants. Partially reduced sulfur species (e.g., sodium thiosulfate) had inadvertently been introduced into the primary system from the containment spray system. It is believed that aggressive concentrations of sodium thiosulfate and oxidizing conditions developed in the failure area from dry out and exposure to air and the cracking occurred during shutdown, while the plant was cooling from a hot test period. Most of the defects were circumferential in geometry and located in the upper part of the upper tubesheet near the weld heat-affected zone or the roll transition. The main protection against recurrence of this type of incident in once-through steam generators with sensitized tubing (due to heat treatment, see Section 2) is to avoid acidic oxidizing conditions by strict water chemistry controls and proper lay-up.

\subsubsection{Outside Diameter Intergranular Stress Corrosion Cracking and Intergranular Attack}

As discussed above in Section 3.2.2, IGSCC requires tensile stress, material susceptibility and a corrosive environment. IGSCC cracks occur along the grain boundaries, normal to the maximum principle stress. IGA is characterized by local, corrosive loss of material along the grain boundaries. Both mechanisms require a concentration of corrosive impurities on the outside surface of the tubing.

Through December 1993, 543 tubes (about $0.25 \%$ of the once-through steam generator tubes inservice) at four plant were removed from service or repaired due to IGSCC/IGA (EPRI 1994). The damage primarily occurred near the upper tubesheet (492 tubes).

\subsection{Russian VVER Steam Generator Tubes}

The horizontal, U-shaped tubing used in the VVER-440 and VVER-1000 reactors has been relatively trouble free. The VVER tubing is made of titanium-stabilized austenitic stainless steel with about $0.08 \%$ carbon, $18 \%$ chrome, $10 \%$ nickel, $\leq 1 \%$ titanium and the rest mostly iron. Through the end of 1989 , only about 2,815 VVER-440 tubes and 655 VVER-1000 tubes had been plugged out of a total of 1,774,480 tubes in operation; e.g., only about $0.2 \%$ of the total number of tubes had been plugged (Titov et al. 1992).

The main cause of damage has been outside surface stress corrosion cracking due to poor secondary-side water chemistry, primarily chloride ion and oxygen excursions, but also low $\mathrm{pH}$ and the presence of various organic compounds. Secondary-side chloride ion 
concentrations of several hundred to several thousand $\mathrm{ppb}$ have been reported for relatively significant times (Raussokhin et at. 1992). Also, the effects of the chloride ions on the stress corrosion rate have been accelerated due to the presence of porous crud deposits in quantities in excess of $150 \mathrm{~g} / \mathrm{m}^{2}$ (the recommended limit). The chloride ions tend to concentrate in the crud capillary structures by factors of $10^{5}$ to $10^{6}$ (Titov et al. 1992, Mamet and Martynova 1993). At some VVER plants, the secondary-side $\mathrm{pH}$ has dropped below 7.8 (the original lower limit which has now been revised to 8.8 for the feedwater and 8.0 for the blowdown water) for up to $20 \%$ of the overall running time, and to the range of 5-6 for up to $2 \%$ of the running time. Also, up to $700 \mathrm{ppb}$ of acetic acid (due to organic compound breakdown) has been found in the feedwater at several plants (Martynova and Mamet 1991).These secondary-side chemistry excursions have also caused pitting corrosion, for example at the grid spacer locations at the Novovoronezh Units. There have also been a few collector weld defects which have resulted in plugged tubes. The repair criteria for the VVER steam generators is tube leakage and the method is plugging; e.g., leaking tubes are plugged, other indications (part throughwall defects) are usually ignored.

\subsection{Steam Generator Tubing Residual Life Estimates}

This section summarizes the steps of an overall approach used by the nuclear industry, but not necessarily approved of by the USNRC, for estimating the rate of degradation of steam generator tubes. The approach employs a statistical technique and an empirical model which is consistent with the known degradation processes. A statistical approach is useful because of the large number of tubes in each steam generator and because the rate of degradation of steam generator tubes is influenced by a number of materials and environmental variables. One statistical technique used by some plant operators is the
Weibull probability distribution which is easy to handle mathematically and has been successfully used to describe the statistics of material failure caused by fatigue and stress corrosion cracking. An alternate to the Weibull distribution is the lognormal probability distribution. This method has proven particularly useful for the analysis of laboratory corrosion results (and is, in fact, suggested by the National Association of Corrosion Engineers for that purpose), and for long-term projections of degradation in operating steam generators. However, in view of its broader use in recent analyses, the Weibull distribution will be emphasized here.

The equation for the two-parameter Weibull distribution (Lipson and Sheth 1973) is

$$
\begin{aligned}
& F(t)=1-\exp \left[-\left(t / t_{r}\right)^{b}\right] \\
& \text { where } \\
& F(t)=\text { cumulative fraction of tubes }
\end{aligned}
$$


The fraction $F(t)$ in the Weibull equation is the fraction of tubes that are "failed" according to a particular criterion. Generally, a tube is considered to have failed when it is removed from service (plugged) or repaired by sleeving because of defects produced by the degradation mechanism being analyzed. For some purposes, it is useful to use a criterion other than plugging or sleeving to define the failed condition for analysis purposes. EFPY is generally used as a convenient measure of time of operation (total energy generated divided by the reactor rated power). This measure of time provides an approximate means of accounting for the effects of changes in operating temperature of the tubes for different reactor operating conditions. If the reactor has operated for an extended period of time at substantially reduced power, equivalent full power years should be used. However, the determination of equivalent full power years requires a value of the activation energy for the degradation mechanism being analyzed (Shah et al. 1992).

The parameters $b$ and $t_{r}$ in the Weibull equation are adjustable parameters generally determined by fitting the distribution function to the observed data. The exponent $b$ defines the slope of the Weibull curve. Its value determines how much scatter there is in times to failure among a given population. This exponent accounts for the random variations of properties between different tubes in one steam generator. The characteristic time $t_{r}$ in the Weibull equation is the basic rate constant of the degradation process. As several of the degradation mechanisms that affect steam generator tubes are considered to be stress assisted, thermally activated processes, the parameter $t_{r}$ is primarily a function of temperature, stress, and chemical environment. For such mechanisms, an Arrhenius equation for the characteristic time $t_{r}$ is used

$$
\mathrm{t}_{\mathrm{r}}=\underset{\left.\left.1 / \mathrm{T}_{\mathrm{o}}\right)\right]}{\mathrm{A} \sigma^{-\mathrm{m}}} \exp [\mathrm{Q} / \mathrm{R}(1 / \mathrm{T}-
$$

where

$\begin{array}{ll}\mathbf{t}_{\mathrm{r}}= & \begin{array}{l}\text { characteristic time ap- } \\ \text { propriate to a specific } \\ \text { location }\end{array}\end{array}$

$\mathrm{T}=$ temperature for the specific location

o $=$ appropriate stress component for the location

$\mathrm{m}=$ constant describing the stress dependence of the degradation mechanism $\mathrm{Q}=\begin{aligned} & \text { activation energy of the } \\ & \text { degradation mechanism }\end{aligned}$

$\mathrm{R}=$ gas constant

$\mathrm{T}_{\mathrm{o}}=$ temperature for a standard reference condition such as full power condition
A $=$ constant determined from $t_{\mathrm{ro}}=A \sigma_{\mathrm{o}}^{-\mathrm{m}}$, where $t_{r o}$ is the characteristic time for reference con- dition $T_{0}, \sigma_{0}$.

Various estimates for the activation energy $Q$ have been derived from laboratory studies and field experience. For example, the estimate for the activation energy for the PWSCC mechanism ranges from 39 to $65 \mathrm{kcal} / \mathrm{mole}$, with a best estimate value of $50 \mathrm{kcal} / \mathrm{mole}$ (Gorman et al. 1991, Stein and Mcllree 1986). The stress exponent value (m) is approximately 4 and is briefly discussed in Section 3.2.1. The constant $A$ is a scaling constant determined by the characteristic time for some standard stress level and reference temperature. The value of $A$ will change whenever there is a systematic change in the material characteristics and chemical 
environment, the average stress level at the location of interest, or other conditions that may differ from plant to plant.

Figure 26 represents the application of the Weibull model for an assessment of PWSCC damage to the hot-leg transition region of recirculating steam generator tubes. Tube inspection data from several plants for PWSCC failure in the hot-leg transition and rolled portion of the tube near the top of the tubesheet have been compiled and plotted using a Weibull distribution. These plants use similar detection technologies and have similar low-temperature mill-annealed tubing material and primary water chemistry. Therefore all the tubes in all the plants are within the same PWSCC population. All the tubes are included in the analysis. The plots illustrate the scatter expected in plant inspection data for PWSCC degradation. The data for each plant lie approximately on a straight line, except where perturbed by application of peening as a remedial measure. Even though the intercepts and the slopes (Weibull exponents $b$ ) for each plot vary, the slopes scatter around the bold dashed line drawn for a Weibull exponent of 3.0. Therefore an exponent of 3.0 can be used to make short extrapolations to predict the future rate of degradation at a plant where insufficient data are available to establish a plant-specific slope. However, when looking at a Weibull plot of steam generator tubing failure data (or eddycurrent indications of defects) over a longer period of time, the slope tends to taper off and the rate of cracking is over predicted when a slope of 3 is used. This has led some plant operators to use log-normal statistics for projections.

Although a number of steam generator experts in the nuclear industry are quite comfortable with this approach, some experts at the USNRC and the national laboratories question its validity. An Arrhenius equation is an empirical correlation which may be qualitatively useful, but may not, and in the case of Alloy 600 tubing, has not always provided accurate life predictions. The failure of the calculated time to correlate with the field experience may arise from several uncertainties in the input variables. Frequently, the activation energy is given as $50 \mathrm{kcal} / \mathrm{mole}$, however, the basis for this value is suspect. Some recent events have suggested that the value is temperature dependent and may be as low as $35 \mathrm{kcal} / \mathrm{mole}$. Additionally, a single value of activation energy may not be valid for both incubation and crack growth, as is generally assumed when life prediction calculations are performed. Also, not all of the variables controlling stress corrosion cracking in steam generator tubes have necessarily been identified, and thus, their omission from the equation can only lead to erroneous results. This opinion is supported by the consistent failure of accelerated laboratory corrosion tests to correlate with field experiences with cracking in Alloy 600 .

\subsection{Pressurized Water Reactor and CANDU Reactor Steam Generator Shell, Feedwater Nozzle, and Tubesheet Degradation}

This section discusses degradation mechanisms in steam generator shells and feedwater nozzles. Corrosion fatigue, high-cycle thermal fatigue, and stress corrosion cracking have caused cracking on the secondary-sides of the PWR steam generator shells. PWR primary-side degradation has not been observed and there has been no PWR tubesheet or CANDU shell, nozzle, or tubesheet degradation reported. Thermal fatigue and erosion-corrosion are responsible for most of the aging degradation that has occurred in PWR feedwater nozzles and the nozzle-to-pipe weld regions. Aging degradation may cause leakage but probably not failure, however, it may also weaken the system and reduce the safety margin so that another event, such as a pressure pulse or a water hammer, could be the final cause of a rupture. Primaryside divider plate damage has occurred at some CANDU units. 


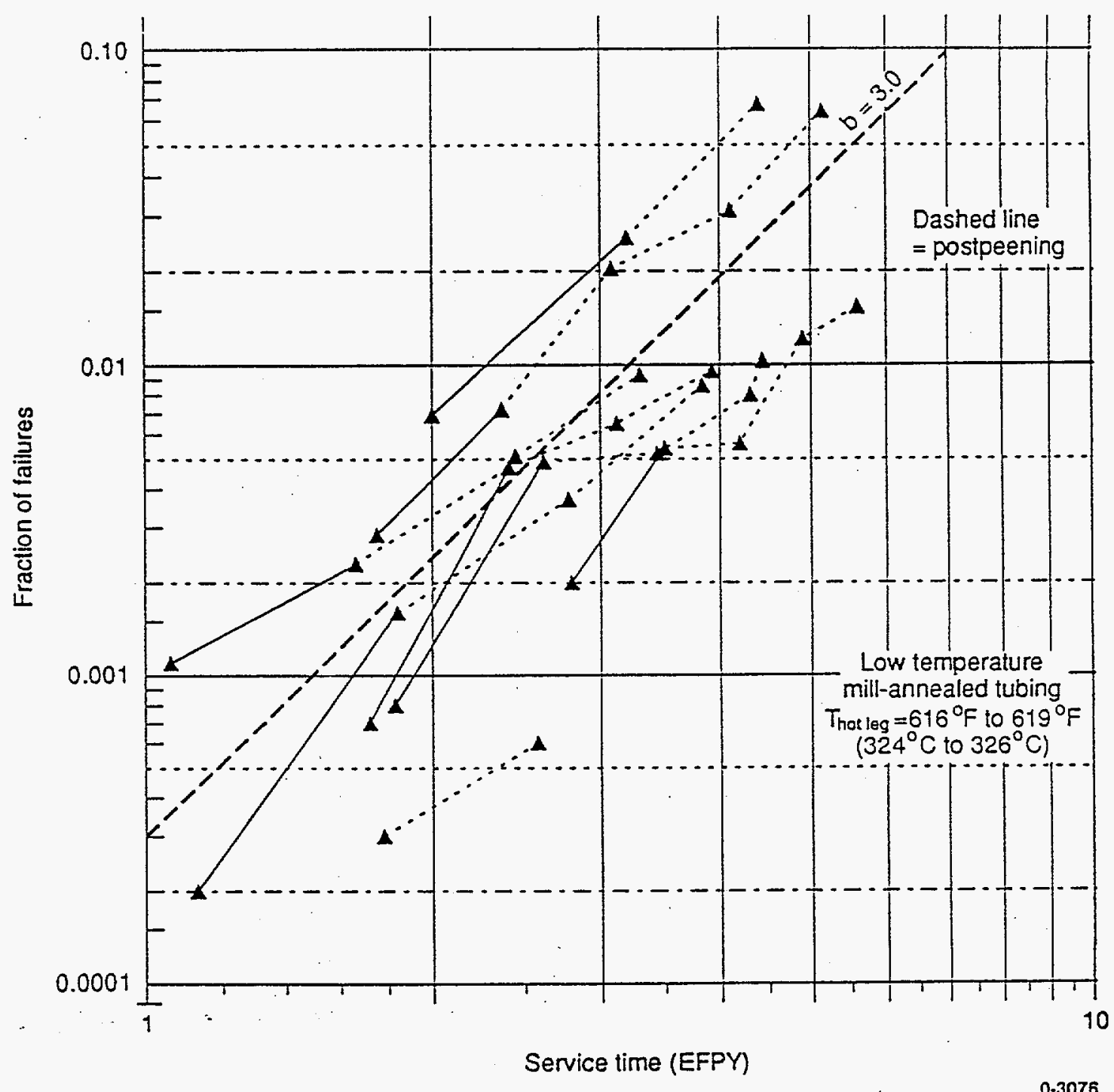

Figure 26. Weibull analysis of data for PWSCC at hot leg roll transitions and rolled area below the top of the tubesheet for plants with full depth rolls. Courtesy of A.P.L. Turner, Dominion Engineering.

Table 11 lists, and ranks by importance, the degradation mechanisms, sites, stressors, failure modes, consequences, and inspection methods for the PWR feedwater nozzles and the steam generator shells. The feedwater nozzle is ranked highest, because a break at this point would cause a much larger leak then from a steam generator shell crack and could not be isolated from the steam generator and could lead to rapid blowdown of the steam generator. Such a break would challenge the integrity of any severely degraded tubes. 
Table 11. Summary of degradation processes for PWR feedwater nozzles and steam generator shell.

\begin{tabular}{|c|c|c|c|c|c|}
\hline Rank* $^{*}$ & Degradation site(s) & Stressors & Degradation mechanism(s) & Potential failure mode & $\begin{array}{l}\text { Inservice inspection } \\
\text { method(s) }\end{array}$ \\
\hline 1 & $\begin{array}{l}\text { Feedwater nozzle and nozzle-10-piping } \\
\text { weld }\end{array}$ & $\begin{array}{l}\text { Flow velocity, } \mathrm{O}_{2} \text { content and } \mathrm{pH} \text { level in } \\
\text { feedwater, impurities, stratified flows, } \\
\text { thermal shocks, water hammer, plant } \\
\text { transients }\end{array}$ & $\begin{array}{l}\text { High and low cycle fatigue, } \\
\text { erosion-corrosion, }\end{array}$ & $\begin{array}{l}\text { Rupture from wall } \\
\text { thinning, leakage through } \\
\text { fatigue cracks, nupture } \\
\text { from water hammer }\end{array}$ & $\begin{array}{l}\text { Ultrasonic testing } \\
\text { radiography }\end{array}$ \\
\hline 2 & Steam generator shell girth welds & $\begin{array}{l}\text { Plant transients, oxygenated coolant } \\
\text { containing copper oxide, in-leakage of } \\
\text { brackish water through condenser tubes, } \\
\text { residual stresses }\end{array}$ & $\begin{array}{l}\text { Corrosion-fatigne, stress } \\
\text { corrosion cracking }\end{array}$ & $\begin{array}{l}\text { Leakage through farigute or } \\
\text { stress-corrosion cracks }\end{array}$ & $\begin{array}{l}\text { Ultrasonic testing, } \\
\text { radiography }\end{array}$ \\
\hline 3 & $\begin{array}{l}\text { Feedwater nozzle bore, blend radius, } \\
\text { shell inside surface beneath the nozzle }\end{array}$ & $\begin{array}{l}\text { Leakage of feedwater through the nozzle } \\
\text { thermal sleeve joint causing turbulent } \\
\text { mixing of cold feedwater and hot stean } \\
\text { generator coolant }\end{array}$ & High-cycle thermal fatigue & $\begin{array}{l}\text { Leakage through fatigue } \\
\text { cracks }\end{array}$ & $\begin{array}{l}\text { Ultrasonic testing, } \\
\text { radiography }\end{array}$ \\
\hline 4 & J-tubes and feedring & $\begin{array}{l}\text { Flow velocity, } \mathrm{O}_{2} \text { content and } \mathrm{pH} \text { level in } \\
\text { feedwater, impurities }\end{array}$ & Erosion-corrosion & $\begin{array}{l}\text { Dantage caused by loose } \\
\text { parts, thermal fatigue to } \\
\text { shell }\end{array}$ & $\begin{array}{l}\text { Problem remedied, } \\
\text { inspection unnecessary }\end{array}$ \\
\hline
\end{tabular}




\subsubsection{PWR Steam Generator Shells}

Corrosion-Fatigue. High-amplitude, low-frequency cyclic stresses, combined with coolant containing oxygen and copper oxides have caused corrosion-fatigue damage to the upper girth weld, i.e. upper shell to transition cone weld, in about seven RSG shells in the U.S. (Note that significant concentrations of copper oxides are associated with copper alloys in the feedtrain.) The presence of oxygen and copper oxides probably contributes to the formation of surface pits, which act as stress raisers, and therefore, as sites for fatigue crack initiation in the steam generator shell. During a few transient events, the water level in the steam generator drops below the girth weld region, and the incoming feedwater impinges on the girth weld and produces rather high stresses (Bamford, Rao, and Houtman 1992). Also, fluctuations in the steam generator water level will impose thermal fatigue cycles on the steam generator shell.

Shallow circumferential cracks have been observed in the girth weld under the feedwater nozzle, mainly in the heat-affected zone, with little penetration in the base metal. This suggests that the fracture toughness of the heat-affected zone was substantially lower than that of the base metal, and that the stresses were large enough to drive the cracks through the heat-affected zone but not through the base metal (Kobayashi and Shockey 1991).

Transgranular Stress Corrosion Cracking. Steam generator shell material subjected to high tensile stresses and oxygenated secondary coolant containing copper oxides is susceptible to transgranular stress corrosion cracking. High tensile stresses include both weld residual and operating stresses. Transgranular stress corrosion cracking and corrosion fatigue are differentiated by their load histories. Transgranular stress corrosion cracking occurs when the applied stresses are constant or have a very small fluctuation, i.e., the ratio of the mini- mum-to-maximum stress intensity factors is close to one. Corrosion fatigue occurs when the applied stresses are cyclic and the ratio of stress intensity factors is smaller than about 0.95 .

Circumferential cracks and linear indications have been detected on the inside surface of the girth welds in 18 steam generators in the U.S., all of which are Westinghouse Models 44 and 51 with a feedring design (USNRC 1990a). This type of cracking was first observed in 1982 when a girth weld of a steam generator leaked at a U.S. plant (USNRC 1982). Linear indications have also been detected at least one non-U.S. plant. In most of these cases, the girth weld region was predominantly subject to static loads and the cracking was caused by transgranular stress corrosion cracking.

Leak-before-break analyses show that a stress corrosion crack will grow through the shell wall and produce a measurable leak before it exceeds the critical flaw size and the vessel ruptures (Westinghouse 1990). Field experience to date supports this analysis. Inspection port holes in the steam generators have also experienced cracking, most likely stress corrosion cracking, on the inside surface. Grinding of the inspection port hole might have introduced the residual stresses needed for stress corrosion cracking.

High-Cycle Fatigue. High-cycle fatigue degradation can be caused by cyclic thermal stratification, thermal striping, and turbulent mixing of leaking cold feedwater (if any) with hot steam generator coolant. Any leakage of the feedwater through the feedwater nozzle-thermal sleeve joint can cause thermal stratification, turbulent mixing, and thermal shocks in the feedwater nozzle. These thermal stresses can promote fatigue damage in the nozzle bore, nozzle blend radius, and the inside surface of the shell. At one PWR plant in the U.S., the feedwater nozzle bore region, blend radius, steam generator shell inside surface beneath the nozzle (see Figure 16a), and feedring support 
bracket welds have all experienced cracking, probably due to both thermal fatigue and stress corrosion.

\subsubsection{Feedwater Nozzles}

Corrosion-fatigue cracks, caused by coolant thermal stratification and the stress concentrations at a counterbore (a joint between the feedwater nozzle and piping with a geometric discontinuity), have been observed in the vicinity of the feedwater nozzles as shown in Figure 16b. Under low feedwater flow conditions, typically during hot standby when the feedwater is supplied by the auxiliary feedwater system, the relatively cool feedwater tends to flow along the bottom of the horizontal sections of the piping adjacent to the feedwater nozzle, with the top portion containing hot water. This thermal stratification may lead to two different stressors which cause fatigue damage: cyclic local stratification and "thermal striping." Cyclic local stratification stresses, caused by small auxiliary feedwater flow fluctuations and subsequent changes in elevation of the interface between the hot and cold layers, can produce significant stress changes at a point in the pipe cross-section. Thermal striping, due to turbulent mixing at the interface of the hot and cold layers, can produce high-cycle fatigue crack initiation, generally a surface effect. Thermal striping does not propagate cracks; however, cyclic thermal stratification may propagate shallow cracks caused by thermal striping. The stress concentration at the sharp transition from the smaller thickness nozzle to the larger thickness feedwater pipe near the nozzle/pipe weld counterbore can also promote cracking in this region (Cofie et al., 1994).

On June 25, 1979, the USNRC issued Bulletin 79-13, requesting examinations of the feedwater nozzles and adjacent piping in the U.S. to address the safety concerns raised by fatigue cracking (USNRC 1979). The resulting inspections revealed pipe cracks in the vicinity of the feedwater nozzles at 18 of the 54 facilities inspected (Cofie et al., 1994). All cracks were corrosion-fatigue cracks caused by cyclic thermal stratification, except the cracks at one plant, which were identified as stress corrosion cracking (USNRC 1979). Recently, feedwater fatigue cracking has again been observed at several U.S. plants, including a throughwall crack at one unit. This cracking appears to have been caused by high stresses at the counterbore and fluctuations in the auxiliary feedwater flow, water chemistry may also have played a secondary role.

Both carbon steel piping material and carbon steel or low-alloy steam generator shell material are susceptible to corrosion fatigue if they contain sulfur inclusions, such as manganese sulfides (Bamford et al. 1987, Van der Sluys and Cullen 1987). The morphology and distribution of the sulfides can cause crack growth in low-alloy pressure vessel steels to differ by a factor of two, depending on the crack plane orientation (Van der Sluys 1982). Environmental effects appear highest for steels with medium-to-high concentrations of sulfur $(>0.015$ wt \%) in highly oxygenated water; environmental effects may be negligible in low sulfur $(<0.010$ wt \%) steels in deoxygenated water.

\subsubsection{Erosion-Corrosion of the Thermal Sleeves, J-tubes, Feedrings, and Divider Plates}

Erosion-corrosion is a flow-assisted corrosion mechanism that affects carbon steel piping carrying single-phase, subcooled feedwater and steam lines carrying wet steam. The damage caused by erosion-corrosion is higher than damage attributed to erosion or corrosion alone. Carbon steel feedwater piping corrodes during normal operation, forming a thin layer of iron oxide [mostly magnetite $\left.\left(\mathrm{Fe}_{3} \mathrm{O}_{4}\right)\right]$ on the inside surface. This layer protects the underlying piping material from the corrosive environment, and in the absence of erosion, limits the corrosion rate. However, if stressors causing 
erosion are present, the layer of iron oxide will dissolve and the uncorroded metal surface will again be exposed to the corrosive environment, and piping corrosion will continue. Thus, the continuous process of oxide growth and dissolution leads to thinning of the pipe wall and ultimately to a catastrophic failure when the pipe is subject to a pressure pulse of large magnitude. Figure 27 presents a simple model describing the phenomena occurring during erosion-corrosion (Sanchez-Caldera 1984).
The factors affecting the erosion-corrosion rate include the following:

- Piping configuration

- Feedwater temperature

- Bulk-flow velocity

- Turbulence

- $\mathrm{pH}$ level

- Oxygen content

- Impurities

- Piping material

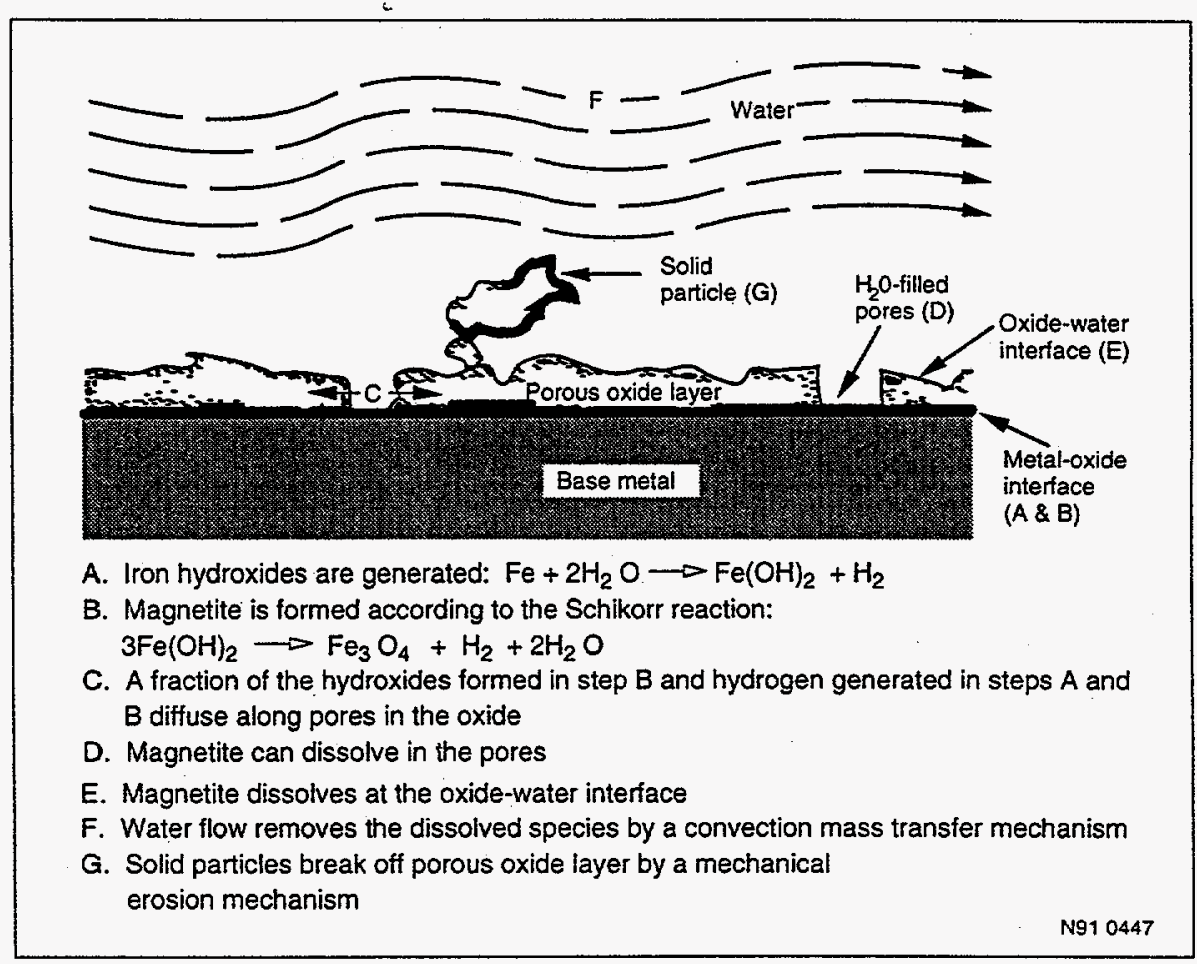

Figure 27. Phenomena occurring during erosion-corrosion (Sanchez-Caldera 1984). 
Carbon steel components with less than $0.1 \mathrm{wt} \%$ $\mathrm{Cr}$ are susceptible to erosion-corrosion damage. Although erosion-corrosion is a greater concern in PWR feedwater piping, steam generator components have also experienced damage from this mechanism. Erosion-corrosion of the thermal sleeve at Diablo Canyon Unit 1 was recently reported (USNRC 1993). The carbon steel $J$-tubes and feedrings within RSGs have also experienced significant erosion-corrosion-induced wall thinning. The affected J-tubes have been repaired or replaced with Alloy $600 \mathrm{~J}$-tubes.

Erosion-corrosion damage of some of the carbon steel primary-side divider plates in the CANDU steam generators, as well as fatigue damage to the divider plate bolts (also carbon steel), has been reported. (The primary-side divider plate is located below the tubesheet in the lower plenum of the RSGs.). The erosion-corrosion of the plate and fatigue of the bolts caused increased divider plate leakage and excessive bypass flow, which decreased the performance of the steam generators somewhat. Fatigue of the bolts may also lead to loose parts damage to the tubesheet.

\subsection{Russian VVER Collector, Shell, and Feedwater Distribution System Degradation}

Although the VVER tubing has been relatively trouble free, stress corrosion cracking of the VVER-1000 cold collectors and erosioncorrosion of the VVER feedwater distribution systems has occurred. The stress corrosion cracking of the collectors is discussed first, followed by a brief discussion of the feedwater problems.

\subsubsection{Stress Corrosion Cracking of the VVER-1000 Collectors}

In contrast with the vertical tube bundles and horizontal flat tubesheets used in the West, the VVER steam generator tube bundles are horizontal and are attached to the walls of two vertical cylindrical collectors or headers.
Primary coolant from the reactor core region enters through the inlet (hot) collector, passes through the U-shaped tubing, and leaves through the outlet (cold) collector. The VVER-1000 collectors are fabricated from pearlitic steel and clad on the inside with austenitic stainless steel. The hot and cold collectors are similar with normal operating temperatures at $320^{\circ} \mathrm{C}\left(608^{\circ} \mathrm{F}\right)$ and $290^{\circ} \mathrm{C}\left(554^{\circ} \mathrm{F}\right)$, respectively. The inner diameter of the VVER-1000 collectors is $834 \mathrm{~mm}$ and the wall thickness is $171 \mathrm{~mm}$.

Higher than normal radioactivity levels were observed in the secondary system of South Ukraine Unit 1 in late 1986. It was determined that three adjoining ligaments in the cold collector of one of the four steam generators had developed throughwall cracks resulting in failure of the tube-to-collector inside surface cladding welds and significant leakage of primary coolant into the secondary system (Titov 1991). This steam generator had been in operation for less than one year. As of July 1993, 33 steam generators at eight VVER-1000 plants had been replaced because of failure or the potential of failure of the cold collectors (Koryakin 1993, Titov 1991). These replacements occurred at only $3-25 \%$ of the design lifetime $(240,000 \mathrm{hrs})$. Cracking and potential rupture of the VVER collectors is of concern not only because of the economic losses associated with repairing or replacing these steam generators, but also because of public safety. Radioactive primary coolant could be discharged to the environment via the main steam atmosphere dump valves if they stick open. Worst case calculations suggest that about 200 tons of primary system, steam generator, and emergency core cooling water might be released. Also, long term cooling might be lost if the atmospheric dump valves do not close properly because there are no isolation valves on the atmospheric dump valve lines (IAEA 1994).

Metallographic examination of failed collector material "showed that the cracks were corrosion- 
induced, mechanical in nature, initiating and propagating from the secondary circuit side, at first via an intercrystalline and then via an intergranular mechanism" (Titov 1991). The maximum crack length (as a sum of the lengths of the affected ligaments) on the secondary-side was about $1,000 \mathrm{~mm}$. The maximum throughwall crack length on the primary-side was about $10-15 \mathrm{~mm}$. To date, cracks have been found only in the cold collectors. However, "indications" have also been reported for the hot collector (IAEA 1993). Three types of cracks have been observed: satellite cracks with widths up to $0.1 \mathrm{~mm}$ and lengths up to $1 \mathrm{~mm}$; planetary cracks between two adjacent holes with widths up to $0.5 \mathrm{~mm}$, lengths across the ligament, and depths up to $30 \mathrm{~mm}$; and arterial cracks through several (up to 30 ) holes with lengths up to 1,000 $\mathrm{mm}$, widths more than $0.5 \mathrm{~mm}$, and depths through the wall $(171 \mathrm{~mm})$. The maximum crack propagation rate was six ligaments within one operating cycle (approximately 18 months).

The metallographic examinations also showed that the cracks usually started at a crevice between the collector hole and a nonexpanded tube, near the nonperforated zone (Vconfiguration) of the collector. The cracks start at pits and grow across the ligaments first, further growth occurs through the wall. The wall is penetrated only after cracking of several ligaments. Ductile cladding failure occurs after the cracks penetrate the collector wall.

Investigation and analysis of the design, fabrication, operational loads, and water chemistry conditions led to the following findings (Titov 1991, Titov 1993):

(a) The tubing in the steam generators with collector cracking had been explosively expanded into the collectors using "rigid" charges. This procedure led to deformation of the collectors, seizure of the upper part of the collector in the steam generator vessel flange, and residual stresses near yield in the collector ligaments.

(b) The collector hole drilling techniques coupled with the explosive tube rolling led to the formation of a layer of embrittled, highly cold work material on the inside surface of the collector holes which was sensitive to cracking.

(c) Crevices with depths up to $20 \mathrm{~mm}$ were present due to under-expansion of the tubes. These crevices collected impurity deposits which promoted stress corrosion cracking. The deposits in the cold collector crevices tended to be porous, whereas, the deposits in the hot collector crevices were generally dense enough to prevent water ingress.

(d) The pearlitic steel used for the VVER1000 collectors undergoes strain aging at about $290^{\circ} \mathrm{C}\left(554^{\circ} \mathrm{F}\right)$. It is also more susceptible to stress corrosion cracking at temperatures below $280^{\circ} \mathrm{C}\left(536^{\circ} \mathrm{F}\right)$ than at higher temperatures.

(e) Abnormal secondary water chemistry conditions accelerated the cracking process, especially a drop in $\mathrm{pH}$ to acid conditions (as low as 4.3) and significant periods when the chlorine ions ranged from a few hundred to a few thousand ppb rather then the specified less than $150 \mathrm{ppb}$ (Gorbatykh 1993, Martynova and Mamet 1991, Rassokhin et al. 1992). Excessive oxygen due to aerated auxiliary feedwater and copper from the condenser tubes may also have contributed to the problem (IAEA 1993). The steel fabrication process may have created MnS inclusions which acted as sites for crack initiation.

To improve the performance of steam generators already in operation, the following changes were 
made: release of the collector upper racks, low temperature heat treatment $\left(450^{\circ} \mathrm{C}\right)$ of the collector perforated zone, and improvements in secondary water chemistry. These changes helped but were not fully effective. For steam generators fabricated but not in operation, a high temperature heat treatment at $650^{\circ} \mathrm{C}$ was conducted along with full depth hydraulic expansion of the tubes. The new VVER-1000U design will probably use titanium stabilized austenitic stainless steel in the perforated regions of the collectors rather then low alloy steel and the tubes will be expanded hydraulically.

The VVER-1000 steam generators fabricated in the Czech Republic by Vitkovice, J. S. C. for the Temelin plant incorporated several improvements to address these problems. All their Type 10GN2MFA low alloy steel was doubly vacuum treated to minimize the gas concentrations and secure a homogeneous chemical composition. The phosphorus and sulfur contents were reduced. The collectors were forged so as to suppress macrosegregations on their inner surfaces. The tubing was expanded to the collector wall by a hydraulic expansion process which minimized the residual stresses and crevices.

\subsubsection{Erosion-Corrosion of the VVER Feedwater Distribution Systems}

As discussed in Section 3.6.3, erosion-corrosion is a flow-assisted corrosion mechanism where damage caused by erosion-corrosion is higher than damage attributed to erosion or corrosion alone. The factors affecting the erosioncorrosion rate include piping configuration, feedwater temperature, $\mathrm{pH}$, bulk-flow velocity, turbulence, oxygen content, impurities and material.

A current issue involves the erosion-corrosion of the VVER-1000 feedwater distribution systems. The VVER-440 feedwater distribution system is shown in Figure 7 and consists of a feedwater pipe which enters the steam generator vessel on the side opposite the hot collector in the steam region, travels across half the table bundle, and then travels down to about the center of the tube bundle where it connects via a tee joint with a horizontal manifold. The horizontal manifold is equipped with a number of nozzles directed down, through which sub-cooled feedwater is injected into the corridor between the two sides of the tube bundle to mix with the saturated liquid. The system was originally fabricated with mild carbon steel. Flow-assisted corrosion of the nozzles has occurred at a number of plants including Dukovany, Paks and Rovno. The damage has ranged from modest wall loss to complete nozzle destruction (the nozzles closest to the tee tend to be more damaged). Erosioncorrosion of the tee joint has also been observed, which could lead to cold feedwater spray onto the hot collector.

Loss of the feedwater distribution nozzles is not considered a major safety issue because experiments conducted at OKB Gidropress has shown that the feedwater flow distribution is still adequate. However, the missing parts may cause fretting damage to the steam generator tubes or damage the valves in the blow down lines (only 2 of the 13 missing feedwater distribution nozzles at Paks have been found). Also, continued erosion-corrosion of the system will eventually destroy the tee joint.

In response to this problem, OKB Gidropress has designed a new VVER-440 feedwater system which has similar geometry but is made of titanium-stabilized austenitic stainless steel. This new system has been installed in the Rovno steam generators and will be installed in the Paks steam generators. Another retrofit design prepared by Vitkovice in the Czech Republic is characterized by a manifold above the water level and feedwater distribution through long downcomers into mixing boxes situated at the level of the previous feedwater manifold. This design has been installed in the Dukovany steam generators (16 steam generators) and one Bohunice steam generator. A slightly different upper feedwater 
system was installed in another Bohunice steam generator. The tee joints were repaired at Loviisa in 1989-1990. Later, on finding extensive damage to the feedwater distribution nozzles, a program of feedwater system piping replacement was begun.

Erosion-corrosion of the VVER-1000 steam generator feedwater distribution system may also be a problem, and alternate designs and materials are being evaluated by OKB Gidropress.

\subsubsection{Failure of Collector Cover Bolts}

The VVER steam generator collectors are sealed at the top with covers (plates) which are bolted to thin flanges around the top of the collectors (see Figures $7 b$ and $8 b$ ). On January 24, 1982 all twenty bolts holding the cover on the hot collector in Steam Generator Number 5 at Rovno Unit-1 broke during a reactor power increase from 75 to $82 \%$. The cover blew off (lifted), creating a break area around the collector circumference with an equivalent diameter of about $120 \mathrm{~mm}$. The primary coolant system pressure dropped rapidly and the reactor was automatically scrammed at 12 seconds. All three trains of emergency core cooling started shortly thereafter. At 13 minutes, the operators shut off the reactor coolant pump in Loop 5 and attempted to close the isolation valve but it would not fully close (the primary coolant pressure was about $4 \mathrm{MPa}$ (580 psi).

Between 30 and 39 minutes the operators were able to improve the leak tightness of the Loop 5 isolation valve, but also noted that Loop 3 was leaking. Eleven of the twenty bolts on the hot collector cover in Steam Generator Number 3 were later found to be broken. The operators shutdown the Loop 3 reactor coolant pump and tried to close the Loop 3 isolation valve. It initially closed only $50 \%$ of the way. The result of these actions (full isolation of Loop 5 and partial isolation of Loop 3 and full emergency core cooling flow) was that the primary system pressure increased to 105 atmospheres at 39 minutes and then all twenty bolts on the cover of the hot collector in Steam Generator 1 broke. (Also, four of the twenty bolts on the cover of the hot collector in Steam Generator 4 broke at some point.) The primary coolant system pressure then dropped back to about 40 atmospheres within about one minute. At 65 minutes, there were indications that some of the steam generators were overfilled and there was water in the steam lines. Eventually, all four defective steam generators were isolated and the plant was cooled using Loops 2 and 6 only. Altogether, about 1,100 tons of primary coolant and emergency core cooling water was lost to the secondary side and about 20 tons were released to the environment along with about 17 curies of radioactive material (Solovyev 1992).

Inspection of the bolts after the accident determined that the failures probably occurred as a result of corrosion-fatigue damage. The bolting material chemical and mechanical properties were within specification, however, there was some non-uniformity in yield strength (56 to 67 $\mathrm{Kg} / \mathrm{m}^{2}$ ) and hardness (19 to 27 Rockwell). Forty percent of the fracture surfaces had a clearly visible striated structure characteristic of fatigue damage. There were differences in grain size ranging from 3 to 9 degrees BALL and carbide inclusions. The "character of the fracture surfaces was brittle" with numerous inter- and trans-granular microcracks. The breaks occurred in the transition region from the threaded to nonthreaded material or in the first few threads. Some of the microcracks appeared to have been present for a considerable period of time. Due to wear of the top cover seals, there had been primary to secondary coolant system leakage from the hot collector covers in Steam generators $1,3,4$, and 5 and the bolts had been screwed down very tight the previous year creating high tensile stresses. Other possible reasons for the bolt cracking include water level oscillations and splashing on the secondary side which caused thermo-cycling and fatigue damage and may have 
caused an accumulation of impurities in the bolt region, a poor choice of bolt lubricant, and high chloride levels on the secondary side (Solovyev 1992, IAEA 1995).

Corrective measures at Rovno included a new procedure for tightening the bolts, a change in the stud lubricant from molybdenum sulfide to copper-graphite, a change in the secondary side chloride limits from 500 to $50 \mathrm{ppm}$, and better secondary side water level control. Also, the bolts and covers on all the Rovno steam generator collectors were replaced. Other VVER-440 plants have also implemented nitrogen-16 monitoring on the main steam lines in response to this accident (IAEA 1995). 


\section{STEAM GENERATOR TUBE RUPTURE EVENTS}

Ten steam generator tube rupture events are discussed in this section. A variety of degradation mechanisms have caused these ruptures including wastage, PWSCC, wear, ODSCC, and high-cycle fatigue. In each case, the rupture caused a complex plant transient which challenged the operators. The operator actions during these accidents were directed towards:

- maintaining the primary coolant subcooled,

- minimizing the leakage from the primary system to the secondary coolant system, and

- preventing the release of radioactivity from the damaged steam generator.

Their success varied somewhat, however, none of these accidents resulted in a significant dose to the public.

The ten steam generator tubing rupture events are discussed in chronological order in Sections 4.1 through 4.10. The leak rate, degradation mechanism, rupture size and location, stressor, and plant transient information for all ten events are summarized and compared in Section 4.11. A few of the more recent and better publicized incipient steam generator tube rupture events in the U.S. are briefly discussed in Section 4.12.

The USNRC classifies a steam generator tube rupture event as a primary to secondary leak through a break in a steam generator tube in excess of the normal charging flow capacity of the reactor coolant system (USNRC 1988a). At Surry Unit 2, the same high pressure pumps are used for both charging and safety injection. The rupture discussed in Section 4.2 resulted in a leak rate that was within the capacity of the pumps, but only when the system was aligned for safety injection. Therefore, the Surry event is considered to be a steam generator tube rupture rather than a steam generator leak. The Fort Calhoun tube rupture discussed in Section 4.6 resulted in a relatively low leak rate that was initially within the normal charging flow capacity of the plant. However, the volume control tank was depleted after about 27 minutes and the charging pumps had to be secured. Therefore, the Fort Calhoun event should also be categorized as a steam generator tube rupture rather than a steam generator leak.

\subsection{Point Beach Unit 1}

A $470 \mathrm{l} / \mathrm{min}$ (125 gpm) leak developed in Steam Generator B at Point Beach Unit 1 on February 26, 1975 (USNRC 1980). The degradation mechanism, size and location of the rupture, and the results of previous and subsequent steam generator inspections are discussed in Section 4.1.1. The plant transient, operator actions, radiation release, and remedial actions are discussed in Sections 4.1.2 through 4.1.5, respectively.

\subsubsection{Cause of the Tube Rupture}

The Point Beach rupture was apparently caused by wastage (relatively uniform corrosion and thinning of the tube on its outside surface), possibly combined with stress corrosion cracking. A boroscope viewing of the ruptured tube identified two adjacent, axially aligned bulges, the total length of which was less than 38 $\mathrm{mm}$ (1.5 in.) and neither of which exceeded about $20 \mathrm{~mm}(0.75 \mathrm{in}$.) in length and width. The shape of the bulges suggest a phosphate corrosion or wastage mechanism which caused significant and relatively uniform thinning and ultimately local ductile rupture. However, eddy-current signals typical of ODSCC were also obtained from the area. The ruptured tube was not removed for a detailed examination. 
The ruptured tube was located in the outer row of the tube bundle on the hot leg side. The ruptures were located at an elevation close to, but above the tubesheet, in the sludge pile region. The ruptured tube had not been inspected prior to the rupture. Subsequent eddy-current inspection of the remaining tubes in both the $\mathrm{A}$ and $\mathrm{B}$ steam generators identified 127 tubes with apparent reductions in wall thickness greater than $60 \%$. The steam generators were Westinghouse Model 44 RSGs with mill-annealed Alloy 600 tubing. The steam generators were replaced in 1984 after 176 tubes were plugged due to wastage and 473 tubes were plugged due to ODSCC in the tubesheet region.

\subsubsection{Plant Transient}

The Point Beach rupture occurred while the plant was operating at full power. The air ejector high-radiation alarm was the first indication of the rupture. This was followed by alarms indicating that the operating charging pump was at maximum flow and the pressurizer level was decreasing, at which point the operators recognized that they had a leak, but thought that it was in the auxiliary building (USNRC 1980). A second charging pump was started at 2 minutes, the reactor let down system was isolated at 8 minutes, and a third charging pump (initially out of service) was started at 19 minutes in an attempt to control the pressurizer level. A portable radiation monitor was used to check the B steam generator blowdown sample cooler and the readings led the operators to conclude (at 28 minutes) that a steam generator tube rupture had occurred. A $5 \%$ per minute load reduction began at 30 minutes and the plant was manually tripped at 47 minutes from $25 \%$ power. The safety injection system did not start, but the safety injection pumps were intermittently used during the subsequent cooldown (after 61 minutes) to control the reactor coolant system inventory.
The main steam isolation valve for the affected Steam Generator B was closed at 48 minutes, however the feedwater to Steam Generator B was not stopped until 58 minutes. At 51 minutes, a reduction in the reactor coolant system pressure and temperature was started by dumping steam from the intact steam generator to the condenser. The B loop reactor coolant pump was manually tripped at 1 hour and 6 minutes and then restarted at 1 hour and 40 minutes, so that the pressurizer spray could be used to help cool the plant down. At 1 hour, 48 minutes, the reactor coolant system pressure was about $6.9 \mathrm{MPa}$ (1000 psi) and the defective steam generator pressure was about $6.3 \mathrm{MPa}(920 \mathrm{psi})$. At 3 hours, 5 minutes, the residual heat removal system was placed in operation, however, the primary system pressure apparently stayed slightly above the defective steam generator secondary pressure for about 6 or 7 hours, which resulted in overfill of the defective steam generator secondary side.

\subsubsection{Operator Actions}

Overall, the slow decrease in pressure and pressurizer level allowed an almost normal shutdown. "The actions taken and the decisions made by the operator during the event were reasonable and prudent. The decision to ramp down the unit prior to tripping prevented the activation of the atmospheric dump valves and/or safety valves, thus keeping radioactive releases as low as possible" (USNRC 1980). However, there were some questionable operator actions. The operators were slow to recognize that a steam generator tube rupture or leak had occurred (28 minutes). Therefore, they were slow to start the load reduction (30 minutes) and slow to isolate the defective steam generator (58 minutes). Also, the defective steam generator received feedwater for about 10 minutes after the main steam isolation valve was shut. This error, along with the fact that the primary system 
pressure remained above the pressure on the secondary side of the defective steam generator for about 6 or 7 hours, led to overfilling the secondary side of the defective steam generator. On a more positive note, the cooldown and depressurization were relatively fast and the residual heat removal system was in operation by 3 hours, 5 minutes.

\subsubsection{Environmental Impact}

The total radioactivity released to the environment through the air ejector and the blowdown tank vent was about $2,265 \mathrm{Ci}$ of Xe133 equivalent over about a 1 hour and 8-minute period. There was probably no significant offsite dose and the release was a small fraction of what could have occurred had the Steam generator B safety valves or atmospheric dump valves opened.

\subsubsection{Remedial Actions}

Point Beach Unit 1 began commercial operation in December 1970 and operated with phosphate secondary water chemistry through the fall of 1974, when it was converted to an all volatile treatment (AVT). A substantial amount of sludge accumulated on the tubesheet during the operation with phosphate water chemistry and was not removed upon initial AVT operation. The first sludge lancing was in January 1975. The sodium phosphate caused wastage and then some of it may have been converted to sodium hydroxide after the AVT was implemented and caused stress corrosion cracking in the tubesheet region. The remedial actions consisted of sludge lancing (completed just before the rupture), additional tube inspections, and plugging of all tubes with eddy-current indications greater than $30 \%$ through the wall.

\subsection{Surry Unit 2}

A $1250 \mathrm{l} / \mathrm{min}(330 \mathrm{gpm})$ leak developed in Steam Generator A at Surry Unit 2 on September 15,
1976 (USNRC 1980). The degradation mechanism, size and location of the rupture, and the results of subsequent tube inspections are discussed in Section 4.2.1. The plant transient, operator actions, radiation release, and remedial actions are discussed in Sections 4.2.2 through 4.2.5, respectively. The leak rate discussed in this section is the leak rate estimated by the USNRC from post-accident analysis rather than the leak rate reported by the plant operator ( 300 $\ell /$ min or $80 \mathrm{gpm}$ ).

\subsubsection{Cause of the Tube Rupture}

The Surry rupture was caused by PWSCC in the U-bend region of the tube located in Row 1, Column 7 (Stoller 1976a). The high stresses that caused the PWSCC resulted from the deformation of the carbon steel tube support plates. The deformation of the plates was caused by corrosion of the plates. As discussed in Section 3.2.5, corrosion of drilled hole carbon steel support plates in the early Westinghouse, French, and Japanese steam generators resulted in the growth of a voluminous corrosion product in the gaps between the tubes and support plates. This caused denting of the tubes and sometimes deformation and cracking of the support plates (Stoller 1976b). There is a row of rectangular flow slots in the tube support plates of the Westinghouse Model 51 steam generators between the hot and cold leg sides of the tube bundle. These slots were originally about 406 $\mathrm{mm}$ (16 in.) long by $70 \mathrm{~mm}$ (2.75 in.) wide and were spaced about $508 \mathrm{~mm}$ (20 in.) center to center. The denting phenomenon deformed the support plates so that the flow slots became hour glassed in shape, that is, the center portion of the parallel flow slot walls moved together. Subsequent measurements indicated that the flow slot openings in the top tube support plate in the Surry Unit 2 A steam generator had decreased to an average opening size of $37 \mathrm{~mm}$ (1.46 in.). The smallest flow slot opening was $35 \mathrm{~mm}(1.38$ in.). The flow slot openings in the top tube support plates of the Surry Unit 1 steam 
generators (which had operated longer) decreased to a minimum value of about $13 \mathrm{~mm}(0.5 \mathrm{in}$.) (Stoller 1976b).

The deformation of the tube support plates in the Surry Unit 2 A steam generator caused each leg of the tubes along the center portions of the flow slots to be displaced inward about $16.5 \mathrm{~mm}(0.65$ in.). This caused significant ovalization of the tubes in the U-bend region and high stresses at the inside surface at the apex of the bend.

Nine U-bend sections were removed from the A steam generator including the six necessary to gain access to the ruptured tube in Column 7 and the next two tubes. The ruptured tube had a $114.3 \mathrm{~mm}$ (4.5 in.) long axial branching intergranular crack which initiated on the top inside surface (Stoller 1976a). Five of the other eight pulled tubes showed significant ovalization and four of the eight had cracks on the inner surface (Stoller 1976b). The tubes with ovalization and cracks were located near the middle of the flow slot. Thirty-one Row 1 Ubend samples were removed from the Turkey Point Unit 4 B steam generator (similar tubes, support plates, and operating conditions) in October of 1976. Similar PWSCC was found in three of the pulled tubes (Stoller 1976c). Neither the Surry or Turkey Point cracks were detected with the eddy-current techniques available at the time.

\subsubsection{Plant Transient}

The Surry rupture occurred while the plant was operating at full power with a satisfactory leak rate $(5.3 \mathrm{\ell} / \mathrm{min}$ or $1.4 \mathrm{gpm}$ total, $2.2 \mathrm{\ell} / \mathrm{min}$ or 0.6 gpm unidentified) and flux mapping in progress (USNRC 1980). The maximum charging flow alarm and a sudden decrease in the reactor coolant system pressure were the first indications of a break. This was followed within 1 minute by the air ejector alarm. The operators responded at 5 minutes by securing the reactor coolant system letdown and starting a second charging pump. Also, the flux mapping was stopped and the control rods were moved to return the average reactor coolant temperature back to program.

At 7 minutes, the operators initiated emergency boration by lining up the discharge of the boric acid transfer pumps with the charging pump suction and commenced a load reduction of $10 \%$ per minute. At 10 minutes, the operators tripped the turbine which caused an automatic reactor trip. At 11 minutes, the operators started the safety injection system [the pressurizer level was off scale low and the reactor coolant system pressure was about $12 \mathrm{MPa}(1800 \mathrm{psig})]$. At 16 minutes, the operators throttled the safety injection flow by stopping both the low head safety injection pumps and one of the two high pressure safety injection pumps, and re-aligning the other high pressure pump discharge to the normal charging flow path (the two high pressure safety injection pumps are also the charging pumps at Surry). The reactor coolant system pressure peaked at about $14 \mathrm{MPa}$ (2100 psig).

Between 17 and 18 minutes, the operators secured the feedwater flow to all three steam generators, determined that the rupture was in the A steam generator, and isolated the A steam generator. At 19 minutes, the reactor coolant pump in the B loop was tripped, it remained off for the rest of the transient. The other two reactor coolant pumps remained in operation which allowed the operators to use the pressurizer spray to help depressurize the reactor coolant system (from the $\mathrm{A}$ and $\mathrm{C}$ loops) and allowed for forced circulation cooling through the $\mathrm{C}$ steam generator. At 21 minutes, the operators restarted the second high pressure charging/safety injection pump and re-aligned the flow from both high pressure pumps back to the safety injection flow path. This increased the pressurizer level back to about $20 \%$ where it was maintained during the rest of the cooldown. The plant was cooled by dumping steam from the intact steam generators to the condenser. At 1 
hour and 10 minutes, the reactor coolant system pressure had been reduced to about $6.8 \mathrm{MPa}$ (1000 psig) which stabilized the level in the defective steam generator at about $75 \%$. (The defective steam generator was not overfilled.) At 11 hours and 20 minutes, the plant reached cold shutdown and the A loop reactor coolant pump was tripped and the A loop was isolated.

\subsubsection{Operator Actions}

The Surry steam generator tube rupture caused a relatively severe transient because of the relatively high leak rate and the fact that the operators were involved in control rod manipulations at the time of the rupture. The control rod movements initially led the operators to believe that the initial pressure drop was caused by control rod induced changes in the average reactor coolant temperature. This led to a short delay in recognizing that a steam generator tube rupture had occurred (about 5 minutes). The operators actions after about 5 minutes were prompt and effective. A load reduction was started at 7 minutes, the turbine was tripped and the reactor scrammed at 10 minutes, the safety injection system was started at 11 minutes and then throttled at 16 minutes, the defective steam generator was isolated at 18 minutes, the pressurizer level was stabilized at 21 minutes, and the primary coolant system pressure was reduced to the defective steam generator secondary pressure within about 1 hour.

As mentioned above, the operators tripped the reactor coolant pump in the $B$ loop at 19 minutes in conformance with their standard operating procedures. There are no pressurizer spray lines from the B loop cold leg and running this pump puts additional energy into the primary coolant system. However, in the case of a steam generator tube rupture at a three loop plant the primary coolant system will cool down faster with forced circulation in both intact loops. Also, the reactor coolant pump in the defective loop operated through out the transient. The leakage from the reactor coolant system could have been further reduced by tripping the reactor coolant pump in the defective (A) loop and closing the loop isolation valves. However, the defective steam generator was not overfilled because of the rapid depressurization of the primary coolant system and the relatively rapid closure of the main feedwater isolation valve (which closed automatically when the safety injection system was started at 11 minutes).

Overall, the operator actions effectively mitigated the transient and the mistakes made in operating the reactor coolant pumps had no significant effect on the outcome of the transient (USNRC 1980).

\subsubsection{Environmental Impact}

Release of radioactivity to the environs was minimized by automatic diversion of the air ejector discharge to the reactor containment (USNRC 1980). The dump and safety valves on the defective steam generator did not open during the transient and the radiological consequences were well below regulatory limits.

\subsubsection{Remedial Actions}

Following the September 15, 1976 tube rupture of Surry Unit 2, the innermost row of tubes were plugged in the Surry Units 1 and 2, Turkey Point Units 3 and 4, Indian Point Unit 2, and San Onofre Unit 1 steam generators (USNRC 1980). In addition, augmented inservice inspection programs were implemented at these plants (increased inspection frequency and sample sizes). The augmented inspection programs included eddy-current and go/no-go gauging inspections of the tubes and support plate examinations. Eventually, the steam generators at the Surry, Turkey Point and Indian Point Unit 3 plants were replaced. The new steam generators have stainless steel support plates and more corrosion resistant tubing (thermally treated Alloy 600). 


\subsection{Doel Unit 2}

A $510 \ell /$ min (135 gpm) leak developed in Steam Generator B at Doel Unit 2 (Antwerp, Belgium) on June 25, 1979 (USNRC 1980). The degradation mechanism, size, and location of the rupture are discussed in Section 4.3.1. The plant transient, operator actions, radiation release, and remedial actions are discussed in Sections 4.3.2 through 4.3.5, respectively.

\subsubsection{Cause of the Tube Rupture}

The Doel rupture was caused by PWSCC in the U-bend region of a Westinghouse Model 44 RSG due to excessive residual stresses caused by ovalization of the tubing during fabrication. Visual and video examination revealed a relatively long axial crack located at the top of the U-bend of the tube in Row 1, Column 24. Row 1 is the innermost row of tubes in the tube bundle. Bending of small radius U-bends causes their cross section to become oval and, therefore, the Row 1 and 2 tubes in the Westinghouse RSGs were bent using an internal ball mandrel to limit the degree of ovalization. The amount of ovalization in the inner row tubes in both steam generators was estimated by pushing various size ball bearings through the tubes. Twenty-four tubes in the B and 50 tubes in the A steam generator had minimum inside diameters less than $18.21 \mathrm{~mm}(0.717 \mathrm{in}$.) as compared with a nominal inside diameter of $19.69 \mathrm{~mm}$ (0.775 in.). This was much more ovalization than expected and suggested improper fabrication practices (USNRC 1980).

\subsubsection{Plant Transient}

The Doel rupture occurred while the plant was being heated to normal operating temperature and pressure and the reactor was not critical. The first indication of a leak was a rapid decrease of the primary system pressure $(0.19 \mathrm{MPa} / \mathrm{min})$. A second charging pump was manually started at 1.8 minutes, the chemical and volume control system let down line was isolated and the pressurizer heaters turned off at 2.4 minutes, and the pressurizer relief line was isolated at 4.6 minutes. At 9.4 minutes, a rapid increase in the defective steam generator water level was noted and the damaged steam generator was isolated. Then the third charging pump was started and the suction for all the charging pumps aligned to the reactor water storage tank at about 10 to 15 minutes and the main coolant pump in the loop with the defective steam generator was shut off at 17.4 minutes. Despite these efforts to control the primary system pressure and pressurizer level, automatic high pressure safety injection (along with diesel generator startup and containment isolation) began at about 19.2 minutes.

The high head safety injection pumps caused the primary system pressure to rapidly increase. Normal pressurizer spray was initiated at 28 minutes in an attempt to decrease the primary system pressure, however, this caused the pressurizer to become filled with water. The auxiliary feedwater flow to both steam generators automatically started at 41 minutes and then the flow to the defective steam generator was stopped at 50 minutes. This helped cool the plant and lower the primary system pressure. Depressurization of the primary coolant system began at 68 to 88 minutes when the safety injection pumps were shut off and the isolation valves in the letdown line opened. The residual heat removal system began operation at 3 hours, 15 minutes.

\subsubsection{Operator Actions}

The operators were generally successful in keeping a sufficiently high degree of subcooling in the primary system by shutting down the loop B main coolant pump (a source of heat) and controlling the pressure. Also, the secondary side of the defective steam generator was isolated early in the transient and the setpoints for the atmospheric dump valves were increased to their maximum value to prevent the escape of radioactive fluid. The reactor coolant system was cooled and depressurized fairly rapidly. 


\subsubsection{Environmental Impact}

There were no radioactive releases.

\subsubsection{Remedial Actions}

The ruptured tube, the tubes immediately surrounding the ruptured tube, and all tubes with an inside diameter less than $18.21 \mathrm{~mm}(0.7169$ in.) were plugged.

\subsection{Prairie Island Unit 1}

A $1,270 \mathrm{l} / \mathrm{min}$ (336 gpm) leak developed in Steam Generator $A$ at Prairie Island Unit 1 on October 2, 1979 (USNRC 1980). The degradation mechanism, size and location of the rupture, and the results of previous and subsequent steam generator inspections are discussed in Section 4.4.1. The plant transient, operator actions, radiation release, and remedial actions are discussed in Sections 4.4.2 through 4.4 .5 , respectively.

\subsubsection{Cause of the Tube Rupture}

The Prairie Island tube rupture was caused by loose parts wear. A steel coil spring $216 \mathrm{~mm}$ (8.5 in.) long, $32 \mathrm{~mm}$ (1.25 in.) in diameter, and made with $2.4 \mathrm{~mm}(0.095 \mathrm{in}$.) wire was found on the tubesheet next to the ruptured tube. One end of the spring was wedged between the tubesheet and a flow blocking device. The wear pattern on the tubesheet indicated that the spring had moved back and forth during operation. The spring was apparently part of some sludge lancing equipment left in the steam generator during an outage prior to installation of the flow blocking device in March of 1976.

The rupture occurred on the hot leg side of the tube at Row 4, Column 1, about $76 \mathrm{~mm}$ (3 in.) above the tubesheet. The rupture was a "fish mouth" opening about $38 \mathrm{~mm}$ (1.5 in.) long with a maximum width of about $13 \mathrm{~mm}(0.5 \mathrm{in}$.). The rupture edges were worn to a "knife edge," indicating a significant and relatively uniform reduction in the tubing wall thickness before ductile failure. The adjacent tubes also showed signs of wear on the tube bundle outer surfaces at about the same elevation.

\subsubsection{Plant Transient}

The Prairie Island rupture occurred while the plant was operating at full power. Again, the air ejector high-radiation alarm was the first indication of the rupture. This was followed by alarms indicating that the pressurizer level and pressure were rapidly dropping, at which point the operators apparently suspected that a steam generator was leaking (USNRC 1980). The operators initiated a load reduction ( $10 \%$ total) at about 7 minutes and started the second and third changing pumps at 9 and 10 minutes, however, an automatic reactor scram on low pressure occurred at 10 minutes, 9 seconds, and the atmospheric dump valves on the defective steam generator lifted for 1 to 2 seconds.

Automatic safety injection on low pressure resulted at 10 minutes, 14 seconds, and the primary system pressure was driven back up to about $13.8 \mathrm{MPa}(2,000 \mathrm{psi})$ from $12.5 \mathrm{MPa}$ $(1,815$ psi) over the next 12 minutes. The reactor coolant pumps were manually tripped at 12 and 13 minutes and the primary system cooled using natural circulation flow for most of the transient. The main steam isolation valve on the defective steam generator was closed at 27 minutes and one safety injection pump was stopped at 42 minutes.

Once the primary system pressure had stabilized at about $13.8 \mathrm{MPa}(2,000 \mathrm{psi})$, a pressurizer power operated relief valve was used intermittently (beginning at 43 minutes) to reduce the pressure in the primary system because normal pressurizer spray was not available because the primary coolant pumps were tripped. Eventually, the operators closed the power operated relief valve, secured the remaining 
safety injection pump (at 52 minutes), and continued cooling the primary system using natural circulation flow and steaming from the undamaged steam generator. The reactor coolant pump in loop B with the intact steam generator was restarted at 7 hours and the cooldown continued (restart procedures were not immediately available). The residual heat removal system began operation at 16 hours, 26 minutes.

\subsubsection{Operator Actions}

The Prairie Island tube rupture resulted in a very rapid drop in the primary system pressure and the pressurizer water level, and an automatic scram and safety injection system actuation. The size of the rupture did not allow time for the operators to maintain the pressurizer level by isolating the reactor coolant system let down flow and increasing charging flow. However, they could have started the second and third charging pumps and started decreasing the reactor power sooner. In any event, the rapidly decreasing pressure would probably still have caused the automatic reactor and turbine trip immediately followed by the safety injection, which, of course, results in a rapidly increasing primary system pressure and more flow out the rupture. As required by NRC Bulletin 79-06C, the operator tripped both reactor coolant pumps upon actuation of the safety injection system and, as a result, lost pressurizer spray capability. This then lead to the decision to open the pressurizer power operated relief valve, which was successful in bringing the reactor coolant system pressure down to $6.3 \mathrm{MPa}(910 \mathrm{psi})$ at 61 minutes, which was the pressure of the defective steam generator secondary side at that point in the transient. Therefore, the primary-to-secondary leakage was terminated relatively early. However, the reactor coolant system cooldown took a long time, in part, because the reactor coolant pump on the intact loop was turned off for a long time and the reactor was cooled only by natural circulation flow. The RHR system was not in operation until 16 hours, 26 minutes after the tube rupture. Also, it took 27 minutes to isolate the damaged steam generator.

\subsubsection{Environmental Impact}

About $30 \mathrm{Ci}$ of $\mathrm{Xe}-133$ equivalent of noble gases and about $1 \mu \mathrm{Ci}$ of $\mathrm{I}-131$ equivalent of iodine isotopes were released. The major sources of airborne releases were the brief release of steam from the defective steam generator through the atmospheric dump valves and the vent on the auxiliary feedwater turbine. Some radioactivity was also released through the air ejector. The off site doses did not exceed 10 CFR Part 100 limits.

\subsubsection{Remedial Actions}

The ruptured tube and four adjacent tubes that showed signs of wear were plugged. The outer peripheral area of the tube bundle and the open flow lane of both steam generators were inspected and additional pieces of the sludge lancing equipment were found and removed. About $12 \%$ of the tubes were inspected with eddy-current equipment including all the tubes on the periphery of the tube bundles. Also, several procedural and equipment changes were identified.

\subsection{Ginna Unit 1}

A $2,900 \mathrm{l} / \mathrm{min}(760 \mathrm{gpm})$ leak developed in Steam Generator B at Ginna on January 25, 1982 (USNRC 1982b, USNRC :1982c). The degradation mechanism, size, and location of the rupture, and the results of previous and subsequent steam generator inspections are discussed in Section 4.5.1. The plant transient, operator actions, radiation release, and remedial actions are discussed in Sections 4.5.2 through 4.5 .5 , respectively. 


\subsubsection{Cause of the Tube Rupture}

The Ginna rupture was caused by loose parts wear (USNRC 1982c). Foreign objects including various size pieces of carbon steel plate and strip fell onto the tubesheet outside the periphery of the tube bundle during steam generator modifications in 1975 and later. The largest piece of debris was a carbon steel plate $12.7 \mathrm{~mm}$ (0.5 in.) thick by $106 \mathrm{~mm}$ (4.18 in.) wide by 160 $\mathrm{mm}$ (6.31 in.) long. It was apparently part of a downcomer flow resistance plate that had been cut out and mostly removed in 1975 . This plate (along with some of the other debris) impacted on some of the exposed peripheral (outermost) tubes during subsequent operation and caused defects at four general locations around the tube bundle, welded lug locations (wedge areas) 2, 4, and 6, and near the tube at Row 39, Column 70. A hot leg tubesheet map is shown in Figure 28, which identifies the locations of the plugged tubes before the rupture event of January 25, 1982 (USNRC 1982c). Flow model testing by Westinghouse confirmed that a steel plate of that size would be mobile in the peripheral region, tending to linger at the wedge areas since those areas tend to be areas of relatively low flow. The initial plugging activity occurred first at the Row 39, Column 70 vicinity in February 1976, and then shifted to wedge areas 2 and 6 during May 1976, and then shifted to wedge area 4 (the rupture location) during July 1977 and thereafter (USNRC 1982c).

Although the damaged tubes on the tube bundle periphery were plugged as a result of eddycurrent inspection indications and/or small leaks, the debris, in conjunction with the hydraulic and pressure loadings, continued to damage the plugged tubes and eventually caused the tubes to collapse and in some cases to become completely severed near the top of the tubesheet. The severed tubes were free to swing over about a $1,270 \mathrm{~mm}$ (50 in.) span, pivoting at the first support plate, and cause fretting type wear of the adjacent (inboard) tubes. These tubes, in turn, were plugged as a result of eddy-current indications or leaks, however, damage continued until they also became severed. Eventually, an unplugged tube in Row 42, Column 55 in wedge area 4 (third row in from the outside) was subjected to fretting wear over about $150 \mathrm{~mm}$ (6 in.) of length and burst.

Inspection of the wedge area 4 region found that a number of tubes had been severed about $50 \mathrm{~mm}$ ( 2 in.) above the top of the tubesheet and two tubes (R45-C54 and R44-C56) were missing, that is, they had severed at two locations, just above the tubesheet and just below the first tube support plate. The two tubes immediately outboard of the ruptured tube were severed just above the tubesheet. The ruptured tube had two long axial wear scars, one of which reduced the original $1.27 \mathrm{~mm}(0.05 \mathrm{in}$.) wall thickness to approximately $0.20 \mathrm{~mm}(0.008$ in.) for approximately $100 \mathrm{~mm}$ (4 in.) in length (an $84 \%$ reduction in wall thickness). The total length of the wear scar was about $150 \mathrm{~mm}$ (6 in.). The burst was ductile in nature and a relatively long "fish mouth" type opening as shown in Figure 29. Five other tubes (immediately outboard from the ruptured tube) showed wear areas similar to those on the burst tube. The severed tube fracture surfaces showed evidence of wear and then fatigue and tearing. Also, evidence of extensive cold work was found on the collapsed surfaces. In summary, the peripheral tube damage mechanisms were primarily mechanical and included impact, collapse, fatigue, fretting type wear, abrasion, and ductile overload and tearing.

The wear on the ruptured tube at Row 42 , Column 55 produced a detectable eddy-current indication in April 1981, which was not interpreted at the time as a pluggable indication. In fact, prior to the rupture, the eddy-current indications from the outermost tubes were generally interpreted as inside diameter indications or bulges even though a tube pulled from the outer periphery in 1978 revealed no evidence of 


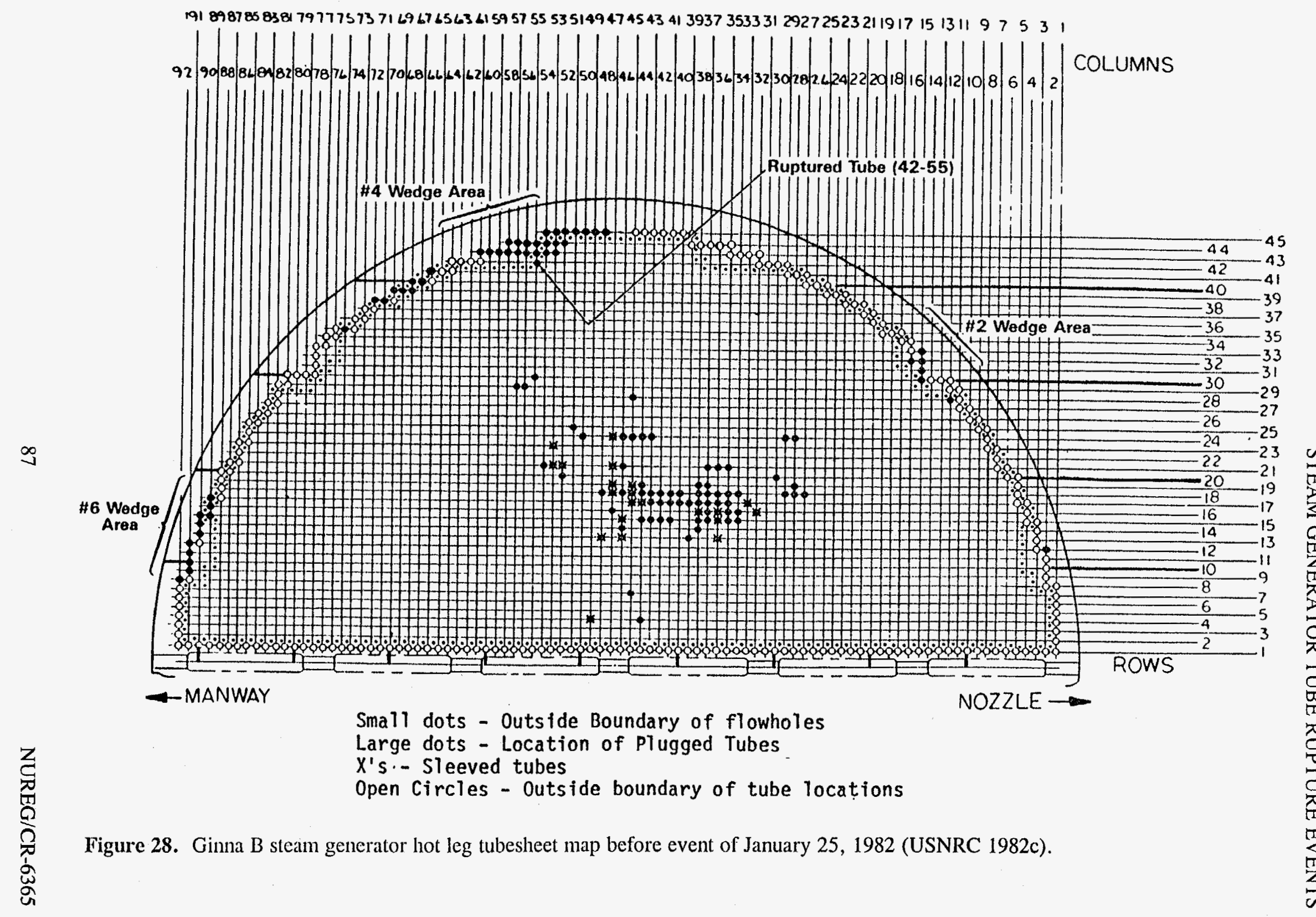

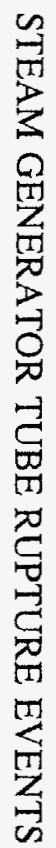




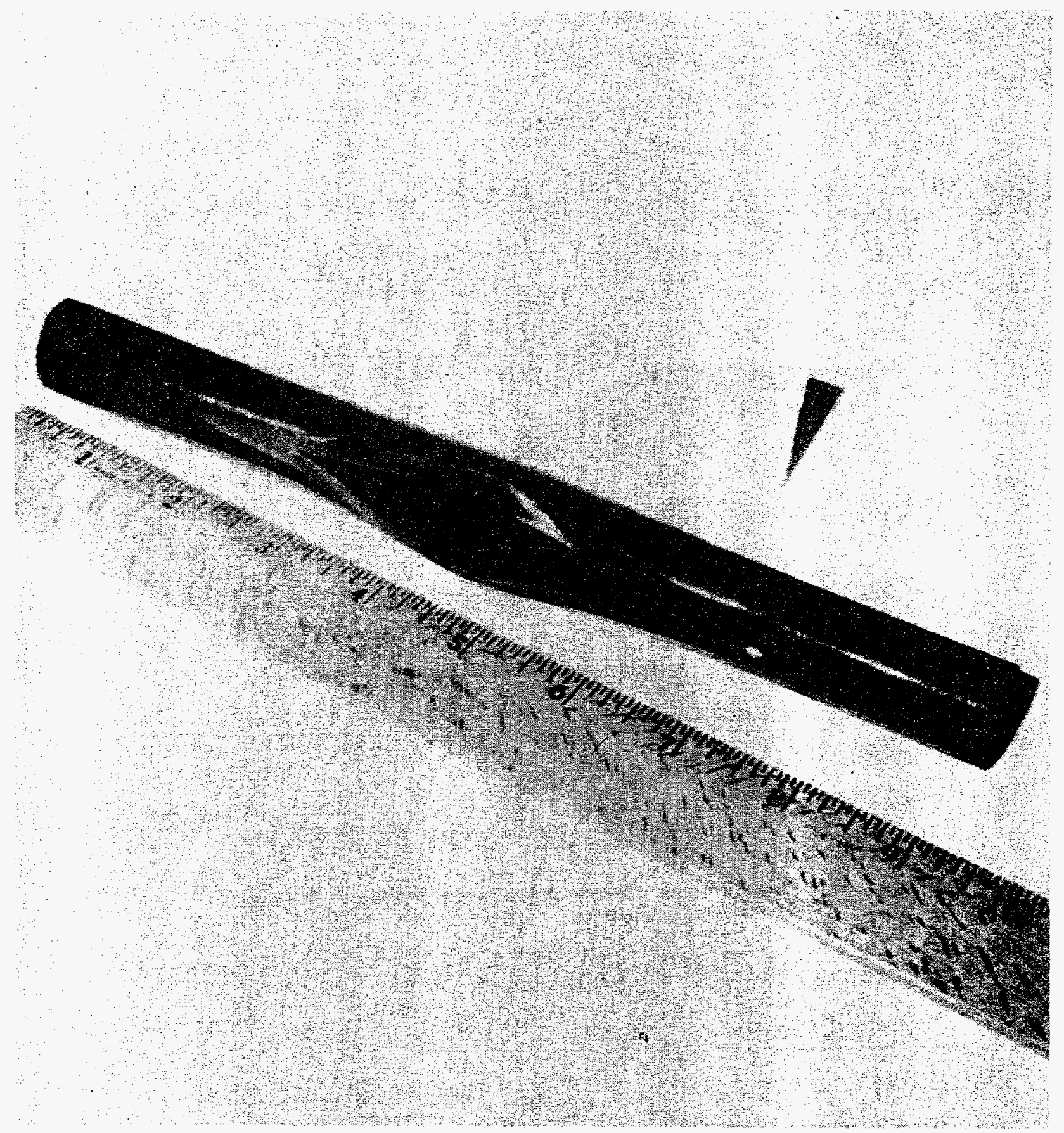

Figure 29. Photograph of segment of ruptured tube (R42-C55) removed from the Ginna steam generator (tubesheet to the right) (USNRC 1982c). 
inside diameter cracking but had shallow peenlike marks and dings, shallow wall thinning on the outside, and local distortions including a bulge. The root cause analyses of the loose parts damage from 1976 to the time of the tube rupture were inadequate.

\subsubsection{Plant Transient}

The Ginna rupture occurred while the plant was operating at full power. A schematic diagram of the Ginna plant is shown in Figure 30 (USNRC 1982c). The air ejector radiation monitor, the pressurizer level and pressure alarms, and the B steam generator level and steam/feed flow mismatch alarms indicated to the operators the existence of a large leak in the B steam generator (at 9:25 am). The operators began a power reduction at 1.5 minutes along with an increase in the number and speed of the operating charging pumps (the third charging pump was started at 2.5 minutes). Also at 2 minutes, the eight main steam dump valves opened automatically in response to a valid error signal from the reactor coolant system temperature and four valves closed automatically at 3 minutes. At 3 minutes there was an automatic reactor scram (at $12.91 \mathrm{MPa}$ or $1,873 \mathrm{psig}$ ) and actuation of all three safety injection pumps (at $11.88 \mathrm{MPa}$ or $1,723 \mathrm{psig}$ ) on low primary system pressure. This was followed by automatic containment isolation, main turbine trip (on reactor trip), automatic start of the auxiliary feed pumps, main feedwater isolation and trip of the charging pumps. At 4 minutes, both reactor coolant pumps were manually tripped as required, the pressurizer was almost empty, and the steam supply valves to the turbine-driven auxiliary feedwater pump opened automatically because of low water levels in the steam generators. At 5 minutes, the remaining four main steam dump valves closed automatically and the initial reactor coolant system depressurization stopped at about 8.27 MPa (1,200 psig), apparently due to the establishment of saturation conditions in the reactor vessel upper head along with the effects of the safety injection. A steam bubble probably formed in the upper head at this time. Plots of the reactor coolant system pressure, the pressurizer level, and the steam generator secondary side pressures are presented in Figure 31 along with the times when (a) the safety injection (SI), charging, and reactor coolant pumps (RCPs) were on; (b) the steam generators were dumping steam to atmosphere; and (c) the pressurizer power operated relief valve (PORV) was open.

At 7 minutes, the B steam generator motor driven auxiliary feedwater pump and steam supply to the turbine-driven pump were secured. At 15 minutes, the B steam generator main steam isolation valve was closed and the defective steam generator isolated. Plant cooldown was continuing by natural circulation in the A loop and by dumping steam from the $\mathrm{A}$ steam generator to the main condenser. However, the water level on the B steam generator continued to rise due to the flow through the ruptured tube. At 30 minutes, the level indicator on the B steam generator went off-scale high and the steam line started to fill with water. At 32 minutes, the safety injection actuation circuitry was reset to allow resetting the containment isolation system and get instrument air to the air-operated valves inside containment. At 42 minutes, the operators attempted to equalize the pressure differential between the reactor coolant system and the secondary side of the B steam generator by opening a pressurizer PORV to stop the break flow. On the fourth cycle (at 44 minutes) the PORV stuck open. The operator then closed the block valve to prevent further loss of reactor coolant through the open PORV and the reactor coolant system pressure increased again. During cycling of the PORV, steam bubbles formed in the reactor vessel upper head and the top of the tubes in the $B$ steam generator and the pressurizer level rose rapidly. However, natural circulation in the A loop and core cooling continued despite the steam bubbles. 
STEAM GENERATOR TUBE RUPTURE EVENTS

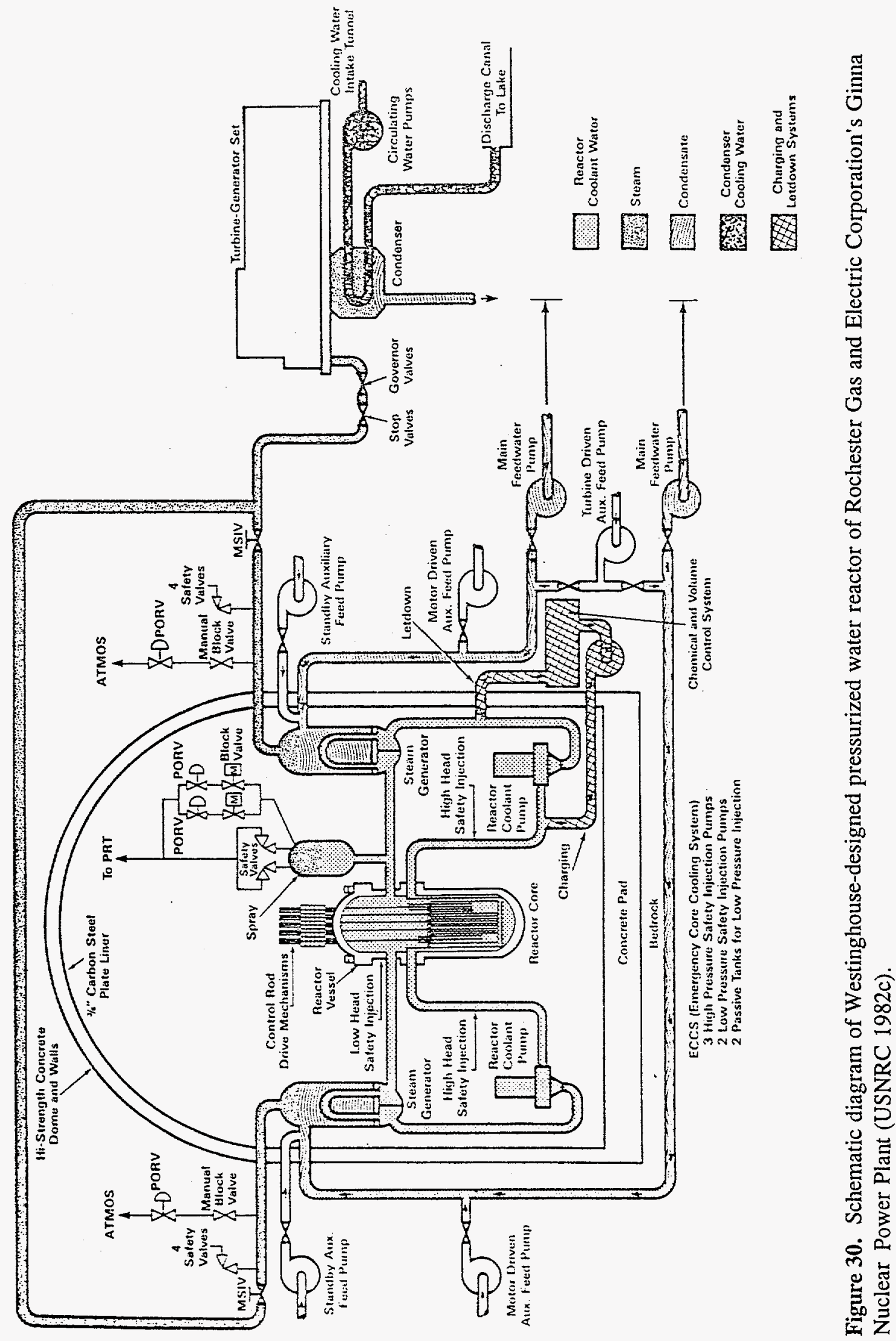


PRESSURIZER LEVEL (\%)
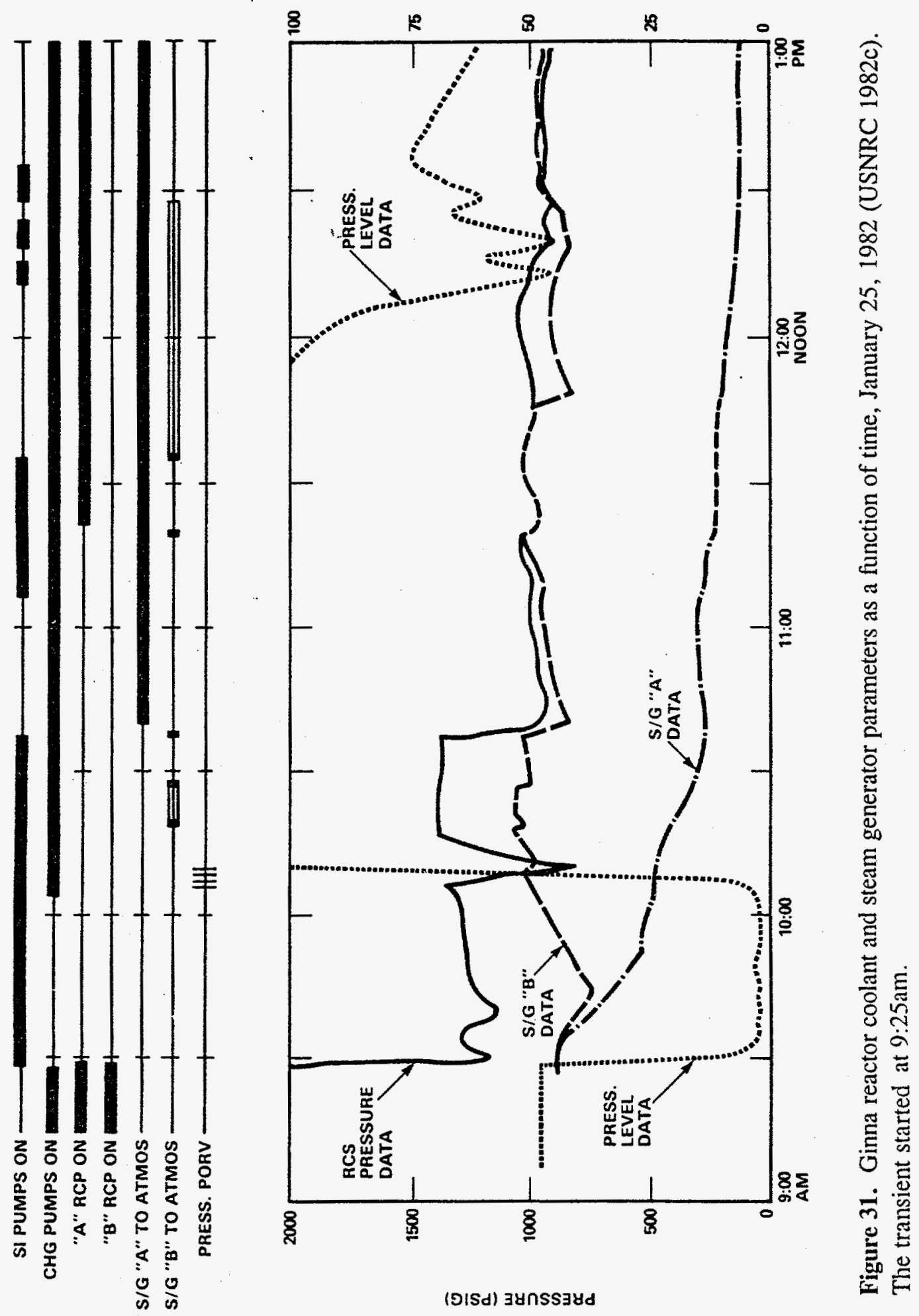
A B steam generator code safety valve lifted (at $1,085 \mathrm{psig}$ ) and then closed at 54 minutes and again at 63 minutes because the safety injection pumps were maintaining the primary system pressure above the B steam generator secondary. pressure, and reactor coolant continued to flow out the tube rupture. At 1 hour and 13 minutes, safety injection was terminated to prevent further steam generator safety valve lifts. At 1 hour and 15 minutes the condensate system was secured to prevent further radioactive contamination of the condensate system. This made the main condenser unavailable for further dumping of steam. To continue the plant cooldown, the operators relieved steam from the A steam generator to atmosphere using its PORV.

At 1 hour and 17 minutes, the pressurizer heaters were re-energized to help reestablish a steam bubble in the pressurizer (they had tripped at 3 minutes due to low level). At 1 hour, 27 minutes, the rupture disc on the pressurizer relief tank bursts (the letdown line was the major contributor). At 1 hour, 42 minutes, one safety injection pump was started to provide a buffer for starting the loop A reactor coolant pump. As a consequence, the B steam generator safety valve lifted and closed at 1 hour, 54 minutes, releasing water rather than steam. At 1 hour, 56 minutes, the loop A reactor coolant pump was started, which accelerated the cooldown and collapsed any remaining steam bubbles in the upper head and $B$ steam generator. At 2 hours, 12 minutes, a fifth lift of the B steam generator safety valve occurred and the safety injection pump was stopped. Although the safety valve on the B steam generator closed, it continued to leak water at about $380 \mathrm{\ell} / \mathrm{min}(100 \mathrm{gpm})$.

At 2 hours, 27 minutes, a steam bubble was reestablished in the pressurizer and the level returned on scale and at 2 hours, 47 minutes, the operators switched from continuous to intermittent use of the safety injection pump to control the pressurizer level. The reactor coolant system and B steam generator secondary side pressure were equalized at 3 hours, 2 minutes. Thereafter, the operators maintained the reactor coolant pressure about 25 psi below the B steam generator secondary pressure to promote backflow. At 9 hours, 15 minutes, the B steam generator water level returned on scale. At 21 hours, 35 minutes, the residual heat removal system was placed in operation.

\subsubsection{Operator Actions}

The operators quickly determined that the plant had experienced a major steam generator tube rupture. The operators confirmed that the fault was in the B steam generator by performing a radiation survey of the main steam line and isolated the B steam generator at 15 minutes. The operators efforts to cool the primary system down were not quite as efficient. They tripped the reactor coolant pumps at 4 minutes as required but did not get the $A$ loop reactor coolant pump back until almost 2 hours had passed. Therefore, most of the heat transfer during the first 2 hours was by natural circulation in the A loop, a slow process. (Their tube rupture procedure required normal pressurizer pressure control before restarting the reactor coolant pumps.) Also, it took the operators over 3 hours to get the primary system pressure below the pressure in the defected steam generator secondary side. This was, in part, because the safety injection pumps were operating too much of the time and the operators had lost control of the pressurizer. However, the operators recognized that there was a steam bubble in the upper head and monitored its existence and further verified core subcooling. Also, "during plant conditions of a pressurizer PORV stuck open, both pressurizer relief block valves shut, a steam bubble in the reactor vessel upper head region, a liquid-filled pressurizer and a faulted steam generator code safety valve periodically relieving reactor coolant to the environment, the operators recognized the need to cooldown the reactor vessel head, collapse the steam bubble and then depressurize the reactor coolant system 
to limit the radioactive material releases to the environment" (USNRC 1982b).

\subsubsection{Environmental Impact}

It was estimated that a total of about 90 curies of noble gases were released, mostly from the steam jet-air ejector. About 0.4 curies of dose-equivalent I-131 (a total of about 5 curies of all isotopes of iodine), and about 1.3 curies of cobalt, molybdenum, barium, and cesium were estimated to have been released, mostly from openings of the faulted steam generator code safety valve. About 25 curies of tritium may have been released, some from the air ejector and trace amounts from the safety valve openings (USNRC 1982b).

Since the reactor coolant iodine inventory prior to the event was only about $2 \%$ of the Technical Specification limit, the iodine releases were well below those calculated for the design-basis steam generator tube rupture. Airborne radionuclide concentrations offsite resulted in doses far less than 10CFR Part 100 guidelines.

\subsubsection{Remedial Actions}

Corrective measures at Ginna included removing the debris and 24 "structurally degraded" tubes, upgrading the quality control practices used for maintenance work, and installation of a loose parts monitoring system.

In response to the Ginna and Prairie Island Unit 1 tube ruptures, the USNRC issued Information Notice No. 83-24, "Loose Parts in the Secondary Side of Steam Generators at Pressurized Water Reactors." This notice warned the utilities that loose parts had been implicated in two of the four rupture events to date and encouraged them to keep foreign material out of their steam generators. Generic Letter 85-02, "Staff Recommended Actions Stemming from NRC Integrated Program for Resolution of Unresolved Safety Issues Regarding Steam Generator Tube Integ- rity," requested that the USNRCs PWR licensees perform visual inspections on their steam generator secondary sides in the tubesheet area (around the outside of the tube bundle and in the tube lane) to identify and remove any foreign material and identify any tube damage. Information Notice No. 88-06, "Foreign Objects in Steam Generators, " again warned the utilities about this problem.

\subsection{Fort Calhoun}

A $425 \mathrm{l} / \mathrm{min}$ (112 gpm) leak developed in Steam Generator B at Fort Calhoun on May 16, 1984 (Jones 1984, Stoller 1984, Kusek 1984). The degradation mechanism, size and location of the rupture, and the results of previous and subsequent steam generator inspections are discussed in Section 4.6.1. The plant transient, operator actions, radiation release, and remedial actions are discussed in Sections 4.6.2 through 4.6.5.

\subsubsection{Cause of the Tube Rupture}

The Fort Calhoun rupture was caused by ODSCC in the U-bend region of a Combustion Engineering RSG. The rupture was located between the scallop bars in the vertical tube support (batwing) on the hot leg side of the steam generator, in a tube in Row 84, Column 29, which is the second peripheral row from the outside. A sketch of the Combustion Engineering RSG AVB arrangement is shown in Figure 13. The main rupture was centered on the righthand vertical tube support bar (the scallop bars are not shown in Figure 13, but are perpendicular to the tube support bars). Two cracks were located in tube R84-C29. The first was a $32 \mathrm{~mm}$ (1.25 in.) long axial crack leading to a small fishmouth type rupture and the second crack was a series of small fissures about $6 \mathrm{~mm}$ $(0.25$ in.) in length which were oriented about $45^{\circ}$ to the axis of the tube. The second crack was about $6 \mathrm{~mm}$ from the hot leg end of the small fishmouth rupture. The fishmouth rupture 
faced downward ( $6 o^{\prime}$ clock position) and the tube was ovalized in the region of the support bars with the major axis (6-12 o'clock) elongated by 1.2 to $3.1 \mathrm{~mm}(0.05$ to $0.12 \mathrm{in}$.) whereas the minor axis (3-9 o'clock) was compressed by 1.1 to $1.8 \mathrm{~mm}(0.043$ to $0.71 \mathrm{in}$.).

A metallographic examination of the ruptured tube revealed the presence of IGSCC across approximately $95 \%$ of the wall thickness. The remaining $5 \%$ of the wall thickness near the inside surface failed by ductile tearing. "The fishmouth fracture was most probably formed from a series of essentially throughwall axially oriented intergranular penetrations, followed by ductile tearing of the material between the penetrations and the remaining tube wall thickness" (Jones 1984). There was no evidence of IGA or wall thinning due to corrosion or plastic deformation. The R84-C29 material had a typical mill-annealed Alloy 600 microstructure and was not sensitized. Measurements of the $\mathrm{pH}$ of the residual deposits near the rupture suggested a caustic environment at some locations.

The Fort Calhoun ODSCC rupture was probably caused by excessive stress due to corrosion product build-up between the tube and the carbon steel vertical supports and the presence of a caustic environment. The corrosion of the vertical tube support bars apparently caused the tube deformation (ovalization) discussed above. "A caustic environment may have occurred in steam blanketed areas at Fort Calhoun as a result of periodic low level condenser in leakage. When concentrated, the cooling water (Missouri River) tends to become alkaline, thereby producing a caustic condition. Caustic SCC has been produced in the laboratory in Alloy 600 at strain levels as low as $0.5 \%$ (Jones 1984).
Tube R84-C29 (the ruptured tube) had been included in the March 1984 steam generator inspection program. Re-evaluation of the data tape from that inspection indicated a $99 \%$ throughwall defect at the rupture location and a $50 \%$ throughwall defect $6 \mathrm{~mm}$ along the tube. These indications were missed during the initial analysis of the data due to human error (Jones 1984). Subsequent multi-frequency eddy-current testing of all the accessible tubes in both steam generators at Fort Calhoun identified three additional tubes with eddy-current indications greater than $40 \%$ throughwall. Tube R18-C37 showed evidence of wastage several inches above the tubesheet, Tube R85-C64 had an ODSCC indication just below the 7th hot leg tube support grid, and Tube R86-L85 had an indication at a vertical tube support bar (batwing).

\subsubsection{Plant Transient}

The Fort Calhoun tube rupture occurred during plant startup after a refueling outage, while the reactor coolant system was being pressurized for a leak test. The reactor coolant system was at a pressure of about $6 \mathrm{MPa}(880 \mathrm{psia})$ and a pressurizer fill was in progress using one charging pump with suction from the safety injection refueling water tank and minimum letdown, when the operators noted that the pressurizer level was no longer increasing and the pressurizer pressure was slowly decreasing. They started the other two charging pumps at 4:18 pm (start of transient) and the pressurizer pressure and level started to slowly increase. At 18 minutes, the operators switched the charging pump suction to the volume control tank and the charging flow increased from 190 to $450 \mathrm{l} / \mathrm{min}$. (50 to $120 \mathrm{gpm}$ ) (inadequate net pump suction head with the safety injection refueling water tank level) and the pressurizer pressure increased rapidly until it reached a peak value of about $12.8 \mathrm{MPa}(1,850 \mathrm{psia})$ at 27 minutes. 
At 24 minutes, the operators isolated the letdown line and noted that the water level in the B steam generator had increased above the setpoint. The operators closed the block valve on the auxiliary feedwater line thinking that the level increase was due to leakage through the auxiliary feedline valve $\mathrm{HCV}-1106$. At 27 minutes, the water level in the volume control tank approached $0 \%$ despite blended makeup and the operators secured two of the charging pumps. A few minutes later the pressurizer pressure began dropping rapidly. At 32 minutes, the operators noted a continuing increase in the $B$ steam generator water level and the auxiliary feedwater pump which usually feeds the B steam generator was secured. At 36 minutes, the pressurizer pressure was down to $3.86 \mathrm{MPa}$ (560 psia) and the reactor coolant system was water solid. At 40 minutes, the main steam line isolation valve from the B steam generator was closed, thereby isolating the defective steam generator. At 41 minutes, cooldown of the reactor coolant system was initiated using the A steam generator and its atmospheric dump valve. The reactor coolant pumps were tripped at 42 and 43 minutes and the system cooled thereafter with natural circulation in the A loop. Shutdown cooling was initiated at 3 hours, 47 minutes.

\subsubsection{Operator Actions}

The operators responded to the decreasing pressurizer level by adding more charging pumps and closing the letdown line, which drove the pressure and leak rate up. It appears that it took the operators more than 32 minutes to recognize that a tube rupture had occurred in the B steam generator, and about 40 minutes to isolate the $B$ steam generator and begin a cooldown of the reactor coolant system. The operator actions after about 40 minutes were effective, however, the reactor coolant system remained above the defective steam generator secondary pressure during most of the transient and the defective steam generator overfilled.

\subsubsection{Environmental Impact}

The Fort Calhoun tube rupture resulted in a primary system depressurization with no release of radioactivity into the environment.

\subsubsection{Remedial Actions}

Several measures were taken to provide additional assurance that steam generator leaks will be detected early. These included improvements in the laboratory capabilities (faster and more accurate analysis of the coolant samples) and more frequent sampling. Also, the steam generator tube rupture emergency procedures were reviewed and minor improvements made and the operators subjected to refresher training. Also, efforts were made to improve condenser integrity and the secondary side chemistry specifications were revised (lowered) to bring them in line with Combustion Engineering recommendations. And finally, all tubes with ODSCC indications in the hot leg vertical support regions were plugged, regardless of the size of the indication.

\subsection{North Anna Unit 1}

A $2410 \mathrm{l} / \mathrm{min}$ (637 gpm) leak developed in Steam Generator C at North Anna Unit 1 on July 15, 1987 (Bowling 1988). The degradation mechanism, size and location of the failure, and the results of previous and subsequent steam generator inspections are discussed in Section 4.7.1. The plant transient, operator actions, radiation release, and remedial actions are discussed in Sections 4.7.2 through 4.7.5, respectively.

\subsubsection{Cause of the Tube Rupture}

The North Anna Unit 1 failure was caused by high-cycle fatigue, with the following contributing factors (USNRC 1988b):

- The failed tube did not have AVB support. 
- Mild denting had occurred at the top of the tube support plate. This resulted in reduced damping of the tube vibrations, compared to a condition with open support in which sliding results in energy dissipation.

- Unequal insertion of the AVBs in the neighborhood of the failed tube led to locally high flow velocities around the failed tube. The original design called for the AVBs to be installed to at least Row 11, however, some were installed as deep as Row 8 (eight tubes from the center of the U-bends). The failed tube was in Row 9.

- The high flow velocities, combined with the lack of AVB support and the reduced damping at the tube support plate resulted in significant out-of-plane deflections of the Ubend portion of the tube above the uppermost tube support plate.

- The denting introduced a high mean stress in the tube wall. A high mean stress significantly reduces the fatigue strength. In fact, with a high mean stress the fatigue strength can be as low as $27.6 \mathrm{MPa}$ (4 ksi) for Alloy 600 in an AVT environment (Connors et al. 1988).

- The combination of high vibration amplitude and low fatigue strength led to fatigue failure.

The failure consisted of a $360^{\circ}$ throughwall fatigue crack located at the top of the upper-most tube support plate, on the cold leg side of the tube in Row 9, Column 51. There were no signs of stress corrosion cracking at or near the fracture face and no degradation other than denting at the tube support plate elevation. For several days prior to the event, the condenser air ejector radiation monitor alarmed in an erratic manner and grab samples were taken. Analysis of the grab samples performed after the rupture indicated increasing primary-to-secondary leakage over a 24 to 36 hour period before the final failure. This provides a rough estimate of the throughwall crack propagation time around the circumference. The condenser air ejector monitor was declared inoperable before the failure.

The rupture occurred on the cold leg side of the $C$ steam generator where the plant Technical Specifications did not require much inspection. Therefore, the utility had inspected all the tubes on the hot leg side during the last refueling outage, but only about $13 \%$ of the tubes on the cold leg side, and not this particular tube. Subsequent inspection of all the steam generator tubes at North Anna Unit 1 identified a number of tubes with suspect indications (Stoller 1988). The utility eventually plugged 178 tubes due to the 7 th support plate fatigue failure issue (EPRI 1994).

\subsubsection{Plant Transient}

The North Anna rupture occurred shortly after the unit reached full power. The high radiation alarm on the $C$ steam generator main steam line was the first indication of the break (at 6:30 am). At the same time, the pressurizer level and pressure began to rapidly decrease. At 3 minutes, the letdown line was isolated, the charging pump suction was realigned to the reactor water storage tank, and a turbine ramp down was initiated. At 5 minutes, the operators began using the steam generator tube leakage procedure and the reactor was manually tripped with the pressurizer level at about $45 \%$ and the pressurizer pressure at $14.5 \mathrm{MPa}(2,100 \mathrm{psig})$. Twenty seconds later, safety injection began and the auxiliary feedwater pumps started. At 10 minutes, the operators moved to the steam generator tube rupture procedure. At 16 minutes, the shift supervisor had confirmed that the C steam generator was defective and the auxiliary feedwater and main steam line isolation valves on the $C$ steam generator were closed. At 18 minutes, the $C$ steam generator supply to the turbine driven auxiliary feedwater pump was isolated, thereby isolating the $\mathrm{C}$ steam generator. 
At 19 minutes, a rapid cooldown was initiated by dumping steam from the $A$ and $B$ steam generators. This took the pressurizer level off scale low at 20 minutes. At 27 minutes, the pressurizer spray control was at $100 \%$ demand and at 28 minutes, the pressurizer level was on scale and increasing. At 34 minutes, one power operated relief valve on the pressurizer was opened to enhance the depressurization and the $\mathrm{C}$ steam generator level was stable (the primary system pressure and the pressure on the secondary side of the $\mathrm{C}$ steam generator were roughly the same).

At 43 minutes, the $\mathrm{C}$ and $\mathrm{B}$ loop reactor coolant pumps were secured. At 48 minutes, the operators began an orderly cooldown and depressurization of the reactor coolant system to cold shutdown conditions using pumped flow in the A loop and natural circulation heat transfer in the B loop. Thereafter, the pressurizer level was kept between about 30 and $50 \%$ and the defective steam generator level was kept between about 10 and $75 \%$. At 1 hour, 26 minutes, the air ejector discharge line was diverted to containment. The residual heat removal system was placed inservice at 5 hours, 49 minutes. The reactor coolant system pressure, the pressurizer level, and the reactor coolant system temperature during the first 58 minutes of the transient are plotted in Figures 32, 33, and 34 .

\subsubsection{Operator Actions}

The defective steam generator was isolated within 18 minutes and its water level was stabilized at 34 minutes, when the reactor coolant system pressure had been reduced to a value near the pressure on its secondary side. Also, the operators retained control of the pressurizer throughout the transient. The operators did neglect to divert the condenser air ejector discharge to containment until 1 hour, 26 minutes because the air ejector radiation monitor was out of service. However, the overall management of the transient was quite good.

\subsubsection{Environmental Impact}

A total of about 0.16 curies of radioactive material was released, which consisted primarily of gases. There was no detectable increase in the normal background levels at the site boundary. The radioactive material release paths to the environment included the condenser air ejector, which discharged to atmosphere until it was manually diverted to the containment, and the steam driven auxiliary feedwater pump until its steam supply from the defective steam generator was isolated.

\subsubsection{Remedial Actions}

The remedial actions included reducing the local fluid forces in the U-bend region by installing downcomer flow resistance plates, preventive plugging of susceptible tubes, failed tube stabilization, and improved leakage monitoring. The utility identified the importance of diverse and redundant leak detection methods for detecting rapidly propagating cracks as a key lesson learned.

In response to the North Anna failure, the USNRC issued Bulletin 88-02, "Rapidly Propagating Fatigue Cracks in Steam Generator Tubes," to licensees with Westinghouse steam generators with carbon steel support plates (USNRC 1988b). The USNRC asked the utilities to review their most recent steam generator inspection data for evidence of denting at the uppermost tube support plate. If the records were not adequate, additional inspections were to be performed. For plants with no denting, the results of future steam generator inspections were to be reviewed. For plants with denting, an enhanced primary-to-secondary leak rate monitoring program was to be implemented which would assure that the plant power level would be reduced to $50 \%$ power or less at least 5 hours before a tube rupture was predicted to occur. The effectiveness of the program was to be evaluated against the assumed time-dependant leakage curve of Figure 35. Also, a program 


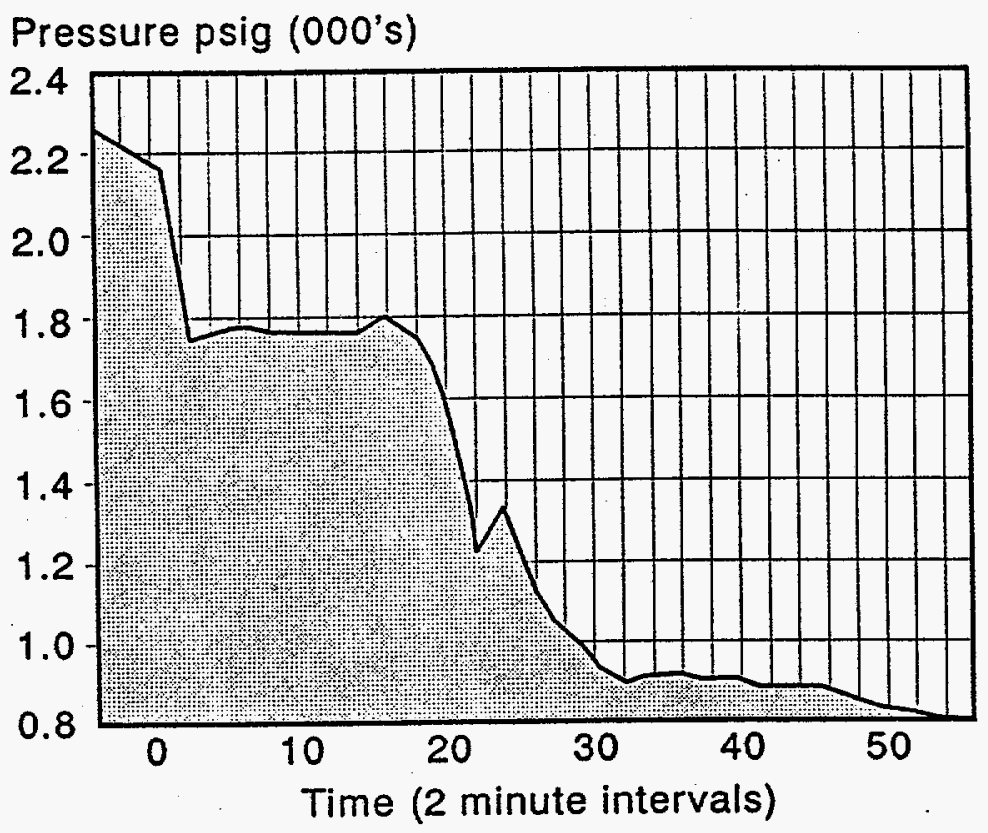

Figure 32. North Anna Unit 1 reactor coolant system pressure versus time during the first 58 minutes of the transient (Bowling 1987). The transient started at 6:30am.

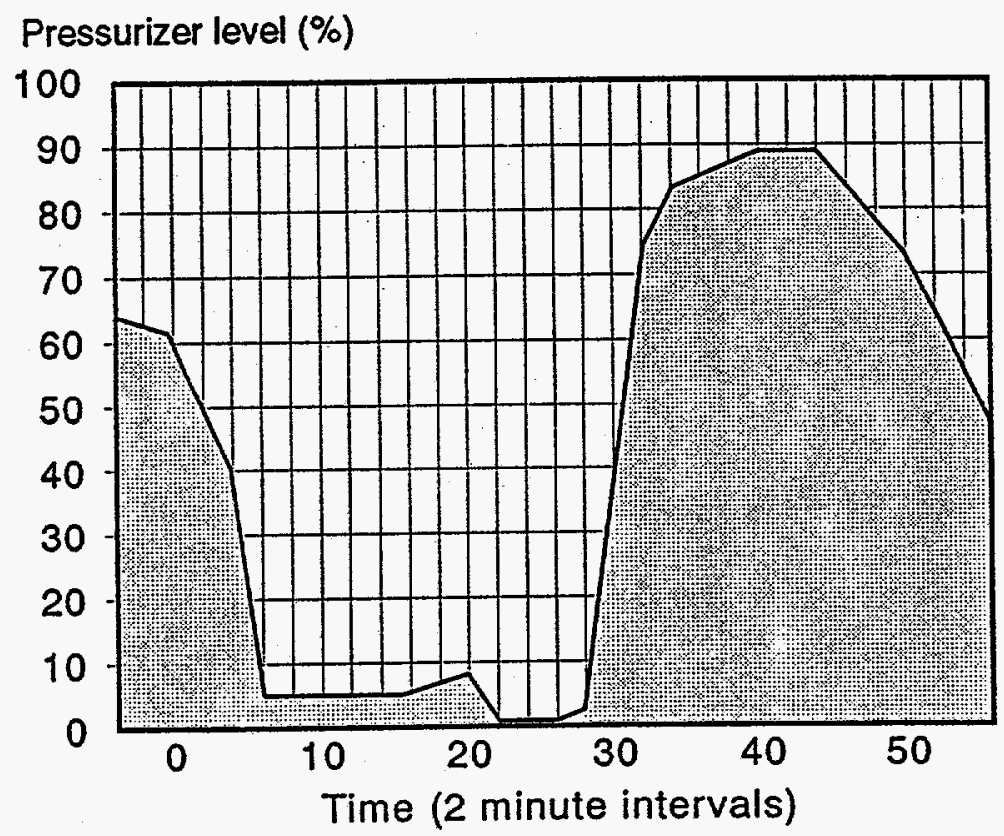

Figure 33. North Anna Unit 1 pressurizer level versus time during the first 58 minutes of the transient (Bowling 1987). The transient started at 6:30am. 


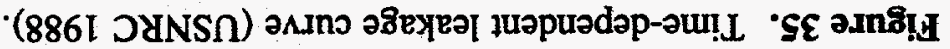
(u!w) ou!!

00090005 000 $000 \varepsilon \quad 0002$ 000 0

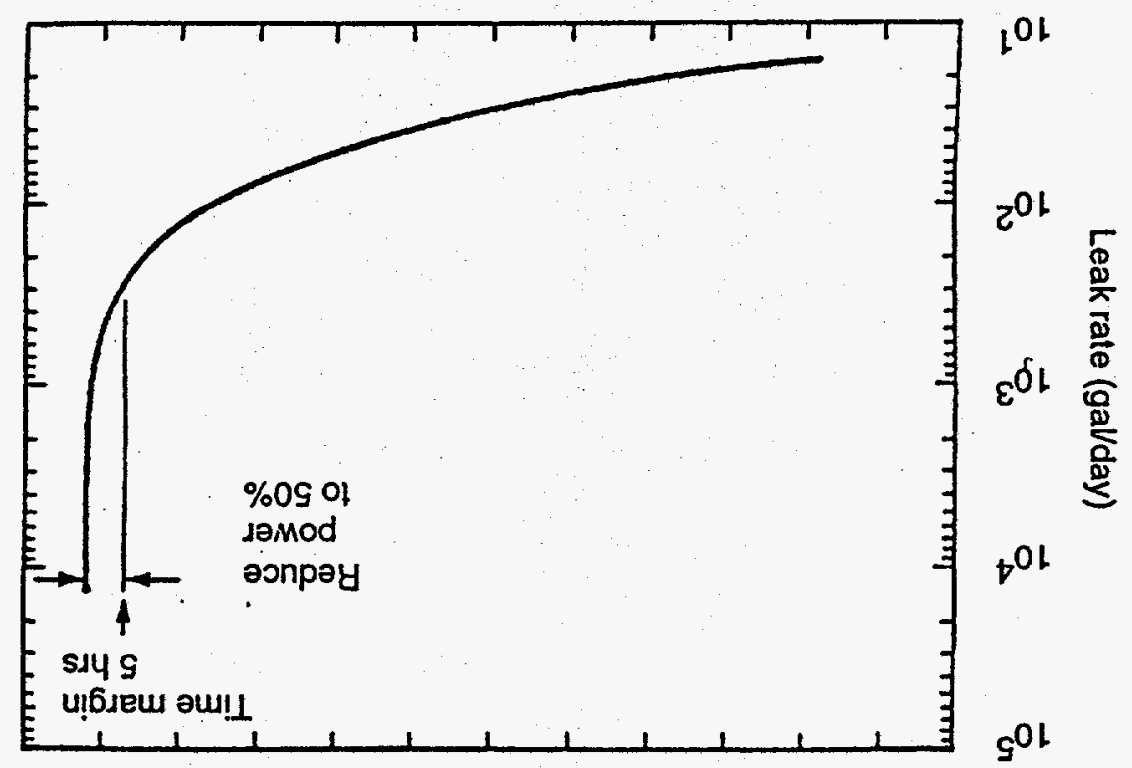

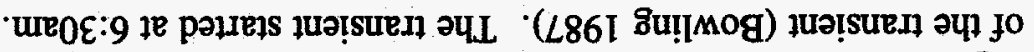

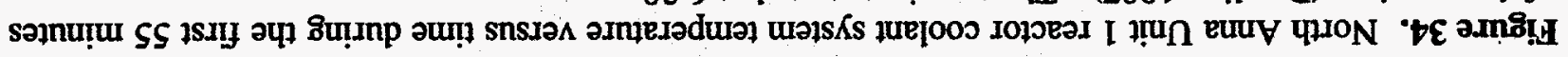

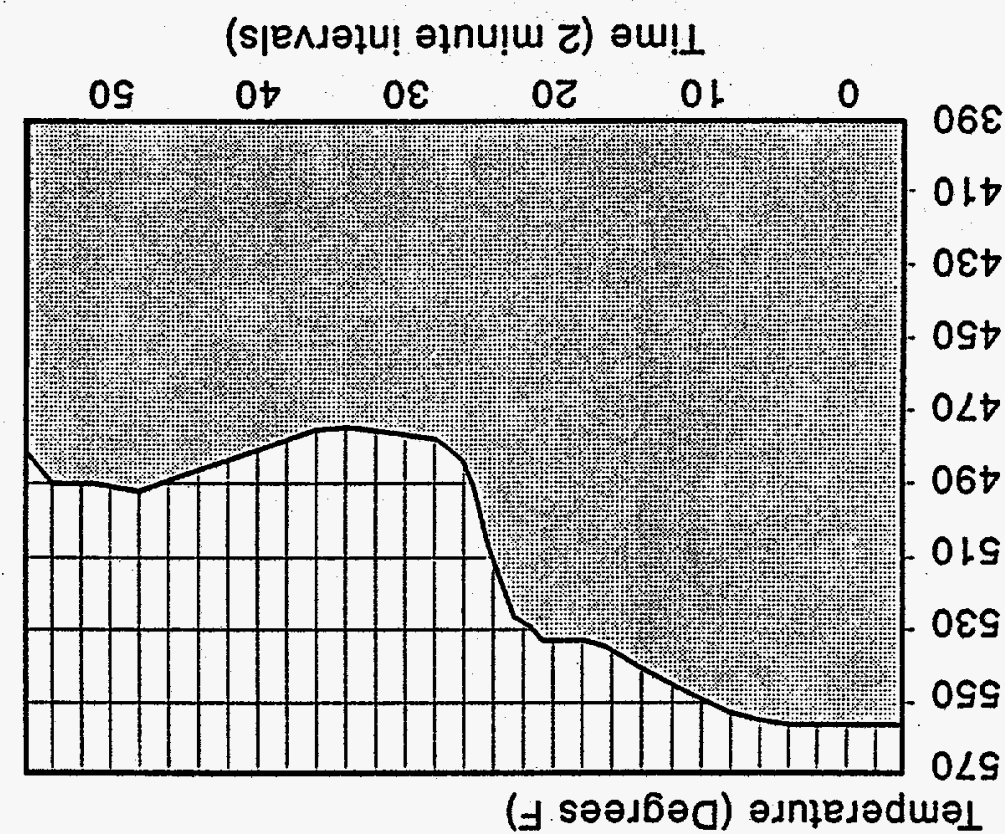


was to be implemented to minimize the probability of a rapidly propagating fatigue failure by, for example, preventive plugging, stabilization of susceptible tubes, or AVB changes. This program was to include an assessment of stability ratios for the most limiting tube locations (including an evaluation of the depth of penetration of each AVB and the effectiveness of the tube support and the magnitude of the flow peaking factors).

\subsection{McGuire Unit 1}

A $1,900 \mathrm{l} / \mathrm{min}$ (500 gpm) leak developed in Steam Generator B at McGuire Unit 1 on March 7, 1989 (Stoller 1989a, USNRC 1989, Sipe 1989). The degradation mechanism, size and location of the rupture, and the results of previous and subsequent steam generator inspections are discussed in Section 4.8.1. The plant transient, operator actions, radiation release, and remedial actions are discussed in Sections 4.8 .2 through 4.8 .5 , respectively.

\subsubsection{Cause of the Tube Rupture}

The ruptured tube was removed from the McGuire steam generator and examined. The rupture was caused by IGSCC on the outside diameter of the tube involving multiple initiation sites, and was contained within a long shallow groove, which was approximately $0.025 \mathrm{~mm}$ $(0.001 \mathrm{in}$.) deep and $1 \mathrm{~mm}(0.04 \mathrm{in}$.) wide on the tube outside diameter, and which ran axially from about $50 \mathrm{~mm}(2 \mathrm{in}$.) below the rupture to about $500 \mathrm{~mm}$ (20 in.) above the rupture. Axial and circumferential cracks were observed along the length of the groove above the rupture. The maximum depth of these cracks was about $30 \%$ of the original wall thickness.

The rupture was a longitudinal split about $95 \mathrm{~mm}$ (3.75 in.) long and $9.5 \mathrm{~mm}(0.375 \mathrm{in}$.) wide at the maximum rupture opening, i.e., a small fishmouth opening. The rupture was located about $710 \mathrm{~mm}$ ( $28 \mathrm{in}$.) above the tubesheet on the cold leg side of the tube in Row 18, Column 25.
The split started below the lowest tube support plate and ran to about $13 \mathrm{~mm}(0.5 \mathrm{in}$.) above the support plate.

The Alloy 600 tubing had a grain size and intergranular carbide content indicative of a low temperature mill-annealed microstructure, as expected. The presence of disturbed metal near the groove indicated that the groove was probably made after tube annealing. X-ray residual stress measurements indicated local values slightly below yield. Energy dispersive spectroscopy scans of the fracture surfaces failed to identify any corrosive species. Prior to the rupture, there were no significant secondary side corrosion problems in the McGuire steam generators and no secondary side chemistry excursions which would lead to such problems. The primary-to-secondary leak rate for the three months leading up to the event had been small varying between 20 and $115 \mathrm{l} / \mathrm{d}$ ( 5 and 30 gpd). Subsequent eddy-current inspection of the other tubes in all four McGuire Unit 1 steam generators and metallurgical examination of a second pulled tube revealed no indications of detectable ODSCC. The utility concluded from all this that this was a unique event and that a contaminant on the surface of the tube in the shallow groove led to crack initiation near start of life. Continued operation then washed this contaminant away and subsequent crack growth occurred slowly over time. The USNRC staff agreed that the McGuire rupture "was unique in the sense that it was not preceded by significant primary-to-secondary leakage which would normally be expected for stress corrosion cracking." However, "the uniqueness of tube R18-C25 in terms of its susceptibility to SCC has not been demonstrated," and the utility was encouraged to perform $100 \%$ rotating pancake coil inspections at the next outage (USNRC 1989).

\subsubsection{Plant Transient}

The McGuire rupture occurred while the plant was operating at full power. The radiation 
monitor on the B steam generator steam line was the first indication of the rupture (at 11:38 pm). The operators observed that the $B$ steam generator feedwater flow was decreasing while the level remained relatively constant and the pressurizer level was decreasing. They immediately recognized the incident as a steam generator tube leak and implemented their tube leakage procedure (rather than their tube rupture procedure). The next indication was when the condensate air ejector radiation monitor alarmed. The operators then initiated a $30 \mathrm{Mwe} / \mathrm{min}$ load reduction (at 4 minutes), started a second charging pump and reduced the letdown flow from $75 \mathrm{gpm}$ to $45 \mathrm{gpm}$ (at 5 minutes), and initiated emergency boration to compensate for the load reduction. This resulted in some fluctuations in reactor coolant temperature and pressurizer pressure and level.

At 8 to 9 minutes, the operators initiated a manual reactor trip which in turn caused an automatic turbine trip. The pressurizer level was now at $36-38 \%$, so the valves to the boron injection tank were opened and the charging pump suction was realigned to the refueling water system storage tank. In addition, the operators began to isolate the B steam generator and initiated reactor coolant system cooldown and depressurization. The main steam bypass valves (steam dumps) to the condenser were opened for short periods of time at 14 and again at 25 minutes to facilitate the cooldown. At 23 minutes, the operators blocked the actuation circuit for the safety injection to prevent unnecessary automatic actuation (in accordance with their shutdown procedure). At 47 minutes, the reactor coolant system pressure and the B steam generator secondary side pressure were essentially equal and the break flow temporarily stopped. The pressurizer level during the first 39 minutes of the McGuire Unit 1 steam generator tube rupture event is shown in Figure 36. The reactor coolant system and the B steam generator secondary side pressure during the entire event are shown in Figure 37.
The reactor coolant system remained at a pressure of about $6.9 \mathrm{MPa}(1,000 \mathrm{psi})$ from 47 minutes to about 5 hours, 20 minutes while the operators established the required boron concentration for cooling down. However, the B steam generator secondary side pressure continued to decrease during that period of time and the flow through the tube rupture into the secondary side of the B steam generator resumed and then continued for about 10 more hours. At about 3 hours and 30 minutes, further cooldown began with additional steam dumps to the condenser, including blowdowns of the defective B steam generator at 3 hours, 34 minutes, and at 4 hours, 32 minutes to control the water level in the B steam generator. The steam dumps from the B steam generator released small amounts of radioactive material through the condenser vent. At about 5 hours, the reactor coolant system temperature reached $425^{\circ} \mathrm{F}$ and an additional depressurization of the reactor coolant system was initiated. However, the reactor coolant system pressure remained above the B steam generator secondary side pressure. At 10 hours, 37 minutes, cooldown of the B steam generator was started using the backfill method. By 17 hours, both trains of the residual heat removal system were inservice.

\subsubsection{Operator Actions}

The initial reactor coolant system depressurization was relatively fast and effective (47 minutes). Also, the defective steam generator was quickly isolated (about 11 minutes). However, flow through the ruptured tube in the B steam generator resumed shortly after 47 minutes and continued for about 10 more hours due to the decision to hold the reactor coolant system at a pressure of about $6.9 \mathrm{MPa}$ ( 1,000 psi) for about 4.5 hours while the boron concentration was adjusted and the subsequent slow cooldown. Therefore, steam from the defective steam generator had to be dumped to the condensers to control the B steam generator level and radioactive material was subsequently 


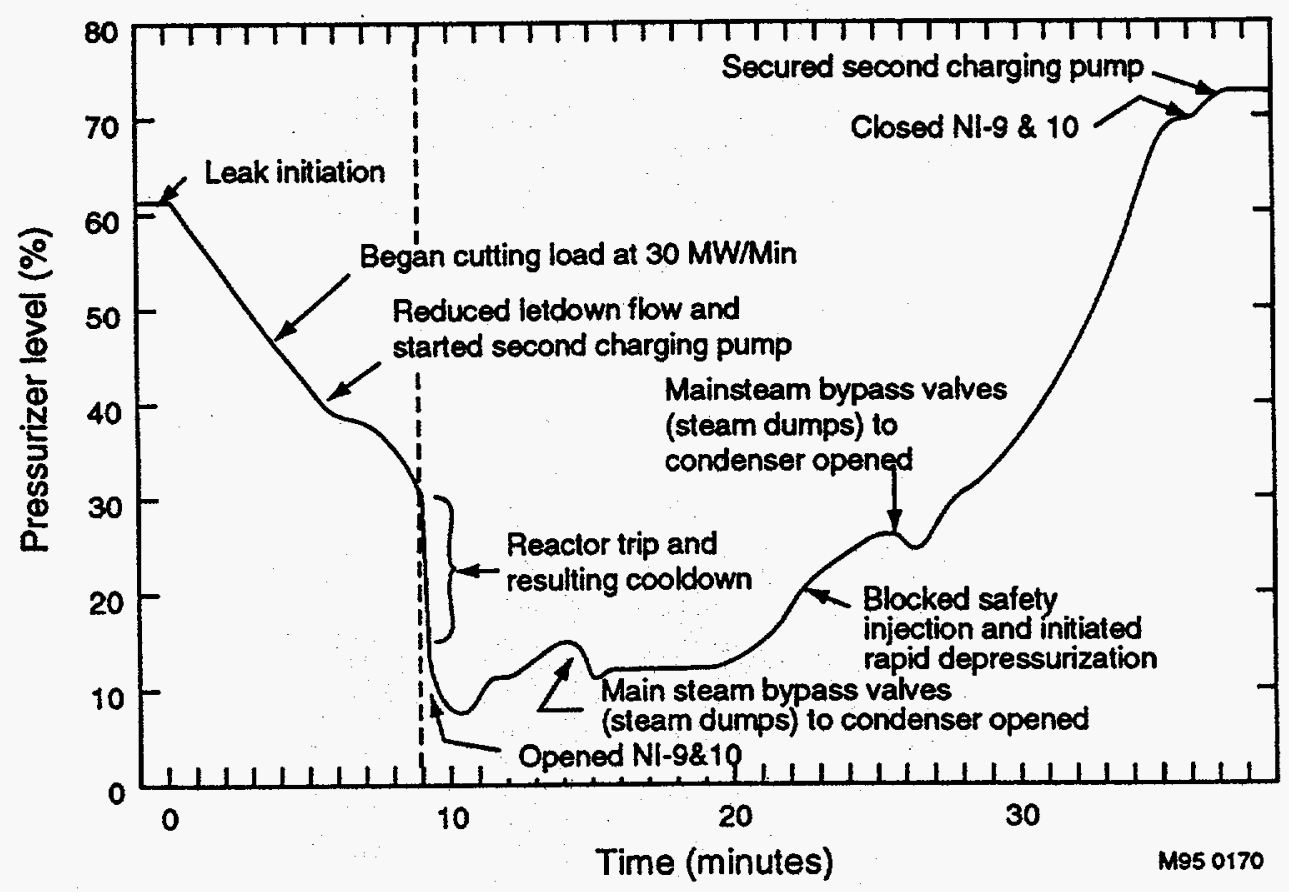

Figure 36. Pressurizer level during the first 39 minutes of the McGuire unit 1 steam generator tube rupture event of March 7 and 8, 1989 (Sipe 1989). The rupture occurred at 11:38pm.

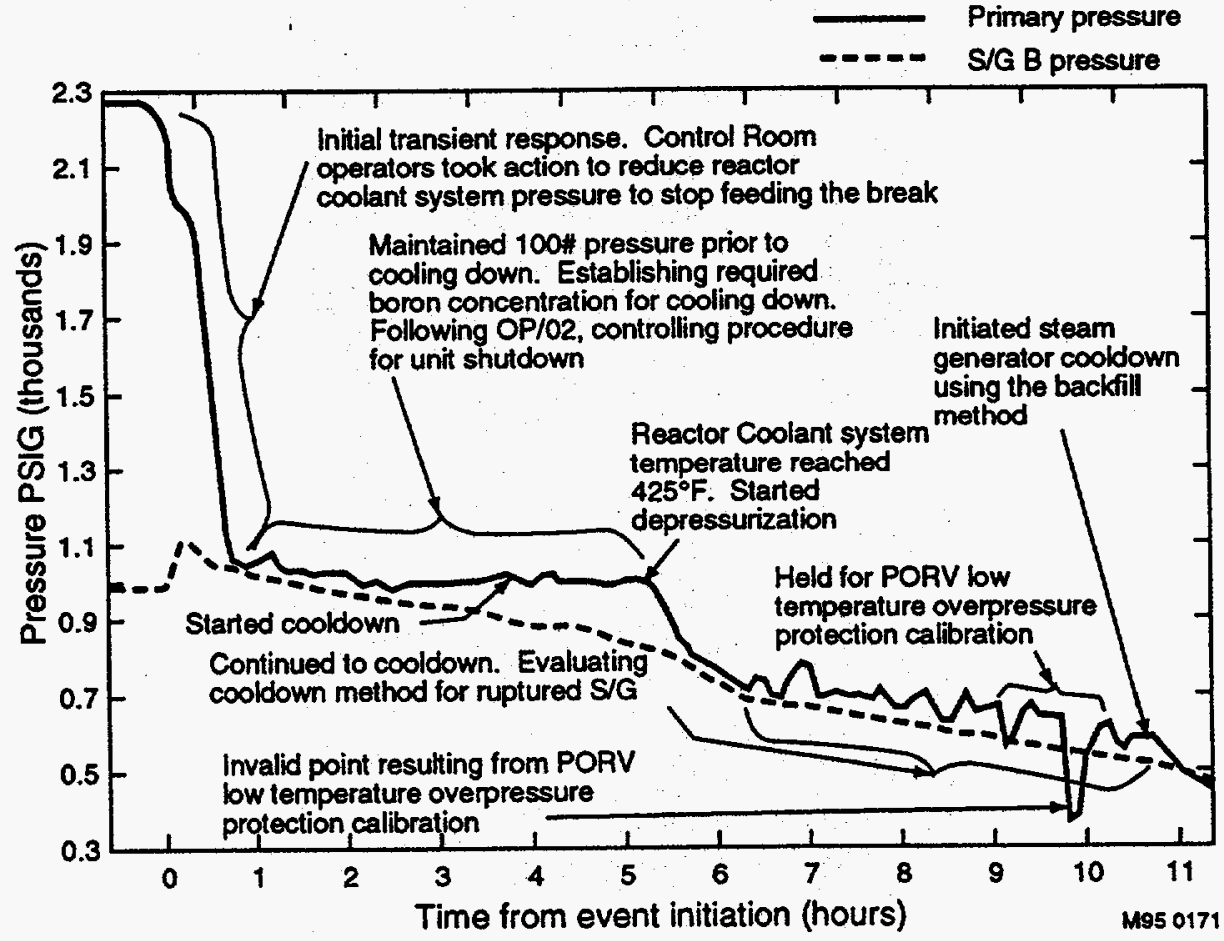

Figure 37. Reactor coolant system and B steam generator secondary side pressure during the McGuire Unit 1 steam generator tube rupture event of March 7 and 8, 1989 (Sipe 1989). The rupture occurred at $11: 38 \mathrm{pm}$. 
vented to the environment. Also, the initial leakage estimate was about 100 to $150 \mathrm{gpm}$ (at 8 minutes) which, in part, resulted in the decision to use the steam generator tube leakage procedure rather than the tube rupture procedure. (The tube leakage was calculated to be about 540 gpm at about 6 hours which was considerably closer to the final estimate of about $500 \mathrm{gpm}$.)

\subsubsection{Environmental Impact}

A total of 43.4 curies of Xenon-133 equivalent and 0.001 curies of iodine-131 equivalent was released as a result of the steam generator tube rupture and the subsequent degassing of the secondary system at McGuire. This release of radioactivity was well within the limits of the McGuire Technical Specifications.

\subsubsection{Remedial Actions}

Based on the Westinghouse Emergency Response Guidelines, this event should have been managed in accordance with the procedures developed for a steam generator tube rupture. In response to USNRC concerns, the utility changed its procedures to eliminate manual realignment of the safety injection flow path while a steam generator tube leak is in progress. Thus, for an event where the primary-to-secondary leak is greater than the normal charging pump capability, a manual or automatic safety injection will be necessary and will cause the tube rupture emergency operating procedure to be used.

Also, the controlling procedure for unit shutdown and the reactivity balance calculations procedure were revised to more clearly allow cooldown initiation before the boron margin for cold shutdown was met, as long as the margin is maintained during cooldown.

\subsection{Mihama Unit 2}

A leak of about $2,600 \mathrm{l} / \mathrm{min}$ (700 gpm) developed in Steam Generator $A$ at Mihama Unit 2 on February 9, 1991 (Stoller 1991a, Stoller 1991b,
Nucleonics Week 1991a, Nucleonics Week 1991b, Nucleonics Week 1991c). The degradation mechanism, size and location of the rupture, and the results of a previous steam generator inspection are discussed in Section 4.9.1. The plant transient, operator response, radiation release, and remedial actions are discussed in Sections 4.9.2 through 4.9.5, respectively. Only limited information is available about this event so the discussion is not as complete as in some sections of this chapter. The leak rate is an estimate based on the North Anna Unit 1 rupture (which was almost the same size and location).

\subsubsection{Cause of the Tube Rupture}

The Mihama rupture was caused by high-cycle fatigue. The rupture was located on the cold leg side of the tube in Row 14, Column 45 at the top of the upper tube support plate (sixth support plate). The R14-C45 tube is in about the center of the tube bundle. The failure consisted of a $360^{\circ}$ circumferential crack that completely severed the tube. Some nearby tubes that had been plugged in the past were deformed and bowed. The severed section was striated, suggesting fatigue failure. There was no indication of denting, stress corrosion cracking, IGA, or corrosion thinning near the rupture location (Nucleonics Week 1991c). Also, there was only a minor buildup of deposits between the tube and support plate.

The AVBs between Columns 44 and 45 and Columns 45 and 46 (i.e., on either side of the failed tube) were about 40 to $50 \mathrm{~cm}$ shorter than designed and were somewhat deformed. (All tubes in Row 11 and higher should have been supported by AVBs). It is believed that when the AVBs were installed, tubes blocked their way and the workers cut them to fit. This resulted in poor support for the failed tube and possibly increased local flows, causing excessive vibration and the observed fatigue failure (Nucleonics Week 1991c). 
The failed tube had been inspected during the unit's last regular outage in July 1990 and had been found to be without defect. The first indication that a new throughwall crack was developing was about 1 hour and 16 minutes before the rupture, when the operators received an alarm signal from steam generator blowdown monitor R-19. The alarm setpoint was $60 \mathrm{cpm}$, compared to the normal reading of $35 \mathrm{cpm}$.

\subsubsection{Plant Transient}

The Mihama rupture occurred while the plant was operating at full power. The air ejector high-radiation alarm was the first indication of a rupture (at $1: 40 \mathrm{pm}$ ). Five minutes later, the secondary steam blowdown radiation monitor alarmed and the operators started the third charging pump. At 8 minutes, the operators started reducing power at $4.2 \%$ per minute to shut the reactor down. At 10 minutes, the reactor was automatically scrammed on low pressurizer water level and the turbine generator tripped. Seven seconds later, the safety injection pumps automatically started on low reactor coolant system pressure and low pressurizer water level signals. At 15 minutes, the operators attempted to close the main steam line isolation valve for the defective steam generator, having determined which steam generator was defective. The valve failed to close and an operator was dispatched to the valve and manually closed it at 22 minutes. It was later determined that the main steam line isolation valve failed to function because the mirror-surfaced finish given to the shaft during the last maintenance outage resulted in its gathering graphite on the surface, which impeded the valve movement.

Also at 22 minutes, the operators opened the steam relief valve on the undamaged steam generator to start cooling the reactor coolant system. This valve stayed open until 37 minutes. The hot leg temperature in the undamaged loop (Loop B) began to decrease at 22 minutes and continued to decline until 54 minutes because of the cooling effects of the steam dump. Between
30 and 45 minutes, the operators also attempted to open two relief valves on the pressurizer to begin the primary system depressurization. Neither valve worked because an operator had erroneously closed a valve in the air supply line to the two relief valves just before the unit's most recent startup.

At 54 minutes, the operators began to depressurize the reactor coolant system using the pressurizer auxiliary spray. The pressurizer water level recovered to within the measurement range by 55 minutes due to the effects of a lower reactor coolant system pressure and, therefore, a lower rupture flow. At 57 minutes, the operators stopped the two high-pressure injection pumps after confirming the recovery of the water level in the pressurizer. At 1 hour, 2 minutes, the hot leg temperature was about $40^{\circ} \mathrm{C}$ below the saturation temperature, however, there may have been some voiding in the upper plenum. Analysis showed that the minimum critical heat flux was about 2.76 , far above the permissible limit of 1.17. At 1 hour, 8 minutes, the reactor coolant system pressure had decreased to the defective steam generator secondary side pressure and the leakage from the primary to the secondary coolant system had stopped.

Overall, about 55 metric tons of primary reactor coolant escaped through the steam generator tube rupture to the secondary coolant system, about 50 metric tons of water was injected by the emergency core cooling system into the primary system, and about 1.3 metric tons of steam escaped from the damaged steam generator's relief valve.

\subsubsection{Operator Actions}

The operators were a little slow in reducing power ( 8 minutes), but tried to isolate the defective steam generator in a timely manner (15 minutes). They were only delayed 7 minutes by the failure of the main steam line isolation valve on the defective steam generator. The operators started dumping steam from the intact steam 
generator at 22 minutes which was effective in cooling the primary system, but the primary system depressurization was delayed (54 minutes), in part, because of the failed pressurized relief valves (Nucleonics Week 1991b, Nucleonics Week 1991c).

\subsubsection{Environmental Impact}

The radioactivity released to the surrounding environment included 0.6 curies of radioactive noble gases, 0.01 curies of radioactive iodine and 0.0002 curies of liquid radioactive substances. The releases were far below regulatory limits and the dose equivalent to the surrounding population was only about $1 / 100,000$ of the natural background dose.

\subsubsection{Remedial Actions}

Remedial actions included inspection of the AVBs in all Japanese steam generators and replacement as necessary. Hardware changes at Mihama Unit 2 included replacement of the under-powered plant computer and redesign of the plant control system. Further research and development of advanced steam generator tube inspection technologies was to be funded. Maintenance procedures were to be improved and additional items inspected. Improved operations manuals, particularly for handling abnormal events, coupled with more training were also promised.

\subsection{Palo Verde Unit 2}

A $910 \mathrm{l} / \mathrm{min}$ (240 gpm) leak developed in Steam Generator 2 at Palo Verde Unit 2 on March 14, 1993 (Bradish 1993, Conway 1993). The degradation mechanism, size and location of the rupture, and the results of previous and subsequent steam generator inspections are discussed in Section 4.10.1. The plant transient, operator actions, radiation release, and remedial actions are discussed in Sections 4.10.2 through 4.10 .5 , respectively.

\subsubsection{Cause of the Tube Rupture}

The Palo Verde rupture was caused by ODSCC which occurred, in part, as a result of tube-totube crevice formation in a free span region of a Combustion Engineering System 80 RSG. The rupture occurred on the hot leg side of the tube bundle between the $08 \mathrm{H}$ and $09 \mathrm{H}$ horizontal, partial eggcrate tube support structures. The rupture tube was located at Row 117, Column 144. A sketch of the Combustion Engineering System 80 upper tube bundle geometry on the hot leg side is shown in Figure 38. A cross section of the tube bundle in the region of the ruptured tube, with defects identified, is shown in Figure 39. The stress corrosion crack was oriented in the axial direction, about $250 \mathrm{~mm}$ (10 in.) long, and started about $760 \mathrm{~mm}$ (30 in.) above the center of the $08 \mathrm{H}$ eggcrate tube support structure (the top of the crack was about $130 \mathrm{~mm}$ (5 in.) below the $09 \mathrm{H}$ eggcrate). The rupture was about a $65 \mathrm{~mm}$ (2.5 in.) long "fishmouth" type opening.

Metallurgical examinations were performed on the ruptured tube and on a number of other tubes with axial crack indications in the eggcrate support and free span areas. The defects were all due to outside diameter initiated IGA and IGSCC, with the cracking tending towards IGSCC as the degradation matured. However, in some cases the IGA was over ten grains deep, and often IGA was observed to be stemming from an IGSCC crack location. The lower $100 \mathrm{~mm}$ (4 in.) of the crack associated with the rupture was examined and found to be covered with a deposit ridge. The average throughwall penetration of the IGSCC was $70.2 \%$ and the maximum penetration was $98.2 \%$ in the lower $100 \mathrm{~mm}$ of the rupture crack. Transgranular cracking was not observed on any tube fracture surface.

Post-accident investigation of the Palo Verde rupture concluded that the key contributing factors were: free span crevice formation, a caustic-sulfate secondary side water chemistry, a 
Relative long supported length

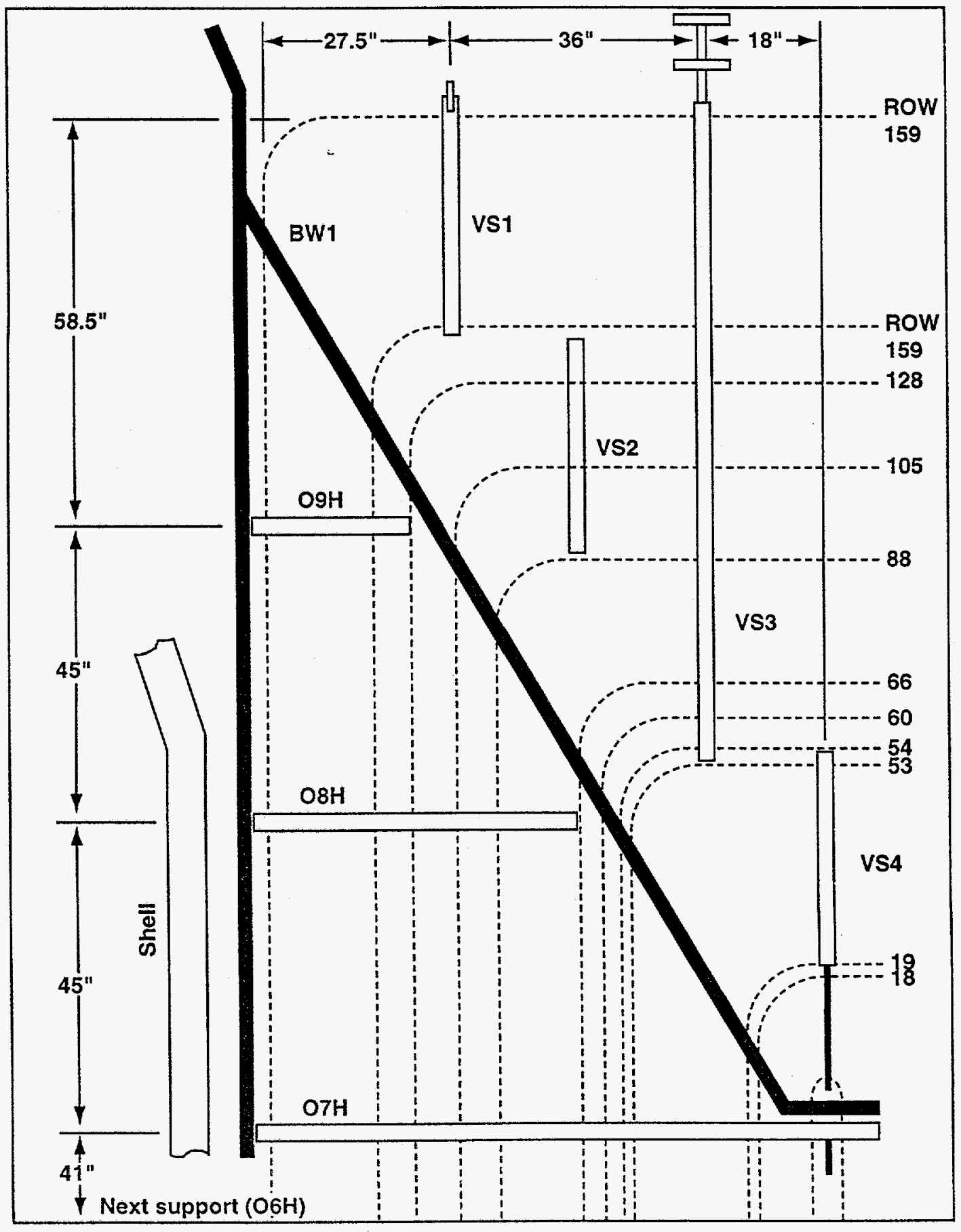

M95 0173

Figure 38. Palo Verde upper tube bundle geometry on the hot leg side (Conway 1993). 

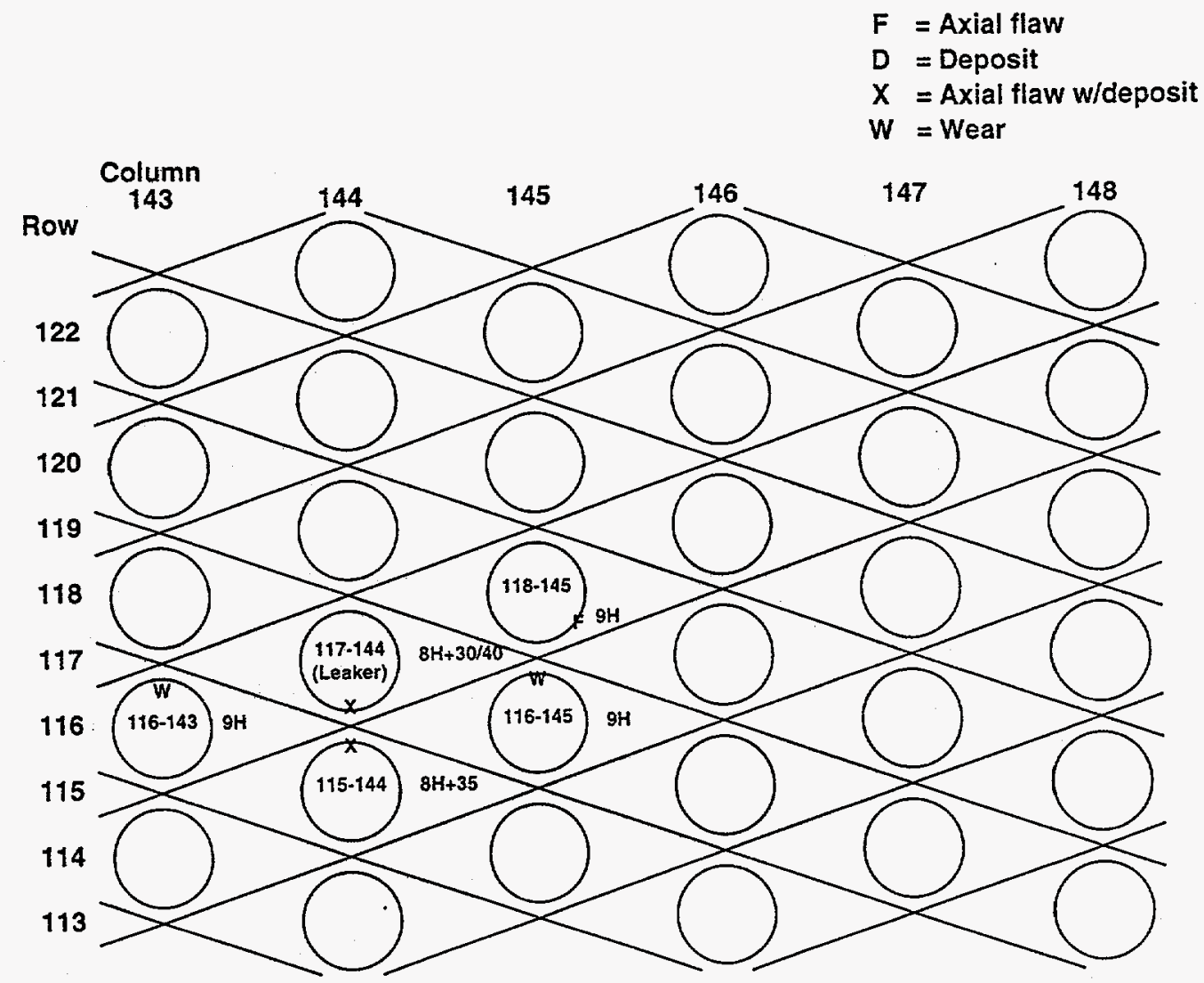

M95 0169

Figure 39. Palo Verde steam generator cross section in the region of the tube bundle with the ruptured tube (Conway 1993).

susceptible microstructure in the ruptured tube, and, possibly, residual stresses due to scratches. These factors are discussed next.

Video inspection performed in the spaces left by the tube removals, documented the presence of bridging deposits in locations where the normal tube triangular pitch spacing is reduced to nearly tube-to-tube contact. These bridging deposits were also detected with rotating pancake coil eddy-current equipment (six of the eight bridging deposits viewed on video were also detected with the eddy-current equipment). As of July 10, 1993, the eddy-current inspections had identified axial bridging deposits over 54 of the 102 midspan axial cracks located in both Palo Verde Unit 2 steam generators (a total of 175 bridging deposits were located in both RSGs). These bridging deposits were generally in the upper region of the bundle (between $07 \mathrm{H}$ and several inches above the batwing) where tube bowing had occurred. The design of the Combustion Engineering upper bundle supports does not prevent lateral or in-plane tube movement which can cause the reduced tube-to-tube spacing observed in the video inspections (Conway 1993). The free span bridging deposits were determined from the metallurgical examinations to be as thick as $0.1 \mathrm{~mm}$ ( 4 mils) whereas the normal scale deposits were about half as thick. Chemical analysis showed a trend for increased concentrations of contaminants in the bridging deposits as the tube bundle height increased, with the following elements and compounds present: $\mathrm{Fe}_{3} \mathrm{O}_{4}, \mathrm{Cu}, \mathrm{NiO}, \mathrm{SiO}_{2}, \mathrm{CaO}, \mathrm{MgO}, \mathrm{ZnO}, \mathrm{MnO}_{2}$, $\mathrm{Al}_{2} \mathrm{O}_{3}, \mathrm{PbO}$, and various sulfur species. 
Although the Palo Verde Unit 2 secondary side water chemistry had been maintained within the plant and EPRI guidelines and out of specification conditions were corrected within the time periods required, the secondary water chemistry had consistently been mildly caustic. That is, the molar ratio of sodium to chloride had consistently been above one. This caused caustic crevice environments which were indicated by the high concentrations of sodium $(400 \mathrm{ppb})$ when the unit down-powered. Also, analysis of the tubing surface and crack surface oxide films identified the presence of sulfates and reduced sulfur, and chromium depletion at the crack tips, all of which occurs in an alkaline (mildly caustic) environment. The source of these impurities was probably condenser leaks and resin intrusion. Failure of a resin retention screen in July 1991 resulted in sulfate levels of about five times the EPRI guidelines.

Microstructural examination of the ruptured tube identified an absence of intragranular carbides and only a few intergranular carbides. A semicontinuous grain boundary carbide coverage was expected. Microstructural characterization of two other pulled tubes indicated less carbide coverage of the grain boundaries then is recognized as optimum, but an improvement over the ruptured tube. Microstructural evaluation of five other pulled tubes indicated acceptable carbide coverage. These results suggest the possibility of heat treatment and/or carbon content fabrication problems. Alloy 600 tubes with few intergranular carbides are much more susceptible to stress corrosion cracking then tubes with good grain boundary carbide coverage.

The tubing surface examinations revealed scratches associated with the ODSCC on a number of the pulled tubes (but not the ruptured tube). Scratched areas result in local cold work and high residual surface tensile stresses which can facilitate stress corrosion cracking.

In summary, the Palo Verde Unit 2 rupture was due to IGA/IGSCC which occurred as a result of tube-to-tube crevice formation. The crevice, together with the consequential heat flux, led to a concentration of caustic impurities and the development of a long, deep crack, part of which ruptured. Contributing factors included: increased sulfate levels due to resin intrusion, a possible surface scratch, and a susceptible microstructure.

The rupture apparently occurred suddenly. Unit 2 had been monitoring small primary-tosecondary leakage since July 1992 . Beginning on March 3, 1993 the leakage increased to about 75 $\ell /$ day (20 gpd). Increases in leak rates were noted during power changes and high rate blowdowns. However, the leak rates were decreasing somewhat during the 2 days prior to the rupture.

\subsubsection{Plant Transient}

The Palo Verde rupture occurred while the unit was operating at $98 \%$ power. The first indication of the rupture was a notable decrease in pressurizer level and pressure along with an alarm (on one channel) from the main steam line radiation monitor on the steam line from Steam Generator 2 (at 4:34 am). In response, the operators suspected that the gas stripper which had been placed in service about 4 hours earlier was leaking. At 2 minutes, the operators started a third charging pump and energized the pressurizer backup heaters. They also checked the containment building sensors to determine if there was a leak inside containment from the gas stripper. At 4 minutes, the radiation monitor on the auxiliary steam condensate receiver tank alarmed. At 6 minutes, letdown flow was isolated and a histogram of radiation monitors associated with a steam generator tube rupture was displayed. Only the two monitors mentioned above had alarmed. The primary indicators of a steam generator tube rupture, the radiation monitors on the steam generator blowdown lines and on the condenser exhaust, had not alarmed. 
At 13 minutes, the pressurizer heaters deenergized due to a low water level in the pressurizer and the reactor was tripped by the operators, which automatically tripped the turbine. Twenty-two seconds later, the safety injection and containment isolation systems were actuated due to a reactor coolant system pressure below $12.67 \mathrm{MPa}(1,837 \mathrm{psia})$. The pressurizer level then dropped below $0 \%$ and the pressurizer pressure dropped to $11.56 \mathrm{MPa}(1,677 \mathrm{psia})$. However, the high pressure safety injection quickly restored the pressurizer level to about $4 \%$ and the pressure to about $12.96 \mathrm{MPa}(1,880$ psia). The reactor coolant pumps $1 \mathrm{~B}$ and $2 \mathrm{~B}$ were also manually tripped at about this time. In the following tens of minutes, the high pressure safety injection and charging pumps slowly increased the pressurizer level while the reactor coolant system pressure was maintained at about $12.9 \mathrm{MPa}(1,875 \mathrm{psia})$. By about 28 minutes, the high pressure safety injection flow was zero, the letdown flow was still isolated, the three charging pumps were in full operation, and the pressurizer level was still increasing slowly, but was relatively low.

The operators, using the Emergency Operations Procedure Diagnostic Logic Tree, diagnosed a reactor trip because plant conditions did not allow the diagnosis for a specific recovery procedure, even though they now suspected a steam generator tube rupture. However, the entry conditions for the reactor trip recovery could not be met because of the low pressurizer level. So, the operators entered the Functional Recovery Procedure due to inconclusive diagnosis with the Logic Tree. As mentioned above, the radiation monitors on the blowdown lines and on the condenser exhaust were the primary indicators of a steam generator tube rupture. However, the blowdown lines had been isolated upon actuation of the safety systems at 13 minutes and the monitor on the condenser exhaust was defective.

At 46 minutes, the operators restored flow in the blowdown lines and at 55 minutes the monitor on the number 2 steam generator alarmed. At 57 minutes, the alarm on the condenser exhaust went off and the operators had confirmation of a steam generator tube rupture. However, the operators continued recovery actions per the Functional Recovery Procedure to restore pressurizer level to greater than $33 \%$. At 1 hour and 30 minutes, a reactor coolant system cooldown to $545^{\circ} \mathrm{F}$ and 10.3 $\mathrm{MPa}(1,500 \mathrm{psia})$ began. The high pressure safety injection increased as the pressure dropped, the pressurizer was restored to $33 \%$ full, the Functional Recovery Procedure was exited, and the Diagnostic Logic Tree finally diagnosed a steam generator tube rupture. At 2 hours and 47 minutes, the reactor coolant system cooldown was restarted using the steam generator tube rupture procedure and at 2 hours and 54 minutes, Steam Generator 2 was isolated.

During the cooldown, Steam Generator 2 was cooled by allowing its secondary pressure to exceed the reactor coolant system pressure, thus back-flowing coolant from the steam generator into the reactor coolant system. This allowed the defective steam generator to be cooled with a series of auxiliary feedwater additions. At about 6 hours, the unit entered the hot shutdown mode.

\subsubsection{Operator Actions}

The Palo Verde Unit 2 operators were burdened with (a) an Emergency Operations Procedure Diagnostic Logic Tree which used a "snap-shot" philosophy (i.e., it considered only what was occurring at a specific time rather then previous trends and alarms), (b) faulty radiation alarms, and (c) preconceived notions of where the leak was that were incorrect. Therefore, they were slow to trip the reactor (13 minutes), slow to confirm that a steam generator tube rupture had occurred (57 minutes), and very slow to start cooling the system down ( 1 hour, 30 minutes). The final cooldown did not start until 2 hours and 47 minutes had passed and the defective steam generator was not isolated until 2 hours and 54 minutes had passed. The primary system pressure remained well above the defective steam 
generator secondary pressure and the primary-tosecondary leakage continued for at least 3 hours and probably nearer 4 hours (this value was not reported). Overall, a fairly slow response to a steam generator tube rupture.

\subsubsection{Environmental Impact}

The concentrations of radionuclides in the reactor coolant system were very low. Therefore, releases were relatively low despite the relatively long time to isolate the defective steam generator. The 2-hour exclusion area boundary thyroid dose was calculated to be less than 0.3 millirem and the 8-hour low population zone thyroid dose was calculated to be less than 0.04 millirem. These values are much less than the USNRC Standard Review Plan criteria of 30 rem thyroid.

\subsubsection{Remedial Actions}

Arizona Public Service Company carried out or planned to carry out a large number of remedial actions including: repair of the condensate demineralizers to ensure resin retention, plugging all tubes with suspected cracks, stabilization of some of the pulled tube segments with stainless steel cable, better molar ratio control of the secondary water chemistry, a resin monitoring program, reduced iron transport to the steam generators, elevated hydrazine, blowdown optimization, periodic down-powers to maximize hideout return, boric acid treatment of the secondary coolant, improved radiation monitor sensitivity (setpoints and monitor location), improved procedures for determining the primary-to-secondary leak rate, and improved emergency operating procedures.

4.11 Summary and Comparison of the Information from the Ten Steam Generator Tube Ruptures

The leak rate, degradation mechanism, rupture size, rupture location, and stressor and contributing factor information associated with the ten steam generator tube rupture events discussed in this section are summarized in Table 12. These ruptures have occurred over the last 20 years at a rate of about one every 2 to 3 years and may continue to occur. The maximum leak rates have ranged from $425 \mathrm{l} / \mathrm{min}(112 \mathrm{gpm})$ to $2,900 \mathrm{\ell} / \mathrm{min}(760 \mathrm{gpm})$. Maximum leak rates less than about $380 \mathrm{l} / \mathrm{min}(100 \mathrm{gpm})$ are generally below the normal charging flow capacity of the reactor coolant system (depending on plant design) and are considered by the USNRC to be from tube defects rather than tube ruptures. The highest possible leak rates calculated for a single tube rupture are on the order of 3,800 $\mathrm{\ell} / \mathrm{min}$ (1000 gpm).

Five different tube degradation mechanisms caused the ten ruptures: three ruptures were caused by ODSCC, two ruptures were caused by high-cycle fatigue, two ruptures were caused by loose parts wear, two ruptures were caused by PWSCC, and one rupture was caused by wastage. Additional ruptures caused by wastage are unlikely because only three reactors worldwide (all outside the U.S.) are now using phosphate water chemistry.

Additional ruptures due to high-cycle fatigue in Westinghouse-type steam generators are less likely than a few years ago because most operators have inspected their steam generators to assure that the AVBs are properly placed and new steam generators are being more carefully fabricated. However, the Indian Point Unit 3 experience discussed in Section 4.12 below suggests that such failures are possible even with proper AVB support. Loose parts and other foreign objects continue to be left in some steam generators and additional ruptures of tubes due to loose parts wear are possible. Also, extensive primary water and outside diameter stress corrosion cracking has occurred in certain steam generators and more ruptures caused by those mechanisms are possible.

The rupture locations have generally been either just above the tubesheet (three ruptures), or in the U-bend region (six ruptures). Only the 
Table 12. Summary of the leak rate, degradation mechanism, rupture size, rupture location, and stressor information associated with the ten ruptures discussed in Section 4.

\begin{tabular}{|c|c|c|c|c|c|c|}
\hline Datc & $\begin{array}{l}\text { Plant, } \\
\text { SG Model }\end{array}$ & $\begin{array}{c}\text { Maximum } \\
\text { Leak Rate } \\
\text { GPM }\end{array}$ & $\begin{array}{l}\text { Degradation } \\
\text { Mechanism }\end{array}$ & $\begin{array}{l}\text { Rupture } \\
\text { Size }\end{array}$ & $\begin{array}{l}\text { Ruplure } \\
\text { Location } \\
\end{array}$ & $\begin{array}{c}\text { Stressors and } \\
\text { Contributing Factors } \\
\end{array}$ \\
\hline $02 / 26 / 75$ & $\begin{array}{l}\text { Point Beach-1 } \\
\text { W } 44\end{array}$ & 125 & Wastage & $\begin{array}{l}2 \text { adjacent ruptured bulges } \\
\text { each about } 20 \mathrm{~mm} \text { long and } \\
\text { wide }\end{array}$ & $\begin{array}{l}\text { Slighthly above the tubeshcet, outer row } \\
\text { on the hot leg side }\end{array}$ & Large sludge pile, ineffective cleaning \\
\hline $09 / 15 / 76$ & $\begin{array}{l}\text { Surry-2 } \\
\text { W-51 }\end{array}$ & $330^{(1)}$ & PwscC & $114.3 \mathrm{~mm}$ long axial crack & $\begin{array}{l}\text { Top of U-bend (apex) in Row 1, Column } \\
7\end{array}$ & $\begin{array}{l}\text { High stresses and ovalization caused by } \\
\text { inward movement of the legs due to } \\
\text { support plate deformation }\end{array}$ \\
\hline $06 / 25 / 79$ & $\begin{array}{l}\text { Doel-2 } \\
\text { ACE-44 }\end{array}$ & 135 & PWSCC & $100 \mathrm{mmi}$ long axial crack & Top of the U-bend in Row 1, Columu 24 & $\begin{array}{l}\text { High residual stresses due to ovalization } \\
\text { during fabrication }\end{array}$ \\
\hline $10 / 02 / 79$ & $\begin{array}{l}\text { Prairie Is.-1 } \\
\text { W-51 }\end{array}$ & $336^{(1)}$ & Loose Parts Wear & $\begin{array}{l}38 \text { min long axial fishmouth } \\
\text { opening }\end{array}$ & $\begin{array}{l}\text { Tube bundle outer surface, } 76 \mathrm{~mm} \text { above } \\
\text { the tubesheet on the hot leg sidc, Row } 4 \text {, } \\
\text { Column } 1\end{array}$ & $\begin{array}{l}\text { Sludge lancing equipment left in the steann } \\
\text { generator }\end{array}$ \\
\hline $01 / 25 / 82$ & $\begin{array}{l}\text { Ginna } \\
\text { W-44 }\end{array}$ & $760^{(1)}$ & $\begin{array}{l}\text { Loose Parts Wear, } \\
\text { Fretting }\end{array}$ & $\begin{array}{l}100 \mathrm{~mm} \text { long axial fislmouth } \\
\text { opening }\end{array}$ & $\begin{array}{l}127 \mathrm{~mm} \text { above the tubesheet on the hot } \\
\text { leg side, Row } 42 \text {, Column } 55 \text { (third row } \\
\text { in from the bundle periphery) }\end{array}$ & $\begin{array}{l}\text { Loose parts (baffle plate debris) left in the } \\
\text { steam generator, wear of peripheral } \\
\text { tubes, fretting of inner tubes }\end{array}$ \\
\hline $05 / 16 / 84$ & $\begin{array}{l}\text { Fort Calhoun } \\
\mathrm{CE}\end{array}$ & 112 & ODSCC & $\begin{array}{l}32 \text { min long axial crack (small } \\
\text { fishmouth opening) }\end{array}$ & $\begin{array}{l}\text { Horizontal run at the top, between the } \\
\text { vertical batwing support bars on the liot } \\
\text { leg side, Row } 84 \text {, Column } 29 \text {, the rupture } \\
\text { faced down }\end{array}$ & $\begin{array}{l}\text { Tube deformation caused by corrosion of } \\
\text { the vertical batwing support bars, caustic } \\
\text { impuritics on the secondary side }\end{array}$ \\
\hline $07 / 15 / 87$ & $\begin{array}{l}\text { North Anna-1 } \\
\text { W-51 }\end{array}$ & 637 & High-Cycle Fatigue & $360^{\circ}$ circumferential break & $\begin{array}{l}\text { Top of the } 7 \text { th upper tube support plate } \\
\text { on the cold leg side, Row } 9 \text {, Column } 51\end{array}$ & $\begin{array}{l}\text { Highl-cycle vibration, denting, lack of } \\
\text { AVB support }\end{array}$ \\
\hline $03 / 07 / 89$ & $\begin{array}{l}\text { McGuire-1 } \\
\text { W-D2 }\end{array}$ & 500 & ODSCC & $\begin{array}{l}95 \mathrm{~mm} \text { long axial crack in a } \\
645 \mathrm{~mm} \text { long groove, } 9.5 \mathrm{~mm} \\
\text { wide at the maximum point }\end{array}$ & $\begin{array}{l}711 \mathrm{~mm} \text { above the tubesheet at the lower } \\
\text { tube support plate on the cold leg side, } \\
\text { Row } 18 \text {, Column } 25\end{array}$ & $\begin{array}{l}\text { Long slaallow groove, possibly a } \\
\text { contaminamt }\end{array}$ \\
\hline $02 / 09 / 91$ & $\begin{array}{l}\text { Milhama-2 } \\
\text { MHI-44 }\end{array}$ & $\approx 700^{(2)}$ & High-Cycle Fatigue & $360^{\circ}$ circumferential break & $\begin{array}{l}\text { Top of the 6th (upper) tube support plate } \\
\text { on the cold leg side, Row } 14 \text {, Column } 45\end{array}$ & $\begin{array}{l}\text { Iligh-cycle vibration, lack of AVB } \\
\text { support }\end{array}$ \\
\hline $03 / 14 / 93$ & $\begin{array}{l}\text { Palo Verde-2 } \\
\text { CE-80 }\end{array}$ & 240 & ODSCC & $\begin{array}{l}65 \text { mm long axial fishmouth } \\
\text { opening in a } 250 \mathrm{~mm} \text { long } \\
\text { axial crack }\end{array}$ & $\begin{array}{l}\text { Freespan region between the } 08 \mathrm{H} \text { and } \\
09 \mathrm{H} \text { tube support structures on the hot } \\
\text { leg side, Row } 117 \text {, Column } 144\end{array}$ & $\begin{array}{l}\text { Tube-to-tube crevice formation, bridging } \\
\text { deposits, caustic secondary water } \\
\text { cliemistry, susceptible material }\end{array}$ \\
\hline
\end{tabular}

("NRC estimates

(2) Estimate based on similarities to the North Anna rupture 
McGuire rupture was near one of the lower support plates. (Although the Palo Verde Unit 2 rupture was in the U-bend region, it was in the straight portion of a Row 117 tube between the $08 \mathrm{H}$ and $09 \mathrm{H}$ partial support structures.) The ruptures caused by loose parts wear have occurred just above the tubesheet whereas the ruptures caused by high-cycle fatigue have occurred just above the top tube support plate. Any future ruptures caused by those mechanisms will probably occur in the same locations.

The three ruptures caused by ODSCC appear to each have some unique contributing factors. The Fort Calhoun tube was subjected to high stresses caused by corrosion of the vertical batwing support bars. The McGuire rupture was located in a long shallow groove which was probably created during fabrication. The Palo Verde rupture occurred in a tube with a susceptible (and abnormal) microstructure. However, excessive caustic impurities on the secondary side were part of the problem in all three cases.

The plant transient information is summarized in Table 13. As mentioned in the introduction to this section, the operators were expected to (a) maintain the primary coolant subcooled, (b) minimize the leakage from the reactor coolant system to the defective steam generator secondary side, and (c) minimize the release of radioactive material from the damaged steam generator. Timing is critical to the successful management of a steam generator tube rupture event. The key operator actions that must be accomplished in a timely manner include:

- Recognition that a steam generator tube rupture event is occurring.

- Control of the pressurizer level using the charging pumps and letdown line (if the rupture is small).

- Power reduction/trip.
- Isolation of the defective steam generator.

- Reactor coolant system cooldown including pumped flow to the intact steam generators and intact steam generator steam dumps to the condenser or atmosphere.

- Reactor coolant system depressurization which generally requires throttling the safety injection and use of the pressurizer sprays or PORVs.

It should be noted that based on the training that reactor operators receive prior to licensing, a steam generator tube rupture is normally easily recognizable. The operators have several indicators that can be referred to that point to the fact that a tube rupture is occurring. The steam line radiation monitors and the air ejector radiation monitors are the prime indicators and are used as Emergency Operating Procedure entry conditions. The operating procedures that are utilized to combat the transient assume that the plant is at power and that the systems are aligned properly.

The success of the operators, as indicated by the times these activities started or finished in Table 13 , is mixed. For example, the Point Beach, Fort Calhoun, and Palo Verde operators took a relatively long time (up to 28,32 , and 57 minutes, respectively) to realize (or prove to themselves) that a steam generator tube rupture had occurred. The result was that they were slow to start reducing power ( 30 minutes at Point Beach where the maximum leak rate was relatively low, 13 minutes at Palo Verde where the leak rate and the initial pressure drop were larger) and slow to isolate the defective steam generators $(58,40$, and 174 minutes, respectively). Whereas, the Ginna, North Anna, McGuire, Surry, and Mihama operators recognized that a steam generator tube rupture event was underway within a few minutes of the first alarm. Their load reductions started within 
Table 13. Summary of plant transient information.

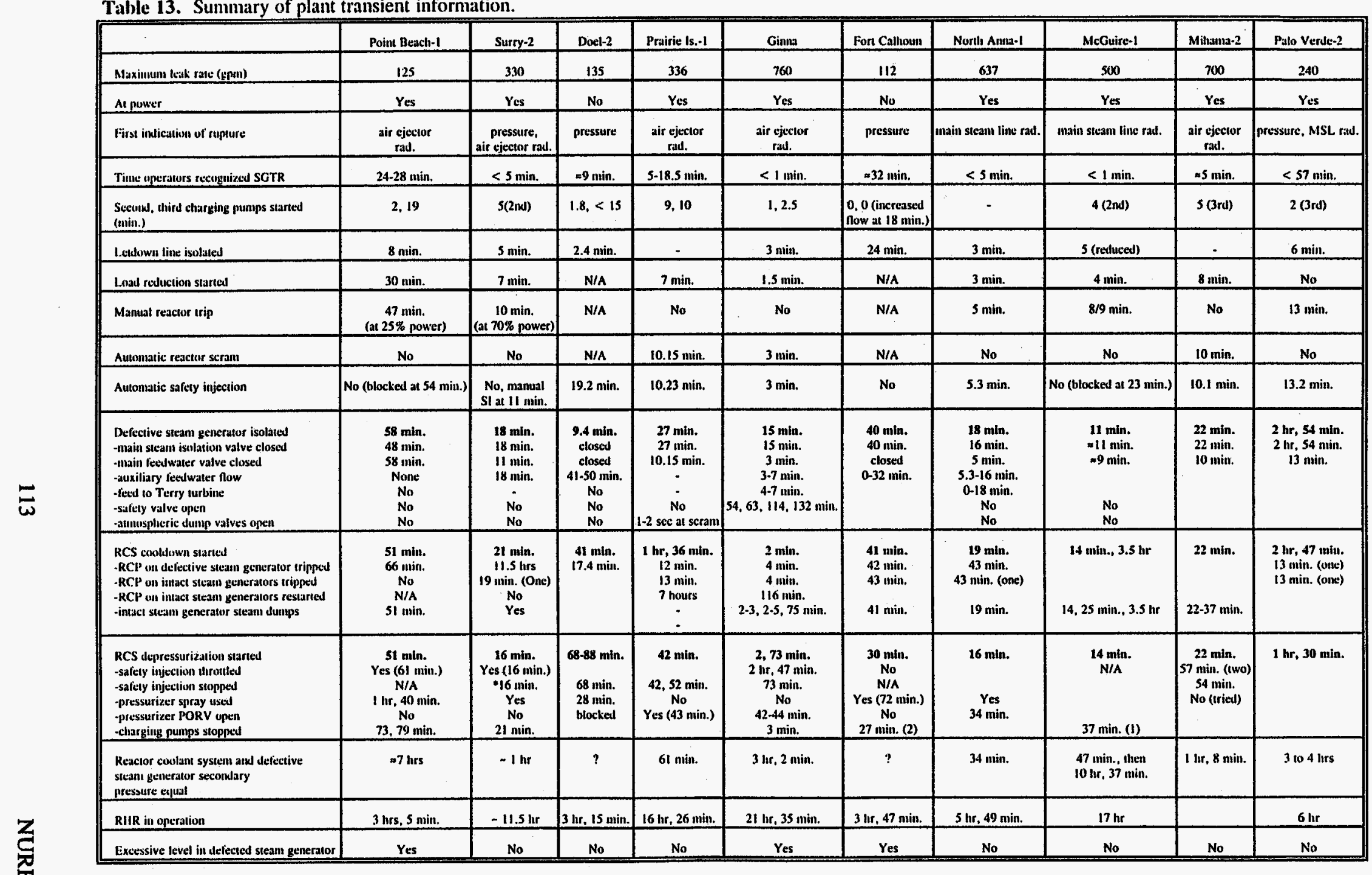

*The liight head safecty injection pumps are also the charging punips, one remained in operation. 
$1.5,3,4,7$, and 8 minutes, respectively, and their defective steam generators were isolated within $15,18,11,18$, and 22 minutes, respectively. (The defective steam generator at Mihama would have been isolated at 15 minutes, had the main steam line isolation valve worked properly.) It should be noted that it is harder for the operators of a plant at or near hot standby (Doel and Fort Calhoun) to detect a steam generator tube rupture. But, the operators at Point Beach, Palo Verde, and probably Prairie Island, should have been able to recognize and identify the event much faster.

Also, a significant drop in pressurizer level should signal the operators to start and set the second and third charging pumps at full flow as well as reduce or isolate the letdown flow, and that happened in most cases. However, the third charging pump did not start at Doel until about 15 minutes, the second and third charging pumps did not start at Prairie Island until 9 and 10 minutes, and the charging pumps at Fort Calhoun were not at full flow until 18 minutes. Adequate charging flow can prevent safety injection (for smaller ruptures) and allow the pressurizer to be used to help control the early depressurization. It is realized that in some instances the third charging pump may be a low volume, high discharge pressure pump that is normally utilized for makeup and is ineffectual in supplying large quantities of water in an emergency.

Another area where timely actions were important is the cooldown and depressurization of the primary system. It is very important to get the reactor coolant system pressure down to a value below the defective steam generator secondary side pressure and keep it there (slightly below, but not so far below that the backflow will significantly effect the primary system boron concentration) while at the same time keeping the reactor coolant system fully subcooled. Reactor coolant system pressures above the defective steam generator secondary side pressure for long periods of time result in overfill of the steam generator secondary side and unnecessary radioactive material releases to the environment. The North Anna, Surry, Prairie Island, and Mihama reactor coolant system pressures were reduced to their defective steam generator secondary pressures in 34,60 , 61 , and 68 minutes, respectively, and there were no defective steam generator overfill problems. The Point Beach, Ginna, and Fort Calhoun reactor coolant system pressures were held well above the defective steam generator secondary side pressures for considerably longer times (about 7, 3, and an unknown number of hours, respectively) and the defective steam generators overfilled. The McGuire depressurization also took a very long time ( 10 hours, 47 minutes), but the defective steam generator at McGuire was not overfilled because of releases to the condenser and through the condenser vent, to atmosphere.

Despite these variations in timing, it should also be noted that in all cases the plants were properly cooled down and the radioactive material releases were small and well below regulatory limits. Also, the operator performance was sometimes hampered by inadequate Emergency Operating Procedures (Palo Verde, for example) or by defective equipment (Mihama, for example). At other times, the operators were hampered by plant conditions that did not allow rapid employment of Emergency Operating Procedures. There are still numerous reasons for (a) continued operator training on steam generator tube ruptures and (b) training on the recognition of events based on the indications that are available. Neither training method should be utilized by itself. It appears that the majority of actions that were carried out were accomplished in accordance with the published procedures. Deviations from procedures appeared to be thought out in advance.

\subsection{Incipient Tube Rupture Events}

Seven incipient tube rupture events which occurred in the U.S. during the last seven years 
are briefly discussed in this Section. The information regarding these events is summarized in Table 14.

Braidwood Unit 1 A $47 \mathrm{l} / \mathrm{hr}$ (12.5 gph) leak developed at Braidwood Unit 1 on October 23, 1993, between 5:45 am and 3:00 pm. A subsequent inspection found that the leak was from a $330 \mathrm{~mm}$ (1.3 in.) long axial crack caused by ODSCC, located above the top tube support plate near an AVB (USNRC 1994).

Arkansas Nuclear One, Unit 2 A 57 l/hr (15 gph) leak developed at Arkansas Nuclear One, Unit 2 on March 9, 1992 (Scott 1992). About 6 hours after the leak was initially detected, the operators began shutting the plant down. A subsequent inspection determined that the leak was from a circumferential crack in the hot leg side of the tube in Row 67, Column 109. The crack was about $4.8 \mathrm{~mm}$ (0.19 in.) above the tubesheet in the explosive transition region of the tube. Examination of three other pulled tubes found $360^{\circ}$ circumferential cracks with average depths between 88 and $94 \%$ of the tube wall thickness, which were caused by ODSCC. The leaking tube was plugged and stabilized, but not removed for inspection. The circumferential cracks had not been detected during a previous inspection in 1991 because of inadequate eddycurrent test procedures and inappropriate equipment.

McGuire Unit 1 A $37 \mathrm{l} / \mathrm{hr}$ (10 gph) leak developed at McGuire Unit 1 on January 16, 1992 (Pedersen 1992). The leakage was $1.3 \mathrm{l} / \mathrm{hr}$ (0.35 gph) eight days earlier, $3.5 \mathrm{l} / \mathrm{hr}$ (0.92 gph) on the morning of the $16 \mathrm{th}$, and $37 \mathrm{l} / \mathrm{hr}$ by about 6:00 pm on the 16th. A subsequent inspection determined that the leak was primarily from a $250 \mathrm{~mm}$ long axial crack on the cold leg side of the tube in Row 47, Column 46. The freespan crack was about $130 \mathrm{~mm}$ ( 5 in.) above the 20 th tube support plate. Additional cracks were found on the same tube between the 14th and 15th tube support plates with depths up to $60 \%$ of the tube wall thickness. About 94 other similar indications were found that required tube plugging. An indication of a crack in the failed tube which may have been greater than $40 \%$ of the tube wall thickness was measured during the previous 1991 eddy-current inspection, but ignored.

Maine Yankee A $318 \mathrm{l} / \mathrm{hr}$ (84 gph) leak developed at Maine Yankee on December 17, 1990 (Oesterling 1990). The plant started shutting down at $4: 50$ am when the leak exceeded $7.9 \mathrm{\ell} / \mathrm{hr}(2.1 \mathrm{gph})$. By 5:21 am the leak rate peaked at $318 \mathrm{l} / \mathrm{hr}$. Subsequent inspections determined that the leak was from a $100 \mathrm{~mm}$ (4 inch) long axial crack at the top of the U-bend apex of the tube in Row 6, Column 43. All three Maine Yankee steam generators were inspected and ten other tubes were found and plugged in Rows 5 through 9 with smaller, but significant axial indications, on both the top and bottom of the tubes, in the U-bend region. These indications and the $100 \mathrm{~mm}$ axial crack are located in a region of the steam generator called the steam blanket region, where the tube supports depress the flow, creating a steam void. Secondary side contaminants are deposited on the tube surfaces in this region and buildup of these contaminants combined with the residual stresses introduced during fabrication, cause ODSCC. The Maine Yankee staff re-analyzed their post eddy-current data and found a 1988 signal which may have been a precursor to the failure.

Three Mile Island Unit 1 A leak of about 115 l/hr (30 gph) developed at Three Mile Island Unit 1 on March 6, 1990 at 8:23 am (Heysek 1990). Plant shutdown started at 9:12 am. Subsequent inspections found that the leak was from a $360^{\circ}$ circumferential crack in Tube A77-1 at the bottom of the upper tubesheet, Tube A77-1 is a peripheral tube located next to the open inspection lane. The crack is believed to be the result of environmentally assisted high-cycle fatigue. No other similar defects were found. The failed tube was plugged and stabilized. 
Table 14. Recent incipient steam generator tube rupture events.

\begin{tabular}{|c|c|c|c|c|c|}
\hline Plant & Datc & $\begin{array}{c}\text { Maximum Léak } \\
\text { Ratc }\end{array}$ & Delect Size & Defect Location & $\begin{array}{l}\text { Degradation } \\
\text { Mechanism } \\
\end{array}$ \\
\hline Braidwood Unit I & October 23, 1993 & $\approx 47 \mathrm{e} / \mathrm{hr}(12.5 \mathrm{ga} / \mathrm{hrr})$ & $\begin{array}{l}330 \operatorname{mum}(1.3 \mathrm{incl1}) \text { axial } \\
\text { crack }\end{array}$ & Above the top tube suppont plate near AVB & odscc \\
\hline $\begin{array}{l}\text { Arkansas Nuclear Onc, } \\
\text { Unit } 2\end{array}$ & March 9, 1992 & $57 \mathrm{l} / \mathrm{hr}(15 \mathrm{ga} / \mathrm{hr})$ & $\begin{array}{l}\text { Circuuffercential through- } \\
\text { wall crack }\end{array}$ & $\begin{array}{l}\text { Hot leg side of the tube in Row 67, Column 109, } 4.8 \mathrm{~mm} \\
\text { above the tubeshect in the explosive transition region }\end{array}$ & oDsCC \\
\hline MeGuire Unit I & January 16, 1992 & 37 e/hr (10 gal/hr) & $250 \mathrm{~mm}$ loug axial crack & $\begin{array}{l}\text { Cold Icg side of the tube in Row 47, Colunn 46, } 130 \mathrm{~mm} \\
\text { above llie lower tube support plate }\end{array}$ & ODSCC \\
\hline Maine Yankce & December 17, 1990 & $318 \mathrm{e} / \mathrm{hr}(84 \mathrm{gal} / \mathrm{hr})$ & $100 \mathrm{mn}$ long axial crack & Top of the U-bend of the tube in Row 6, Column 43 & ODSCC \\
\hline $\begin{array}{l}\text { Three Mile Island } \\
\text { Unit } 1\end{array}$ & March 6, 1990 & $=115 \mathrm{e} / \mathrm{hr}(30 \mathrm{gal} / \mathrm{hr})$ & $360^{\circ}$ circuniferemtial crack & $\begin{array}{l}\text { Peripheral tube A77-1 Inext to dic open inspection lane, } \\
\text { bottom of upper tubesticet }\end{array}$ & $\begin{array}{l}\text { High-cycle fatiguc (environuentally } \\
\text { assisted) }\end{array}$ \\
\hline Beaver Valley Unit 2 & Junc 21, 1989 & $80 \mathrm{l} / \mathrm{ir}(21 \mathrm{ga} / \mathrm{hr})$ & $\begin{array}{l}\text { 97\% ullrougliwall wear, } \\
\text { small rupture }\end{array}$ & $\begin{array}{l}\text { Hot leg side of the ubbe in Row } 31 \text {. Column } 16,25 \mathrm{~mm} \\
\text { above the tubesheet }\end{array}$ & Loose parts damage \\
\hline Indian Point Unit 3 & October 19, 1988 & $456 \mathrm{k} / \mathrm{hr}(120 \mathrm{ga} a / / \mathrm{tr})$ & $250^{\circ}$ circunfercutial crack & $\begin{array}{l}\text { Tube in Row 45, Columu 51, just above upper support } \\
\text { platc }\end{array}$ & Higl-cycle fatigue, denting \\
\hline
\end{tabular}


Beaver Vallev, Unit 2 A leak of about $80 \mathrm{l} / \mathrm{hr}$ (21 gph) developed at Beaver Valley Unit 2 on June 21, 1989 (Stoller 1989b). Subsequent investigations found that the leak was from a tube in Row 31, Column 16. The tube defect was about $25 \mathrm{~mm}$ ( 1 in.) above the tubesheet on the hot leg side and was due to loose part wear, which removed about $97 \%$ of the tube wall thickness. Three adjacent tubes (R31/C15, $\mathrm{R} 32 / \mathrm{C} 16$, and $\mathrm{R} 33 / \mathrm{C} 16$ ) were also damaged, with wall thickness losses ranging from 62 to $97 \%$ at about $25 \mathrm{~mm}$ above the tubesheet. The loose part was found resting on the tubesheet between the damaged tubes and was identified as an anti-rotation pin from a feedwater regulating valve which had failed earlier.

Indian Point Unit 3 A $456 \mathrm{l} / \mathrm{hr}$ (120 gph) leak developed at Indian Point Unit 3 on October 19, 1988 (Coulehan 1988) The leak developed over a period of 1 to 2.5 hours, but leveled off and remained constant until plant shutdown. Subsequent inspections identified a $250^{\circ}$ circumferential high-cycle fatigue crack in the tube in Row 45, Column 51, just above the upper most support plate. The tube was dented at the support plate due to support plate corrosion and the buildup of magnetite in the tube-to-support plate crevice. However, the Indian Point Unit 3 tube was properly supported by its AVBs.

Summary For some of these incipient steam generator tube rupture events, the operators were able to quickly shutdown the reactor and isolate the defective steam generator. (In other cases, the cracks stopped growing for unknown reasons.) These actions limited the contamination of the secondary coolant and may have prevented actual tube rupture. Also, some of these events demonstrated how quickly very low leak rates can increase as the crack grows. Leak rate monitoring programs that provide close to real time information can limit the frequency of steam generator tube ruptures. "At some sites, data from the air ejector radiation monitors is continuously displayed in the control room. At other sites, main steamline radiation monitors promptly detect increases in nitrogen-16 activity. When combined with appropriate alarm setpoints and operational limits, this information can quickly alert operators to implement response procedures to monitor increases in leak rates or to shut down the reactor and isolate the affected steam generator" (USNRC 1994). 


\section{THERMAL-HYDRAULIC RESPONSE OF A TYPICAL PWR PLANT WITH A DEFECTIVE STEAM GENERATOR}

Analyses were performed to investigate the consequences of a single steam generator tube rupture and to investigate the consequences of one or more tube ruptures during a design basis accident (a steam line break outside containment). As discussed in Section 4, a steam generator tube rupture is a break in a steam generator tube which results in a primary to secondary coolant system leak in excess of the normal charging flow capacity of the reactor coolant system (USNRC 1988a). In the event of a steam generator tube rupture, the goal of the operators is to safely place the reactor coolant system in a shutdown cooling mode, while minimizing radiological releases to the environment and maintaining adequate core cooling. The analysis presented in this section is based on a series of expected operator actions to terminate the break flow through the ruptured steam generator tube. The operator should reduce the reactor coolant system pressure below that of the affected steam generator and then continue the cooldown of the reactor coolant system to the point where the residual heat removal systems can be placed in operation.

A steam line break concurrent with a steam generator tube rupture was also evaluated. This event presents the possibility of a core melt since the break and emergency core cooling flow are lost to the secondary side of the defective steam generator and the cooling water from the refueling water storage tank will eventually be depleted with no accumulation of water in the containment sump. If the reactor coolant system is not cooled down in a timely manner, and boiling in the core is not prevented prior to exhaustion of the refueling water storage tank, core uncovery and core damage will ensue. Analysis of a multiple tube rupture, steam line break event was also performed to show that with as many as 15 failed tubes, timely actions by the operators can ensure that the plant can be safely placed in a long term cooling mode.

A description of the RELAP5 model is presented in Section 5.1. The symptoms and key operator actions are discussed in Section 5.2. The results of a double-ended steam generator tube rupture and a steam generator tube rupture combined with a steam line break analyses are presented in Sections 5.3 and 5.4, respectively. Section 5.5 presents the results of the multiple tube rupture, steam line break while Section 5.6 discusses the importance of the timing of the operator actions to recover from combined tube rupture, steam line break events. Section 5.7 summarizes the results and conclusions.

\subsection{Surry Plant and RELAP5 Model}

The Surry nuclear steam supply system was used for the accident simulations. Surry is a three loop, $2441 \mathrm{MWt}$, Westinghouse designed, pressurized water reactor. The RELAP5 code was used to simulate the thermal-hydraulic conditions in the reactor vessel, the piping in all three primary coolant loops, the pressurizer, the three steam generators, and selected parts of the secondary systems. This model consists of 208 thermal-hydraulic control volumes, 209 junctions connecting the control volumes, and 245 heat structures.

In the tube rupture event, a single, double-ended tube failure was assumed to occur just above the tube sheet at the inlet side of the primary tubes. This corresponds to a break size of $6.09 \mathrm{~cm}^{2}$ $\left(0.006555 \mathrm{ft}^{2}\right)$.

For the combined steam line break and tube rupture event, a double ended rupture of a tube was assumed to occur in the same location, however, a double-ended rupture of the steam 
line is also assumed to occur resulting in the maximum secondary side break of $0.13 \mathrm{~m}^{2}(1.4$ $\mathrm{ft}^{2}$ ). This break size is limited to this value due to the flow restrictor in the secondary steam lines.

Operator actions were also modeled to simulate the actions to throttle emergency cooling system injection, cooldown the reactor coolant system, and initiate operation of the residual heat removal systems. These actions are necessary to terminate the break flow for the tube rupture event, prevent boiling in the reactor coolant system, and prevent long term core uncovery for the combined steam generator, tube rupture steam line break accident.

The reactor vessel nodalization is shown in Figure 40. As indicated in the figure, the core is modeled with ten axial volumes. The upper head was also nodalized with additional volumes to simulate the voiding and associated nonequilibrium effects that develop in this region during the event.

Nodalization of the primary coolant loop $\mathrm{C}$ is shown in Figure 41 . With the exception of the pressurizer and associated surge line piping, similar nodalizations and number conventions are included in the model to represent primary coolant loops A (designated with 200 series of numbers) and B (designated with the 300 series of numbers) for Surry. Both fluid volumes and heat structures were included to represent the primary coolant loop piping, the pressurizer and associated surge line, and the steam generators. The emergency core cooling system is comprised of three accumulators, two high pressure safety injection pumps, and two low pressure safety injection pumps. The analyses assumed both trains of injection were available. The steam generator main and auxiliary feedwater systems and associated piping were also included in the secondary system modeling. Auxiliary feedwater is automatically actuated on low steam generator level. The external surfaces of all heat structures were assumed to be adiabatic.

A single valve was used to represent both PORVs connected to the pressurizer. Similarly, a single valve was used to represent all three pressurizer safety relief valves. It was assumed that there was sufficient plant air and battery power to allow operation of the valves throughout the transients where PORV actuation was credited.

For the tube rupture analysis, the break was modeled in Figure 41 as a junction connecting volume no. $408-1$ in the loop $\mathrm{C}$ generator to the secondary volume no. 476-1. For the combined steam line break-tube rupture event, the broken steam line was modeled as a junction from volume 482 to the atmosphere.

The residual heat removal (RHR) system was also modeled using the RELAP5/MOD3 control system logic. Appendix A describes the model used to compute the primary and shell side outlet temperatures for use in simulation of RHR system heat removal. Both RHR trains were modeled and were attached to loops B and C. The control system in RELAP5 was setup to extract water from the hot legs, cool the water with the RHR system and then re-inject the cooler water into the discharge legs of the reactor coolant pumps. Design data was used to compute the key parameters needed to calculate the heat removal capabilities of the RHR system.

A discussion of the steam generator tube rupture and combined steam line break and tube rupture events is presented in the following sections. Before the analysis results are presented, background information regarding the steam generator tube rupture event, along with a summary of the expected operator actions, are first presented. 


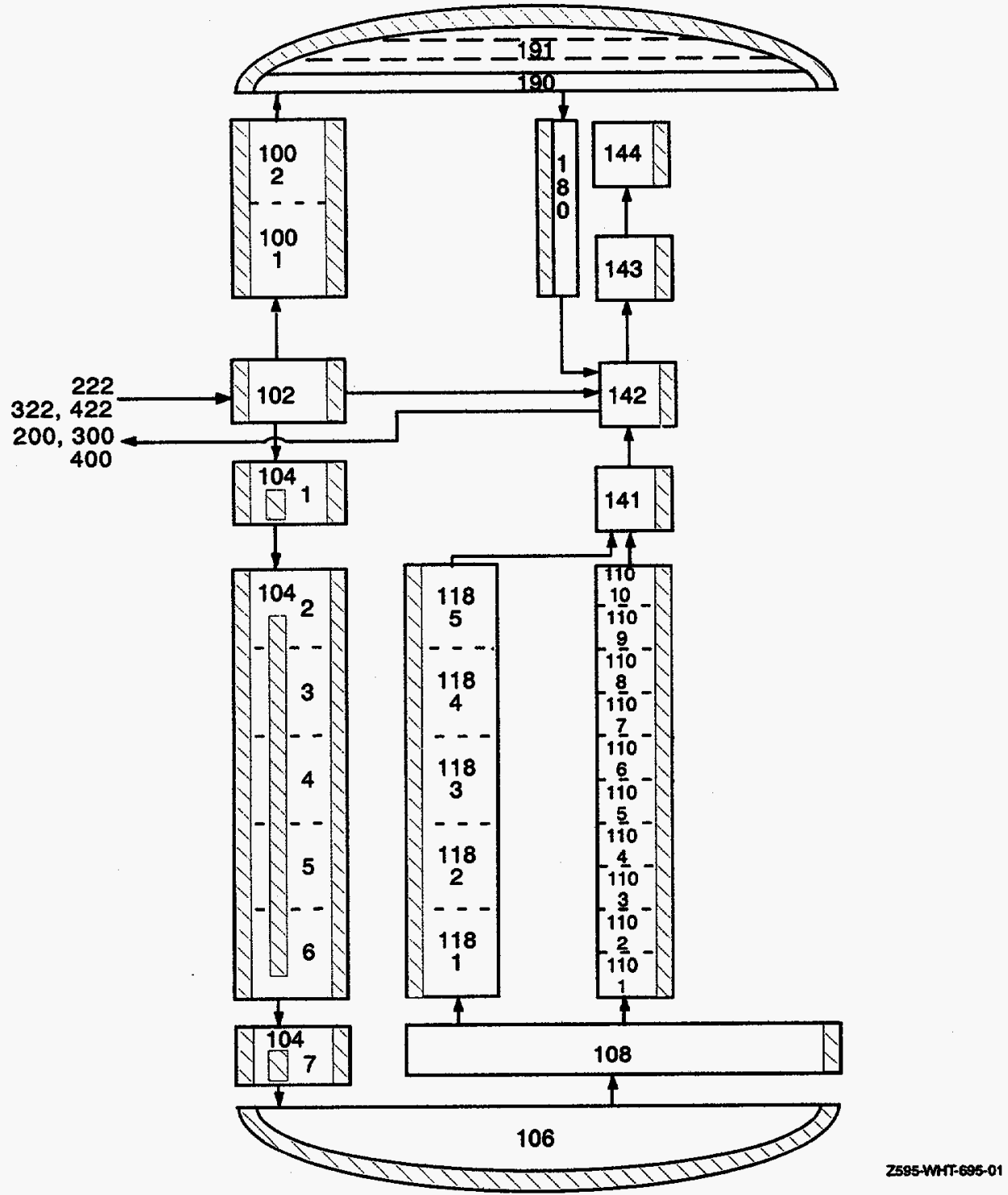

Figure 40. Surry reactor vessel nodalization. 

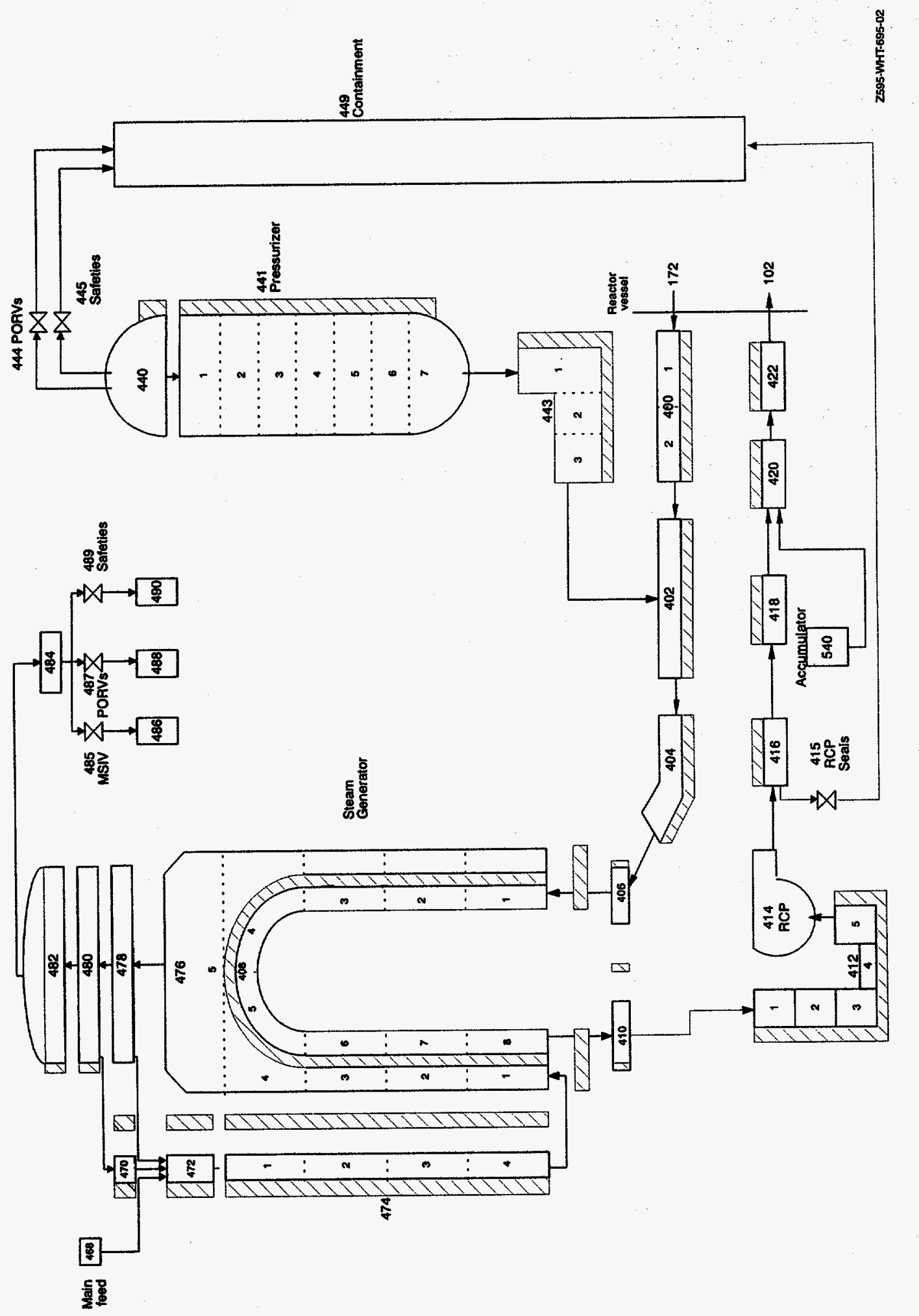

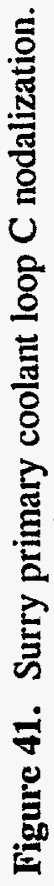




\subsection{Evaluation of the Steam Generator Tube Rupture Event}

As discussed above, the steam generator tube rupture event represents a violation of the barrier between the reactor coolant system and the main steam secondary system. The rupture can range from a failure of a small pit or crack in one tube to multiple, double-ended tube ruptures in a single generator or simultaneous ruptures in all steam generators.

For a double-ended rupture of a single tube, a reactor trip is expected within ten minutes should there be no operator intervention. Multiple failures would result in a more rapid depressurization. However, if the break flow is within the makeup capacity of the charging system, an automatic reactor trip may not occur. In this case, a controlled shutdown of the reactor would be performed utilizing the appropriate non-emergency procedures.

The following symptoms are characteristic of a steam generator tube rupture event:

- decreasing pressurizer level and pressure,

- decreasing level in the volume control tank,

- unaccounted increase in the charging and/or a decrease in the letdown flow rates,

- radiation monitors indicate an activity increase in the air ejectors, steam generator blowdown lines, the turbine or auxiliary building ventilation monitors, the stack monitor, and/or steam generator liquid sample,

- $\quad$ steam generator secondary level remains constant for a small rupture or increases slowly indicating a large rupture as a result of the primary to secondary leakage, and

- containment pressure and temperature remains unchanged.

The steam generator tube rupture event poses challenges to two safety functions; reactor coolant system inventory control and containment isolation or prevention of radionuclide release. As such, the objective in responding to a tube rupture event is to control reactor coolant system inventory and prevent radiological release. After isolating the leaking steam generator, this is accomplished by preventing the actuation of the secondary relief valves. The secondary relief valves can be lifted by heat addition from the primary side or by primary to secondary leakage with the reactor coolant system at pressures greater than the secondary relief valve setpoint. The optimum response to control the reactor coolant system inventory and radionuclide containment is to minimize the reactor coolant system to secondary system pressure differential as soon as possible by reducing reactor coolant system pressure below the secondary safety valve setpoint, and to control reactor coolant system temperature to preclude lifting the secondary valves through the addition of heat from the primary.

Fission products and activated corrosion products normally suspended in the reactor coolant system will be transferred from the primary to secondary plant during a tube rupture event. The steam plant vents and exhausts provide a potential path to the environment for these radioactive products. The passage of fission and activated corrosion products from the primary to the secondary side of the failed steam generator will produce increased levels of activity in the steam generator liquid sample. A high radiation alarm could occur in the steam generator blowdown monitoring system. Activated products (mostly noble gases) will be carried into the steam plant by the main steam flow. The non-condensible 
gases may eventually be expelled to the environment by way of the stack through the air ejector exhaust and may actuate the radiation monitoring system. As a result of emitted gases and the build-up of activity in the failed steam generator general area, radiation levels in the turbine and auxiliary building may also increase and actuate the radiation alarms in these areas.

In summary, following a steam generator tube rupture, cooldown of the reactor coolant system is initiated, so that once the affected steam generator is isolated, the reactor coolant system is prevented from transferring sufficient heat to cause the secondary relief valves to lift. The actions to control reactor coolant system inventory combined with control of reactor coolant system pressure also preclude the release of radioactivity through the secondary relief valves. A summary of the key operator actions following a tube rupture event is given below.

- $\quad$ Assure a reactor trip and emergency core cooling system is actuated.

- Identify and isolate the failed steam generator.

- $\quad$ Assure containment isolation exists.

- Initiate reactor coolant system cooldown by dumping steam to condenser or opening secondary PORVs.

- Depressurize the reactor coolant system using normal pressurizer or auxiliary spray until the reactor coolant system pressure is below the affected steam generator pressure. Pressurizer PORVs are used if sprays are unavailable.

- Throttle emergency core cooling injection while maintaining minimum subcooling of $16.7^{\circ} \mathrm{C}\left(30^{\circ} \mathrm{F}\right)$.
•

\begin{abstract}
Continue cooldown of reactor coolant system to shutdown cooling conditions and actuate RHR for long-term decay heat removal. The RHR system can be placed in operation once reactor coolant system pressure has been reduced below 3.2 $\mathrm{MPa}$ (465 psia) and temperature has been reduced to $177^{\circ} \mathrm{C}\left(350^{\circ} \mathrm{F}\right)$.
\end{abstract}

\subsection{Results of the RELAP5 Simulation of a Double-Ended Rupture of a Steam Generator Tube}

This section presents the results of the RELAP5 simulation of the double-ended steam generator tube rupture event. The analysis includes the actuation of the residual heat removal system.

The transient begins with the tube rupture, which causes the RELAP5 calculated reactor coolant system pressure, shown in Figure 42, to decrease producing a reactor trip at about 272 seconds.

The loss of coolant from the reactor coolant system also causes the RELAP5 calculated pressurizer level to decrease during the first 300 seconds, as shown in Figure 43. During the initial depressurization, a safety injection actuation signal is produced, actuating the high pressure safety injection system, which begins refilling the pressurizer after about 300 seconds. Actuation of high pressure safety injection also repressurizes the reactor coolant system to about 14.5 $\mathrm{MPa}$ (2100 psia) from about 800 to 1,200 seconds as shown in Figure 42. The RELAP5 calculated high pressure safety injection and break flow rates are plotted in Figure 44. Note that the high pressure safety injection flow exceeds the break flow initially, then decreases as the high pressure safety injection pumps repressurize the reactor coolant system until the high pressure safety injection matches the break during the 800 to 1,200 second internval. This condition is undesirable due to the continued primary to secondary break flow and the heat 


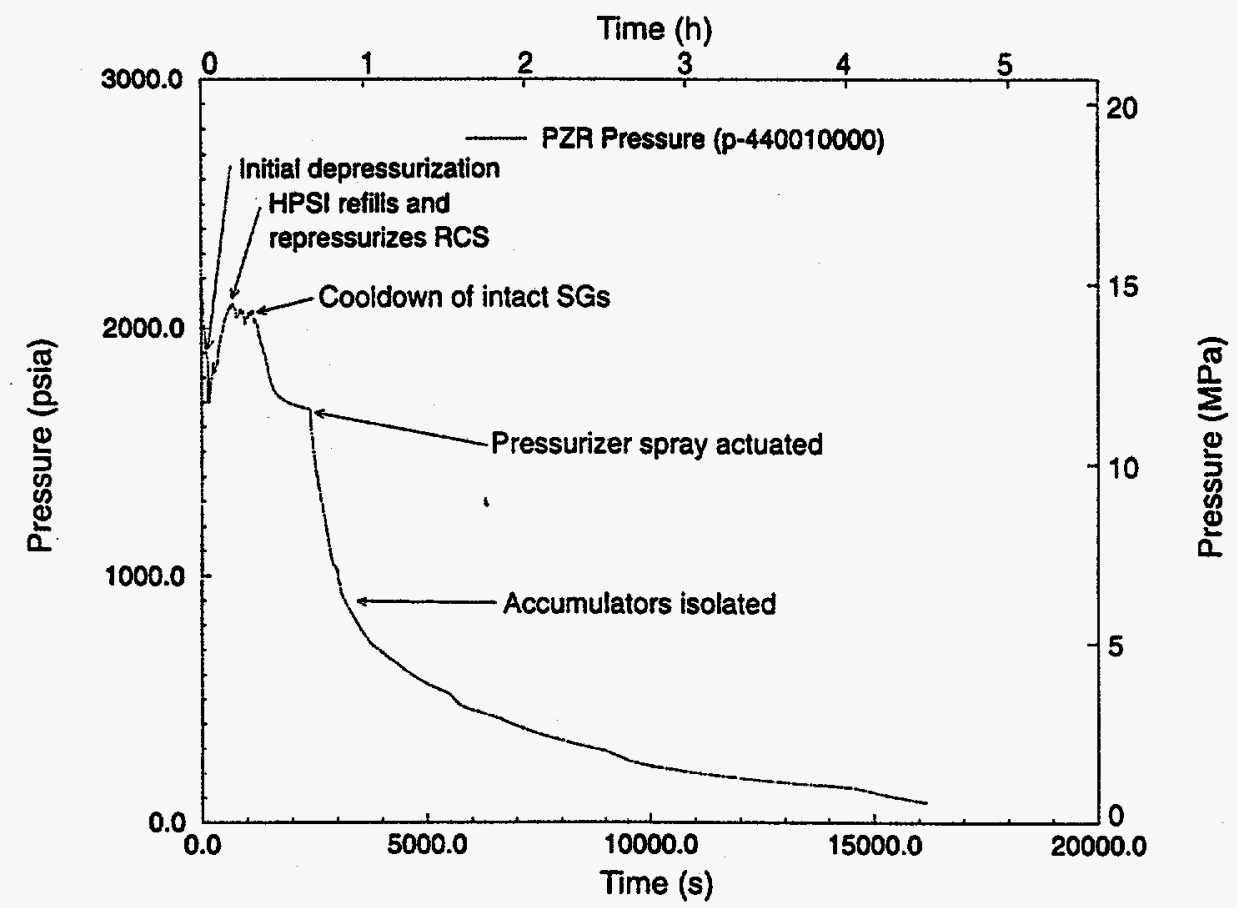

Figure 42. Pressurizer pressure vs. time (steam generator tube rupture).

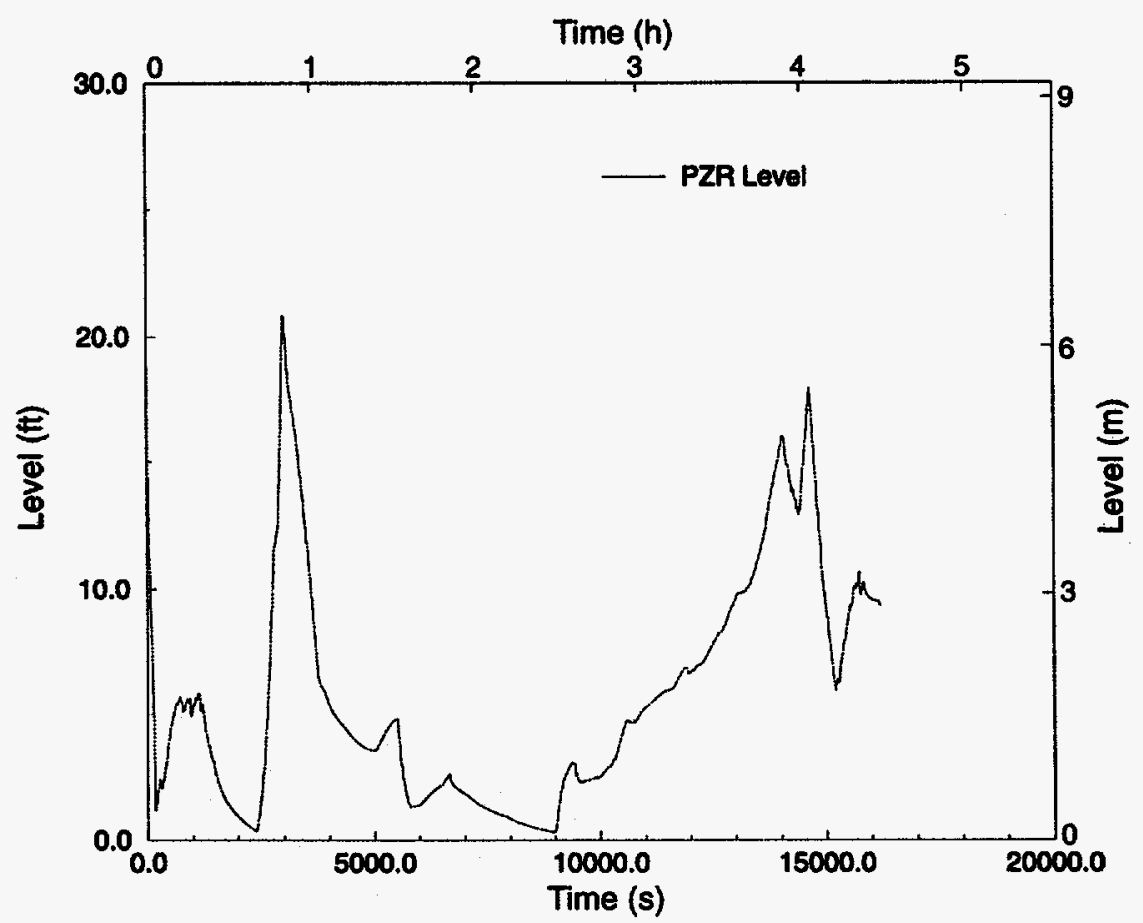

Figure 43. Pressurizer level vs. time (steam generator tube rupture). 


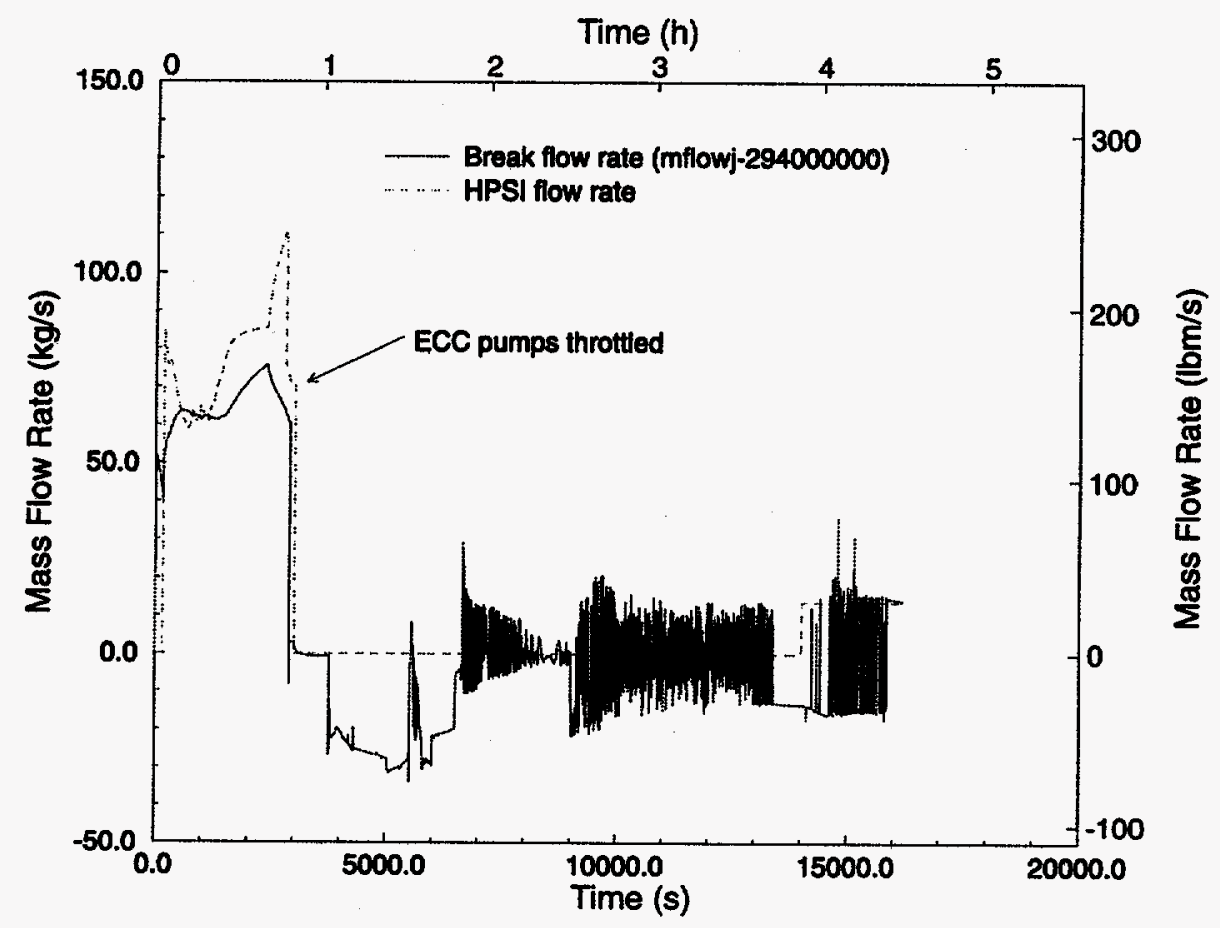

Figure 44. Break and high pressure safety injection flow vs. time (steam generator tube rupture).

transfer from the primary to secondary system which causes the secondary relief valves to lift early in the event. The secondary PORVs are opened on the intact steam generators at 1,200 seconds to facilitate cooldown of the reactor coolant system. Figure 45 shows the intact and affected steam generator pressures and the depressurization of the intact generators which was initiated at 1,200 seconds into the event. As noted in Figure 42, cooldown of the reactor coolant system using the intact steam generators reduces reactor coolant system pressure after 1,200 seconds. However, to enhance the depressurization and terminate the release of radioactivity through the secondary relief valves, the pressurizer sprays are actuated at 2,400 seconds into the event. Actuation of the sprays produces a marked increase in the depressurization rate as shown in Figure 42, effectively terminating the break flow as a result of reducing reactor coolant system pressure below the affected steam generator pressure. Figure 46 shows the primary pressure reduction in the affected steam generator. The reactor coolant system pressure is finally reduced below the affected steam generator pressure at about 3,000 seconds, terminating the break flow. The release of radioactivity through the affected steam generator is also terminated at this time, preventing any further releases through the relief valves at approximately 3,000 seconds, as shown in Figure 47. As noted in Figure 44, high pressure safety injection flow is also throttled at about 2,800 seconds to prevent overfilling of the 
THERMAL-HYDRAULIC RESPONSE

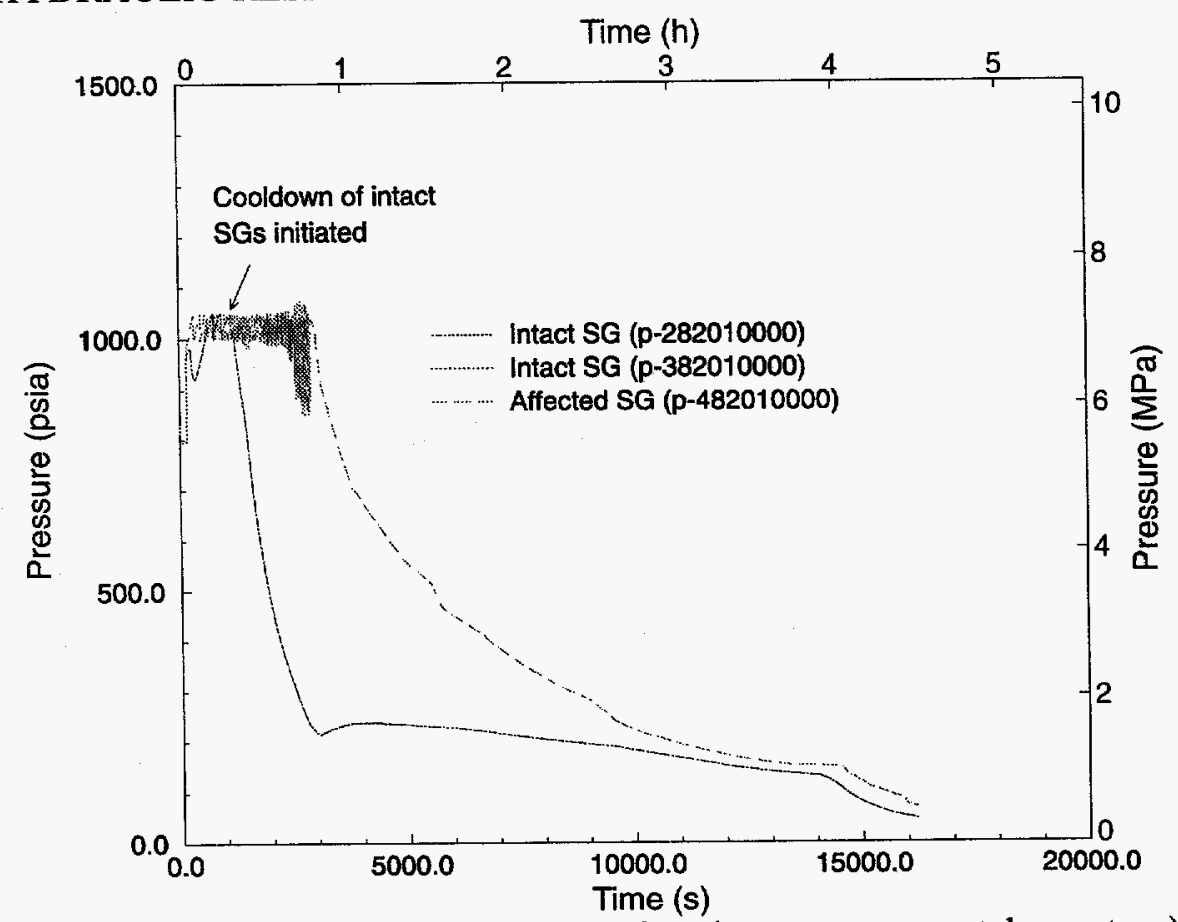

Figure 45. Steam generator secondary pressure vs. time (steam generator tube rupture).

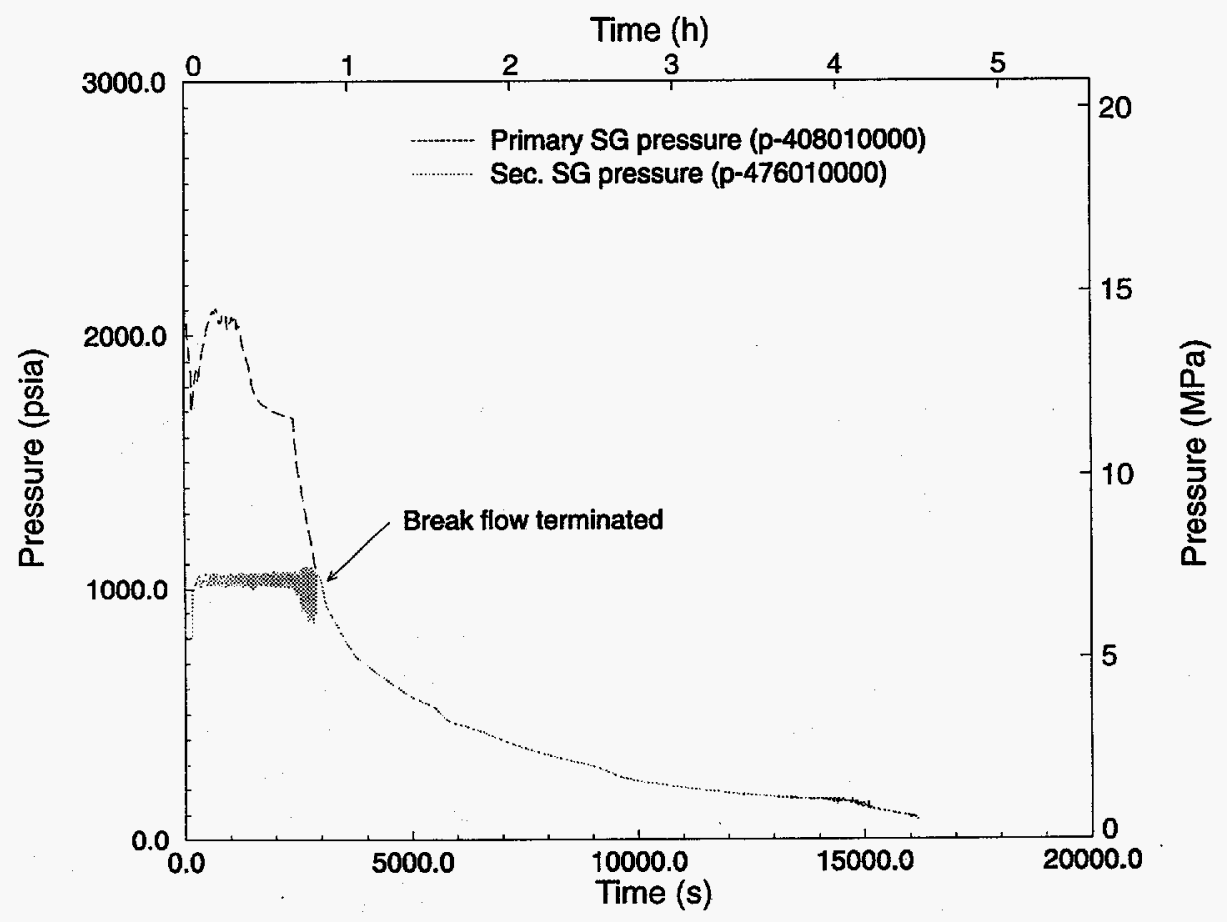

Figure 46. Primary steam generator and secondary pressure vs. time (steam generator tube rupture). 


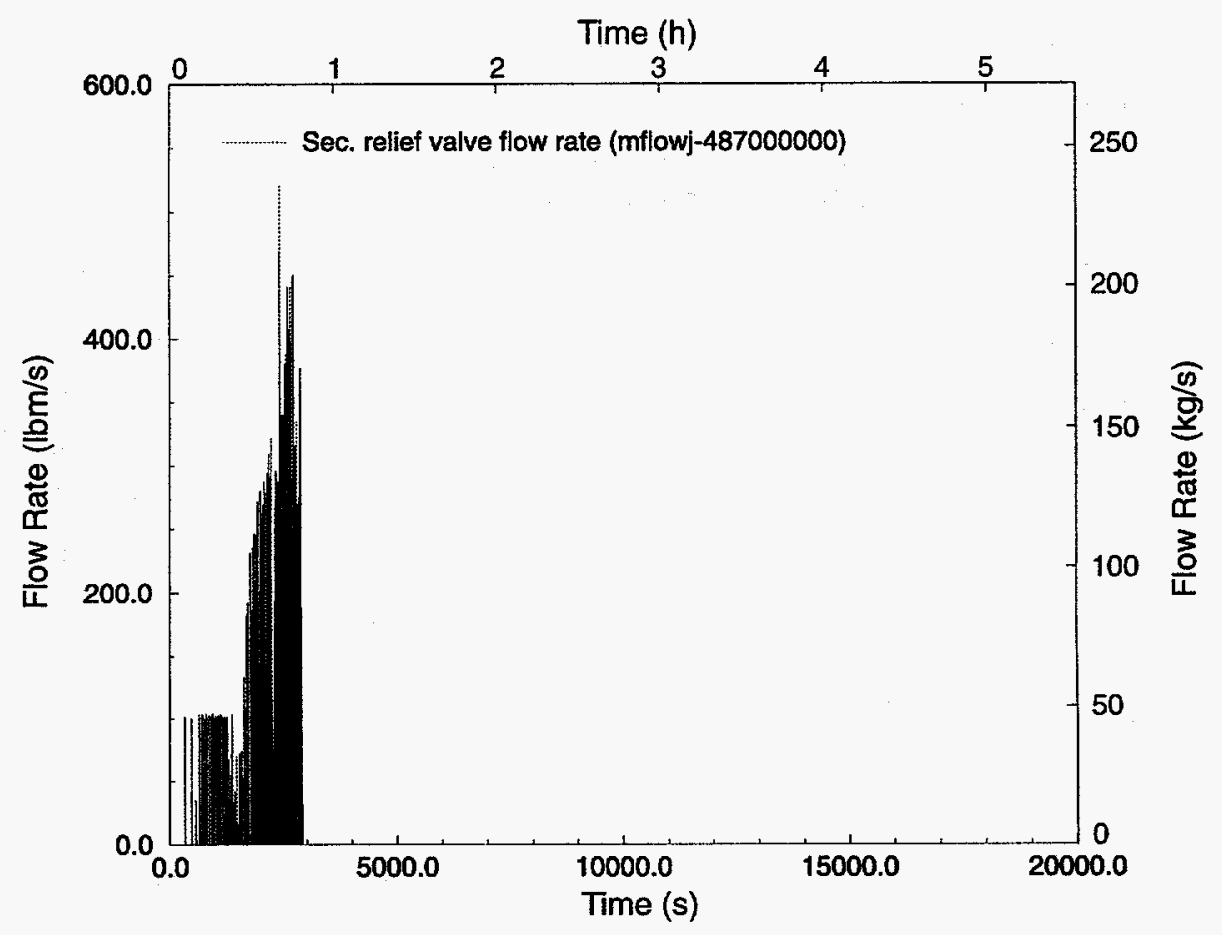

Figure 47. Secondary relief valve flow rate vs. time (steam generator tube rupture).

pressurizer and pressurizing of the reactor coolant system. The pressurizer sprays, along with the letdown flow and high pressure safety injection, are used throughout the remainder of the event to control the pressurizer level and facilitate reactor coolant system depressurization until the residual heat removal systems can be placed in service. As noted in Figure 48, the RHR system is actuated at 14,000 seconds, when the reactor coolant system temperature was reduced below $177^{\circ} \mathrm{C}\left(350^{\circ} \mathrm{F}\right)$ and the reactor coolant system pressure was reduced below 3.2 MPa (465 psia). As depicted in Figure 48, actuation of the RHR system accelerates the cooldown of the reactor coolant system as the shutdown cooling mode is established and decay heat can be removed for an extended period of time.

Figures 49 through 53 present the remainder of the parameters of interest to the tube rupture event.
Figure 49 shows the wide and narrow range secondary levels in the affected steam generator, displaying the increase in level characteristic of a double-ended steam generator tube rupture event.

Figure 50 shows the RHR system inlet and outlet temperatures following actuation of the residual heat removal system at 14,000 seconds.

Figure 51 presents the pressurizer spray flow rate while the letdown flow rate is given in Figure 52. Note that the pressurizer flow rate is decreased and the letdown flow is increased during the 3000 to 9000 second interval to prevent overfilling and cooling of the pressurizer. Note that the letdown flow is needed to control the pressurizer level during the event since once the reactor coolant system pressure has been reduced below the affected steam generator pressure, the affected steam generator becomes a source of water for the reactor coolant system. See Figure 44 after about 3,800 seconds into the event. 


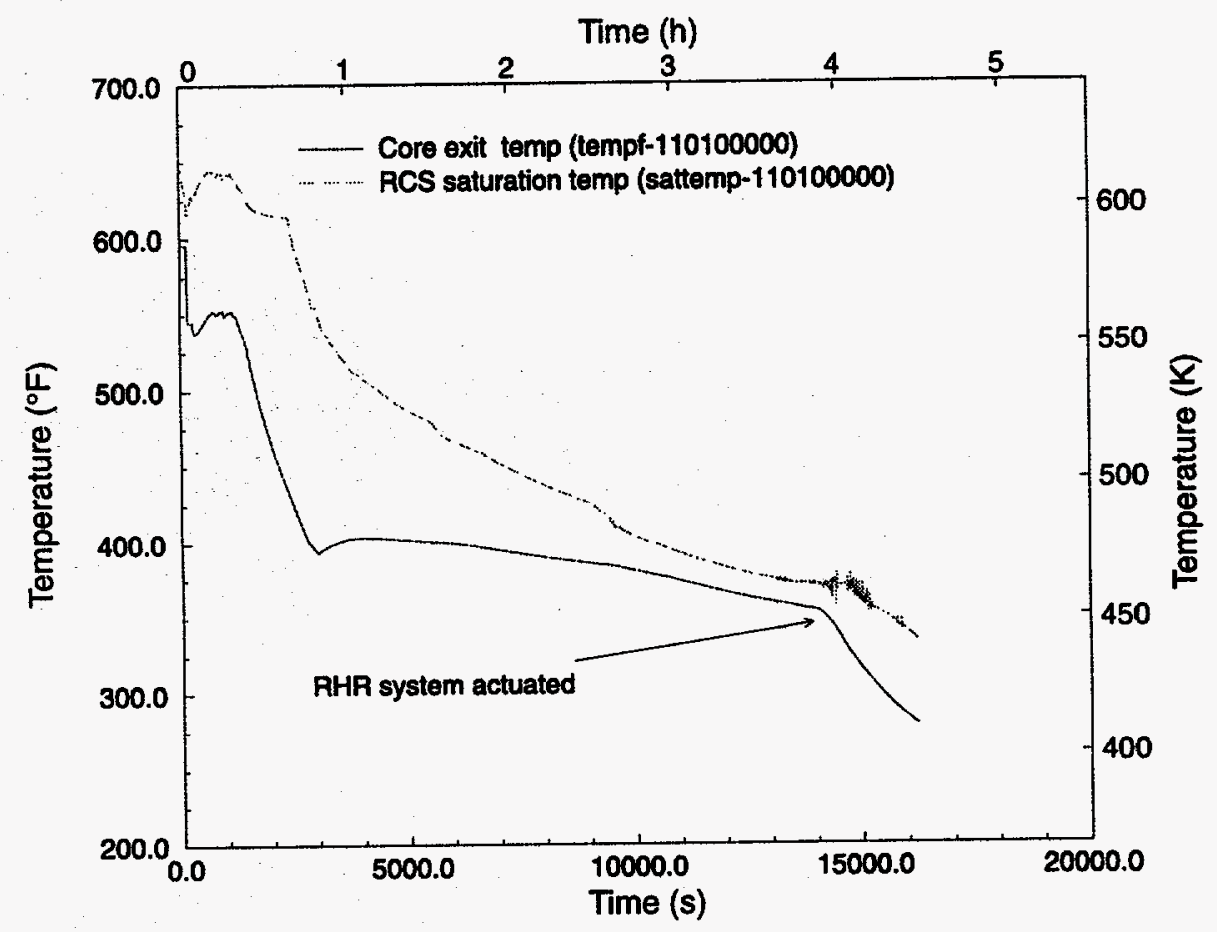

Figure 48. Reactor coolant system subcooling vs. time (steam generator tube rupture).

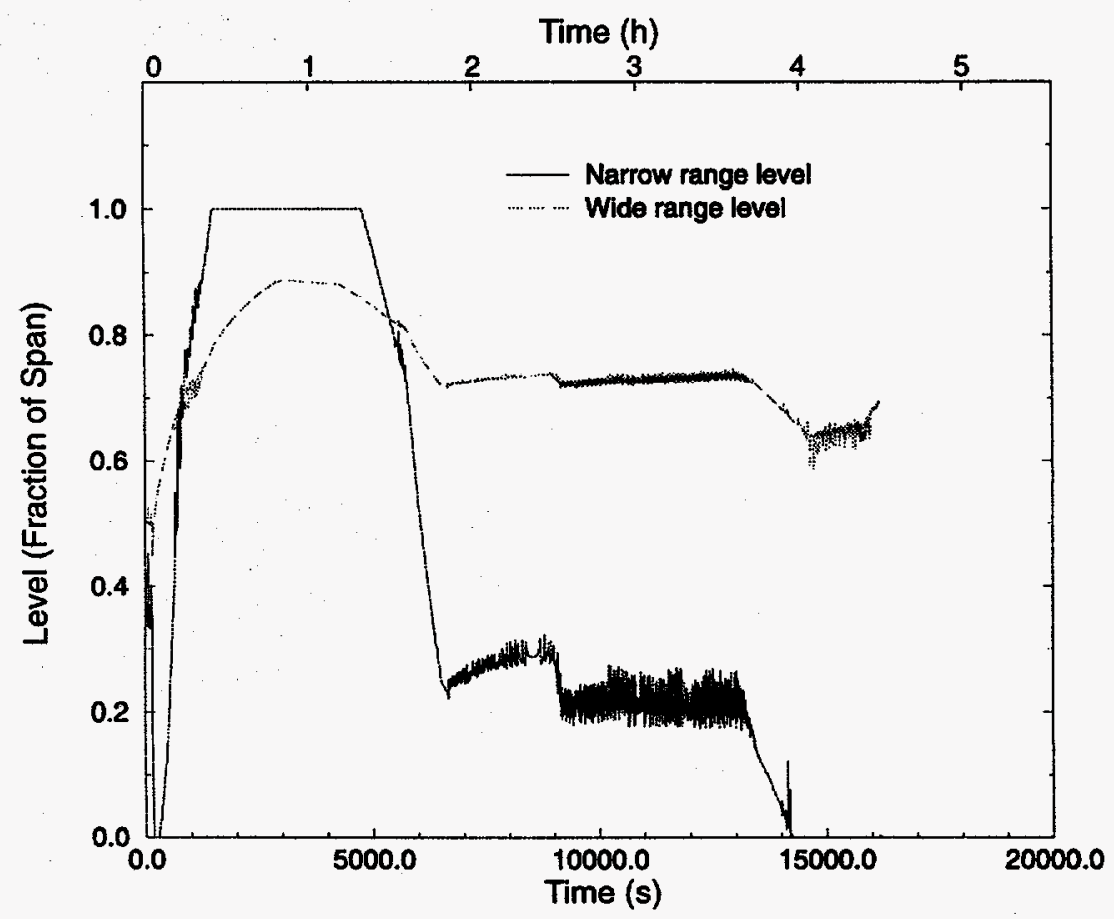

Figure 49. Failed steam generator wide and narrow range levels vs. time (steam generator tube rupture). 


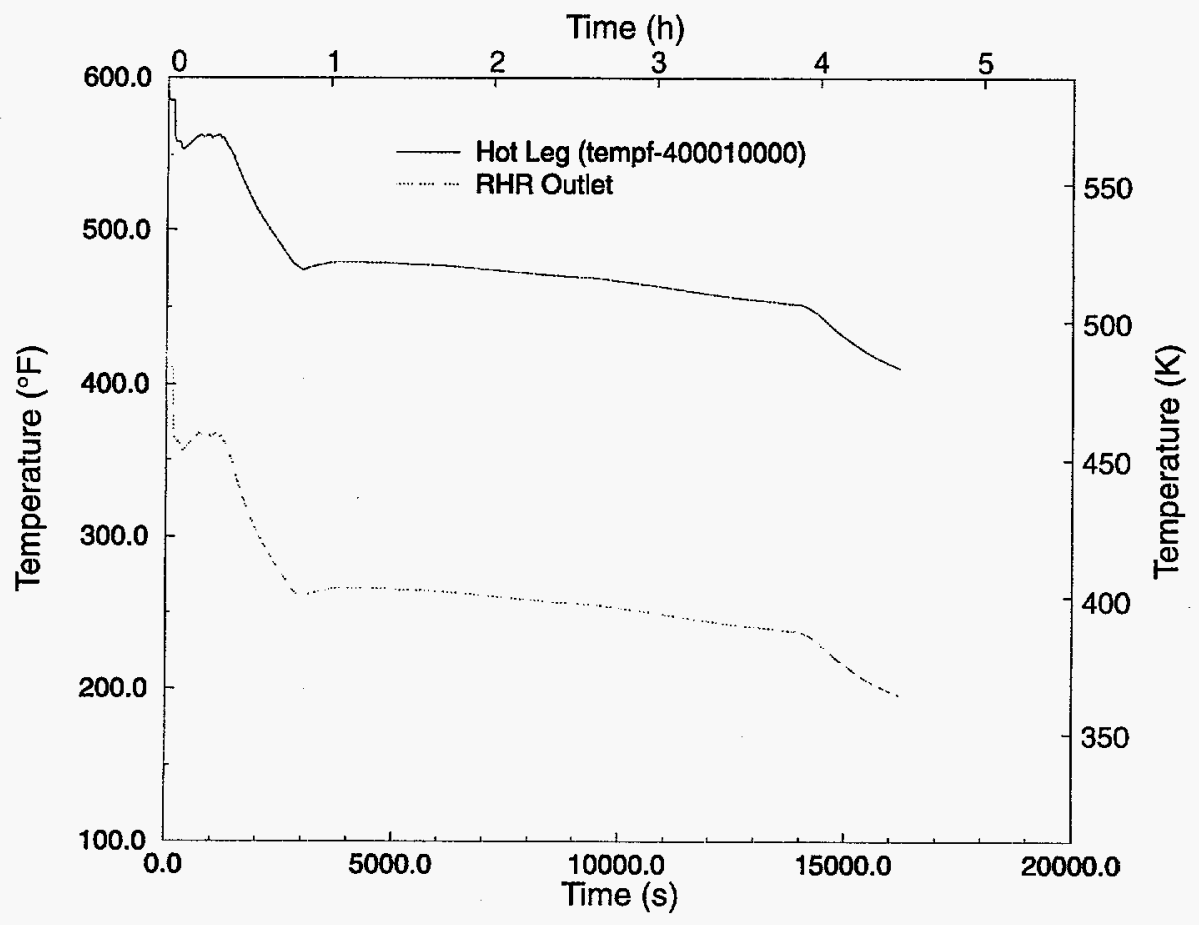

Figure 50. Residual heat removal system inlet and outlet temperatures vs. time (steam generator tube rupture).

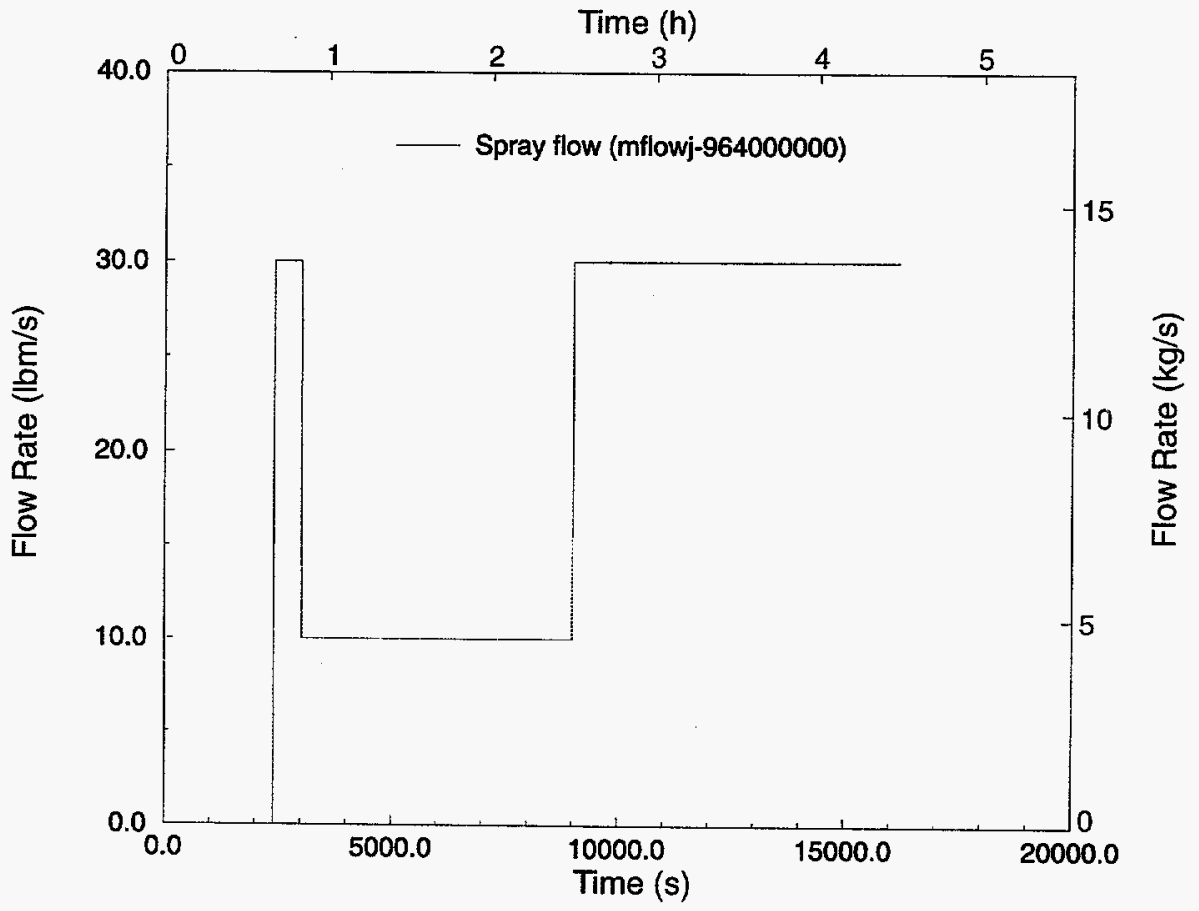

Figure 51. Pressurizer spray flow rate vs. time (steam generator tube rupture). 


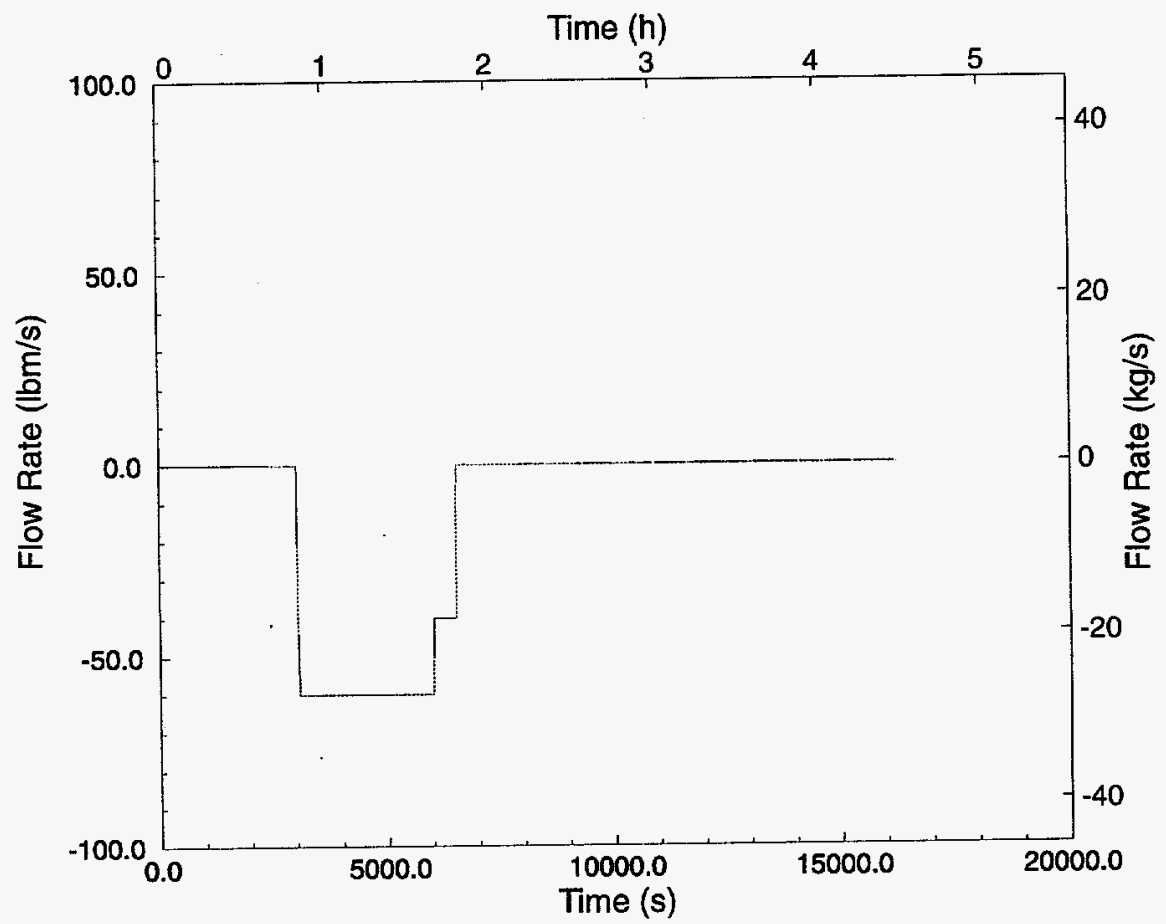

Figure 52. Reactor coolant system letdown flow rate vs. time (steam generator tube rupture).

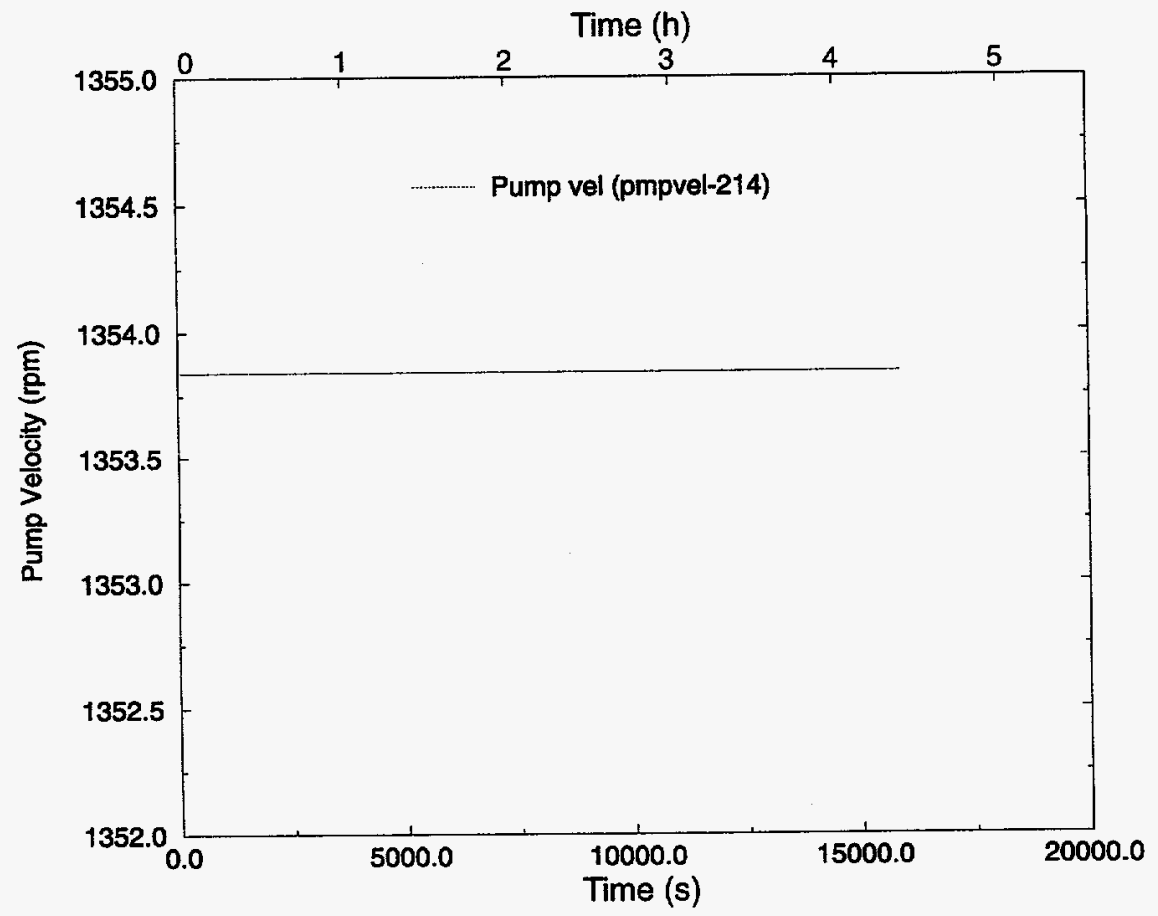

Figure 53. Reactor coolant pump velocity vs. time (steam generator tube rupture). 
Figure 53 presents the reactor coolant pump velocity showing that conditions were not achieved requiring trip of these pumps. As such, normal spray is available and cooldown of the reactor coolant system is very effective.

A summary of the key events and operator actions for this event is summarized in Table 15 .

\subsection{Results of the RELAP5 Simulation of a Steam Line Break with One Steam Generator Tube Failed}

This section discusses the results of the steam line break combined with a single steam generator tube rupture. Figure 54 presents the RELAP5 calculated reactor coolant system pressure (pressurizer pressure) for a single, double-ended tube rupture concurrent with a steam line break. The steam line break causes an initial rapid depres- surization during the first 100 seconds. The excessive reactor coolant system heat removal due to the secondary break causes the system to contract and the pressurizer quickly empties during this 100 second period, as shown in Figure 55. The RELAP5 calculated reactor vessel level is shown in Figure $\mathbf{5 6}$ for additional information. Actuation of the two high pressure safety injection pumps occurs from a low pressurizer pressure signal. With only a single tube ruptured, the high pressure safety injection pumps quickly refill the reactor coolant system, marked by the increase in pressurizer level at about 300 seconds as noted in Figure 55. The reactor coolant system subcooling is not lost due to the overcooling and actuation of the high pressure safety injection. As such, the hot leg temperature remains well below the saturation temperature as shown in Figure 57.

Table 15. Double-ended failure of a steam generator tube: Sequence of events and key assumptions.

Steam Generator Tube Break Size (double-ended rupture)

Reactor Coolant Pump Trip Time

Secondary Cooldown Initiation Time Using Atmospheric Dump Valves (Intact Steam Generators)

Pressurizer Sprays Actuated

Time High Pressure Safety Injection First Throttled

Break Flow Terminated due to Depressurization

Secondary Relief Valve Flow Terminated

Accumulators Isolated

Conditions Achieved for RHR Entry

Time RHR Placed Inservice

$$
\begin{aligned}
& =0.006555 \mathrm{ft}^{2} \\
& =\quad 272 \mathrm{sec} \\
& =\quad 1,200 \mathrm{sec} \\
& =\quad 2,400 \mathrm{sec} \\
& =\quad 2,800 \mathrm{sec} \\
& =\quad 3,000 \mathrm{sec} \\
& =\quad 3,000 \mathrm{sec} \\
& =\quad 3,600 \mathrm{sec} \\
& =\quad 14,000 \mathrm{sec} \\
& =\quad 14,000 \mathrm{sec}
\end{aligned}
$$


THERMAL-HYDRAULIC RESPONSE

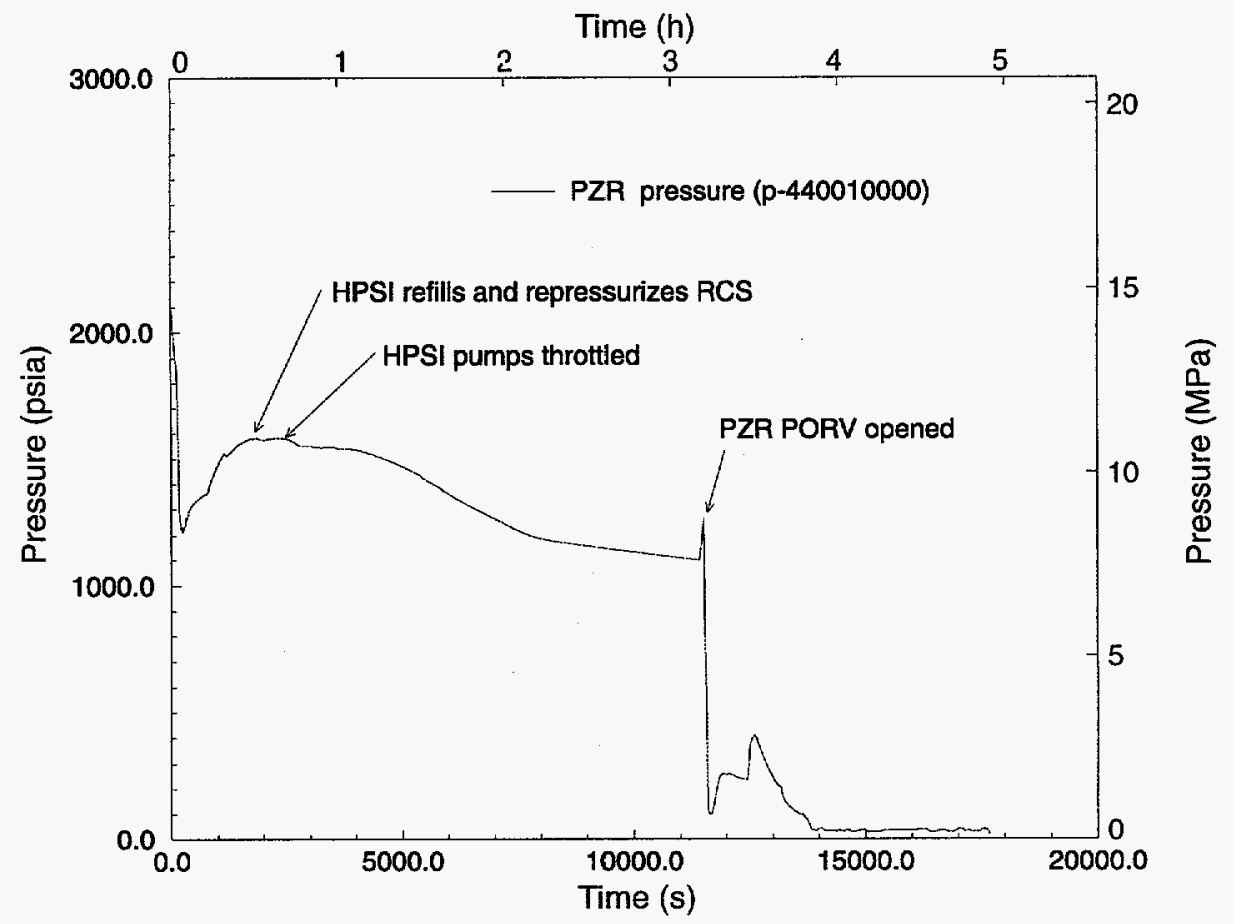

Figure 54. Pressurizer pressure vs. time (steam line break with 1 SGTR).

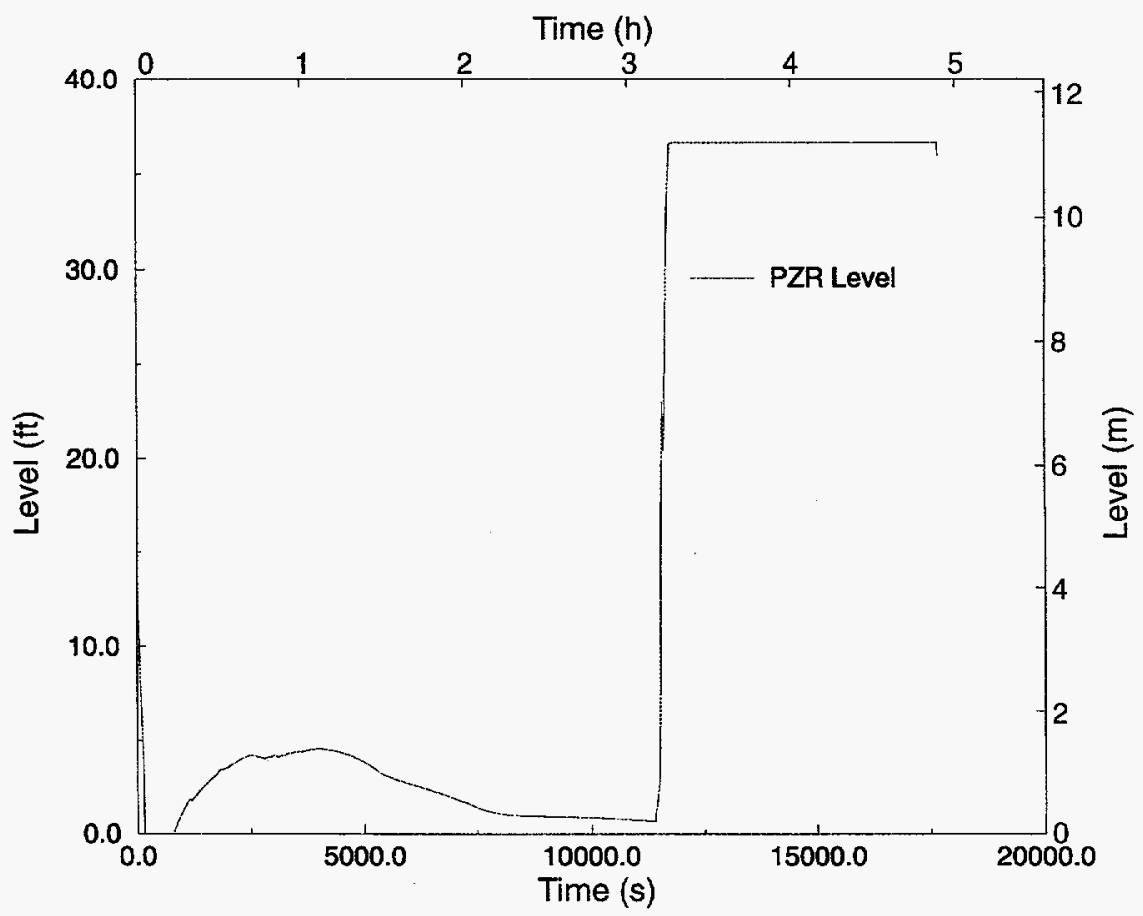

Figure 55. Pressurizer level vs. time (steam line break with 1 SGTR). 


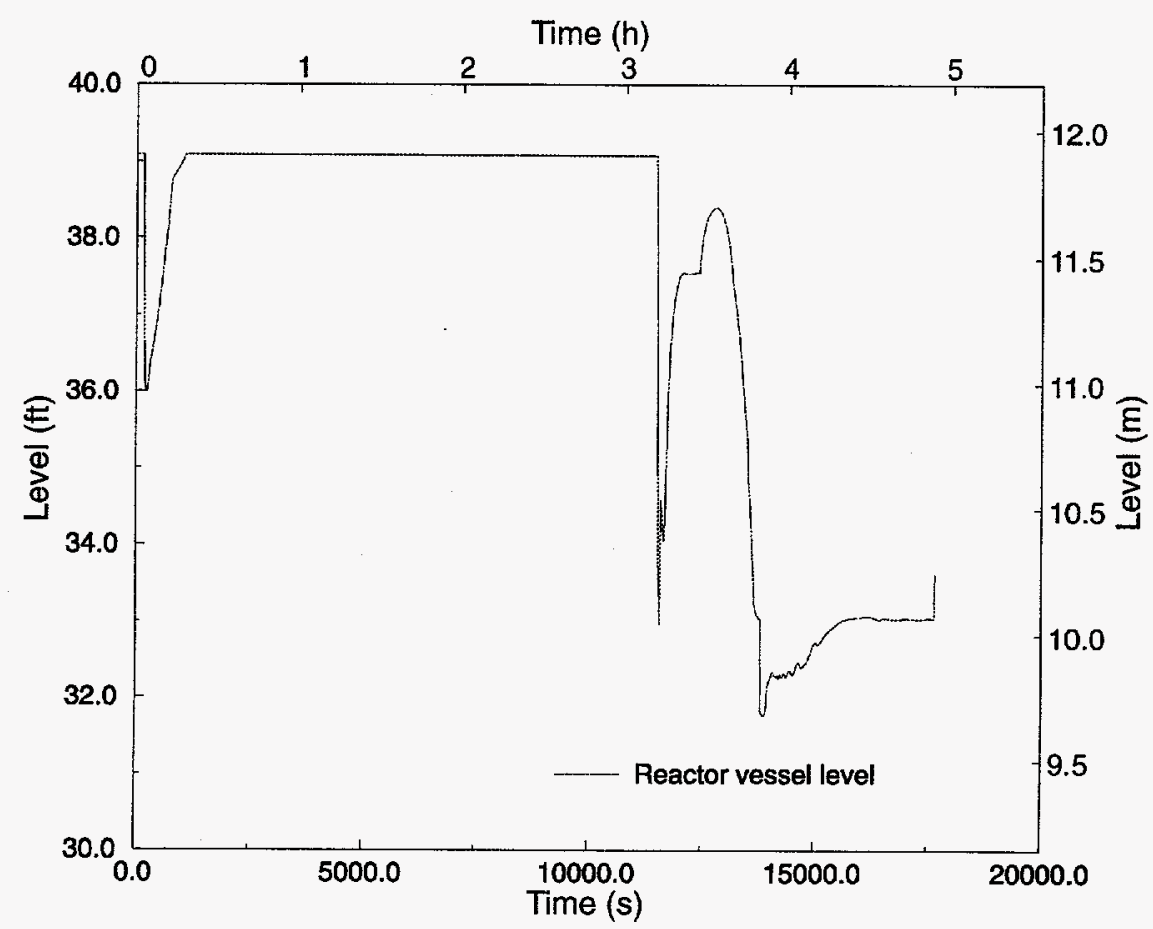

Figure 56. Reactor vessel level vs. time (steam line break with 1 SGTR).

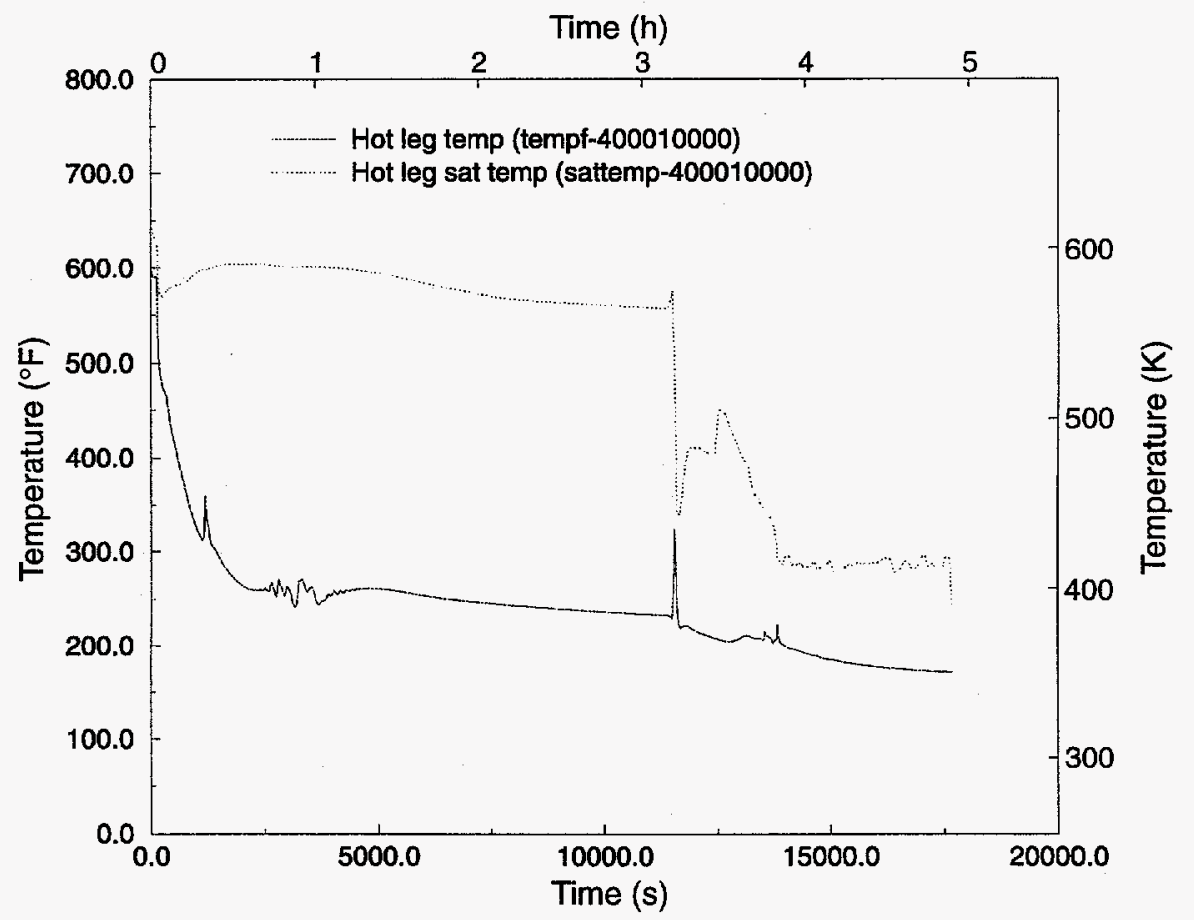

Figure 57. Reactor coolant system hot leg temperature vs. time (steam line break with 1 SGTR). 
With high pressure safety injection actuation, the increasing inventory in the pressurizer causes the reactor coolant system pressure to recover at about 2,000 seconds into the event and stabilize at a value of about $11 \mathrm{MPa}$ (1600 psia), as noted in Figure 54. This peak pressure is controlled by the high pressure safety injection pumps, which have pressurized the reactor coolant system to the condition where the injection flow approaches the break flow through the failed steam generator tube at about 2,000 seconds, as illustrated in Figure 58.

At 1,800 seconds, high pressure safety injection flow is reduced, as shown in Figure 58, to reduce reactor coolant system pressure while also preventing loss of pressurizer level. To prevent the pressurizer from draining, the high pressure safety injection is throttled slowly during the remainder of the event. Because reactor coolant system pressure cannot be reduced in sufficient time to initiate RHR operation at 3.1 MPa (450 psia) prior to exhaustion of the refueling water storage tank, the pressurizer PORV is actuated at 11,500 seconds to reduce the reactor coolant system pressure, as shown in Figure 54. Note that Figure 59 presents the integrated injection flow versus time, where with extrapolation of the initial injection rates, loss of refueling water storage tank inventory would occur at about 19,000 seconds or at a refueling water storage tank inventory of $1.45 \times 10^{6} \mathrm{Kg}(387,100 \mathrm{gal})$.

Note that the high pressure safety injection shown in Figure 58 is increased to the maximum prior to opening of the PORV. Once pressure has stabilized, the high pressure safety injection flow is again throttled and the low pressure safety injection flow is terminated to maintain a low reactor coolant system pressure for the remainder of the event. This final emergency core cooling throttling will delay exhaustion of the refueling water storage tank until about 26,000 seconds, based on the extrapolation shown in Figure 59. With the reactor coolant system pressure and hot leg temperature below entry conditions for the RHR system operation, a single RHR train is placed in operation at 13,000 seconds, as shown in Figure 60. Figure 60 presents the RHR inlet and outlet temperature responses demonstrating that reactor coolant system hot leg temperature is reduced below about $100^{\circ} \mathrm{C}\left(212^{\circ} \mathrm{F}\right)$ at approximately 14,000 seconds into the event. The operation of at least one RHR train will maintain the core in a subcooled condition for the duration of the event. With the break in the steam generator active tube region, the reactor coolant system liquid level will not recede much below the elevation of the break in the steam generator. Continued operation of at least one RHR system is essential to maintain the core in a subcooled condition for an extended period of time.

Figure 61 presents the secondary pressure in the broken steam generator. Comparison with Figure 54 shows the large pressure differential that can develop between the primary and secondary system during this event.

Figure 62 shows the steam flow rate from the broken steam line. Figure 63 presents the pressurizer PORV flow rate during the transient, showing actuation at 11,500 seconds.

Figure 64 presents the reactor coolant pump coastdown showing the manual trip at about 200 seconds into the event. A reactor coolant pump trip is required should reactor coolant system pressure decrease below 9.4 MPa (1390 psia).

Figure 65 presents the intact steam generator pressure during the event. To assist in reactor coolant system cooldown, the secondary steam dump valves using the secondary PORVs were also opened at 1800 seconds. The secondary steam dump flow rate during the transient is shown in Figure 66.

Table 16 presents a summary of the key assumptions and events for steam line break tube rupture event discussed below. 


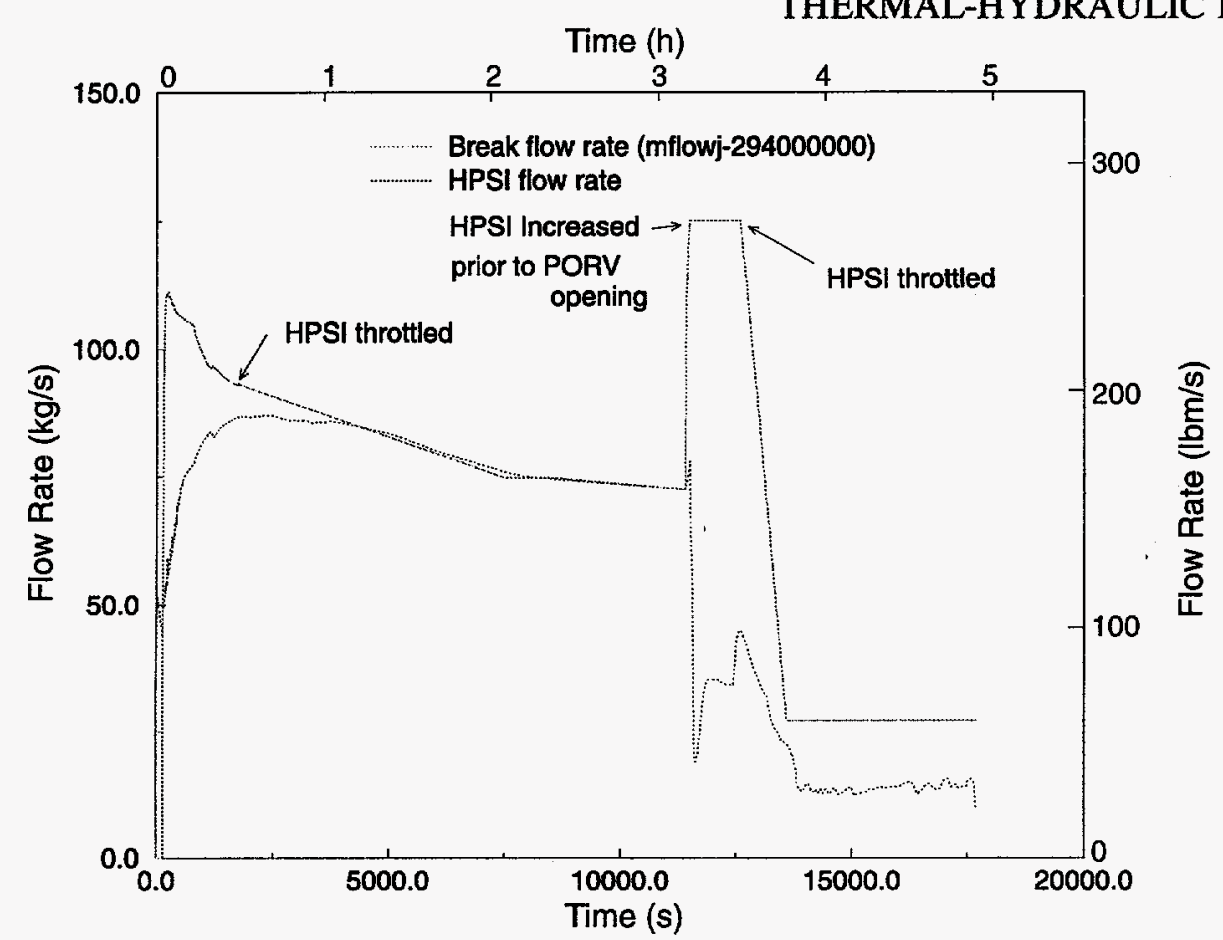

Figure 58. Break and high pressure safety injection flow rates vs. time (steam line break with 1 SGTR).

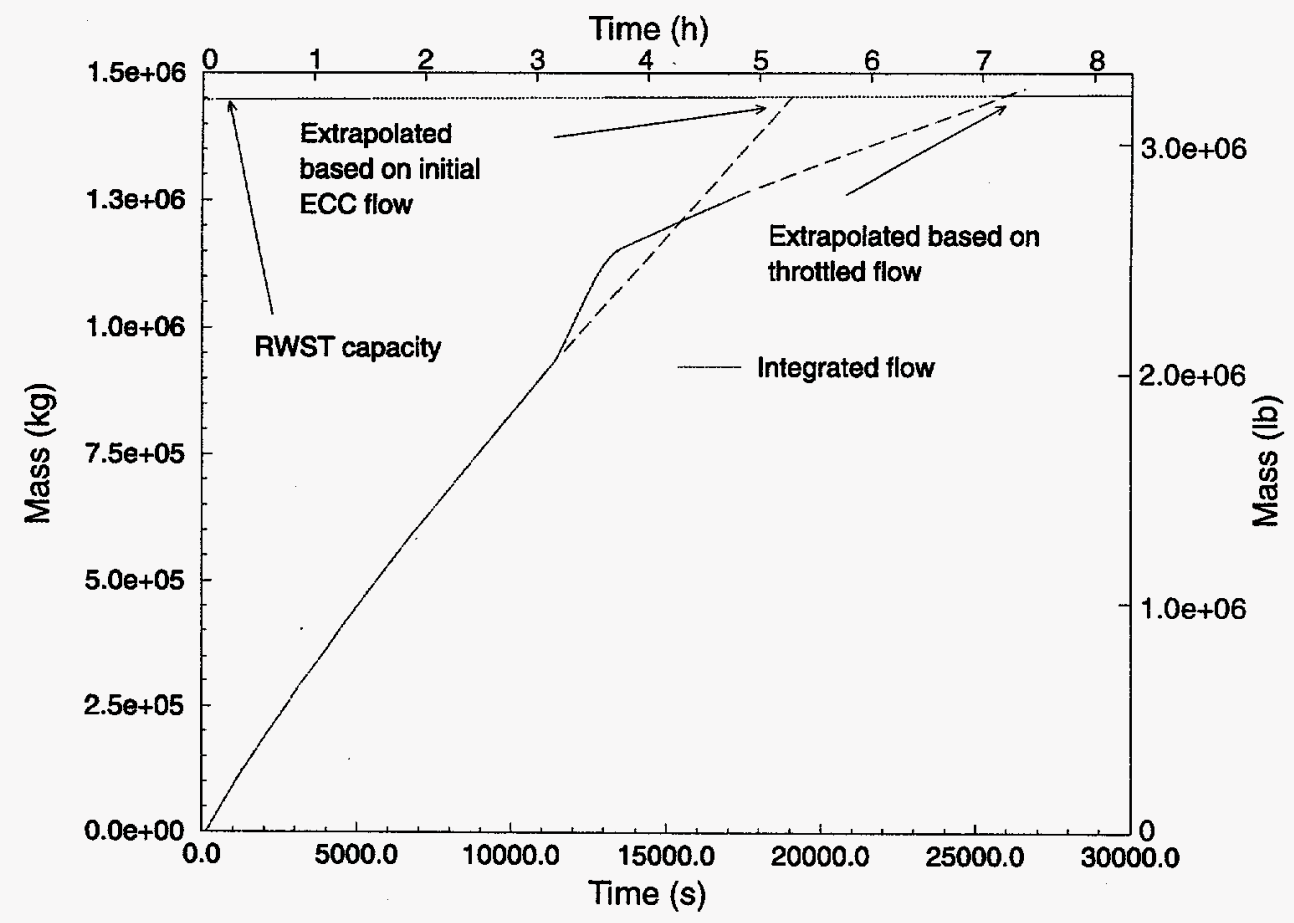

Figure 59. Integrated safety injection flow vs. time (steam line break with 1 SGTR). 


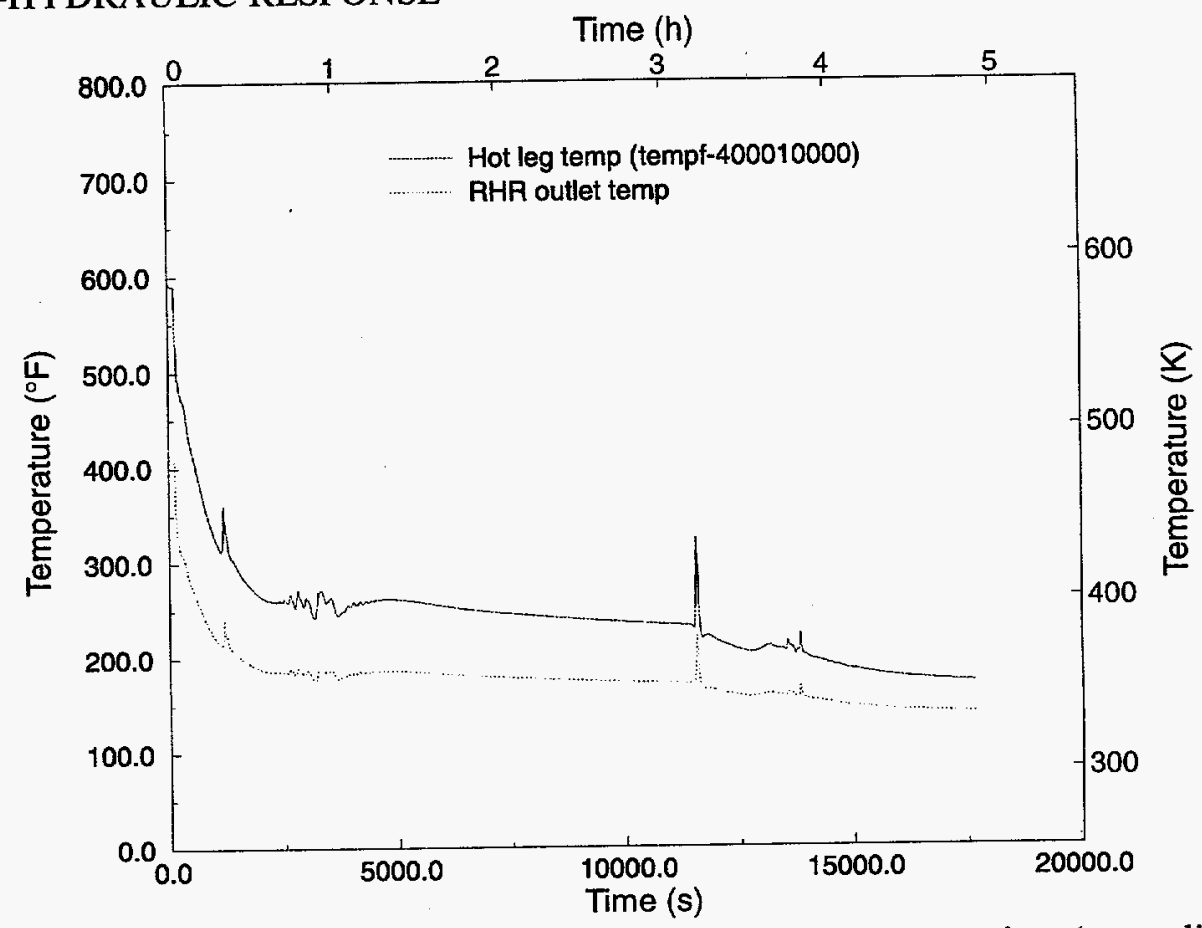

Figure 60. Residueal heat removal system inlet and outlet temperature vs. time (steam line break with 1 SGTR).

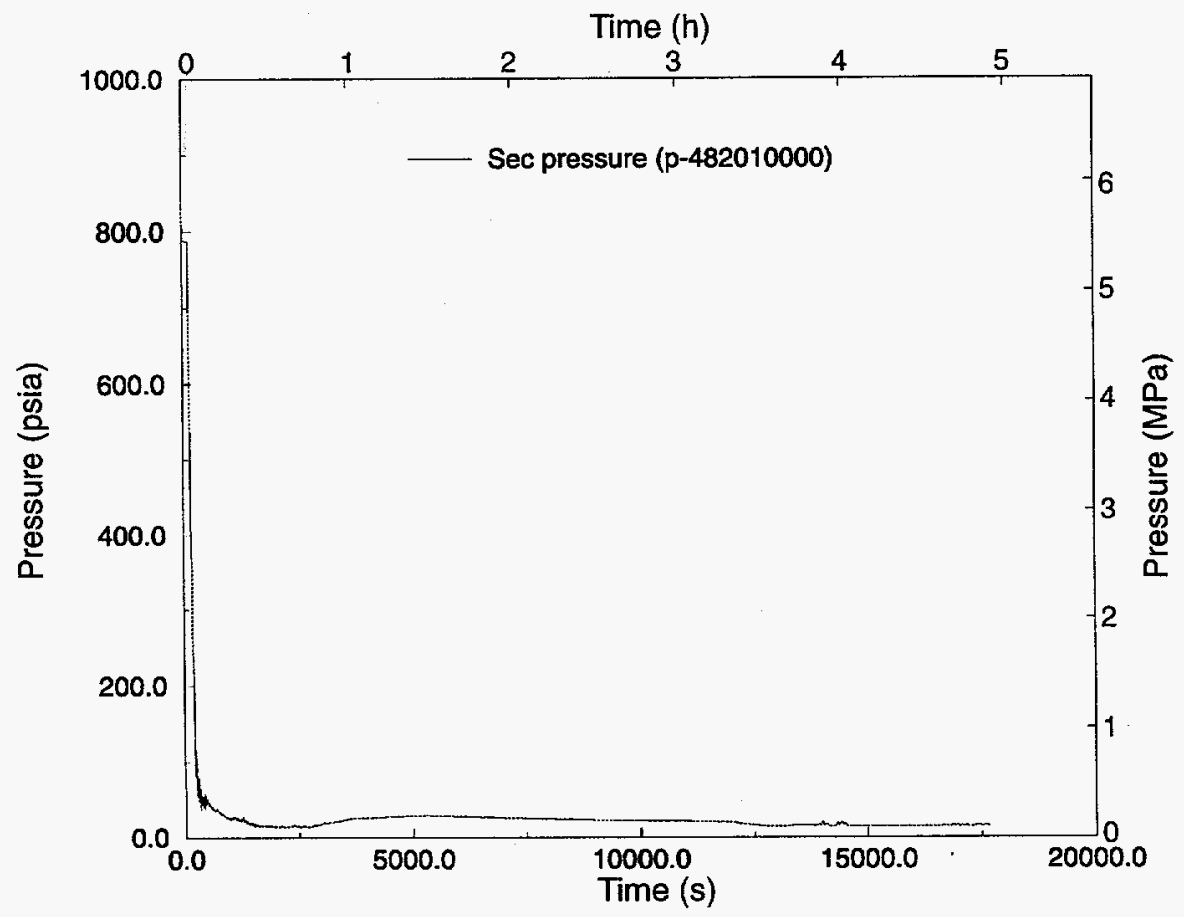

Figure 61. Failed steam generator secondary pressure vs. time (steam line break with 1 SGTR). 


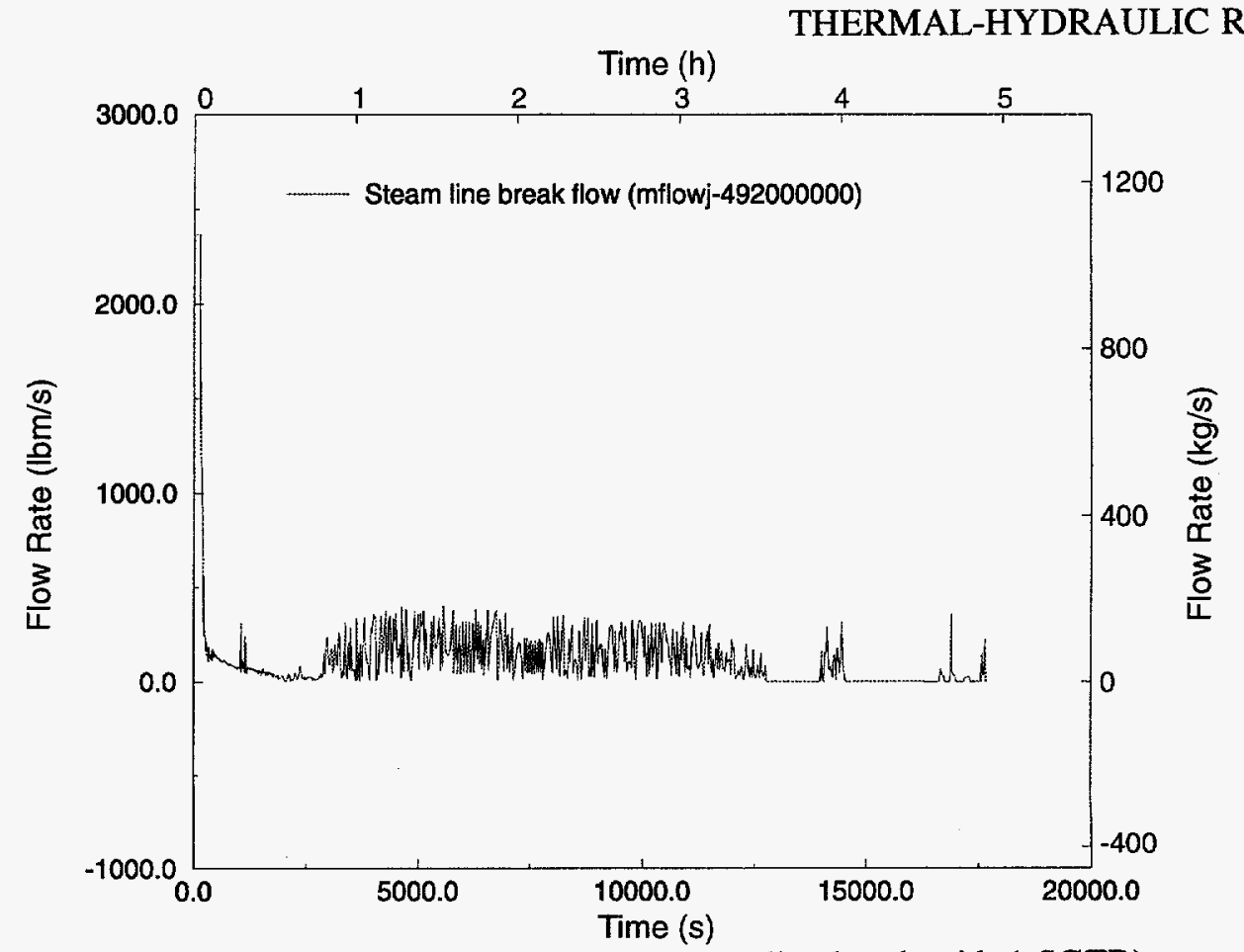

Figure 62. Failed steam line break flow rate vs. time (steam line break with 1 SGTR).

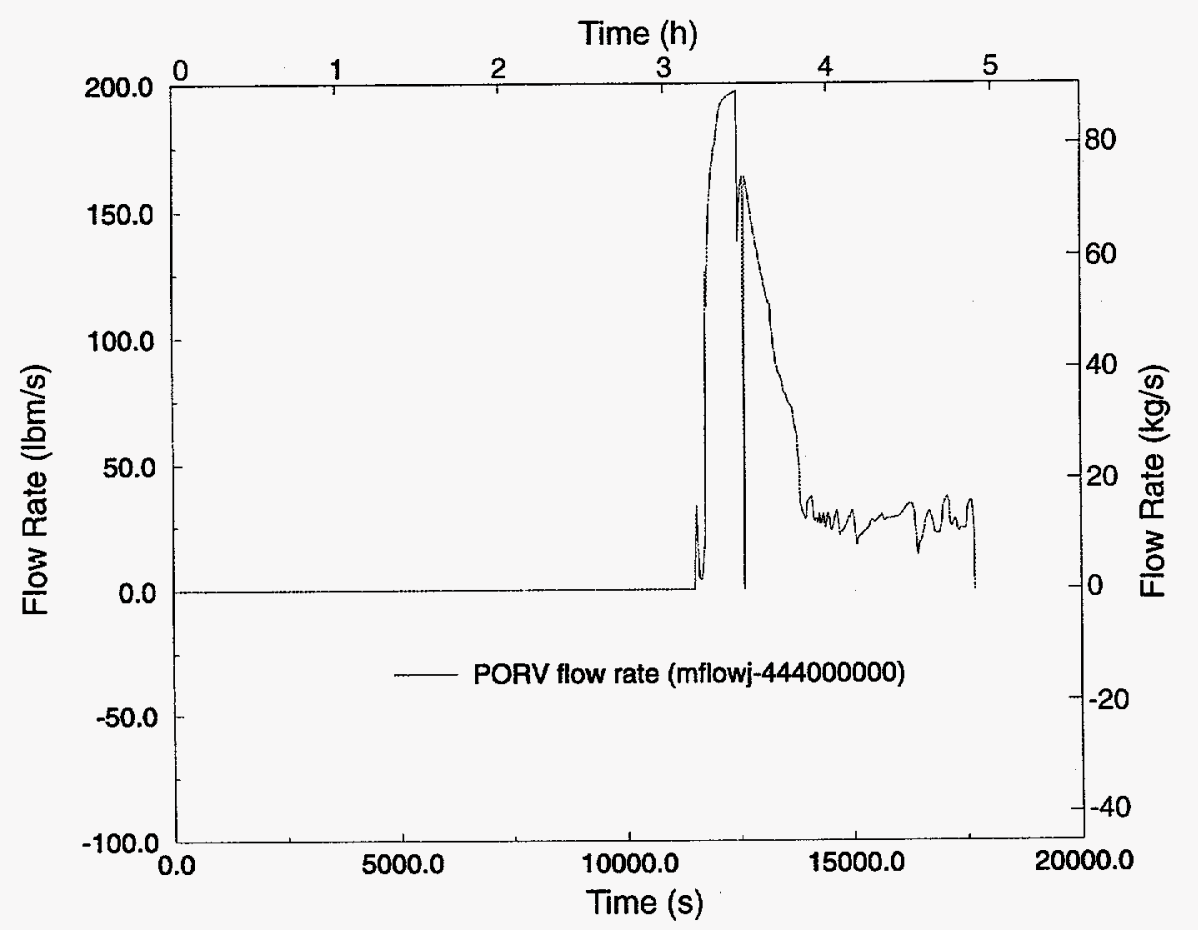

Figure 63. Pressurizer PORV flow rate vs. time (steam line break with 1 SGTR). 
THERMAL-HYDRAULIC RESPONSE

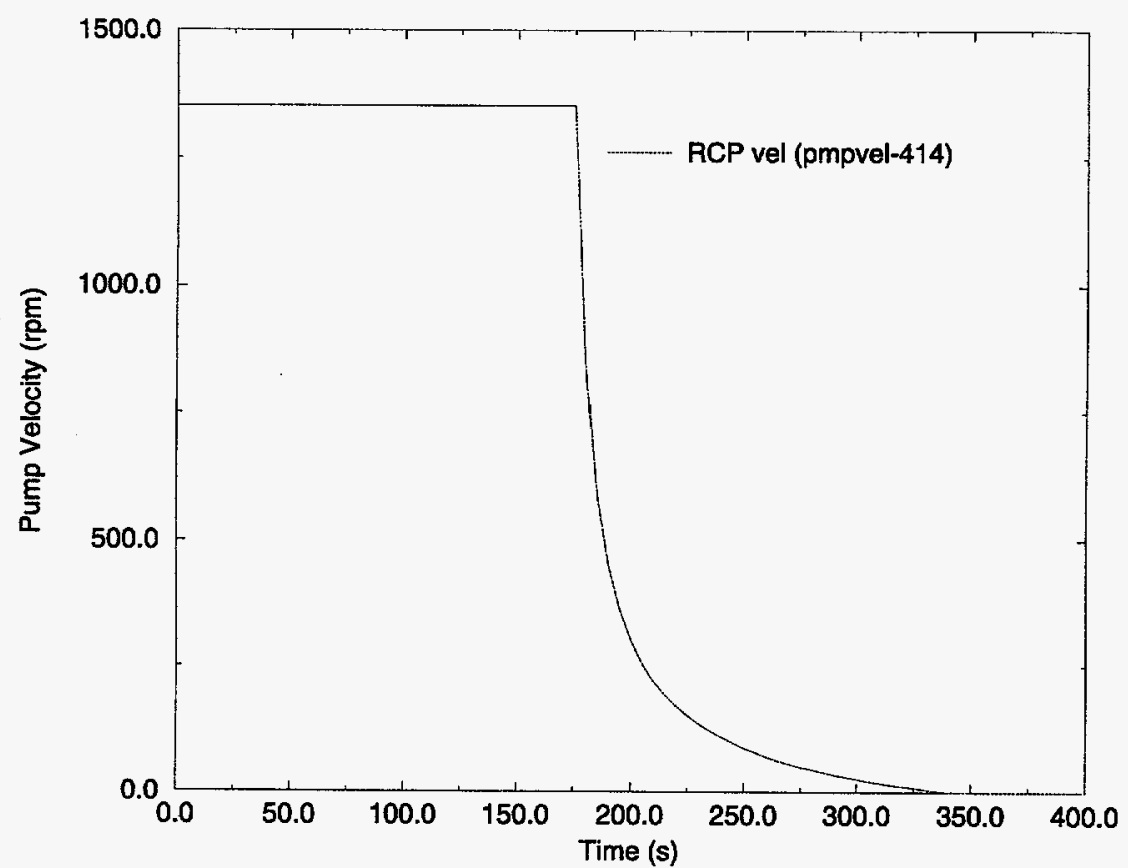

Figure 64. Reactor coolant pump speed vs. time (steam line break with 1 SGTR).

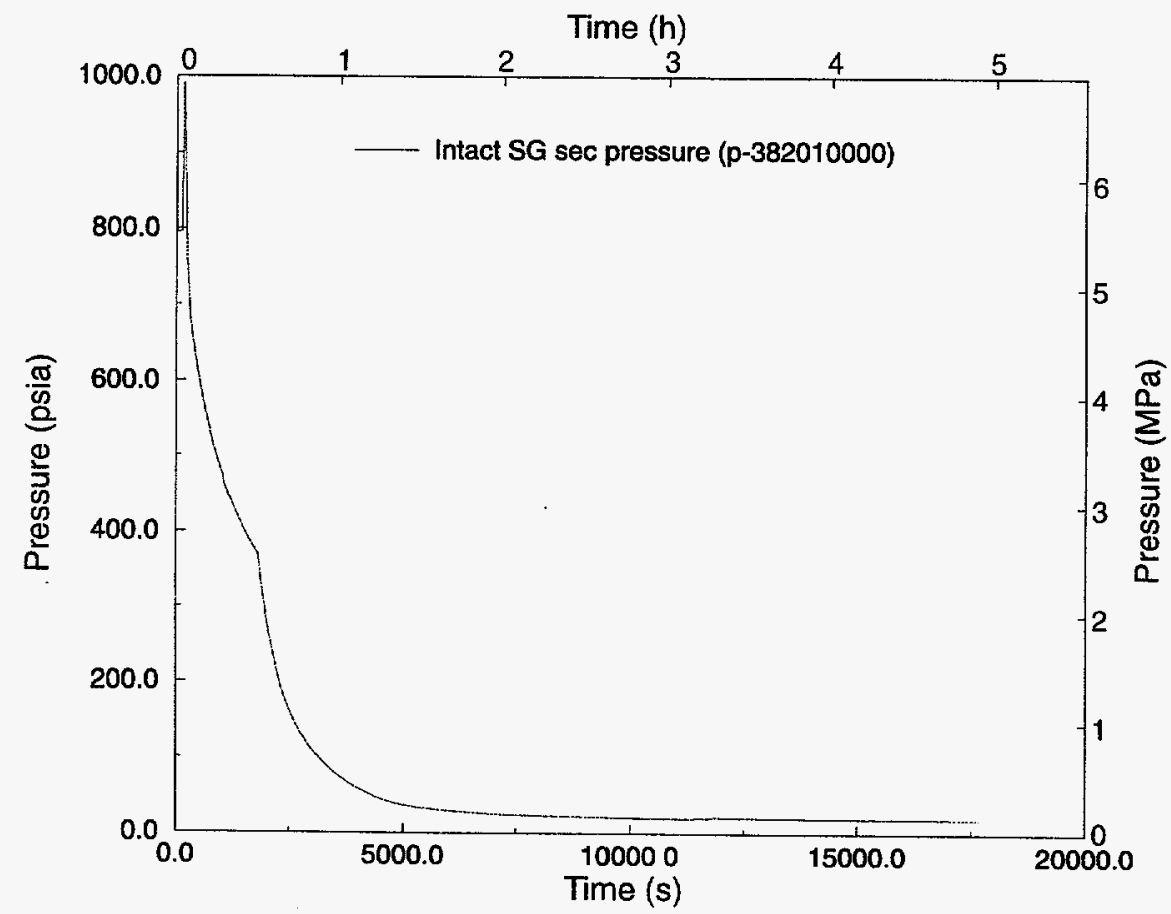

Figure 65. Intact steam generator pressure vs. time (steam line break with 1 SGTR). 


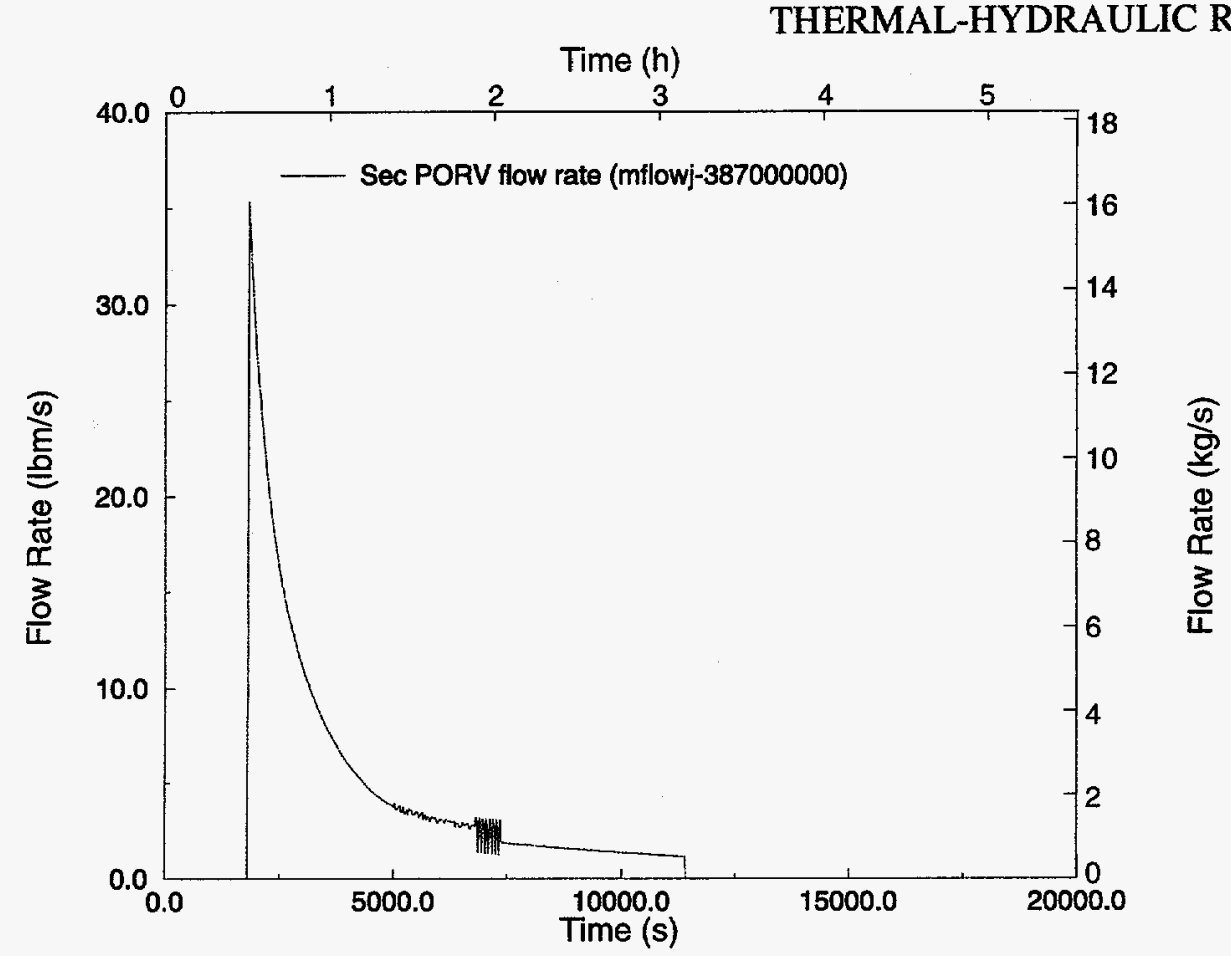

Figure 66. Steam generator steam dump flow rate vs. time (steam line break with 1 SGTR).

Table 16. Steam line break with one steam generator tube failed: sequence of events and key assumptions.

Steam Line Break Size

Steam Generator Tube Break Size (double-ended rupture)

Reactor Coolant Pump Trip Time

Auxiliary Feedwater to Ruptured Steam Generator Terminated at

Secondary Cooldown Initiation Time Using Atmospheric Dump Valves (Intact Steam Generators)

Pressurizer PORVs Opened

Time High Pressure Safety Injection First Throttled

Time Low Pressure Safety Injection Terminated

Accumulator Actuation Isolated at

Conditions Achieved for RHR Entry

Time RHR Placed Inservice

RWST Exhaust Time
$=$

$=$

$=$

$=$

$=$

$=$

$=$

$=$

$=$

$=$

$=$

$=$
$1.4 \mathrm{ft}^{2}$ $0.006555 \mathrm{ft}^{2}$ $200 \mathrm{sec}$ $300 \mathrm{sec}$ $1,800 \mathrm{sec}$ $11,500 \mathrm{sec}$ $1,800 \mathrm{sec}$ $1,800 \mathrm{sec}$ $1,800 \mathrm{sec}$ $12,000 \mathrm{sec}$ $13,000 \mathrm{sec}$ $26,000 \mathrm{sec}$ 
It is important to note that success is directly dependent upon (1) the throttling of the high pressure safety injection pumps and termination of low pressure safety injection flow, (2) opening of at least one pressurizer PORV, and (3) the placement of at least one RHR system into service to cool the reactor coolant system below $100^{\circ} \mathrm{C}\left(212^{\circ} \mathrm{F}\right)$ and remove decay heat on a long term basis. Cooldown of the reactor coolant system to temperatures below $100^{\circ} \mathrm{C}$ will prevent boiling due to unanticipated changes in reactor coolant system pressure and would allow for the eventual transition to mid-loop operation. Isolation of the accumulators was also assumed to occur prior to reducing reactor coolant system pressure below the accumulator actuation pressure of 4.1 MPa (600 psia).

\subsection{Results of the RELAP5 Simulation of a Steam Line Break with 15 Steam Generator Tubes Failed}

An analysis of the failure of 15 steam generator tubes combined with a steam line break was performed to show that even under these extreme failure conditions, effective operator intervention and actions to throttle emergency core cooling injection and actuate the RHR system will result in safely reaching a mode of long term cooling. Failures in excess of 15 tubes produces a system response where reactor coolant system subcooling cannot be recovered prior to exhaustion of the refueling water storage tank. Recovery from a steam line break with more than 15 failed tubes would require replenishment of the refueling water storage tank. Figure 67 presents the reactor coolant system pressure response with 15 failed steam generator tubes. Because of the multiple tube break size coupled with the steam line break, the reactor coolant system depressurizes rapidly. As a consequence, pressurizer level, shown in Figure 68, is quickly regained because of actuation of both the high and low pressure safety injection systems. Figure 69 presents the reactor vessel level depicting the rapid inventory loss in the early portion of the event, which is recovered due to the actuation of both the high and low pressure safety injection systems. Reactor coolant system subcooling is presented in Figure 70 and indicates that the temperature conditions exist [i.e. hot leg temperature less that $177^{\circ} \mathrm{C}\left(350^{\circ} \mathrm{F}\right)$ ] for entry into shutdown cooling very early into the event or about 1,000 seconds. Since sufficient reactor coolant system subcooling exists, high and low pressure safety injection are throttled at about 2,500 seconds, as shown in Figure 71 , to delay exhaustion of the refueling water storage tank so entry into shutdown cooling can be achieved. Figure 72 presents the integrated emergency core cooling injection flow showing the delayed refueling water storage tank exhaustion time due to the necessary throttling of the injection flow.

Actuation of RHR at 3,000 seconds demonstrates that the reactor coolant system hot leg temperature can be cooled below $100^{\circ} \mathrm{C}\left(212^{\circ} \mathrm{F}\right)$ within 1 hour following event initiation, as noted in Figure 70. Note that Figure 72 indicates that approximately 6,600 seconds is required to exhaust the refueling water storage tank inventory. Since the reactor coolant system temperature is reduced below $100^{\circ} \mathrm{C}\left(212^{\circ} \mathrm{F}\right)$ within 1 hour of the event initiation, loss of the refueling water storage tank inventory is of no consequence.

To demonstrate that one RHR train can maintain the core in a subcooled condition following loss of all emergency core cooling injection, the transient was continued to about 10,000 seconds. Note that in Figure 70, the hot leg temperature increases at the time of loss of injection at about 6,500 seconds due to the loss of the additional subcooling provided by the high pressure safety injection. However, with one RHR train in operation, reactor coolant system temperature is maintained below $100^{\circ} \mathrm{C}\left(212^{\circ} \mathrm{F}\right)$ for the duration of the event. Therefore, one RHR train is capable of preventing reactor coolant system boiling following loss or termination of all emergency core cooling. Long term decay heat removal is guaranteed with continued operation 
THERMAL-HYDRAULIC RESPONSE

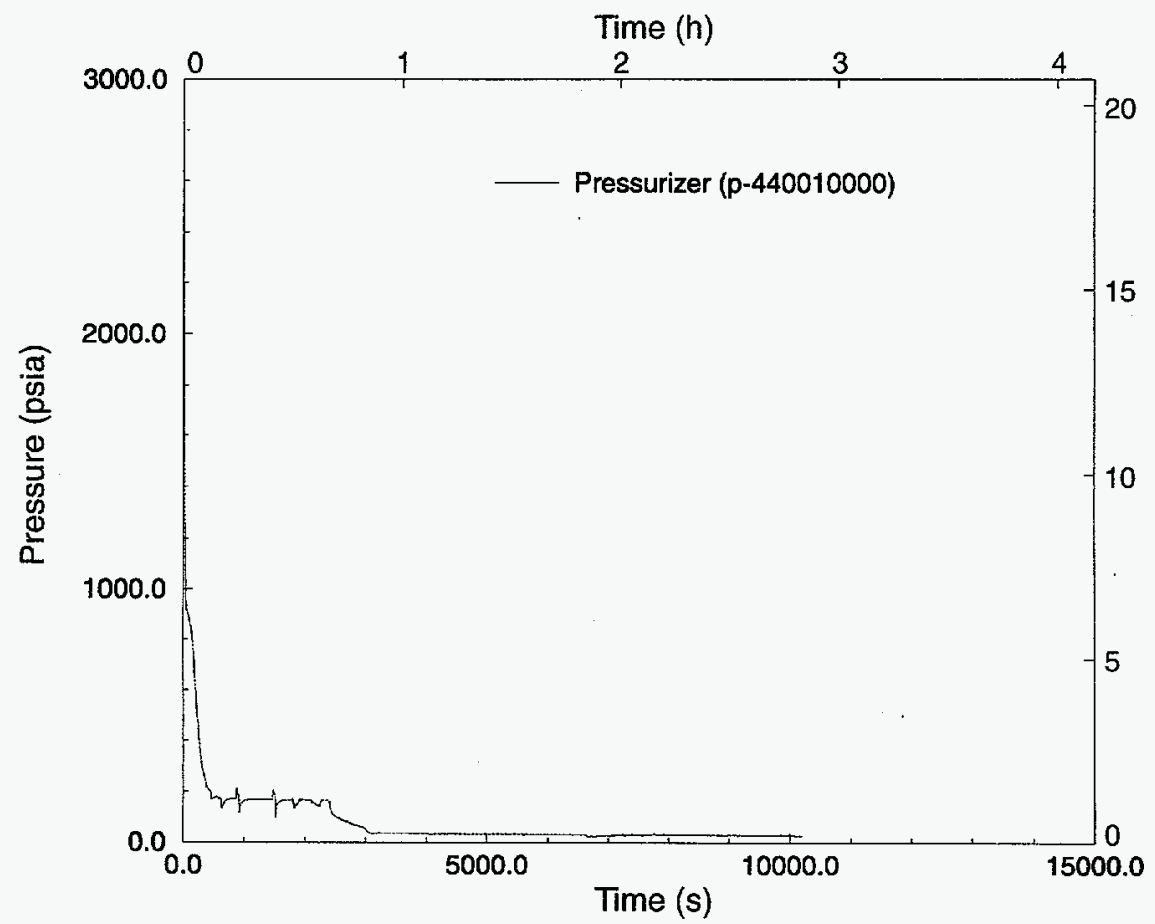

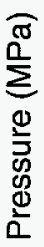

Figure 67. Pressurizer pressure vs. time (steam line break with 15 SGTRs).

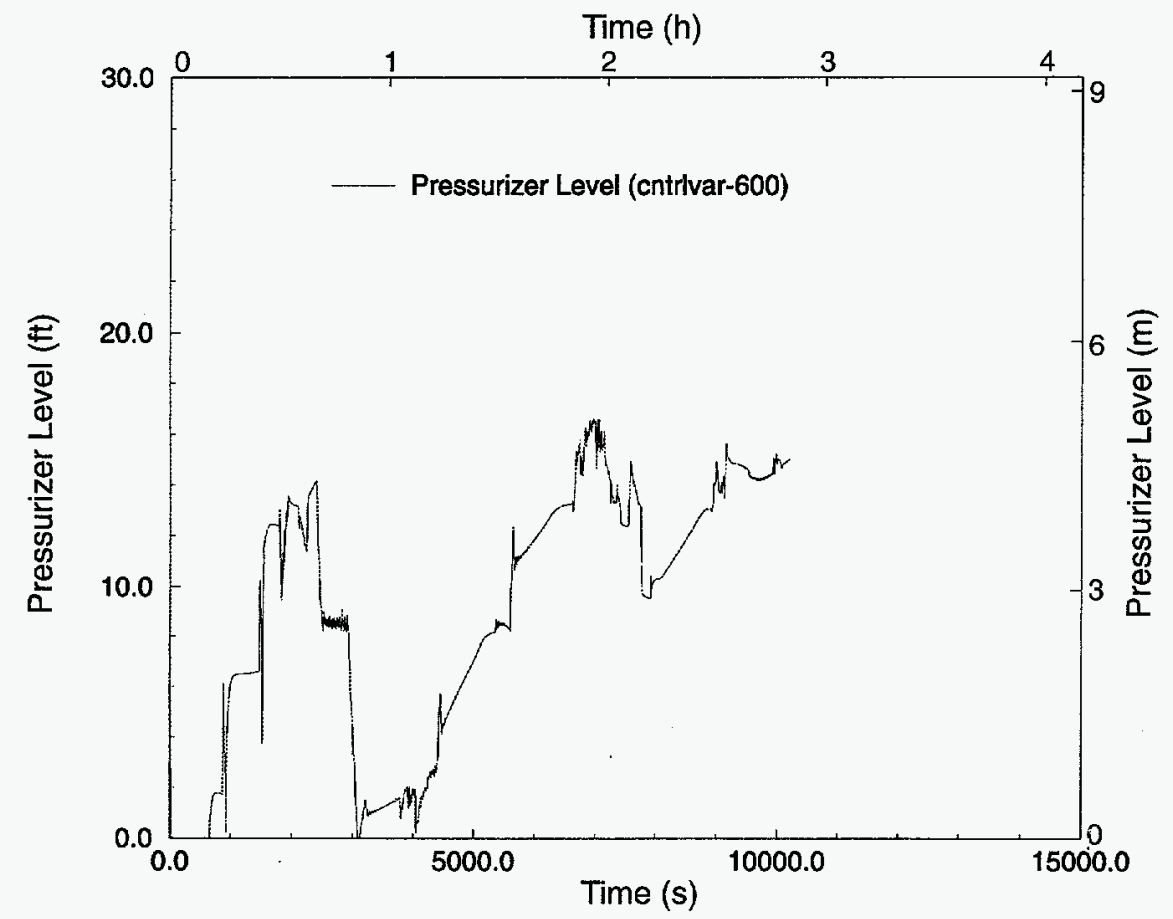

Figure 68. Pressurizer level vs. time (steam line break with 15 SGTRs). 


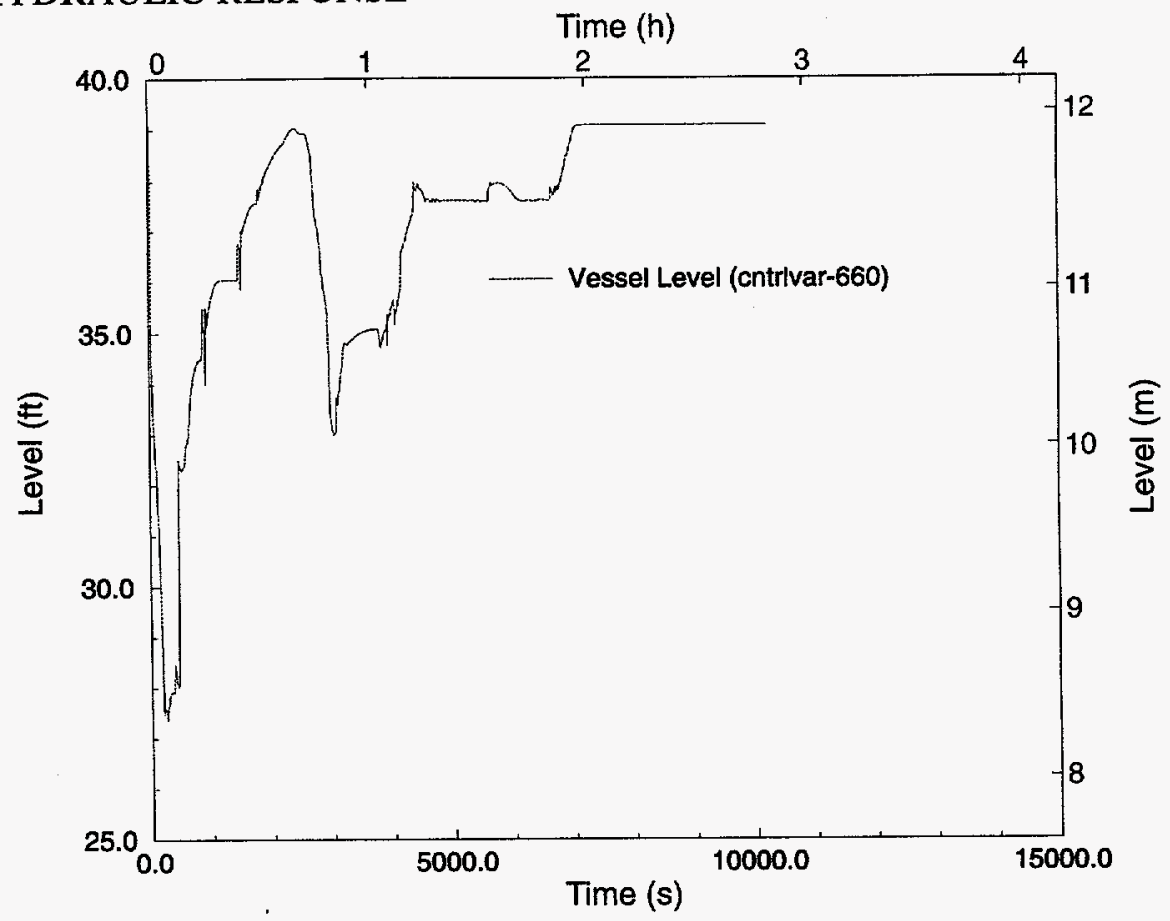

Figure 69. Reactor vessel level vs. time (steam line break with 15 SGTRs).

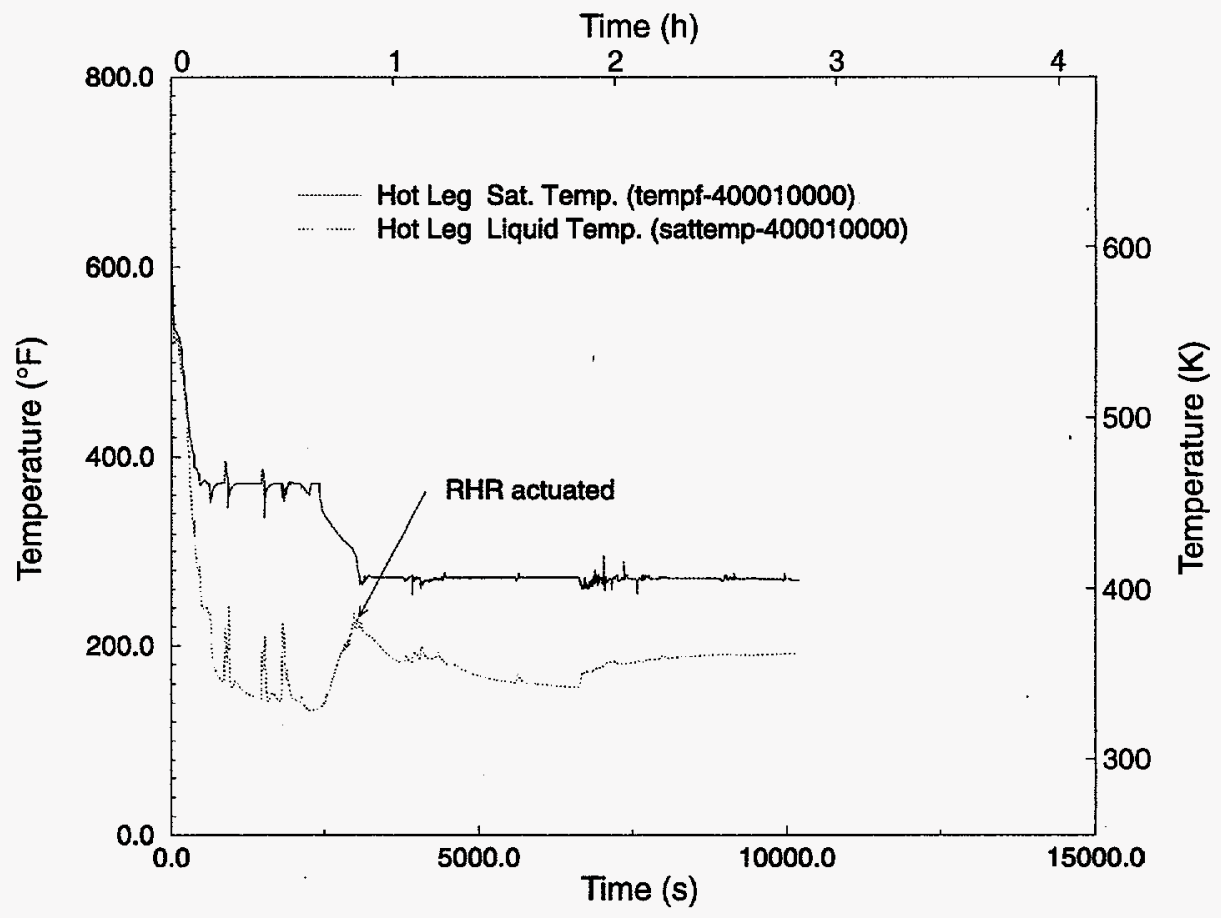

Figure 70. Hot leg temperature vs. time (steam line break with 15 SGTRs). 


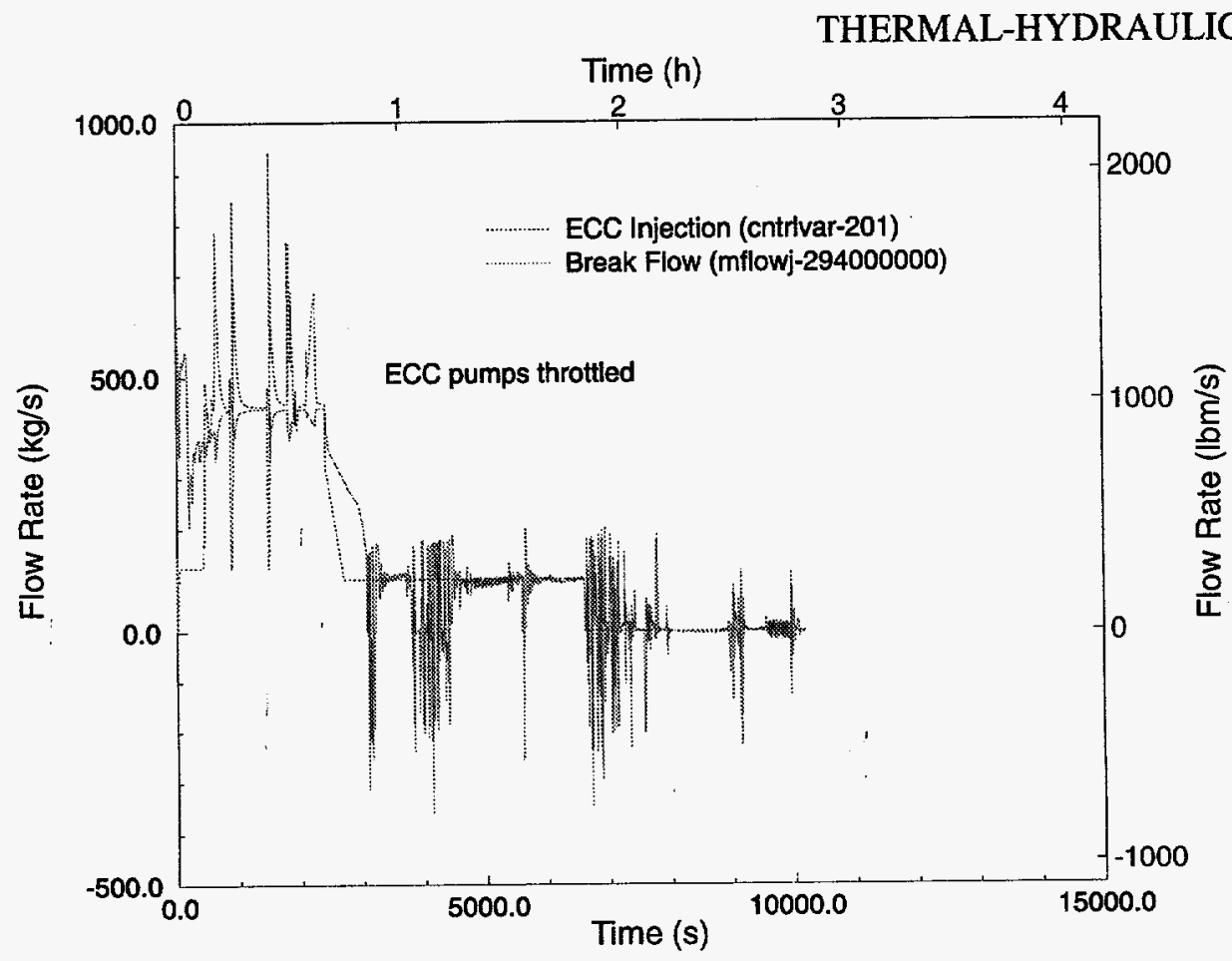

Figure 71. Break and emergency core cooling injection flow rates vs. time (steam line break with 15 SGTRs).

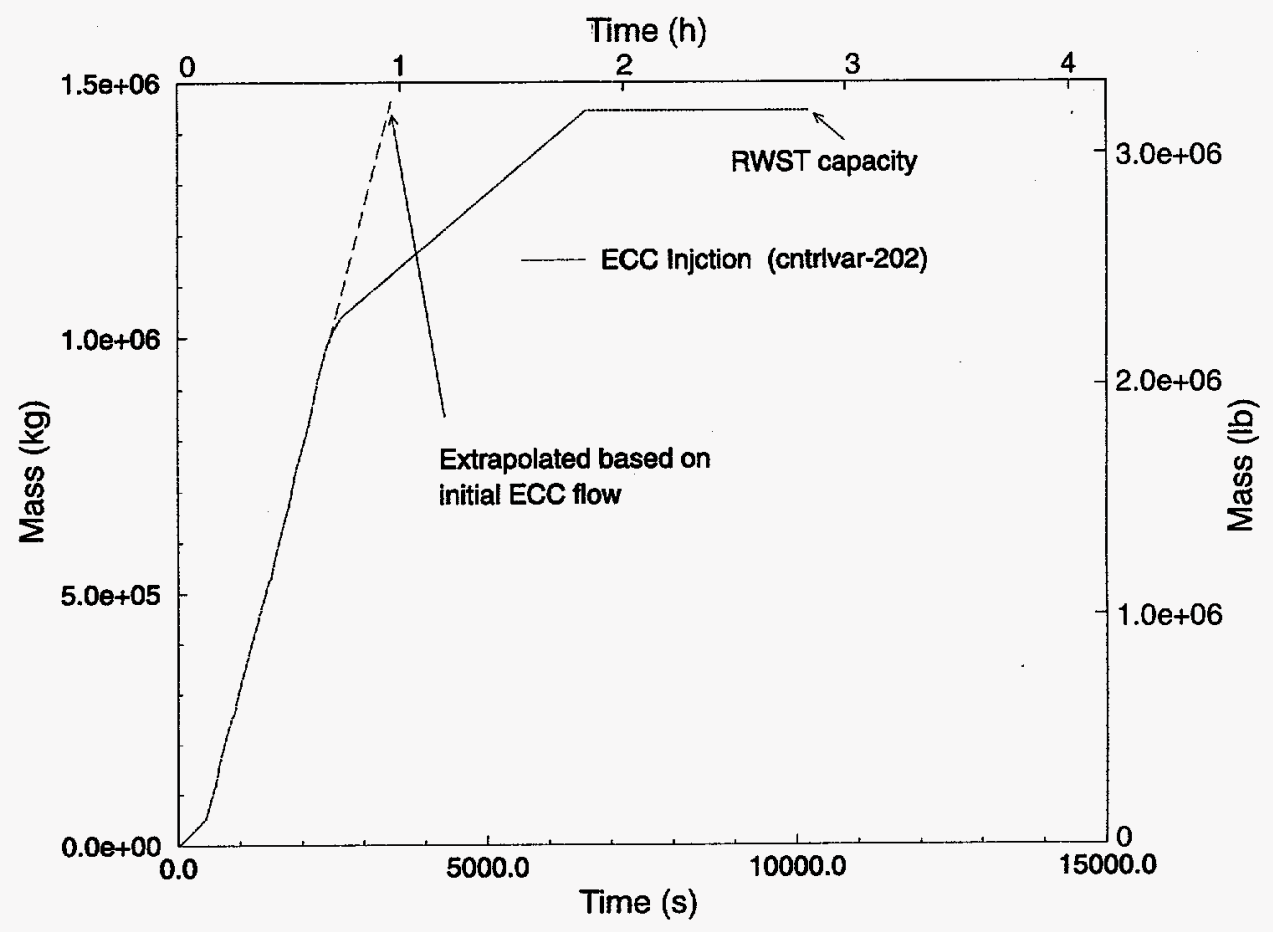

Figure 72. Integrated safety injection flow vs. time (steam line break with 15 SGTRs). 
of at least one of the two RHR trains in operation. The RHR inlet and outlet temperatures are displayed in Figure 73.

Table 17 presents the sequence of events and key assumptions for this event.

\subsection{Results of the RELAP5 Simulation of a Steam Line Break with 15 Steam Generator Tubes Failed and No Operator Actions}

An analysis of 15 failed steam generator tubes combined with a steam line break was performed without operator action to show the effect of no operator actions on the timing of core uncovery. Unlike the analyses described above, no throttling of emergency core cooling injection is assumed nor is actuation of the RHR system credited in this evaluation.

Figure 74 presents the reactor coolant system (pressurizer) pressure response. Figure 75 presents the reactor coolant system subcooling and since the emergency core cooling was not throttled, the refueling water storage tank is exhausted at 3500 seconds (as shown in Figure 76), which results in a loss of reactor coolant system subcooling at approximately 4000 seconds into the event. Without emergency core cooling, the core decay heat depletes the liquid above the core due to boiling and causes the two-phase level to eventually recede into the core, exposing the top portion of the core to steam cooling. Figure 77 shows the fuel rod cladding surface temperature. At about 24,000 seconds into the event core uncovery is initiated, producing an increase in fuel surface temperature. Note that it is necessary to deplete the liquid in the reactor coolant system above the top of the core in addition to the liquid contained in the affected steam generator before core uncovery will occur. Without re-initiation of emergency core cooling, the fuel will continue to heat up and eventually melt.
This analysis shows the importance of the early operator actions to throttle emergency core cooling and delay exhaustion of the refueling water storage tank. That is, the operator must diagnose the event and take appropriate actions to throttle emergency core cooling to permit a timely actuation of the RHR system. The analysis of the 15 steam generator tube rupture event combined with the steam line break clearly shows that the operator must throttle the emergency core cooling injection pumps within the first hour of the event initiation, to enable sufficient time to actuate RHR and cool the reactor coolant system below the boiling point, and thereby prevent the long term uncovery and melting of the core.

\subsection{Operator Actions During Combined Steam Line Break-Tube Rupture Events}

The analyses of the steam line break combined with steam generator tube ruptures clearly demonstrates the need for timely operator action to assure the plant can be safely placed in a mode of long term cooling. Since this event represents a potential core melt bypass sequence where the reactor coolant is lost from the containment, precluding the capability to recirculate fluid lost from the reactor coolant system, it is important to establish operation of the decay heat removal system to prevent boiling and uncovery of the core during the long term. Analysis of the steam line break tube rupture event shows that the need for operator action varies from several hours for the single tube failure event, to less than one hour for the 15 tube failure event, to assure that the core is safely cooled. For the single tube failure event, the refueling water storage tank is exhausted in 19,000 seconds if the operator fails to throttle the high and low pressure safety injection. For the 15 tube failure event, loss of the refueling water storage tank occurs at about 3500 seconds. Clearly more time is available for the case with only one failed tube. 


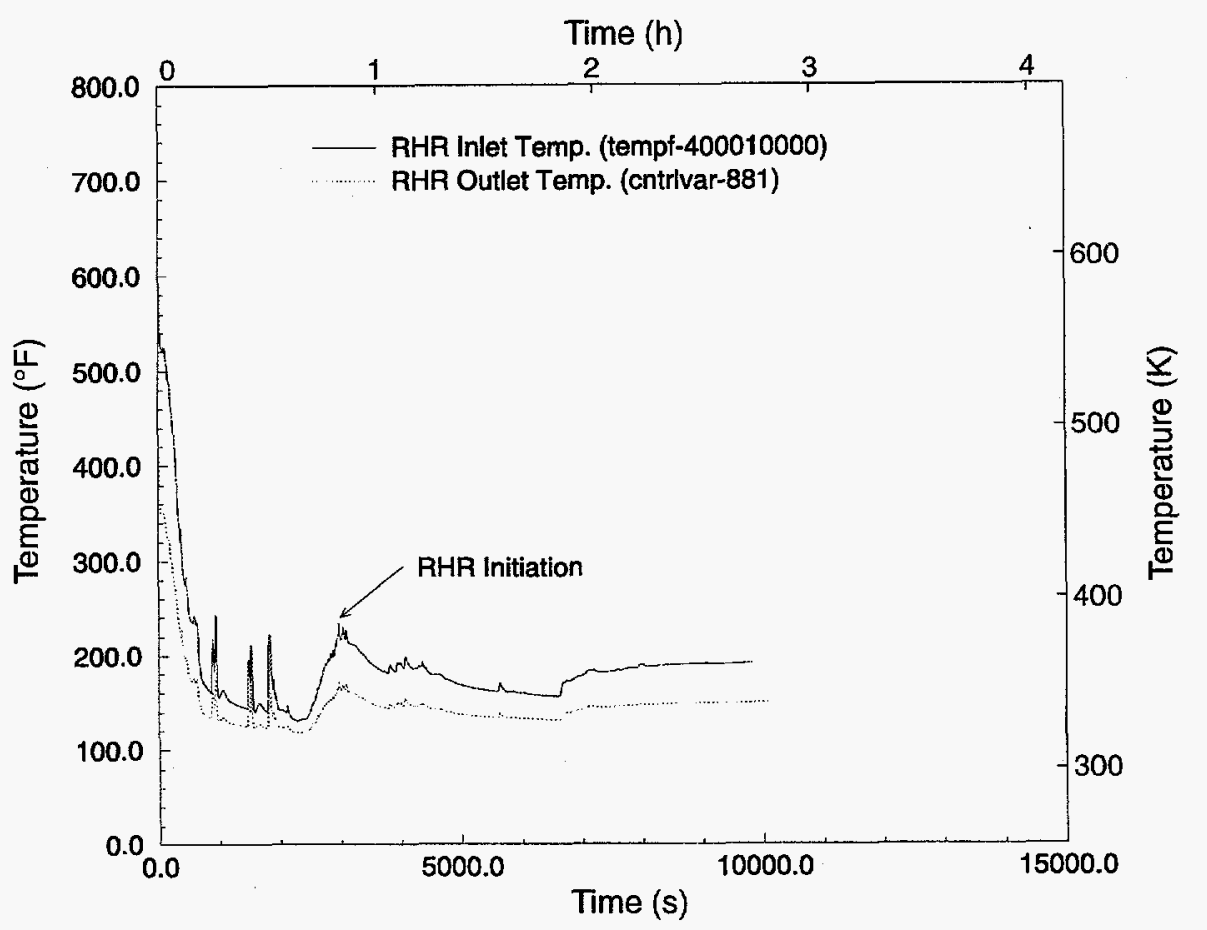

Figure 73. Residual heat removal system inlet and outlet temperatures vs. time (steam line break with 15 SGTRs).

Table 17. Steam line break with 15 steam generator tubes failed: Sequence of events and key assumptions.

Steam Line Break Size

Steam Generator Tube Break Size (double-ended ruptures)

Auxiliary Feedwater to Ruptured Steam Generator Terminated at

Reactor Coolant Pump Trip Time

Secondary Cooldown Initiation Time Using Atmospheric Dump Valves (Intact Steam Generators)

Time High Pressure Safety Injection First Throttled Time Low Pressure Safety Injection Terminated Accumulator Actuation

Accumulators Discharged

Time Conditions Achieved for RHR Entry

Time RHR Placed Inservice

Refueling Water Storage Tank Exhaust Time

$\begin{array}{rr}= & 1.4 \mathrm{ft}^{2} \\ = & 0.098325 \mathrm{ft}^{2} \\ = & 300 \mathrm{sec} \\ & \\ = & 200 \mathrm{sec} \\ & 1800.0 \mathrm{sec} \\ & \\ = & 2400.0 \mathrm{sec} \\ = & \text { Not Isolated, }\end{array}$

$$
\begin{array}{rr}
= & 1000 \mathrm{sec} \\
= & 3000 \mathrm{sec} \\
= & 6600 \text { sec. }(1.83 \text { hours })
\end{array}
$$




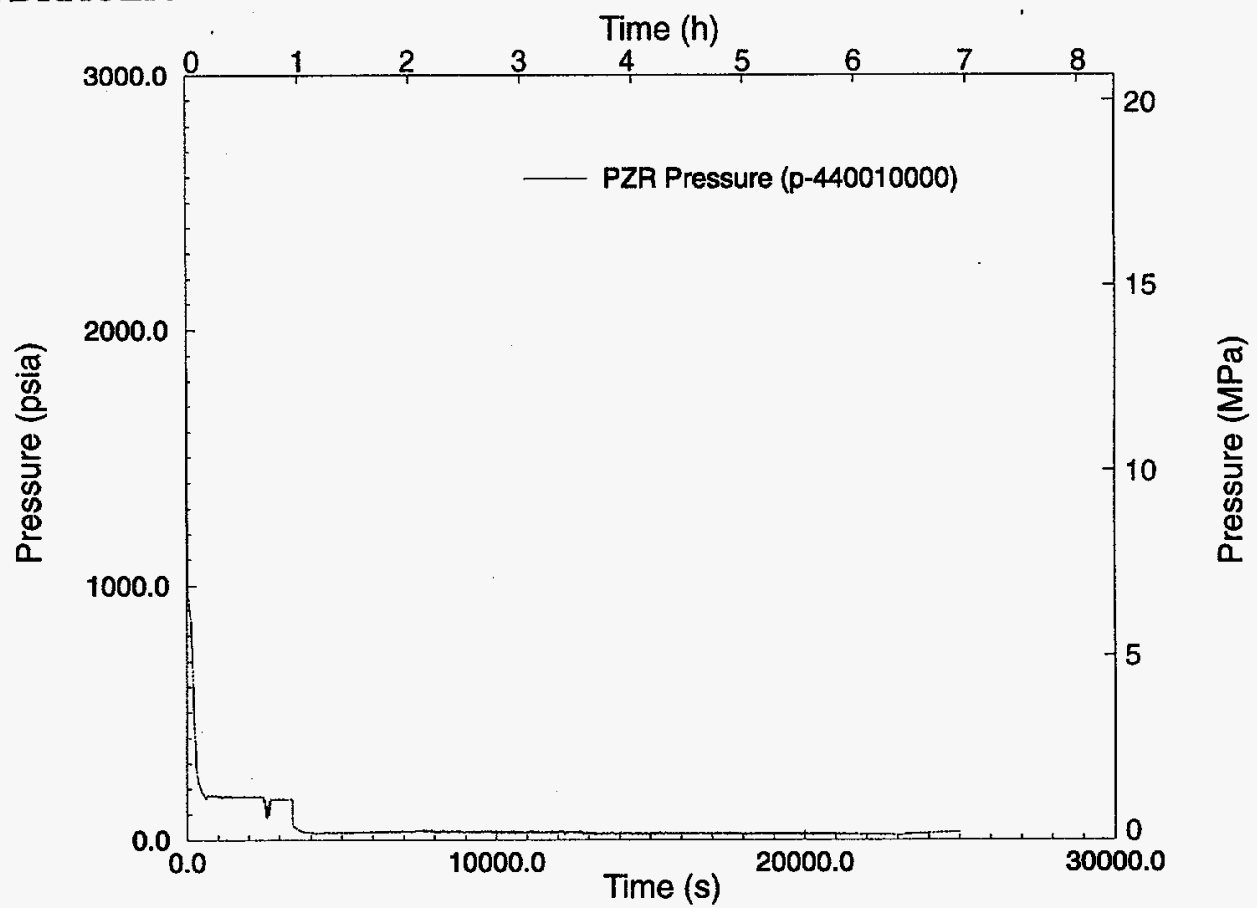

Figure 74. Pressurizer pressure vs. time (steam line break with 15 SGTRs, no operator action).

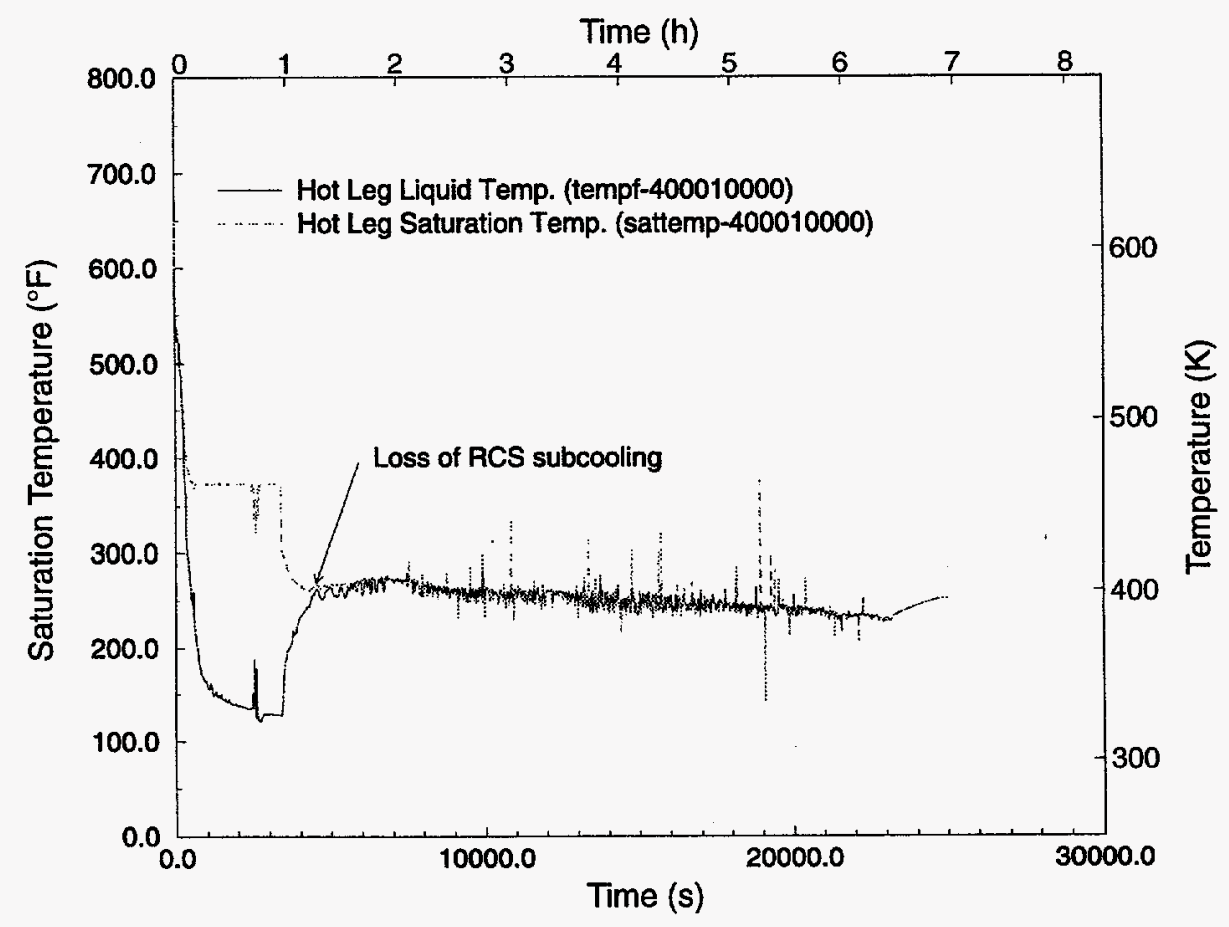

Figure 75. Reactor coolant system hot leg temperature vs. time (steam line break with 15 SGTRs, no operator action). 
THERMAL-HYDRAULIC RESPONSE

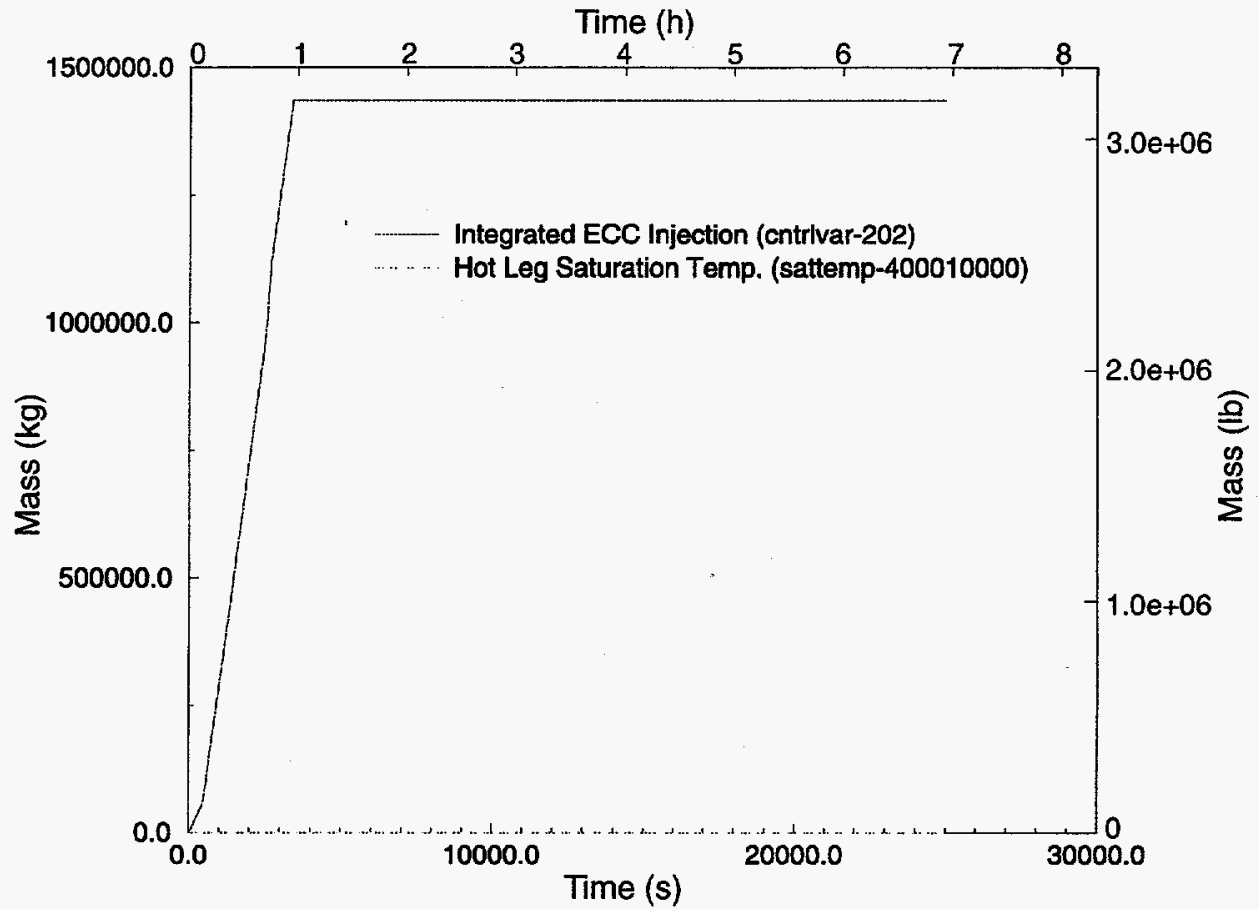

Figure 76. Integrated emergency core cooling injection flow vs. time (steam line break with 15 SGTRs, no operator action).

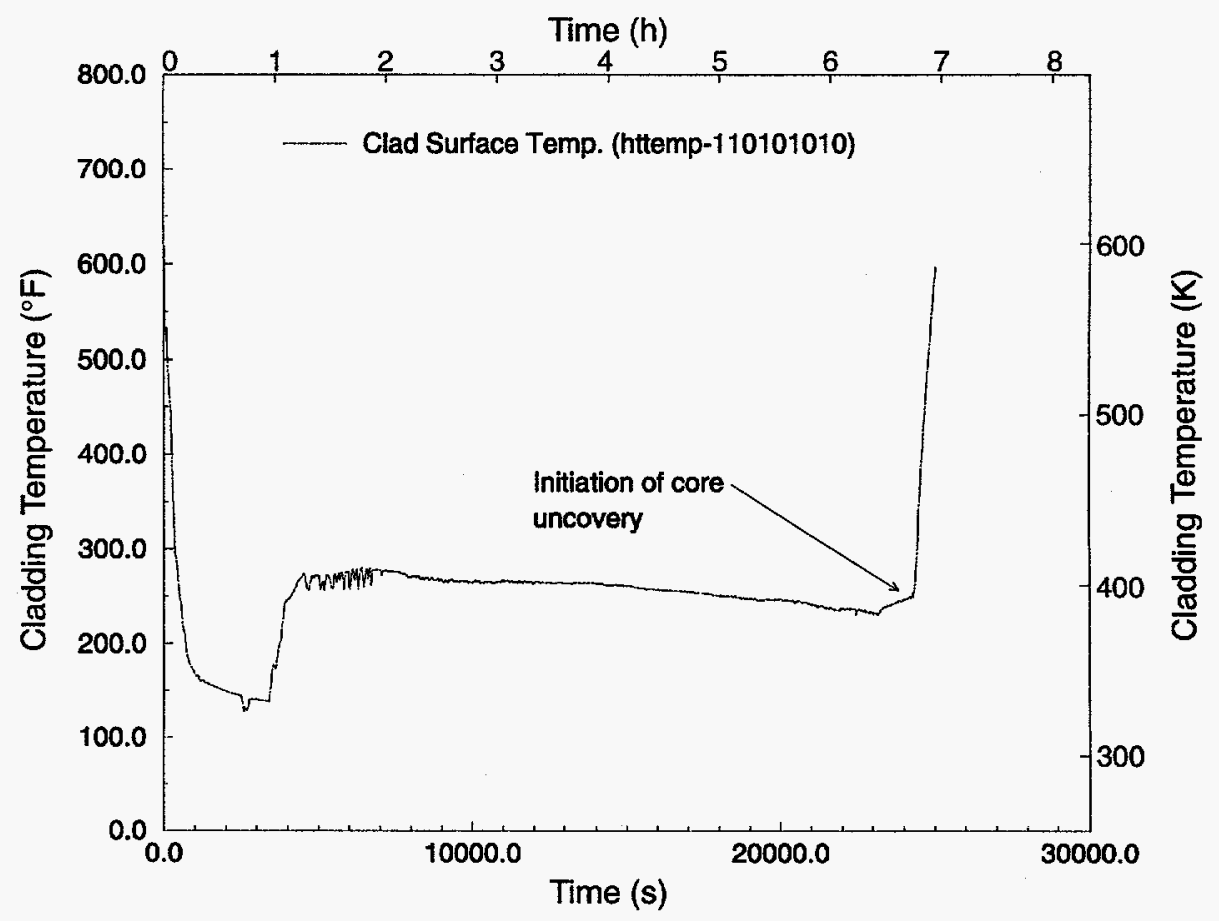

Figure 77. Fuel rod cladding surface temperature vs. time (steam line break with 15 SGTRs, no operator action). 
However, as with all bypass loss-of-coolant accident sequences, the operators cannot delay the actions to throttle and cool down the reactor coolant system because a procrastinated operator intervention could lead to an eventual core melt scenario.

Section 4 discusses steam generator tube failure events and noted in some instances, operator actions to control emergency core cooling and reduce reactor coolant system pressure did not occur before two to three hours into the event. Clearly, for events that include only a ruptured steam generator tube, bypass of the emergency core cooling injection is not a concern and operator timeliness is not as critical as that for combined steam line break, tube rupture events. The importance of these calculations is that early operator intervention is mandatory to assure long term cooling for combined steam line break, tube rupture events. Delays in the operator actions for tube rupture, steam line break events could lead to core uncovery and melt.

\subsection{Conclusions}

Analyses of the steam generator tube rupture and combined steam line break and tube rupture events were performed to demonstrate methods which can be used to cooldown a typical pressurized water reactor coolant system to shutdown cooling conditions while minimizing radiological release and controlling reactor coolant system inventory.

The results of the steam generator tube rupture event demonstrate that the break flow and release of secondary steam from the affected steam generator can be terminated within one hour of initiation of the tube failure. Cooldown and initiation of RHR for long term cooling can be achieved in approximately four hours following opening of the break.

Following a combined steam line break, tube rupture event, it is necessary to cooldown and throttle emergency cooling system flow as soon as possible to prevent exhaustion of the refueling water storage tank. Since the combined steam line break, tube rupture event results in exhausting the refueling water storage tank through the secondary system (when the emergency core cooling system is not throttled), it is not possible to develop a containment sump inventory to eventually transfer injection from the refueling water storage tank. As a consequence, there is need to more quickly cooldown the reactor coolant system using the PORVs to provide a timely depressurization of the reactor coolant system. This action, plus throttling of the emergency cooling system injection, delays exhaustion of the refueling water storage tank and maximizes the time available to cooldown the reactor coolant system to RHR initiation conditions. Unlike the tube rupture event where reactor coolant system pressure need only be reduced below the affected steam generator relief valve setpoint, cooldown of the reactor coolant system to actuation of RHR is required to assure successful control of the combined steam line break, tube rupture event. Actuation of the RHR system is necessary to preclude boiling in the reactor coolant system and assure that long term core cooling can be maintained. Analysis of this event demonstrates that a timely cooldown of the reactor coolant system and throttling of the emergency cooling system injection can facilitate operation of the RHR system at $17,000 \mathrm{sec}(4.7$ hrs) or well within the 7.2 hours required to exhaust the refueling water storage tank. Evaluation of the multiple steam generator tube failure, steam line break event demonstrates that under the extreme case when 15 tubes are failed, operator action is required within 1 hour of event initiation to assure that the core is safely cooled. The importance of the tube rupture, steam line break events is that early operator action is mandatory to assure that a long term stable state can be achieved for this class of accidents. A procrastinated operator intervention can lead to an early core uncovery and core melt sequence for these events. 


\section{THE RISK SIGNIFICANCE OF STEAM GENERATOR TUBE RUPTURE ACCIDENTS}

\subsection{Introduction}

Steam generator tube rupture accidents can be categorized as spontaneous or induced tube ruptures. A spontaneous steam generator tube rupture is the rupturing of one or more steam generator tubes that is not caused by another event or an upset in normal expected operational parameters. Unlike spontaneous steam generator tube ruptures, an induced steam generator tube rupture is an accident that is associated with an upset condition. Induced steam generator tube ruptures are conditional based on the occurrence of other events.

Three important contributions make up the risk profile of an operating nuclear plant. These three contributions are:

- the core damage frequency,

- the amounts and types of radioactive material entering the environment, given an accident, and

- the accident's environmental consequences.

Both spontaneous and induced steam generator tube ruptures may be risk significant due to the fact that the radionuclides may bypass the reactor containment building during these events. Containment bypass events result in a disproportionate amount of radionuclides being released to the environment, when compared to other possible accident scenarios.

Risk is typically calculated as the product of the core damage frequency multiplied by the offsite consequences. This risk measure produces a frequency of offsite early and latent fatalities due to the accident. Accident sequences that result in containment bypass are important contributors to a nuclear facility's risk profile. Steam generator tube rupture is typically a high total contributor to the containment bypass frequency.

Insights into the U.S. steam generator tube rupture risk profile can be gained from an examination of the USNRC and industry probablistic risk assessment and IPE program results. The risk associated with a steam generator tube rupture is dominated by a few significant failures. Typically the dominate contributors are human error (operator fails to depressurize) and failures that cause loss of reactor water storage tank inventory.

\subsection{U.S. Individual Plant Examination Core Damage Frequency and Risk Profile}

The U.S. nuclear power plant core damage distribution is shown in Figure 78. This figure was constructed based on the results of the IPE submittals to the USNRC. As this figure indicates, there is a wide variation in the core damage frequency among the U.S. nuclear power plant designs. The various nuclear power plant vendors, utility preferences, and the regulatory environment in the U.S. have produced a wide variety of different nuclear plant designs. These design variations produce a wide variation in core damage frequency. However, all of these designs meet current U.S. certification requirements.

Table 18 provides a summary of the relevant IPE results for 18 US PWRs. The total core damage frequency caused by internal events, percent of the total core damage frequency caused by spontaneous steam generator tube ruptures, and the percent of the containment bypass fraction caused by spontaneous steam generator tube ruptures are listed for each plant. Since only 


\section{RISK SIGNIFICANCE}

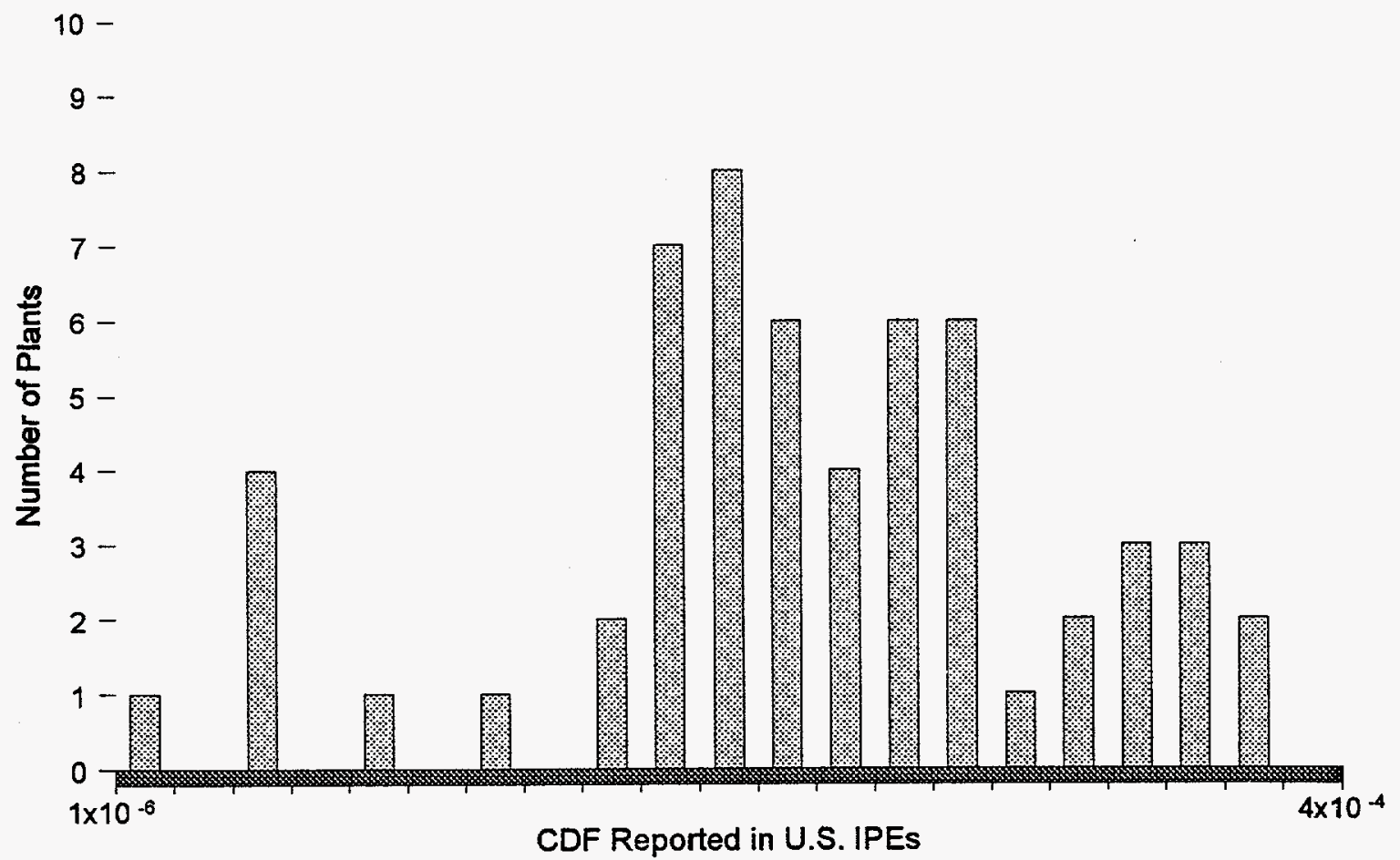

Figure 78. The U.S. nuclear power plants' core damage frequency distribution as reported to the U.S. NRC by the IPE programs.

spontaneous tube ruptures were considered, the percent of the containment bypass fraction caused by tube ruptures is also essentially the percent of the total risk due to steam generator tube ruptures. As this table indicates, the total core damage frequency caused by internal events at these 18 plants ranges from a low of about $3 x$ $10^{-5}$ to about $3 \times 10^{-4}$ per year. The spontaneous tube rupture contribution to the total core damage frequency varies from $1 \times 10^{-8}$ to $1 \times 10^{-5}$ per year, and the percent of the total core damage frequency caused by spontaneous steam generator tube ruptures varies from $0.02 \%$ to about $11 \%$. The contributions of the various types of possible accident sequences to the total core damage frequency at a typical plant is shown in Figure 79. In this case, the spontaneous steam generator tube ruptures account for about $4 \%$ of the total core damage due to internal events. Most of the core damage frequency is due to support system faults, loss of coolant accidents and transient with scram. 
Table 18. U.S. PWR IPE results.

\begin{tabular}{|c|c|c|c|}
\hline U.S. Plant Name & $\begin{array}{l}\text { Total core damage } \\
\text { frequency caused by } \\
\text { internal events }\end{array}$ & $\begin{array}{l}\text { Percent of the total } \\
\text { core damage } \\
\text { frequency caused } \\
\text { by spontaneous } \\
\text { steam generator } \\
\text { tube ruptures }\end{array}$ & $\begin{array}{c}\text { Percent of } \\
\text { containment } \\
\text { bypass fraction } \\
\text { caused by } \\
\text { spontaneous steam } \\
\text { generator tube } \\
\text { rupture } \\
\end{array}$ \\
\hline Arkansas 1 & $5 \times 10^{-5}$ & $0.4 \%$ & $26 \%$ \\
\hline Callaway & $4 \times 10^{-5}$ & $2 \%$ & $10 \%$ \\
\hline Catawba & $4 \times 10^{-5}$ & Not Reported & Not Available \\
\hline Comanche Peak & $4 \times 10^{-5}$ & $6 \%$ & $7 \%$ \\
\hline Cook & $6 \times 10^{-5}$ & $11 \%$ & $11 \%$ \\
\hline Diablo Canyon & $9 \times 10^{-5}$ & $2 \%$ & $11 \%$ \\
\hline Farley & $1 \times 10^{-4}$ & $0.04 \%$ & $9 \%$ \\
\hline Kewaunee & $7 \times 10^{-5}$ & $8 \%$ & $99 \%$ \\
\hline Indian Point 2 & $3 \times 10^{-5}$ & $7 \%$ & $20 \%$ \\
\hline Indian Point 3 & $4 \times 10^{-5}$ & $5 \%$ & $79 \%$ \\
\hline McGuire & $4 \times 10^{-5}$ & $0.02 \%$ & $2 \%$ \\
\hline Seabrook & $7 \times 10^{-7}$ & $1 \%$ & Not Available \\
\hline Sequoyah & $2 \times 10^{-4}$ & $4 \%$ & $75 \%$ \\
\hline Surry & $2 \times 10^{-4}$ & $5 \%$ & Not Available \\
\hline South Texas & $4 \times 10^{-5}$ & $5 \%$ & $22 \%$ \\
\hline Trojan & $6 \times 10^{-5}$ & $2 \%$ & Not Available \\
\hline Vogtle & $5 \times 10^{-5}$ & $4 \%$ & $12 \%$ \\
\hline Watts Bar & $3 \times 10^{-4}$ & $3 \%$ & $6 \%$ \\
\hline
\end{tabular}

1. All numbers have been rounded to one significant digit.

2. The steam generator tube rupture percentage of containment bypass values were estimated based on information presented in the IPEs. In some cases it was difficult to determine these percentages and they had to be estimated based on supporting information. 


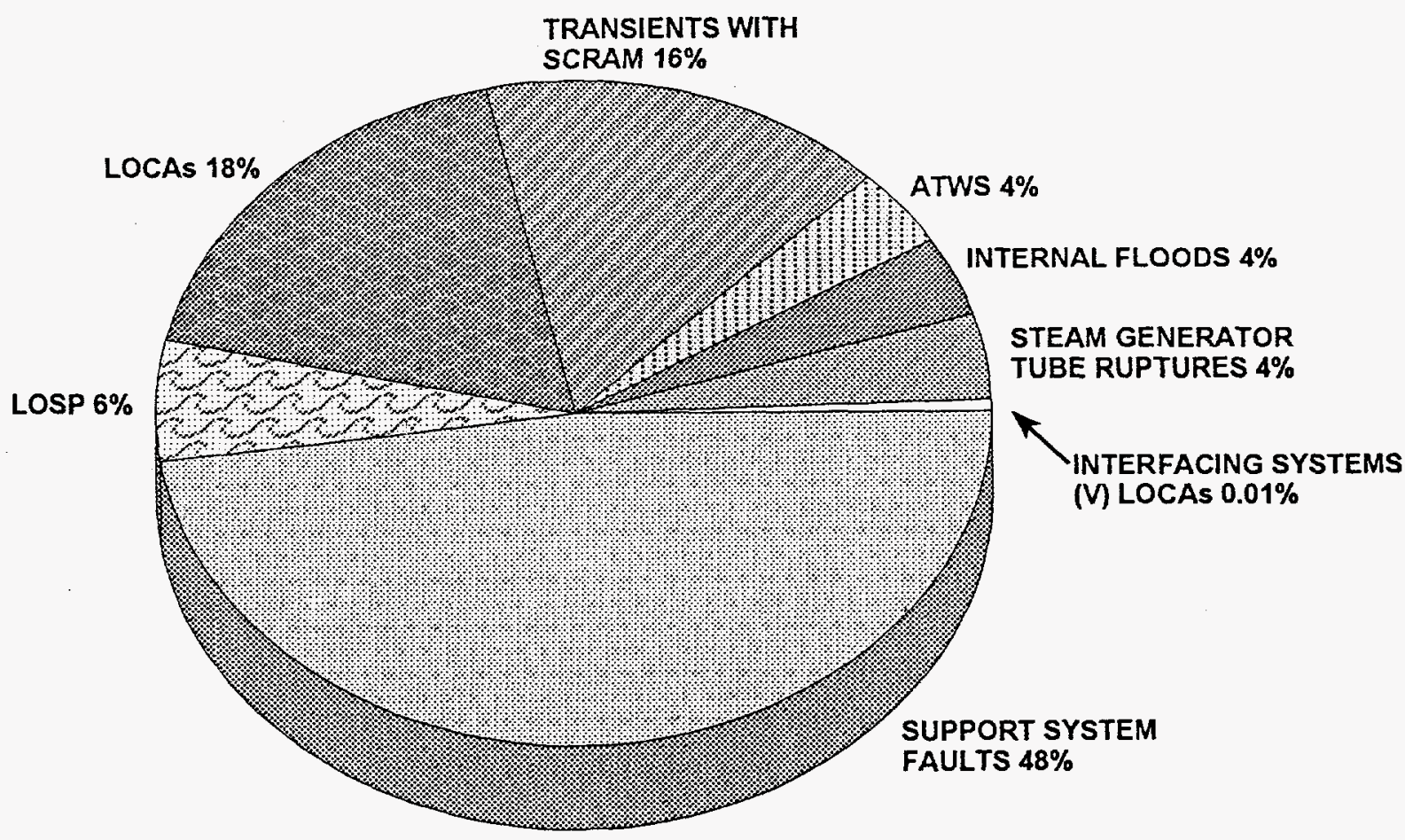

Figure 79. Typical steam generator tube rupture contribution to the total core damage frequency (note: these results are from the Sequoyah nuclear power plant's IPE submittal).

However, the contribution of the spontaneous steam generator tube ruptures to the total core damage frequency should not be used to determine the risk acceptance of various steam generator designs or degraded conditions. This is because steam generator tube rupture accidents generally result in containment bypass and therefore the offsite risk profile is much more strongly influenced by this event than is the core damage frequency. In other words, the containments used in the US and elsewhere reduce or eliminate the offsite doses from most of the other, higher core damage frequency, accidents such that the risk contribution from the spontaneous steam generator tube rupture event becomes more significant. The data in Table 18 indicate that the fraction of the total risk associated with spontaneous steam generator tube ruptures at most PWRs is above about $10 \%$ and at some plants is quite high ( $75 \%$ to $99 \%$ ).

The U.S. ice condenser containment plants might be expected to have a lower percentage risk contribution from steam generator tube rupture. The ice condenser containments have a lower design pressure than other types of containment. Therefore, early containment failure during certain other higher core damage frequency accidents is possible. Early containment failure would increase the contributions of the other core damage accidents to the overall core damage frequency and the net contribution from steam 
generator tube rupture would be expected to be lower. However this generalization cannot be made. As Figure 80 indicates, even for the ice condenser containments the steam generator tube rupture contribution can be large.

Induced steam generator tube ruptures have not been considered in the US IPEs, but are being evaluated by the USNRC as part of the steam generator rule-making program. The IPEs used only the spontaneous tube rupture history discussed in Chapter 4, and did not consider the incipient tube rupture information or the steam generator tubing degradation information discussed in Chapter 3.

\subsection{Steam Generator Tube Rupture Risk Contributions}

The risk profile of an operating nuclear power plant is composed of a variety of core damage accidents. The core damage contributors include loss of coolant accidents, losses of offsite power (including station blackout), transients, anticipated transients without scram, and steam generator tube rupture. As mentioned in the introduction to this section, there are two important steam generator tube rupture risk contributors. These are:

$$
\begin{aligned}
& \text { - spontaneous steam generator tube } \\
& \text { rupture, and }
\end{aligned}
$$

- $\quad$ induced steam generator tube rupture.

A spontaneous steam generator tube rupture is the rupture of a tube that is not caused by another event or an upset in normal expected operational parameters. An induced steam generator tube rupture is an accident that is associated with an upset condition. Induced steam generator tube ruptures are conditional based on the occurrence of other events. Each of these two contributors are further discussed in the following sections.
The relative risk importance of spontaneous steam generator tube ruptures and induced steam generator tube ruptures is a function of the amount of tube degradation found in the steam generators. Induced steam generator tube ruptures become more risk important as the steam generator tubes' ultimate pressure capacity degrades because the probability of core melt is much higher during an induced (multiple) tube rupture event.

\subsubsection{Spontaneous Steam Generator Tube Rupture}

One spontaneous steam generator tube rupture event has occurred about every 2 years during the last 20 years (see Table 12 in Chapter 4). These spontaneous steam generator tube rupture events have been associated. only with Westinghouse and Combustion Engineering designed steam generators. However, Babcock $\&$ Wilcox plants have experienced leaks and incipient tube ruptures (see Table 14). The frequency of the spontaneous steam generator tube rupture events has been estimated to be about $2.5 \mathrm{E}-2$ per reactor year of operation. This value is computed by dividing the total number of tube ruptures by the reactor years of operation. (The steam generator tube rupture frequencies used in the IPEs range from $1 \mathrm{E}-2$ to about $3 \mathrm{E}-2$ per reactor year.)

The lack of an exact break point for the onset of a tube rupture has led to some uncertainty in the determination of the frequency of spontaneous steam generator tube ruptures. There have been a large number of leaking tubes, some of these leaks have been large enough that the tube is considered ruptured in some studies and not in others. As discussed in Chapter 4, the USNRC classifies a steam generator tube rupture as a break in a steam generator tube which causes a primary to secondary coolant system leak in excess of the normal changing flow capacity of 


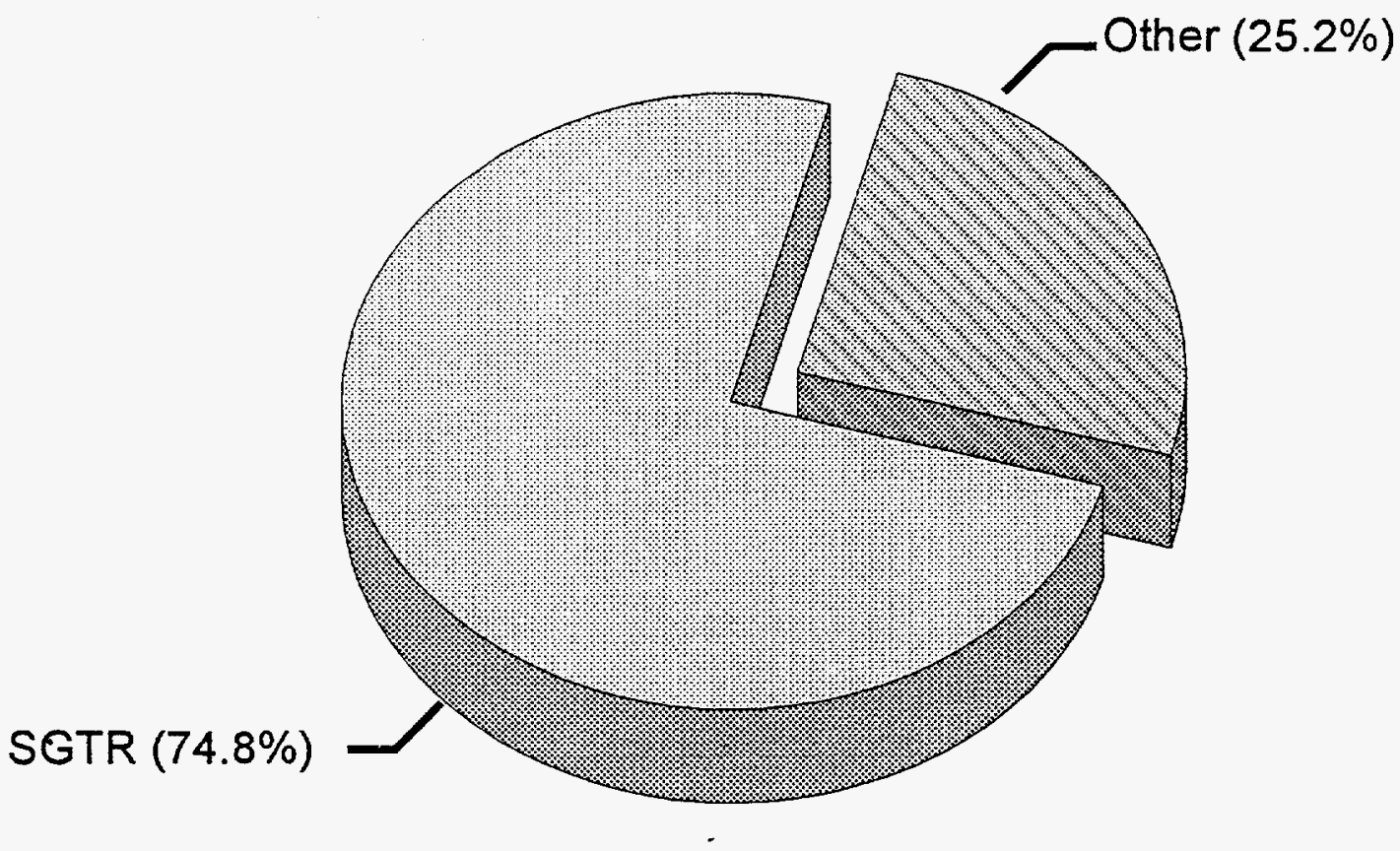

Figure 80. Steam generator tube rupture contribution to the total containment bypass fraction at the Sequoyah nuclear power plant (ice condenser containment)

the reactor coolant system (USNRC 1988a). As a result, tube rupture condition may be a function of the tube size, the plant operating conditions, tube break size, and the capacity of the plant's charging system.

\subsubsection{Induced Steam Generator Tube Rupture}

Induced steam generator tube ruptures have contributions from the following type of events:

- operational transients,

- $\quad$ rare events, and

- $\quad$ severe accidents.
These events introduce moderate to large increases in the pressure differential across the steam generator tubes. For aged or degraded tube conditions, the moderate to large increases in the pressure differential can increase the probability of steam generator tube failure. As a result, induced steam generator tube ruptures are typically associated with steam generator tubes that have degraded with time beyond some threshold; the tube's pressure capacity has degraded when compared to a spectrum of pristine tubes. The tube failure probability is a function of the amount of tube degradation. If the tube degradation is large enough, the induced 
steam generator tube rupture accidents can have a higher risk contribution than the spontaneous steam generator tube rupture events. No recorded induced steam generator tube rupture event has occurred to date. Induced steam generator tube rupture events can be controlled by maintaining good mechanical integrity of the steam generator tubes.

Operational Transients. Operational transients occur frequently and may result in slight or moderate increases in the pressure drop across the steam generator tubes. These types of transients include:

- turbine trip,

- loss of main feed,

- temporary loss of off site power,

- $\quad$ failed open turbine bypass valve, and

- $\quad$ loss of a reactor coolant pump.

The frequency of occurrence of these events and an upper bound to the pressure drop across the steam generator tubes are provided in Table 19.

The operational transients can become risk significant when the steam generator tubes are severely degraded. When the operational transients are combined with a failed or stuck open atmospheric dump valve or secondary side safety relief valve, an increase in the pressure differential challenges the steam generator tube integrity and the risk increases.

The impact of a stuck-open turbine bypass valve on peak steam generator tube differential pressure should also be investigated in conjunction with the operational transients. A stuck-open or spuriously opening turbine bypass valve may also introduce a large differential pressure similar to a stuck-open atmospheric dump valve, or secondary side safety relief valve. Some plants have turbine bypass valves with a $100 \%$ load rejection capacity. These plants may experience a more significant steam generator tube overpressure. An operational event with these types of single failures may be the most risk significant of all steam generator tube rupture events when the steam generator is badly degraded.

Rare Events. Rare events are design basis or other events that have a low frequency of occurrence, but may result in significant steam generator tube overpressures. These types of events typically include:

- $\quad$ main feed line break,

- main steam line break,

- anticipated transients without scram, and

- loss of coolant accidents (reversed pressure drop).

These events are less risk significant than the operational events with degraded steam generator tubes due to their lower frequency of occurrence. However, these events are typically used to conservatively bound the worst case accident for regulatory purposes.

Severe Accidents. Severe accidents are very low frequency events. In some cases, severe accidents may cause much higher pressuretemperature conditions in the steam generators than expected during typical design bases accident conditions. Tube degradation in association with these elevated pressuretemperature conditions can increase the probability of tube failure. Typical severe accidents of concern for degraded steam generator tubes include:

\footnotetext{
- anticipated transient without scram,

- $\quad$ station black out, and

- station blackout with a stuck open atmospheric dump valve or safety relief valve.
} 
Table 19. Identification of Initiating Events.

\begin{tabular}{|c|c|c|}
\hline Event Description & $\begin{array}{l}\text { Peak Tube Differential } \\
\text { Pressure }\end{array}$ & $\begin{array}{l}\text { Initiator } \\
\text { Frequency } \\
\text { (per year) }\end{array}$ \\
\hline \multicolumn{3}{|c|}{ Decrease in Reactor Coolant System Inventory } \\
\hline $\begin{array}{l}\text { Event represents the inadvertent opening of a PORV, leading to a small leak path } \\
\text { for reactor coolant system inventory. Initiator frequency obtained from Gentillon } \\
\text { et al. (1994). }\end{array}$ & $\begin{array}{l}<9.7 \mathrm{MPa} \\
(1,400 \mathrm{psi})\end{array}$ & $\begin{array}{l}\lambda=7.4 \mathrm{E}-3 \\
\sigma=2.5 \mathrm{E}-3 \\
\mathrm{EF}=10.1 \\
\end{array}$ \\
\hline $\begin{array}{l}\text { Event represents either a medium or large loss of coolant accident, with rupture } \\
\text { diameter greater than } 2 \text { inches. Initiator frequency obtained from Ericson et al. } \\
(1990) \text {, medium and large loss of coolant accident. }\end{array}$ & $\begin{array}{l}<9.7 \mathrm{MPa} \\
(1,400 \mathrm{psi})\end{array}$ & $\begin{array}{c}\lambda=1.5 \mathrm{E}-3 \\
\sigma=3.6 \mathrm{E}-3 \\
\mathrm{EF}=9.7\end{array}$ \\
\hline \multicolumn{3}{|c|}{ Increase in Heat Removal by Secondary System } \\
\hline $\begin{array}{l}\text { Event represents a feed water system failure which causes an increase in feed } \\
\text { water flow in one loop. Initiator frequency obtained from Gentillon et al. (1994). }\end{array}$ & $\begin{array}{l}<9.7 \mathrm{MPa} \\
(1,400 \mathrm{psi})\end{array}$ & $\begin{aligned} \lambda & =5.6 \mathrm{E}-2 \\
\sigma & =1.2 \\
\mathrm{EF} & =11.0\end{aligned}$ \\
\hline $\begin{array}{l}\text { Event represents the inadvertent opening of a steam generator relief valve, } \\
\text { resulting in low pressure in the secondary system. Initiator frequency obtained } \\
\text { from Mackowiak et al. (1985), PWR Category } 29 \text {. }\end{array}$ & $\begin{array}{l}\sim 12.8 \mathrm{MPa} \\
(1,850 \mathrm{psi})\end{array}$ & $\begin{array}{c}\lambda=2.0 \mathrm{E}-2 \\
\sigma=0.18 \\
\mathrm{EF}=31.6\end{array}$ \\
\hline $\begin{array}{l}\text { Event represents the rupture of the main steam line. Initiator frequency obtained } \\
\text { from Ericson et al. (1990). }\end{array}$ & $\begin{array}{l}\sim 17.2 \mathrm{MPa} \\
(2,500 \mathrm{psi})\end{array}$ & $\begin{array}{l}\lambda=5.0 \mathrm{E}-4 \\
\sigma=1.2 \mathrm{E}-3 \\
\mathrm{EF}=9.7\end{array}$ \\
\hline \multicolumn{3}{|c|}{ Decrease in Heat Removal by Secondary Side } \\
\hline $\begin{array}{l}\text { The loss of the plant external power grid. Initiator frequency obtained from } \\
\text { Gentillon et al. (1994). }\end{array}$ & $\begin{array}{l}<9.7 \mathrm{MPa} \\
(1,400 \mathrm{psi})\end{array}$ & $\begin{array}{c}\lambda=3.5 \mathrm{E}-2 \\
\sigma=0.44 \\
\mathrm{EF}=11.9\end{array}$ \\
\hline $\begin{array}{l}\text { Trip of the turbine generator that decreases steam flow to the turbine. Initiator } \\
\text { frequency obtained from Gentillon et al. (1994). }\end{array}$ & $\begin{array}{l}<12.8 \mathrm{MPa} \\
(1,850 \mathrm{psi})\end{array}$ & $\begin{array}{l}\lambda=0.40 \\
\mathrm{a}=1.6 \\
\mathrm{EF}=5.3\end{array}$ \\
\hline $\begin{array}{l}\text { Event represents a loss of alternating current power to the secondary heat removal } \\
\text { system. Initiator frequency obtained from Mackowiak et al. (1985), PWR } \\
\text { Category } 37 \text {. }\end{array}$ & $\begin{array}{l}<12.8 \mathrm{MPa} \\
(1,850 \mathrm{psi})\end{array}$ & $\begin{array}{c}\lambda=0.11 \\
\sigma=0.40 \\
\mathrm{EF}=14.6\end{array}$ \\
\hline $\begin{array}{l}\text { The loss or reduction of normal feedwater flow for one loop. Initiator frequency } \\
\text { obtained from Gentillon et al. (1994). }\end{array}$ & $\begin{array}{l}<12.8 \mathrm{MPa} \\
(1,850 \mathrm{psi})\end{array}$ & $\begin{array}{c}\lambda=0.43 \\
\sigma=2.2 \\
\mathrm{EF}=5.8\end{array}$ \\
\hline $\begin{array}{l}\text { The rupture of the feedwater line. Initiator frequency obtained from Ericson et al. } \\
\text { (1990). }\end{array}$ & $\begin{array}{l}-17.2 \mathrm{MPa} \\
(2,500 \mathrm{psi})\end{array}$ & $\begin{array}{c}\lambda=5.0 \mathrm{E}-4 \\
\sigma=1.2 \mathrm{E}-3 \\
\mathrm{EF}=9.7\end{array}$ \\
\hline \multicolumn{3}{|c|}{ Decrease in Reactor Coolant System Flow Rate } \\
\hline $\begin{array}{l}\text { The loss of reactor coolant system flow in one loop (e.g., reactor coolant system } \\
\text { pump failure). Initiator frequency obtained from Gentillon et al. (1994). }\end{array}$ & $\begin{array}{l}<12.8 \mathrm{MPa} \\
(1,850 \mathrm{psi})\end{array}$ & $\begin{array}{c}\lambda=4.2 \mathrm{E}-2 \\
\sigma=0.63 \\
\mathrm{EF}=9.1\end{array}$ \\
\hline \multicolumn{3}{|l|}{ Transients } \\
\hline $\begin{array}{l}\text { A transient with subsequent failure to SCRAM the reactor. Initiator frequency } \\
\text { obtained from Gentillon et al. (1994), all transients, and Ericson et al. (1990), Vol. } \\
\text { 3, failure to scram the reactor. }{ }^{\text {. }}\end{array}$ & $\begin{array}{c}\sim 17.2 \mathrm{MPa} \\
(2,500 \mathrm{psi})\end{array}$ & $\begin{array}{c}\lambda=1.4 \mathrm{E}-4 \\
\sigma=1.0 \mathrm{E}-3 \\
\mathrm{EF}=7.9\end{array}$ \\
\hline
\end{tabular}




\title{
Table 19. (continued)
}

\author{
Notes
}

a. $\lambda$ is the initiating event frequency; $\sigma$ is the standard deviation of the initiating event frequency; EF is the associated error factor of the log-normal distribution. The initiator was developed by adding the large loss-of-coolant (LOCA) and the medium LOCA initiators together. The resulting initiator parameters were calculated by using Monte Carlo simulation with the equation: Large LOCA + Medium LOCA, where Large LOCA was assumed to be a lognormal distribution with mean of 5.0E-4 and standard deviation of 1.2E-3 and Medium LOCA was assumed to be a lognormal distribution with mean of 1.0E-3 and standard deviation of 2.5E-3.

b. The initiator was developed by multiplying the overall transient initiator by the probability of failing to scram the reactor. The resulting initiator parameters were calculated by using Monte Carlo simulation with the equation: $\mathrm{f}$ (transients) * $\mathrm{P}$ (fail to scram|transient), where $\mathrm{f}$ (transient) was assumed to be a lognormal distribution with mean of 2.4 and standard deviation of 2.2 and $\mathrm{P}$ (fail to scram/transient) was assumed to be a lognormal distribution with mean of $6.0 \mathrm{E}-5$ and standard deviation of $7.6 \mathrm{E}-5$.

Historically, severe accident analyses have assumed that pristine steam generator tubes will remain intact and failures in the hot leg/surge line will probably occur first. This conclusion is based on the existence of a loop seal in the cold leg and good mixing of the counter-current hot leg flow in the inlet plenum of the steam generator. The severe accident natural circulation flows that may induce reactor coolant system failures and that also increase the temperature in the steam generator tubes are discussed later in this section.

If a severe accident induced steam generator tube rupture occurs, it occurs from one of two causes. These causes are: (a) high temperature creep rupture of the steam generator tubes, or (b) high temperature-high pressure induced rupture of defective tubes. The probability of steam generator tube rupture becomes larger than the probability of creep rupture as the tubes degrade (e.g, as the cracks become larger). The tubes may degrade to the point where only tube ruptures occur during a severe accident that induces high pressure/high temperature steam generator tube conditions.

\subsection{Risk Significant Steam Generator Tube Rupture Failures}

The risk significant failures and mistakes during the course of a steam generator tube rupture accident can be broken down into a few high level items. These key items controlling risk are:
- failure to promptly depressurize,
- $\quad$ reactor water storage tank failures, - loss of suction - depletion

- failure to promptly isolate the defective steam generator, and

- $\quad$ failure to achieve RHR entry conditions in a reasonable time period.

The dominant contributors listed above are a typical result of steam generator tube rupture probabilistic risk assessment analyses (discussed in more detail in the following paragraph). These failure contributors should only be considered typical. The variations in PWR 
designs and emergency response procedures can have an impact on the risk significant operator actions and component and system failures.

These risk significant operator actions and component failures are typically identified using classical probabilistic risk assessment techniques. Best estimate thermal-hydraulic calculations are performed to determine the minimal set of operator actions and equipment needed to prevent fuel damage and also to identify the possible range of accident sequences. This information is then used to develop the plant response models. These models consist of event trees and fault trees or other system logic models. The event tree accident sequences reflect the results of the actions that are successful in preventing fuel damage and those that are not successful. The event tree accident sequences are processed and quantified to determine the minimal set of failures that result in core damage. The dominant failure modes are then identified as the high frequency core damage events.

After linking, the failure probability associated with the various operator actions and components can then be set to one or zero to determine the importance of the various failure modes. The operator actions and components are then ranked in terms of their increase or decrease on the frequency of the occurrence of the accident. This ranking determines the impact on risk of the reliability of the individual operator actions and components. This ranking is based on best estimate thermal-hydraulic calculations, the reliability of the plant's systems, and standard operating procedures.

\subsection{Containment Bypass}

Containment bypass events are very important in understanding the steam generator tube rupture accident's progression and the risk associated with steam generator tube rupture. The important containment bypass effects are:
- containment bypass influences the number, reliability, and types of systems needed to prevent core damage from occurring,

- containment bypass events influence the core damage frequency distribution associated with a range of multiple tube rupture events, and

- containment bypass provides a direct release path to the environment for the radionuclides.

It has been noted from combined thermalhydraulic and probabilistic risk assessment sensitivity studies that the number of steam generator tubes failing during a steam generator tube rupture event impacts the risk profile when the containment is bypassed. The impact on the plant risk (defense in-depth) of a given number of steam generator tube failures is listed in Table 20.

Table 20. The impact of the number of tubes failed on defense in depth.

\begin{tabular}{ll}
$\begin{array}{l}\text { Number of Tubes } \\
\text { Failed }\end{array}$ & $\begin{array}{l}\text { Impact on Defense } \\
\text { In-Depth }\end{array}$ \\
\hline A few & $\begin{array}{l}\text { Requires operator to depres- } \\
\text { surize the reactor coolant } \\
\text { system. }\end{array}$ \\
Greater than a few & $\begin{array}{l}\text { Plant automatically depres- } \\
\text { surizes. }\end{array}$ \\
$\begin{array}{l}\text { Greater than about } \\
\text { about } 15 \text { tubes }\end{array}$ & $\begin{array}{l}\text { Reactor water storage tank } \\
\text { inventory is depleted before } \\
\text { RHR entry conditions can be } \\
\text { achieved. }\end{array}$ \\
\hline
\end{tabular}

The information in Table 20 suggests that the integrity of the steam generator tubes needs to be controlled to prevent an operational transient from inducing a large number of multiple tube ruptures. If a large number of tubes fail, the typical steam generator tube rupture accident 
mitigation strategies may become ineffective and the containment bypass steam generator tube rupture events may result in core damage and a significant increase in the public risk. Steam generator tube inspection procedures need to be such that they protect against reaching the no defense-in-depth break point number of severely defected tubes. In other words, the inspection and maintenance procedures must adequately identify and correct the tube degradation to prevent serious consequences.

The number of failed tubes for the categories shown in Table 20 are a function of the specific plant and the plant's systems. Typically a few tubes is less than four, more than a few between four and fifteen, and a large number greater than fifteen. It should be noted that these break points will be different for different plants. They are a function of the RWST inventory, the steam generator tube size and the emergency core cooling system flow rates.

\subsection{Steam Generator Tube Degradation}

As discussed in Section 3, the three most widespread types of tube degradation affecting U.S. PWR steam generator tubes today are (a) PWSCC in the tube sheet and tight radius U-bend regions, (b) IGA and IGSCC on the secondary side of the tubes at the tube supports and for some plants in the tubesheet and free span regions, and (c) fretting, wear and thinning. Other corrosion degradation, such as wastage, pitting, and denting have occurred in many older steam generators, but these types of degradation have been avoided in most newer steam generators by changes in operating practices. Some of the older generators that were severely affected by wastage, pitting, or denting have been replaced, and improvements in operating practices have generally arrested these types of degradation at most other plants. However, significant attack by pitting is continuing at a small number of plants. Other types of degradation, such as erosion-corrosion, corrosion fatigue, and fatigue at U-bends have been observed, but these have affected very few plants and relatively few tubes. Two instances of a sudden rupture of a steam generator tube in the U-bend region from fatigue crack growth have occurred. Also, 6 of the 10 steam generator tube ruptures that have occurred to date have been in the U-bend region.

\subsection{Conditional Tube Rupture Probability}

The conditional probability of a steam generator tube(s) failing is a function of the aging degradation mechanisms and the extent of the degradation. The thermal-hydraulic conditions imposed on the tube are also important. The important parameters are:

- steam generator tube temperature,
steam generator tube pressure differ-
ential.

These conditions are a function of the transient and/or accident.

The accidents that can challenge the integrity of the steam generator tubes are the main steam line break, feedwater line break, and anticipated transients without scram initiators. The main steamline break initiator is composed of those initiators that result in loss of steam generator secondary side integrity. These items include failed secondary PORVs, turbine bypass valves, atmospheric dump valves, etc. This reduced set of initiating events was identified from reviewing a list of initiators that challenge both the primary and secondary side pressure integrity of the steam generators.

The identification of the reduced set of steam generator tube rupture accident initiators was determined by an evaluation of a range of grouped initiators. This grouped review included initiators that: (a) result in a decrease in reactor coolant system inventory, (b) result in an increase in heat removal by the secondary 
system, (c) result in a decrease in the heat removal by the secondary system, (d) result in a decrease in the reactor coolant system coolant's flow rate, and (e) result in a transient. A summary description of the grouped initiators is provided in Table 19. Table 19 also summarizes the expected initiating event frequency, standard deviation, and log-normal error factor. The peak primary-to-secondary pressure differential is also provided. This pressure differential is utilized to estimate the conditional tube rupture probability given the occurrence of the initiator. (Note: It may be desirable to reanalyze the peak overpressures found in Table 19 since the pressures are based on worst design basis accident analysis for a number of different plants. However, these pressures are adequate for the purpose of a preliminary screening analysis.)

A review of Table 19 identified the events most likely to challenge the steam generator tubes (largest initiating event frequency and pressure differential). These events are associated with: (a) the loss of secondary side integrity, and (b) anticipated transients without SCRAM. The loss of secondary side integrity includes a main feedline break and main steamline break.

\subsubsection{Initiating Events}

The five groups of steam generator tube rupture accident initiators listed in Table 19 are each discussed in the following paragraphs.

Decrease in Reactor Coolant System Inventory. These accident initiators are the loss of coolant accidents. The initiating event frequency review included inadvertent opening of a primary side PORV, along with the medium and large break loss of coolant accidents. The total initiating event frequency for this group is in the range of $7 \times 10^{-3}$ per year. The maximum expected pressure drop across the generators is in the range of $9.7 \mathrm{MPa}(1,400 \mathrm{psi})$. These accidents can be screened from further consideration since the pressure differential is not excessive, the combined initiating event frequency is low, and the tubes are placed in compression.

Increase in Heat Removal by the Secondary System. Three accident initiators were grouped into this category. These accidents include loss of feedwater control in one loop; inadvertent opening of a steam generator relief valve, turbine bypass valve, or atmospheric dump valve; and a rupture of the main steamline. The total frequency of events in this category is of the order of 0.1 per reactor year. The frequency is dominated by loss of feedwater control resulting in excessive feedwater. The inadvertent opening of an steam generator relief valve/atmospheric dump valve or turbine bypass valve along with rupture of a main steam line makeup the remainder of the contribution. The most significant pressure challenge to the steam generator tubes occurs from the later events with the lowest frequency. For the purposes of analysis the steam line break and inadvertent opening of a relief valve may be grouped as having similar system success and mitigation paths.

Decrease in the Heat Removal by the Secondary System. This set of accident initiators contains five events. Only the break or rupture of the main feedwater line was identified as strongly challenging the steam generator tubes. This event has a low frequency but provides the most significant pressure drop across the steam generator tubes. The remaining four events are (a) loss of offsite power, (b) turbine trip, (c) loss of power to the secondary heat removal system and (d) loss or reduction in normal feedwater flow. The frequency of these events is dominated by loss of feedwater flow and turbine trips.

\section{Decrease in the Reactor Coolant System} Coolant's Flow Rate. There is only one initiating event contained in this group, the loss of flow in one reactor coolant system loop. It is 
caused by complete loss of a reactor coolant pump. The frequency of occurrence was estimated to be $4.2 \mathrm{E}-2$ per year of operation.

Transients. This group contains only one event, a transient with subsequent failure of the reactor to scram. The event may result in substantial challenges to the steam generator tubes. The peak differential pressures may approach 17.2 MPa (2,500 psi).

\subsubsection{Screening Analysis Methodology}

Analytical methods exist to quantify the frequency of occurrence of induced steam generator tube rupture. The frequency of induced failure of steam generator tubes can be expressed as a function of the conditional failure probability and the frequency of occurrence of the initiator. The conditional tube failure probability when multiplied by the accident initiating frequency determines the induced steam generator tube rupture frequency for each initiator. These contributors can then be ranked. The conditional failure probability is a function of steam generator tube degradation, and is the primary link relating the physical condition of the tubing to the plant system performance and ultimately risk. The screening techniques available to determine the conditional tube failure probability and thus the dominant induced steam generator tube rupture accident sequences are provided in the following section.

Estimation of Conditional Steam Generator Tube Failure Probability. The frequency of experiencing an induced steam generator tube rupture is dependent upon several tube-condition and operational parameters. Two of the more important parameters in the tube-failure probability assessment process are: (1) the pressure retaining capacity of the tube at the time of the initiating event, and (2) the maximum expected differential pressure that will be placed on the tube.
The pressure retaining capacity of a steam generator tube depends on the tube type (e.g., tube diameter, material, wall thickness), and the degradation and wear of the tube. Initially, an average pristine tube will be able to withstand a differential pressure of about 60 to $70 \mathrm{MPa}$ $(9,000$ to $10,000 \mathrm{psi})$. If the tube pressure capacity degrades to below the expected pressures ranges for various plant transients, the tube may rupture. Normal operational and minor transient tube differential pressures are expected to be approximately 9.7 MPa $(1,400 \mathrm{psi})$. Major transient tube differential pressures may reach approximately $17.2 \mathrm{MPa}(2,500 \mathrm{psi})$.

The induced steam generator tube rupture frequency is determined by multiplying the initiator frequency by the conditional steam generator tube rupture probability. The frequency of tube rupture is found by:

$\lambda_{\mathrm{TR}}=\sum \lambda_{\mathrm{IE}} * \mathrm{P}(\mathrm{TR} \mid \mathrm{IE}) * \mathrm{P}_{\mathrm{i}}$

where

$\begin{array}{ll}\lambda_{\mathrm{TR}} & =\text { the frequency of tube rupture, } \\ \lambda_{\mathrm{IE}} & =\text { initiating event frequency, } \\ \mathrm{P}(\mathrm{TR} \mid \mathrm{IE})= & \begin{array}{l}\text { conditional probability of a tube } \\ \text { rupture given an initiating event, } \\ \text { and }\end{array}\end{array}$

$\mathrm{P}_{\mathrm{i}} \quad=$ probability of I number of tubes rupturing.

There is much uncertainty in the determination of the conditional tube rupture frequency as a function of pressure and tube condition. Previous analyses have utilized various assumed interpolation formula. These interpolation formula have yet to be fully verified with data and contain much uncertainty. The following paragraphs summarize the NUREG-0844 techniques and a 
linear interpolation scheme. A methodology based on stress/strain and crack propagation failure mechanisms is discussed in Section 6.7.5.

NUREG-0844 Methodology. It was estimated in NUREG-0844 that the conditional tube rupture probability is approximately 0.027 . This probability was based upon an estimated vulnerability time period for the steam generator tube rupture events that had occurred through mid-1986, and differential pressure of about 17.2 to $17.9 \mathrm{MPa}(2,500$ to $2,600 \mathrm{psi})$. Further, a conservative estimate of the industry average induced tube rupture probability of 0.05 was used. Assuming that the tube rupture probability can be adequately modeled with a lognormal distribution, the resulting lognormal distribution (at 17.2 $\mathrm{MPa}$ or $2,500 \mathrm{psi}$ ) has a mean value of 0.027 and a standard deviation of 0.012 [the error factor (EF) is equal to 2].

For initiator-caused overpressures lower than the $17.2 \mathrm{MPa}(2,500 \mathrm{psi})$ level, the tube rupture probability may be lower than the 0.027 value. It is assumed that the tube rupture pressure for normal differential pressures will be approximately zero $\left(\sim 10^{-4}\right.$ in this analysis). To determine the tube rupture probability as a function of steam generator differential pressure, some method of extrapolation had to be performed. NUREG-0844 gave the tube rupture probability as only distributed on pressure:

$P_{T R I}=P_{T R}($ at high pressure $)\left(\frac{\Delta P_{i}-\Delta P_{n}}{\Delta P_{a}-\Delta P_{n}}\right)^{2}$

where:

$\mathrm{P}_{\mathrm{TR} 1}=$ Conditional tube rupture probability for at least one tube during the $\mathrm{i}^{\text {ih }}$ initiator

$\mathrm{P}_{\mathrm{TR}}=$ Conditional tube rupture probability for at least one tube during a high pressure initiator
$\Delta \mathrm{P}_{\mathrm{i}} \quad=$
Peak tube differential pressure during the $i$ 'th initiator
$\Delta \mathrm{P}_{\mathrm{n}}=$ Normal operating tube differ- ential pressure
$\Delta \mathbf{P}_{\mathrm{a}}=$ Maximum peak tube differential pressure during any initiator

The distribution of the number of steam generator tubes ruptured also needed to be estimated. NUREG-0844 gave the probability of two to ten tubes rupturing as 0.5 and the probability of more than ten tubes rupturing as 0.01 . Consequently, the probability that only one tube ruptures is 0.49 . These values are applicable for a differential pressure of about 17.2 MPa (2,500 psi).

Linear Interpolation. A second potential method for estimating the conditional probability of a tube rupture is a linear fit of the tube rupture probability between the normal operational differential pressure and the maximum differential pressure. Using the NUREG-0844 endpoint probabilities, the resulting equation for the linear fit is given by:

$$
P_{T R 2}=2.45 \times 10^{-5}\left(\Delta P_{i}\right)-3.44 \times 10^{-2}
$$

where:

$\mathrm{P}_{\mathrm{TR} 2}=$ Conditional tube rupture probability for at least one tube during the i'th initiator

$\Delta \mathrm{P}_{\mathrm{i}}=$ Peak tube differential pressure during the $i$ 'th initiator.

Figure 81 provides a comparison between the linear and quadratic conditional tube rupture probability interpolation methods. As can be seen in the figure, the linear interpolation method provides higher probabilities for the same differential pressure than does the NUREG-0844 method. 


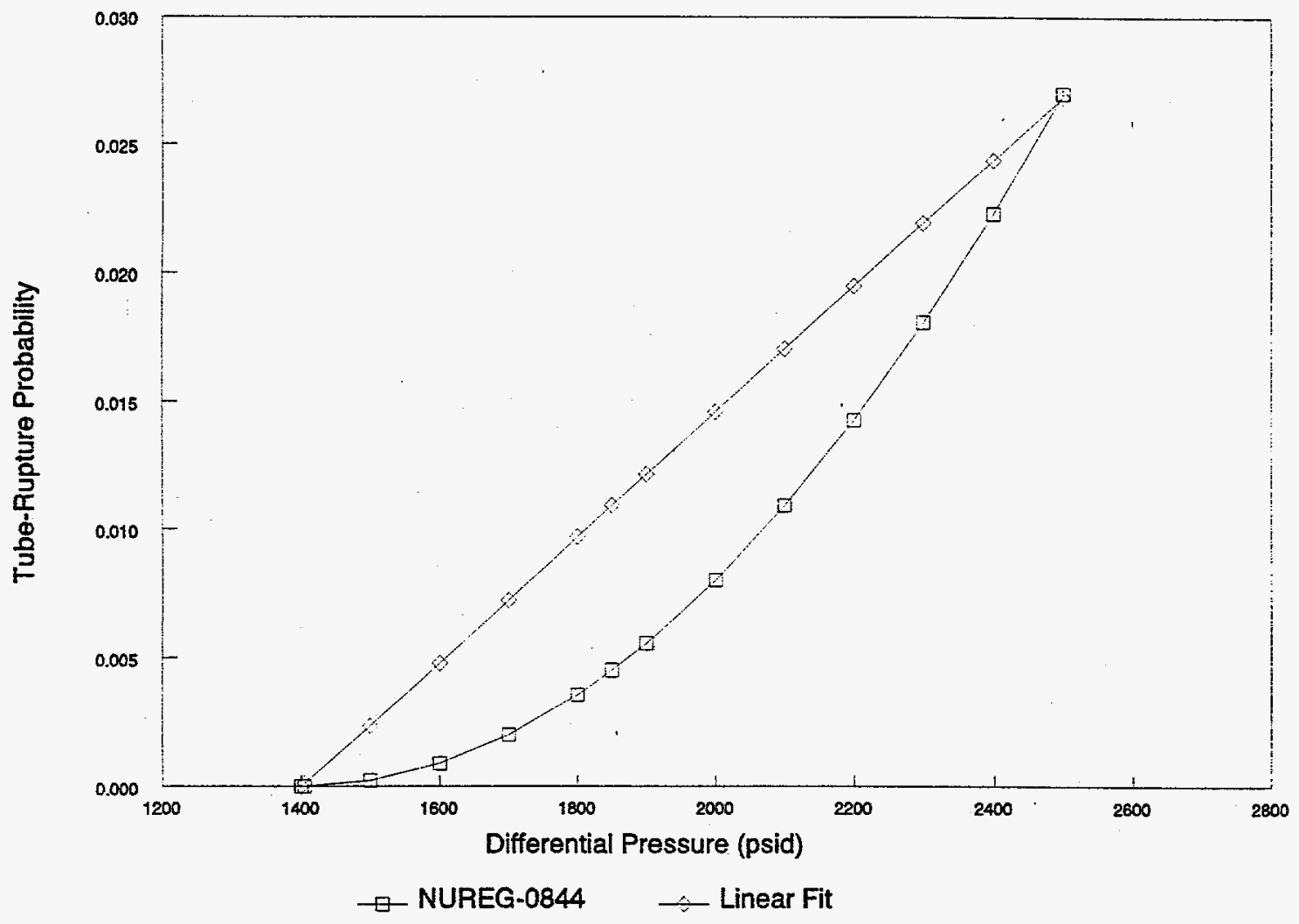

Figure 81. Comparison of two different conditional tube rupture probability screening methods.

\subsubsection{Screening Computation of Induced Steam Generator Tube Rupture Probabilities}

As presented earlier, the induced steam generator tube rupture frequency is determined by multiplying the initiating event frequency by the conditional steam generator tube-rupture probability. The frequency of tube rupture is found by:

$$
\lambda_{\mathrm{TR}}=\sum \lambda_{\mathrm{IE}} * \mathrm{P}(\mathrm{TR} \mid \mathrm{IE}) * \mathrm{P}_{\mathrm{i}}
$$

The initiating event frequency information that has been developed is provided in Table 19 and has been discussed. The induced steam generator tube failure frequencies provided in Table 21 are developed when the information in Table 19 is combined with the NUREG-0844 methodology. Table 21 provides a summary of the frequency of induced steam generator tube rupture. Note that these values should be considered screening values only, since they are not based on a mechanistic quantification of the impact of tube defects on the burst probability. However, the values identify the initiating events where a detailed evaluation of the impact of tube degradation on the potential for induced steam generator tube rupture is needed. A more 
Table 21. Information for screening induced steam generator tube rupture.

\begin{tabular}{|c|c|c|c|c|}
\hline \multirow[t]{2}{*}{ INITIATING EVENT IDENTIFIER } & \multicolumn{3}{|c|}{ FREQUENCY OF RUPTURING FOR VARIOUS NUMBERS OF TUBES } & \multirow[b]{2}{*}{$\begin{array}{l}\text { TOTAL TUBE RUPTURE } \\
\text { FREQUENCY }\end{array}$} \\
\hline & 1 TUBE & $\begin{array}{r}2 \text { TO } 10 \\
\text { TUBES } \\
\end{array}$ & $\begin{array}{c}\text { MORE TIIAN } \\
10 \text { TUBES } \\
\end{array}$ & \\
\hline Loss of normal feedwater & $9.5 \mathrm{E}-4$ & $9.5 \mathrm{E}-4$ & $2.0 \mathrm{E}-5$ & 1.9E-3 \\
\hline Turbine generator trip & $8.7 E-4$ & $8.7 E-4$ & $1.8 \mathrm{E}-5$ & $1.8 \mathrm{E}-3$ \\
\hline Reactor coolant system flow loss in one loop & $9.3 \mathrm{E}-5$ & 9.3E-5 & $2.1 \mathrm{E}-6$ & 1.9i- -4 \\
\hline $\begin{array}{l}\text { Alternating current power loss secondary } \\
\text { side }\end{array}$ & $2.4 E-4$ & $2.4 \mathrm{E}-4$ & $5.0 \mathrm{E}-6$ & $4.9 \mathrm{E}-4$ \\
\hline $\begin{array}{l}\text { Inadvertent opening of a secondary side } \\
\text { safety relicf valve }\end{array}$ & $4.4 \mathrm{E}-5$ & 4.4E-5 & $9.0 \mathrm{E}-7$ & $8.9 \mathrm{E}-5$. \\
\hline Steanl line rupture & $6.6 \mathrm{E}-6$ & $6.6 \mathrm{E}-6$ & $1.4 \mathrm{E}-7$ & $1.3 \mathrm{E}-5$ \\
\hline Main feedwater line rupture & $6.6 \mathrm{E}-6$ & $6.6 \mathrm{E}-6$ & $1.4 \mathrm{E}-7$ & $1.3 \mathrm{E}-5$ \\
\hline $\begin{array}{l}\text { Feedwater failure that results in a flow } \\
\text { increase in one loop }\end{array}$ & $2.8 \mathrm{E}-6$ & $2.8 \mathrm{E}-6$ & $5.6 \mathrm{E}-8$ & $5.7 \mathrm{E}-6$ \\
\hline Transient with failure to scram & $1.8 \mathrm{E}-6$ & $1.8 \mathrm{E}-6$ & $3.6 \mathrm{E}-8$ & 3.6E-6 \\
\hline Loss of offsite power & $1.7 \mathrm{E}-6$ & $1.7 \mathrm{E}-6$ & $3.5 \mathrm{E}-8$ & 3.4E-6 \\
\hline Inadvertent opening of a PORV & $3.6 \mathrm{E}-7$ & 3.6E-7 & 7.4E-9 & 7.3E-7 \\
\hline Large or medium loss of coolant accident & $7.4 \mathrm{E}-8$ & $7.4 \mathrm{E}-8$ & $1.5 \mathrm{E}-9$ & $1.5 \mathrm{E}-7$ \\
\hline
\end{tabular}


mechanistic technique for identifying the impact of tube degradation is provided in Section 6.7.5.

The screened sequences have been ranked in terms of their frequencies. Shown in Table 21 is the initiator identifier, the number of tubes ruptured, the frequency of rupturing "I" number of tubes, and the total calculated frequency of tube rupture for the various initiating events.

\subsubsection{Identification and Selection of Dominant Induced Steam Generator Tube Rupture Accident Contributors}

The frequency values provided in Table 21 provide a useful indicator of the important contributors to induced steam generator tube rupture. The induced steam generator tube rupture contributors can be grouped into high and low frequency contributors. The high frequency contributors are the normal plant operational failures that induce challenges to the steam generator tubes. The low frequency contributors are the postulated accidents that strongly challenge the integrity of the tubes.

Induced Steam Generator Tube Rupture Contributors of the Order $10^{-3}$. There are two contributors that induce steam generator tube ruptures in the range of $10^{-3}$ per reactor year. These contributors are the loss of feedwater flow and the trip of the turbine generator. Each of these initiators provide similar challenges to the steam generator tubes in terms of overpressure and have similar initiating event frequencies $(\sim 1.5$ per year $)$.

Induced Steam Generator Tube Rupture Contributors of the Order $10^{-4}$. The contributors in this range are the loss of a reactor coolant pump and the loss of alternating current power to the secondary side. These initiators provide similar challenges to the steam generator tubes in terms of overpressure and have similar initiating event frequencies ( $\sim 0.10$ per year).
Induced Steam Generator Tube Rupture Contributors of the Order $10^{-5}$. There are a large number initiating events that contribute to induced steam generator tube rupture with a frequency in the $10^{-5}$ range per year. The two dominant contributors are: (a) the inadvertent opening of a secondary side relief path, for example, an atmospheric dump valve, turbine bypass valve, PORV, steam generator relief valve, etc., and (b) reduction of feedwater in one loop with a corresponding increase in feedwater flow in another loop. The loss of feedwater initiator has a much higher frequency of occurrence that the inadvertent opening of a secondary side steam relief path. The pressure challenges to the generators are different, with the low frequency initiator causing a higher steam generator peak over pressure. The remainder of the initiators in this contribution range are: (a) loss of offsite power, (b) anticipated transients without scram, (c) feedwater line rupture, and (d) steam line break. Initiators (b) to (d) are accidents that can induce significant challenges to the steam generator tubes because of the high pressure drop across the tubes that occurs during these events.

Induced Steam Generator Tube Rupture Contributors of the Order $10^{-6}$. This category consists of only two contributors. These two contributors are the inadvertent opening of a primary side PORV and other loss of coolant accidents. These scenarios result in reverse pressure differential across the steam generators.

\subsubsection{Mechanistic Induced Steam Generator Tube Rupture Frequency}

The conditional steam generator tube rupture probability can be estimated somewhat more mechanistically by using Monte-Carlo methods. The fragility (failure probability) of the steam generator tubes can be modeled as a function of a normal or log-normal probability distribution as follows: 


$$
P_{s g}=\int f\left(p_{i}, p_{f a i l}\right) d p_{i}
$$

where:

$$
\begin{aligned}
& \mathrm{P}_{\mathrm{sg}}=\begin{array}{l}
\text { probability of steam generator } \\
\text { tube failure, }
\end{array} \\
& \mathrm{p}_{\mathrm{I}}=\begin{array}{l}
\text { steam generator differential } \\
\text { pressure, }
\end{array} \\
& \mathrm{p}_{\text {fail }}=\begin{array}{l}
\text { median failure pressure of a } \\
\text { single steam generator tube. }
\end{array}
\end{aligned}
$$

The function $f$ is represented by the following normal distribution:

$$
f\left(p_{i}, p_{f a i l}\right)=\frac{1}{\sqrt{(2 \pi)} \sigma_{f}} \exp \frac{-\frac{1}{2}\left(p_{i}-p_{\text {fail }}\right)^{2}}{\sigma_{f}^{2}}
$$

where $\sigma$ is the standard deviation of the tube's failure pressure.

The function $\mathrm{f}$ may also be represented by a lognormal distribution. The Monte-Carlo method samples points over the parameter's uncertainty distribution to determine a mean failure probability as a function of a tube overpressure and defect size. A variance can also be calculated with each failure probability.

The probability associated with a given number of failed steam generator tubes can be estimated from a binomial distribution. The probability of $\mathrm{n}$ tubes failing out of a total number $\mathbf{N}$ tubes with a given defect size is:

$$
P_{f a i l}(n)=\frac{N !}{n !(N-n) !} P_{s g}^{n}\left(1-P_{s g}\right)^{N-n}
$$

The probability that less than $\mathrm{x}$ tubes fail is given by:

$$
P_{\text {fail }}=\sum_{n=0}^{x} P(n)
$$

The binomial distribution only applies to components with the same failure probability.
The defects need to be grouped and the failure probabilities of the groups integrated in order to apply the model to a steam generator with a tube defect size distribution.

To estimate the conditional tube rupture probability, information concerning the median failure pressure of degraded tubes must be available. The ASME code (Section XI, Subsection IWB-3640 and Appendix C) and the experimental work of the Pacific Northwest Laboratories (PNL) provide useful correlations for this application. The ASME has developed and recommended equations for the effect of axial cracks on the burst pressure of tubes. The ASME and PNL model equations assume that the defect is independent of the tube material properties. Comparison of the applicable equations shows good agreement between the ASME code and the PNL experimental data correlations for Alloy 600 Steam generator tubes. The applicable experimental and analytical tube burst pressure correlations are described in the following sections.

PNL Equations. The experimental work at the PNL in assessing the median failure pressure of steam generator tubes with various sized defects can be utilized to estimate the failure pressure associated for each degradation mechanism. PNL developed the following equations to represent the failure pressure of steam generator tubes as a function of the tube degradation mechanism (Kurtz et al. 1990):

slots and cracks

$$
\frac{p}{p_{f}}=1-\frac{a}{t}+\left(\frac{a}{t}\right) \exp \left(\frac{-0.373 L}{\sqrt{(R t)}}\right)
$$

\section{uniform wall thinning}

$$
\frac{p}{p_{f}}=\left(1-\frac{a}{t}\right)^{1-\exp \frac{-0.13 L}{\sqrt{(R(t-a))}}}
$$


elliptical wastage

$$
\frac{p}{p_{f}}=\left(1-\frac{a}{t}\right)^{0.604}
$$

where:

$$
\begin{array}{lll}
\mathrm{p} / \mathrm{p}_{\mathrm{f}} & = & \text { ratio of defected to undefected } \\
\text { burst pressure, } & \\
\mathrm{a} & = & \text { defect depth, } \\
\mathrm{t} & = & \text { wall thickness, } \\
\mathrm{R} & = & \text { inner radius of tube, } \\
\mathrm{L} & = & \text { defect length. }
\end{array}
$$

These equations were developed for normal operating temperature conditions.

ASME Analytical Expressions. The ASME has an analytical expression that is useful in assessing the likelihood that an axial crack will burst (ASME 1992). The ASME code recommends the following equation for assessing the burst pressure that is associated with axial cracks in the steam generator tube walls.

$$
\frac{\Delta p R}{t}=\left(\frac{3 S_{m}}{S F}\right)\left[\frac{\frac{t}{a}-1}{\frac{t}{a}-\frac{1}{m}}\right]
$$

where $m$ is given by:

$$
m=\sqrt{1+1.61 \frac{L^{2}}{4 R t}}
$$

$\mathrm{R}$ is the tube radius, $\Delta \mathrm{p}$ is the differential pressure across the tube, and the other parameters in the above equations are: $S_{m}$ design flow stress limitation; in this case the flow stress at bursting, and SF - safety factor; taken to be 1 in this analysis. The above equation is roughly equivalent to the PNL slots and crack equation. However, the ASME equation shows a more rapid decline in the pressure capacity of deep cracks as the crack length becomes large when compared to the corresponding PNL equation. Both equations provide roughly the same asymptotic burst pressure as the crack length becomes large.
The ASME code's axial crack equation is valid for cracks not exceeding $75 \%$ of the tube's wall thickness. The ASME equation is also only applicable for cracks with a length less than a critical length determined from the solution of:

$$
\frac{P R}{t}=\frac{3 S_{m}}{m}
$$

ASME Section XI subsection IWB-3514.3 should be used to calculate the burst pressure if the tube's flaw length are greater than this critical value.

Material Properties Effects. Variations in material properties between tubes subjected to different fabrication processes is an important factor in determining burst pressures. Steam generator tubes fail by an elastic-plastic fracture process. The burst pressure of tubes with different material properties can be obtained by normalizing the results to the flow stress of the material. The flow stress corresponds to a value between the yield strength $S_{y}$ and ultimate tensile stress $S_{u}$ of the material. For Alloy 600 tubes, the flow stress given by:

$$
S_{m}=\frac{1}{2}\left[S_{y}+S_{u}\right]
$$

has been widely used. Other Alloy 600 flow stress equations have been developed, as well.

Steam Generator Tube Burst Pressure Correlation Standard Deviations. Uncertainty exists in the burst pressure correlations. This uncertainty is associated with the data scatter; the uncertainty in the model to mean burst pressures; uncertainty in the undefected burst pressure, and uncertainty in the estimated steam generator tube pressure differential.

The data scatter between the mean burst pressure and the data drives the quantification of the tube rupture probability. The standard deviation associated with this scatter can be used in a 
normal or log-normal distribution to estimate the conditional failure probability. Typically, if about $95 \%$ of the data are within $20 \%$ of the mean, the standard deviation is about $10 \%$ of the data scatter.

The data from the PNL experiments suggest that the burst pressure standard deviation is a few percent of the burst pressure. A maximum of $5 \%$ was noted from the experiments. The PNL correlations tended to reproduce the data within 10 to $15 \%$. This uncertainty may be incorporated into the Monte-Carlo analyses by uniform sampling over the estimated model and data's variance. Figure 82 was constructed to demonstrate the impact of a long axial crack on the probability of tube failure. This figure was constructed from the above listed PNL slot and cracks equation for demonstration and screening purposes. Separate calculations based on best estimate burst pressure standard deviations should be used for actual assessment purposes. Also, the calculations should assess the uncertainty in the empirical correlations and determine a standard deviation.

Temperature Dependent Steam Generator Burst Correlation. Severe accidents can pose high temperature challenges to the steam generator tubes. These accidents may increase the steam generator tubing temperatures into the range of 800 to $900 \mathrm{~K}$. These accidents pose high pressure and temperature conditions that may increase the frequency of tube rupture when the steam generator tubes have degraded.

The flow stress of a material can be used to evaluate the tube burst pressure as a function of temperature. Alloy 600 yield and ultimate tensile stresses as a function of temperature have been developed for the temperature range from 300 to 1373K. This data can be used to evaluate the effect of material properties on the tube's burst pressure from:

$$
P(T)=P\left(T_{r e f}\right) \frac{S_{m}(T)}{S_{m}\left(T_{r e f}\right)}
$$

This extrapolation is thought to be valid since the impact of axial wall cracks is not impacted by the materials properties (ASME 1992). However, experiments should be performed to evaluate the analytical predictions of the impact of tube temperature on the burst pressure of defected tubes.

\subsubsection{Typical Values for the Induced Steam Generator Tube Rupture Containment Bypass Frequencies}

The frequency of induced steam generator tube rupture, can be determined by combining the conditional tube rupture probabilities with the core damage initiating event frequency values obtained from the probabilistic risk assessments. Figure 83 provides a summary of typical results obtained by this combination. This figure was constructed for a steam generator that contains a single degraded tube with the axial crack lengths shown. As the figure and the PNL data indicate, long axial cracks show an asymptotic behavior in the burst pressure probability. Shorter steam generator tube crack lengths will significantly shift the curves toward lower tube failure frequencies. (Note that this figure is for demonstration purposes only, and should not be used as typical of a specific facility.)

Figure 83 is a demonstration plot of the frequency of induced steam generator tube rupture with core damage resulting from three different initiating events for a steam generator with a single degraded steam generator tube. (Note: The figure does not consider a steam generator with a distribution of flaws and thus should not be viewed as representative of the risk of induced steam generator tube rupture.) The figure's initiating events are: (a) turbine trip with a stuck open atmospheric dump valve; (b) a main steam line break induced steam generator tube rupture; and (c) a station blackout with a stuck 


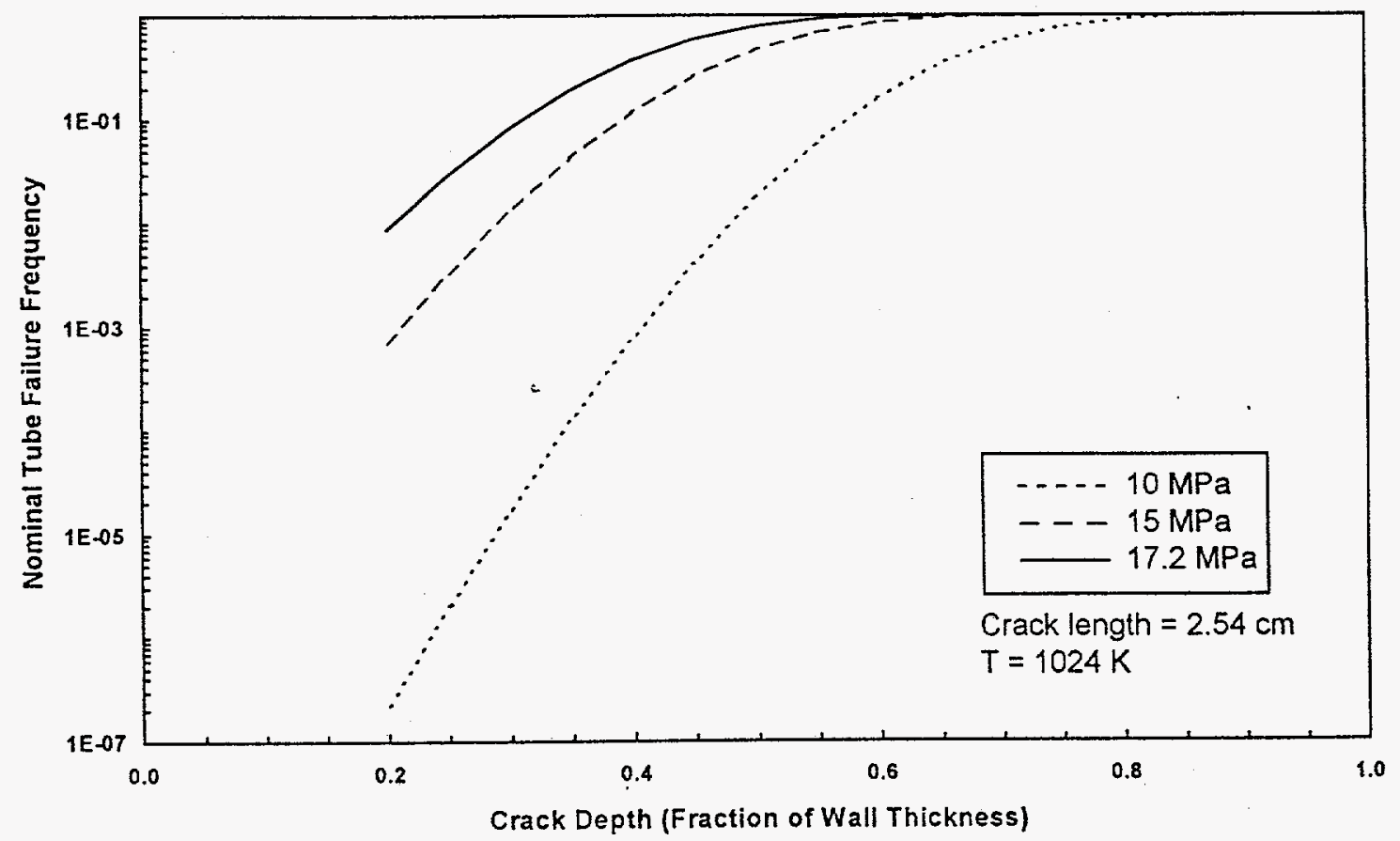

Figure 82. Estimated steam generator tube failure probability as a function of pressure and crack depth.

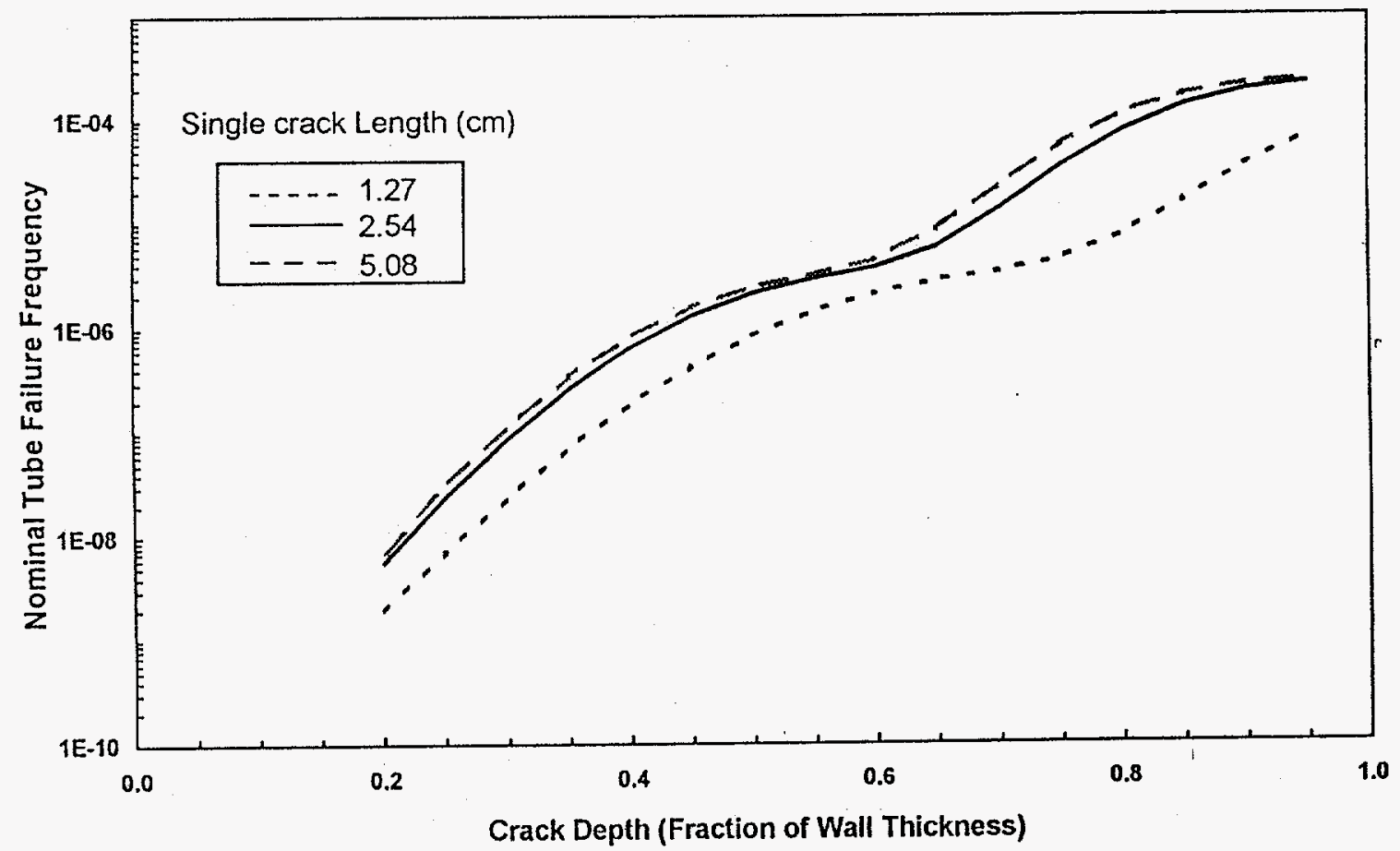

Figure 83. Demonstration of induced steam generator tube rupture frequency for a single defective tube. 
open atmospheric dump valve. The station blackout event dominates the tube failure frequency at low crack depths and the turbine trip with a failed open atmospheric dump valve dominates at the larger crack depths. The tube failure frequency of these three events have been summed to produce Figure 83 . This figure indicates that as the steam generator tubes degrade the frequency of induced steam generator tube rupture may increase rapidly.

The temperature of the steam generator tubes also has a strong impact on the tube failure probability. The steam generator temperatures during a severe accident are controlled by the natural circulation counter current flows in the hot leg and the mixing in the lower plenum of the steam generator. A description of the natural circulation flows and the factors affecting these flows is provided in Section 6.8.

\subsection{Reactor Coolant System Natural Circulation}

As stated earlier, severe accident analyses have historically assumed pristine steam generator tube conditions, the existence of a loop seal in the cold leg, and good mixing of the counter-current hot leg flow in the inlet plenum of the steam generator. This section provides an overview of the severe accident natural circulation flows that may induce steam generator tube rupture.

\subsubsection{Importance of Natural Circulation Flows}

The significance of natural circulation flow is that it transfers energy from the core to other regions of the reactor coolant system. This energy transfer both slows the core heatup, delaying fuel damage, and increases the temperature of structures elsewhere in the reactor coolant system (upper plenum, hot leg and surge line piping, steam generator tubes, etc.) so that they may get hot enough to melt or fail. The slower core heatup provides additional time for system recovery or operator actions, either of which could terminate the transient by returning the core to a water covered, cooled state.

A reactor coolant system pressure boundary breach results if the piping gets hot enough to fail, either through melting or creep rupture. This failure allows the reactor coolant system to depressurize into the containment. A containment bypass path is established if the failure location is the steam generator tubes. In this case, fission products released from the fuel can flow through the failed tubes to the secondary side of the steam generator, and from there through atmospheric dump valves or secondary side safety relief valves to the environment, bypassing the containment. This sequence of events is very risk significant to the surrounding population.

PWRs with U-tube steam generators will have vigorous hot leg natural circulation. The Babcock \& Wilcox "candy cane" hot leg and once-through steam generator design does not allow the steam generators to participate as significant heat sinks unless the loop seals clear of liquid. The countercurrent hot leg flow is driven only by heat transfer to the hot leg piping. The piping has a very small heat transfer surface area and heat capacity compared to the steam generators.

Mixing in a recirculating steam generator plenum is a controlling phenomenon for the hot leg natural circulation flow. It limits the mass flow in the hot leg by increasing the temperature (and lowering the density) of the vapor returning from the steam generator along the bottom of the hot leg. It limits the heat transfer in the steam generator by reducing the temperature of the hot vapor entering the tubes.

A simulation of the hot leg flow behavior, neglecting the mixing in the steam generator inlet plenum, will yield steam generator tube temperatures and hot leg mass flow rates that are 
higher than would be expected. Hot leg countercurrent flow affects the structural integrity of the reactor coolant system piping. Heating of the pipes and steam generator tubes may lead to melting or creep rupture failure of those components. Steam generator tubes are very thin compared to the loop or surge line piping, and can be quickly heated if exposed to high temperature vapor. Should the tubes fail, a direct path outside of containment (through the steam line relief valves) becomes available to any fission products carried in the coolant.

\subsubsection{Hot Leg Countercurrent Flow in Recirculating Steam Generators}

The natural circulation flow pattern during a severe accident at a plant with U-tube steam generators consists of hot leg counter-current flows between the reactor pressure vessel and the inlet plenums of the steam generators. Mixing of the counter-current flow steams occurs in the inlet plenums of the steam generators. However, there are uncertainties in the amount and extent of mixing when experimental data are scaled from small scale experiments to the full scale of the steam generator inlet plenum. Also, the case of no-mixing in the inlet plenum is not expected to occur but has been used in the past to asses worst case severe accident steam generator tube boundary conditions. Counter 'current flow mixing occurs when the cooler vapor flows back to the reactor vessel along the bottom of the hot legs. When the hotter vapor enters the steam generator inlet plenum, it will mix and cool and then rise toward the steam generator tubes. The mixed vapor enters some of the tubes, displacing the cooler steam that was in the tubes. The displaced vapor enters the outlet plenum, then reenters other steam generator tubes, forcing vapor into the inlet plenum. A density gradient is thus established between tubes. This density gradient then pulls more mixed vapor into the tubes, displacing additional cooler steam. The process continues until a steady flow is establish- ed, with mixed vapor flowing from the inlet plenum to the outlet plenum through some of the steam generator tubes, and cooler vapor returning to the inlet plenum through the remaining tubes.

The hot $\left(T_{h}\right)$ and cold $\left(T_{c}\right)$ fluid temperatures at three locations will be examined considering the flow streams shown in Figure 84. These flow streams are: (1) the hot leg nozzle, (2) the steam generator end of the hot leg, and (3) the inlet to the steam generator tubes. At each of the locations, the hotter fluid flows from the reactor vessel toward the steam generator outlet plenum, and the colder fluid flows toward the reactor vessel.

The hot vapor entering the hot leg from the reactor vessel flows toward the steam generator along the top of the pipe. As it flows, heat is transferred to both the hot leg piping and the returning cooler fluid streams. There may also be some mass transfer between the two fluid streams. The result is that $T_{h, 1}>T_{h, 2}$. As the flow enters the steam generator inlet plenum, it mixes with the fluid in the plenum and with the cold flow exiting from some of the steam generator tubes. The mixing reduces the temperature of the steam entering the steam generator tubes, and $\mathrm{T}_{\mathrm{h}, 3}<\mathrm{T}_{\mathrm{h}, 2}$. Heat is transferred to the tubes as the steam flows through the steam generators. When the flow returns to the inlet plenum, it mixes with the hot leg flow. This mixing raises the temperature of the steam returning through the hot leg, so that $T_{c, 2}>T_{c, 3}$. As the flow proceeds along the bottom of the hot leg to the reactor vessel, heat transfers from the hotter fluid above into this cooler steam, and from this cooler steam to the hot leg pipe. Whether these energy transfers result in a net heating or cooling of the return flow has not been quantified, but the vapor temperature will probably not change significantly along the bottom of the hot leg. Assuming a steady flow, the total energy transfer in the coolant loop is the 


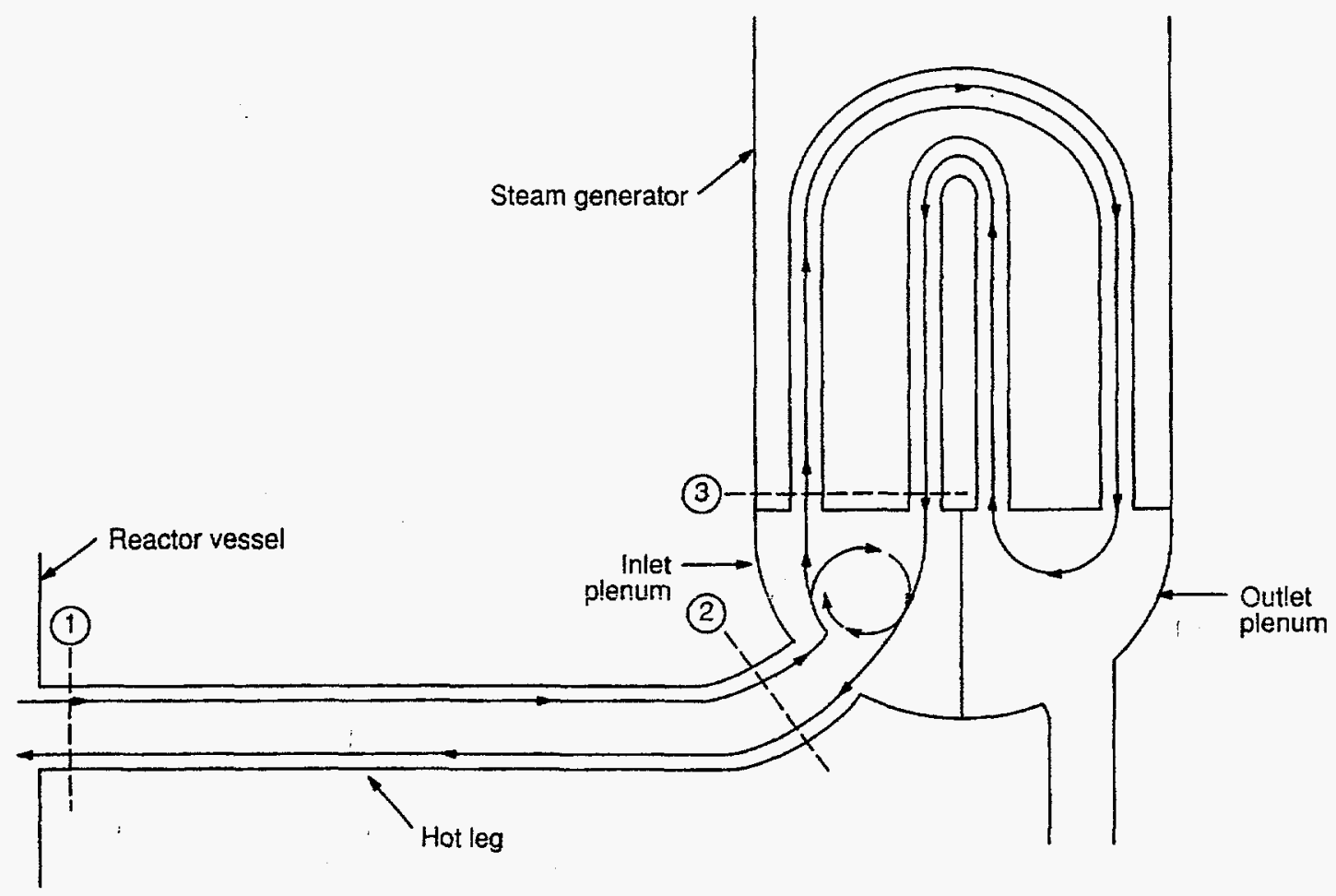

Figure 84. Hot leg natural circulation stream flows.

product of the hot leg mass flow rate, the average heat capacity of the flowing vapor, and the temperature difference between the opposing flows at the hot leg nozzle. The analyses associated with the Westinghouse natural circulation experiments showed that the hot leg mass flow rate is a function of geometric parameters, the fluid density, and the square root of the temperature difference $\left(T_{h, l}-T_{c, 1}\right)$. Thus, the heat transferred by the hot leg natural circulation flow depends on the temperature difference at the nozzle, and interactions that tend to increase the cooler vapor temperature will reduce the flow rate and the heat transfer. Both the mixing in the steam generator inlet plenum and heat transfer from the hotter vapor above act to increase the temperature of the returning vapor.

Similarly, the heat transfer in the steam generator tubes is the product of the mass flow rate through the tubes, the average vapor heat capacity, and 
the temperature difference $\left(T_{h, 3}-T_{c, 3}\right)$. The heat transfer in the tubes will be affected by interactions that alter either of these temperatures. Again, the mixing in the inlet plenum tends to reduce $T_{h, 3}$, thereby limiting the heat transfer in the steam generators.

Now consider the case in which there is no mixing in the steam generator inlet plenum. The hot vapor temperatures in the hot leg will change little; a lower temperature in the cooler vapor (in the bottom of the hot leg) will increase the amount of heat transferred between the opposing flow streams slightly. However, $T_{h, 3}=T_{h, 2}$. The higher temperature fluid entering the steam generator tubes will result in increased heat transfer to the tubes. The absence of mixing also means that $T_{c, 2}=T_{c, 3}$, so that the flow returning through the hot leg is colder., Since the flow is driven by the temperature difference between the hot and cold fluid streams in the, hot leg, the mass flow will increase. The higher mass flow rate will increase the heat transfer in the loop, slowing the core heatup. The higher steam generator tube temperatures will also change the relative energy deposition between the hot leg and the tubes, with more energy being transferred to the tubes.

Fission product behavior may also be affected by the flow to the steam generators. An extremely large surface area is available on the steam generator tubes for deposition of fission products. If the tubes remain cool, deposited species may remain there and not be released from the reactor coolant system. If the tubes continue to heat up so that revolatilization occurs, the flow may simply carry the resuspended fission products to cooler parts of the tubes, where they would again be deposited. The mixing in the steam generator inlet plenum may also play a part in the fission product behavior. If gaseous fission products are carried with the hot vapor along the top of the pipe, the sudden cooling associated with interaction with the cooler fluid in the inlet plenum may result in the condensation of the vapors, either on existing aerosols or as newly generated aerosols. In liquid form, these fission products would be deposited more quickly, and probably in the inlet plenum rather than in the tubes. The countercurrent flow in the hot leg itself may also affect the fission product transport. If gravitational settling is an important mechanism for fission product deposition in the hot leg, fission products falling from the flow that is heading toward the steam generators would enter the return vapor stream, where they would be carried back toward the reactor vessel, rather than away from it. This phenomenon is beyond the capability of current analytical methods, which are for one-dimensional flows. However, the magnitude of the effect should be calculable for a given analysis since the amount of deposition caused by gravitational settling should be known from fission product transport calculations.

The impact of fission product heating on the hot leg counter current flow is expected to be minimal. : An NRC Office of Research assessment $^{\mathrm{a}}$ has indicated less than $1 \%$ of the total heat added to the steam generators during a station blackout accident is contributed by the fission products.

\subsubsection{Coolant Loop Flow}

Should the loop seals clear of liquid during a transient with the reactor coolant pumps off and the steam generators removing heat from the reactor coolant system, loop natural circulation would be reestablished. (Note: This requires the vessel coolant level to be below the downcomer skirt. Normally this does not occur until after failure of the hot leg or surge line piping. Only in some unusual cases does this coolant loop flow occur.) In contrast to the natural circulation that occurs following the reactor coolant pump

a. Memorandum to R. C. Jones from C. E. Ader, February 2, 1996 
coastdown early in a transient, the fluid flowing through the coolant loops would now be superheated vapor. Loop natural circulation flow is a buoyancy-driven one-dimensional flow with heat addition in the core and heat rejection primarily in the steam generators. However, in this situation heat would be transferred to the piping throughout the coolant loops. Because of the resulting large vapor density differences and the height of the steam generators, this flow is generally large enough that it disrupts any multidimensional natural circulation flows that might exist in the hot leg or reactor vessel.

The high flow rate and large amount of metal structures available as heat sinks result in a much slower core heatup. The slower heatup rate could result in complete oxidation of the cladding before any of the zircaloy melts. Fuel rod relocation would be delayed for several hours. Failure of the piping anywhere in the reactor coolant system is possible, although the steam generator tubes would be particularly susceptible because they are much thinner than the hot or cold leg piping. Heating of all the piping will also tend to reduce the extent of fission product retention in the reactor coolant system.

\subsubsection{Description of Scenarios Leading to Natural Circulation}

Natural circulation does not play an important role in all severe accidents. Those accidents in which natural circulation is significant have several characteristics in common. Typically these characteristics are:

- The reactor coolant pumps cannot be running, since forced flow through the reactor coolant system precludes the existence of natural circulation flows,

- there should be no pumped emergency core coolant injection, and
- there should be no large breaks in the system.

There are two severe accident transients that result in significant natural circulation flows, designated the TMLB' and S2D sequences.

The TMLB' station blackout sequence has traditionally been used in severe accident natural circulation studies. The steam generators receive no feedwater, there is no ac power available for the duration of the accident, and the core undergoes a high-pressure boil-off with relief valves cycling. If reactor coolant pump seal leaks are considered, the reactor coolant system pressure will depend on the size of the leak. The pressure may still be controlled by the relief valves, or it may approach and fall below the accumulator pressure.

The S2D sequence is a small break loss of coolant accident with no high-pressure coolant injection. This transient will result in a core boiloff somewhere above the accumulator pressure, with the reactor coolant system pressure depending on the size of the break.

\subsection{Summary}

A risk measure used in assessing the safety of nuclear facilities is given by the product of the core damage frequency multiplied by the offsite consequences. This risk measure produces a frequency of offsite early and latent fatalities due to the accident. Three important contributions make up the risk profile of an operating nuclear plant. These three contributions are:

- the core damage frequency,

- the conditional probability of containment bypass given a core melt accident, and 
the accident's environmental consequences.

A nuclear facility's risk measures are generally dominated by accident sequences that result in containment bypass. A steam generator tube rupture event is typically a high total contributor to the containment bypass frequency

Based on the information in this section, we conclude that:

steam generator tube degradation needs to be controlled to prevent a significant increase in the risk profile of a pressurized water reactor, steam generator tube ruptures are small contributors to the total core damage frequency but may be risk significant due to containment bypass effects,

risk significant steam generator tube rupture accidents can be induced by operational transients (high frequency) and rare events (low frequency) when the steam generator tubes are degraded beyond a threshold amount, and

- both spontaneous and induced steam generator tube rupture core damage events are risk significant due to the potential to bypass the reactor containment building. 


\section{REGULATORY PRACTICES AND FITNESS-FOR-SERVICE GUIDELINES IN VARIOUS COUNTRIES}

\subsection{Tubing Inspection Requirements}

The probability of steam generator tube failures can be reduced through timely and effective inspections. The steam generator tube inspection requirements in the U.S. are discussed first because a number of countries with PWR and CANDU units have used those requirements as a starting point for their own requirements. The tubing inspection practices in the Czech Republic, France, Germany, Japan, Slovenia, Spain, Sweden, and Switzerland are summarized in Table 22 and also discussed in this section. The tubing inspection practices used in Russia and those recommended by EPRI are also discussed.

The tubing inspection requirements are somewhat different in these and other countries because:

- Different steam generator designs and materials and specific plant sites are susceptible to different types of aging degradation. Some types of degradation are easier to detect or have less severe safety consequences than other types of degradation.

- An appropriate level or steam generator and plant safety can only be maintained by a suitable combination of inspection and acceptance (fitness-for-service) requirements. Some countries have chosen to have somewhat more conservative fitness-for-service criteria and less inspection. Other countries have chosen less conservative fitness-forservice criteria (thereby saving money on repairs) and more inspection. Some countries have more or less of both compared to other countries.

- The frequency and extent of the inspections often increase as problems develop.

- Some countries are willing to accept more risk than other countries.

Complementary information concerning the fitness-for-service guidelines in various countries is presented in Section 7.3.

\subsubsection{Tubing Inspection Requirements in the United States}

The requirements for the steam generator tubing inspections at US plants are included in the plant Technical Specifications, which are prepared by the plant operator and approved by the USNRC. Originally, those requirements generally followed the guidelines presented in the USNRC's Regulatory Guide 1.83 (USNRC 1975). These guidelines are organized as follows; access, equipment and procedures, baseline inspection, sample selection, supplementary sampling, inspection intervals, acceptance limits, and corrective measures. In summary, the steam generator should be designed with sufficient access to facilitate inspection and plugging, eddycurrent or equivalent equipment that is "sensitive enough to detect imperfections $20 \%$ or more through the tube wall" should be used (unfortunately, reliable detection of certain defect types at such a shallow depth is not within the state of the art), and a baseline inspection of all tubes should be performed prior to service, and after any major secondary side water chemistry changes. 
Table 22. Steam generator tubing inspection guidelines.

\begin{tabular}{|c|c|c|c|}
\hline & Baseline Inspection & Number of Tubes to be Inspected & Inspection Intervals \\
\hline *United States & $\begin{array}{l}\text { All tubes prior to service and } \\
\text { after any major change in } \\
\text { secondary water chemistry. }\end{array}$ & $\begin{array}{l}\text { - First inspection, } 3 \% \text { of the total steam } \\
\text { generator tubes at a unit } \\
\text { - Subsequent inspections, see Table } 23\end{array}$ & $\begin{array}{l}\text { - First inspection, } 6-24 \text { months } \\
\text { - Subsequent inspections, } 12-24 \text { months } \\
\text { - If less than } 5 \% \text { of inspected tubes with } \\
\text { indications and no defective tubes, } 40 \\
\text { months } \\
\text { - If more than } 10 \% \text { degraded or more than } \\
1 \% \text { defective, }<20 \text { months. }\end{array}$ \\
\hline Czech Republic & - All tubes prior to service. & $\begin{array}{l}\text { - At least } 10 \% \text { of the tubes in each steam } \\
\text { generator must be inspected full length } \\
\text { - Usually inspect all the tubes from the hot } \\
\text { collector and } 50 \% \text { of the tubes from the cold } \\
\text { collector }\end{array}$ & $\begin{array}{l}\text { - Every } 4 \text { years } \\
\text { - Every } 4 \text { years }\end{array}$ \\
\hline France & $\begin{array}{l}\text { - All tubes prior to service } \\
\text { - All tubes every } 10 \text { years (1st } \\
\text { after } 30 \text { months) }\end{array}$ & $\begin{array}{l}\text { - If susceptible tubing: all of the tubes are } \\
\text { inspected in the hot leg roll transition, tube } \\
\text { support plate and sludge pile regions, and the } \\
\text { U-bend region of the first row in service, } \\
\text { with an appropriate probe. } \\
\text { - If less susceptible tubing: Sample of tubes } \\
\text { inspected full length } \\
\text { - All tubes inservice with a previous defect } \\
\text { indication }\end{array}$ & $\begin{array}{l}\text { - Every outage for roll transition and small } \\
\text { radius U-bend regions } \\
\text { - Every other outage for TSP and sludge pile } \\
\text { regions } \\
\text { - Sample every } 2 \text { years } \\
\text { - Each outage }\end{array}$ \\
\hline Germany & - All tubes prior to service & $\begin{array}{l}\text { - } 10 \% \text { of the tubes per steam generator per } \\
\text { inspection }\end{array}$ & $\begin{array}{l}\text { - Every } 4 \text { years all steam generators } \\
\text { - Every } 2 \text { years, one-half of the steam } \\
\text { generators }\end{array}$ \\
\hline Japan & $\begin{array}{l}\text { - All tubes prior to service } \\
\text { - Insertion depth of antivibration } \\
\text { bars }\end{array}$ & $\begin{array}{l}\text { - If no leakage and no defects: } 30 \% \\
\text { - If any leakage or defects: } 100 \%\end{array}$ & $\begin{array}{l}\text { - If no leakage and no defects, every other } \\
\text { year } \\
\text { - If leakage or defects, every year }\end{array}$ \\
\hline Slovenia & - All tubes prior to service & $\begin{array}{l}\text { - } 100 \% \text { using bobbin coil and all reported } \\
\text { indications, roll transitions and inner bends } \\
\text { with pancake coil }\end{array}$ & - Each refueling outage \\
\hline Spain & - All tubes prior to service & $\begin{array}{l}\text { - If susceptible tubing: } 100 \% \text { using bobbin coil } \\
\text { and all indications and roll transition regions } \\
\text { with rotating pancake coil } \\
\text { - If less susceptible tubing: } 9 \text { to } 20 \%\end{array}$ & - Each refueling outage \\
\hline Sweden & - All tubes prior to service & $\begin{array}{l}\text { - Random sample of } 15-17 \% \text { full length } \\
\text { - } 100 \% \text { hot leg tubesheet } \\
\text { - } 20-100 \% \text { of other selected regions }\end{array}$ & - Each year \\
\hline Switzerland & $\begin{array}{l}\text { - All tubes after } 1 \text { year of } \\
\text { operation }\end{array}$ & $\begin{array}{l}\text { - If susceptible tubing: } \\
\text { - inspect the hot leg side up through the U- } \\
\text { bend region to the top tube support plate } \\
\text { on the cold side } \\
\text { - full inspection } \\
\text { - If less susceptible tubing: random sample of } \\
5.5 \% \text { of all tubes }\end{array}$ & $\begin{array}{l}\text { - Every outage } \\
\text { - Every } 3 \text { years } \\
\text { - Every } 3 \text { years }\end{array}$ \\
\hline
\end{tabular}

*If more than $10 \%$ of inspected tubes show indications, additional $3 \%$ in that steam generator and $3 \%$ in remaining steam generators. If more than $10 \%$ of second batch show indications, inspect additional $6 \%$ in area of indications. 
Regulatory Guide 1.83 recommends that at least $3 \%$ of the tubes in each steam generator be tested over their entire length during the first inspection, which should be performed after six effective full power months but before 24 calendar months. Subsequent inspections should not be less than 12 or more than 24 calendar months apart and may be limited to one steam generator encompassing $3 \%$ of the total tubes at the plant. All nonplugged tubes with previous indications ( $>20 \%$ ) should be inspected. If any new indications are found $(>20 \%)$ or if previous indications exhibit growth $(>10 \%)$ the remaining steam generators should be inspected.

If more than $10 \%$ of the inspected tubes show indications $(>20 \%)$ or one or more tubes must be plugged ( $>40 \%$ ), an additional $3 \%$ of the tubes must be inspected. If the additional inspection indicates that more than $10 \%$ of the additionally inspected tubes have indications or one or more of those tubes must be plugged, $6 \%$ more tubes should be inspected in each steam generator. If two consecutive inspections result in less than $10 \%$ of the inspected tubes with indications $(>20 \%)$ and no further penetration of previous indications $(<10 \%)$, the inspection frequency should be extended to 40-month intervals. Unscheduled inspections should be conducted in the event of primary-to-secondary coolant system leaks exceeding the technical specifications or various design basis accidents (seismic, loss-of-coolant, main steam or feedwater line breaks).

Regulatory Guide 1.83 was used as the basis for the steam generator inspection requirements in the Technical Specifications for only a few years. By the early 1980 s, the US utilities were following the steam generator tube sample selection guidance in Table 23 (USNRC 1981, Southern California Edison Co. 1982, Northern States Power Co. 1985, Georgia Power Co. 1987, Commonwealth Edison Co. 1987). The tubes selected for each inservice inspection include at least $3 \%$ of the total number of tubes in all the steam generators at a unit and are selected randomly except:

a. where experience in similar plants with similar water chemistry indicates critical areas to be inspected, then at least $50 \%$ of the tubes inspected shall be from these critical areas; and

b. the first sample of tubes selected for each inservice inspection of each steam generator generally includes all the tubes in service with previous indications greater than $20 \%$ of the wall thickness; tubes in areas where experience has indicated potential problems; and tubes adjacent to badly degraded tubes.

The results of each sample inspection are classified into one of the following three categories:

\section{Category Inspection Results}

C-1 Less than $5 \%$ of the total tubes inspected are degraded tubes and none of the inspected tubes are defective.

C-2 One or more tubes, but not more than $1 \%$ of the total tubes inspected are defective, or between $5 \%$ and $10 \%$ of the total tubes inspected are degraded tubes.

C-3 More than $10 \%$ of the total tubes inspected are degraded tubes or more than $1 \%$ of the inspected tubes are defective.

Degraded tubes are tubes with indications greater than or equal to $20 \%$ of the nominal wall thickness, but less than a defective tube, and which exhibit a defect with a greater than $10 \%$ additional wall thickness penetration since the last 
Table 23. Steam generator tube inspection requirements in the United States.

\begin{tabular}{|c|c|c|c|c|c|c|}
\hline \multicolumn{3}{|c|}{ IST SAMPLE INSPECTION } & \multicolumn{2}{|c|}{ 2ND SAMPLE INSPECTION } & \multicolumn{2}{|c|}{ 3RD SAMPLE INSPECTION } \\
\hline Sample Size & Result & Action Required & Result & Action Required & Result & Action Required \\
\hline \multirow{9}{*}{$\begin{array}{l}\text { A minimum of } \\
\text { S Tubes per } \\
\text { S.G. }\end{array}$} & C-1 & None & N.A. & N.A. & N.A. & N.A. \\
\hline & \multirow[t]{5}{*}{$\mathrm{C}-2$} & \multirow{5}{*}{$\begin{array}{l}\text { Plug or sleeve defective tubes and } \\
\text { inspect additional } 2 S \text { tubes in this } \\
\text { steam generator (S.G.) }\end{array}$} & $\mathrm{C}-1$ & None & N.A. & N.A. \\
\hline & & & \multirow[t]{3}{*}{$\mathrm{C}-2$} & \multirow{3}{*}{$\begin{array}{l}\text { Plug or sleeve defective tubes and } \\
\text { inspect atditional } 4 S \text { tubes in this } \\
\text { S.G. }\end{array}$} & $\mathrm{C}-1$ & None \\
\hline & & & & & C-2 & Plug or sleeve defective tubes \\
\hline & & & & & $\mathrm{C}-3$ & $\begin{array}{l}\text { Perform action for } \mathrm{C}-3 \text { result of } \\
\text { first sample }\end{array}$ \\
\hline & & & $C-3$ & $\begin{array}{l}\text { Perform action for } \mathrm{C}-3 \text { result of } \\
\text { first sample }\end{array}$ & N.A. & N.A. \\
\hline & \multirow[t]{3}{*}{$C-3$} & \multirow{3}{*}{$\begin{array}{l}\text { Inspect all tubes in this S.G., plug } \\
\text { or sleeve defective tubes and } \\
\text { inspect } 2 S \text { tubes in each other S.G. } \\
\text { Notification to NRC pursuant to } \\
\$ 50.72(\text { b)(2) of } 10 \text { CFR Part } 50 .\end{array}$} & $\begin{array}{l}\text { All other } \\
\text { S.G.s are } \\
\text { C-1 }\end{array}$ & None & N.A. & N.A. \\
\hline & & & $\begin{array}{l}\text { Some S.G.s } \\
\text { C-2 but no } \\
\text { additional } \\
\text { S.G.s are } \\
\text { C-3 }\end{array}$ & $\begin{array}{l}\text { Perform action for } \mathrm{C}-2 \text { result of } \\
\text { second sample. }\end{array}$ & N.A. & N.A. \\
\hline & & & $\begin{array}{l}\text { Additional } \\
\text { S.G. is C-3 }\end{array}$ & $\begin{array}{l}\text { Inspect all tubes in each S.G. and } \\
\text { plug or sleeve defective tubes. } \\
\text { Notification to NRC pursuant to } \\
\text { \$50.72(b)(2) of } 10 \text { CFR Part } 50 .\end{array}$ & N.A. & N.A. \\
\hline
\end{tabular}

$S=3 N / n \%$ where $N$ is the number of steam generators in the unit, and $n$ is the number of steam generators inspected during an inspection. 
inspection. Defective tubes are tubes with indications greater than or equal to the removal from service (plugging) or repair limit which is often but not always $40 \%$ of the nominal wall thickness.

The first sample inspection defined in Table 22 requires a full end-to-end survey of each of the tubes. The tubes selected as the second and third samples (if required) during each inservice inspection may be subjected to a partial tube inspection provided:

a. the tubes selected for these samples include the tubes from those areas of the tubesheet array where the tubes with imperfections were previously found; and

b. the inspections include those portions of the tubes where imperfections were previously found.

The inservice inspections shall be performed at intervals of not less than 12 nor more than 24 calendar months after the previous inspection. If two consecutive inspections, not including the pre-service inspection, result in all inspection results falling into the $\mathrm{C}-1$ category or if two consecutive inspections demonstrate that previously observed degradation has not continued and no additional degradation has occurred, the inspection interval may be extended to a maximum of once per 40 months. If the results of the inservice inspection of a steam generator conducted in accordance with Table 22 at 40month intervals fall in Category C-3, the inspection frequency shall be increased to at least once per 20 months. Additional, unscheduled inservice inspections shall be performed after the following conditions: reactor-to-secondary tube leaks (not including leaks originating from tubeto-tubesheet welds) in excess of the limits of the Technical Specifications; or a seismic occurrence greater than the Operating Basis Earthquake; or a condition IV loss-of-coolant accident requiring actuation of the engineered safety features; or a condition IV main steam line or feedwater line break.

Two steam generators are inspected during the first outage at units with four steam generators (4-loop Westinghouse-type plants) and then one steam generator is inspected during the second and subsequent outages, unless additional inspections are required because of extensive degradation as indicated in Table 23. Only one steam generator is inspected during the first and subsequent outages at 2- and 3-loop Westinghouse-type plants and at Combustion Engineering plants unless additional inspections are required because of extensive degradation as indicated in Table 23.

If alternative fitness-for-service guidelines for ODSCC at tube support plates are used, more comprehensive inspections must be required by the plant Technical Specifications (USNRC 1995b). These include bobbin coil probe inspections of all the hot-leg tube support plate intersections, all the cold-leg intersections down to the lowest cold-leg tube support plate with known ODSCC, and $20 \%$ of the tubes full length. In addition, rotating pancake coil inspections are required for all bobbin coil indications greater than 1.0 volt $(19 \mathrm{~mm}$ diameter tubes) or 2.0 volts ( $22 \mathrm{~mm}$ diameter tubes). Also, rotating pancake coil inspections are required at all tube-to-tube support plate intersections with (a) interfering signals from copper deposits, (b) dent signals greater than 5 volts, or (c) large mixed residuals.

\subsubsection{Tubing Inspection Requirements in the Czech Republic}

The Czech regulatory agency requires a baseline inspection before operation and then a minimum of $10 \%$ of the tubes in each steam generator inspected full length every four years. (Each of the six steam generators at each VVER-440 unit are inspected every four years.) However, 
recent practice has been to inspect all of the tubes from the hot collector side and $50 \%$ of the tubes from the cold collector side.

\subsubsection{Tubing Inspection Requirements in France}

The French regulatory agency requires a baseline inspection before operation, periodic inspections at least every two years, and complete inspections (presumably $100 \%$ of the tubes full length) every ten years. The EdF guidelines for steam generators with susceptible tubing (Alloy 600 ) require a $100 \%$ inspection of the hot leg roll transition region and the U-bends of the first row in service every outage and $100 \%$ inspections of the hot leg tube support plate and sludge pile regions every other outage, with follow-up inspections of indications during the next outage. The roll transition and small radius U-bend inspections must be done with rotating pancake coil eddy-current equipment. The tube support plate and sludge pile inspections can be done with bobbin coil eddy-current equipment.

\subsubsection{Tubing Inspection Requirements in Germany}

The scope and frequency of the steam generator tubing inspections in the Federal Republic of Germany are specified in KTA 3201.4. 10\% of the tubes in each steam generator must be fully inspected every four years and half the steam generators must be inspected every two years. However, the actual inspections have been more frequent and some Siemens/KWU steam generators have been inspected every operating period over much of their life.

\subsubsection{Tubing Inspection Requirements in Japan}

The Japanese require that $30 \%$ of the tubes be inspected every other year when a steam generator has had no leakage and no tube degradation. If any primary-to-secondary coolant system leakage or any tube defects are detected, $100 \%$ of the tubes have to be inspected each year over their full length. Before each inspection, the steam generator tubes are subjected to a 13.8 MPa (2000 psi) differential pressure test to open tight cracks and make them more detectable. Bobbin coil eddy-current equipment is used above the tubesheet region. $8 \times 1$ eddy-current probes are used in the hot-leg tubesheet region in most steam generators in order to detect circumferential degradation. Rotating pancake coil eddy-current equipment is used in the tubesheet region of one Japanese plant in order to detect pitting.

\subsubsection{Tubing Inspection Requirements in Russia}

Russian steam generator tube inspections are performed when leakage of the primary coolant into the secondary coolant system is detected. All the tubes are inspected using "visual and hydro-luminescent" methods. Eddy-current inspection is being introduced at some Russian nuclear power plants. Primary-to-secondary leak rates are monitored using $\mathrm{a}^{24} \mathrm{Na}$ device.

\subsubsection{Tubing Inspection Requirements in Slovenia}

Initially, the sampling procedure outlined in USNRC R.G.1.83 was followed. However, the condition of both steam generators triggered more extensive inspection. Current practice is full length inspection of all tubes with bobbin coil probes. Additionally, all bends in Rows 1 and 2 and hot-leg transition zones are inspected with multifrequency rotating pancake coil probes. Bobbin coil indications at the tube support plates are also re-inspected with multifrequency rotating pancake coil probes for confirmation. The expanded tubes in the preheater section (cold leg) are also inspected using rotating pancake coil probes. A complete inspection is performed during each refueling outage. 
All sleeves and the tube areas behind the sleeves are also inspected during each refueling outage. Also, an ultrasonic baseline inspection was used to confirm the quality of the sleeve-to-tube welds. I-coil and Plus-Point eddy-current probes have been implemented for subsequent examinations.

\subsubsection{Tubing Inspection Requirements in Spain}

All Spanish steam generators with susceptible material are inspected during each refueling outage. $100 \%$ of the tubes are inspected over their full length using bobbin coil eddy-current equipment. All the hot-leg tubesheet areas and all the indications detected by the bobbin coil are also inspected with rotating pancake coil eddycurrent equipment. Fewer tubes are inspected in the Spanish steam generators with less susceptible material. For example, only $20 \%$ of the thermally treated Alloy 600 tubes in the Westinghouse Model F steam generators at one plant are inspected over their full length every outage with a bobbin coil, plus a random sample are inspected with rotating pancake coil eddycurrent equipment (the Model $F$ has stainless steel quatrefoil support plates). In another plant with Alloy $800 \mathrm{M}$ tubing, $9 \%$ of the tubes are inspected over their full length every outage.

\subsubsection{Tubing Inspection Requirements in Sweden}

In Sweden, a random sample of $15-17 \%$ of all tubes must be inspected full length using bobbin coil eddy-current equipment each year. In addition, an augmented inspection of $20-100 \%$ of all tubes at specific regions (roll transition, tube support plate, etc.) is performed. The augmented inspections include $100 \%$ of the hot-leg tubesheet area. The Swedish regulatory authority must witness the inspections.

\subsubsection{Tubing Inspection Requirements in Switzerland}

The Swiss utility (NOK) practice is to do a $100 \%$ inspection of their newer steam generators with Alloy 690TT tubing (which are not particularly susceptible to degradation) after one year of operation and then a random sample of $5.5 \%$ of all tubes must be inspected every three years thereafter. In addition to a full inspection every three years, all the tubes in the older steam generators with Alloy 600 tubing are inspected on the hot-leg side, and up through the U-bend region to the sixth support plate on the cold leg side, every outage. Multifrequency bobbin coil eddy-current equipment is used for these inspections, supplemented by rotating pancake coil inspections of the U-bends in Rows 1 and 2 as well as indications within the tubesheet (including the roll transition region). The Swiss regulatory authority must witness the inspections.

\subsubsection{EPRI Tubing Inspection Recommendations}

When the EPRI alternative fitness-for-service guidelines for defects in the roll transition region are used, EPRI recommends a rotating pancake coil eddy-current inspection of all in-service hotleg tube expansion zones at each scheduled inspection outage. When the EPRI alternative fitness-for-service guidelines for defects in the tube support plate regions are used, EPRI recommends a bobbin coil eddy-current inspection of all hot-leg tube support plate intersections, and all cold leg tube support plate intersections down to the lowest tube support plate with indications every outage. Supplemental rotating pancake coil inspections of a sample of tubes with bobbin coil voltages less than the tube repair limit is also recommends to characterize the defects. 
It should be noted that the USNRC has not accepted the EPRI fitness-for-service guidelines for defects in the roll transition region, and, therefore, the EPRI tubing inspection recommendations for that defect type and location are currently not in the Technical Specifications at the US plants. The USNRC has accepted certain alternative fitness-for-service guidelines for ODSCC at tube support plates (see Section 7.3.2), but requires a somewhat more extensive examination than recommended by EPRI, as discussed in Section 7.1.1.

\subsection{Tubing Repair Criteria}

Repair or removal from service (plugging) of excessively damaged steam generator tubing is necessary to prevent:

- $\quad$ single or multiple tube ruptures

- excessive primary to secondary leakage

However, a continuing issue has been exactly what constitutes excessive damage and which degraded tubes are or are not still fit for service. Some of the earliest guidance on this subject was published in the U.S. Code of Federal Regulations and in the ASME Pressure Vessel and Boiler Code and is discussed in Section 7.2.1 below. The ASME code states that for U-tube steam generators, the allowable outside diameter flaw shall be less than $40 \%$ of the tube wall. And, this type of criterion was initially implemented in most countries with PWR or CANDU plants. However, alternative criteria are allowed by the ASME code if accepted by the regulatory authority and USNRC Regulatory Guide 1.121 provides guidance on how to develop alternative criteria. Essentially, four items must be addressed:

- the maximum (critical) size of a defect which ensures stability of the damaged tube (analytical and experimental verification);
- the propagation rate of the defect until the next inspection;

- the ability of the inspection methods to detect defects of a critical size;

- the accuracy of the inspection methods to size defects of a critical size.

In recent years, a number of countries have found the original ASME criterion overly conservative and inflexible and have developed revised or new fitness-for-service criteria, often in conjunction with revised inspection requirements. Although the new fitness-forservice criteria used in most countries follow the general guidance contained in Regulatory Guide 1.121, there are substantial differences in implementation. However, the currently implemented repair criteria can be grouped into two families: generic and defect type and location specific criteria. Both these types of fitness-for-service criteria are briefly introduced below and then discussed in more detail in Section 7.3.

\subsubsection{Generic Fitness-For-Service Criteria}

No flaws. The simplest, most straight forward, and most conservative generic approach is to define a minimum detection threshold, inspect all the tubes on a regular basis, and remove from service or repair any tubes with indications above the noise level. This implies, of course, that there will be no leakage. (Should any leakage start, the plant will immediately be shutdown and the tubes inspected.) However, this approach provides little or no incentive to improve the inspection and leak detection methods.

Wall thickness. The most widely implemented fitness-for-service criterion is a minimum wall thickness criterion (either the value specified in the ASME code or some other value). The minimum wall thickness value is determined by assuming uniform wall thinning around the circumference of the tube and calculating a wall thickness which will sustain all postulated loads 
with appropriate margin. Generally, a plastic load limit analysis is performed with margins against tube burst of 3 and 1.43 for normal and accident conditions, respectively. Leak rate calculations are not required since throughwall defects are not expected. A minimum wall thickness criterion works well for degradation mechanisms that remove considerable material such as loose parts wear, wastage, etc. However, a minimum wall thickness criterion can be overly conservative and costly for small defects such as pitting, axial ODSCC within the tube support plates, etc.

\subsubsection{Defect Type and Location Specific Repair Criteria}

The occurrence in recent years of new types of tube degradation such as PWSCC within the tubesheet or axial ODSCC within the support plates initiated the development in some countries of defect type and location specific repair criteria. These criteria were developed to reduce the extent of the steam generator repair or plugging work without sacrificing plant safety by reducing the unnecessary conservatisms of the generic criteria. This was done by taking into account specific defect and location characteristics which may reduce the chances of tube rupture or leakage. To date, four broad groups of defect specific repair criteria are in use.

$\mathbf{P}^{*}$ and $\mathbf{F}^{*}$ Criteria. Tubes with flaws in the region where the tube has been expanded against the tubesheet will not burst and probably will not leak. Therefore, criteria were developed specifically for partial and full tubesheet depth expanded tubes, which allow tubes with flaws in the tubesheet region to remain in service without repair, regardless of defect size. However, the flaws must be some distance below the top of the tubesheet or bottom of the roll transition, whichever is lower, so as to prevent pull out of the damaged tube should it separate at the flaw. The $\mathrm{F}^{*}$ distance for full depth rolled steam generators is typically 38 to $51 \mathrm{~mm}$. (The exact $\mathrm{F}^{*}$ distance is established by considering the length of roll expansion needed to resist the tube pull out forces.) The $\mathrm{P}^{*}$ distance is typically about 32 to $38 \mathrm{~mm}$. It is established by considering the ability of other tubes to prevent tube pull out (Gorman et al. 1994). The tube sheet thickness is usually between 525 and 610 $\mathrm{mm}$.

Crack length criteria for axial PWSCC in the residual stress dominated expansion transition zones. This type of repair limit was originally developed and implemented in some European countries (France, Belgium, Spain, Sweden, Slovenia), Axial cracks located close to the top of the tubesheet and shorter than about $10 \mathrm{~mm}$ (3/4" tubes) or $13 \mathrm{~mm}$ ( $7 / 8^{\prime \prime}$ tubes) may remain in service even if they are throughwall. Implementation requires special inspection techniques which are able to detect and size the length of the axial cracks and, depending upon the degree of the degradation, up to $100 \%$ yearly inspections.

The main underlying assumption is that Alloy 600 is very ductile. Therefore, reasonably short throughwall axial cracks exhibit slow propagation (typically about a $\mathrm{mm} / \mathrm{year}$ ) and do not tend to result in catastrophic tube failure. Rather simple analytical models (e.g., Erdogan 1976, for application see Flesch and Cochet 1990) fit very well to the experimental results and enable reliable predictions of critical crack lengths. Crack growth predictions are estimated on the basis of statistical analyses of consecutive inspection results. The accuracy of the inspection methods is determined using the results of metallographic examinations of pulledout tubes.

Leakage from tubes with various size cracks has been measured in the laboratory (Flesch and Cochet 1990). It was shown that the leak rate through a single throughwall crack of about critical length is less than $70 \mathrm{l} / \mathrm{h}(0.3 \mathrm{gpm})$. 
Therefore, reduced operational leak rate limits (below $70 \ell / \mathrm{hr}$ per steam generator) and on-line leak rate monitoring (such as nitrogen-16) were implemented as an additional safety precaution.

The Swedish application of this criterion has an additional very interesting feature. The final value of the repair limit is chosen on the basis of probabilistic risk assessment analysis. The acceptable conditional tube rupture probability, given a steam line break, was set to $1 \%$ which implies an acceptably low core melt frequency (Gorman 1994, and references therein).

Leak before risk of break criteria for axial PWSCC. This approach is of French origin and is very similar to the crack length criteria. In the early implementation stage, leak detection was considered to be as reliable as tube inspection. Only samples of tubes were therefore inspected while the non-inspected, and possibly nearly critical, defects were expected to be reliably detected by nitrogen-16 on line leak monitoring. However, some of the long throughwall cracks are rather leak tight, which can cause rather unreliable predictions of the leak rates. The current tendency is therefore to put increasing weight on the use of inspections and use leak detection as an additional safety feature.

Voltage criteria for ODSCC at the tube support plates. The very complex morphology of ODSCC forced the industry to a completely statistical approach. The signal amplitude of the bobbin coil eddy-current testing inspection method was taken as the measure of defect severity. Based on degraded pulled-out tubes and specimens prepared in the laboratory, two correlations were developed: (1) bobbin coil signal amplitude versus tube burst pressure and (2) bobbin coil signal versus leak rate (individual defect in a tube). The burst pressure correlation together with allowances for defect progression and inspection uncertainties is used to define the structural repair limit in the first step. The leak rate correlation together with the recent population of defects in the steam generator under consideration, and allowances for defect progression and inspection uncertainties then gives an estimate of total leak rate during postulated accident conditions (e.g., steam line break). Should the total leak rate exceed the predefined acceptable value, the plant operator has the following options:

- repair or remove from service (plug) additional tubes;

- lower the reactor coolant system activity limits; or

- reduce the time between inspections.

Thus, the repair limit may depend on the condition of the steam generator, the growth rate of the defects, the coolant activity levels and other factors, and may be updated at each inspection and repair campaign.

Note that the voltage criterion is not based on a mechanistic description or modeling of the defect in contrast to other criteria. Rather a simple correlation between a selected parameter, obtained from inspection, and experimental results (burst pressure and leak rate measurements) is derived.

A comparison of the important parameters for each group of repair criteria is given in Table 24 .

\subsection{Tubing Fitness-For-Service Guidelines in Various Countries}

The purpose of this section is to review and discuss the steam generator tubing fitness-forservice requirements in various countries and to describe in a general way how they are applied. The countries included in this review are Belgium, Canada, France, Germany, Japan, Russia, Slovenia, Spain, Sweden, Switzerland, and the U.S. The U.S. fitness-for-service guidelines are discussed first because a number 
Talsle 24. Gencral informattion on repair criteria currently implemented.

\begin{tabular}{|c|c|c|c|c|c|c|}
\hline \multirow[b]{2}{*}{ Parameter } & \multicolumn{2}{|c|}{ Generic Criteria } & \multicolumn{4}{|c|}{ Defect Specific Criteria } \\
\hline & Now leak, no flaw & Wall thickness & $\frac{P^{\prime}, F^{*}}{\text { (full deptl ralled tules) }}$ & 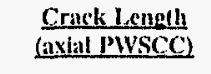 & $\begin{array}{l}\frac{\text { Leak before risk of hreak }}{\text { (axial PWSCC) }} \\
\text { (1) }\end{array}$ & 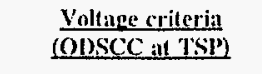 \\
\hline $\begin{array}{l}\text { Repair limit } \\
\text { Measurere af defect severity } \\
\text { Typical alluwable value }\end{array}$ & $\begin{array}{l}\text { N/A } \\
\text { detection } \\
\text { thresthold }\end{array}$ & $\begin{array}{l}\text { remaining wall thickness [\%] } \\
40-50 \%\end{array}$ & $\begin{array}{l}\text { distance from the top of TS } \\
>38-76 \text { nm }\end{array}$ & $\begin{array}{l}\text { crack length } \\
\left.<10 \mathrm{~mm}(3 / 4)^{\prime \prime}\right) \\
<13 \mathrm{~mm}\left(7 / 8^{\prime \prime}\right)\end{array}$ & $\begin{array}{l}\text { crack length and leak rate } \\
<13 \mathrm{~mm}\left(7 / 8^{*}\right)\end{array}$ & $\begin{array}{l}\text { signal amplitude }[\mathrm{V}] \\
\mathrm{l}-15 \mathrm{~V}^{1}\end{array}$ \\
\hline$\frac{\text { Insipection }}{\text { Methusd }}$ & $\begin{array}{l}\text { adequate to detect } \\
\text { degradatation }\end{array}$ & loubbin & boblhin & MRPC, UT & MRPC & $\begin{array}{l}\text { bolbhin, confirmed by } \\
\text { MRPC }\end{array}$ \\
\hline $\begin{array}{l}\text { Exxent (min.) } \\
\text { P'requency (max) }\end{array}$ & $\begin{array}{l}1(10) \% \\
1 \text { year }\end{array}$ & $\begin{array}{l}3 \% \\
3 \text { years }\end{array}$ & $\begin{array}{l}100 \%(\mathrm{TS}) \\
1 \text { year }\end{array}$ & $\begin{array}{l}100 \% \text { (top of } T S) \\
1.2 \text { years }\end{array}$ & $\begin{array}{l}12 \% \text { (top of TS) } \\
1 \text { year }\end{array}$ & $\begin{array}{l}100 \% \text { bobshin }{ }^{2} \\
\text { I year }\end{array}$ \\
\hline 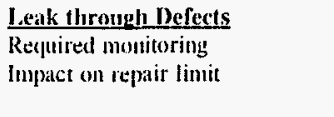 & $\begin{array}{l}\text { sampling, on-line } \\
\text { none }\end{array}$ & $\begin{array}{l}\text { sampling } \\
\text { none }\end{array}$ & $\begin{array}{l}\text { sampling } \\
\text { none }\end{array}$ & $\begin{array}{l}\text { on-line } \\
\text { none }\end{array}$ & $\begin{array}{l}\text { on-line } \\
\text { none }\end{array}$ & $\begin{array}{l}\text { on-line } \\
\text { yes, increases number of } \\
\text { plugged tubes }\end{array}$ \\
\hline 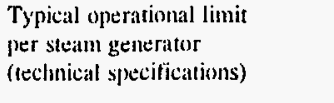 & 0 & $3.8 \mathrm{l} / \mathrm{min}(1 \mathrm{gpm})$ & $3.8 \mathrm{t} / \mathrm{min}(1 \mathrm{gpm})$ & $\begin{array}{l}<1.91 / \min (0.5 \\
\mathrm{gpm})\end{array}$ & $<0.4 \mathrm{l} / \mathrm{min}(0.1 \mathrm{gpm})$ & $<1.91 / \min (0.5 \mathrm{gpm})$ \\
\hline$\frac{\text { Burst Sirengelle }}{\text { Sirtuctural noudel }}$ & as design & as design & Reinforcement by TS & $\begin{array}{l}\text { plistic limit load } \\
\text { leak--xetore-break }\end{array}$ & with plassic limit loadd & No structural moxle!! \\
\hline 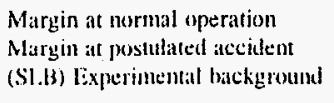 & $\begin{array}{l}\text { design } \\
\text { designn } \\
\text { designn }\end{array}$ & $\begin{array}{l}>3 \\
>1.4 \\
\text { design! }\end{array}$ & $\begin{array}{l}\text { margin againsi tube pull-out } \\
\text { ageuilst pull-out } \\
\text { pull-outt }\end{array}$ & $\begin{array}{l}>3 \\
>1.4 \\
\text { burst, leak }\end{array}$ & $\begin{array}{l}>3 \\
>1.4 \\
\text { burst, leak }\end{array}$ & $\begin{array}{l}3,95 \% \text { confitence } \\
\text { 1.4, 95\% confistence } \\
\text { burst, leak }\end{array}$ \\
\hline
\end{tabular}

'strongly depends on the inspection hardware and software, which differs in different countries (USA, France, Belgiun...)

2hot-leg only 
of countries started with the U.S. guidelines and then modified them. The basis and implementation approach of the fitness-for-service guidelines used in these countries are summarized in Table 25. Much of the following material was taken from Gorman et. al. 1994.

\subsubsection{Regulatory Practices and Fitness-For- Service Guidelines in the United States}

Appendix A of Section 10 CFR 50 of the U.S. Code of Federal Regulations requires that (a) U.S. nuclear power plant owners assure that their reactor coolant pressure boundaries have an extremely low probability of abnormal leakage, of rapidly propagating failure, and of gross rupture and (b) the reactor coolant system and associated auxiliary, control, and protection systems be designed with sufficient margin to assure that the design conditions of the reactor coolant pressure boundary are not exceeded during normal operation, including anticipated operational transients. $10 \mathrm{CFR} 50$ also invokes the ASME Code, including Section XI, which has specific inspection requirements for steam generator tubing and Section III, which has general design guidance appropriate for the analysis of steam generator tubing burst or rupture. Detailed requirements are contained in each nuclear power plant's Technical Specifications, which are part of the plant's license from the USNRC, and are often patterned on the USNRC Standard Technical Specifications.

\section{Article IWB-3521.1 of Section XI of the ASME}

Code states that the allowable outside diameter flaws in the tubing in U-tube steam generators shall not exceed $40 \%$ of the tubing wall thickness. Many U.S. nuclear power plants have this criterion in their Technical Specifications. However, Article IWB-3630 of Section XI does allow alternative criteria to be used, if approved by the USNRC and a number of US plants use somewhat higher values in their Technical Specifications. For example, a 50\% wall thick- ness criterion is used for most defects at Prairie Island Units 1 and 2, except general wall thinning (Northern States Power Co. 1985); and a 44\% wall thickness criterion is used for all defects at San Onofre Units 2 and 3 (Southern California Edison Co. 1982).

Article F-1341.4 of Appendix F of Section III of the ASME code limits the applied load to 0.7 times the plastic instability load, which is determined from either an elastic-plastic analysis or testing. The plastic instability load is defined in Article NB-3213.26 of Section III as the load at which unbounded plastic deformation occurs without an increase in load. This corresponds to a safety factor of $1.0 / 0.7=1.43$ for design basis accident loads such as the loads that would be applied during a main steam line break. If the steam generator tubing is assumed to behave like austenitic piping, which is a reasonable approximation, Article IWB-3642 of Section XI of the ASME Code can be used to determine the factors of safety. It specifies a safety factor of 3 on normal loads and 1.5 on accident loads.

Detailed fitness-for-service guidance is provided to the U.S. nuclear power plant owners in Regulatory Guide 1.121 (USNRC 1976). However, it should be noted that the USNRC regulatory guides are not mandatory and the legal requirements applicable to a plant are those in its Technical Specifications, which are reviewed and approved by the USNRC. Regulatory Guide 1.121 suggests that three factors be considered when developing a fitnessfor-service limit: "(1) the minimum tube wall thickness needed in order for tubes with defects to sustain the imposed loadings under normal operating conditions and postulated accident conditions, (2) an operational allowance for degradation between inspections, and (3) the crack size permitted to meet the leakage limit allowed per steam generator by the technical specifications of the licenses" (USNRC 1976). 
Table 25. Fitness-for-service guidelines in eight countries.

\begin{tabular}{|c|c|c|}
\hline Bases & How Implemented & Where Used \\
\hline 1. No detectable flaws or leakage & $\begin{array}{l}\text { - No wall thinning }>20 \% \text {, no defects over } \\
\text { noise level }\end{array}$ & Japan \\
\hline $\begin{array}{l}\text { 2. Flaws limited to a size which is } \\
\text { calculated not to burst during normal } \\
\text { operation and accident conditions }\end{array}$ & $\begin{array}{l}\text { - Use safety factors of } 3 \text { for normal } \\
\text { operation and } 1.4 \text { and } 1.5 \text { for accidents and } \\
\text { conservative analysis methods } \\
\text { - Often } 40 \% \text { of wall thickness }\end{array}$ & $\begin{array}{l}\text { USA } \\
\text { Canada }\end{array}$ \\
\hline $\begin{array}{l}\text { 3. Flaws limited to a size which is } \\
\text { calculated not to burst during normal } \\
\text { operation and accident conditions }\end{array}$ & $\begin{array}{l}\text { - Use safety factors of } 2.7 \text { for normal } \\
\text { operation and } 1.43 \text { for accidents and margins } \\
\text { for accuracy and growth } \\
\text { - } 50 \% \text { of wall thickness }\end{array}$ & Germany \\
\hline $\begin{array}{l}\text { 4. Flaw limited to a size which is not } \\
\text { expected to burst during normal } \\
\text { operation and accident conditions }\end{array}$ & $\begin{array}{l}\text { - Use safety factor of } 3 \text { for normal operation } \\
\text { and } 1.4-1.5 \text { for accidents with best estimate } \\
\text { analysis; or conservative analysis methods } \\
\text { with no safety factor; use most conservative } \\
\text { result }\end{array}$ & $\begin{array}{l}\text { Belgium } \\
\text { Slovenia }\end{array}$ \\
\hline $\begin{array}{l}\text { 5. Flaws limited to a size so that there } \\
\text { is a low probability of tubing burst } \\
\text { during accident conditions }\end{array}$ & $\begin{array}{l}\text { - Use conservative analysis methods for each } \\
\text { degradation mechanism (degradation specific } \\
\text { management) - no explicit safety factors but } \\
\text { aggressive inspections } \\
\text { - Rely on a reliable nitrogen-16 leak } \\
\text { detection system }\end{array}$ & France \\
\hline $\begin{array}{l}\text { 6. Flaws limited to a size which is not } \\
\text { expected to burst during normal } \\
\text { operation and accident conditions }\end{array}$ & $\begin{array}{l}\text { - Use conservative analysis methods } \\
\text { supplemented by } 100 \% \text { inspections of } \\
\text { affected areas and tight leak rate limits }\end{array}$ & Spain \\
\hline $\begin{array}{l}\text { 7. Set defect size based on allowable } \\
\text { risk of rupture during steam line break }\end{array}$ & $\begin{array}{l}\text { Estimate probability of rupture for each } \\
\text { defect, and require sum for all defects to be } \\
<\text { allowed limit (e.g., } 1 \% \text { ) }\end{array}$ & Sweden \\
\hline $\begin{array}{l}\text { 8. No leakage, detectable flaws of any } \\
\text { size which do not leak are allowed }\end{array}$ & - Plug any tube with detectable leakage & Russia \\
\hline $\begin{array}{l}\text { 9. Ensure total leakage for all defects } \\
\text { meets dose limits under normal } \\
\text { operating and accident conditions }\end{array}$ & $\begin{array}{l}\text { - Estimate leakage for all defects present at } \\
\text { end of interval, make sure total leakage is } \\
\text { significantly less than applicable site dose } \\
\text { limits. }\end{array}$ & $\begin{array}{l}\text { Canada } \\
\text { USA } \\
\text { Belgium } \\
\text { Slovenia } \\
\text { Sweden }\end{array}$ \\
\hline
\end{tabular}


The minimum acceptable wall thickness is defined such that:

- Tubes with part through-wall degradation should not be stressed beyond the elastic range during normal operation;

- There is at least a margin of safety of 3 against tube rupture or burst during normal operation;

- There is at least a margin of safety of 1.43 against tube rupture or burst during design basis accidents (ASME Code, Section III, Articles NB-3225 and F-1341.4);

- Any increase in the primary-to-secondary leak rate must be gradual enough to allow corrective actions to be taken prior to tube failure.

The method used to estimate the operational allowance (fraction of the total thickness to compensate for degradation during the next operating period) should be based on evaluation of the continuing degradation rate and a consideration of measurement error. A defect "that reduces the remaining tube wall thickness to less than the sum of the minimum acceptable tube wall thickness plus the operational degradation allowance is designated as an unacceptable defect" and a tube with that defect "should be plugged" (USNRC 1976). Regulatory Guide 1.121 also suggests that conservative analytical models be used to establish the minimum acceptable tube wall thickness. The wall thickness must meet the design limits of the ASME Code as discussed above and the stress calculations for defective tubes must consider all stresses and deformations expected during several design basis accidents. A summary of the analysis performed must be provided to the USNRC when applying for alternate fitness-for -service guidelines.

Regulatory Guide 1.121 also suggests that the primary coolant system-to-secondary coolant system leak rate in the Technical Specifications be adjusted so that the allowable leakage rate during normal operation is less than "the leakage rate determined theoretically or experimentally from the largest single permissible longitudinal crack, " so that remedial action can be taken if the cracks propagate suddenly. Also the leak rate should be less than the permissible leak rate based on the site boundary radiation dose. Although not included in Regulatory Guide 1.121 , practice in the U.S. has been to ensure that the total of all primary system leaks will not exceed the site dose limits set by 10 CFR 100 during design base accidents, especially the main steam line break.

\subsubsection{Alternative U.S. Fitness-For-Service Guidelines for Outside Diameter IGSCC/IGA at Tube Support Plates}

The tubes in the steam generators at the Trojan Nuclear Plant (now shutdown) near Portland, Oregon, experienced considerable outside diameter IGSCC/IGA damage at the tube support plate locations. Because of the large number of tubes with suspect indications, the Trojan staff eventually decided to develop alternate fitnessfor-service guidelines based on bobbin coil voltage, to limit the number of tubes requiring repair or plugging (Westinghouse 1991). This involved correlating bobbin coil eddy-current voltage with burst pressures. The experimental work was performed by Westinghouse using pulled tubes from a number of PWRs as well as model boiler tubes tested at room temperature without tube support plate reinforcement. The results were then adjusted to the operating temperature of the steam generator using Alloy 600 temperature-dependent mechanical properties. A lower $95 \%$ curve was established and the voltages corresponding to (a) three times the normal operating pressure difference across the tubing walls and (b) 1.43 times the pressure drop during a main steam line break were determined. The expected growth rate in volts during the next operating cycle was computed based on limited prior experience and subtracted from the burst correlation results, along with an allowance for 
measurement uncertainty (analysis, probe wear, and calibration standards). Because of the uncertainty in the growth rate and the limited experience with this type of guideline a limit for the bobbin coil voltage of 1.0 volt was chosen.

The Trojan alternate fitness-for-service guidelines required an extensive inspection program. All the tubes were inspected during the next outage with bobbin coil eddy-current equipment. All indications and all intersections up to the 5th tube support plate were then inspected with rotating pancake coil eddy-current equipment. Care was taken to determine when a bobbin coil signal was a "possible indication" and a rotating pancake coil signal was something other than background noise. To provide additional assurance that the Trojan outside diameter IGSCC/IGA defects would be detected, the allowable primary-tosecondary coolant system leak rate was reduced to 492 liters (130 gallons) per day per steam generator and 1514 liters (400 gallons) per day for all four steam generators and nitrogen-16 monitors were installed on the main steam lines. In parallel with the work at Trojan, EPRI commissioned a committee of U.S. and foreign experts in steam generator tubing degradation issues to recommend an alternative fitness-forservice guideline for outside diameter IGSCC/IGA defects (EPRI 1993a, EPRI 1995). Their approach is intended to be consistent with the NRC Regulatory Guide 1.121 and the ASME Section III philosophy, but is based on experimentally determined voltage limits, as follows:

$$
\mathrm{V}=\mathrm{V}_{\mathrm{SL}}-\mathrm{V}_{\mathrm{NDE}}-\mathrm{V}_{\mathrm{CG}}
$$

Where $\mathrm{V}$ is the voltage limit for repair, $\mathrm{V}_{\mathrm{SL}}$ is a voltage structural limit from correlations of burst pressure versus bobbin coil measurement, $V_{\mathrm{NDE}}$ is the measurement error, and $V_{C G}$ is the voltage growth associated with the expected crack growth during the next operating cycle. The values for $\mathrm{V}_{\mathrm{NDE}}$ and $\mathrm{V}_{\mathrm{SL}}$ were taken from an EPRI database, and $V_{C G}$ is based on either plant specific data or

NUREG/CR-6365 conservative values developed by EPRI. All indications with a bobbin coil eddy-current voltage greater than the calculated limit require repair. The development of these correlations is discussed in somewhat more detail in the next few paragraphs.

To develop the burst pressure versus bobbin coil eddy-current correlation, EPRI compiled results from pulled tubes from a number of plants and model boiler tubes with diameters of 3/4-inches and $7 / 8$-inches. The eddy-current measurements were generally made before the tubes were removed from the steam generators. The burst tests were performed at room temperature without tube support plates. Tube support plate reinforcement was not used because eggcrate and quatrefoil tube supports do not provide coverage around the entire circumference and drilled hole tube support plates may move during a main steam line break accident, thereby uncovering the cracks. A curve fit at the lower $95 \%$ prediction interval was then determined and adjusted to $344^{\circ} \mathrm{C}\left(650^{\circ} \mathrm{F}\right)$ using established temperature dependent lower bound mechanical properties. The lower value of the bobbin coil voltage at three times normal operating pressure or 1.43 times the main steam line break pressure drop was then determined. This was found to be $4.0 \mathrm{~V}$ for the 3/4-inch tubing and $4.5 \mathrm{~V}$ for the $7 / 8$-inch tubing (for the data available at that time).

To calculate the expected voltage growth during the next operating cycle, data from consecutive operating cycles at six plants was evaluated. The percent voltage growth for each indication and an average plant value was calculated for each plant, then a bounding average growth rate greater than all the plant average values was computed. This value was shown to be $35 \%$ /EFPY.

The measurement uncertainty associated with probe wear and analyst interpretation was also determined. Probe wear was varied from 0 to $0.5 \mathrm{~mm}$ on the centering buttons and numerous scans made of a four hole calibration standard. 
The calibration standard was prepared per ASME Code Section V, Article 8, Appendix II - 860.22. A standard deviation of $7 \%$ was determined. The largest 592 indications from a plant with confirmed outside diameter IGSCC/IGA at the tube support plates was evaluated by six analysts. The standard deviation of the voltage readings was found to be $10.3 \%$. A combined root-mean squares deviation for measurement error of $20.5 \%$ was then calculated.

Using the EPRI values discussed above and an expected cycle length of 1.3 EFPYs, the repair limits are 2.4 volts for 3/4-inch tubing and 2.7 volts for $7 / 8$-inch tubing. It should be noted that use of these limits requires $100 \%$ bobbin coil eddy-current inspection, and supplemental rotating pancake coil eddy-current inspections to characterize the indications as outside diameter IGSCC/IGA.

To use the EPRI voltage criteria, the primary-tosecondary coolant system leakage during various design basis accidents must also be estimated. Therefore, EPRI correlated leak rate and probability of leakage with bobbin coil voltage by testing pulled tubes and model boiler tubes at estimated main steam line break pressure differences of 16.1 and 18.3 $\mathrm{MPa}$ (2335 and 2650 psi). (However, not all the tubes were tested at both pressures, and analytical adjustments were used.) Using the best fit curves and standard deviations, along with the crack growth rate and measurement uncertainty distribution, a Monte Carlo analysis can be performed to calculate an accident leak rate at the end of the next operating cycle. (The leak rate for a given crack size is the probability of leakage multiplied by the leak rate.) The sum of the upper $95 / 95$ probability/confidence level values is then used as the conservative upper bound leak rate and compared to the site boundary limits.

Also, to minimize the probability of rupture, the EPRI guidelines recommend that the allowable steam generator leak rate be reduced from 1893 to 568 liters per day ( 500 to $150 \mathrm{gpd}$ ).

The USNRC provided guidance to U.S. utilities who wished to implement the EPRI (or similar) alternative fitness-for-service guidelines for ODSCC at tube support plates in Generic Letter 95-05 (USNRC 1995b). Although the USNRC approved the basic approach discussed above, a number of key parameters were modified and made more restrictive (conservative). Also, the repair criteria discussed in Generic Letter 95-05 only applies to Westinghouse-designed steam generators with $19 \mathrm{~mm}(3 / 4 \mathrm{in}$.) and $22 \mathrm{~mm}(7 / 8$ in.) diameter Alloy 600 tubes and drilled-hole tube support plates and axially oriented ODSCC confined within the tube-to-tube support plate intersections.

The USNRC voltage repair limits are:

- $22 \mathrm{~mm}(7 / 8$ in.) diameter tubes with bobbin coil probe indications less than 2.0 volts may remain in service.

- $19 \mathrm{~mm}$ (3/4 in.) diameter tubes with bobbin coil probe indications less than 1.0 volt may remain in service.

- Tubes with bobbin coil indications greater than the above values but less than an upper voltage repair limit (calculated using the basic EPRI approach) may remain in service if a subsequent rotating pancake coil probe inspection does not confirm the indication.

- Tubes with other indications (above the upper limit, or between the lower and upper limit and confirmed by rotating pancake coil inspection) must be repaired.

As with the EPRI fitness-for-service guidelines, the upper voltage repair limit is determined by first determining the lower $95 \%$ prediction boundary for an appropriate set of roomtemperature burst pressure versus bobbin coil 
voltage data, then reducing this lower limit to account for the lower $95 / 95 \%$ tolerance bound of the tubing material properties at $343^{\circ} \mathrm{C}\left(650^{\circ} \mathrm{F}\right)$. The structural limit voltage, $\mathrm{V}_{\mathrm{SL}}$, is then determined for a free span burst pressure of 1.4 times the differential pressure calculated for a main steam line break design basis accident. The structural limit voltage is then reduced to account for flaw growth during the next operating cycle and voltage measurement uncertainty. The flaw growth allowance should be based on the voltage growth rates observed at that plant during the last one or two inspection cycles or $30 \%$ per effective full power year, whichever is larger. The voltage measurement uncertainty should consider probe wear and the variability among data analysts and should be the $95 \%$ cumulative probability value (about $20 \%$ ).

The total leak rate during a main steam line break accident must also be calculated by (a) determining the frequency distribution of the bobbin coil voltage indications, (b) determining an end of cycle distribution based on the expected crack growth and estimated measurement error and (c) use of empirical probability of leak and leak rate versus bobbin coil voltage indication models. The total leak rate must, of course, be within the licensing basis. The beginning of cycle bobbin indication frequency distribution must be scaled upward by a factor of 1/POD to account for non-detected cracks, where POD is the probability of detection of ODSCC flaws and can be assumed to be 0.6. Monte Carlo techniques can then be used to project the beginning of cycle voltage distribution to the end of the cycle, using the expected crack growth values and measurement uncertainties discussed above. Once the projected end of cycle voltage distribution is determined, the leakage is calculated by multiplying the voltage distribution by (a) an empirical probability of leakage as a function of voltage value and (b) an empirical leak rate as a function of voltage value. These empirical models should be developed from appropriate experimental data from either 22 or $19 \mathrm{~mm}$ tubing, as applicable.
Implementation of a voltage-based repair criteria must include enhanced inspections. The bobbin coil inspection should include all the hot-leg tube support plate intersections and all the cold-leg intersections down to the lowest cold-leg tube support plate with known ODSCC. In addition, $20 \%$ of the tubes should be inspected over their full length with a bobbin coil probe. Rotating pancake coil inspections should be performed for all bobbin coil indications exceeding 2.0 volts from $22 \mathrm{~mm}$ ( $7 / 8 \mathrm{in}$.) diameter tubes or 1.0 volt from $19 \mathrm{~mm}$ ( $3 / 4 \mathrm{in}$.) diameter tubes. Also, rotating pancake coil inspections should be performed at all intersections with (a) interfering signals from copper deposits, (b) dent signals greater than 5 volts, or (c) large mixed residuals. Any indications found at such intersections with a rotating pancake coil should cause the tube to be repaired or plugged. The bobbin coil should be calibrated against the standard used to develop the voltage-based approach. Probe wear should be controlled. The data analyst's performance should be consistent with the measurement uncertainties used.

Implementation of a voltage-based repair criteria must also include a program of steam generator tube removals and testing. Two tubes (at least four intersections) must be removed (pulled) from each plant when the voltage-based repair criteria is first implemented. An additional tube (at least two intersections) must be removed during each outage following 34 effective full power months of operation, or after three refueling outages, which ever is shorter. The removed tubes must be subjected to leak and burst tests under simulated main steam line break conditions. The tube intersection areas must also be destructively examined to confirm that the degradation is axial ODSCC.

Implementation of a voltage-based repair criteria must also include reduced leakage limits (568l per day or 150 gal per day) and adequate leakage monitoring equipment. Also, tubes with known leaks must be repaired or plugged. 


\subsubsection{Alternative U.S. Fitness-For-Service Guidelines for PWSCC in the Roll Transition Region Proposed by EPRI}

Primary water stress corrosion cracking has been found in the roll transition region of full- and part-depth rolled PWR steam generators worldwide. One of the first alternative fitnessfor-service guidelines was the $\mathrm{F}^{*}$ criterion which is being used in a number of U.S. plants. The $F^{*}$ criteria applies to steam generators with partial or full tubesheet depth hard rolled tubes and allows defects, regardless of size, detected below a certain distance from the bottom of the roll transition or top of tubesheet, whichever is lower, to remain in-service. The $\mathrm{F}^{*}$ distance is established by considering the length of roll expansion needed to resist tube pull out forces and is typically 38 to $50 \mathrm{~mm}$ ( 1.5 to $2.0 \mathrm{in}$.). In other words, the $\mathrm{F}^{*}$ criteria has been applied at locations where there is a very low possibility of steam generator tube rupture or burst because the defect remains tightly enclosed within the tubesheet.

Recently, EPRI also commissioned a committee of U.S. and foreign experts in steam generator repair issues to develop alternative fitness-forservice guidelines for tubes with axial PWSCC above the $F^{*}$ distance (EPRI 1993b). The following equation is used to find the largest allowable axial crack which can remain inservice:

$$
\mathrm{A}=a+\mathrm{a}_{\mathrm{TS}}-\mathrm{a}_{\mathrm{CG}}-\mathrm{a}_{\mathrm{NDE}} .
$$

Where $\mathrm{A}$ is the allowable crack length, $a$ is a reference crack length from a rupture correlation, $\mathrm{a}_{\mathrm{TS}}$ is a correction for tubesheet constraint, $\mathrm{a}_{\mathrm{CG}}$ is the allowance for crack growth during the next operating cycle, and $a_{N D E}$ is a measurement uncertainty factor. To develop the rupture correlation ( $a$ versus burst pressure) EPRI compiled results from tests performed on 3/4-inch and 7/8-inch tubing by BELGATOM, Framatome and EdF, Westinghouse, and CEGB in Great Britain. The data were normalized and a bounding equation determined and then adjusted to the steam generator operating temperature.

The tubesheet correction factor was developed by BELGATOM as follows (for 3/4-in. tubing):

$$
\begin{array}{ll}
0<a<4.5 \mathrm{~mm} & \mathrm{a}_{\mathrm{TS}}=4.5 \mathrm{~mm} \\
4.5<a<18 \mathrm{~mm} & \mathrm{a}_{\mathrm{TS}}=6.0-a / 3 \mathrm{~mm} \\
18 \mathrm{~mm}<a & \mathrm{a}_{\mathrm{TS}}=0
\end{array}
$$

These values reflect the tubesheet reinforcement provided relatively short axial cracks at the roll transition.

The allowance for average crack growth during the next operating cycle $\left(\mathrm{a}_{\mathrm{CG}}\right)$ was determined to be $0.76 \mathrm{~mm} / \mathrm{EFPY}$ using data from Doel 2 for cracks with beginning-of-cycle lengths of 3 to 11 $\mathrm{mm}$ (Doel 2 has an inlet temperature of $330^{\circ} \mathrm{C}$ ). However, use of plant specific data is recommended. To determine the measurement uncertainty $\left(\mathrm{a}_{\mathrm{NDE}}\right)$, EPRI compiled results from comparisons of true crack length with crack length as measured by rotating pancake coil eddy-current equipment in France, Belgium, Sweden, Spain, and the U.S. The 201 data points provided the following relationship: True crack length equals the eddy-current measured crack length less $0.39 \mathrm{~mm}$ with a two sigma distribution of $2.12 \mathrm{~mm}$. Subtracting 0.39 from $2.12 \mathrm{~mm}$ provides an NDE error estimate of $1.73 \mathrm{~mm}$. [i.e., the average true length is 0.39 $\mathrm{mm}$ shorter than the measured length but at the $95 \%$ confidence level ( 2 sigma) the true length is $1.73 \mathrm{~mm}$ longer than the measured length.]

Using safety factors of 3 on the normal pressure drop and 1.43 on the design basis accident pressure drop, a critical crack length for a 7/8inch tube of $10.7 \mathrm{~mm}$ is calculated. Use of this criterion required a $100 \%$ rotating pancake coil eddy-current inspection of all in-service hot-leg tube expansion zones. It also required a primaryto-secondary coolant system leakage calculation, similar to the leakage calculation discussed in Section 6.2.2 above. 
Also, to minimize the probability of rupture, EPRI recommends that the leak limit during normal operation be reduced to 568 liters per day (150 gpd) per steam generator.

The USNRC has not approved use of the EPRI proposed fitness-for-service guidelines for PWSCC in the roll transition region in the U.S. As discussed below, certain other countries are using variations of these guidelines.

\subsubsection{Other Alternative Fitness-For-Service Guidelines in the U.S.}

Extensive pitting in the Indian Point Unit 3 steam generator caused by a large Hudson River water excursion into the secondary coolant system in 1981 , resulted in alternative fitness-for-service guidelines at Indian Point Unit 3 during the period 1981 to 1985 . Limits of $65,50,55$ and $63 \%$ of the tubing wall thickness were used at various times. These limits were based on burst testing of pulled tubes and various estimates of next cycle crack growth and measurement uncertainty. In 1985, Indian Point returned to the ASME $40 \%$ criterion and repaired or plugged all tubes with indications over $40 \%$ of the wall thickness.

Extensive circumferential IGSCC/IGA was found in 1991 on the outside surfaces of the tubes in the three North Anna Unit 1 steam generators. These defects were located in the tubesheet expansion region and directly above and below the hot-leg tube support plates. All tubes with significant indications were plugged. However, due to the rapid increase in the extent of the stress corrosion damage, the utility decided that a mid-cycle outage in 10 months was needed. In an attempt to justify a normal 18 month fuel cycle, the utility burst tested pulled tubes and reevaluated their previous NDE data to develop a conservative crack growth correlation (over $50 \%$ of the 1991 indications were identifiable in
1989). Also, analysis and testing were performed to determine if fatigue at the defect locations could lead to tube rupture. Despite these efforts, it was decided that a mid-cycle inspection was necessary. The utility concluded that the results of that inspection showed that the models developed at the end of the previous operating cycle overestimated the number and size of the tubesheet expansion zone defects, but underestimated the number and size of the defects near the tube support plates. The mid-cycle and future inspections of North Anna Unit 1 consisted of $100 \%$ full length bobbin coil eddy-current inspections, $100 \% 8 \times 1$ probe inspections of the hot-legs, $100 \%$ rotating pancake coil inspections near the top of the tubesheet, and follow-up of all bobbin and $8 \times 1$ probe indications with a rotating pancake coil eddy-current inspection.

\subsubsection{Regulatory Practices and Fitness-For- Service Guidelines in Belgium}

The starting point for the Belgian fitness-forservice guidelines was the original U.S. requirements discussed in Section 7.3.1 above, however, the Belgians consider the $40 \%$ of tube wall thickness limit in Section XI of the ASME Code too conservative for some locations and some defect types, and too inflexible. For these reasons, the Belgians have revised their requirements for in-service inspection of steam generator tubes and have defined the objectives to be met, but assigned the responsibility to the plant operator to meet them. The revised technical specification

- states that the objectives of inspection are to: (1) determine whether tube degradation is occurring and identify the specific modes involved, (2) assess the rate of defect growth and compare it with values used in establishing plugging/repairing criteria, and (3) identify the tubes that require plugging/repairing. 
- defines the content of the inspection program, which must include: (1) definition of inspection techniques and procedures, (2) tubes and zones to be inspected and (3) the plugging/repairing criteria to be used for each type of degradation.

- gives general requirements: (1) requiring inspection methods to be selected such that they can reliably detect defects of concern, and (2) establishing the minimum sample size for inspection(3\%) and requiring the sample size to be expanded and additional inspection to be used, if necessary, to achieve the objectives.

Based on the revised inspection requirements, alternate plugging/repairing criteria, i.e. defect specific fitness-for-service guidelines, have been developed by the plant operator aiming at (1) ensuring the structural integrity of the tubes, with adequate safety margin, under normal and during postulated accident conditions and (2) limiting the total primary-to-secondary leakage during and following an accident to a value consistent with the offsite dose limit. The controlling accident is considered to be a feedwater/steam line break. With regard to the safety factors, the Belgians generally use the safety factors on loadings required by the USNRC Regulatory Guide 1.121 and the ASME Code.

The fitness-for-service guidelines are submitted to the safety authority for approval. They are reassessed after each inspection to take into account the latest degradation growth rates, the accuracy of the inspection technique, and any change in the acceptance criteria (e.g. additional burst test data).

The fitness-for-service guidelines in Belgium are both defect specific and location specific. For example, one type of fitness-for-service guide- lines is for axial PWSCC at the roll transition at the top of the tubesheet of full depth rolled tubes. Other fitness-for-service guidelines have been developed for axial IGA/IGSCC at tube support plate intersections, for IGA/IGSCC in the sludge pile, and circumferential ODSCC at the roll transition at the top of the tubesheet. The fitnessfor-service guidelines are of two general types, deterministic and statistical. Deterministic fitness-for-service guidelines are used when the morphology of the defect is such that reliable sizing is possible using available non-destructive examination methods, and the size of the defect can be reliably correlated with tube burst data. In these cases, the measured size is compared to an allowed defect size, which includes margins for sizing error and growth up to the next inspection, and required safety factors. Statistical fitness-for-service guidelines are used when accurate defect sizing by non-destructive examination technique is not possible. In this case, a statistical correlation is developed between a measured non-destructive examination parameter, such as bobbin coil voltage amplitude, and the burst strength of tubes with defects generally obtained from tubes removed from service. The lower confidence limit of this correlation, when combined with the required safety margin, is the maximum permissible value of the non-destructive examination parameter at the next inspection, i.e. after allowing for growth.

Predicted primary-to-secondary leakage during accidents. is calculated on a combined deterministic-probabilistic basis, taking into account the measured crack size or measured non-destructive examination parameter at the start of the operating interval, probable crack sizes or non-destructive examination parameters at the end of the operating interval, and probable leakage behavior based on tests of tubes removed from service. 


\subsubsection{Fitness-for-Service Guidelines in Canada}

The regulatory requirements for steam generator tubing fitness-for-service assessments in Canada are stated in Clause 14 of CAN/CA N285.4, "Periodic Inspection of Nuclear Power Plant Components" (Canadian Standards Association 1994). In general, the only flaw indications allowed in unrepaired tubes are where the predicted wall loss does not exceed $40 \%$ of the nominal wall thickness prior to the next inspection. However, the most recent version of this standard allows for indications exceeding the basic $40 \%$ criteria, when a satisfactory fitnessfor-service assessment is performed. The fitnessfor-service methodology discussed below is based on recent assessments carried out at Ontario Hydro for Bruce-A Unit 2 and Bruce-B (Gorman et al. 1995).

The fitness-for-service assessment requires demonstration that the incremental risk associated with continued operation of a steam generator with a known degradation mechanism is justified, understood and controlled. This has led to the following acceptance criteria;

1. Demonstrate that the predicted probability of steam generator tube rupture remains unchanged thus ensuring the frequency of the event is unchanged from that considered in support of the operating license.

2(a). Demonstrate, for all design basis events with possible induced tube failures, that there are justifiable margins between estimated doses due to consequential tube leakage and the applicable dose limits.

2(b) Demonstrate that post-accident operating conditions are manageable and procedures adequate such that overall consequences remain acceptable.
It has been the experience to date that the response to design basis events (criterion 2(a)), has defined the permissible degree of tube degradation in affected CANDU plants (Grant 1994). Criterion (1) has been demonstrated for the degradation mechanisms experienced by CANDU units to date, but it may not always be possible to do that for all degradation mechanisms which might affect the tubes in the future.

CANDU plants routinely monitor steam generator leakage with methods capable of detecting leaks below $10^{-3} \mathrm{~kg} / \mathrm{s}$. Plant operating procedures require shutdown when the leak rate exceeds $15 \mathrm{~kg} / \mathrm{hr}$. However, the correlation of leak rate with degradation is usually poor, because of the dependence of the leak rate on other variables such as applied loads, crack morphology, crud, etc. Leak monitoring is a useful precaution, but it does not in itself preclude the existence of large flaws or tube ruptures, it needs to be supplemented by other actions such as in-service examinations (Grant 1994).

Criterion (2(a)) leads to the development of a Maximum Allowable Leak Rate per unit against which a Total Estimated Consequential Leak Rate due to an event is compared.

The general fitness-for-service assessment methodology consists of the following steps:

Determination of Degradation Mechanism and Root Cause. The first step in the assessment process determines the degradation mechanism and the root cause of the problem (more than one degradation mechanism may be affecting the tubes). This leads to two possible paths of action depending on how widespread the problem is. If the population of affected tubes is known to be small, i.e. the degradation is not generic, then the affected tubes are either taken out of service or 
are allowed to remain in service if the tube flaw indications are less than the $40 \%$ plugging criterion. Actions may also take place to remove the cause of the problem. For example, if the degradation was caused by debris there is an effort to remove it from the steam generator. If the tube degradation is found to affect a large population of tubes in the steam generators, i.e. the degradation is generic in nature, then the fitness-for-service assessment continues.

Failure of the Tube(s) under Normal Operating Conditions. For normal operating conditions, it is necessary to determine the specific degradation mechanism(s); characterize the tube flaw characteristics and material properties, the loadings and the tube behavior under such loadings; and, determine the mode(s) of failure of the degraded tube and the resulting leak rate. Sources of information for this step include non-destructive and destructive (tube pulls) examinations and structural testing of tubes containing characterized defects. This information is required to demonstrate that degradation induced failure of the tube will occur in a stable controlled manner. This leads to an evaluation of the increase in probability of boiler tube rupture under normal operating conditions and an evaluation of the adequacy of the basic Shutdown Leak Rate. Criterion (1) is satisfied if it can be shown that the maximum predicted probability of boiler tube rupture remains unchanged. This criterion must be satisfied for the fitness-for-service assessment to continue.

Failure of the Tubes as a Consequence of Design Basis Events. In order to estimate a total leak rate for a particular tube degradation mechanism as a consequence of a specific event, it is necessary to answer the following questions:
How are the tubes likely to fail?

(ii) How many tubes are at risk of failing at the end of the operating cycle, i.e. just prior to the next inspection?

(iii) What remedial measures could be put in place to correct or mitigate the degradation and what is the impact of these measures on the safety assessment?

Determine Failure Mode of Tubes. Again, it is necessary to determine the specific degradation mechanism(s); characterize the tube flaw characteristics and material properties, the loadings and the tube behavior under such loading; and, determine the mode(s) of failure of the degraded tube and the resulting leak rate. This is required to determine the level of degradation beyond which credit can not be taken for pressure boundary integrity for a particular event (i.e. the tube is at risk of leaking). This is referred to as the Accident Specific Degradation Threshold Value (ASDTV). To determine the ASDTV, event specific loadings are considered. These loadings are obtained from thermal hydraulic analyses of each design basis event and include the appropriate factors of safety. The ASDTV is analytically calculated using flaw models which have been validated by suitable structural tests.

Determine Number of Tubes at Risk of Failing by the End of the Operating Cycle. To predict how many tubes are likely to fail by the end of the operating cycle, the future condition of the tubes must be predicted by determining the present condition, the rate of change of the degradation and the duration of the operating period to the next inspection. In-service examin- 
ation results and probability models provide an estimate of the future condition of the tubes. In the Bruce-A Unit 2 case the ODSCC was extremely difficult to detect and required the development of a new eddy-current inspection probe, called Cecco-3. This sensitive probe was a key factor in the success of the overall assessment. The impact of any remedial action on both the present condition and the rate of change is also included in the assessment.

In the fitness-for-service assessment, a maximum tolerable flaw size (MTFS) is also calculated (based on ductile collapse of flawed tubes) and is used to establish the plugging criterion which considers the inspection interval, expected growth rate, and inspection uncertainty. The loadings considered for determining the MTFS are the loadings which represent bounding loading conditions for the ASME Service Levels $\mathrm{A}, \mathrm{B}, \mathrm{C}$ and $\mathrm{D}$. The assessment then considers the future condition of the tubes and the calculated threshold value ASDTV to predict the total number of tubes at risk of leaking by the end of the operating cycle.

Remedial Actions. To determine appropriate remedial actions, which could be corrective or preventive in nature, the degradation mechanism, the root cause and contributing factors must be thoroughly understood. Further, the impact of all remedial actions must be taken into account in the safety assessment.

Total Estimated Consequential Leak Rate. The total Estimated Consequential Leak Rate is determined by evaluating the product of the total number of tubes at risk at the end of the operating cycle and the total leak rate per tube. Criterion (2) is satisfied if it can be shown, for all design basis events, that there are justifiable margins between the estimated consequential doses due to tube leaks and the applicable dose limits and that the overall post accident consequences remain acceptable.
Fitness-for-Service Assessment. The steam generators in the unit are judged to be fit for continued service if criteria (1) and (2) are satisfied. If these relationships are not shown to be true then additional measures must be implemented to either further correct the situation (new plugging limits, internal modifications, cleaning, etc.) or shortening the operating interval and/or reducing the power levels. The assessment is then repeated.

\subsubsection{Regulatory Practices and Fitness-For- Service Guidelines in the Czech Republic}

Defective steam generator tubes with $80 \%$ or grcater wall thickness reduction have been plugged. This value was recommended by the manufacturer, Vitkovice, and has not been approved by the Czech regulatory body. Additional work to determine the final criterion is under way (burst testing). Leakage limits were developed and approved by the Czech regulatory body in 1993 .

\subsubsection{Regulatory Practices and Fitness-For- Service Guidelines in France}

The measures taken by EdF and the French regulatory authority, DSIN, to prevent tube rupture or burst during normal, off-normal, or accident conditions are based on aggressive inspection and leak detection programs supported by defect type and location specific fitness-forservice criteria (Cochet 1989, Saudan 1992, Lemaire 1993). To find PWSCC in the roll transition region of steam generators susceptible to PWSCC, the hot leg side roll transition region of every tube is inspected during each outage using rotating pancake coil eddy-current equipment. To find PWSCC in the small radius U-bends, the U-bend region of all the tubes in the first row still in service and a sample of the tubes in the second row are inspected during each outage, using a flexible rotating coil (susceptible steam generators). To find outside diameter IGSCC/IGA at the tube support plates, the hot 
leg tube support plate locations are inspected during every other outage, using bobbin coil eddy-current equipment (susceptible steam generators). Follow-up inspections of affected tubes still in service are performed during the next outage. Also, $100 \%$ of the hot leg tube length in the sludge pile is inspected using bobbin coil eddy-current equipment every other outage. The accuracy of the examination techniques are assessed by comparing the measurements to the results of pulled tube destructive examinations (more than 350 to date).

The primary-to-secondary coolant system leak rate in EdF steam generators at plants that have experienced tube degradation is measured by both manual and nitrogen-16 monitors. The plant must be immediately shutdown when the nitrogen-16 monitor detects a leak greater than $72 \mathrm{l} / \mathrm{hr}$. The leak rates measured manually that require plant shutdown are:

- Steam generators not susceptible to PWSCC in the roll transition zones: $3 \mathrm{l} / \mathrm{hr}$

- Steam generators susceptible to PWSCC in the roll transition zones: $5 \mathrm{l} / \mathrm{hr}$, an increase of $1 \mathrm{l} / \mathrm{hr}$, or a difference between steam generators of $3 \mathrm{l} / \mathrm{hr}$.

These values are important because the French use, in part, a leak before risk of break approach for some defects which is based on the ability to "demonstrate that any risk of rupture of a tube under the most extreme operating conditions is necessarily preceded by an allowable leak under normal operating conditions, whose detection makes it possible to shut down the nuclear steam supply system as a preventative measure" (Gorman et al. 1994). Therefore, the French have developed leak rate models for predicting the expected primary-to-secondary coolant system leak rates of tubes with various defects.
The defect type and location specific fitness-forservice guidelines used in France are summarized, as follows:

Axial PWSCC in the roll transition zone. The axial crack length limit is based on an analysis of crack growth and tube burst during a main steam line break, which is considered to be the design basis accident that imposes the highest loads. Correlations of critical crack length versus burst pressure have been developed from experiment. The analysis uses these correlations and the maximum tube diameter and minimum wall thickness, adverse mechanical properties, upperbound temperatures and pressures, a conservative allowance for crack growth during the next operating cycle, and margin for NDE error. Safety factors are not applied. In developing these correlations, the French concluded that a crack with an end within the tubesheet where the tube is in contact with the tubesheet can propagate in an unstable manner in only one direction. The maximum allowable free crack length is $13 \mathrm{~mm}$, for the 900 MWe plants. A temporary criterion of $13 \mathrm{~mm}$ has also been adopted for the $1300 \mathrm{MWe}$ plants. A definitive plugging criterion will be established after completion of certain probabilistic risk studies.

Circumferential PWSCC. Tubes with circumferential PWSCC must be plugged because (a) the leak before risk of break approach does not apply since the cracks are often not throughwall until the tube is close to rupture (i.e., the cracks tend to propagate around the tube first), and (b) the rotating pancake coil eddy-current detection limit is only about $50 \%$ of the wall thickness. In other words, the French do not believe that there is much margin between initial detection of circumferential PWSCC and possible rupture under extreme accident conditions. 
PWSCC in the inner row U-bends. All tubes with indications measured with bobbin coil and flexible rotating coil eddy-current equipment must be plugged. This is because it is almost impossible to pull tubes and develop correlations of actual crack length versus NDE results and prove that leak before risk of break applies. Preventive plugging of tight U-bend tubes susceptible to PWSCC was carried out at several French units to improve the availability of the plants.

Outside diameter IGSCC/IGA at tube support plates. The repair or plugging criteria is a bobbin coil voltage of 2 volts, which corresponds to approximately 17 volts in the U.S.. This rather large limit (as compared to a typical U.S. repair criteria of 1 to 2 volts) is due to the assumption that the tubing will be supported in those regions by the tube support plates during various design basis accidents. The 17 volt value was apparently obtained from an experimental correlation between bobbin coil eddy-current voltage and tubing burst strengths with support plates present, plus a voltage value for the expected crack growth during the next operating period, plus an allowance for measurement error. A more conservative value ( 1 volt) is used for defects at the higher tube support plate elevations of some steam generators (e.g. the model 51A).

Outside diameter IGSCC/IGA in the sludge pile. A bobbin coil eddy-current voltage of $500 \mathrm{mV}$ without an axial crack, or $200 \mathrm{mV}$ with an axial crack of $10 \mathrm{~mm}$ or greater (detected by rotating pancake coil), or any ODSCC indication from both bobbin coil and rotating pancake coil equipment, are the repair or plugging limits for IGSCC/IGA in the sludge pile.

Other indications. All other indications except those discussed above, including wear caused by foreign objects, AVBs, etc., and free-span defects are judged against the ASME $40 \%$ of wall criterion.

\subsubsection{Regulatory Practices and Fitness-For- Service Guidelines in Germany}

The repair or plugging criteria in the Federal Republic of Germany are designed to prevent rupture during normal operation or design basis accident loadings (Azodi et al. 1987). Defected steam generator tubes are evaluated on a case by case basis. However, wall degradation of $50 \%$ or greater generally results in plugging. This value was obtained from burst test results and:

- a measurement uncertainty of $\pm 10 \%$ for eddy-current testing and about $\pm 5 \%$ for ultrasonic examinations

- a factor of safety of 2.7 against rupture during normal operation and 1.43 against rupture during design basis accident loadings

- an operational allowance for crack growth or additional wastage during the next operating period of about $3 \%$ of the wall thickness (steam generators with phosphate water chemistry).

\subsubsection{Regulatory Practices and Fitness-For- Service Guidelines in Japan}

The fitness-for-service guideline issued by the Japanese Ministry of International Trade and Industry is simply steam generator tubing "flaws are not allowed" (Shizuma 1992). The term "flaw" is interpreted to mean any indication (crack, pit or general wall thinning) greater than $20 \%$ of the nominal wail thickness. Obviously, primary-to-secondary coolant system leakage is not allowed and a plant with a leak must be immediately shut down upon detection of the leak. Indications of degradation with a depth less than $20 \%$ are considered acceptable if the eddycurrent signal shows no change from the previous inspection. Preventive plugging of tight U-bend tubes susceptible to PWSCC has been performed at two units. 


\subsubsection{Regulatory Practices and Fitness-For- Service Guidelines in Russia}

The fitness-for-service guideline currently used in Russia (and presumably in the rest of the former Soviet Union) is no steam generator tubing leakage. All tubing with throughwall cracks which cause detectable primary-to-secondary coolant system leakage are plugged. All other defect indications are ignored. There has been no sleeving in the VVER steam generators.

\subsubsection{Regulatory Practices and Fitness-For- Service Guidelines in Slovenia}

The fitness-for-service guidelines in Slovenia were traditionally based on the $40 \%$ tube wall loss repair criterion. For the power plant located in Krško, a plant specific value of $45 \%$ was derived and implemented. However, this approach was considered overly conservative which lead to the implementation of the degradation specific guidelines outlined below. The defect type and location specific approach is mainly based on extensive inspection (see section 7.1.7) and additionally supported by on-line leak detection monitoring (nitrogen-16) and allowable leak rates of $40 \mathrm{l} / \mathrm{hr}$ per steam generator.

Axial stress corrosion cracking in the roll transition area. The $\mathrm{P}^{*}$ and crack length repair criteria are currently implemented. The $\mathrm{P}^{*}$ criterion allows for any defects located at least 38 to $76 \mathrm{~mm}$ (depending on the position of the tube) below the top of tubesheet and for axial defects anywhere inside the tubesheet. The crack length repair criterion is actually based on the Belgian approach described above and allows for axial cracks in the expansion transitions, and for both PWSCC and ODSCC in the sludge regions, if the axial cracks are shorter than $6 \mathrm{~mm}$. An additional restraint is that tubes with cracks located more than $7 \mathrm{~mm}$ above the tubesheet have to be repaired if the $45 \%$ criterion is violated.
Circumferential stress corrosion cracking in the roll transition area. Any tube with detected defects of this kind is to be repaired or plugged.

PWSCC in the inner row U-bends. Any detected defect triggers repair or plugging of the tube.

ODSCC at tube support plates. Recently, a conservative version of the EPRI based voltage methodology has been implemented for ODSCC at the tube support plates. Initially, $100 \%$ of the tubes are inspected using a bobbin coil probe. All bobbin coil indications with a signal amplitude exceeding 1 volt and depth reading exceeding $45 \%$ are inspected again using a multifrequency rotating pancake coil probe. Tubes with defects confirmed by multifrequency rotating pancake coil probes are then repaired. Probabilistic analyses addressing events of tube burst and excessive leakage during a steam line break were performed and are currently being refined to support the implementation of this approach.

Other. Tubes with defects exceeding the traditional $45 \%$ loss of tube wall thickness are repaired.

Sleeved tubes. All sleeved tubes and all sleeves are inspected during each outage. A $45 \%$ loss of tube wall thickness criterion is applied for both the intact part of the tube and the load carrying portion of the sleeve. In practical terms this means repair of all tubes with detected indications, as no wall depth readings can be obtained from the I-coil and Plus-Point eddycurrent probes.

\subsubsection{Regulatory Practices and Fitness-For- Service Guidelines in Spain}

A research program was launched in Spain to manage steam generator degradation. Partici- 
pants included the utilities, manufacturers (ENSA), inspection agency (Tecnatom), and research centers (Ciemat) (Bollini 1993). The fundamental objective of the Spanish fitness-forservice criteria is the same as the French criteria, that is to assure that the critical crack length under accident conditions is not exceeded during normal operation, so that tube rupture will not occur during a design basis accident. Defect type and location specific fitness-for-service criteria, along with aggressive inspections of defected steam generators, are used.

The Spanish defect type and location specific fitness-for-service guidelines are discussed below.

Axial PWSCC in the roll transition area. Two guidelines are used, the first is the $\mathrm{P}^{*}$ criterion, which allows a tube with axial PWSCC to remain in-service if the indication is below the top of the tubesheet and motion in the vertical direction is controlled by an essentially nondefective tube. The second guideline is based on the French leak before risk of break approach which assumes that accurate leak rate measurement during normal operation will detect crack growth before the crack reaches the critical length. Primary-tosecondary coolant system leak rate correlations as a function of crack size are, of course, needed for this approach and were based on the French work, modified with Spanish data. The largest allowable crack length is $8 \mathrm{~mm}$, which is based on a critical crack length of $13 \mathrm{~mm}(12.6 \mathrm{~mm}$ when the rolling is non-standard) less an upper bound crack growth of $4 \mathrm{~mm}$ per fuel cycle and a measurement uncertainty of $1 \mathrm{~mm}$. All tubes with indications equal to or longer than $8 \mathrm{~mm}$ (7.6 $\mathrm{mm}$ in the case of non-standard rolling) must be repaired or plugged. The maximum number of parallel axial cracks in a tube is 20 . Tubes with axial PWSCC more then $18 \mathrm{~mm}$ above the tubesheet must be repaired or plugged when the defect is deeper than $40 \%$ of the wall thickness.

Circumferential PWSCC in the roll transition area. Tubes with circumferential PWSCC in the roll transition area or above the $\mathrm{P}^{*}$ criterion limit must be repaired or plugged. The $\mathrm{P}^{*}$ criterion allows tubes to remain in-service if the circumferential indication is located $38 \mathrm{~mm}$ or more (for most of the non-peripheral tubes) below the top of the tubesheet and motion in the vertical direction is controlled by an essentially non-defective tube.

Outside diameter IGSCC/IGA at the tube support plates. The Spanish utilities have proposed a fitness-for-service guideline of $78 \%$ of the wall thickness for these defects. The Spanish regulatory agency Consejo de Seguridad Nuclear has not yet approved that criteria and the Spanish utilities are considering the EPRI bobbin coil voltage criteria discussed above.

Other indications. The plugging criterion for fretting damage at the antivibration bar intersections is $55 \%$ of the wall thickness. All indications other than the defect type and location specific defects discussed above are judged against the ASME $40 \%$ of wall thickness criteria.

The maximum primary to secondary leak rate for steam generators with susceptible tubing is limited to $5 \ell / \mathrm{hr}$ above a steady leak rate at the beginning of the cycle of $5 \ell / \mathrm{hr}$ or less. The maximum primary to secondary leak rate for steam generators with Alloy $800 \mathrm{M}$ or thermally treated Alloy 600 tubing is $72 \ell / \mathrm{hr}(1728 \ell /$ day $)$ during normal operation.

\subsubsection{Regulatory Practices and Fitness-For- Service Guidelines in Sweden}

The starting point for the Swedish fitness-forservice guidelines are the U.S. requirements, except that the tubes must be repaired or plugged when the defect indication is greater than $50 \%$ of the wall thickness, rather than the $40 \%$ specified in the ASME code. However, defect type and location specific requirements have been developed for axial PWSCC in the tubesheet region and outside diameter IGSCC/IGA at the tube support plates. 
The Swedish approach for judging axial PWSCC in the tubesheet region is probabilistic or risk based in nature (Hedner 1992). The objective is to limit the probability of steam generator tube burst during a main steam line break to less than $1 \%$, i.e., the sum of all tubes with an indicated crack length, times the probability of burst for that crack length, must be less than 0.01 .

In equation form:

$$
\sum \mu_{\mathrm{x}} \mathrm{P}_{\mathrm{x}}<0.01
$$

where $\mu_{\mathrm{x}}$ is the number of cracks of length $\mathrm{x}$ and $P_{x}$ is the probability of burst or rupture of a tube with a crack of length $x$. The probability of burst includes the expected crack growth during the next fuel cycle and measurement error and varies as a function of crack length and distance above the tubesheet. For example, a $12.4 \mathrm{~mm}$ crack is calculated to have a probability of burst of $1 \%$, a $9 \mathrm{~mm}$ crack is calculated to have a probability of burst of $0.34 \%$, and $6 \mathrm{~mm}$ crack is calculated to have a probability of burst of $0.0001 \%$. Only the lengths of cracks above the tubesheet are considered. Tubes with axial cracks below the top of the tubesheet can remain in-service without repair. Tubes with circumferential PWSCC can remain in-service when the cracks are below the $\mathrm{P}^{*}$ distance $(38 \mathrm{~mm}$ below the top of the tubesheet). Tubes with circumferential PWSCC above the $\mathrm{P}^{*}$ distance must be repaired or plugged.
Outside diameter IGSCC/IGA indications at tube support plates with depths up to $70 \%$ of the wall thickness can remain in-service provided that the indication is within the length of the tube support plate and is in the lower five tube support plates. These limits are based on tube burst testing with a tube support plate present and analysis to determine tube support plate deflection during design basis accidents. Defects at the upper tube support plates are allowed when the bobbin coil voltage is less than $1.5 \mathrm{~V}$.

\subsubsection{Fitness-For-Service Guidelines in Switzerland}

The repair criteria used by the Swiss utility (NOK) is that all tubes with clear indications within the tubesheet, independent of their depth, will be sleeved and all tubes with indications outside the tubesheet and greater than $50 \%$ of the wall thickness will be plugged. Multifrequency bobbin coil eddy-current equipment is used outside the tubesheet region and rotating pancake coil eddy-current equipment is used for supplemental examination of indications within the tubesheet. 


\section{STEAM GENERATOR TUBE DEFECT DETECTION RELIABILITY AND SIZING ACCURACY}

A typical PWR plant has two to four steam generators each with a total tube surface area of about 2,500 to $12,000 \mathrm{~m}^{2}(25,000$ to 130,000 $\mathrm{ft}^{2}$ ). Eddy-current testing is well suited for inspecting thin-walled tubes with large surface areas, because it offers both very high scanning speed and high sensitivity. In addition, eddycurrent testing does not require direct contact with the test material and, therefore, a coupling medium is not necessary. Also, eddy-current inspections can be easily automated.

However, eddy-current inspection of steam generator tubes has faced two types of challenges that have made reliable detection of defects difficult: appearance of newer and much more subtle forms of degradation in the aging steam generator tubes, and the presence of a variety of design features and deposits on the outside surface of the tubes which produce signals that mask the responses produced by the defects. In the last 25 years, steam generator tubes have been damaged by wastage, denting, intergranular attack and intergranular stress corrosion cracking, pitting, high-cycle fatigue, fretting, erosion-corrosion, and corrosion fatigue on the secondary side and primary water stress corrosion cracking on the primary side. The geometry of damage caused by these degradation mechanisms can be complex and different. Wall thinning caused by wastage results in a large change in volume, stress corrosion cracks and pitting are small-volume flaws, and the damage caused by denting results in a significant deformation of the tube cross-section. Some of the flaws are shallow and others are deep and they initiate from either the outside or inside surface, or both. Generally flaws found at a given location have primarily been either axial or circumferential, but in some instances both axial and circumferential flaws are found at the same location and flaws with other orientations have also been found. Tight spacing between pits also makes interpretation of eddy-current test signals difficult.

The various steam generator designs introduce several features that make eddy-current inspection difficult. These features include the roll-transition region where the diameter of the tube and its wall thickness are continuously changing, the U-bend region where the tube cross section is somewhat elliptical instead of circular, a thick tubesheet [typically 0.53 to $0.6-\mathrm{m}$ ( 21 to 23.5 -in.) thick] to which the tube ends are welded and which also constitutes a boundary between primary and secondary coolants, structures to support the tubes at different elevations, ÁVBs to support the tubes in the U-bend region, and baffle plates to support the tubes within the economizer. Two additional design features are present in some steam generators, a crevice in the tubesheet region, typically $0.15-\mathrm{mm}(0.006-\mathrm{in}$.) wide radial gap, and a small annular gap between tube and support plates with drilled holes. Cold work present in the roll transition and U-bend regions, especially the U-bends of the first few rows, also affect eddy-current inspection results.

Deposits on the secondary side of the tubesheet or adhering to the outside surface of the tubes also make eddy-current inspection difficult. Corrosion of the carbon steel components in the secondary feedtrain, dissolution of heat exchanger tubing, and condenser leakage are the main sources for the sludge deposited on the tubesheet and tubes. The sludge includes magnetite, which is ferromagnetic and has a high permeability and affects the impedance of the eddy-current coil. The sludge often includes copper, which has a high conductivity. Copper plating on a tube provides a strong eddy-current signal, which can mask the presence of pits. 
Several different mitigation and repair techniques used for steam generator tubes also pose challenges to the eddy-current inspections. Shot peening and nickel plating have been used to reduce the susceptibility of steam generator tubes to PWSCC. Shot peening introduces cold work on the surface. Nickel is ferromagnetic and has high permeability. Sleeves have been used for tube repair and plugs have been used to take tubes out of service. Inspection of the portion of the parent tube covered by a sleeve and inspection of plugs also places new requirements on the eddy-current probes.

This section first describes the conventional eddy-current technologies and includes a discussion of the principles of eddy-current inspection, basic probes and their characteristics, and multifrequency/multiparameter inspection techniques. Then the advanced eddy-current probes including motorized rotating pancake coils, array probes, transmit/receive probes, and I-coils and Plus-Point probes (for sleeve inspection) are discussed. Next, inspection of sleeved tubes, nickel plated tubes, and tube plugs is discussed. The need for and use of ultrasonic inspection techniques are discussed next. The limitations of the inservice inspection methods (accuracy and reliability) are summarized. Finally summary and conclusions are presented.

\subsection{Conventional Eddy-Current Techniques}

Because eddy-currents are sensitive to many parameters, eddy-current testing is extremely versatile and can be used to sense and test many aspects of a material. However, this advantage also has a negative aspect. Irrelevant parameters can mask the desired information and cause misinterpretation of the test results. Therefore, all the factors that affect probe impedance must be considered and a high level of analyst training and expertise is critical in recognizing these factors. Also, eddy-current inspections are based on indirect measurements and, therefore, correlations between the instrument readings and the defect location, orientation, and size, and other structural characteristics of the component being inspected must be carefully and repeatedly established.

\subsubsection{Principles of Eddy-Current Testing}

The basic eddy-current system consists of a test coil, an alternating current source (or oscillator), and instrumentation to sense changes in the coil caused by changes in the magnitude and phase of the eddy-currents within the test material. Typical frequencies for steam generator tube inspection range from $10 \mathrm{kHz}$ to $1 \mathrm{MHZ}$ (EPRI NDE Center 1987).

The alternating electric current in a test coil produces a time-varying primary magnetic field that surrounds the coil. The magnetic field is oriented normal to the current in the coil or parallel to the coil's axis. When the primary magnetic field comes in the vicinity of a conductive medium, secondary electric currents, called eddy-currents, are produced through the process of electromagnetic induction. The eddycurrents flow normal to the direction of the magnetic flux and parallel to the direction of the electric current in the test coil. The eddycurrents, in turn, produce a secondary magnetic field in the material, which opposes the primary magnetic field and reduces its net magnetic flux. This reduction in the primary field of the test coil causes a change in the coil's impedance. Any variation in the material that impedes the flow of the eddy-currents, such as a discontinuity in the material or changes in the conductivity or permeability of the material, produces changes in the primary and secondary magnetic fields and thereby alters the test-coil impedance. The change in the impedance is sensed by the associated instrumentation.

Factors that influence the magnitude and path of the eddy-currents are the coil impedance, the electrical conductivity and magnetic permeability of the test material, the lift-off and fill factors 
(defined below), and the amplitude and frequency of the applied field. Impedance is the total opposition a coil presents to an alternating current. Impedance $(Z)$ is a vector quantity and has two components: the resistance of the wire, $R$, and the inductive reactance, $X_{L}$. The magnitude of the impedance is given by $Z=\left(R^{2}+X_{L}^{2}\right)^{1 / 2}$, and the associated phase angle $\theta$ is equal to $\operatorname{Tan}^{-1}\left(X_{L} \backslash R\right)$. The conductivity of Alloy 600 is $1.7 \%$ IACS and its relative permeability is 1.0 since this material is not ferromagnetic. Changes in the spacing between the coil and the part being inspected alter the eddy-current signal, and are called lift-off. The lift-off effect produced by small changes in spacing can mask the eddy-current response from defects that are of primary interest. For a bobbin type coil, a condition comparable to lift-off is known as a fill factor, which measures how well the test coil fills the inside of the tube being inspected. A small change in the inside diameter of the tube can produce a large change in the eddy-current signal.

Additional factors specific to inspection of steam generator tubes are cracking, deformation of the tube cross-section (i.e., denting the tube, expansion in the transition region, etc.) and wall thinning. These factors affect the primary magnetic field and the flow of the eddy-currents in the tubes. The presence of a tubesheet, support plates (nearby, but not necessarily in contact), and material deposits also affect the flow of eddy-currents.

The most common method for measuring the impedance changes in a steam generator eddycurrent inspection coil is an impedance plane analysis. As mentioned, the coil impedance is the vector sum of the resistance and the reactance and therefore, can be plotted and displayed using an $\mathrm{X}-\mathrm{Y}$ storage oscilloscope or the equivalent (Hagemaier 1983). Modern instruments use a flying-dot approach to display the phase and amplitude of the impedance change. The resulting data that is traced on the display is called a Lissajous signal and is shown in Figure 85.

Penetration, Frequency, and Phase Lag. Eddy-currents are not uniformly distributed within the test sample but are concentrated at the near surface, that is, the inside surface of the tube. The density of eddy-currents decreases exponentially with depth in the material. This is called the skin effect and can be explained as follows: eddy-currents flowing at any depth in the tube produce secondary magnetic fields which oppose the primary field, thus reducing the magnetic flux of the primary field at a greater depth, which in turn induces eddy-currents of smaller density. Eddy-current penetration is a function of the material conductivity and permeability, and the test frequency of the inspection coil. Since conductivity and permeability are material properties that cannot be changed, frequency is the primary operating variable and can be optimized to meet the inspection objective. For eddy-current testing, penetration power is normally determined in terms of the standard depth of penetration $(\delta)$ and is defined as the depth at which the density of the eddy-currents is reduced to $37 \%$ of that at the surface. It can be calculated as follows:

$$
\delta=1.98\left(\rho / \mathrm{f} \mu_{\text {rel }}\right)^{1 / 2} \mathrm{~mm},
$$

where $\rho$ is the material resistivity ( $\mu$ ohm-cm), $\mathrm{f}$ is the test frequency (hertz), and $\mu_{\text {rel }}$ is the relative permeability (a dimension-less quantity and equal to 1 for non-ferromagnetic tubing). The attenuation of the eddy-current density with depth implies that defects located at different depths will change the probe impedance by different amounts. So, the amplitude of the eddy-current signal from a large subsurface defect could be similar to the signal from a small surface defect. Therefore, additional information is generally needed to determine the severity of a defect. This problem is addressed by measuring both the amplitude and phase angle of the signal. Measurement of the phase angle is of 


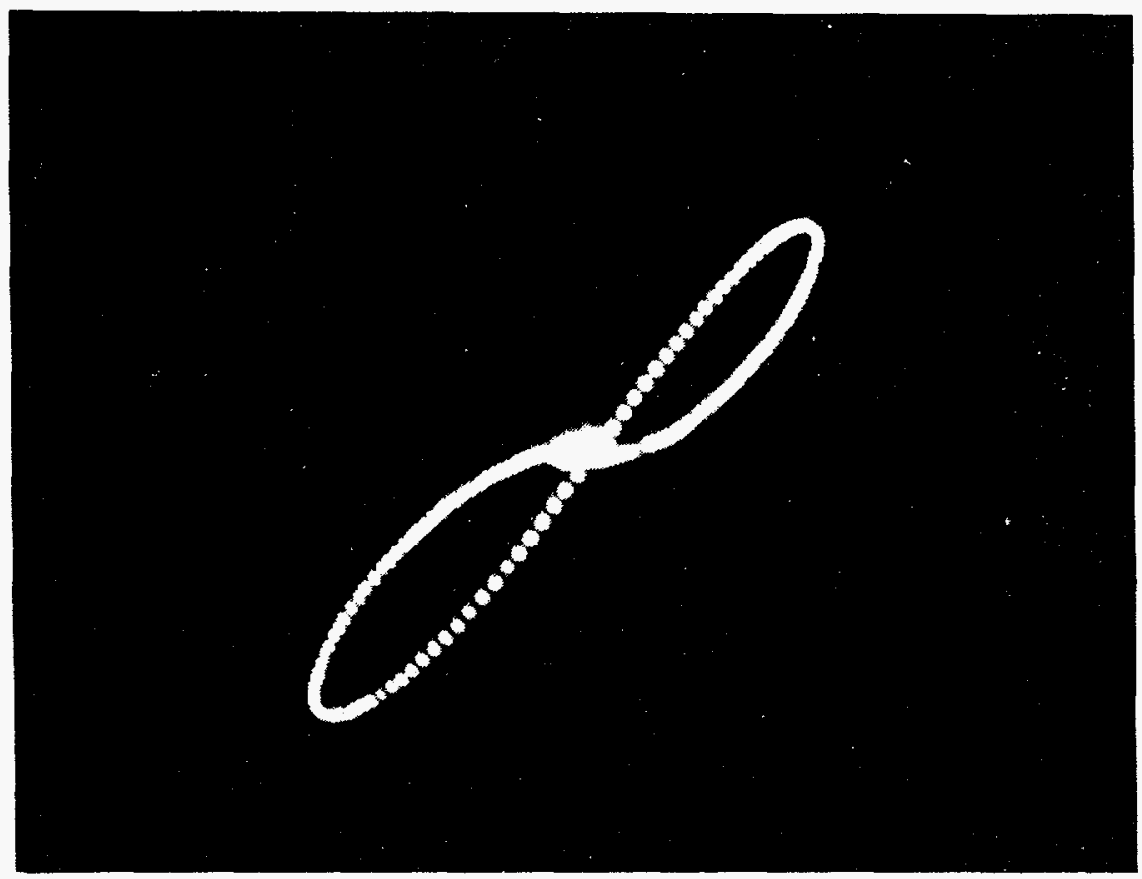

Figure 85. Typical eddy-current signal displayed on a cathode ray tube (Courtesy of M. Klatt, Zetec, Inc.).

prime importance because it permits characterization of certain defects as well as a reliable estimation of their depth.

Eddy-currents are not generated simultaneously throughout the test part, but require time to penetrate the material. This difference in time or phase lag is a key analysis factor for determining crack location (inside versus outside) and depth. It is generally expressed as:

$$
\theta=\mathrm{X} / \boldsymbol{\delta}
$$

where $\theta$ is the phase lag angle in radians and $\mathrm{X}$ is the depth within the material. At the depth of $\mathrm{X}=\boldsymbol{\delta}$, the resulting phase lag is 57 degrees.

For thin-walled tubing, a frequency is often selected to provide a sufficient eddy-current density at both the inside and outside surface for crack detection, but another frequency is selected to provide an adequate phase separation to resolve near surface and far surface indications. The frequencies are determined by considering the material thickness and calculating the penetration of eddy-currents within the material. As an example, a high frequency can be used to selectively examine near surface regions. Conversely, low frequencies can be used if additional penetration is needed. However, when low frequencies are used, sensitivity is sacrificed and it may not be possible to detect small flaws.

\subsubsection{Basic Probes}

The heart of an eddy-current inspection system is the probe. Selection of a coil configuration is crucial for a reliable inspection. For crack detection, the inspection coil must be configured such that eddy-currents are generated normal to the crack orientation to maximize the response from the crack. For steam generator tube 
inspection, there are two basic probe types. Bobbin coils and surface or pancake coils. The bobbin coil is generally used, but its major limitation is that it cannot reliably detect circumferential cracks. Conversely, the pancake coil is capable of detecting cracks at all orientations, including circumferential cracks. There are several variations of the surface coil design that will be discussed later in the section.

Bobbin Coils. A typical bobbin coil is shown in Figure 86 (ASM 1989). Bobbin coils have long been a mainstay for steam generator inspection because of their mechanical reliability and rapid inspection rates. The coil's axis is parallel to the tube axis and the current flows in a circumferen- tial direction. The resulting primary magnetic field is oriented along the tube axis, and the flow of eddy-currents induced in the tube is along the circumferential direction, parallel to the current in the test coil. Therefore, bobbin coils are sensitive to the presence of axial cracks, which impede the flow of the eddy-currents, but are much less sensitive to circumferential cracks. However, a bobbin coil may not detect an axial crack if it is present in the region of major geometry change such as roll transition region. Bobbin coils are also sensitive to volumetric discontinuities such as wastage, pitting, and fretting. An advantage of bobbin coils is that a 360-degree segment of the tube is examined at the same time. However, resolution and discon-

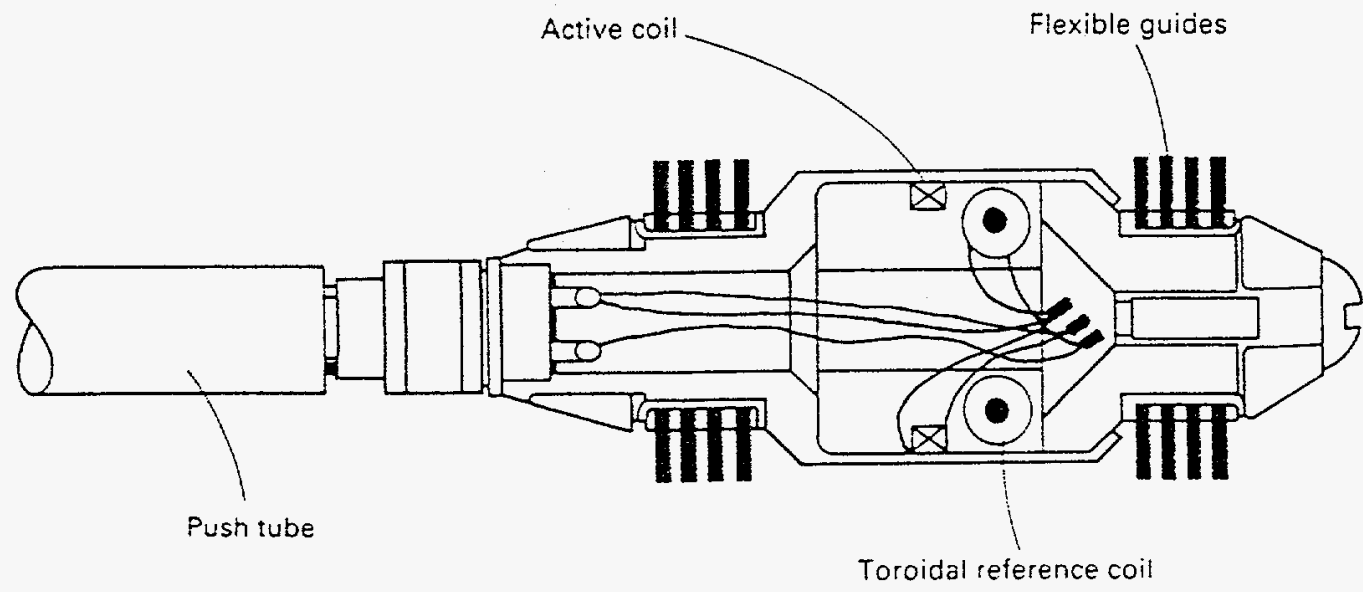

Figure 86. Eddy-current bobbin probe with flexible wafter guides, used for inspection of steam generator tubesheet rolled joints (ASM 1989). Copyright ASM International, reprinted with permission. 
tinuity characterization (type, number, sizing, etc) are limited because of this design (Clark 1993).

The eddy-current probes are operated at frequencies that offer the highest signal-to-noise ratio. This ratio is determined by operating the eddycurrent instrument over a wide frequency range and monitoring the probe signal responses from samples containing known flaws and the noise responses from extraneous sources such as support plates, dents, and copper deposits. In one case, the probes were operated over a 100 to $800 \mathrm{kHz}$ frequency range. The results showed that signal-to-noise ratio from large volume flaws peaked at $300 \mathrm{kHz}$ and the signal-to-noise ratio from small-volume flaws peaked at $200 \mathrm{kHz}$. The results also showed that at any frequency between 100 to $800 \mathrm{kHz}$, a dent signal is greater than a flaw signal, which was evident from the flaw signal-to-noise (dent signal) ratio of less than 1.0 (Krzywosz 1990).

Laboratory test results show that an optimal signal response is obtained when the operating frequency of the probe is near its resonance. For conventional bobbin coils, the resonant frequency is about $300 \mathrm{kHz}$, and the optimal operating frequency is in the range of $200-300 \mathrm{kHz}$. Large volume flaws, including volumetric defects (wastage, wear, etc) and axial flaws, result in a maximum signal-to-noise ratio at $300 \mathrm{kHz}$, and circumferential and smaller volume flaws of less than throughwall penetration result in a maximum signal-to-noise ratio at $200 \mathrm{kHz}$ (Krzywosz 1990).

In addition, bobbin coil sensitivity to three different defects was measured: varying depths of 0.25 -in. long axial notches; varying depths of 90-degree circumferential notches, and varying lengths of throughwall circumferential fatigue cracks. The signal amplitude was used to evaluate the sensitivity. The results show that bobbin coils, when operated at $300 \mathrm{kHz}$ frequency, are most sensitive to throughwall axial flaws and least sensitive to fatigue cracks and circumferential notches (Krzywosz 1990).

Absolute and Differential Probes. The eddycurrent bobbin probes normally use two coils which are located in adjacent arms of a bridge as shown in Figure 87a (Cecco and Van Drunen 1985). If one of the coils is a test coil and another one a reference coil, as shown in Figure $87 \mathrm{~b}$, it is an absolute probe. If both coils sense the material under test equally, as shown in Figure $87 \mathrm{c}$, it is a differential probe. Absolute probes respond to all variables that affect eddycurrent flow, such as conductivity, magnetic permeability, and defects. In contrast, differential probes compare adjacent material sections. When the test conditions for one of the coils is altered, an unbalance between the two coils occurs and this unbalance is used as an indication of the material condition. The absolute probe responds to both sudden and gradual changes in properties and dimensions and responds along the entire length of the defect. In contrast, the differential probe is not sensitive to gradual changes in properties or dimension and can only detect the ends of long defects and may miss a long gradual defect entirely. The absolute probe is prone to drift due to temperature changes, whereas the differential probe is not. The absolute probe is more sensitive to probe wobble than the differential probe. Both absolute and differential probes are used for inspection of steam generator tubes.

Figure 88 shows some typical common impedance plane eddy-current signals encountered during inspection of a calibration tube with an internal bobbin coil probe (Cecco and Van Drunen 1985). The test frequency is $250 \mathrm{kHz}$. Figure 88a shows the results from using an absolute probe and Figure $88 \mathrm{~b}$ shows the results from using a differential probe. In this case, the signal from the defect has a phase angle between 0 and 90 degrees, whereas signals from support plates or outside surface deposits have a phase angle greater than 90 degrees. The defects on 


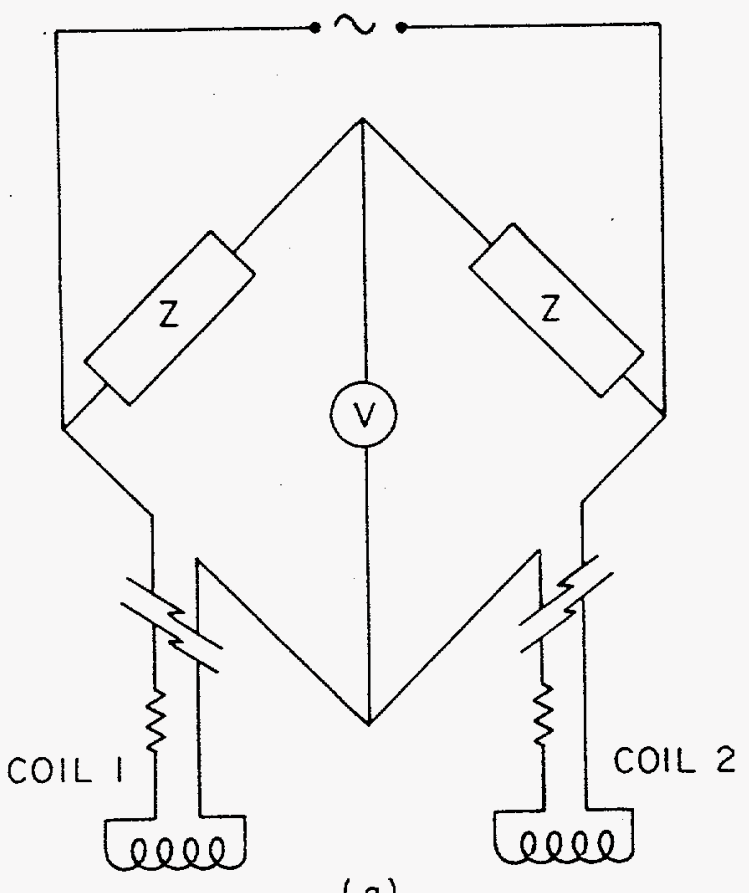

(a)

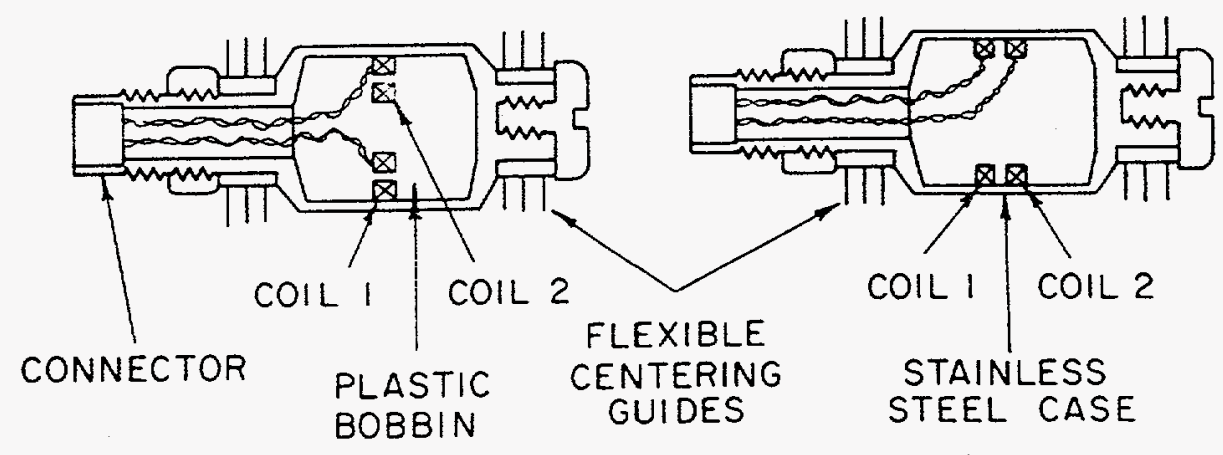

(b)

(c)

Figure 87. Schematic showing (a) the location of the probe coils in an ac bridge circuit, (b) an absolute probe configuration, and (c) a differential probe configuration (Cecco and Van Drunen 1985). Copyright Academic Press; reprinted with permission. 


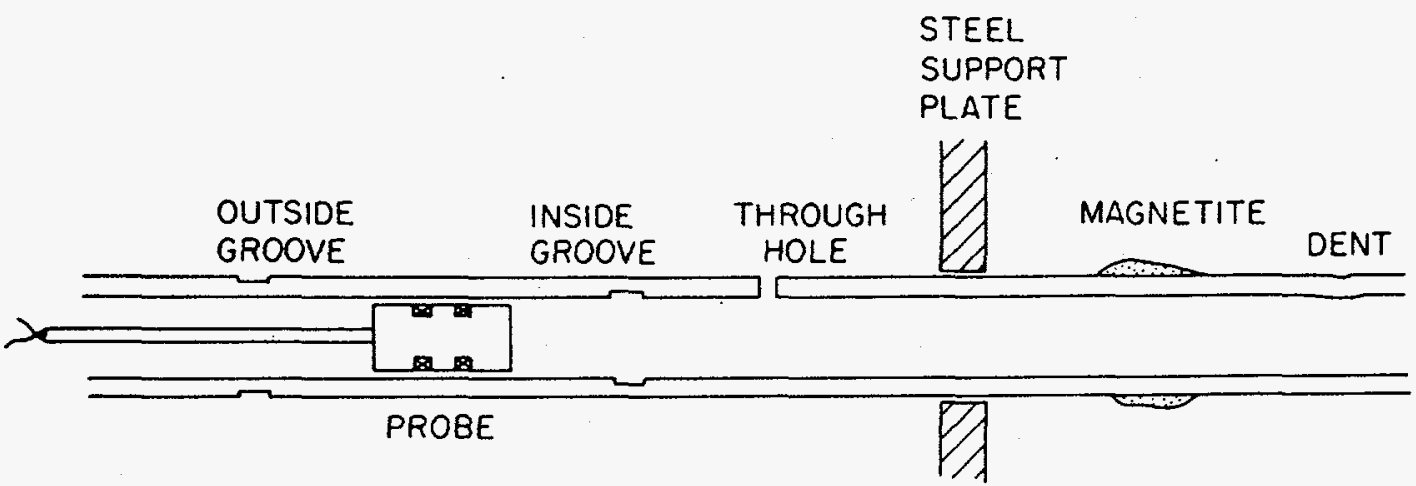

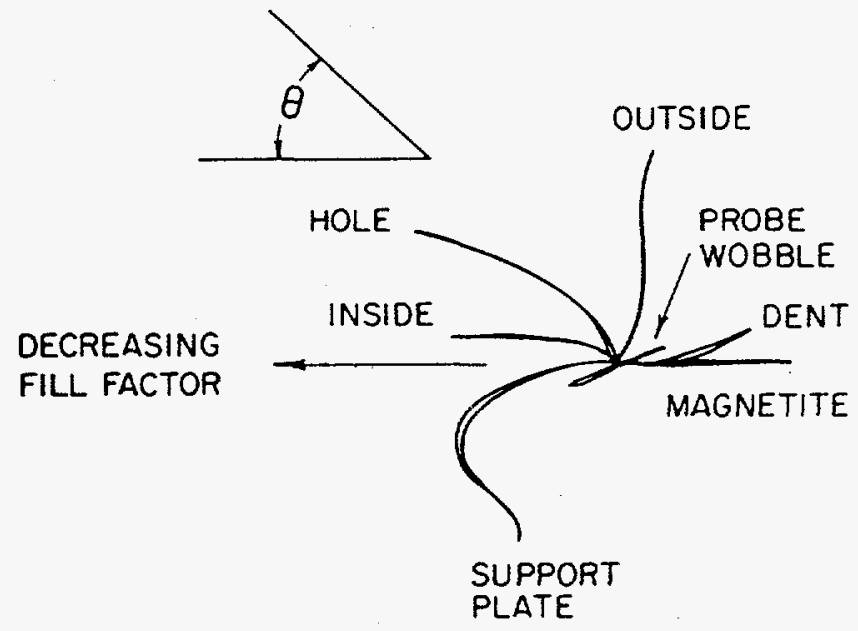

(a)

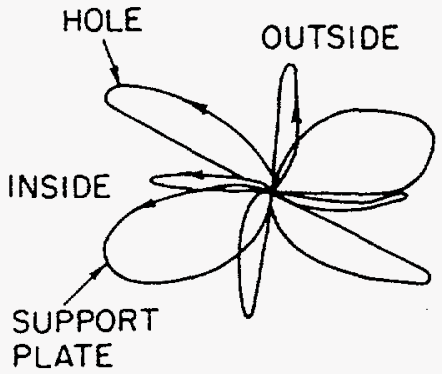

(b)

Figure 88. Eddy-current signals from a typical calibration tube using (a) an absolute probe and (b) a differential probe (Cecco and Van Drunen 1985). The tube material is Alloy 600, 12.7mm outside diameter by $1.1 \mathrm{~mm}$ wall thickness, $250 \mathrm{kHz}$ test frequency. Copyright Academic Press; reprinted with permission.

the inside surface have a smaller phase angle, whereas defects on the outside surface have a phase angle near 90 degrees; the signals from through-wall defects fall between these two signals. As mentioned above, the phase angle for a given defect is not a fixed value and it can be increased or decreased by increasing or decreasing the test frequency. The phase angle of the signal provides an approximate indication of the depth of a defect.
Even though a bobbin coil has an inherent capability for an accurate measurement of the length of an axial crack, existing probes do not normally provide sufficient accuracy for tubing integrity considerations. Therefore, a repeat inspection with a rotating pancake coil, which is discussed later, is normally performed to further characterize the axial extent of any defect (Clark 1993). 
Pancake Coils. Another basic probe type used for inspection of steam generator tubes is the surface or pancake coil as shown in Figure 89, which is designed to detect cracks at all orientations (Cecco and Van Drunen 1985). The pancake coil is a small-diameter coil, typically 2 $\mathrm{mm}(0.08 \mathrm{in}$.) or $2.9 \mathrm{~mm}$ (0.115 in.) in diameter, spring-loaded to ride on the inside surface of the tube and minimize lift-off effects. The axis of the coil is normal to the tube surface. The primary magnetic field induced by the pancake coil is perpendicular to the tube surface and the resulting eddy-currents flow in small circular patterns parallel to the tube surface and in the same direction as the current in the test coil. The flow of these eddy-currents is impeded by cracking at any orientation (axial, circumferential, or branched). Because the pancake coils cover a relatively small area, they are extremely valuable for detailed sizing and characterization. A 2-mm pancake coil with a high frequency (200 to 600 $\mathrm{kHz}$ ) usually exhibits good sensitivity to inside

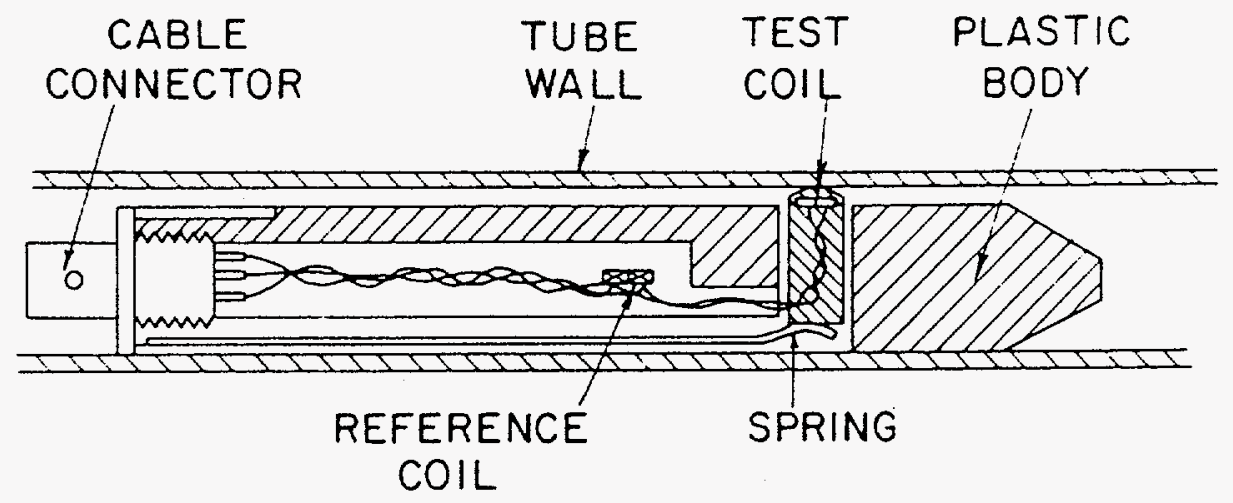

Figure 89. A cross section of an eddy-current probe showing how the spring loaded pancake coil is arranged in an absolute mode (Cecco and Van Drunen 1985). Copyright Academic Press; reprinted with permission. 
surface cracking (EPRI NDE Center 1987). But use of a low test frequency does not increase the eddy-current penetration of a 2-mm coil appreciably. So in addition to a low test frequency $(100$ to $400 \mathrm{kHz})$, a $2.9 \mathrm{~mm}-(0.115$ in.-) diameter coil is used for penetration to the outside surface. However, the sensitivity to small defects decreases because the ratio of the defect volume to the inspected volume becomes smaller as the diameter is increased.

The 2- and 2.9-mm pancake coils can only interrogate a small region of the tube because of their small size and, therefore, complete coverage is a time-intensive process. For this reason, pancake coil examinations are usually limited to critical regions of the tube (e.g., at the tubesheet and at supports plates) or used to evaluate indications detected by bobbin coils. Practical automated systems using pancake coils have been developed to scan the complete circumference of the critical regions of a tube. Two such automated systems, rotating pancake coil and array probe, are discussed in Section 8.2.

Hybrid Coils. Hybrid coils can combine the characteristics of either bobbin coils or surface coils and are known more commonly as reflection, driver/pick-up, through transmission, and primary/secondary probes. An example is shown in Figure 90 (Libby 1971). In general, hybrid coils operate in the transmit-receive mode where one coil induces eddy-currents into the test material, and the second coil senses the secondary field. In general, these types of probes are designed to meet specific application needs and have shown significant promise in steam generator tube examination. Probes using hybrid coils are further discussed in Section 8.2.3.

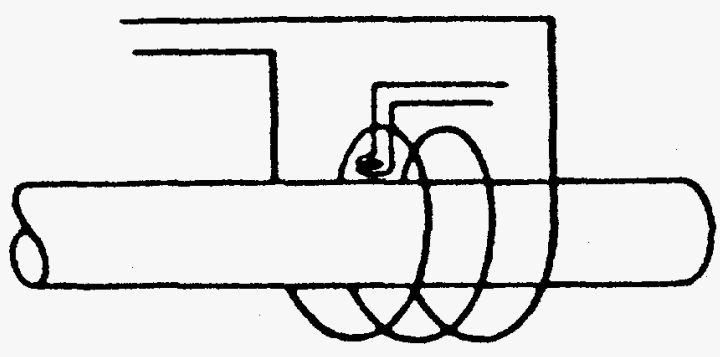

Figure 90. Typical differential hybrid coil arrangement (Libby 1971). Copyright 1971 John Wiley and Sons, Inc.; reprinted with permission. 


\subsubsection{Multifrequency/Multiparameter Eddy- current Methods}

Multifrequency/multiparameter eddy-current (MFEC/MPEC) methods employing bobbin coils are widely used for steam generator tube inspections. These methods provide more reliable detection and additional characterization information on the secondary side of the steam generator tubes in the presence of extraneous test variables such as the tubesheet or tube supports. The tubesheet and the tube supports produce large changes in an eddy-current signal (impedance response) that mask or modulate the changes produced by a defect. Denting of steam generator tubes, first reported in mid 1970s, also made reliable defect detection difficult and provided an impetus for the use of these new methods. The MFEC/MPEC methods isolate the changes produced by a defect (a wanted parameter) by suppressing the changes produced by other unwanted parameters such as support plates and denting.

Fortunately, the response from each of the wanted and unwanted parameters is frequency dependent and can be identified and compensated for. Separation of wanted and unwanted parameters is commonly accomplished by combining the eddy-current signal obtained using a flaw detection test frequency with those from one or more lower and higher frequencies. A lower test frequency can provide better sensitivity to support plate and magnetic deposits that have accumulated on the tube outside diameter. On the other hand, testing at a higher frequency provides increased sensitivity to variations on the inside diameter of the tube.

Analog or digital instrumentation can be used to combine signals from a number of frequencies, which should be at least equal to the total number of parameters. For example, using two different frequencies, the suppression of the support plate signal is carried out as follows. With analog instrumentation, the response from a carbon steel ring simulating a support plate is obtained using a lower frequency channel. This lowerfrequency response is rotated and scaled such that the resulting signal closely matches another response from the carbon steel ring obtained using a higher-frequency channel, which is generally used for flaw detection. Then, these two channels are combined in such a way that the unwanted signal from the simulated support plate is subtracted out. With digital instrumentation, the responses from the two channels can be matched and combined using analytical techniques on a computer to eliminate the unwanted support plate signal. One approach includes establishing simultaneous linear equations relating the parameters (independent variables) and instrument readings, which may be the magnitude and phase of the signal at each frequency. The equations are solved by a leastsquare method to determine the coefficients of the independent variables (Dodd and Deeds 1981).

Figure 91 shows an example of support plate suppression by using three different frequencies (Davis 1980, Davis 1981). Figure 91a shows a normal single frequency response from a $60 \%$ through-wall flaw at the outside surface away from the support plate. Figure $91 \mathrm{~b}$ shows the same response when the flaw is located under the edge of a support plate. Changes in the signal produced by the support plate mask the changes produced by the flaw and it is difficult to characterize the flaw. Figure 91c shows the information resulting from the use of three frequencies and the MFEC/MPEC method, which suppresses the changes produced by the support plate. The MFEC/MPEC methods are also used for characterization of dents, profiling the inside diameter of tubes that have been expanded in a non-standard manner with mechanical rollers, and detection of sludge and conductive metal deposits (Davis 1981). However, the MFEC/MPEC methods cannot detect a shallow flaw on the inside surface if a significant fill-factor resulting from probe wobble 

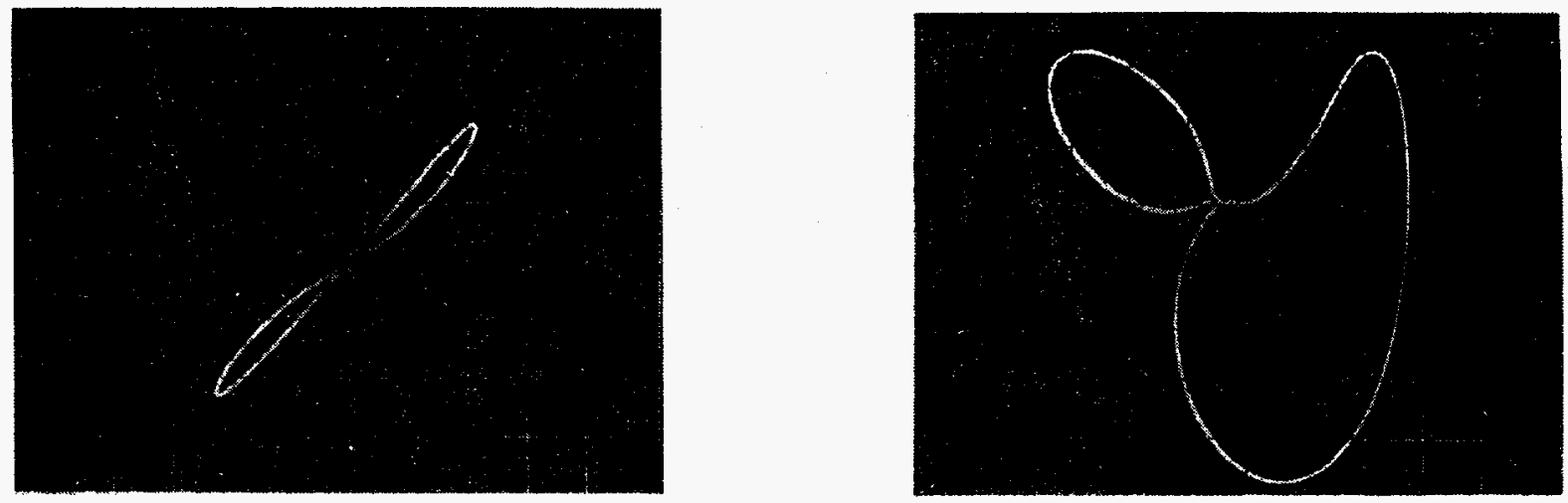

A

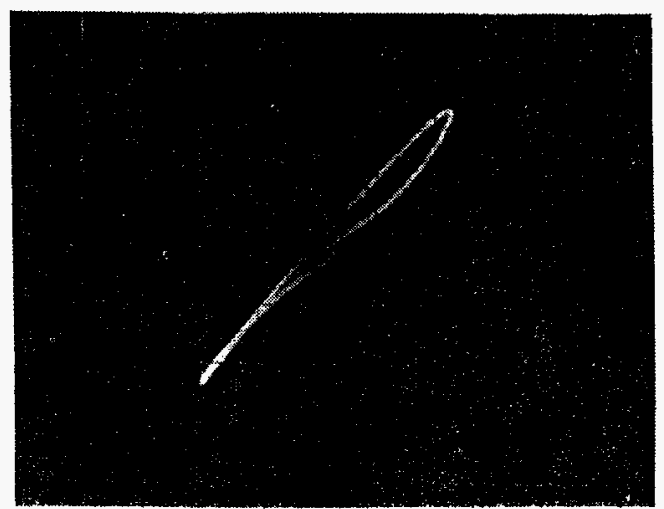

C

Figure 91. Example of support-plate suppression; (a) shows a normal single-frequency response from a $60 \%$ flaw, (b) shows the same response when the flaw is under a support plate, (c) shows the response of a three-frequency multi-parameter mix (Davis 1980). Copyright Electric Power Research Institute, Inc.; reprinted with permission. 
or inside surface irregularities is present. This limitation arises because the signal from a shallow flaw is indistinguishable from that of the fill factor for all normal test frequencies (Cecco and van Drunen 1985).

Most eddy-current equipment manufacturers offer bobbin coils capable of performing inspections using MFEC/MPEC methods. The bobbin coils may be either absolute or differential, both of which are generally used. Multi-frequency scanning is accomplished either continuously or sequentially. With the continuous method, the desired test frequencies are superimposed in the driving current and impressed on the coil simultaneously. The resulting output from the coil is then separated using bandpass filters to extract the response from each of the individual inspection frequencies. With the sequential method, individual test frequencies are induced through multiplexing, which involves rapidly switching between frequencies (ASM 1989).

In summary, the main reason for using the MFEC/MPEC methods is to perform a rapid bobbin coil inspection of a tube with more reliable detection and additional characterization information, by suppressing the unwanted parameters. Scanning time can be minimized and wanted and unwanted parameters can be discriminated without the need for multiple scans. Moreover, rotating pancake coils, which are discussed next, are generally used for detailed characterization of damage, including sizing of steam generator tube defects.

\subsection{Advanced Eddy-Current Techniques}

The basic eddy-current probes were discussed in the previous section. Due to increasing demands for reliable steam generator inspection methods, a variety of new probes have been developed to address a range of flaw types and orientations, and to overcome interfering conditions (i.e., tubesheets, tube denting, sleeving, etc.). A number of the more prevalent techniques are presented here.

\subsubsection{Rotating Pancake Coil}

The rotating pancake coil probe is an automated probe for eddy-current inspection. Inspection of a larger region of a steam generator tube can be done in a shorter time than required by the manual pancake coil discussed in Section 8.1.2. During the inspection, the probe is rotated by a motor while it is pulled through the tube. The result is a helical scan pattern as shown in Figure 92. The original rotating pancake coil consisted of three coils: a $2 \mathrm{~mm}-(0.080$ in.-) diameter, shielded pancake coil and two directional coils, all of which were spring-loaded to ride on the inside surface of the tube as shown in Figure 93. Industry considers that the pancake coil is the primary inspection coil whereas the directional coils are supplementary coils that provide information on the orientation of the crack (Siegal and Klatt 1994). The directional coils are essentially pancake coils standing on edge such that the flow of the eddy-currents is either in the axial or circumferential direction only. Data from all three coils should be evaluated.

The 3-coil rotating pancake coil was originally developed for the detection and sizing of cracking initiating on the inside surface, but was not effective for detecting shallow outside diameter flaws because, as discussed earlier, the $2 \mathrm{~mm}$ diameter pancake coil did not produce a sufficient eddy-current density near the outside surface. A modified version was thus developed for outside diameter crack detection in the freespan regions. In this probe, a larger diameter coil [ $2.9 \mathrm{~mm}(0.115 \mathrm{in})$.$] without shielding is$ used to improve penetration to the outside surface. Inspection using this probe was performed at Palo Verde, Arkansas Nuclear One, and Prairie Island during 1993-94. Field experience shows that this coil has better sensitivity to shallow outside diameter flaws, but 


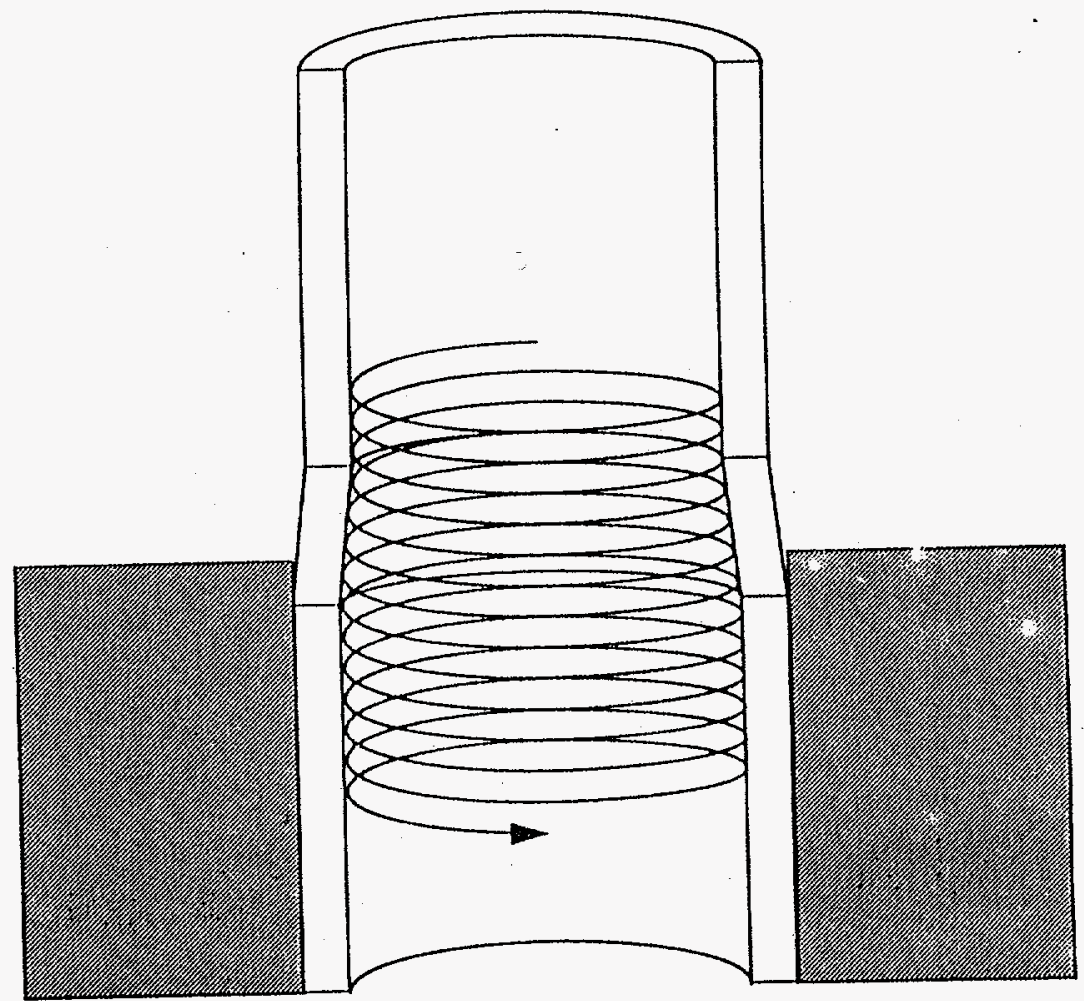

Figure 92. Illustration of a motorized rotating pancake coil helical scan (Courtesy of M. Klatt, Zetec, Inc.).

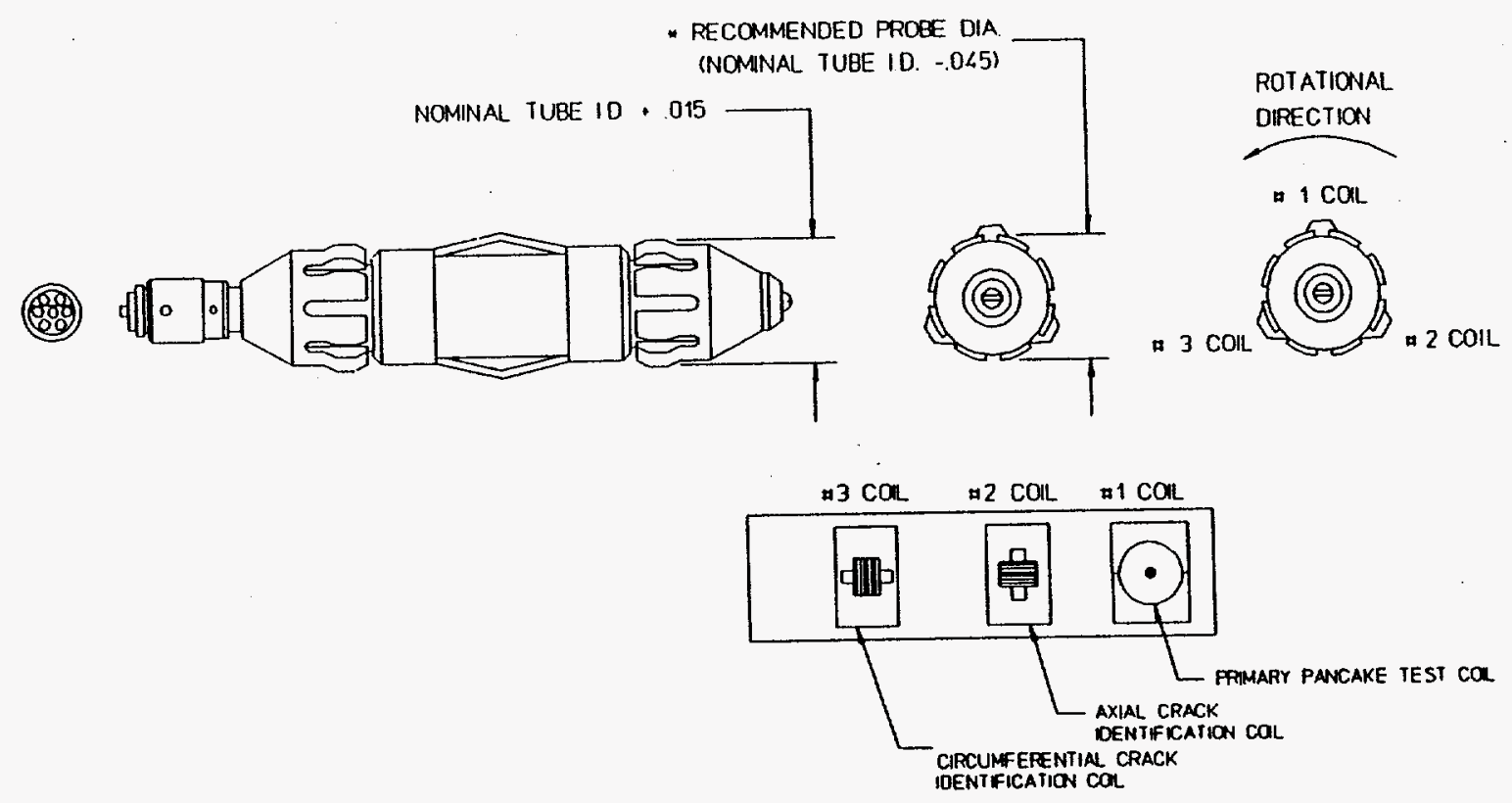

Figure 93. Schematic of a shielded 3-coil motorized rotating pancake coil probe (Siegal and Klatt 1994). 
some resolution may be sacrificed for inside diameter cracking caused by PWSCC. This reduced resolution is due to the larger coil size, lack of shielding, and greater concentration of eddycurrents at the outside surface (Siegal and Klatt 1994).

EdF has developed a flexible rotating pancake coil probe for inspection of the bent portions of the U-tubes, mainly the small radius bends in Rows 1 and 2. The probe is used in absolute mode. This probe is more reliable than a bobbin coil probe and provides better detection and characterization of defects such as cracks. EdF has also designed a 10-meter rotating pancake coil probe for inspection of the straight portion of the tubing. The performance of this probe with regard to detection and characterization of defects is identical to that for the rotating pancake coil probe.

Complete coverage of the steam generator tube with a rotating pancake coil probe can be a time consuming process. Therefore, the rotating pan- cake coil is generally used to screen indications identified with a bobbin coil, or to scan only critical regions of a tube.

\subsubsection{Array Probes}

An alternative method of deploying pancake coils is to use an array of pancake coils. Most of the commercially available probes are named by the coil arrangement, i.e., $8 \times 1$ or $8 \times 2$. The $8 \times 1$ coil arrangement has eight equally spaced, surface riding coils arranged around the circumference. This arrangement offer the advantage of scanning the full tube circumference with a scan speed similar to that of a bobbin coil. However, because of the equal spacing of the coils, coverage gaps are present between the coils, and the $8 \times 1$ probe is susceptible to missing indications (especially axial indications). A seemingly obvious solution to this problem is to use the $8 \times 2$ array probe, in which one row of coils is off-set by 22.5 degrees from the other row and the two rows are located at different axial positions, as shown in Figure 94.

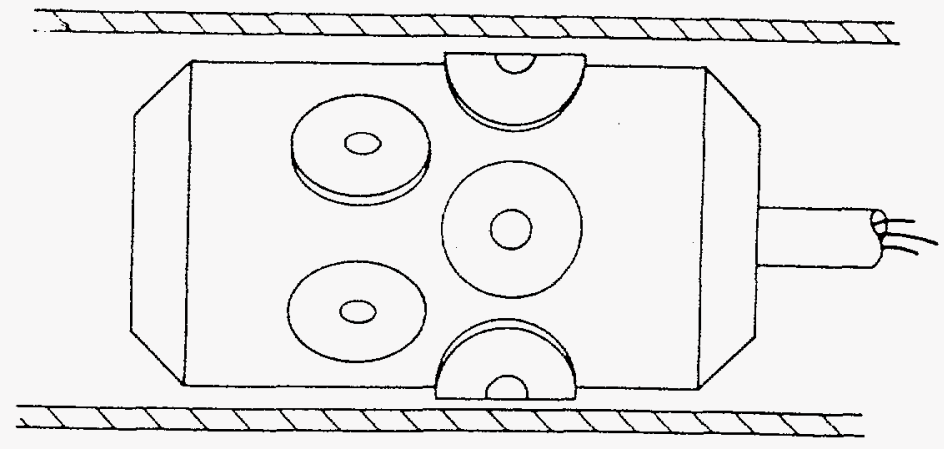

Figure 94. A multiple coil probe for detecting circumferential cracks in steam generator tubing (Cecco and Van Drunen 1985). The two rows of coils are staggered. Copyright Academic Press; reprinted with permission. 
Theoretically, complete coverage can be obtained this way. However, each additional coil adds to the complexity of the probe and the potential for failure, and more complex instrumentation is required to operate the coils simultaneously. In addition, the data from each coil must be analyzed.

Array probes have a higher sensitivity to intergranular attack and circumferential cracking and a reduced sensitivity to tube denting, as compared to bobbin coil probes. The commercially available array coils were redesigned to operate at a higher resonant frequency for improved inspection of the inside surface of the tube, and reduced sensitivity to the conditions at the outside surface such as deposits (Lareau and Sapia 1987). An array probe with a set of eight contactless pancake coils, spaced 45 degrees apart, has also been designed to measure the inner profile of a tube. Each coil measures the distance between the inner surface of the tube and outer surface of the probe. This probe records a complete inner tube profile with a diameter accuracy of $\pm 0.02 \mathrm{~mm}$. It can detect a missing roll in the expanded area of the tube. This probe can also be used for accurate sizing of dents (Dobbeni 1991).

Array probes are susceptible to lift-off due to probe wobble. Lift-off problems can be minimized by spring-loading each coil, but this creates a problem with coil wear and adds to the complexity of the probe. A potential improvement in this area is the balloon probe being developed at Westinghouse (Clark 1993). In this probe, the coils are imbedded in a plastic housing and inflated with water or air pressure to maintain constant contact.

In one test of the relative sensitivity of bobbin coils, rotating pancake coils, and array coils, it was found that array probes offer higher sensitivity, that is, produced greater signal amplitudes from several different discontinuities. However, among all the probes tested, a single rotating pancake coil is preferable for flaw detection due to its superior signal-to-noise ratio (Krzywosz 1990).

\subsubsection{Transmit/Receive Probes}

Transmit/receive probes are hybrid probes that use one coil (transmit coil) to induce a primary magnetic field and the eddy-currents and a second coil or coils (receive coils) to sense the secondary magnetic field produced by the eddycurrents. Typically, there are two receive coils for each transmit coil. Transmit/receive probes can be absolute or differential and can be configured in a variety of ways to meet the requirements of the inspection application (i.e., through transmission when the probes are on opposite sides of the test material or reflection when the probes are on the same side). Thus, transmit/receive probes can be configured to detect circumferential and/or axially oriented flaws and can be used to provide full-length coverage of the tube.

Transmit/receive probes overcome some of the attenuation problems of pancake coils because the field extends further into the material than that of standard impedance pancake coils. Therefore, transmit/receive probes are sensitive to both outside and inside surface cracking.

One type of transmit/receive probe, the Cecco-3 probe, has been developed at Chalk River Nuclear Laboratory specifically for detecting circumferential cracking in steam generator tubes (Malinowski 1995). This probe cannot detect axial cracking. The Cecco-3 probe consists of an array of pancake coils with four sets of alternating transmit and receive coils arranged in two groups along the probe axis, configured in a differential mode and operating at four multiplexed frequencies (Obrutsky et al. 1994).

Obrutsky et al. $(1994,1996)$ state that the Cecco3 probe is more sensitive to circumferential cracks on the tube outside surface, generates 
lower lift-off noise, and has a higher signal-tonoise ratio than the RPC probes. The Cecco-3 probe has no moving parts, making it considerably more durable than the spring loaded rotating pancake coil probes. And, the Cecco-3 probe permits single-pass inspections which are as fast as the bobbin coil probe inspections.

Obrutsky et al. (1994) report that a comparison between Cecco-3 inspection results and destructive examination results indicates that the Cecco-3 probe can reliably detect circumferential ODSCC as shallow as $50 \%$ of the wall thickness. The sizing accuracy is $15 \%$ of the wall thickness for a crack deeper than $50 \%$ throughwall. Field results show that the $\mathrm{Cecco-3}$ probe inspection results are as good or better than the industrystandard rotating pancake coil.

A Cecco-3 probe with eight transmit/receive units has also been developed to further improve the sensitivity to circumferential ODSCC shallower than 50\% deep (Obrutsky et al. 1994 and 1996). This probe is based on the design of the four transmit/receive unit probe, but is converted into an eight transmit/receive unit probe by exciting every other transmit coil at different multiplexed time segments and reading the four received voltages in both time segments. This allows each set of four receive coils to detect a signal from one transmit coil at a time. As a result, the probe achieves higher resolution for circumferential defects, that is, it can detect a shorter circumferential defect at the outside surface. Obrutsky et al. (1996) report that this probe can detect and size a circumferential ODSCC as shallow as $40 \%$ of the wall thickness, and, in general, the sizing accuracy is $\pm 15 \%$ of the wall thickness for cracks deeper than about $50 \%$ of the wall thickness.

Another transmit/receive probe has been developed to improve sensitivity to axial cracks without losing the ability to detect circumferential cracks. This probe, called the Cecco- 5 probe, is configured with coils positioned at an angle (45 degrees) such that it is sensitive to both axial and circumferential cracks. Although some sensitivity to circumferential cracks is lost due to coil configuration, the probe is still effective for all crack orientations. Because of it's versatility, it appears that industry is moving towards the use of the Cecco- 5 probe over the Cecco- 3 probe (Obrutsky et al. 1996). Malinowski (1995) reports that the Cecco-5 probe is qualified for detection of axial and circumferential indications in undented tubes, expansion-transition regions, and dented tube-support plate intersections.

\subsubsection{Sleeve Inspection}

The types of sleeves installed in PWR steam generator tubes and discussed in this report are kinetically welded, standard welded, laser welded, and hybrid expansion joints. A majority of the sleeves installed before 1995 have hybrid expansion joints, however, most of the new sleeves installed in the last few years have laser welded joints. The Figure 95 shows a typical sleeved steam generator tube with hybrid expansion joints (Westinghouse 1994). The lower and upper ends of the sleeve are hydraulically expanded and the middle portion of the expanded region is further expanded with hard-rolling (mechanical rolling), which makes it a leak-limiting joint. Figure 96 illustrates the details of the upper joint between the sleeve and parent tube (Westinghouse 1994). The parent tube at the elevation of the upper hard-roll transition and above is part of the primary pressure boundary. Cracking, especially circumferential cracking, in the upper joint region has raised concerns about the structural integrity and leak tightness of sleeved tubes. Industry tests of the integrity of the upper joint region of a sleeved tube indicate that a 360 degree throughwall circumferential crack in the parent tube at the upper end of the lower hardroll transition or at a higher elevation within the joint degrades the axial strength of the joint to less than the requirements of $R G_{1} 1.121$ and significantly reduces the leak resistance (Westing- 

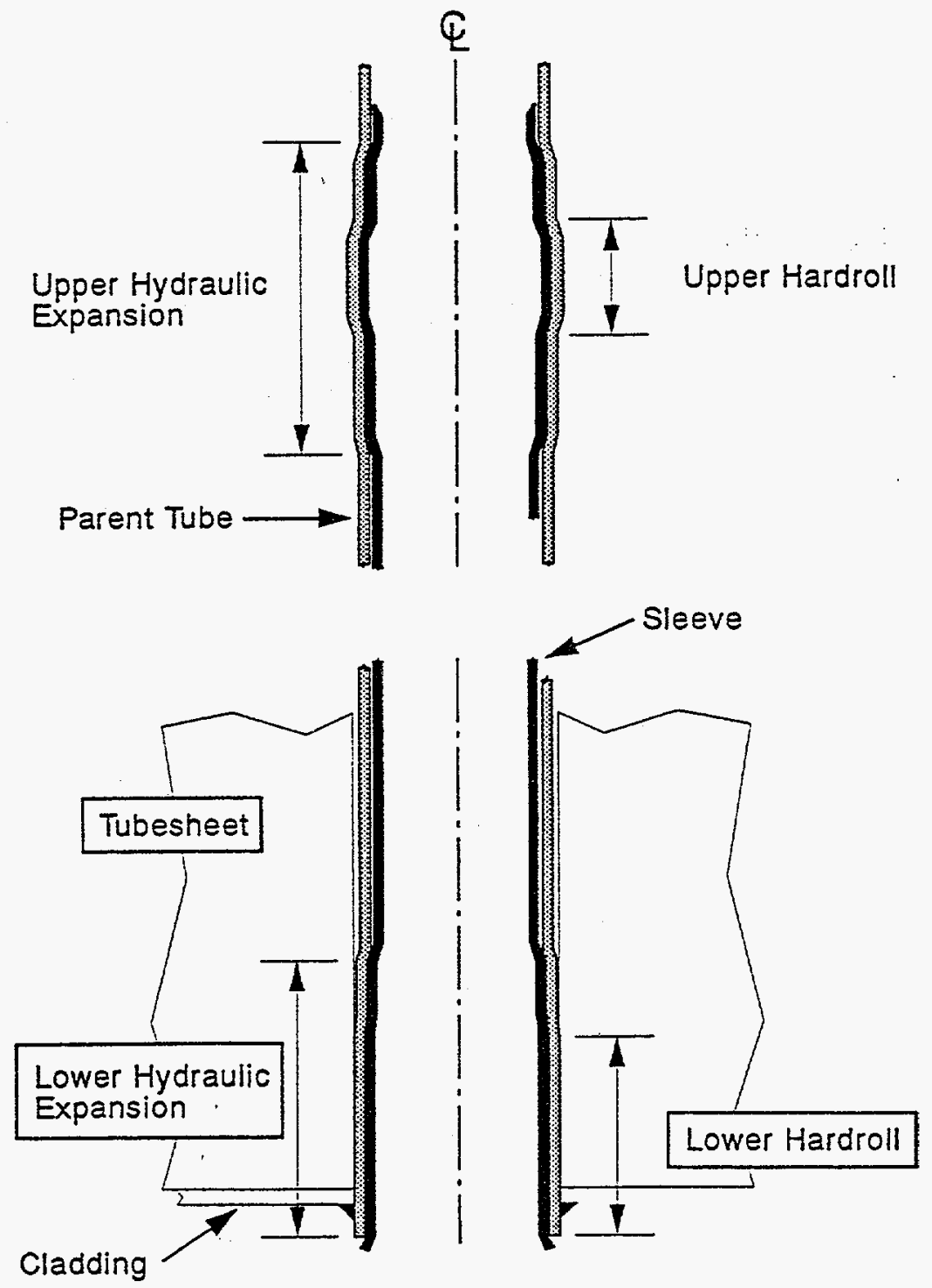

Figure 95. Typical hybrid-expansion-joint sleeve installation (Westinghouse 1994). Copyright Westinghouse Electric Corporation; reprinted with permission. 


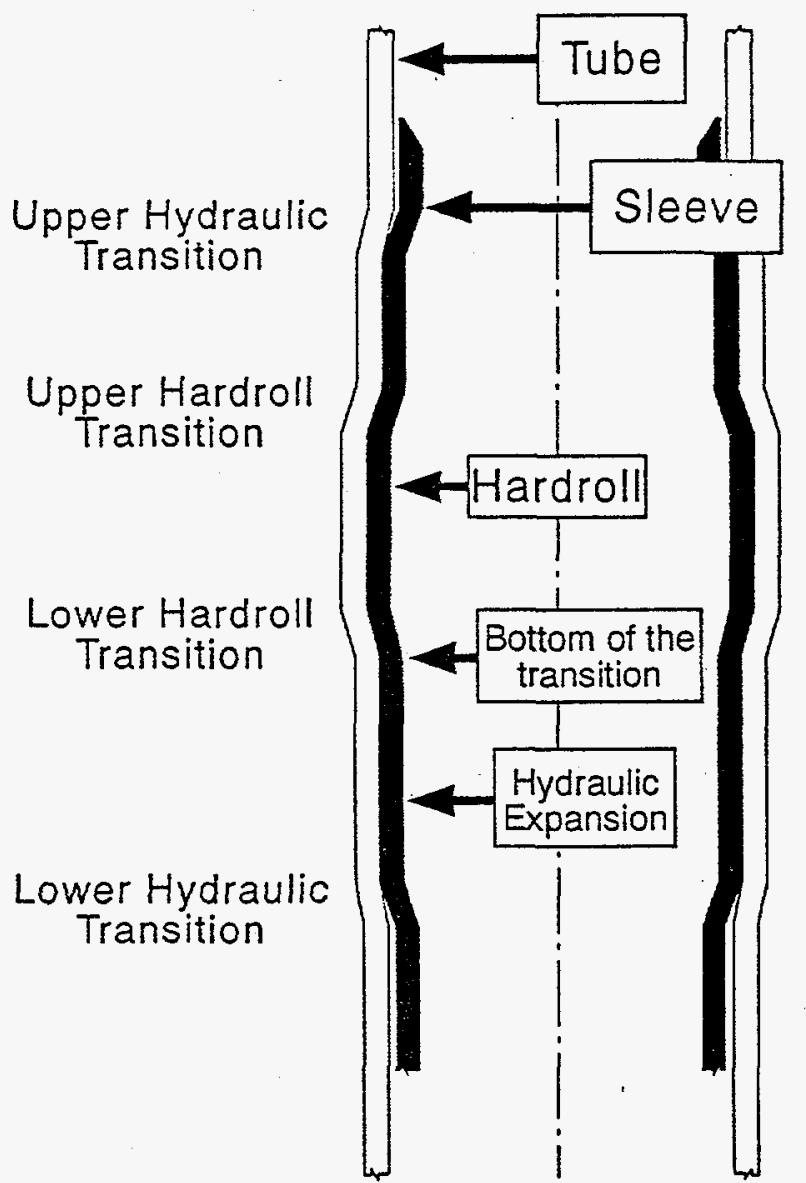

Figure 96. Configuration of hybrid-expansion-joint (Westinghouse 1994). Copyright Westinghouse Electric Corporation; reprinted with permission.

house 1994). However, a similar circumferential crack at a lower elevation within the joint does not significantly reduce the axial strength or the leak resistance. The industry tests also indicate that throughwall axial cracking in the parent tube in the hard-roll region does not degrade the axial strength of the joint; however, the leak resistance is degraded.

Cracking of about 300 parent tubes have been reported at eight plants including four U.S. plants, seven of these cracks were throughwall (Hermann 1995). In addition, four standard welded sleeves have collapsed at two U.S. plants. For example, a throughwall, 180-degree circumferential PWSCC crack has been reported in the parent tube at one non-U.S. plant. An axial and several circumferential indications, most likely ODSCC, were detected at the lower hard-roll transition in a U.S. plant. One circumferential indication was also detected at the upper hydraulic transition. Eddy-current inspection probes developed for inspection of these sleeves and the laser-welded sleeves are described here. 
Initially, Zetec, Inc. developed the crosswound differential bobbin coils shown in Figure 97 for sleeve inspections (Siegal and Klatt 1994). This probe was designed to minimize the effects of the roll-transition region of the sleeve, but the inspection results were difficult to interpret and could not detect flaws in the parent tube during mock-up sleeving trials. In addition, flaws were found in the expansion area at several operating plants that were not detectable with the crosswound bobbin coil. As a replacement for the cross-wound bobbin probe, the I-Coil probe was also developed by Zetec using surface riding absolute, directional coils on the rotating pancake coil inspection head (Figure 98) (Siegal and Klatt 1994). This probe, which was used successfully at Kewaunee and Prairie Island for inspection of Westinghouse and CE sleeves, provided better penetration for detection of outside diameter flaws and detected cracking in the expansion and sleeve weld zones.

An improvement to the I-Coil probe, the PlusPoint probe, was recently developed by Zetec which provides an improved signal-to-noise ratio and better crack detection capability (Zetec
1995). Zetec originally developed the Plus-Point probe to detect cracks in the vicinity of weld and heat affected zones. It is designed as a differential probe with the two coils crossing at a point so that both coils are affected simultaneously and similarly by lift-off due to weld geometry and changes in material properties in the heat affected zone. The orientation of the coils in the Plus-Point probe and typical responses from a weld scan are shown in Figure 99. This probe essentially combines the capabilities of the two rotating pancake coil directional coils and provides the ability of differentiating axial cracks from circumferential cracks. Due to the design, the Plus-Point probe is most sensitive to cracks oriented perpendicular to the coil windings and least sensitive to cracks oriented 45 degrees from the direction of the windings (Zetec 1988). Factors such as surface geometry that affect both coils are not detected. Therefore, it is also an effective examination method for cracking in the expansion-transition region. The Plus-Point probe detected shallow circumferential PWSCC cracking (average depth $26 \%$ ) at Maine Yankee (Stellfox 1995).

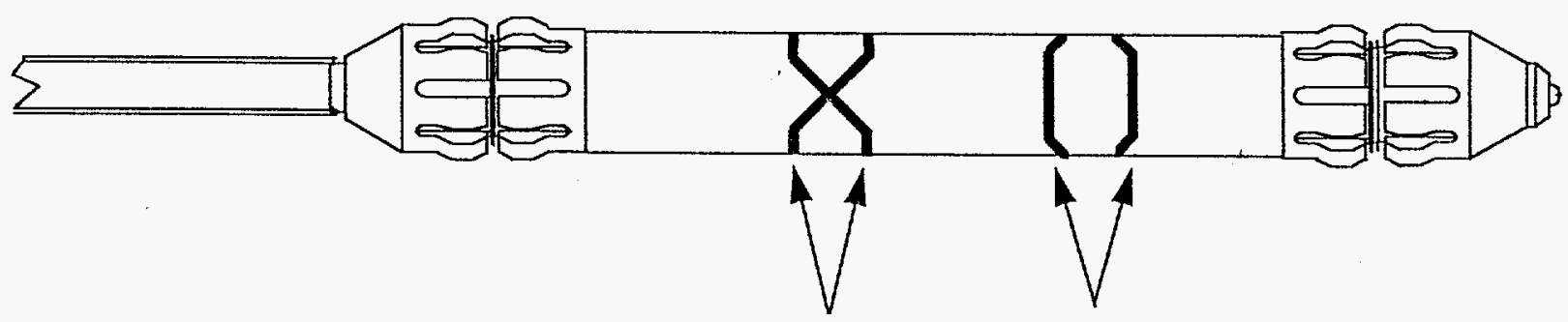

Cross Wound Differential Bobbin Coils

Figure 97. Schematic of a cross wound bobbin coil probe for sleeve inspections (Siegal and Klatt 1994). 


\section{Circumferential Coil}

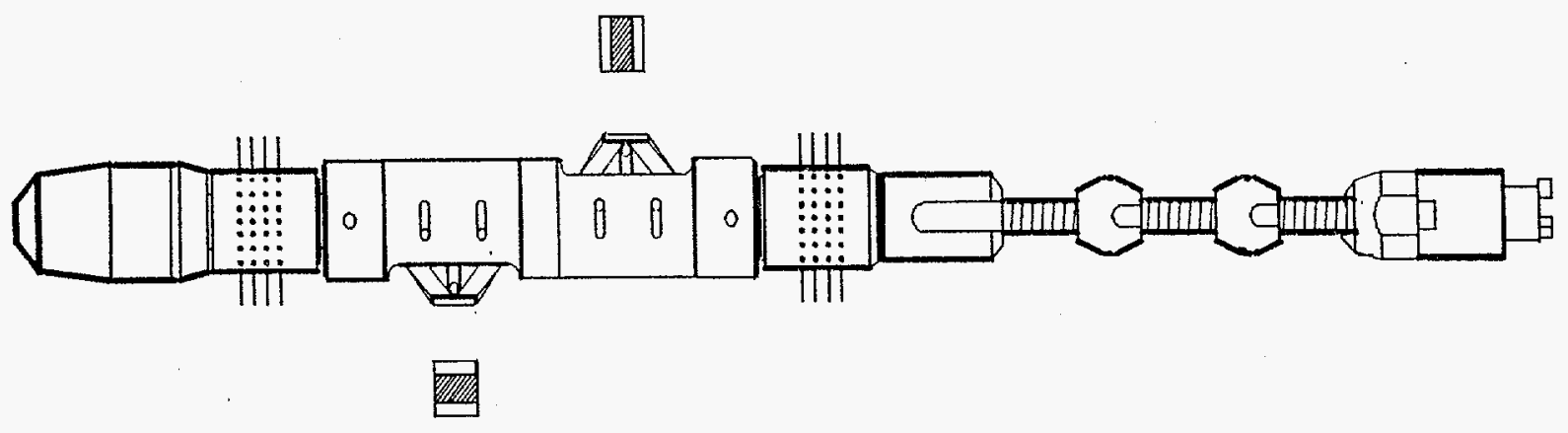

Axial Coil

Figure 98. Schematic of the "I" type motorized rotating pancake coil probe for sleeve inspections (Siegal and Klatt 1994).

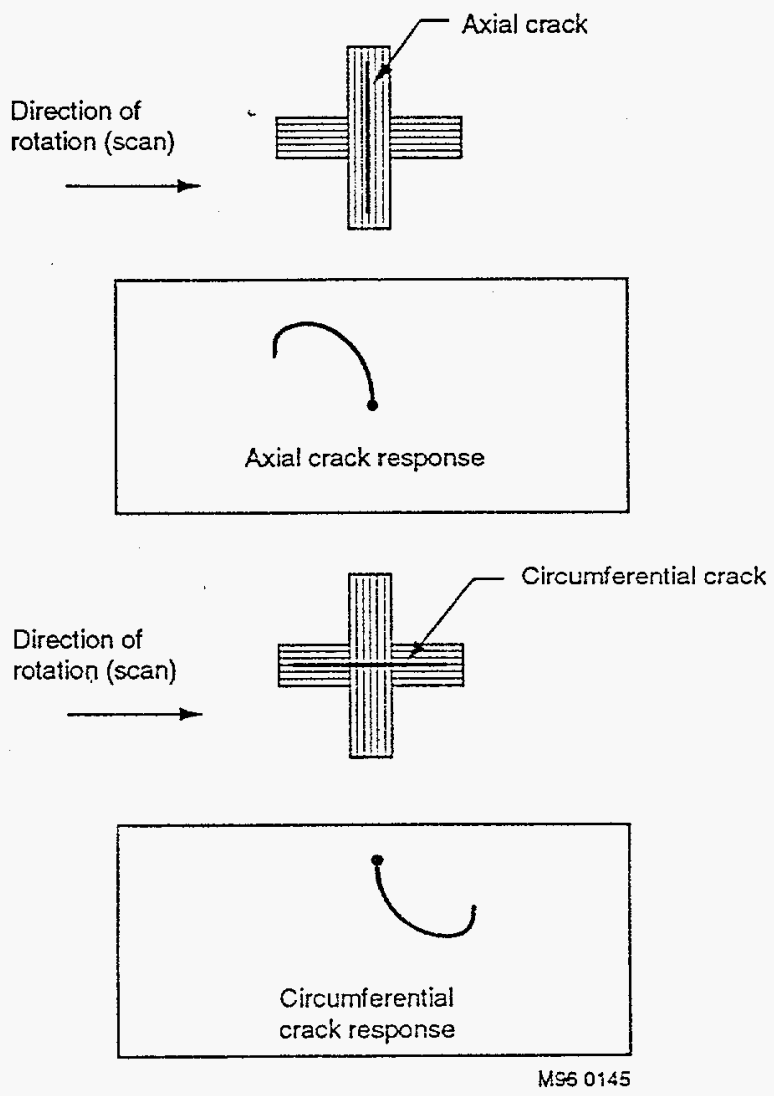

Figure 99. Orientation of the coils in the Zetec Plus-Point probe and typical responses from a weld scan with the probe configured in the standard differential mode (Zetec 1988). 
Recently, the Cecco-3 and Cecco-5 probes have been used to examine both laser-weld and hybridexpansion sleeve joints. A large scale inspection of both types of sleeve joints was conducted at Doel 4 using the Cecco-3 probe for circumferential crack detection. The hybridexpansion type sleeves at Cook 1 and Point Beach 2 were inspected with the Cecco-5 probe. The laser welded sleeves at Farley 2 were also inspected with the Cecco-5 probe. The Cecco series probes were also used at Salem 1 for examination of Wextex transition regions and support plate dent regions (Malinowski 1995).

\subsubsection{Inspection of Nickel Plated Tubing}

As mentioned previously, eddy-current test methods are sensitive to numerous parameters of the test material including the conductivity and permeability. For most tube testing, material permeability is not a concern (with the exception of ferromagnetic deposits on the outside surface and the effects of the tubesheet and support plates). However, in some cases, such as nickel plated tubes, spatial variations in the material permeability at the inside surface does need to be considered.

Nickel plating, as shown in Figure 100, was developed as an alternative to sleeving tubes with PWSCC (EPRI 1985b). More than 1,700 tubes have been repaired with nickel plating in five European PWRs. There are two problems associated with performing eddy-current inspections of ferromagnetic materials. First is that the magnetic field tends to concentrate at the surface in ferromagnetic metals such as iron and nickel. Thus, lower frequencies are required to provide adequate wall thickness penetration. Secondly, the differences in signal response due

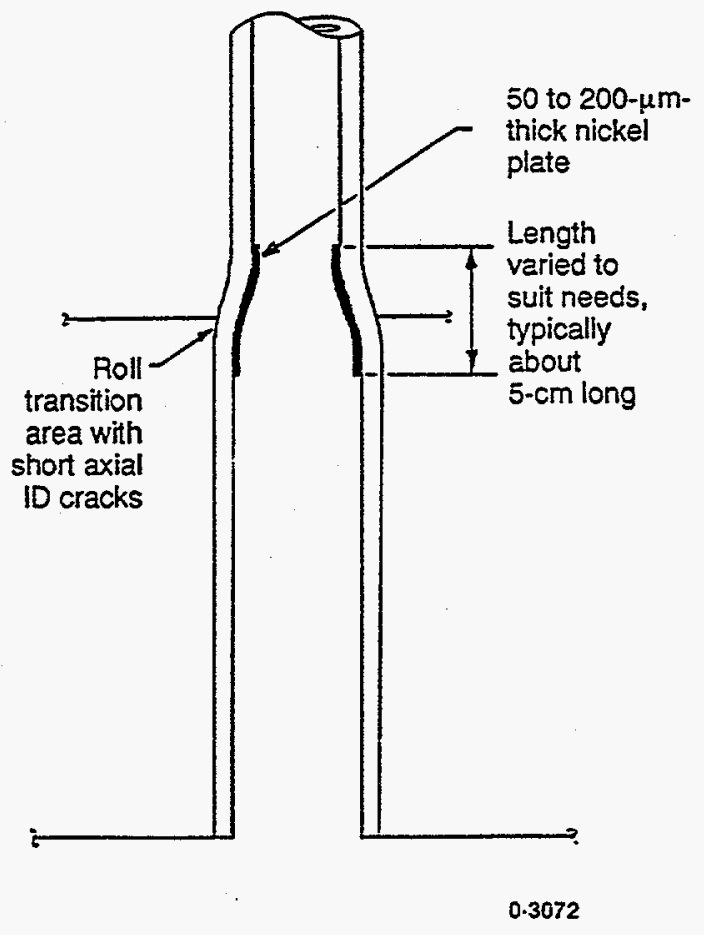

Figure 100. Nickel plating of a roll-transition region with PWSCC cracks (EPRI 1985b). Copyright 1987 Electric Power Research Institute; reprinted with permission. 
to large permeability variations near the inside surface can overwhelm the signal response from discontinuities and thereby mask relevant indications. Magnetic saturation eddy-current probes can be used to overcome the permeability effects of the nickel-plating. When a ferromagnetic material becomes saturated, the permeability becomes constant and the eddycurrent inspection can be performed effectively. There are some practical problems associated with saturating a steam generator tube due to tube size and other physical restraints. However, innovative approaches such as pulsed magnetic saturation can be used to overcome these problems (Dodd et al. 1988).

Ultrasonic techniques have also been developed for inspection of nickel plated tubes. One important parameter of the nickel plating process is related to the ultrasonic signal-to-noise ratio. In several tubes, the nickel plating produced some pits or roughness on the nickel surface. When these pits are numerous, the ultrasonic reflections from them become large and mask signals from potential cracks in the nickel and the tube material below the surface. These tubes have generally been repaired with a dedicated nickel plating process so as to suppress the pits. ${ }^{a}$ The use of ultrasonic techniques for steam generator tube inspection is discussed in Section 8.3 .

\subsubsection{Inspection of Mechanical Plugs}

Plugging was the only countermeasure available for PWR steam generator tubes with unacceptable flaws until the early 1980s. Denting and stress corrosion cracking have caused several hundreds of tubes plugged in some plants. Even now, plugging is often done for unacceptable degradation above the tubesheet region because the current sleeving techniques

a. V. N. Shah, personal communication with D. Dobbeni, Laborelec, Belgium, July 1995. are difficult or expensive to implement high up in a steam generator. More than 103,000 plugs are currently installed worldwide in PWR and CANDU plants. The plugs were typically made from bar stock of Alloy 600 material; however, Alloy 690 material is now being used.

A certain type of Alloy 600 plugs, mainly the mechanical plugs shown in Figure 101, are susceptible to PWSCC-type degradation and rupture, and need to be inspected because the upper portion of the plug constitutes part of the primary pressure boundary. In fact, circumferential PWSCC occurred at North Anna unit 1 nearly throughwall all around the circumference of a plug, as shown in Figure 101. The remaining ligament broke during a plant transient in February 1989 and allowed the top part of the plug to be propelled up the tube until it hit the U-bend, which it penetrated, causing a tube leak.

The mechanical plug has a very complicated inner geometry. There is an expander in the middle section and the inner diameter varies axially in the lower part of the plug. An extremely elaborate sensor mechanism is required to access the inner surface area above the expander. The probe scanning mechanism consists of vertical and rotating drive mechanisms which facilitate helical scanning. The probe uses a $100 \mathrm{kHz}$ frequency to monitor the sensor position in the plug, and 400 and $800 \mathrm{kHz}$ to detect the flaw. Comparison of laboratory inspection results and destructive analysis results indicate that the probe can detect $60 \%$ deep circumferential PWSCC above the expander (Fukui et al. 1992).

\subsection{Ultrasonic Testing}

Typical ultrasonic testing systems for steam generator tube examination consist of a rotating immersion probe head that scans in a helical pattern much like that of the rotating pancake coil. A water column is provided by sealing-off 


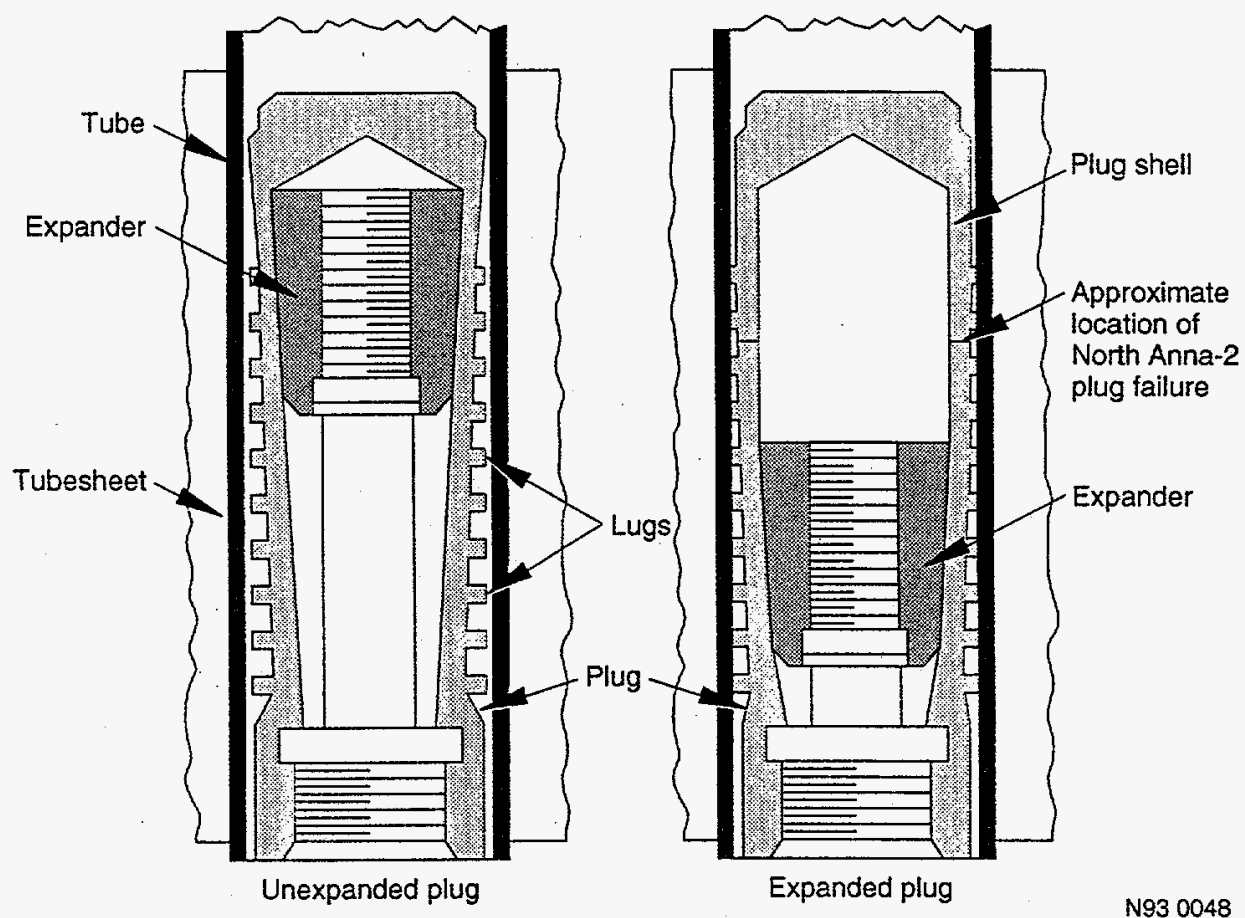

Figure 101. Sketches of unexpanded and expanded mechanical plugs (Westinghouse 1989); reprinted with permission.

the tube around the probe head and flooding the area. The transducer directs sound into the tube wall at the desired incident angle either directly by placing the transducer element normal to the probe axis, or by using a rotating mirror to reflect the sound energy in the desired direction as shown in Figure 102. In either case, the beam is oriented at the proper incident angle to produce the desired refracted angle in the material under test (typically 45-degree shear waves).

One of the first commercially available inspection systems (developed by NUCON) used the approach shown in Figure 102 to characterize fretting wear located at support plates (Dobbeni 1991). Destructive examination of circumfer- ential cracks in pulled tubes has shown that the rotating ultrasonic inspection system can detect defects deeper than $30 \%$ throughwall (Roussel 1994). Framatome has also developed a rotating ultrasonic testing system for the detection of shallow ODSCC, particularly in the roll transition zone at the tubesheet.

Initially the ultrasonic techniques were primarily based on a pulse-echo method. This method provides a reliable crack detection capability but does not accurately measure crack depths. The ultrasonic techniques have been recently modified by adding both transmission and crack tip diffraction capabilities, which provide both a reliable crack detection capability and good crack 


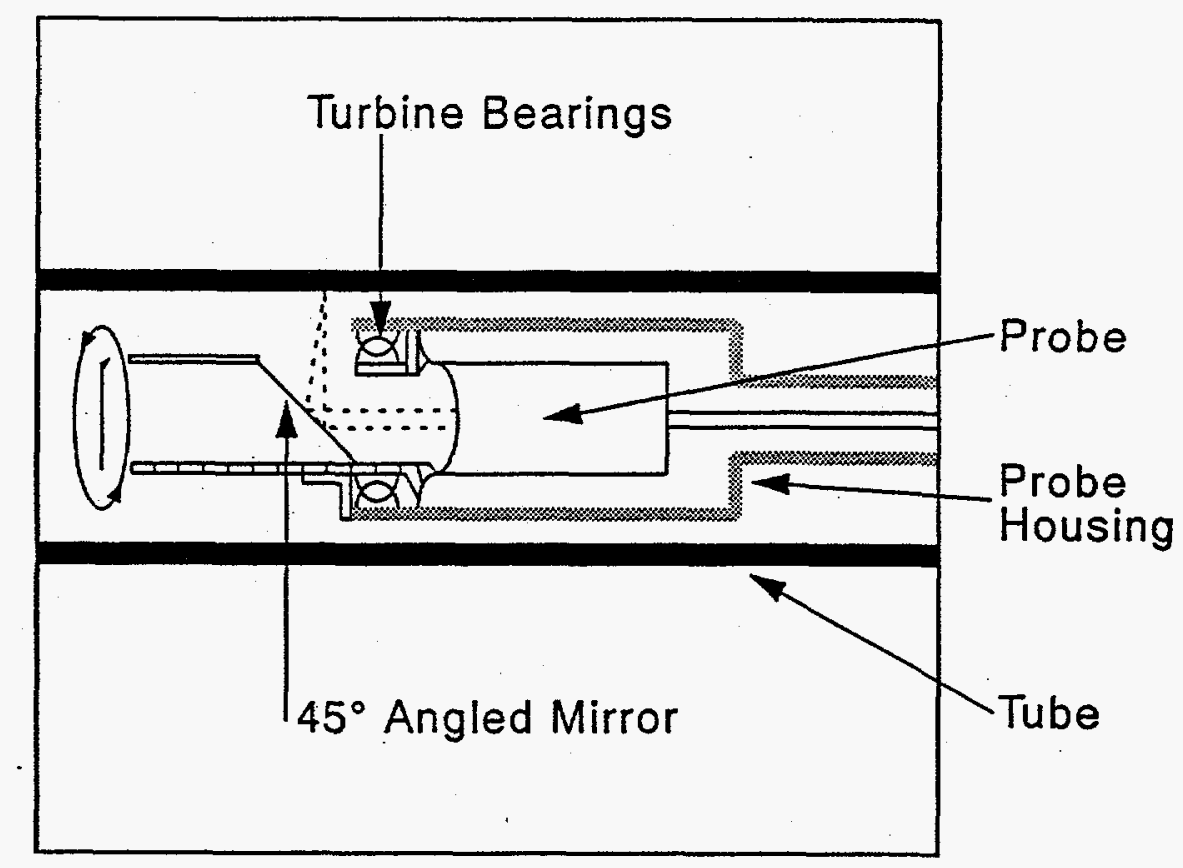

Figure 102. Schematic of rotating ultrasonic beam scanning device. Courtesy of Russell Technologies, Incorporated, Edmonton, Alberta, Canada.

depth sizing. ${ }^{\text {, }}$, It should be noted that the crack tip diffraction techniques have been successfully used for detection and sizing of tight stress corrosion and fatigue cracks. For example, the crack tip diffraction techniques have been used for inspection of PWR control rod drive mechanism nozzles susceptible to PWSCC, BWR recirculation piping susceptible to IGSCC, and

a. Harada, Y., et al. 1995. "Development of Depth Sizing Technology using Ultrasonic Testing in Steam Generator Tubes," presented at the 14th EPRI Steam Generator NDE Workshop, August 7-9, Bellevue, Washington.

b. V. N. Shah, personal communication with D. Dobbeni, Laborelec, Belgium.
PWR feedwater piping susceptible to thermal fatigue cracking.

In the past, ultrasonic testing methods were not utilized because they were considered slow, compared to eddy-current bobbin coils, and required a couplant to be effective. However, due to the more complex geometry of the numerous types of degradation in certain regions of the tube (e.g. the roll-transition region), and the need for reliable detection and sizing information, ultrasonic examinations may be warranted.

Extensive development of ultrasonic testing techniques for steam generator tube inspections have been carried out in Belgium for last 10 years. The Belgian experience indicates that 
ultrasonic testing can supplement eddy-current testing for nondestructive examination of steam generator tubes. A comparison between ultrasonic testing and rotating pancake coil measurements of circumferential IGSCC and destructive analysis of pulled tubes at some Belgian PWR plants concluded that ultrasonic testing measurements are more reliable and accurate. Ultrasonic testing was found to have a better detection capability, higher resolving power along the axial and azimuthal direction, and an improved capability for sizing both length and depth. ${ }^{c}$ The development of the Belgian ultrasonic testing inspection system was motivated by the failure in 1986 of a rotating pancake coil probe to detect a small circumferential PWSCC crack $(3.5 \mathrm{~mm}$ long and $65 \%$ throughwall) masked by nearby multiple axial cracks. The small crack was incidently discovered while inspecting a pulled tube for axial cracks. Ultrasonic testing provides better resolution because the ultrasonic beam has a smaller sensing area $(0.7 \mathrm{~mm})$ than the eddycurrent sensing area of a pancake coil $( \pm 5 \mathrm{~mm})$.

The final and perhaps the most significant argument in favor of a ultrasonic testing system came from a comparison between rotating pancake coil and ultrasonic testing measurements and the results of a destructive examination of several pulled tubes during 1991-1993. This comparison showed two deficiencies in the rotating pancake coil measurements: (1) rotating pancake coils were unable to accurately size the depth of circumferential IGSCC at the top of the tubesheet, and (2) rotating pancake coils did not detect two unexpectedly deep circumferential cracks. The tightness and orientation of the IGSCC cracks were the main reasons for the poor measurements. As a result, the Belgian

c. Dobbeni and Degrève (1993). "Circumferential IGSCC: UT The Only Choice," presented at the EPRI 12th Steam Generator Workshop. inspection policy now requires a $100 \%$ ultrasound inspection at the top of the tube sheet for steam generators with circumferential IGSCC. ${ }^{a}$ Ultrasonic testing can also provide accurate measurements of the tube geometry (wall thickness, profilometry) because it is not effected by the electro-magnetic properties of the materials within the steam generator (i.e., the tubesheet, support plates, nickel plating, etc.).

An ultrasonic technique is well suited for the purpose of performing detailed examinations of limited regions. This technique achieves coverages equivalent to that of a rotating pancake coil. For example, during the first $100 \%$ ultrasonic testing inservice inspection of more than 15,000 tubes at the top of the tube sheet in three Belgian Model E steam generators, the average inspection speed was 40 tubes per hour.

At Ontario Hydro, an ultrasonic system was developed that is capable of sizing pits to within $1 \%$ in the laboratory and $2 \%$ in the field (Moles et al. 1994). In addition to thickness measurements, ultrasonic testing can also be used to determine the radial profilometry by measuring the displacement of the tube wall in relation to the central axis of the probe (Bodson, et al. 1991). This enables inspectors to determine the tube distortion present at rolltransition and U-bend regions and the distortion caused by denting.

Although ultrasonic testing is gaining acceptance, it is not a fool-proof method by any means. At ANO-2, a ultrasonic inspection failed to detect a 360-degree ODSCC with an average throughwall depth of $88 \%$, and substantially under-

a. Degrève and Dobbeni (1993). "An Industrial UT Inspection System Field Tested on 15,000 Tubes," presented at the EPRI 12th Steam Generator Workshop. 
estimated two other 360-degree, outside-diameter cracks (Sheron 1995). The results from a rotating pancake coil probe were within $8 \%$ for these tubes. Laboratory destructive examinations of circumferential cracks in pulled tubes also indicate that the rotating ultrasonic inspection system underestimates crack depth (Roussel 1994). Thus, ultrasonic testing still needs development, but appears to be a useful technique to supplement eddy-current techniques in some situations.

Laborelec has recently developed a combined ultrasonic and eddy-current rotating probe that provides the best of both inspection techniques: a high detection and accurate sizing capability with the ultrasonic examination (it is able to detect outside surface defects which penetrate $20 \%$ to $30 \%$ of the wall thickness) and a good identification of the location of the defect with the eddy-current examination (detection of sludge, top of tubesheet, support plate, etc.). With this complementary information, ultrasonic indications produced by deposits and scratches can be distinguished from indications produced by tube degradation. This combined rotating probe may be used at plants with both axial and circumferential stress corrosion cracking at the expansion-transition and/or support plate locations. The combined probe has been applied at three Belgian plants since February 1995. ${ }^{\mathrm{a}}$

One experimental approach being considered to improve the efficiency and sensitivity of ultrasonic inspections of steam generator tubing is a cylindrically guided wave inspection technique (Rose et al. 1994). In this technique, the wave is launched down the length of the tube and can travel several meters before attenuating. When it encounters a defect in the tube, a signal is reflect in the opposite direction and detected by the sending probe. The obvious advantage of this

a. V. N. Shah, personal communication with D. Dobbeni, Laborelec, Belgium, July 1995. approach is that long sections of tubing can be examined completely and rapidly without the need for complicated and expensive tooling to insert and rotate the probe. Thus far, experimental data taken in the laboratory show promise and indicate that circumferential cracking as small as $11 \%$ through-wall is detectable with this technique. However, refinements are still needed to determine effective wave modes and optimize the technique so it is sensitive to certain types of defects, while being relatively insensitive to tube boundary conditions such as water or sludge loadings.

\subsection{Limitations of Inservice Inspection Methods for Steam Generator Tubes}

The eddy-current and ultrasonic methods discussed in this section have some limitations in detecting degradation damage to steam generator tubes. The sizing capabilities for these inspection methods are particularly limited. In some cases, the uncertainties in sizing of the defects are being determined by comparing the eddy-current measurements, and sometimes ultrasonic measurements, with destructive examinations of pulled tubes. The limitations of the inspection methods for characterizing the damage caused by each of the different steam generator tube degradation mechanisms are discussed next in the following order: primary water stress corrosion cracking, intergranular attack, outside diameter stress corrosion cracking, pitting, wastage, denting, high-cycle fatigue, and wear.

\subsubsection{Primary Water Stress Corrosion Cracking}

Primary water stress corrosion cracking has generally been found at the expansion-transition region near the tube sheet, any roll-expansion region within the tube sheet, the U-bend region of the first few rows, and near dents. The expansion-transition regions include both rolltransition and explosive-transitions. The PWSCC in a roll-transition region is mostly axial, though 
occasional short circumferential cracks occur between the axial cracks. Cracks at an explosive-transition are typically circumferential in orientation. Cracks in the roll-expansion region have both an axial and circumferential orientation. In the U-bend region, the PWSCC is typically axial and confined to the transition zone between the straight to U-bend sections of the innermost rows of tubes; occasionally offaxial cracks have been detected. PWSCC with an axial orientation has also been reported at the apex of the U-bends.

It has been difficult to detect and reliably size PWSCC in the tubesheet region with bobbin coil probes because the signal from the PWSCC is generally associated with a poor signal-to-noise ratio. The noise in this case is due to such geometric factors as tube ovality, the expansiontransition, roll expansion, and denting, all of which produce large amplitude signals that mask the small amplitude signals from the cracks. By the time the crack signal becomes large enough to be detected, the crack would have grown through the wall. The results of the extensive field studies performed by Laborelec show that bobbin coils can detect PWSCC in roll-transition regions only when multiple axial cracks with near throughwall depth are present.

Bobbin coil probes are generally used in both absolute and differential modes for inspection of small radius $U$-bends. However, cracks in the U-bend region are difficult to detect because of the eccentricity of the probe while traveling in the bend. The probe diameters may have to be smaller, typically below an $80 \%$ fill factor, to allow passage through the tight bend. An absolute signal provides unambiguous flaw indications at the transition areas, whereas a differential probe identifies the transition area (EPRI NDE Center 1987). The bobbin coil probe appears to be able to detect axial cracks in the U-bend regions only when the total number of cracks is beyond a certain threshold or the cracks are long. Reinspection with an rotating pancake coil may be necessary used to resolve any distorted signal.

Axial PWSCC can be detected and sized with rotating pancake coil probes. One estimate of the accuracy of measuring the length of an axial PWSCC crack using a rotating pancake coil probe is $\pm 1.5 \mathrm{~mm}$. This estimate was obtained by comparing the rotating pancake coil length measurements with the actual maximum length of about 60 cracks in the roll transition region of six pulled tubes from a Belgian PWR (Van Vyve and Hernalsteen 1991).

A 3-coil rotating pancake coil can reliably detect circumferential PWSCC in the expansiontransition region once it exceeds about $50 \%$ throughwall depth. However, any distortion in the expansion-transition region may mask the PWSCC cracks. Therefore, tubes with such distortions should be examined with probes that can differentiate geometry variations from the inside diameter cracks. Generally eddy-current inspection is performed while pulling the probe through the tube. However, for the expansion transition region, it is recommended that the rotating pancake coil inspections be performed during insertion to eliminate the drop through effect and improve the quality of the inspection results. Other eddy-current inspection methods such as array, Plus-Point, Cecco-3, and Cecco-5 probes, and ultrasonic inspection methods can also detect circumferential cracks.

The eddy-current and ultrasonic inspection methods capable of detecting circumferential cracks cannot reliably size the length and depth of those cracks. Currently industry is working on developing qualified sizing techniques. The results of eddy-current inspections using rotating pancake coil probes and metallographic data from circumferential crack samples are being used to develop these techniques, The samples were explosively expanded in a simulated tubesheet and the cracks were produced in an accelerated acid environment. This configuration simulates 
a Combustion Engineering design steam generator. World wide pulled tube metallographic data are also being used to develop the sizing techniques. The pulled tube data show that eddycurrent inspections generally underestimate the actual arc length of a circumferential crack as shown in Figure 103 (Malinowski 1995). For example, an actual arc length of a circumferential crack was 360 degrees whereas the correspond- ing eddy-current result was about 100 degrees. Enhanced analysis of the rotating pancake coil inspection results can reduce this deficiency (Malinowski 1995). Some industry efforts are also directed towards developing improved eddycurrent techniques for sizing the maximum depths of circumferential cracks, which are needed for tube integrity assessments (Dembek 1995).

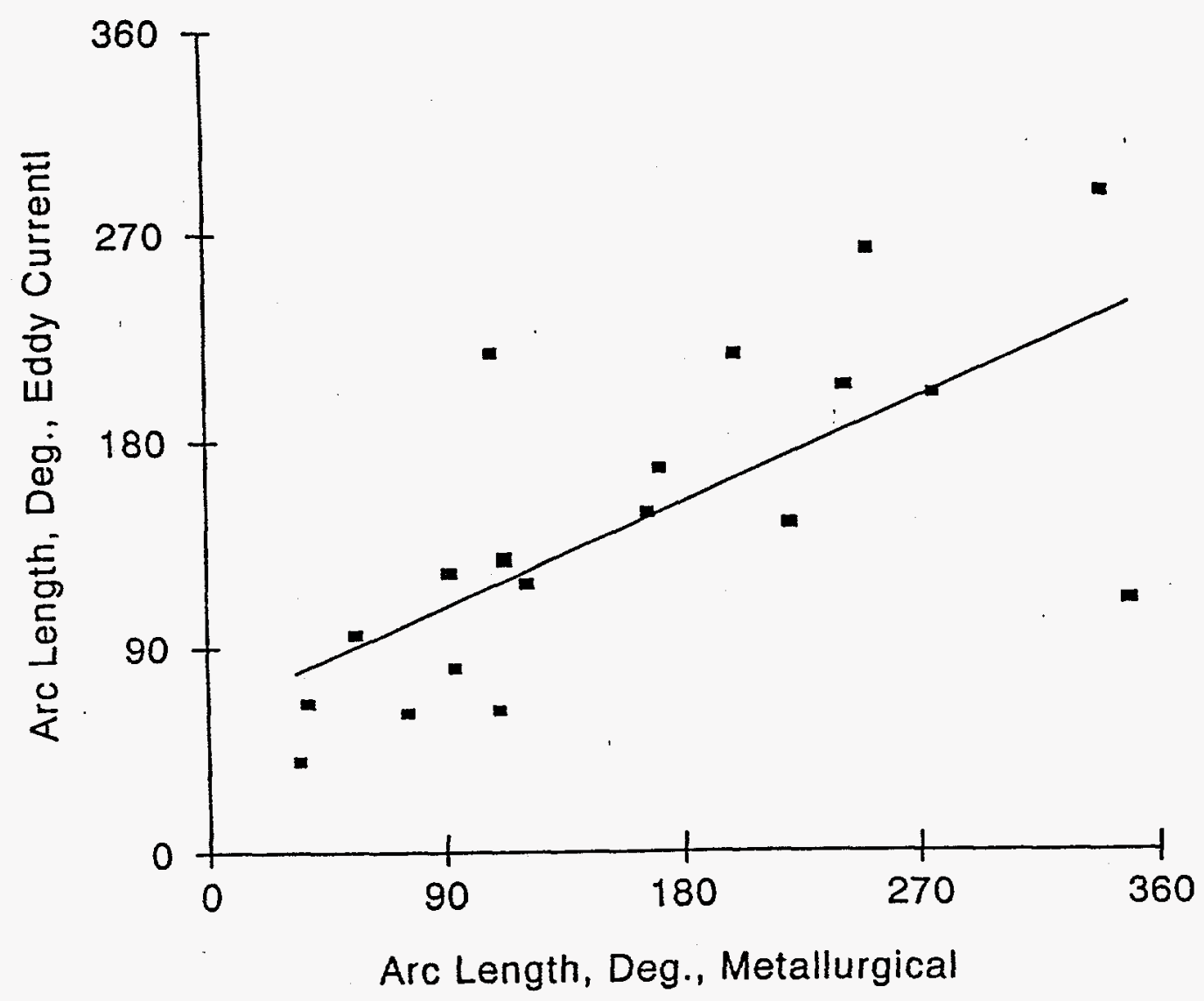

Figure 103. Comparison of actual arc length of circumferential cracks in pulled tubes with the ones estimated using eddy-current inspection (Malinowski 1995). The data represent worldwide experience as of 1992. 
Eddy-current techniques are not effective for detecting cracks with more complex morphologies than a pure axial or circumferential orientation. As discussed earlier, in one Belgian plant, large axial cracks in the roll transition region masked the response from a small circumferential crack that was also present in the roll transition region; a rotating pancake coil probe did not detect the circumferential crack. As discussed in Section 8.3, ultrasonic inspection methods are being used for detection of cracks with such complex geometries.

Inservice inspection results show that the crack propagation rate of axial cracks on the inside surface in the roll-transition region can be estimated. However, crack propagation kinetics for circumferential PWSCC are not yet well characterized.

\subsubsection{Intergranular Attack}

The morphology of IGA is characterized by a relatively uniform attack on all grain boundaries at the tube surface. It can occur without large tensile stresses being present. It is believed that IGA is often a precursor to IGSCC, that is, a relatively uniform IGA occurs until the stresses increase (as a result of wall thinning) to the point that isolated fingers of IGA accelerate and become cracks (EPRI 1985, Partridge 1986a,b,c). IGA is often found along with IGSCC. Inspection of IGSCC is discussed in the next section. IGA has been noted predominantly in the crevice region of the hot leg side of partdepth rolled Westinghouse-type steam generators where local boiling and chemical concentration can occur, in the region above the tube sheet where sludge accumulation is sufficient to cause dry-out and steam blanketing, and in the crevice region between the tube and tube support plates.

IGA is difficult to detect and characterize with conventional eddy-current testing. This is supported by the eddy-current inspection experience at the Trojan plant, which indicated that the threshold at which intergranular attack can be reliably detected with rotating pancake coil and bobbin coil probes is not well understood (USNRC 1991). Intergranular attack results in a slow and progressive change in the electrical conductivity and magnetic permeability of the material. Therefore, a bobbin coil probe in an absolute mode can provide detection and some information about the extent of the attack, but a bobbin coil probe configured in a differential mode is not sensitive to the small changes in the conductivity and permeability of the material. However, it has been difficult to characterize the damage using absolute bobbin coils. An $8 \times 1$ array probe can characterize deep localized IGA. These probes can also estimate the circumferential extent of the IGA. Therefore, any IGA type indications found during an absolute bobbin coil inspection should be reexamined to confirm their presence and to obtain more reliable characterization of their depth and extent (EPRI NDE Center 1987). Other specialized pancake coil probes, such as the rotating pancake coil probe, or ultrasonic probes, which are sensitive to axial and circumferential cracks but insensitive to geometrical or magnetic discontinuities, are not likely to detect intergranular attack (Roussel and Mignot 1991).

Some eddy-current data 'show that the IGA growth rate is slow. For example, a growth rate of $15 \%$ was estimated based on the comparison of successive eddy-current inspection data from one of the affected Spanish PWRs (EPRI NDE Center 1987).

\subsubsection{Outside Diameter Stress Corrosion Cracking}

ODSCC has occurred predominantly in the crevice region on the hot-leg side of part-depth rolled Westinghouse-type steam generators, in the region above the tube sheet where sludge accumulation is sufficient to cause dry-out and steam blanketing, in the crevice regions between 
the tubes and tube supports, especially in the steam generators with drilled-hole support plates where local boiling and chemical concentration can occur, and in free span regions where crud accumulates. If denting occurs, the resulting stresses can accelerate the rate of ODSCC.

The ODSCC corrosion morphology consists of single or multiple major cracks with minor to moderate amounts of branching.; Generally the ODSCC cracks in the crevice regions and freespan locations have an axial orientation. The dominant morphology of ODSCC at the drilled hole tube support plates is either a single axial crack or a network of multiple axial cracks. Limited local patches of intergranular attack have sometimes been observed as well. Shallow circumferential cracks may sometimes occur in the IGA affected regions producing a grid-like pattern of axial and circumferential cracks termed cellular corrosion. Shallow cellular corrosion exhibits a transition to dominantly axial cracks as the cracking progress in depth. Field experience shows that the axial cracks are generally short and sometimes may be through the wall.

Theoretically, a bobbin coil in the differential mode is suited for ODSCC detection and sizing because of the primarily axial nature of the ODSCC cracks. However, the signal-to-noise ratio is less than one. The amplitude of any outside surface signal of interest is less than the interfering noise signals from dents, tube supports, magnetic and non-magnetic deposits, and other artifacts on or near the outside surface. [A low-frequency (such as $20 \mathrm{kHz}$ ) bobbin coil probe is used to evaluate outside surface artifacts such as the sludge height above the top tube sheet, the presence or absence of magnetite at the tube-support intersections, and the integrity of the tube support plates (EPRI NDE Center 1987)]. Therefore, multiple-frequency bobbin coil probes, typically a two-frequency mix, are used in both absolute and differential modes. The use of multifrequency probes minimizes the effects of such outside surface artifacts as copper deposits, the tubesheet, the support plates, etc., resulting in higher signal-to-noise ratios, and provides improved detection and sizing of deep ( $>40 \%$ throughwall) axial cracks. A 0.115-in. diameter unshielded rotating pancake coil probe is generally used to inspect indications identified by a bobbin coil inspection.

However, reliable detection and sizing of ODSCC at a tube support plate with eddy-current probes is difficult because of the low signal-tonoise ratios frequently exhibited by such cracks. In one case, metallographic examination of a pulled tube revealed axial cracks within two 30degree-wide bands on opposite sides of the tube, with the deepest one being $62 \%$ through wall. However, the previous field inspection with a bobbin coil probe did not detect these cracks, using the plant voltage threshold criteria (USNRC 1990).

The reliability of eddy-current inspection methods were further questioned by the ODSCC degradation experienced at the Trojan plant. In 1991, an extensive eddy-current inspection was performed at Trojan to identify defects at the tube support plates that required repair. Bobbin coils were used to detect and size the depth of the indications. Then a rotating pancake coil inspection was performed to confirm each bobbin coil possible indication, and all confirmed ODSCC/IGA defects were repaired or removed from service. However, a destructive analysis of a tube pulled to confirm the inspection results showed that not all the defects at the tube support plates requiring repair (defect depth greater than $40 \%$ throughwall) were identified during the inspection. The destructive analyses showed that the throughwall depths of the IGA/IGSCC defects at the first three support plates were 92,48 , and $55 \%$, of which only the first one had been identified during the inspection. Reanalyses of the bobbin coil data using more conservative criteria to find possible indications and confirmation of these indications with rotating pancake coil inspections led to plugging of many 
additional tubes. Two additional tubes were pulled to analyze the effectiveness of the bobbin coil data reevaluation. The destructive examination revealed three cracks at the tube support plates with throughwall depths, which were not properly identified by the rotating pancake coil probe because of a low signal-tonoise ratio and, therefore, had not been repaired. Because of the large number of tubes with similar suspect indications, Portland Gas and Electric developed an alternate repair criterion for axial ODSCC/IGA at the tube support plates (discussed in Section 7). This criterion was based on bobbin coil voltage and replaced the $40 \%$ depthbased repair limit. Several additional tubes were plugged according to this alternate repair criterion (Gorman et al. 1995). A total of 1,542 tubes in the Trojan steam generators were plugged in 1991 because of ODSCC defects at the support plates and 1,061 tubes were repaired by sleeving (EPRI 1994, PGE 1991).

The rotating pancake coil probes are qualified for detection of circumferential cracks. However, these probes underestimate the length of the circumferential cracks, including ODSCC cracks, and depth sizing of these cracks is difficult. The underestimation of crack length is illustrated in Figure 104, which presents a comparison of eddy-current measurements of the arc length of a variety of circumferential cracks with the corresponding metallographic examination results (Dembek 1995). For example, an actual arc length of a crack was about 270 degrees whereas the corresponding eddy-current measured arc length was 90 degrees. However, enhanced analysis of the rotating pancake coil inspection results can provide better agreement between the inspection and actual arc lengths (Malinowski 1995).

Improved guidelines for rotating pancake coil inspections of circumferential ODSCC at expansion-transition regions and support plate regions are being developed. Based on the metallographic data for pulled tubes, the Wextex
Owners Group has reported that the length of a circumferential crack in a Wextex expansion region can be estimated with an accuracy of \pm 39 degrees. (As discussed in Chapter 2, the Wextex expansion is an explosive expansion of the tube over the full depth of the tubesheet. This expansion method was used in the Westinghouse-type steam generators during the early 1970s.) In January 1995, the EPRI Inservice Inspection Guidelines Committee coordinated a series of circumferential arc length measurements using rotating pancake coil probes from several vendors plus Cecco-5 estimates from Westinghouse. All these measurements estimated the arc lengths within \pm 37 to 45 degrees, which is consistent with the Wextex Owners Group estimate (Malinowski 1995).

In 1991, pulled tube results at North Anna 1 confirmed circumferential cracking in dents at the tube support plate. However, the analysis of the rotating pancake coil inspection results using prevailing industry guidelines did not report these cracks. Expert review of these rotating pancake coil inspection results concluded that the detection limit for circumferential ODSCC cracks in dents at the support plate is about $50 \%$ throughwall and a 50-degree arc length, or $100 \%$ throughwall and a 23-degree arc length (Malinowski 1995).

The nuclear industry is currently working on developing qualified techniques for sizing the depth of circumferential cracks. Verification of depth sizing via analyses of pulled tubes and destructive analyses of laboratory grown cracks is being pursued for further qualifying the various inspection techniques. Plus Point probes, which are sensitive to both circumferential and axial indications, are being investigated for this purpose. Use of Plus Point probes permits inclusion of 2 and $2.9 \mathrm{~mm}$ diameter pancake coils; this arrangement is preferred when both outside surface and ID initiated indications exist. (EPRI 1995b, Richards 1995). 


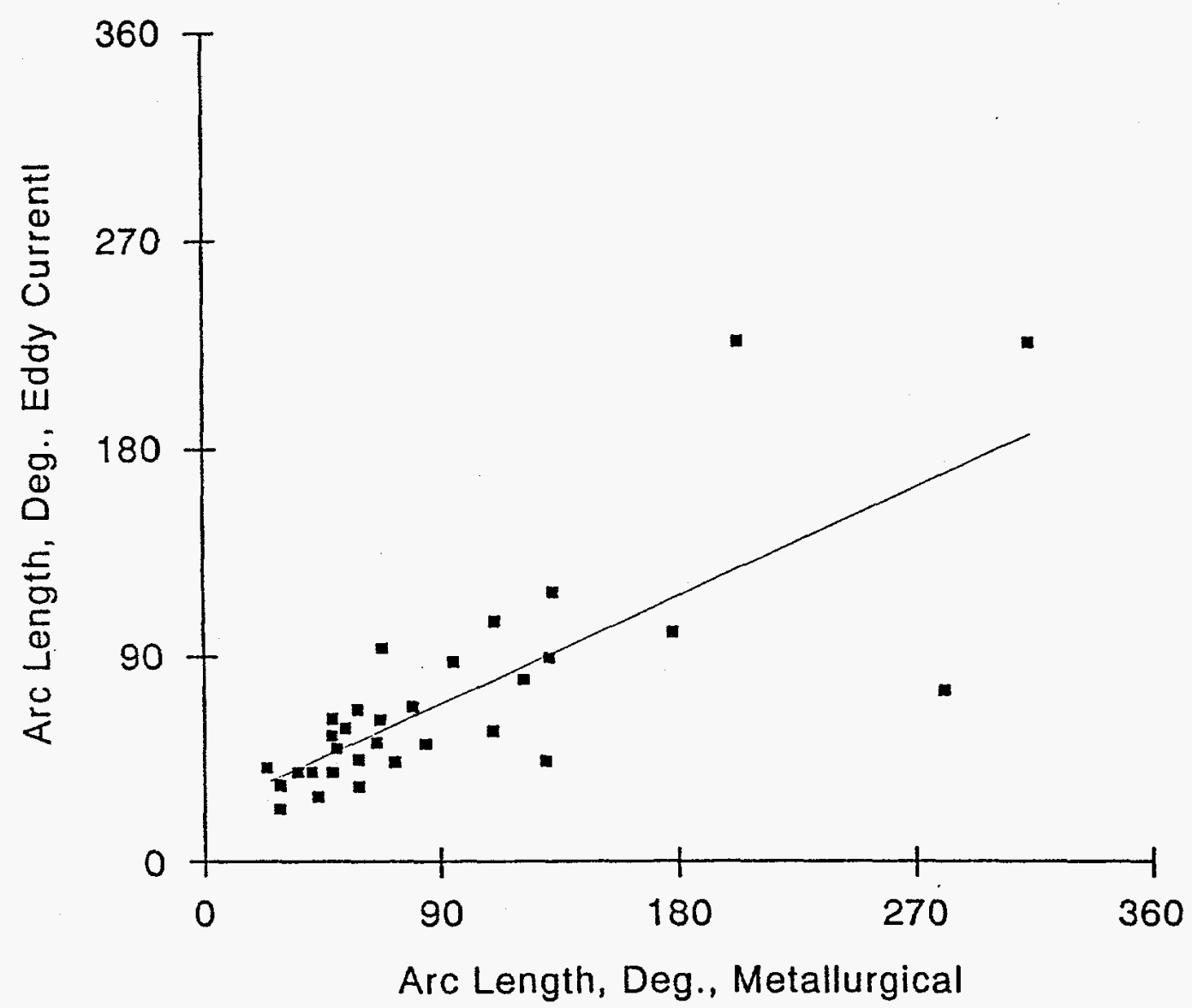

Figure 104. Comparison of actual arc length of circumferential ODSCC cracks in pulled tubes with the ones estimated using eddy-current inspection (Malinowski 1995).

Ultrasonic inspection methods are used at some plants to size the length and depth of the ODSCC cracks detected during eddy-current inspections. For example, rotating pancake coil inspections of the expansion-transition region of the Millstone 2 steam generator tubes revealed extensive circumferential ODSCC. The macrocracks, as defined by the rotating pancake coil inspections, consisted of several discontinuous microcracks that were separated by small ligaments of sound material. The discontinuous nature of the array of microcracks was confirmed by the ultrasonic inspection results and by the examination of pulled tube specimens. The ultrasonic measurements compared well with the actual crack profile (Maurer 1995). According to ultrasonic measurements, the macrocracks ranged in circumference from 84 to 329 degrees and ranged in depth up to $100 \%$ throughwall (USNRC 1990).

\subsubsection{Pitting}

Pitting appears as a group of small diameter wall penetrations and is found between the top of the tube sheet and the first support on the cold-leg 
side of the steam generators, with a limited extent of pitting found on the hot-leg side. Pits are found within or near the top of sludge pile. The pits are characterized by an undercut geometry (i.e., having a larger subsurface than surface diameter) and are typically found to be filled with corrosion products such as chromium oxide, sulfides, and copper metal. Examination of pulled tube samples from Millstone 2 and Indian Point 3 , where extensive pitting had been found, showed that the pit diameter-to-depth ratio was equal to or greater than 1.0. Once pitting has initiated, the rate of new pit formation can be rapid. The growth of pitting indications has not been well-quantified. Pits have grown up to $50 \%$ throughwall depth per cycle, but the degradation is generally considered to progress at approximately $10 \%$ throughwall depth/cycle.

Detection and characterization of pits in the presence of interfering variables such as copper deposits is difficult for the eddy-current techniques. The accuracy of the eddy-current pit depth measurements is severely limited because of the small size of the pits and because the pits are often filled with copper containing corrosion products which have a high electric conductivity. The induced eddy-currents react more strongly with the copper than with the pits, causing a distorted signal output. Therefore, twofrequency $(100$ and $600 \mathrm{kHz}$ ) multiparameter eddy-current inspection techniques are used for copper suppression (EPRI NDE Center 1987).

Ontario Hydro Technologies has developed a rotating ultrasonic inspection system for measurement of pit depths in Monel 400 steam generator tubes. High ultrasonic frequencies, on the order of $25 \mathrm{MHZ}$, are used to obtain the required pit depth accuracy and water is used as a couplant. The inspection system is capable of accurately measuring pit depths to $\pm 2 \%$ of the tube wall thickness, which is equivalent to measuring a pit depth within $1 \mathrm{~mm}$. The depth measurement results on pulled tubes compared well with the metallographic results (Moles et al. 1994).

\subsubsection{Wastage}

There is a general consensus that wastage can be accurately detected and sized using a bobbin coil probe when the wall loss is higher than $10 \%$ to $20 \%$. Operating experience shows that the propagation rate of wastage is compatible with the frequency of inservice inspection.

\subsubsection{Denting}

Tube denting has been found at carbon steel support plate, at tubesheet, and in sludge pile. Denting at the support plate elevation is typically limited to the drilled-hole support plates. As denting proceeds, the tube does not deform uniformly. Denting has been found at both hotleg and cold-leg side of the steam generator. The denting growth can be considered as slow and its evolution as well controlled. Bobbin coils are usually employed to detect and size denting (Roussel and Mignot 1991). Specialized probes such as array probes with eight contactless pancake coils or rotating ultrasonic inspection probes are being used for estimating the radial profiles of a dented tube cross-sections (Dobbeni 1991, Bodson et al. 1991).

\subsubsection{High-Cycle Fatigue}

High-cycle fatigue cracking has occurred in once-through, recirculating, and CANDU steam generator tubes. The cracking occurred in oncethrough steam generator tubes in the early 1980 s. The cracks were located at the top tube support plate (15th tube support plate) and at the bottom of the upper tubesheet in the inspection lane region. The inspection lane region includes about three rows of tubes on either side of the inspection lane and a few additional rows at the periphery. The cracks initiated at the outside surface of the tubes, propagated both circumfer- 
entially and throughwall, leading to leakage from some tubes. In the late 1980s, high-cycle fatigue has also caused circumferential throughwall cracking in the U-bend region of recirculating steam generator tubes, leading to the rupture of two tubes. Most of the earlier tube failures in the CANDU steam generator tubes with Alloy 600 have been because of high-cycle fatigue. The fatigue cracks initiated at the outside surface and located at the upper support plate and more recently in the U-bend region. The cracks were circumferential.

It is difficult to detect a high-cycle fatigue crack in a steam generator tube with an eddy-current probe because the crack produces a lowamplitude signal as compared to the large amplitude signals that are obtained from such flaws as AVB fretting or corrosion wastage. In addition, the presence of the tube support plates makes the inspection of high-cycie fatigue cracks difficult. In one case, a bobbin coil inspection of a once-through steam generator tube did not detect any flaw indication. But further examination with an array probe $(8 \times 1$ pancake coil) detected a $40 \%$ throughwall flaw indication. Subsequent metallographic examination of the pulled tube identified the flaw as a high-cycle circumferential crack with $62 \%$ throughwall penetration. If an $8 \times 1$ array probe is used with frequencies of $400 \mathrm{kHz}$ and $600 \mathrm{kHz}$, no significant effects of geometric structures are anticipated and the reliability of flaw detection and accuracy of flaw sizing is expected to increase (EPRI NDE Center 1987).

High-cycle fatigue-induced tube ruptures in recirculating steam generators pose another problem; the initiation time for a high-cycle fatigue crack is quiet long and the crack growth is very rapid. Mitsubishi Heavy Industries has evaluated the use of pancake coils for detection of circumferential fatigue cracks. Because the fatigue cracks are tight and rather straight, the evaluation focused on how the delectability is affected by the width of the crack and the type of coil. The experimental results for impedance of an artificial circumferential fatigue crack, $2 \times 10^{-3}$ $\mathrm{mm}$ wide and $50 \%$ throughwall, compared well with their analytical results for a similar crack, and, thus, validated the numerical analysis approach. The numerical solution for different crack widths showed that for a very narrow circumferential flaw such as a fatigue crack, the delectability of a fatigue crack is not affected by the crack width, and such a crack can be detected by the pancake coil type probe (Miyake et al. 1992). Ultrasonic examination with tip diffraction techniques could be used for detection and characterization of high-cycle fatigue cracks in the tubes; no such inspection results have been yet reported.

\subsubsection{Fretting and Wear}

Fretting and wear have occurred at the tube-tobaffle plate intersections on the cold leg side in the Westinghouse Models D and E steam generators with preheaters. Fretting and wear have also occurred at the AVBs in the recirculating steam generators of several different designs. Loose parts have also caused wear of peripheral tubes. Wear causes loss of material at the tube outside diameter. The shape of fretting induced wear is determined by the contact area with the supporting structure and its length is limited to the thickness of the supporting structure. Fretting induced wear is also limited to some critical tubes, which makes inspection much easier. This damage is relatively easy to detect and size with a bobbin coil probe.

Most of the observed fretting at the baffle plates occurred in the inlet section of the preheater, and the areas of fretting were found predominantly on the tubing surface facing either in the flow direction or opposite to the flow direction. Examination of pulled tubes from two European plants showed that there is a correlation between the wear volume and wear depth when the wear depth is less than $40 \%$ of the wall thickness. Above $40 \%$ of the wall thickness, the dependence 
of wear depth on wear volume is greatly reduced. This is attributed to the fact that tapered wear is present when the penetration is below $40 \%$ of the wall thickness, whereas more uniform wear is present at deeper penetrations. The axial and circumferential extent of the uniform wear becomes about $19 \mathrm{~mm}(0.75 \mathrm{in}$.) and 180-200 degrees, respectively. This information was used for inspection of tube fretting damage at the baffle plates. The fretting damage at the baffle plates evolves rather fast, in a matter of months, especially when the plant is operated above $50 \%$ of the full capacity. For example, in one plant, fretting damage lead to a leak after the plant had operated only 3,000 effective full power hours at power levels greater than 50\% (EPRI NDE Center 1987).

The preheater designs have been modified in the plants affected with fretting damage at the baffle plates. The proposed modifications in D4, D5, and E2 steam generator involved minimizing tube vibrations at critical locations within the preheater. The modifications include roll expansion of several tubes at two baffle plate locations and splitting the feedwater flow by diverting about $15 \%$ of the main feedwater flow through an auxiliary feedwater nozzle. Postmodification examination results from the affected plants indicate that the modifications have been effective. However, the tubes roll expanded at the baffle plates require different types of eddy-current examination because of the high potential for stress corrosion cracking at those locations. No stress corrosion cracking has yet been reported in the roll expanded region of the tubes at the baffle plate.

Tube fretting between tubes and AVBs is generic to Westinghouse-type steam generators. The extent of tube fretting is dependent on the bar material, the shape of the bars, the clearance, and the bar support design. Unlike the fast growth rate of preheater fretting, the growth rate for $U_{-}$ bend fretting is rather slow, about 5 to $10 \%$ per year. Eddy-current inspection of tube fretting at AVBs is difficult because the bars, which are made from Alloy 600 or 690 , are typically chromium plated. In addition, it is difficult to estimate the wear depth because fretting wear may take place at one or both sides of the outer tube surface, depending on the AVB configuration. The phase angle of the eddycurrent signal provides a measure of the depth of the fretting wear, whereas the amplitude of the signal provides a measure of the fretting volume. If the wear is on one side, the fretting volume is minimum and the signal has a minimum amplitude. On the other hand, if wear is on both sides of the tube, the fretting volume is maximum and the corresponding signal amplitude is maximum. This wear volume/signal amplitude approach to eddy-current signal analysis provides information on the minimum and maximum wear depths for a given phase angle measurement. For each AVB design and material, amplitude calibration standards were developed for onesided and two-sided wear at selected depths to determine the range of amplitudes for given wear depths, as determined by phase angle measurements. Tube fretting damage can be characterized with a two-frequency eddy-current inspection system, which minimizes the geometric effects of AVBs, using these calibration standards. A follow up inspection using an $8 \times 1$ array probe can be performed to further verify a specific wear depth and its geometric features (EPRI NDE Center 1987).

Loose parts induced wear is generally limited to peripheral tubes and is also relatively easy to detect when it is suspected. However, the sizing of the affected area is less accurate than for fretting induced wear because the shape of the wear is unpredictable. Also, the rate of loose parts induced wear is unpredictable. A long rapidly progressing wear scar has lead to tube rupture in less than a fuel cycle. 


\subsection{Summary}

Inspection of the steam generator tubes is critical to the safe and economical operation of nuclear power plants. Eddy-current inspections using bobbin coil probes were fast and effective in detecting and sizing the degradation that took place in early steam generators. However, newer forms of degradation have appeared in recent years that require development of more sophisticated inspection tools. Often, different characteristics of the damage require different types of inspection tools. In addition, the degradation of the sleeves and plugs used for tube repair is difficult to detect and characterize. The degradation mechanisms, damage characteristics and location, and the inspection tools are summarized in Table 26. 


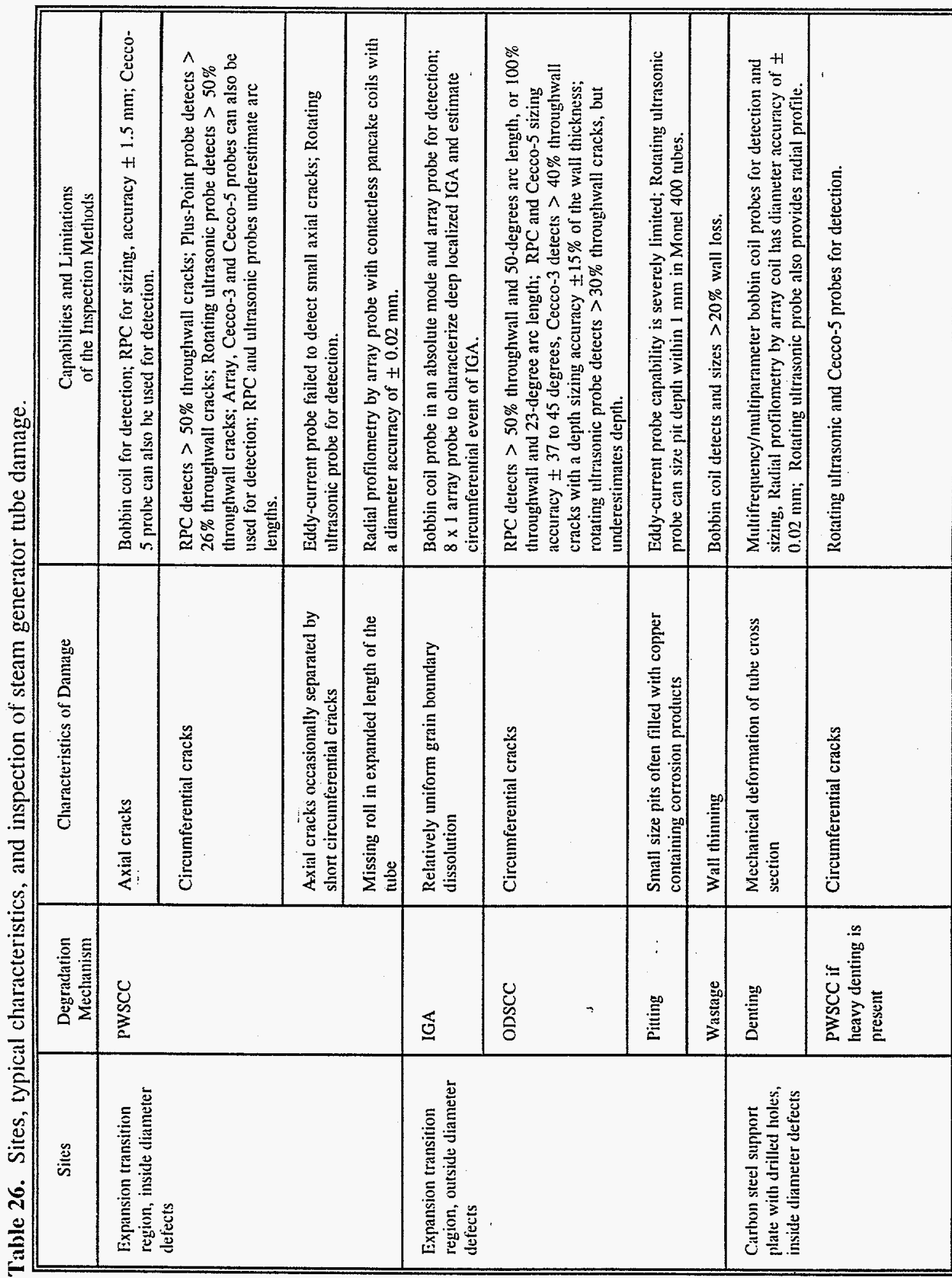




\begin{tabular}{|c|c|c|c|}
\hline Sites & $\begin{array}{r}\text { Degradation } \\
\text { Mechanism }\end{array}$ & Characteristics of Damage & $\begin{array}{l}\text { Capabilities and Limitations } \\
\text { of the Inspection Methods }\end{array}$ \\
\hline \multirow[t]{4}{*}{$\begin{array}{l}\text { Support plate with drilled } \\
\text { boles, outside diameter } \\
\text { defects }\end{array}$} & IGA & $\begin{array}{l}\text { Relatively uniform grain boundary } \\
\text { dissolution }\end{array}$ & $\begin{array}{l}\text { Bobbin coil probe in an absolute mode and array probe for detection; } 8 \\
\times 1 \text { array probe to claracterize deep localized IGA estimate } \\
\text { circumferential extent of IGA. }\end{array}$ \\
\hline & ODSCC & Axial cracks & $\begin{array}{l}\text { Multifrequency/multiparameter methods with bobbin coil probes and } \\
\text { RPC with } 0.115 \text {-in.-diameter pancake coil for detection. }\end{array}$ \\
\hline & $\begin{array}{l}\text { ODSCC } \\
\text { associated with } \\
\text { significant } \\
\text { denting (carbon } \\
\text { steel support } \\
\text { plates) } \\
\end{array}$ & Circumferential cracks & $\begin{array}{l}\text { Cecco- } 3 \text { probe detects }>40 \% \text { throughwall cracks with a depth sizing } \\
\text { accuracy of } \pm 15 \% \text { of the wall thickness; } 8 \times 1 \text { array probe for detection } \\
\text { and sizing. }\end{array}$ \\
\hline & $\begin{array}{l}\text { Wastage (first } \\
\text { two support } \\
\text { plates) }\end{array}$ & Wall thinning & Bobbin coil probe for detection an sizing $>20 \%$ wall loss. \\
\hline $\begin{array}{l}\text { Free span region } \\
\text { (presence of surface } \\
\text { scratches or reduced } \\
\text { tube-to-tube spacing) } \\
\end{array}$ & oDSCC/IGA & $\begin{array}{l}\text { Axial crack and presence of heavy crud } \\
\text { deposits }\end{array}$ & $\begin{array}{l}\text { Multifrequency/multiparameter bobbin coil probes for detection and } \\
\text { sizing; A 3-coil RPC with a } 0.115 \text {-in.-diameter pancake coil for } \\
\text { detection and sizing. }\end{array}$ \\
\hline $\begin{array}{l}\text { U-bend, inside diameter } \\
\text { defecrs (inner row tubes) }\end{array}$ & PWSCC & Axial cracks & $\begin{array}{l}\text { Flexible rotating pancake coil probe for both detection and sizing; } \\
\text { Bobbin coil probe for detection. }\end{array}$ \\
\hline \multirow[t]{2}{*}{$\begin{array}{l}\text { U-bend, outside diameter } \\
\text { defects }\end{array}$} & $\begin{array}{l}\text { Fretting at } \\
\text { antivibration bar } \\
\text { supports }\end{array}$ & Wall thinning & $\begin{array}{l}\text { Two-Frequency bobbin coil probe for detection and sizing; } 8 \times 1 \text { array } \\
\text { probe for characterization. }\end{array}$ \\
\hline & $\begin{array}{l}\text { High-cycle } \\
\text { fatigue of } \\
\text { improperly } \\
\text { supported tules }\end{array}$ & Circumferential cracks & $\begin{array}{l}\text { Difficult to detect because crack initiation time is quite long and the } \\
\text { crack growth is rapid. }\end{array}$ \\
\hline $\begin{array}{l}\text { Peripheral tubes near } \\
\text { tubeshett }\end{array}$ & $\begin{array}{l}\text { Fretting caused } \\
\text { by loose parts }\end{array}$ & Wall thinning & Bobbin coil probe for detection; sizing of affected area less accurate. \\
\hline \multirow{2}{*}{$\begin{array}{l}\text { Sleeved tubes with } \\
\text { hybrid expansion joints } \\
\text { (transition expansion } \\
\text { region) }\end{array}$} & $\begin{array}{l}\text { PWSCC in } \\
\text { parent lubes }\end{array}$ & Circumferential cracks & Plus-Point probe for detection. \\
\hline & $\begin{array}{l}\text { ODSCC in } \\
\text { parent tubes }\end{array}$ & Axial and circumferential cracks & I-coil and Plus-Point probes for detection. \\
\hline Alloy 600$)$ plugs & Pwscc & Axial and circumferential crack & $\begin{array}{l}\text { MHI eddy-current probe detects }>60 \% \text { throughwall circumferential } \\
\text { cracks. }\end{array}$ \\
\hline
\end{tabular}




\section{OBSERVATIONS AND CONCLUSIONS}

Widespread degradation of the steam generator tubing has occurred at a relatively large number of nuclear power plants. This is a safety issue because the thin-walled steam generator tubes are an important part of the reactor coolant pressure boundary, representing over $50 \%$ of the area of the reactor coolant pressure boundary. Rupture of the steam generator tubing can result in the release of radionuclides to the environment outside the reactor containment through the pressure relief valves, the condenser off-gas, or other paths in the secondary system.

Ten spontaneous steam generator tube ruptures ${ }^{\mathrm{a}}$ have occurred over the last 20 years. These ruptures have been caused by a variety of tubing degradation mechanisms including stress corrosion of the outside surface of the tubing, high-cycle fatigue, loose parts wear, stress corrosion on the inside surfaces, and wastage (uniform corrosion). The 10 tuptures resulted in leak rates ranging from $425 \mathrm{l} / \mathrm{min}$. (112 gpm) to $2,900 \mathrm{l} / \mathrm{min}(760 \mathrm{gpm})$ and complex plant transients which have not always been easy for the operators to control.

Certain nuclear power plant design basis accidents, such as a sudden break in the steam line, can lead to rapid depressurization of the secondary coolant system. The pressure difference across the tubing walls generated during these accidents may result in simultaneous leakage or rupture of a number of steam generator tubes when an active degradation mechanism has severely damaged a large number of tubes. Simultaneous leakage or rupture of several tubes can lead to a plant transient that

a. A spontaneous tube rupture is the rupture of one or more steam generator tubes that is not caused by another event or an upset in normal expected operational parameters. is even more difficult to control than a spontaneous tube rupture transient, and radioactivity released to the environment may exceed site limits: The analysis of such transients in PWRs indicate that effective operator intervention and actions to throttle the emergency core cooling injection and actuate the residual heat removal system will result in a successful recovery from a main steam line break with up to about 15 induced steam generator tube ruptures. ${ }^{b}$ More than about 15 induced steam generator tube ruptures produces a system response where the reactor coolant system subcooling cannot be recovered prior to exhaustion of the normally available emergency core cooling water (which in some plants can be replenished from outside sources).

The frequency and consequences of steam generator tube failures can be significantly reduced with qualified inspection techniques, timely inspections, and plugging or sleeving of excessively damaged steam generator tubing. Most steam generators are routinely inspected during plant outages, when their internal structures become accessible to non-destructive inspection equipment, and the defective tubes repaired or plugged as necessary. A continuing issue has centered on what constitutes an appropriate and timely inspection, and when partly defective tubes are still fit for service. Also, a wide variety of steam generator inspection equipment is used in various countries. Unfortunately, the most widely used inspection techniques (eddy-current bobbin coils and rotating pancake coils) are not able to detect and size all of the degradation of interest, and

b. An induced steam generator tube rupture is an accident that is caused by or associated with an upset condition. 
equipment that is able to detect certain degradation is slow and expensive. More effective equipment for detecting certain degradation is being developed.

The objective of this report is to put the issue of steam generator tubing failure, and its impact on nuclear plant safety, in perspective. To do this, we have summarized much of the available information on the following topics.

- $\quad$ steam generator degradation,

- $\quad$ steam generator tube ruptures,

- the thermal-hydraulic response of a nuclear power plant with a defective steam generator,

- the risk significance of steam generator tube rupture accidents,

- $\quad$ steam generator tubing inspection requirements and fitness-for-service criteria in various countries, and

- $\quad$ steam generator tube defect detection reliability and sizing accuracy.

Our key observations and findings for those various topics are listed below.

\section{Steam Generator Tubing Degradation}

- $\quad$ About 10,000 to 12,000 tubes are being plugged each year at about one-half of the PWR plants in the world. In addition, significant numbers of tubes are being sleeved (a total of about 48,000 as of December 1994). These data indicate that at any given time, and prior to their tubes being sleeved or 'plugged, a significant number of the PWR plant steam generators are operating with tubing defects near, or beyond the limits set by their country. Although steam generator tubes with defects at the plugging limits are not expected to fail during a design basis accident such as a main steam line break, the probability of induced tube failure during such events increases when the defect population is significantly above the plugging limits.

- $\quad$ Sleeving steam generator tubes can lead to degradation at new sites on the tubes; this degradation is not easy to detect.

- $\quad$ Not all steam generators are degrading equally. At least 14 plants have plugged and sleeved over 2,000 tubes. However, 7 to $10 \%$ of the plants report no problems after 5 years of operation.

- The relative impact of the various tube degradation mechanisms has dramatically changed over time. In 1994, ODSCC (42\%), PWSCC (22\%), and fretting (4\%) accounted for about $68 \%$ of all the tubes plugged. However, the degradation mechanism is unknown for a significant number of defective tubes (about $30 \%)$.

- Most of the steam generator tubes which have failed over the years have been mill-annealed Alloy 600 tubes. However, thermally treated Alloy 600 failures are becoming more frequent in steam generators with roll-transitions. The Monel-400 tubes have also been susceptible to pitting degradation. Tubes made of Alloy $800 \mathrm{M}$ and Alloy 690 have been resistant to stress corrosion cracking and have exhibited few failures.

- PWSCC occurs at expansion-transition, dent, and U-bend locations where significant residual stresses remain. Both axial and circumferential cracks can occur at some expansion-transition and dent regions. An axial PWSCC crack 
will generally leak before the critical crack size for rupture is achieved; however, the evolution of circumferential cracks is not known and they are usually plugged or sleeved upon detection. Tubes with axial cracks have ruptured before the leakage was detected.

ODSCC has occurred in the tubesheet crevice, sludge pile, tube support plate intersection, and free-span locations with crud buildup (bridging) where aggressive impurities concentrate. Because ODSCC can take several forms (short or long axial cracks, circumferential cracking, cellular corrosion, etc.) and the ease of detection of these various kinds of ODSCC degradation varies considerably, the potential safety consequences at separate plants can be quite different. Tube ruptures have occurred due to undetected ODSCC in free-span regions.

Fretting defects have occurred at over $50 \%$ of the plants world-wide and are occurring in some of the newer steam generator designs as well as in the older plants. Fretting damage at AVBs is likely to continue.

The diversity and persistence of the damage mechanisms suggest that no one remedy will resolve all the problems and effective remedies are not easily found.

- The VVER tubing has been relatively trouble free; however, the collectors in the VVER-1000 steam generators have been a problem. As of July 1993, 33 steam generators at 8 VVER-1000 plants had been replaced because of failure or the potential of failure of the cold collectors. Unfortunately, many (most) of the replacement steam generators are not significantly different than the original equipment so additional collector cracking is expected. The collector cracks and crack propagation rates can be large. Cracks up to $1,000 \mathrm{~mm}$ in length have been found and crack propagation rates up to six ligaments per operating cycle have been observed.

\section{Steam Generator Tube Ruptures}

- Ten steam generator tube ruptures have occurred over the last 20 years at a rate of about one rupture every 2 years. In addition, incipient tube rupture events have been occurring in the U.S. at the rate of about once a year in recent years.

The ten ruptures have been caused by a variety of tubing degradation mechanisms including stress corrosion cracking of the outside and inside surfaces of the tubing, high-cycle fatigue, loose parts wear, and wastage. Additional ruptures caused by wastage are unlikely because only three reactors are now using phosphate water chemistry. Additional ruptures due to high-cycle fatigue in Westinghouse-type steam generators are somewhat less likely than a few years ago because most operators have inspected their steam generators to assure that the AVBs are properly placed and new steam generators are being more carefully fabricated with better AVBs. Loose parts and other foreign objects continue to be left in some steam generators and additional ruptures of tubes due to loose parts wear are possible. Also, extensive primary water and outside diameter stress corrosion cracking has occurred in certain steam generators and more ruptures caused by those mechanisms are possible.

- Ruptures caused by stress corrosion cracking are associated with axial cracking. No rupture has been caused 
because of circumferential stress corrosion cracking.

The rupture locations have generally been either just above the tubesheet (three ruptures), or in the U-bend region (six ruptures). Only the McGuire rupture was near one of the lower support plates. A rupture in the upper region of a steam generator can release radionuclides to the steam, which will result in less retention of the water soluble fission products.

- The 10 ruptures resulted in leak rates ranging from $425 \mathrm{l} / \mathrm{min}$ (112 gpm) to $2,900 \mathrm{l} / \mathrm{min}(760 \mathrm{gpm}$ ) and complex plant transients which have not always been easy for the operator to control.

During a tube rupture transient, the reactor operators are expected to (a) maintain the primary coolant subcooled, (b) minimize the leakage from the reactor coolant system to the faulted steam generator secondary side, and (c) minimize the release of radioactive material from the damaged steam generator. The success of the reactor operators has been mixed, some were slow to understand what was occurring, slow to start reducing power, and slow to isolate the defective steam generator. Others reduced power and isolated the faulted steam generator promptly. Some operators were slow to cool and depressurize the primary system, others took prompt action. The result was that the faulted steam generators were overfilled in a number of cases and more radioactive material was released to the environment than would have occurred if the transient was better managed.

- In all cases, the plants were properly cooled down and the radioactive material releases were small and well below regulatory limits.

\section{Thermal-hydraulic Response of a Typical PWR with a Defective Steam Generator}

- Analysis of a single spontaneous steam generator tube rupture demonstrates that the operators can utilize the pressurizer sprays or PORVs to depressurize and utilize the intact steam generators to cool the reactor coolant system to the residual heat removal system operating conditions within 4 hours.

- Unlike the spontaneous steam generator tube rupture event, the combined steam line break-induced tube rupture events have well defined time constraints within which cooldown of the reactor coolant system and actuation of the residual heat removal system must be accomplished to prevent core damage. As the number of induced tube ruptures increases from 1 to 15 , the time available for action decreases from about 7 hours to about 1 hour.

- $\quad$ For the case of a main steam line break and one to three induced tube ruptures, the high pressure safety injection must be throttled and the low pressure safety injection terminated along with accumulator isolation to enable cooldown and depressurization of the reactor coolant system to the residual heat removal system operating conditions. The pressurizer sprays and the high pressure safety injection are then used to control the pressurizer level and the reactor coolant system subcooling and pressure. In the event the sprays are unavailable, the pressurizer PORVs must be used to depressurize the reactor coolant system. 
For the case of a main steam line break and three or more tubes ruptured, the high pressure safety injection and the low pressure safety injection must be throttled to delay the refueling water storage tank exhaustion and provide adequate time to initiate the residual heat removal system. Should the emergency core cooling throttling be delayed, there may be insufficient time available to align for the residual heat removal system operation and core damage could result.

With 15 tube ruptures, operator actions to throttle the emergency core cooling and initiate the residual heat removal system for long-term cooling must be accomplished within 1 hour of the event initiation. Preparation for use of the residual heat removal system must be initiated as early as is possible to assure the residual heat removal system can be actuated prior to exhaustion of the refueling water storage tank. Failure to initiate the residual heat removal system prior to exhaustion of the refueling water storage tank could lead to core damage.

Analyses of the combined steam line break-steam generator tube rupture event requires only one residual heat removal system to be actuated to prevent boiling during the long term.

- The emergency operating procedures do not emphasize the need for timely operator actions in the event of a steam line break-steam generator tube rupture. The addition of this information to the emergency operating procedures should be considered for these bypass events since a delayed operator response could lead to core damage.
- The time available for operator action to successfully place the plant in a long term cooling mode of heat removal following a combined steam line breaksteam generator tube rupture event is very sensitive to plant specific equipment behavior. The time required to exhaust the refueling water storage tank is highly dependent on emergency core cooling capability, refueling water storage tank capacity, and the variations in the emergency operating procedures and the resultant operator actions.

- More than 15 induced steam generator tube ruptures produces a system response that could lead to core melting.

\section{The Risk Significance of Steam Generator Tube Rupture Accidents}

- $\quad$ Spontaneous and induced steam generator tube ruptures are small contributors to the to the total core damage frequency but are risk significant due to the potential for the radionuclides to bypass the reactor's containment building.

- Risk significant steam generator tube rupture accidents can be induced by operational transients (high frequency) and rare events (low frequency) in steam generators with tubes that have degraded beyond a threshold amount.

- The steam generator tube rupture risk profile is dominated by a few risk significant failures. Typically, the dominant steam generator tube rupture contributor is human error followed by failures that cause a loss or depletion of the refueling water storage tank's coolant inventory. 
- $\quad$ Steam generator tube degradation may need to be controlled to prevent a significant increase in the risk profile of a pressurized water reactor.

Tubing Inspection Requirements and Fitnessfor-Service Guidelines in Various Countries

- $\quad$ An appropriate level of steam generator and plant safety can only be maintained by a suitable combination of inspection and acceptance (fitness-for-service) requirements. Some countries have chosen to have somewhat more conservative fitness-for-service criteria and less inspection. Other countries have chosen less conservative fitness-for-service criteria (thereby saving money on repairs) and more inspections. Some countries have more or less of both compared to other countries.

- The frequency and extent of the inspections often increase as problems develop.

- Some countries group their steam generators into two categories with quite different numbers of tubes inspected in each category. The categories used are either "susceptible tubing and less susceptible tubing" or "previous defects or no defects." Other countries apply the same inspection criteria to all their steam generators.

- Some countries inspect a small fraction of the tubes (for example $3 \%$ ) and then more tubes when defects are found. Other countries inspect a much larger fraction of the tubes, especially in steam generators with susceptible tubing, or previous defects. Some countries inspect all the tubes every year in steam generators with defects.
Some countries inspect a fraction of the steam generators at a unit every outage; other countries inspect every other outage, or even every 4 years. Some countries inspect every year.

- Some countries inspect the full tube length; other countries focus their inspections on selected areas where the degradation is most likely to be found. Some countries do both.

- $\quad$ Repair or removal from service criteria can be grouped into two families: generic and defect-type and location specific fitness-for-service criteria.

- The simplest and most conservative generic approach is no detectable defects.

- The most widely implemented fitnessfor-service criterion is a minimum wall thickness criterion, usually the value specified in the ASME Code.

- The occurrence in recent years of new types of tube degradation, such as PWSCC within the tubesheet or axial ODSCC within the support plates, led to the development of defect-type and location specific repair criteria.

- The $\mathrm{P}^{*}$ and $\mathrm{F}^{*}$ criteria allow tubes with flaws in the tubesheet region to remain in service without repair if the flaws are low enough so that the damaged tube remains in the tubesheet even if it separates at the flaw.

- Because steam generator tubing is very ductile, reasonably short through wall axial cracks exhibit slow propagation. Therefore, axial cracks located close to the top of the tubesheet, and shorter than about 10 to $13 \mathrm{~mm}$, may remain in ser- 
vice in some countries even if they are through the wall.

- $\quad$ Some countries depend, in part, on very good leak detection (nitrogen-16) and the assumption that degraded steam generator tubes will leak before they rupture. However, long throughwall cracks have been found that are rather leak tight The current tendency is, therefore, to put increasing weight on the use of inspections and use leak detection as an added safety feature.

- $\quad$ The complex morphology of ODSCC and the difficulties in detecting and sizing this degradation have lead some plants to use a statistical voltage based criteria. The allowable eddy-current signal is based on: (1) a burst pressure correlation together with allowances for defect progression and inspection uncertainties, and (2) a leak rate correlation, the recent population of defects in the steam generator, and, again, allowances for defect progression and inspection uncertainties.

\section{Steam Generator Tube Defect Detection Reliability and Sizing Accuracy}

\section{Inspection of PWSCC and ODSCC}

- $\quad$ Eddy-current probes with bobbin coils and rotating pancake coils are generally used for inspection of steam generator tubes. Generally these probes reliably detect flaws, but their detection threshold is high, some deep cracks have been missed, and defect sizing is not accurate.

- $\quad$ Bobbin coils are sensitive to axial cracks and volumetric flaws, but not to circumferential cracks. Field studies have shown that bobbin coils can detect PWSCC in a roll-transition region only when multiple axial cracks with near throughwall penetration are present. Similarly, the bobbin coil probe appears to be able to detect axial cracks in the Ubend regions only when the total number of cracks are beyond a certain threshold or the cracks are long.

- Comparison with pulled tube results show that a rotating pancake coil can measure axial PWSCC within $\pm 1.5 \mathrm{~mm}$.

- Multifrequency/multiparameter eddycurrent methods employing bobbin coils are used for inspection of axial ODSCC. These methods suppress the changes produced by the extraneous variables and can detect and size deep ODSCC ( $>40 \%$ throughwall). However, reliable detection and accurate sizing of ODSCC/IGA defects with bobbin coil probes is difficult. Some ODSCC/IGA defects greater than $40 \%$ throughwall have been missed. Therefore, the indications detected with bobbin coils are often confirmed with rotating pancake coil inspections.

- A rotating pancake coil probe can reliably detect circumferential PWSCC in the expansion-transition region once it exceeds $50 \%$ throughwall depth. However, any distortion of the region will mask the signal. The Plus-Point probe can be used for inspection of flaws in a distorted expansion-transition region because it is not affected by surface geometry. This probe has detected a shallow circumferential flaw (average depth $26 \%$ ) in a roll transition region.

- Transmit/receive probes (Cecco-3 and Cecco-5 probes) are more sensitive to both outside and inside surface cracking as compared to rotating pancake coil probes. A Cecco-3 probe can detect and 
size a circumferential flaw as shallow as $40 \%$ of the wall thickness with a sizing accuracy of $\pm 15 \%$ of the wall thickness. A Cecco-5 probe will detect both axial and circumferential flaws. The Cecco series of probes have been used for examination of Wextex transition regions, support plate dent regions, and laser-welded and hybrid-expansion type sleeves.

- No eddy-current methods are qualified at present for sizing the length and depth of circumferential cracks. Plus-Point probes, which are sensitive to both circumferential and axial indications are being investigated for this purpose.

- Eddy-current techniques are not effective for detecting cracks with more complex morphologies than pure axial or circumferential orientations. Ultrasonic inspection methods are being developed and used for detection and sizing of cracks consisted of several discontinuous microcracks separated by small ligaments of sound material.

- Rotating ultrasonic inspection probes using crack-tip diffraction techniques apparently provide more reliable crack detection, more accurate sizing, and improved resolution than rotating pancake coil probes.

- The Plus-Point probe can detect flaws in the vicinity of welds and the heat affected zone of welded sleeve joints. This probe has two differentially connected coils crossing at a point. Therefore, the probe is not affected by lift-off due to weld geometry and the changes in the material properties of the heat affected zone.

\section{Inspection of IGA}

- Conventional bobbin coil and rotating pancake coil probes are not sensitive to the IGA-induced slow changes in the electrical conductivity and magnetic permeability. Therefore, these probes cannot reliably detect and characterize IGA damage.

- $\quad$ Array probes with an $8 \times 1$ or $8 \times 2$ surface riding pancake coil arrangement can detect intergranular attack and estimate its circumferential extent and depth.

\section{Inspection of Pitting}

- The accuracy of the eddy-current pit depth measurements is severely limited because of the small size of the pits and because the pits are often filled with copper containing corrosion products with a high conductivity. A rotating ultrasonic inspection probe has accurately measured pit depths to $\pm 2 \%$ of the wall thickness in Monel 400 tubes (CANDU steam generators).

\section{Inspection of Dents}

- A rotating ultrasonic inspection probe or an array probe with contactless pancake coils has been successfully used for estimating the profiles of dented tube cross-sections.

\section{Inspection of High-Cycle Fatigue Cracking}

An $8 \times 1$ array probe is likely to provide a reliable detection and accurate sizing of circumferential fatigue cracks found at the 15th support plate in the oncethrough steam generators. 
- Timely detection of high-cycle fatigue cracks in the U-bend regions of recirculating steam generators is difficult because the initiation time is long and crack growth rate is rapid.

\section{Inspection of Fretting and Wear}

- Tube fretting damage at the AVBs can be characterized with a two-frequency eddycurrent inspection system, which minimizes the geometric effects of the ABVs on the eddy-current signal.
Loose part induced wear is generally limited to peripheral tubes and is relatively easy to detect when it is suspected. However, the sizing of the affected area is not accurate. 



\section{REFERENCES}

ASM (ASM Committee on Eddy Current Inspection) 1989. "Eddy Current Inspection" pp. 164-194 in ASM Handbook, Vol. 17, Nondestructive Evaluation and Quality Control, ASM International, Materials Park, Ohio.

ASME 1992, 1992 ASME Boiler and Pressure Vessel Code, Section XI, Article IWB-3640 and Appendix C.

Airey, G. P., and F. W. Pement 1982. "A Comparison of Intergranular Attack in Alloy 600 Observed in the Laboratory and in the Operating Steam Generators," Presentation to the National Association of Corrosion Engineers, March 22-26, 1982, Houston, Texas.

Angwin, M. J. 1984. "High Temperature Pitting in PWR Steam Generator," Proceedings of the International Congress on Metallic Corrosion, Volume 1, Toronto, Ontario, June 3-7, 1984, National Research Council of Canada, Toronto, pp. 250-256.

Azodi, D., et al. 1987. "On the Integrity of Steam Generator Tubes and Plugging Assessment," Structural Mechanics in Reactor Technology, Transactions of the 9th International Conference, Lausanne, August 17-21.

Balkrishnan, P. V., and R. S. Pathania 1988. "Correlation of Tube Support Structure Corrosion Studies." Proceedings of the Third International Symposium on Environmental Degradation of Materials in Nuclear Power systems-Water Reactors, Traverse City, Michigan, The Metallurgical Society, Warrendale, Pennsylvania, pp. 489-499.

Bamford, W. H.; G. V. Rao and J. L. Houtman 1992. "Investigation of Service-Induced Degradation of Steam Generator Shell Materials," Proceedings of the Fifth International Symposium on Environmental Degradation of Materials in Nuclear Power Systems - Water Reactors, August 25-29, Monterey, California, pp. 588-595.

Bamford, W. H., et al. 1987. "Integrity Issues in PWR Steam Generator and Feedwater Systems," Performance and Evaluation of Light Water Reactor Pressure Vessels, PVP-Vol. 119, American Society of Mechanical Engineers, New York, pp. 19-30.

Bandy, R., and D. van Rooyen 1984. "Initiation and Propagation of Stress Corrosion Cracking of Alloy 600 in High Temperature Water," Proceedings of the Third International Symposium on Environmental Degradation of Materials in Nuclear Power Systems-Water Reactors, Houston, Texas, National Association of Corrosion Engineers, Houston, p. 763

Bandy, R., and D. van Rooyen 1984a. "Stress Corrosion Cracking of Inconel Alloy 600 in High Temperature Water-An Update," Corrosion, 40, No. 8.

Baum, A. J., et al. 1987. Steam Generator Cold Leg Thinning in Operating Plants, EPRI NP-5140, Electric Power Research Institute, Palo Alto. 


\section{REFERENCES}

Begley, J. 1988. "Application of the Gerber-Garud Strain Rate Damage Model to PWSCC," Proceedings: 1987 EPRI Workshop on Mechanisms of Primary Water Intergranular Stress Corrosion Cracking, EPRI NP-5987SP, Electric Power Research Institute, September, pp. D6-1 to D6-11.

Benson, J. 1988. "Application of an $\mathrm{F}^{*}$ Probe at Connecticut Yankee," presented at the EPRI Steam Generator Workshop, Myrtle Beach, South Carolina, June 7-9.

Berge, Ph., 1993. "After 33 Years, It is Time to Solve Pure Water Cracking," Keynote speech in Proceedings: 1992 EPRI Workshop on PWSCC of Alloy 600 in PWRs, EPRI TR-103345, December (proprietary report; not publicly available).

Berge, Ph., and J. R. Donati, 1981. "Materials Requirements for Pressurized Water Reactor Steam Generator Tubing," Nuclear Technology, Vol. 55, October, pp. 88-104.

Blomgren, J. C. 1986. "Experience at Zion," presented at the EPRI Workshop on Fretting and Wear Susceptibility in Nuclear Steam Generators, Washington, D.C., March 19-20, 1986.

Bodson, F. et al. 1991. "Specific Ultrasonic Inspection Methods for Steam Generator Tubes," NEA/CSNI-UNIPEDE Specialist Meeting on Operating Experience with Steam Generators, Brussels, Belgium, 16-20 September.

Bollini, G., 1993. "Steam Generator Inspection Reliability and Safety," Second ASME/JSME International Conference on Nuclear Engineering (ICONE), San Francisco, March.

Bowling, M. L. 1988. North Anna Unit 1 Steam Generator Tube Rupture, July 15, 1988, Revision 3, Virginia Power Company.

Bradish, T. R. 1993. "Manual Reactor Trip Following a Steam Generator Tube Rupture," Licensee Event Report No. 93-01, Rev. 2, Docket No. 5000529, August 14.

Bruemmer, S. M., L. A. Charlot, and C. H. Henager, Jr. 1988. "Microstructure and Microdeformation Effects on IGSCC of Alloy 600 Steam Generator Tubing," Proceedings: 1987 EPRI Workshop on Mechanisms of Primary Water Intergranular Stress Corrosion Cracking, EPRI NP-5987SP, Electric Power Research Institute, Palo Alto, September, pp. C3-1 to $\mathrm{C} 3-31$.

Canadian Standard Association 1994. "Periodic Inspection of CANDU Nuclear Power Plant Components," CAN/CSA-N285.4.

Campbell, C. A. and S. Fyfitch 1994. "PWSCC Ranking Model for Alloy 600 Components," Sixth International Symposium on Environmental Degradations of Materials in Nuclear Power Systems-Water Reactors, San Diego, California, pp. 863-870. 
Cecco, V. S. and Van Drunen, G. 1985. "Recognizing the Scope of Eddy Current Testing," Chapter 6 in Research Techniques in Nondestructive Testing - Volume VIII, Academic Press, New York, pp. 269-301.

Clark, R. A., and M. Lewis 1985. "Observations of Denting and Other Deterioration in the Surry Steam Generator," Proceedings of the International Conference in Nuclear Power Plant Aging, Availability Factor and Reliability Analysis, San Diego, California, July 8-12, 1985, V. S. Goel (ed.), American Society for Metals, Metals Park, Ohio, pp. 193-195.

Clark, W. G., Jr. 1993. "Multiple-Element Eddy Current Probes for Enhanced Inspection," Materials Evaluation, July, pp.794-802.

Cochet, B., 1989. Tube Plugging in the Tubesheet Area Leak Before Break Analysis - Tube Plugging Criteria, December.

Cofie N. G. et al. 1994. "Management of Steam Generator Feedwater Nozzle Cracking in PWRs," 1994 Pressure Vessels and Piping Conference, Minneapolis, Minnesota, June 19-23, 1994, ASME PVP Vol. 286, Changing Priorities of Codes and Standards: Failure, Fatigue, and Creep.

Commonwealth Edison Co. 1987. Technical Specifications for Braidwood Station Units 1 and 2, Appendix $A$ to License No. NPF-72, Docket Nos. STN 50-456 and STN 50-457, also published by the USNRC as NUREG-1276, July.

Connors, H. J., et al. 1988. Beaver Valley 1 Evaluation for Tube Vibration Induced Fatigue, WCAP11800, Westinghouse Electric Company, Pittsburgh.

Conway, W. F. 1993. Palo Verde Nuclear Generating Station Unit 2 Steam Generator Tube Rupture Analysis Report, July 18. Docket No. STN 50-529

Coriou, H., et al. 1959. "Corrosion Fissurante Sous Contrainte De L'Inconel Dans L'Eau A Haute Temperature," in Third Colloque de Metallurgie Corrosion, Center d'Etudes Nucleaires de Saclay, France, North Holland Publishing Co., Amsterdam, p. 161.

Coulehan, V. R. 1988. "Manual Reactor Shutdown Due to 2 Gallon Per Minute Steam Generator Primary to Secondary Leak in Number 31 Steam Generator Caused by Degraded Tube," Licensee Event Report 88-007, Rev. 1, October 19.

CSGORG (Counterflow Steam Generator Owners Review Group) 1983. "Appendix B, Independent Evaluation of Proposed Modifications to Westinghouse D4, D5, and E Steam Generators," Safety Evaluation Report related to the D4/D5/E Steam Generator Design Modification, NUREG-1014.

Davis, T. J. 1981. "Advanced Multifrequency Eddy-Current System for Steam-Generator Inspection," Eddy Current Characterization of Materials and Structures, ASTM STP 722, American Society for Testing and Materials, pp. 255-265. 


\section{REFERENCES}

Davis, T. J. 1980. Multifrequency Eddy-Current System for Inspection of Steam Generator Tubing, EPRI NP-1621, November.

de Keroulas, F., and L. Lunven 1990. "Fissuration en Milieu Primaires des Tubes Generateurs de Vapeur des Reacteurs 900 et 1,300 MWe: Resultats des Examens Metallurgiques sur Tubes Extraits," International Symposium, Fontevraud II, Volume 1, Royal Abbey of Fontevraud, September 10-14, 1990, Sociéte Francaise d'Energie Nucléaire, pp. 206-214.

Dembek, S. 1995. "Summary of Electric Power Research Institute (EPRI) Led Presentation on Steam Generator (SG) Tube Circumferential Cracking Sizing Techniques," Memorandum to J. Strosnider, USNRC, March 13, 1995.

Dobbeni, D. 1991. "Ultrasonic Inspection Methodology," NEA/CSNI - UNIPEDE Specialist Meeting on Operating Experience with Steam Generators, Brussels, Belgium, 16-20 September.

Dobbeni, D. and Degreve, D. 1990. "Adapting Ultrasonics to Examine PWSCC in Steam Generators," Nuclear Engineering International, May.

Dobbeni, D., et al. 1985. "Belgian Approach to Non-Destructive Examination of Primary Side Stress Corrosion Cracking," presented at the SGOG/EPRI Workshop at St. Petersburg Beach, Florida, December 10-12, 1985.

Dodd, C. V., et al. 1988. "Eddy Current Inspection of Ferromagnetic Materials Using Pulsed Magnetic Saturation," Material Evaluation 46, 12, pp. 1592-1597.

Dodd, C. V. and Deeds, W. E. 1981. "In-Service Inspection of Steam Generator Tubing Using Multiple-Frequency Eddy Current Techniques," Eddy Current Characterization of Materials and Structures, ASTM STP 722, American Society for Testing and Materials, pp. 229-239.

Engstrom, J. 1985. "Comparison of Eddy Current Test Results in Steam Generator Tubesheet Roll with Results from Metallographic Examination of Pulled Tubes," presented at the SGOG/EPRI Workshop at St. Petersburg Beach, Florida, December 10-12, 1985.

EPRI 1995. PWR Steam Generator Tube Repair Limits - Technical Support Document for Outside Diameter Stress Corrosion Cracking at Tube Support Plates, EPRI TR-100407, Rev. 2A, January.

EPRI 1995a. Steam Generator Progress Report, Rev. 11, EPRI TR-106365.

EPRI 1995b. "NDE of Circumferential Cracks," presented at the NRC/NEI Meeting on Circumferential Cracking NDE, Rockville, MD, September 8, 1995.

EPRI 1994. Steam Generator Progress Report, Rev. 10, Energy Management Services, Inc., Little Rock, Arkansas, November. 
EPRI 1993a. PWR Steam Generator Tube Repair Limits - Technical Support Document for Outside Diameter Stress Corrosion Cracking of Tube Support Plates, EPRI TR-100407, Rev. 1, August.

EPRI 1993b. PWR Steam Generator Tube Repair Limits: Technical Support Document for Expansion Zone PWSCC in Roll Transitions, EPRI NP-6864-L, Rev. 2, August.

EPRI 1993c. PWR Secondary Water Chemistry Guidelines, Rev. 3, EPRI TR-10234, Rev. 3, May.

EPRI 1990a. Alloy 690 for Steam Generator Tubing Application, EPRI NP-6997-SD, October.

EPRI 1990b. PWR Primary Water Chemistry Guidelines: Revision 2, EPRI NP-7077, Electric Power Research Institute, Palo Alto, November.

EPRI NDE Center 1987. Advanced Eddy-Current Data Analysis for Steam Generator Tubing.

EPRI 1985a. Steam Generator Reference Book, Steam Generator Owners Group, Electric Power Research Institute, Palo Alto, CA (proprietary report; not publicly available).

EPRI 1985b. Proceedings: 1985 Workshop on Primary-Side Stress Corrosion, St. Petersburg Beach, Florida, December 10-12, EPRI NP-5158.

Ericson, D. M. et al, 1990. "Analysis of Core Damage Frequency: Internal Events Methodology," NUREG/CR-4550, Vol. 1, Rev. 1.

Erdogan, F., 1976. “Ductile Fracture Theories for Pressurized Pipes and Containers," International Journal of Pressure Vessels and Piping, Vol. 4, pp. 253-283.

Flesch, B., and B. Cochet, 1990. "Leak-Before-Break in Steam Generator Tubes," International Journal of Pressure Vessels and Piping, Vol. 43, pp. 165-179.

Fukui, S. et al. 1992. "Eddy Current Inspection System for Mechanical Plug of Steam Generator Tube," Proceedings of the 11th International Conference on the NDE in the Nuclear and Pressure Vessel Industries, Albuquerque, New Mexico, USA, 30 April-2 May.

Gentillon, C. D., J. B. Hudson, and J. A. Schroeder, 1994. Rates for Initiating Events in U.S. Commercial Nuclear Power Plants, 1989-1993, INEL-94-0270.

Georgia Power Co. 1987. "Steam Generator Technical Specification 3/4.4.5" in Vogtle Electric Generating Plant Unit 1 and 2 Technical Specifications, 1987 (Unit I) and 1989 (Unit 2), Appendix $A$ to Operating Licenses NPF-68 and NPF-81, Docket Nos. 50-424 and 50-425.

Giacobbe, F. S., et al. 1988. "IGA/IGSCC of Sensitized Alloy 600 Tubing in TMI Unit 1 OTSGs," 1987 EPRI Workshop on Secondary-Side Intergranular Corrosion Mechanisms: Proceedings, EPRI NP-5971, Volume 2, Electric Power Research Institute, Palo Alto. 


\section{REFERENCES}

Gorbatykh, V. P., 1993. "The Corrosion Life of Metal," Thermal Engineering, Vol. 40, No. 7.

Gorman, J. A., et al. 1995. "Steam Generator Tube Fitness-for-Service Guidelines," AECB Report INFO-0572, July.

Gorman, J. A., et al., 1994. Steam Generator Tube Fitness-For-Service Guidelines, Atomic Energy Control Board, Ottawa, Canada, DEI-399, August.

Gorman, J. A., et al. 1991. Statistical Analysis of Steam Generator Tube Degradation, EPRI-NP7493, Electric Power Research Institute, Palo Alto.

Gorman, J. A., 1989. Survey of PWR Water Chemistry, NUREG/CR-5116, ANL-88-43.

Gorman, J. A., and E. S. Hunt 1986. Status of Cracking and Remedial Measures for PWR Steam Generators with Full-Depth Expanded Tubing, EPRI NP-4459-LD, Electric Power Research Institute, Palo Alto.

Grant, I. M., 1994. "Canadian Approach to Regulation of Steam Generator Safety," Steam Generator and Heat Exchanger Conference Proceedings, Toronto.

Hagemaier, D. J. 1983. "Eddy Current Impedance Plane Analysis," Materials Evaluation, Vol. 41, No. 2, February.

Harberts, C. N. 1986. "Steam Generator Tubing Wear Experience at San Onofre Units 2 and 3," presented at the EPRI Workshop on Fretting and Wear Susceptibility in Nuclear Steam Generators, Washington, D.C., March 19-20, 1986.

Hedner, G., 1992. "Regulatory Practices and Experiences on Steam Generators," Presented at OECDCNRA Special Issue Meeting on Regulatory Practices and Experience on Steam Generators, Paris, June 25-26.

Herman, R. 1995. "Minutes of Steam Generator Sleeving Status Review Meeting," Memorandum to Brian Sheron, February 7, 1995.

Heysek, W. G. 1990. "Plant Shutdown Due to Steam Generator Tube Leak," Licensee Event Report 90-005, March 6.

Hofmann, P. J., et al. 1986. "Pressurized Water Reactor Steam Generator Tube Fretting and Fatigue Wear Characteristics," ASME Pressure Vessels and Piping Conference, Chicago, Illinois, Paper 86-PVP-2, American Society of Mechanical Engineers, New York.

Hunt, E. S. and D. J. Gross 1994. PWSCC of Alloy 600 Materials in PWR Primary System Penetrations, EPRI TR-103696, EPRI TR-103345, Electric Power Research Institute, Palo Alto, July. 
Hunt, E. S., and J. A. Gorman 1986. Status and Suggested Course of Action for Nondenting-Related Primary-Side IGSCC of Westinghouse-Type Steam Generators, EPRI NP-4594-LD, Electric Power Research Institute, Palo Alto, May 1986.

IAEA 1995. Draft Report of A Consultants Meeting on Safety Issues and Their Ranking for WWER 440 Model 213 Nuclear Power Plants, WWER-SC-108, 1995-04-07.

IAEA 1993. Steam Generator Collector Integrity of WWER-1000 Reactors, Final Report of Consultants' Meetings, Vienna, Austria, May and November, WWER-RD-057, Distribution Restricted.

INSIDE NRC 1995. "Maine Yankee May Sleeve All Steam Generator Tubes in Extended Outage," April 17.

Jacko, R. J. 1983. Fatigue Performance of Ni-Cr-Fe Alloy 600 Under Typical PWR Steam Generator Conditions, EPRI- NP-2957, Electric Power Research Institute, Palo Alto.

Jones, J. D., et al. 1982. TMI-1 OTSG Failure Analysis Report, GPU Nuclear Corporation, Parsippany, New Jersey.

Jones, W. C. 1984. "Omaha Public Power District, Fort Calhoun Station, Steam Generator Tube Rupture Incident, Final Report," June 19.

Kobayashi, T. and D. A., Shockey 1991. Fractographic Analysis of a Crack in a Zion Steam Generator, EPRI NP-7420, Electric Power Research Institute, Palo Alto.

Koryakin, Y. I. 1993. "SG Cracks: Counting the Costs," Nuclear Engineering International, July, pp. 43 to 45 .

Krzywosz, K. J. 1990. Eddy Current Probe Characterization, EPRI NP-6990, Electric Power Research Institute, Palo Alto, October.

Kuchirka, P. J., and J. W. Cunningham 1986. Examination of Steam Generator Tubes R18C53HL and R18C43HL from the Jose Cabrera (Zorita) Nuclear Power Station, EPRI NP-4760-LD, Electric Power Research Institute, Palo Alto.

Kurtz, R., et al. 1990. "Steam Generator Tube Integrity Program/Steam Generator for Group Project, Final Project Summary Report," NUREG/CR-5117, PNL-6446.

Kusek, L. T., 1984. "Steam Generator Tube Rupture," Licensee Event Report No. 84-08, Docket No. 5000285, June 15.

Lareau, J. P. and Sapia, M. A. 1987. Array Coil Probe, EPRI NP-5009, Electric Power Research Institute, Palo Alto, March. 


\section{REFERENCES}

Laskowski, L. J., and M. J. B. Hudson 1986. "Recirculating Steam Generator Corrosion at Northeast Utilities Nuclear Plants: A Review," presented at the Joint ASME/IEEE Power Generation Conference, Portland, Oregon, October 19-23, 1986, Paper 86-JPGC-NE-4, American Society of Mechanical Engineers, New York.

Lemaire, P., 1993. "Current Status of ODSCC at EdF Plants," Presented at IGA/SCC EPRI Workshop, Minneapolis, Minnesota, October 14-15.

Libby, H. L., 1971. Introduction to Electromagnetic Nondestructive Test Methods, John Wiley and Sons, Inc., New York

Lipson, C., and N. J. Sheth (1973). Statistical Design and Analysis of Engineering Experiments, New York: McGraw-Hill

Lott, R. G., et al. 1992. "Primary Water Stress Corrosion Crack Growth Rates in Alloy 600 Steam Generator Tubing," Proceedings of the Fifth International Symposium on Environmental Degradation of Materials in Nuclear Power Systems-Water Reactors, August 25-29, 1992, pp. 525-532.

Mackowiak, D., C. D. Gentillon, and K. L. Smith, 1985. Development of Transient Initiating Event Frequencies for Use in Probabilistic Risk Assessments, NUREG/CR-3862.

Malinowski, D. D. 1995. "Detection and Evaluation of Circumferential Cracking," presented at the NRC/NEI Meeting on Circumferential Cracking NDE, Rockville, MD, September 8, 1995. Presentation slides are attached to a memo from Dembek, S. to Strosnider, J., USNRC, March 13, 1995.

Mamet, V. A., and O. I. Martynova 1993. "Hideout in NPP Steam-Generator Boiler Water and its Effect on the Operating Reliability of Equipment," Thermal Engineering, Vol. 40, No. 7, pp. 497 to 502 .

Martynova, O. I., and V. A. Mamet 1991. "Problems of Selecting Water Chemistry for the Secondary Loop of a Water-Moderated Water-Cooled VVER-1000 Reactor," Thermal Engineering, Vol. 38 , No. 7 , pp. 351 to 355 .

Maurer, R. S. 1995. "Recent NDE Experience with Circumferential Cracking," presented at the NRC/NEI Meeting on Circumferential Cracking NDE, Rockville, MD, September 8, 1995.

McKay, A. M., 1983. "Mechanisms of Denting in Nuclear Generators," Materials Performances, 22, 3, pp. $42-48$.

Miglin, B. P., and J. M. Sarver 1991. Investigation of Lead as a Cause of Stress Corrosion Cracking at Support Plate Intersections, EPRI NP-7367-M, Electric Power Research Institute, Palo Alto.

Millett, P. J. and C. J. Wood 1994. "Mediterranean Reflections-Recent Development in Water

Chemistry," Nuclear Engineering International, August, pp. 14-15. 
Miyake, Y., et al. 1992. Eddy Current Detectability for Fatigue Crack of Steam Generator Tube," Proceedings of the 11th International Conference on NDE in the Nuclear and Pressure Vessel Industries, Albuquerque, New Mexico, USA, 30 April - 2 May, pp. 71-73.

Moles, M. D. C., et al. 1994. "Ultrasonic Measurement of Steam Generator Tube Pit Depth," presented at the steam generator conference, Toronto, Canada.

Monter, J. V., and G. J. Theus 1982. OTSG Tube Failures: Upper Tubesheet corrosion Tests, EPRI NP-2790, Electric Power Research Institute, Palo Alto.

Nordmann, F., et al. 1983. "Experimental Investigation on Denting in PWR Steam Generators: Causes and Corrective Actions," Journal of Engineering for Power, Transactions of the ASME, 105, 4, pp. 755-762.

Northern States Power Co. 1985. "Steam Generator Tube Inspection, Technical Specifications 4.12-1, October 1985," in Technical Specifications for Prairie Island Nuclear Generating Plant Units 1 and 2, Appendix A to Facility Operating Licenses DPR-42 and DPR-60, Docket Nos. 50-282 and 50-306.

Nucleonics Week 1991a. "More Minor Malfunctions Attend Mihama-2 Shutdown, Sequence Shows," Vol. 32 No. 10, March 7, p. 3.

Nucleonics Week 1991b. "Kansai: Mihama-2 Break Involved Human Error, Fabrication Flaw," Vol. 32 No. 11, March 14, p. 1.

Nucleonics Week 1991c. "Summary of MITI's Report on Mihama-2 Steam Generator Tube Rupture," Vol. 32 No. 24, June 13, pp. 6-9.

Nucleonics Week 1990. "1,300-MW Steam Generator Tube Crack Ills Less Than Thought," March 15, p. 5.

Nucleonics Week 1989. "EDF Mystified by Widespread Tube Denting in Newer Steam Generators," Nucleonics Week, June 13, p. 7.

Obrutsky, L. S., et al, 1996. "Transmit-Receive Eddy Current Probes for Circumferential Cracks in Steam Generator Tubes," Materials Evaluation, January, pp. 93-98.

Obrutsky, L. S., et al, 1994. "Transmit-Receive Eddy Current Probes for Circumferential Cracks in Steam Generator Tubes, " presented at the Steam Generator and Heat Exchanger Conference, Toronto, Canada.

Oesterling, L. M. 1990. "Plant Shutdown Due to Steam Generator \#1 Tube Leak," Licensee Event Report 90-012, December 17. 


\section{REFERENCES}

Owens, C. M. 1987a. "A Historical View of the Importance of the Final Anneal on Primary Side SCC Resistance of Alloy 600 Steam Generator Tubing," Proceedings: 1983 Workshop on Primary-Side Stress Corrosion Cracking of PWR Steam Generator Tubing, EPRI NP-5498, Electric Power Research Institute, Palo Alto, pp. 14-1 to 14-19.

Partridge, M. J. 1986a. Proceedings: 1985 EPRI Workshop on Remedial Actions for Secondary-Side Intergranular Corrosion, EPRI NP-4929, Electric Power Research Institute, Palo Alto.

Partridge, M. J. 1986b. Proceedings: 1984 Workshop on Secondary-Side Stress Corrosion Cracking and Intergranular Corrosion of PWR Steam Generator Tubing, EPRI NP-4478, Electric Power Research Institute, Palo Alto.

Patridge, M. J. 1986c. Proceedings: 1983 Workshop on Secondary-Side Stress Corrosion Cracking and Intergranular Corrosion of PWR Steam Generator Tubing, EPRI NP-4458, Electric Power Research Institute, Palo Alto.

Pederson, T. L. 1992. "A Technical Specification Violation Occurred Because of Failure to Remove a Steam Generator Tube From Service, As Necessary, During the Unit 1 End of Cycle 7 Refueling Outage," Licensee Event Report 92-001, Rev. 1, January 28.

Pinard-Legry, G., and G. Plante, 1983. Intergranular Attack of Alloy 600: High Temperature Electrochemical Tests, EPRI NP-3062 Electric Power Research Institute, Palo Alto.

PGE (Portland Gas and Electric) 1991. "Steam Generator Inspections Result in C-3 Classification," Licensee Event Report No. 91-027-01, Trojan Nuclear Plant.

Rao, G. V. 1994. "Methodologies to Assess PWSCC Susceptibility of Primary Component Alloy 600 Locations in Pressurized Water Reactors," Sixth International Symposium on Environmental Degradations of Materials in Nuclear Power Systems-Water Reactors, San Diego, pp. 871-882.

Rassokhin, N. G., et al. 1992. "Predicting the Service Life of Thermal Power Plant with Respect to Stress-Corrosion Cracking Conditions," Thermal Engineering, Vol. 39, No. 5, pp. 265-270.

Richards, T. A., 1995. "Steam Generator Tube Nondestructive Examination," presented at the NRC/NEI Meeting on Circumferential Cracking NDE, Rockville, MD, September 8, 1995.

Rose, J. L., et al. 1994. "A guided wave inspection technique for nuclear steam generator tubing", NDT\&E International Volume 27, Number 6

Roussel, G. 1994. "Steam Generator Tube Degradation Problems in Belgium - Status of the Recent Developments at Doel 4 and Tihange 3 plants, " presented at the Principal Working Group No. 1 Meeting, Paris, September.

Roussel, G. and Mignot, P. 1991. "Safety Significance of Steam Generator Tube Degradation Mechanisms," NEA/CSNI - UNIPEDE Specialist Meeting on Operating Experience with Steam Generators, Brussels, Belgium, 16-20 September. 
Raussokhin, N. G., et al. 1992. "Predicting the Service Life of Thermal Power Plant with Respect to Stress-Corrosion Cracking Conditions," Thermal Engineering, Vol. 39, No. 5, pp. 265 to 270.

Sanchez-Caldera, L. 1984. Corrosion-Erosion in Steam Extraction Line of Power Stations, PhD. Thesis, Massachusetts Institute of Technology.

Saudan, G., 1992. "Regulatory Practices and Experience on Steam Generator in France," Presented at the OECD-CNRA Special Issue Meeting on Regulatory Practices and Experience on Steam Generators, Paris, June 25-26.

Schever 1987. "Palo Verde Steam Generator Tube Vibration," NRC Docket Number STN 50-470-F, July 13.

Scott, T. F. 1992. "Eddy Current Analysis Personal Error Results in Inadequate Steam Generator Tube Technical Specification Surveillance," License Event Report 92-002, Rev. 1, March 17.

Sedriks, A. J., et al. 1979. "Inconel Alloy 690," Boshoku Gijutsu, Vol. 28, No. 82.

Shah, V. N., et al. 1992. "Assessment of Primary Water Stress Corrosion Cracking of PWR Steam Generator tubes," Nuclear Engineering and Design, 134, pp. 199-215.

Sheron, B. W. (USNRC) 1995. "Technical Issues Developed as a Result of Contractor Review of Steam Generator Degradation Specific Management Topicals," Letter to A. Marion, Nuclear Energy Institute, April 14.

Shizuma, H., 1992. "Regulatory Practices and Experience on Steam Generators in Japan," Presented at OECD-CNRA Special Issues Meeting on Regulatory Practices and Experience on Steam Generators, Paris, June 25-26.

Siegel, J. and Klatt, M., 1994. "Coil Design and Technique Parameter Development for Early Detection of O.D. Cracking", The 13th Steam Generator Workshop, LaJolla, CA, July 25-27.

Sipe A., 1989. "A Steam Generator Tube Rupture Occurred on March 7, 1989 and Resulted in an Alert Being Declared and an Unplanned Release of Radioactivity," Licensee Event Report No. 89-04, Docket No. 5000369, March 7.

Snider, J. H. 1989. "OTSG Operating Experience: A Tube Integrity Update," EPRI Steam Generator NDE Workshop, Williamsburg, Virginia, August 9-11, 1989.

Solovyev S. P., 1992. Accidents and Incidents in Nuclear Power Plants, Lecture Notes, Obninsk.

Southern California Edison Co. 1982. "Steam Generator Tube Inspection, Technical Specifications 3/4.4.4, February 1982" in San Onofre Unit 2 Technical Specifications, Appendix A to License NPF-10, Docket No. 50-361, also published by the USNRC as NUREG-0741. 


\section{REFERENCES}

Stein, A. A., and A. R. McIlree 1986. "Relationship of Annealing Temperature and Microstructure to Primary-Side Cracking of Alloy 600 Steam Generator Tubing and the Prediction of Stress Corrosion Cracking in Primary Water," Proceedings of the Second International Symposium on Environmental Degradation of Materials in Nuclear Power Systems-Water Reactors, American Nuclear Society, La Grange Park, Illinois, pp. 47.

Stellfox, D., 1995. Inside NRC, April 17.

Stoller (S. M. Stoller Corporation) 1991a. "Reactor Trip - SG Tube Rupture on Uppermost Plate, Cold Leg Side - Pressurizer Relief Valve Failed to Open During Cooldown," Nuclear Power Experience, Vol. PWR-2, Steam Generators, pp. 260-261, pp. 272-274.

Stoller 1989b. "Plant Shutdown - SG Tube Leakage - Tubes Damaged by Loose MFRV Anti-rotation Pin," Nuclear Power Experience, Vol. PWR-2, Steam Generators, pp 241-242.

Stoller 1991b. "Incidents Involving Rapid Increases in Primary-to-Secondary Leak Rate - Tubesheet and Support Plate Cracks, Circumferential Rupture of SG Tube - High Cycle Fatigue," Nuclear Power Experience, Vol. PWR-2, Steam Generators, pp. 270-272.

Stoller 1989a. "Unit Shutdown, SG Tube Rupture, Radioactive Offsite Release-Corrosion-Other Anomalies Noted," Nuclear Power Experience, Vol. PWR-2, Steam Generators, p. 233.

Stoller 1988. "Manúal Unit Trip-SG Tube Rupture, Radiation Release - Cold Leg Side Metal Fatigue, Water Dynamics," Nuclear Power Experience, Vol. PWR-2, Steam Generators, p. 202.

Stoller 1984. "SG Tube Failure - IGSCC - Defects Missed During Testing," Nuclear Power Experience, Vol. PWR-2, Steam Generators, pp. 179-180.

Stoller 1979. "Steam Blanketing Accelerated Local Corrosion, Tube Leaks," Nuclear Power Experience, $P W R-2, V, D, 24$, pp. 6-7.

Stoller 1976a. "SG Tube Cracking, Denting-Surry 2-Sept. 76-100\% Power," Nuclear Power Experience, Vol. PWR-2 Steam Generators, P. 48.

Stoller 1976b. "Summary of Inspection Results for Surry SG Tube Cracks-Surry 1 and 2-Nov. 76 to Feb. 77-Shutdown," Nuclear Power Experience, Vol. PWR-2 Steam Generators, pp. 57-59.

Stoller 1976c. “Small Bend Radius SG Tubes Cracked-Turkey Pt. 4-Oct. 76," Nuclear Power Experience, Vol. PWR-2 Steam Generators, p. 49.

Stuhmiller. J. H., et al. 1988. Prediction of Localized Flow Velocities and Turbulence in a PWR Steam Generator, EPRI NP-5555, Electric Power Research Institute, Palo Alto.

Theus, G. J., and P. L. Daniel 1984. "Corrosion in Steam Generating Systems," Corrosion in Power Generating Equipment, M. O. Speidel and A. Atrens (eds.), Plenum Press, New York, pp. 185-232. 
Titov, V. F. 1993. "Causes of Damage to Cold Headers for Horizontal PGV-1000 Steam Generators and Measures for Increasing their Operational Reliability and Lifetime," Thermal Engineering, Vol. 40 , No. 12, pp. 959 to 966 .

Titov, V. F., et al. 1992. "Damage to Heat Exchanger Tubes in Steam Generators on Nuclear Power Stations with Water-Moderated Water-Cooled Reactors," Thermal Engineering, Vol. 39, No. 3, pp. 158 to 160 .

Titov, V. F. 1991. "Repairing and Replacing SGs at Soviet 1000 MWe PWRs," Nuclear Engineering International, January, pp. 20 to 22 .

Togo, et al. 1985. "Preventing Tube Degradation in Japan," Nuclear Engineering International, 30, 365 , pp. 43-44.

USNRC 1995a. "Circumferential Cracking of Steam Generator Tubes," NRC Generic Letter 95-03, April 28.

USNRC 1995b. "Voltage-based Repair Criteria for Westinghouse Steam Generator Tubes Affected by Outside Diameter Stress Corrosion Cracking," NRC Generic Letter 95-05, August 3.

USNRC 1994. "Operational Experience on Steam Generator Tube Leaks and Tube Ruptures," NRC Information Notice 94-62, August 30.

USNRC 1993. Thermal Fatigue Cracking of Feedwater Piping to Steam Generators, NRC Information Notice 93-20.

USNRC 1991. "Problems with the Reliable Detection of Intergranular Attack (IGA) of Steam Generator Tubing," NRC Information Notice 91-67, October 21, 1991.

USNRC 1990. "Stress Corrosion Cracking in PWR Steam Generator Tubes," NRC Information Notice No. 90-49, August 6, 1990.

USNRC 1990a. "Cracking of the Upper Shell-to-Transition Cone Girth Welds in Steam Generators," USNRC Information Notice 90-04.

USNRC 1989. "Safety Evaluation by the Office of Nuclear Reactor Regulation, Recovery from SGTR Event at McGuire 1," Docket No. 50-369, May 16.

USNRC 1988a. NRC Integrated Program for the Resolution of Unresolved Safety Issues A-3, A-4, and A-5 Regarding Steam Generator Tube Integrity, NUREG-0844, September.

USNRC 1988b. "Rapidly Propagating Fatigue Cracks in Steam Generator Tubes," Bulletin 88-02 and NEA IRS Incident Report, June 24. 


\section{REFERENCES}

USNRC 1985. "Staff Recommended Actions Stemming From NRC Integrated Program for the Resolution of Unresolved Safety Issues Regarding Steam Generator Tube Integrity," Generic Letter 85-02, April 17.

USNRC 1983. Safety Evaluation Report Related to the D4/D5/E Steam Generator Design Modifications, NUREG-1014.

USNRC 1982a. "Cracking In the Shell-to-Transition Cone Girth Weld of a Steam Generator at an Operating Pressurized Water Reactor," USNRC Information Notice 82-37.

USNRC 1982b. NRC Report on the January 25, 1982, Steam Generator Tube Rupture at R.E. Ginna Nuclear Power Plant, NUREG-0909, April.

USNRC 1982c. Safety Evaluation Report Related to the Restart of R.E. Ginna Nuclear Power Plant, NUREG-0916, Docket No: 50-244, May.

USNRC 1981. Standard Technical Specifications for Westinghouse Pressurized Water Reactors, NUREG-0452, Revision 4, pp. 3/4 4-13 to 4-19.

USNRC 1980. Evaluation of Steam Generator Tube Rupture Events, NUREG-0651, March.

USNRC 1979. "Cracking in Feedwater System Piping," USNRC Bulletin 79-13, Revision 2.

USNRC 1976. "Regulatory Guide 1.121, Bases for Plugging Degraded PWR Steam Generator Tubes," August.

USNRC 1975. "Regulatory Guide 1.83, In-Service Inspection of Pressurized Water Reactor Steam Generator Tubes," Revision 1, July.

Van der Sluys, W. A., and W. H. Cullen 1987. "Fatigue Crack Growth of Pressure Vessel Materials in Light-Water-Reactor Environment," Performance and Evaluation of Light-Water Reactor Pressure Vessels, PVP 119, American Society of Mechanical Engineers, New York, pp. 63-71.

Van der Sluys, W. A. 1982. Corrosion Fatigue Characterization of Reactor Pressure Vessel Steels, EPRI NP-2775, Electric Power Research Institute, Palo Alto.

Van Vyve, J. And P. Hernalsteen, 1991. "Tube Plugging Criteria for Axial and Circumferential Cracks in the Tubesheet Area," NEA/CSNI-UNIPEDE Specialist Meeting on Operating Experience with Steam Generators, Brussels, Belgium , 16-20 September.

Weakland, D. 1988. "ISI Experience Report, Duquesne Light Company, Beaver Valley Power Station Unit 1," EPRI Steam Generator NDE Workshop, Myrtle Beach, South Carolina, June 7-9, 1988.

Westinghouse (Westinghouse Electric Corporation) 1994. Technical Evaluation of Hybrid Expansion Joint (HEJ) Sleeved Tubes Containing Indications Within the Upper Joint, WCAP-14182, Nonproprietary, Class 3, August. 
Westinghouse (Westinghouse Electric Corporation) 1991. Trojan Nuclear Plant Steam Generator Tube Repair Criteria of Indications at Tube Support Plates, WCAP-13130, Rev. 1, December.

Westinghouse (Westinghouse Electric Corporation) 1990. Indian Point Unit 2-Steam Generator Inspection, Repair, and Restoration Program-Presentation to Nuclear Regulatory Commission, June 1990, prepared for Consolidated Edison Company.

Zetec 1995. "Review of Circumferential Cracking NDE Methodology," Presentation to US Nuclear Regulatory Commission, February 22. Presentation slides are attached to a memo from Dembek, S. to Strosnider, J., USNRC, March 13, 1993.

Zetec 1988. "Weld Scan Probes," New Product Bulletin, September, 14. 
APPENDIX A 


\section{APPENDIX}

This Appendix describes the heat transfer modeling of the Residual Heat Removal (RHR) Systems for the Surry Nuclear Steam Supply System.

The RHR systems are single pass, parallel flow heat exchangers. In the model, the inlet temperatures and mass flow rates on the shell and primary sides of the RHR systems are used to calculate the respective outlet temperatures. Design conditions are used to compute the mean value of the overall heat transfer coefficient times the total heat transfer surface area $\left(U_{m} A\right)$.

Using the following design input data for each RHR system,

$$
\begin{aligned}
\mathrm{T}_{\mathrm{a} 1}= & 140^{\circ} \mathrm{F}, \text { hot leg temperature } \\
\mathrm{T}_{\mathrm{a} 2}= & 124^{\circ} \mathrm{F}, \mathrm{RHR} \text { discharge temperature } \\
\mathrm{T}_{\mathrm{b} 1}= & 105^{\circ} \mathrm{F} \text {, shell side inlet temperature } \\
\mathrm{T}_{\mathrm{b} 2}= & 112^{\circ} \mathrm{F} \text {, shell side outlet temperature } \\
\mathrm{W}_{\mathrm{a}}= & 555.6 \mathrm{lbs} / \mathrm{sec}, \text { primary flow rate } \\
\mathrm{W}_{\mathrm{b}}= & 1236.1 \mathrm{lbs} / \mathrm{sec}, \text { shell side flow rate } \\
\mathrm{C}_{\mathrm{pa}}= & \text { specific heat of primary fluid, } \\
& \text { Btu } / \mathrm{lb}-{ }^{\circ} \mathrm{F} \\
\mathrm{C}_{\mathrm{pb}}= & \text { specific heat of shell side fluid, } \\
& \text { Btu } / \mathrm{lb}-{ }^{\circ} \mathrm{F} \\
\mathrm{Q}= & 9166.7 \mathrm{Btu} / \mathrm{sec} \text {, heat removal rate }
\end{aligned}
$$

$\mathrm{U}_{\mathrm{m}} \mathrm{A}$ is calculated from

$$
U_{m} A=\frac{\dot{Q}}{(\Delta T)_{m}}
$$

where $\mathrm{Q}$ is the heat removal rate $(\mathrm{Btu} / \mathrm{sec})$ and $\Delta T_{m}$ is the log-mean temperature distribution. $\Delta \mathrm{T}_{\mathrm{m}}$ is calculated from

$$
(\Delta T)_{m}=\frac{\left(T_{a}-T_{b}\right)_{1}-\left(T_{a}-T_{b}\right)_{2}}{\ln \frac{\left(T_{a}-T_{b}\right)_{1}}{\left(T_{a}-T_{b}\right)_{2}}}
$$

With the RHR systems in operation, the outlet temperature for the shell side of the RHR heat exchanger can be computed from

$$
T_{b 2}=T_{b I}+\left(\frac{1}{a}\right)\left(T_{a 1}-T_{b I}\right)(1.0-e
$$

where

$$
\begin{gathered}
a=\left(1+\frac{W_{b} C_{p b}}{W_{a} C_{p a}}\right) \\
\text { and } \\
\alpha=\left(\frac{1}{W_{b} C_{p b}}+\frac{1}{W_{a} C_{p a}}\right) U_{m} A
\end{gathered}
$$

With the shell side outlet temperature $\left(\mathrm{T}_{\mathrm{b} 2}\right.$ determined from Eq. 3, the outlet temperature of the RHR primary side fluid can then be calculated from

$$
T_{a 2}=T_{a 1}-\left(\frac{W_{b} C_{p b}}{W_{a} C_{p a}}\right)\left(T_{b 2}-T_{b l}\right)
$$

Figure A1 shows the RHR primary side inlet temperature and resultant outlet temperatures computed by Eq. 5 over the range 350 to $140^{\circ} \mathrm{F}$. Figure A2 shows the shell side outlet temperatures computed for this range using Eq. 3. 


\section{APPENDIX}

temperatures, $T_{a 1}$ and $T_{b 1}$ were used to recompute the outlet temperatures, $T_{a 2}$ and $T_{b 2}$, using Eqs. 3 through 5 , thereby verifying the model. The calculated values for $T_{a 2}$ and $T_{b 2}$ are identified in Figs. A1 and A2 with the data symbol (square).

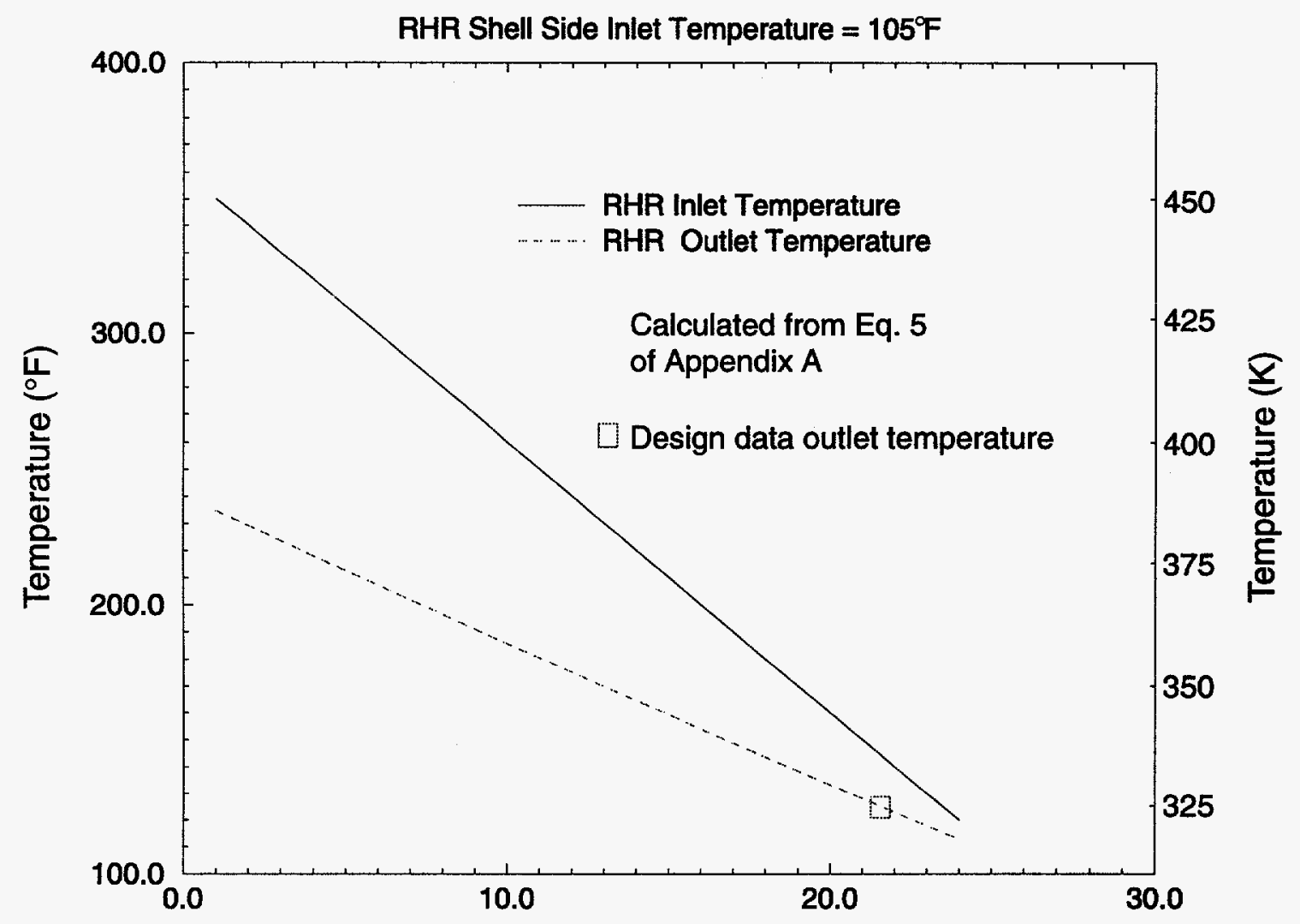

Figure A1. RHR Primary Inlet and Outlet Temperatures 


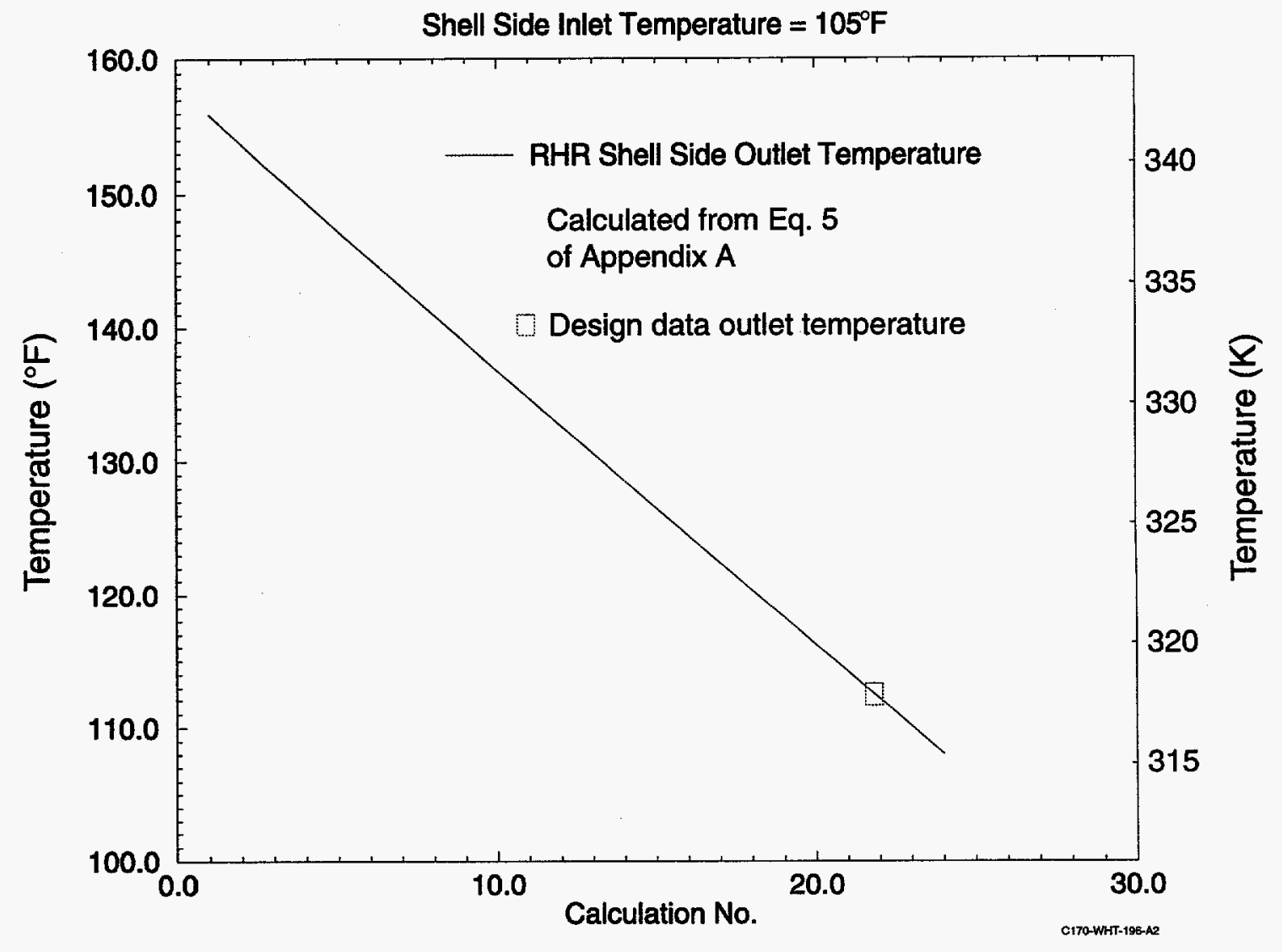

Figure A2. RHR Shell Side Temperatures 


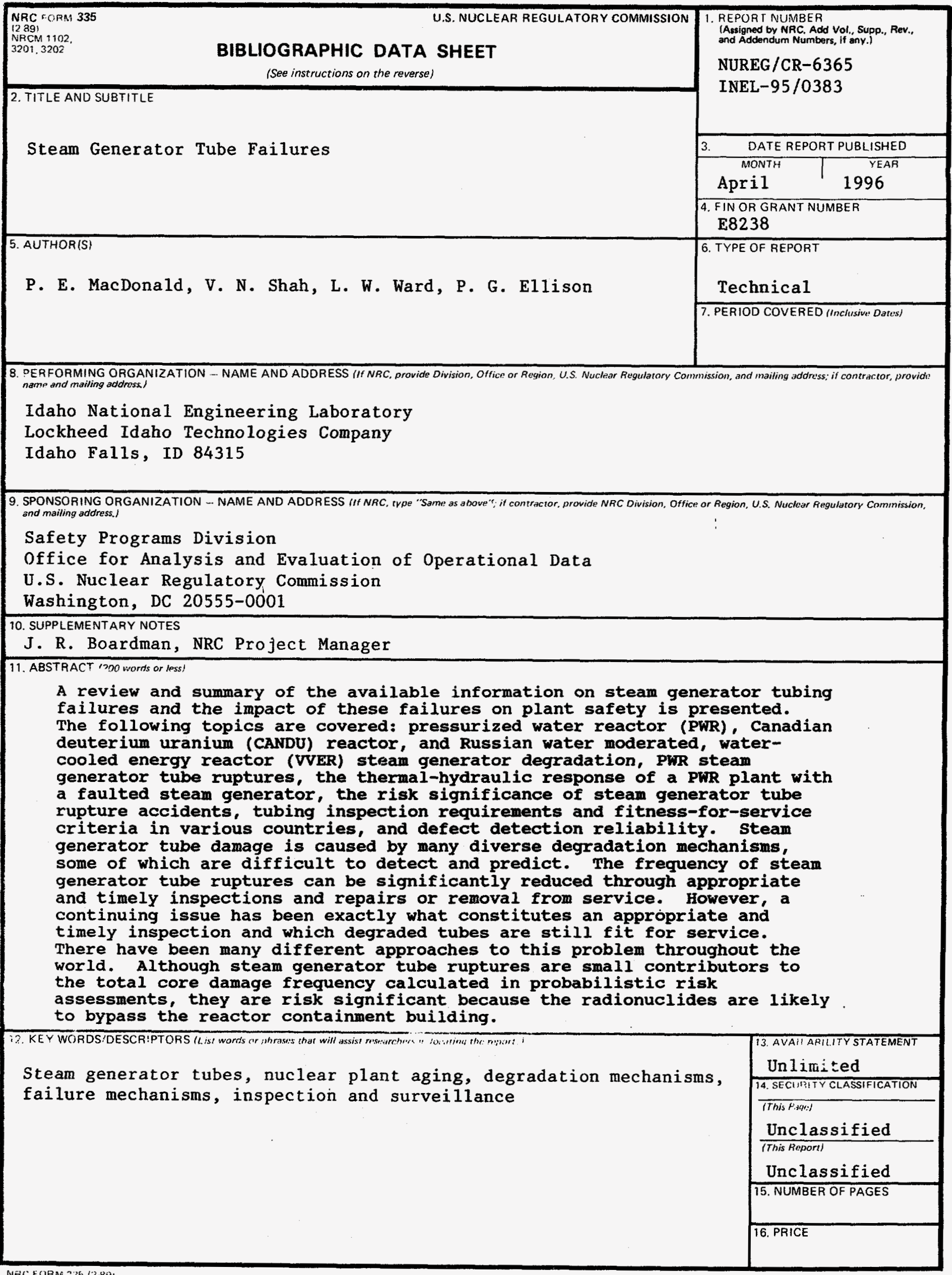

